\title{
USA oder Sowjetunion?
}

Konkurrierende Modernitätsentwürfe in den Massenmedien der Weimarer Republik

V\&R 


\section{Schnittstellen}

Studien zum östlichen und südöstlichen Europa

Herausgegeben von

Martin Schulze Wessel und Ulf Brunnbauer

Band 12 
David M. Franz

\section{USA oder Sowjetunion?}

Konkurrierende Modernitätsentwürfe in

den Massenmedien der Weimarer Republik

Vandenhoeck \& Ruprecht 
Gedruckt mit freundlicher Unterstützung der Graduiertenschule für Ost- und Südosteuropastudien der Universität Regensburg.

Zugleich: Dissertation Universität Regensburg 2016.

Bibliografische Information der Deutschen Nationalbibliothek:

Die Deutsche Nationalbibliothek verzeichnet diese Publikation in der Deutschen Nationalbibliografie; detaillierte bibliografische Daten sind im Internet über https://dnb.de abrufbar.

(C) 2019, Vandenhoeck \& Ruprecht GmbH \& Co. KG, Theaterstraße 13, D-37073 Göttingen Das Werk ist als Open-Access-Publikation im Sinne der Creative-Commons-Linzenz BYNC-ND International 4.0 (»Namensnennung - Nicht kommerziell - Keine Bearbeitung«) unter dem DOI 10.13109/9783666310812 abzurufen. Um eine Kopie dieser Lizenz zu sehen, besuchen Sie https://creativecommons.org/licenses/by-nc-nd/4.0/. Jede Verwendung in anderen als den durch diese Lizenz erlaubten Fällen bedarf der vorherigen schriftlichen Zustimmung des Verlages.

Umschlagabbildung: Theo Matejko: »Amerika!«, Titelseite der Berliner »Illustrirten« Zeitung, Nr. 18 vom 29. April 1928.

Satz: textformart, Göttingen | www.text-form-art.de

Vandenhoeck \& Ruprecht Verlage | www.vandenhoeck-ruprecht-verlage.com

ISSN 2566-6614

ISBN 978-3-666-31081-2 


\section{Inhalt}

I. Einführung $\ldots \ldots \ldots \ldots \ldots \ldots \ldots \ldots \ldots \ldots$

1. Ziele und zeitlicher Rahmen $\ldots \ldots \ldots$. . . . . . . . . . 11

2. Die Forschungslage $\ldots \ldots \ldots \ldots \ldots \ldots \ldots$

3. Die Quellen . . . . . . . . . . . . . . . . . . . 21

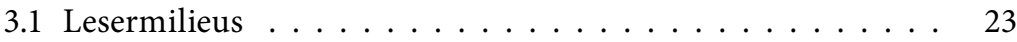

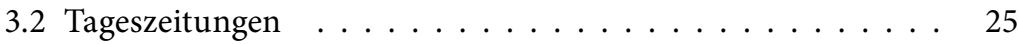

3.3 Illustrierte . . . . . . . . . . . . . . . . . . . . . 29

3.4 Massenmedien und Gesellschaft . . . . . . . . . . . . 33

4. Theoretische und methodische Grundlagen . . . . . . . . . 36

5. Modernität und Krise . . . . . . . . . . . . . . . . . . . . 44

II. Modernitätsdiskurse der Weimarer Republik ～. . . . . . . . . . 47

1. Kultur der Rationalisierung und Rationalisierungskulte . . . . . 56

1.1 Amerikas Tradition der Zukunft . . . . . . . . . . . . 63

1.2 Taylorismus und Fordismus in der Kritik . . . . . . . . . 67

1.3 Henry Ford zur Ehrenrettung des Fordismus . . . . . . . . 74

1.4 Deutsche Rationalisierungseuphorie . . . . . . . . . . 78

1.5 Arbeitsorganisation in der Sowjetunion . . . . . . . . . . 80

$1.6 »$ Neue Arbeit, neue Menschen" . . . . . . . . . . . . . . 88

1.7 Rationalisierung und Massengesellschaft . . . . . . . . . 93

1.8 Zusammenfassung . . . . . . . . . . . . . 101

2. Frauenbilder und Frauenemanzipation … . . . . . . . 103

2.1 Die »Vermännlichung« der Frau . . . . . . . . . . . . . . 108

2.2 Geschlechterverhältnisse und Politik . . . . . . . . . . . . . 119

2.3 Zusammenfassung . . . . . . . . . . . . . 130

3. Minderheiten: Emanzipation und Modernitätsbruch . . . . . . 133

3.1 Die Black Community in den USA . . . . . . . . . . . 140

3.2 Rassismus als Bruch amerikanischer Modernität . . . . . . 148

3.3 Aufbegehren und Aufbruch . . . . . . . . . . . . 162

3.4 Indigene Bevölkerung Nordamerikas . . . . . . . . . . . . 174

3.5 Die Minoritäten und Nationalitäten der UdSSR . . . . . . . . 178 
3.6 Bilder sowjetischer Juden _. . . . . . . . . . . . . . . 180

3.7 Zusammenfassung . . . . . . . . . . . . . 188

4. Politische Ordnungen . . . . . . . . . . . . . . . . . . . . . 190

4.1 Symbolik und Repräsentation: Amerikas Demokratie . . . . . 198

4.2 »Innerparteiliche Demokratie« in der Sowjetunion . . . . . . 213

4.3 Der bolschewistische $»$ Kirchenkampf $«$. . . . . . . . . . . . 224

4.4 Zusammenfassung .................. 232

5. Sport, Jugend und Bildung: Fundamente der neuen Zeit . . . . . . 235

5.1 Sport und Körperkult(ur) . . . . . . . . . . . . . . . . . . . . . . . . . . . . 237

5.2 Jugend in jungen Ländern . . . . . . . . . . . . . . . . . . . . 245

5.2.1 »Wie man in Amerika Bürger macht» . . . . . . . . . . . 249

$5.2 .2 »$ Kinderhölle« und Pioniergeist . . . . . . . . . . . . . . . . . 254

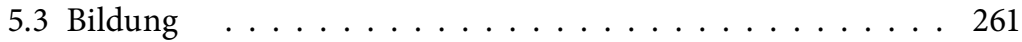

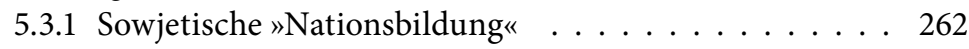

5.3.2 Geistesleben als Spiegel des »Volkscharakters« . . . . . . 272

5.4 Zusammenfassung . . . . . . . . . . . . 277

III. Schlussbetrachtung . . . . . . . . . . . . . . . . . . . 281

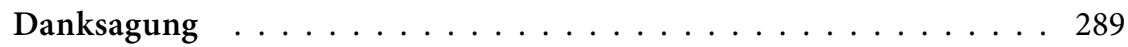

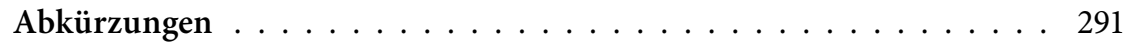

Quellen- und Literaturverzeichnis . . . . . . . . . . . . . . . . 293

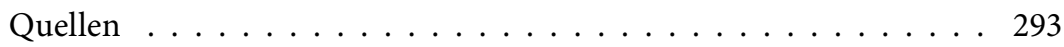

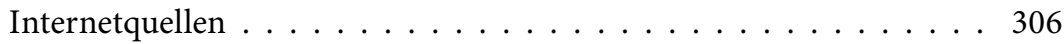

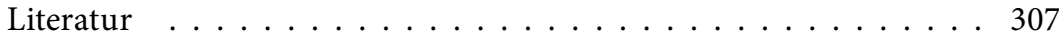

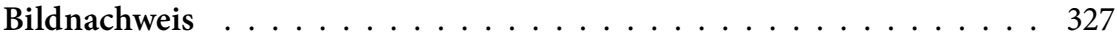

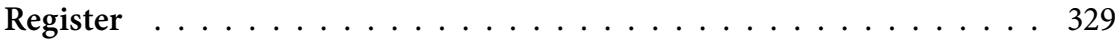




\section{Einführung}

Die aufgeregte und unversöhnliche politische Debatte prägt bis heute unser Bild von der Weimarer Republik. Wir erschließen uns diesen schwer greifbaren Diskurs meist entlang politischer und gesellschaftlicher Frontverläufe, ordnen verschiedenen Akteuren Positionen zu und stecken Konfliktfelder ab. In dieser übersichtlichen Konstellation streiten Parteigänger, Kirchenleute, Gewerkschafter, Links- und Rechtsradikale sowie Vertreter gesellschaftlicher Klassen heftig über Gewesenes, Akutes und Kommendes: Zu Kaiser, Krieg und Revolution hatte ein jeder ebenso handfeste Positionen anzubieten wie zu Wirtschaftskrise, Völkerbund und Notverordnungen. Die Härte der politischen Auseinandersetzung resultierte aus der unhinterfragbaren Apodiktik, mit der die verschiedenen Lager auf tagespolitische Sachverhalte blickten.

Ungleich schwerer fiel es den rivalisierenden Kräften, sich selbst und der eigenen Klientel die tiefgreifenden Modernisierungsprozesse ihrer Zeit begreiflich zu machen. Der rasche Wandel der politischen Ordnung, des Wirtschaftsprozesses oder der Geschlechterrollen musste sinnstiftend in die eigene Weltanschauung und Zukunftsvision eingefügt werden. Diese Wandlungsprozesse waren als globale Modernisierungsphänomene der Tagesaktualität und dem deutschen Kontext enthoben. Der Rahmen, in dem man über solch überwölbende Prozesse diskutieren konnte, musste folglich größer gezogen werden. Es bedurfte passender Projektionsflächen, die von der Kakophonie der innerdeutschen Debatte abgegrenzt waren, zugleich aber Anknüpfungspunkte für die Auseinandersetzung mit den Zumutungen und Segnungen der Moderne boten.

Besonders dynamisch entfalteten sich Diskurse über Modernisierungsprozesse unter Bezugnahme auf die USA und die UdSSR. Diese beiden politisch-gesellschaftlichen Systeme versinnbildlichten die Ambivalenz der neuen Zeit. Beide wurden in Deutschland nach 1918 als staatgewordene Modernisierungsprojekte wahrgenommen. Sowohl im Vergleich miteinander als auch in Abgrenzung zur deutschen Selbstwahrnehmung bildeten sie einander entgegengesetzte Modelle. Der amerikanische Liberalismus und der sowjetische Autoritarismus boten ein hochproduktives Spannungsfeld für die Selbstverortung der deutschen Gesellschaft in der Moderne des 20. Jahrhunderts. Durch ihre Gegensätzlichkeit zeigten die Gesellschafts- und damit Modernitätsentwürfe der USA und der UdSSR ein Spektrum möglicher Entwicklungspfade auf, an dem sich der Selbstbeschreibungsprozess der Deutschen orientieren 
konnte. ${ }^{1}$ Fremdbetrachtung und Selbstbeschreibung beeinflussten sich also wechselseitig.

Nach dem Scheitern der Kriegsanstrengung, ja des alten deutschen Gesellschafts- und Staatsmodells per se, fand sich ein und dieselbe Gesellschaft nach 1918 in einem neuen Staat und in einer neuen Zeit wieder. Der Bedarf nach Selbstvergewisserung war größer denn je, hatten sich alte Gewissheiten doch als Trugbilder aus Idealismus und Nationalismus erwiesen. Das öffentliche Sprechen über die USA und die UdSSR gab dem selbstvergewissernden Monolog der Deutschen Impulse, auf die der ausgezehrte Ideenhaushalt der besiegten Nation in hohem Maße angewiesen war.

Der »Amerikanismus ${ }^{2}$ - zeitgenössisch definiert als das Bewusstsein, »im Weltgeschehen von einer höheren Fügung zu einer führenden, wenn nicht der führenden Rolle ausersehen zu sein $\aleph^{3}-$ stieß Entwicklungsimpulse an, die über Europa als "Amerikanisierung « hereinbrachen. ${ }^{4}$ Schon seit Ende des 19. Jahrhunderts waren die Neuerungen aus Übersee zu konkreten Bezugsgrößen geworden, an Hand derer man sich als Individuum wie als Gesellschaft zu Fluch und Segen der Moderne positionieren konnte. Über Amerika sprechen hieß immer auch, in das Lamento oder Loblied auf die "modernen Zeiten" einzustimmen. Diese sah man in Gestalt der aus den USA übernommenen Wirtschafts- und Kulturformen heraufziehen. »Amerika« war längst zu einer Chiffre der Moderne geworden. Die traditionelle konnotative Ineinssetzung von »Moderne« und »Amerika« erscheint angesichts des effektvollen Auftretens der UdSSR jedoch als allzu festgefügt und selbstverständlich. Immerhin

1 Ausgehend von unterschiedlichen kulturellen und historischen Ausgangspositionen, die sich in jeweils kulturspezifischen Mustern den Weg in die Moderne strukturieren. Vgl. dazu: Eisenstadt, Shmuel: Die Vielfalt der Moderne. Weilerswist 2000.

2 Den Selbstfindungs- und Abgrenzungsprozess der Vereinigten Staaten als eigenständige und von Europa unabhängige Kultur beschrieb Adelheid von Saldern mittels einer eingehenden Analyse der publizistischen Selbstkonstruktion in amerikanischen Magazinen. Ihre Darstellung des sich gegen die zuvor unvollständige Selbstkonzeption als kulturelles, wirtschaftliches und politisches Subjekt durchsetzenden amerikanischen Selbstverständnisses legt dar, aus welchen inneren diskursiven Quellen sich der auf der anderen Seite des transatlantischen Austauschs als »Amerikanisierung « erfahrene Einfluss speiste: Saldern, Adelheid, von: Amerikanismus. Kulturelle Abgrenzung von Europa und US-Nationalismus im frühen 20. Jahrhundert. Stuttgart 2013.

3 Trausil, Hans: Was ist Amerikanismus? In: DAZ Nr. 443 vom 22.09.1926, $1 \mathrm{f}$.

4 In den großen europäischen Ländern, namentlich dem Vereinigten Königreich, Deutschland, Frankreich und Italien wurde die Konfrontation mit dem stetig wachsenden Einfluss der Vereinigten Staaten verschiedentlich wahrgenommen, ebenso wie innerhalb dieser nationalkulturellen Kontexte wiederum thematische und diachrone Konstellationen die Bewertung des amerikanischen Einflusses bestimmten. Zum Verlauf dieser vielfältigen Wahrnehmungs-, vor allem aber Transferprozesse von Amerika nach Europa: Ellwood, David: The Shock of America. Europe and the Challenge of the Century. Oxford 2012. 
sollte das 1917 in Russland gestartete revolutionäre Projekt der Bolschewiki das 20. Jahrhundert ebenso nachhaltig prägen wie die USA. ${ }^{5}$

Die USA und die UdSSR teilten bestimmte Charakteristika, die beide gleichermaßen als Impulsgeber der Moderne qualifizierten. Die Vereinigten Staaten waren ein aus dem Geist der Aufklärung inspiriertes Projekt der universellen Ideale. Ebenso bezogen die ab 1917 in Russland angestoßenen Umwälzungen ihre Dynamik aus dem Anspruch, dereinst die Welt einer kommunistischen Utopie entgegenzuführen. Ähnlich wie die Ideen der Amerikanischen Revolution 1776 beanspruchte auch die Ideologie der Bolschewiki universelle Gültigkeit für sich. Den Anspruch, die kommende Zeit nach ihren Prämissen umzugestalten, teilten die Revolutionäre von 1917 mit denen von 1776. Beide meinten der Moderne zu ihrem Recht verhelfen zu müssen.

Die theoretische Basis der sozialistischen Bewegungen, unter ihnen auch die russischen Bolschewiki, war als Reaktion ihres Vordenkers Karl Marx auf sich beschleunigende Modernisierungsprozesse (des Kapitalismus) in die Welt gekommen. Die von Marx als viel zu ungleichmäßig kritisierten Entwicklungen von Wirtschaft und Gesellschaft wiederum waren dem Denken der Aufklärung entsprungen - und fanden sich nirgends so konsequent realisiert wie in den USA. Auf der Ebene der longue durée erscheint dies geradezu als eine Art Reiz-Reaktions-Schema zwischen Liberalismus, Konservatismus, Autoritarismus und Sozialismus - Strömungen, denen Deutschland in besonderer und äußerst wechselvoller Weise ausgesetzt war.

Die transatlantische Welle von Ideen, Konzepten und Praktiken brach sich 1914 in Deutschland und 1917 in Russland an machtvollen illiberalen Gegenströmen. Nach 1918 sortierten sich dann in Deutschland die politischen und gesellschaftlichen Ideen neu, zunächst auch unter direktem amerikanischen Einfluss. ${ }^{6}$ Verbliebene Rinnsale illiberalen Denkens, der konstante transatlantische Ideenfluss und der neue sowjetische Einstrom durchdrangen sich wechselseitig und wurden in der innerdeutschen Debatte nutzbar gemacht. Die USA und die UdSSR entfalteten als "Länder der Zukunft ${ }^{7}$ machtvollen Einfluss auf die Vision eines zukünftigen Deutschlands. Lange war hierzulande die Er-

5 Die sowjetische Politik orientierte sich über weit längere Zeit als weithin zugestanden an der revolutionären Handlungslogik Lenins. Dazu: Figes, Orlando: Hundert Jahre Revolution. Russland und das 20. Jahrhundert. Berlin, München 2014.

$6 \mathrm{Zu}$ den äußeren politischen Bedingungen des Verhältnisses zwischen Deutschland und den USA während des Beobachtungszeitraums unter anderem: Ambrosius, Lloyd E.: Nationale Selbstbestimmung im Ersten und im Zweiten Weltkrieg. Eine Vergleichsstudie von Wilson bis Roosevelt. In: Berg, Manfred/Gassert, Philipp (Hg.): Deutschland und die USA in der internationalen Geschichte des 20. Jahrhunderts. Festschrift für Detlef Junker. Stuttgart 2004, 237-262. Und: Schwabe, Klaus: Eine neue Weltordnung? Der Beitrag Amerikas zur Lösung der Deutschlandfrage durch den Friedensschluss von Versailles. Ebd., 263-278.

7 Anon.: Die neue Zeit. Länder der Zukunft. In: DAZ Nr. 1 vom 01.01.1928, 1 f. 
kenntnis gereift, »daß die Vereinigten Staaten [...] zur schicksalsgestaltenden Macht des Abendlandes geworden ${ }^{8}{ }^{8}$ waren. Niemand bezweifelte ernstlich, dass sich ein zukünftiges und zukunftsfähiges Deutschland zur Gestaltungsmacht Amerikas auf die eine oder andere Weise verhalten musste.

Zugleich erkannte man »keine anderen zwei Länder, die so aufeinander angewiesen " seien und »sich derartig in allem ergänzen« könnten »wie Deutschland und Rußland«. Beide könnten "miteinander gewissermaßen sin Symbiose leben $",{ }^{9}$ lautete der Einwurf jener Publizisten, die sich mit einer an Amerika orientierten Modernisierung Deutschlands nicht abfinden mochten. Dieses Denken wies über eine wirtschaftliche Symbiose hinaus. Statt sich der Hegemonie des westlichen Zivilisationsmodells zu ergeben, träumte man von einer umfassenden deutsch-russischen Partnerschaft. Obendrein könne die deutsche Kultur durch eine Orientierung gen Osten vor dem bewahrt werden, was von vielen zeitgenössischen Akteuren als verderbter Charakter westlicher Zivilisation wahrgenommen wurde: »Wenn überhaupt Europa eine Grenze gegen Asien haben« solle, so argumentierte etwa Anabert Vorreiter im Jahr 1922, sei es "für Deutschland besser «, diese Grenze läge »im Westen, über dem Rhein, nicht in den Rokitnosümpfen. ${ }^{10}$ Deutschland unter russischem Einfluss? Kein abwegiger Gedanke.

Jenseits differenzierterer Zwischentöne stand also eine grundlegende Richtungsentscheidung an, für die sich mithilfe des amerikanischen und sowjetischen Beispiels plakative Kategorien gegeneinander in Stellung bringen ließen: West oder Ost? Liberalismus oder Autoritarismus? Kapitalismus oder Sozialismus?

Die vielfältigen Darstellungen der USA und der UdSSR, die zu einer entsprechenden Zielbestimmung ins Feld der öffentlichen Debatte geführt wurden, waren durch Presseberichte vermittelt. Sie knüpften zugleich an historisch tradierte Wahrnehmungsmuster beider Länder an. Dabei ging es den beteiligten Journalisten nicht darum, ein möglichst authentisches oder vollständiges Länderprofil zu erstellen. Aufgegriffen wurden in der Betrachtung vielmehr jene Themen, die im innerdeutschen Deutungskampf von besonderer Relevanz waren. So wurde die Frauenemanzipation oder das Heraufziehen der Massengesellschaft an konkreten Beispielen aus den USA und der UdSSR medial verhandelt, denn solche Fragen trieben die Deutschen um. Einzelne thematische Schwerpunkte aus der innerdeutschen Debatte fügten sich auf diese Weise zu einer zwingend verzerrten Wahrnehmung der Vereinigten Staaten einerseits und der Sowjetunion andererseits zusammen. Eine stark selektive Anzahl umkämpfter thematischer Schwerpunkte aus der innerdeutschen Debatte fügte

9 Vorreiter, Anabert: Rußland und Europa. In: VZT Nr. 572 vom 03.12.1922, 21.

10 Ebd. 
sich auf diese Weise zu einem spezifischen Prisma zusammen, durch das die Vereinigten Staaten einerseits und die Sowjetunion andererseits zwingend verzerrt wahrgenommen werden mussten. Die Feinmechanik und Funktionsweise dieser diskursiven Filterungs-, Darstellungs-, Wahrnehmungs- und Aushandlungsprozesse stehen im Zentrum der vorliegenden Studie.

\section{Ziele und zeitlicher Rahmen}

Ziel der folgenden Betrachtung ist eine nach einzelnen Themenkomplexen gegliederte Analyse der sich während der Zeit der Weimarer Republik in der deutschen Massenpresse intensivierenden Modernitätsdiskurse, in denen Bezug auf die USA und die UdSSR genommen wurde. Dabei wird die Frage geklärt werden, auf welche Weise die Wahrnehmungen beider Länder in Deutschland den Referenzrahmen für Debatten bildeten, in denen sich die Presseöffentlichkeit mit Phänomenen der Moderne auseinandersetzte. Mit den USA und der Sowjetunion werden damit beide taktgebenden Mächte des 20. Jahrhunderts gleichberechtigt einbezogen. ${ }^{11}$ Der Untersuchungsrahmen soll also entlang des Dreiecks USA - Deutschland - UdSSR gezogen sein und so den auf die deutsche Öffentlichkeit aus Ost wie West einströmenden Impulsen gerecht werden. ${ }^{12}$ Dabei werden visuelle Medieninhalte in gleichem Maße Beachtung finden wie textuelle. Der Eigen- und Mehrwert des Visuellen in einer solchen Untersuchung wird in den nachfolgenden theoretisch-methodologischen Anmerkungen verdeutlicht. Die Einbindung der UdSSR als Bezugspunkt deutscher Selbstbeschreibung soll die Vergleichsperspektive öffnen, die Einbeziehung visueller Inhalte die Quellengrundlage qualitativ erweitern. Die bisher stark auf den Einfluss der USA fixierte und vornehmlich auf textuelle Quellen abstellende Betrachtung von Weimarer Modernisierungsdebatten wird auf diese Weise substantiell ergänzt und teilweise neu entwickelt.

11 Der Erkenntniswert einer entsprechenden triangulären Analyse ist für die wesentlich direkter sich vollziehenden und plastischer nachweisbaren Einflussprozesse seitens der USA und der Sowjetunion nach 1945 längst erkannt worden und mündete bereits mehrfach in Untersuchungen, welche diese Dreierkonstellation mit hohem Erkenntnisgewinn fruchtbar machen konnten. Zum Beispiel: Jarausch, Konrad/Siegrist, Hannes (Hg.): Amerikanisierung und Sowjetisierung in Deutschland 1945-1970. Frankfurt a. M., New York 1997.

12 Und zwar zugeschnitten auf potentielle Vorbilder beziehungsweise Gegenentwürfe einer »deutschen Moderne«. Damit soll auch einer der zentralen Forderungen der neueren Forschungen zu transnationaler Geschichte entsprochen werden, für den zu behandelnden Zeitabschnitt 1918 bis 1933 die Frage nach der "potentiellen globalen Zivilgesellschaft" zu beantworten. Vgl. dazu: Budde, Gunilla/Conrad, Sebastian/Janz, Oliver (Hg.): Transnationale Geschichte. Themen, Tendenzen und Theorien. Göttingen 2006. 
Der gewählte zeitliche Rahmen von 1918 bis 1933 stellt nur eine von mehreren denkbaren Einteilungen dar, gerade in einer Betrachtung medialer Fremdwahrnehmungsdiskurse. ${ }^{13}$ Zwar liegen die politischen Zäsuren klar zutage (Kaiserreich, Republik, »Drittes Reich«). In Bezug auf kulturell tradierte wie medial vermittelte Länderbilder, die über lange Zeit in einer breiten Öffentlichkeit debattiert werden und oftmals langfristig wirksame Narrative ausbilden, franst aber jeder Zeitrahmen aus. Schließlich werten weder Waffenstillstandsverträge noch "Machtergreifungen « stehenden Fußes die mentalen Landkarten einer ganzen Nation um. Dennoch soll der klassische Zeitrahmen von 1918 bis 1933 beibehalten werden. Im publizistischen Bereich ist eine scharfe Scheidung der Epochengrenzen nämlich durchaus zu rechtfertigen: Die deutsche Medienöffentlichkeit erfreute sich im Vergleich zur kriegsbedingt verschärften Zensur bis 1918 und der "Gleichschaltung« ab 1933 einer vor größeren Eingriffen verschont bleibenden Freiheit des Wortes und Bildes zu den Ausnahmen später. Dieser Umstand gibt hinreichenden Anlass, die hergebrachte zeitliche Verortung von »Weimar« als historischem Komplex beizubehalten: zwischen "Novemberrevolution« 1918 und »Machtergreifung» 1933.

\section{Die Forschungslage}

Das Vorhaben, Spezifika der deutschen Wahrnehmung Amerikas und der Sowjetunion zu untersuchen, steht auf drei Säulen: der Geschichtsschreibung zur Weimarer Republik und den einschlägigen Betrachtungen zur Geschichte der Vereinigten Staaten und der Sowjetunion respektive ihrer Wahrnehmung in Deutschland.

Heinrich August Winklers »Geschichte der ersten deutschen Demokratie « ${ }^{14}$ gab dem Verlauf der politischen Geschehnisse in Zwischenkriegsdeutschland

13 Die starre Periodisierung 1918-1933 kann mit einigem Recht als eine von mehreren möglichen zeitlichen Einteilungen bezeichnet werden. Überprüfenswert wäre beispielsweise die Fixierung auf den 31. Januar 1933 als Ende der Weimarer Ordnung. Einiges spräche dafür, statt dieses abrupten Endes die ab 1930 von Heinrich Brüning betriebene sukzessive Schwächung des Reichstags als allmähliche Abkehr vom pluralistischen Gedanken zu sehen, welche in der "Machtergreifung 1933 lediglich ihren Abschluss fand. Genauso könnte man die chronologische Einordnung breiter, zwischen der Selbstinstallierung des Duumvirats Hindenburg-Ludendorff 1916 und dem auch verfassungsmäßigen Ende der Weimarer Ordnung mit den Scheinwahlen von 1936 aufstellen, wie dies Anthony McElligott in seiner legalistischen Studie getan hat. Vgl. McElligott, Anthony: Rethinking the Weimar Republic. Authority and Authoritarianism 1916-1936. London 2013, 9 f. und $209 \mathrm{f}$.

14 Winkler, Heinrich August: Weimar 1918-1933. Die Geschichte der ersten deutschen Demokratie. München 1994. Knapper aber ebenso präzise und stärker um die Kondensation verschiedener Forschungsmeinungen bemüht: Kolb, Eberhard: Die Weimarer Republik. 
eine klare Struktur und erfüllte gleichzeitig den Anspruch auf Vollständigkeit. Das Bild dieser zwar kurzen, aber dennoch als solche zu bezeichnenden Epoche ist geprägt durch die zahlreichen Widrigkeiten, vor die sich die junge Demokratie gestellt sah. Die nicht verwundene Kriegsniederlage, die halbherzige, aber für viele dennoch an Hochverrat grenzende Revolution sowie wechselnde politische und ökonomische Krisen ließen eine zerrissene deutsche Gesellschaft kaum zur Ruhe kommen. Zerrissen zwischen dem Verharren in den sozialen Erblasten des Kaiserreichs und dem überaus lebendigen Versprechen sozialer, kultureller und wirtschaftlicher Modernität. Das Schwanken zwischen Vertrautem und Neuem manifestierte sich besonders im Hinblick auf die Projektionsflächen USA und UdSSR, an denen sich der Fokus der hier vorliegenden Untersuchung orientieren soll.

Das Versprechen einer von Demokratie, Prosperität und Pluralität gekennzeichneten Zukunft der Weimarer Republik kontrastierte Eric D. Weitz mit dem historisch katastrophalen Befund einer zutiefst polarisierten Gesellschaft. ${ }^{15}$ Neben der vielfachen politischen Spaltung finden bei Weitz auch kulturelle und soziale Spannungsfelder wie die Konflikte um neue Geschlechterrollen breiten Raum. Diesen thematischen Blick nach außen zu wenden, um von außerhalb Deutschlands kommende Impulse für jene Konflikte zu erörtern, verspricht neue Perspektiven auf die öffentlichen Selbstverständigungsprozesse der Weimarer Republik.

Die von Detlev Peukert entlang gesellschaftlicher Konfliktlinien ausgerichtete Verortung der Weimarer Republik inmitten der »Krisenjahre der klassischen Moderne ${ }^{16}$ steht konzeptionell zwischen den Überblicks- und Spezialdarstellungen. Peukert bezieht durch seine Absage an die Relevanz des deutschen »Sonderweg «-Paradigmas für das Scheitern der Republik einerseits Stellung zum politikgeschichtlichen Forschungsgang. ${ }^{17}$ Andererseits legt er durch die Wahl seiner Beobachtungsfelder (Emanzipationskämpfe, Rationalisierung, Massenkultur) seinen Fokus auf Probleme, die in jener Zeit exemplarisch für die Verwerfungen gesellschaftlicher Modernisierungsprozesse

München, Wien 1984. Ausführlicher und die neuere Weimarforschung einbeziehend, versehen mit umfangreichem Datenmaterial zu Wirtschaft und Politik: Büttner, Ursula: Weimar, die überforderte Republik 1918-1933: Leistung und Versagen in Staat, Gesellschaft, Wirtschaft und Kultur. Stuttgart 2008. Die aktuellste Überblicksdarstellung der Forschungsdiskussion zu Weimar, erschienen in der von Arnd Bauerkämper, Peter Steinbach und Edgar Wolfrum herausgegebenen Reihe »Kontroversen um die Geschichte«, ist: Gessner, Dieter: Die Weimarer Republik. Darmstadt 2015. Für den Überblick einschlägiger und repräsentativer Quellen nach wie vor unverzichtbar: Longerich, Peter (Hg.): Die Erste Republik. Dokumente zur Geschichte des Weimarer Staates. München 1992.

15 Weitz, Eric D.: Weimar Germany: Promise and Tragedy. Princeton, NJ 2007.

16 Peukert, Detlev: Die Weimarer Republik. Krisenjahre der Klassischen Moderne. Frankfurt a.M. 1987.

17 Vgl. ebd., 271. 
waren. Seine Zuspitzung auf die krisenhafte Modernisierungserfahrung bleibt eingebettet in eine übergreifende Darstellung. Gesellschaftliche Debatten und politischer Diskurs werden gleichermaßen einbezogen, wie sich dies auch nachfolgende Untersuchungen politisch-kultureller Wirkkomplexe der Weimarer Zeit zum Vorbild nahmen. ${ }^{18}$

Eng verknüpft mit der Wahrnehmung von Modernisierungsprozessen sind die sehr unterschiedlichen Vorstellungen, die man sich von deren Ergebnis machte. Rüdiger Graf hat in seiner Dissertation »Die Zukunft der Weimarer Republik « ${ }^{19}$ eine von den Zukunftsvorstellungen verschiedener politisch-weltanschaulicher Milieus ausgehende Analyse vorgelegt. Er verabschiedet sich durch die Wahl einschlägiger Zeitungen als Quellenkern von politischen Elitendiskursen, die bis dahin entsprechende Betrachtungen dominierten. ${ }^{20} \mathrm{Graf}$ identifiziert die USA und die UdSSR als »topisierte Utopien ${ }^{21}$ im Weimarer Pressediskurs. Er weist damit beide Fremdsysteme als potentielle Taktgeber einer deutschen Moderne aus. Seine Erkenntnis regt dazu an, den Gedanken einer Vorbildfunktion beider Länder breiter auszubauen und zunächst deren Wahrnehmung in Deutschland zu rekapitulieren.

Seit dem Zeitalter der Revolutionen von 1776 und 1789 dehnte sich der Einfluss der Vereinigten Staaten auf immer mehr Bereiche des europäischen Lebens und Denkens aus. Die Wirkung Amerikas wurde seither kontrovers diskutiert, weshalb sich die Forschung zu deutschen Amerikabildern ebenso umfangreich wie vielgestaltig ausnimmt. Die Auswahl der im Folgenden erwähnten Untersuchungen erklärt sich zum einen durch ihre zeitliche Nähe zur Weimarer Republik, zum anderen durch ihren thematischen und methodischen Zuschnitt. Zentrale Topoi wie die "genetisch « anmutende Fortschrittlichkeit oder das Gründerbekenntnis zu Freiheit und Demokratie bestimmten von der Amerikanischen Revolution an mit schwankender Intensität und Sympathie das Denken und Sprechen über Amerika.

18 Grundlegend zu den Perspektiven der demokratischen Ordnung und den Gründen ihres Scheiterns: Mommsen, Hans: Aufstieg und Untergang der Republik von Weimar. 1918-1933. Berlin 1998. Spezifischer zur politisch-sozialen Entwicklung und innovativ hinsichtlich der politischen Phaseneinteilung: Lehnert, Detlef: Die Weimarer Republik. Parteienstaat und Massengesellschaft. Stuttgart 1999. Zur Entwicklung der politischen Kultur Deutschlands unter dem Eindruck der Krisenerfahrung: Hardtwig, Wolfgang (Hg.): Ordnungen in der Krise. Zur politischen Kulturgeschichte Deutschlands 1900-1933. München 2007. Sowie: Ders. (Hg.): Politische Kulturgeschichte der Zwischenkriegszeit 1918-1939. Göttingen 2005. Zur Wirkung der politischen Entwicklungen auf die kulturelle Moderne: Wirkus, Bernd: Die kulturelle Moderne zwischen Demokratie und Diktatur. Die Weimarer Republik und danach. Konstanz 2007.

19 Graf, Rüdiger: Die Zukunft der Weimarer Republik. Krisen und Zukunftsaneignungen in Deutschland 1918-1933. München 2008.

20 Vgl. ebd., 52.

21 Ebd., $250 \mathrm{f}$. 
Volker Depkat hat jenseits von Intellektuellen- und Fachdiskursen die Frage untersucht, welche amerikabezogenen Topoi zwischen 1789 und 1830 im deutschen politischen Diskurs existierten. Wie diese das Handeln und die Selbstabgrenzung politischer Lager, insbesondere der Konservativen und Liberalen, beeinflussten, erklärte er an Hand von Periodika aus dem Dunstkreis jener politischen Familien. Depkats Dissertation »Amerikabilder in politischen Diskursen $\aleph^{22}$ beleuchtet nicht nur das Trennende unterschiedlicher Perzeptionen und Adaptionen konkurrierender politischer Lager. Auch das einende Moment geteilter Ansichten zu Amerika als Raum und politische Idee arbeitet er heraus. Deutlich kommt dabei die ausgeprägte Ambivalenz deutscher Amerikabilder zur Geltung, die unzweifelhaft eine Grundkonstante europäischer und deutscher Wahrnehmungen Amerikas darstellt.

Alexander Schmidt-Gernig ordnet seine später ansetzenden »Reisen in die Moderne ${ }^{23}$ stärker nach sozialen und lebensweltlichen Themen wie dem Geschlechterverhältnis und der Bildungssituation aus. Die ambivalente Wahrnehmung Amerikas durch das europäische Bürgertum zwischen 1890 und 1914 stellt er an ausgewählten Themenblöcken heraus. Seine auf Reiseberichten basierende Schilderung zeigt, dass globale Modernisierungsprozesse primär mit den Vereinigten Staaten assoziiert wurden. Dies galt gleichermaßen für negative wie positive Einschätzungen jener Prozesse - eine Tendenz, die sich über das 20. Jahrhundert hinweg fortsetzte und verstärkte. Amerika wurde nicht nur räumlich, sondern auch zeitlich als der Alten Welt enteilt imaginiert. Als scheinbar geschichtsloser und vom Ballast des Vergangenen befreiter Handlungsraum bot Amerika einen Fluchtpunkt für die Visionen und Befürchtungen europäischer Betrachter. Die bürgerliche Wahrnehmung Amerikas entwickelte sich mit den sozialen Nivellierungen während und nach dem Ersten Weltkrieg zu einer Massenwahrnehmung und damit auch $\mathrm{zu}$ weitgehendem medialem Konsens. Man meinte sich durch den Blick über den Atlantik vorab des Kommenden vergegenwärtigen zu können. Die Zäsur des Ersten Weltkriegs veränderte den Blick auf ein nunmehr siegreiches, (über-) mächtiges Amerika. In Europa, in Deutschland zumal, sah man sich nun als Objekt eines die eigene Strahlkraft übertreffenden äußeren Einflusses, nachdem zuvor scheinbar die Welt um Europa gekreist war.

Dass in der Bewertung des amerikanischen Einflusses einzig die Ambivalenz konstant war, zeigt Egbert Klautke in seiner Vergleichsstudie zur Amerikanisierungsdiskussion in Frankreich und Deutschland. ${ }^{24}$ Einhelligkeit

22 Depkat, Volker: Amerikabilder in politischen Diskursen. Deutsche Zeitschriften von 1789 bis 1830. Stuttgart 1998.

23 Schmidt, Alexander: Reisen in die Moderne. Der Amerika-Diskurs des deutschen Bürgertums vor dem Ersten Weltkrieg im europäischen Vergleich. Berlin 1997.

24 Klautke, Egbert: Unbegrenzte Möglichkeiten. "Amerikanisierung« in Deutschland und Frankreich (1900-1933). Stuttgart 2003. 
herrschte dabei weder im jeweiligen nationalen Kontext noch hinsichtlich fest umrissener Themenfelder. Neben dem Hinweis auf parallele Diskursstrukturen in Deutschland und Frankreich ist vor allem Klautkes Befund wegweisend, der Amerikadiskurs sei lediglich das Brennglas gewesen, in dem sich unübersichtliche Modernisierungsprozesse wie diffuses Licht bündeln ließen. ${ }^{25}$ Die Amerikanisierungsdiskussion half den Zeitgenossen in Deutschland und Frankreich, Modernisierungsprozesse zu ordnen. Richtung, Ausmaß und Intensität der diskursiven Auseinandersetzung mit den auf Kultur, ${ }^{26}$ Wirtschaft und Politik wirkenden Impulsen aus Amerika war durch das jeweils diskutierte Einzelthema bedingt.

Die Ambivalenz und thematische Variabilität deutscher Amerikanisierungserfahrungen zeigen auch Alf Lüdtke, Inge Marßolek und Adelheid von Saldern in ihrem Sammelband auf. ${ }^{27}$ Sie stellen an Hand mehrerer Fallstudien den Traum von wirtschaftlich-technologischem Fortschritt dem Albtraum kultureller Vermassungs- und Überfremdungsängste gegenüber. ${ }^{28}$ Die Autorinnen und Autoren des Bandes zeigen, dass in Kaiserreich, Weimarer Republik und »Drittem Reich» das komplexe Konzept Amerika höchst selektiv

25 Zur»Amerikanisierung «als Analysekategorie von Modernisierungsprozessen hat für die Zeit nach dem Zweiten Weltkrieg Lars Koch Untersuchungen mit thematisch jeweils sehr unterschiedlichen Schwerpunkten zusammengestellt. Sie zeigen, dass sich sowohl die thematische Vielfalt als auch die Stellvertreterfunktion des Amerikanisierungsparadigmas im Diskurs zu darüber hinausweisenden Entwicklungsprozessen auch in die zweite deutsche Nachkriegszeit fortsetzte. Koch, Lars (Hg.): Modernisierung als Amerikanisierung? Entwicklungslinien der westdeutschen Kultur 1945-1960. Bielefeld 2007. Kaspar Maase stellte dieselbe Frage, benutzte aber statt des Begriffs der Amerikanisierung den der Globalisierung. Doch auch bei ihm wird die Zuhilfenahme eines nationalen Rahmens für tatsächlich entgrenzte und entgrenzende Entwicklungsprozesse problematisiert. Maase, Kaspar: »Amerikanisierung der Gesellschaft«. Nationalisierende Deutung von Globalisierungsprozessen? In: Jarausch/Siegrist: Amerikanisierung und Sowjetisierung, 219-241.

26 Kulturelle »Amerikanisierungs«-Prozesse, die tatsächlich kulturelle Expansionsprozesse waren, wurden im kulturkritischen Diskurs Deutschlands weniger in der Hoch- als vielmehr in der Alltagskultur verhandelt und waren auf der politischen Ebene stets mit der Skepsis gegenüber der Eignung der "Massen« zum demokratischen Souverän des Staates verknüpft. Die Widerstände gegen die vermeintlich korrumpierende Wirkung der "Massenkultur« ging Hand in Hand mit tiefer Demokratieskepsis. Dazu: Maase, Kaspar: Happy Endings? Massenkultur und Demokratie in Deutschland im 20. Jahrhundert. In: Linke, Angelika / Tanner, Jakob (Hg.): Attraktion und Abwehr. Die Amerikanisierung der Alltagskultur in Europa. Köln u. a. 2006, 137-160.

27 Lüdtke, Alf/Marßolek, Inge/Saldern, Adelheid von (Hg.): Amerikanisierung: Traum und Alptraum im Deutschland des 20. Jahrhunderts. Stuttgart 1996.

$28 \mathrm{Zu}$ den Bedingungen der Akzeptanz und Adaption spezifisch amerikanischer Wirtschafts-, Geschäfts- und Produktionsmethoden sowie den je nach Milieu und politischer Vision vollkommen unterschiedlichen Hoffnungen und Ängsten, die man in Deutschland mit diesen Innovationen verband: Nolan, Mary: Visions of Modernity: American Business and the Modernization of Germany. New York 1994. Und: Dies.: The Transatlantic Century. Europe and America, 1890-2010. New York 2012, hier 76-103. 
wahrgenommen wurde. Die Schieflage verlief dabei von der positiven Beurteilung von Rationalisierung und Fordismus zum skeptisch beurteilten freiheitlich-egalitären Gesellschaftsverständnis. Miriam Hansen beschäftigt sich im selben Zusammenhang mit der Ablehnung amerikanischer Einflüsse seitens des Intellektuellenmilieus. In ihrem Aufsatz zeigt sie am Beispiel des Kulturkritikers Siegfried Kracauer, dass in der Weimarer Republik die Amerikanisierung als Katalysator für kulturellen und politischen Verfall identifiziert wurde. ${ }^{29}$ Alf Lüdtke wartet mit einer Analyse der Ikonographie Amerikas und seiner Stilisierung zum Ideal der Moderne auf, wie sie nicht nur während der Zeit der Weimarer Republik, sondern anfangs auch im »Dritten Reich" festzustellen war. ${ }^{30}$

Philipp Gassert wählte für seine Untersuchung "Amerika im Dritten Reich $\aleph^{31}$ eine diachrone Perspektive. Das selektive Amerikabild der Deutschen vor 1933 prägt die innenpolitische Rolle des »Wilson-Verrats«, die Bewunderung der wirtschaftlichen Dynamik Amerikas sowie die Skepsis gegenüber vermeintlich charakteristischen Eigenschaften amerikanischer Kultur. $\mathrm{Zu}$ diesen zählt auch ein angeblich alles durchsetzender Kulturfeminismus. ${ }^{32}$ Gasserts Analyse der Perzeption Amerikas und deren Wirkung auf politische Debatten in Deutschland ist nicht nur aus Gründen der chronologischen und thematischen Nähe von Relevanz für die hier vorliegende Untersuchung. Sie ist es vor allem aufgrund von Gasserts Weigerung, ein monolithisches Amerikabild im »Dritten Reich « zu identifizieren. Stattdessen stellt der Autor miteinander kollidierende Auffassungen und Interpretationen der Rolle der USA im deutschen Kontext heraus. In der Auseinandersetzung mit Gasserts Arbeit wurde angemerkt, ein Vergleich des während der Zwischenkriegszeit entstandenen Bildes der USA mit dem der Sowjetunion sei im Hinblick auf die Nachkriegsgeschichte ertragreich gewesen. ${ }^{33}$ Dieser Forderung soll hier nachgekommen werden.

Die verschärfte Form von Amerikaskepsis stellt der Antiamerikanismus dar, der so alt ist wie die Vereinigten Staaten selbst. Wie Dan Diner kursorisch

29 Hansen, Miriam: America, Paris, the Alps: Kracauer and Benjamin on Cinema and Modernity. Ebd, 161-198.

30 Lüdtke, Alf: Ikonen des Fortschritts. Eine Skizze zu Bild-Symbolen und politischen Orientierungen in den 1920er und 1930er Jahren in Deutschland. Ebd., 199-212.

31 Gassert, Philipp: Amerika im Dritten Reich. Ideologie, Propaganda und Volksmeinung 1933-1945. Stuttgart 1997.

32 Zur geschlechterspezifischen Dimension der Amerikanismus- und Amerikanisierungsdiskurse der Weimarer Republik: Thurner, Manuela Andrea: Girlkultur and Kulturfeminismus. Gender and Americanism in Weimar Germany 1918-1933. New Haven, CT 1999.

33 Dies regte Rüdiger Hachtmann in einer Rezension zu Gasserts Buch an. Vgl. Hachtmann, Rüdiger: Rezension zu: Gassert, Philipp: Amerika im Dritten Reich. Ideologie, Propaganda und Volksmeinung 1933-1945. Stuttgart 1997. In: HSozKult, 12.09.1997. URL: http://www.hsozkult.de/publicationreview/id/rezbuecher-335 (am 18.12.2011). 
beschreibt ${ }^{34}$ nahm der deutsche Antiamerikanismus bereits in der Ablehnung des rationalistischen Projekts Amerika seitens deutscher Romantiker seinen Anfang. ${ }^{35}$ Mit dem wachsenden Einfluss der USA und besonders nach der deutsch-amerikanischen Konfrontation 1917 nahm über politische Milieugrenzen hinweg die Ablehnung des amerikanischen Modells zu. Während der Zwischenkriegszeit reichte das Spektrum antiamerikanischer Vorbehalte von der Kultur- und Kapitalismuskritik Bürgerlicher und Linker bis zu antisemitisch-antiamerikanischen Verschwörungsängsten der Nationalsozialisten. ${ }^{36}$ Diner setzt bei seiner Charakterisierung der deutschen Stimmungslage in der Zwischenkriegszeit beim Begriffspaar antimodern und antiamerikanisch sowie bei der These des deutschen Sonderweges an. Er zeigt für die Zeit der Weimarer Republik, dass die Stimmung zwischen proamerikanischen Modernisierungstendenzen in der Wirtschaft und der rigorosen Ablehnung der sozialen »Vermassung « und »Einebnung" schwankte. Diner weist in Ansätzen bereits auf die mit der Amerikawahrnehmung verbundene diskursive Verhandlung von Modernität hin.

Im Falle der Sowjetunion trifft man auf eine thematisch wie chronologisch wesentlich gröber gegliederte Forschungsgrundlage. ${ }^{37}$ Russische Publikationen zur deutschen Wahrnehmung der Sowjetunion existieren vereinzelt, behandeln aber bis auf wenige Ausnahmen nur die Zeit des Zweiten Weltkriegs. ${ }^{38}$ Russische Elemente fehlen in der Forschungsliteratur zur gegenseitigen Wahrnehmung von Deutschen und Russen während der Zeit der Weimarer Republik leider völlig.

34 Diner, Dan: Feindbild Amerika. Über die Beständigkeit eines Ressentiments. Berlin 2002.

35 Ebd., $42 f$

36 Ebd., $66 \mathrm{f}$. und $90 \mathrm{f}$. Andere Akzente und eine andere chronologische Einbettung - von 1871 bis zu heutigen, außenpolitisch konnotierten Formen des Antiamerikanismus nimmt Christian Schwaabe in seiner Untersuchung auf. Die nationalkulturelle Abgrenzung vom westlichen "Händlertum « durch die »Ideen von 1914" (15f.) und der konservativen Revolution (62f.) sowie das selektive Amerikabild der Nationalsozialisten (91 f.), bilden die Untersuchungsschwerpunkte, die hier von besonderer Relevanz sind. Schwaabe, Christian: Antiamerikanismus. Wandlungen eines Feindbildes. München 2003. $\mathrm{Zu}$ den Ursprüngen, wichtigen intellektuellen Weiterentwicklungen und den Bedingungen der heutigen Instrumentalisierbarkeit des Ideologems Antiamerikanismus: Schwark, Sebastian: Zur Genealogie des modernen Antiamerikanismus in Deutschland. Baden-Baden 2008.

$37 \mathrm{Zu}$ den Ursprüngen des modernen Russlandbildes in Deutschland: Blome, Astrid: Das deutsche Rußlandbild im frühen 18. Jahrhundert. Untersuchungen zur zeitgenössischen Presseberichterstattung über Rußland unter Peter I. Wiesbaden 2000. Mit größerer thematischer und chronologischer Rahmensetzung: Groh, Dieter: Rußland im Blick Europas. 300 Jahre historische Perspektiven. Frankfurt a. M. 1993.

38 An der Universität Wladiwostok wurde eine Dissertation zu dem Thema vorgelegt, die aber nicht übersetzt wurde. Übersetzt lautet der Titel: Galechko, Igor: Vorstellungen der Deutschen der Weimarer Republik von Sowjetrussland, 1919-1933. Univ.-Diss., Universität Wladiwostok 2002. 
Mit »Deutschland und Russland ${ }^{39}$ widmete sich Walter Laqueur Mitte der 1960er Jahre Hitlers Wahrnehmung der Sowjetunion. Diese habe erst allmählich auf die Ablehnung alles Russischen, Slawischen und Bolschewistischen eingeschwenkt. Entscheidend dafür sei Alfred Rosenbergs »Nachweis« des jüdischen Ursprungs des Bolschewismus gewesen. ${ }^{40}$ Dieser Wendung sei jedoch eine unter Rechtskonservativen wie Nationalsozialisten weit verbreitete Faszination am illiberalen Ansatz Lenins vorausgegangen. Die bedingungslose Ausrichtung einer ganzen Gesellschaft auf die Autorität einer Partei, letztlich sogar einer einzigen Person erschien ihnen als reizvolles Zukunftsmodell. Die verblüffenden Parallelen zwischen bolschewistischem und nationalsozialistischem Gesellschaftsentwurf lohnen ebenso einen zweiten, aktuelleren Blick wie das Narrativ vom vermeintlich jüdischen Ursprung des Bolschewismus.

Einen anderen Versuch, deutsch-russische Wahrnehmungsmuster zu ergründen, unternahm Manfred Hildermeier. ${ }^{41}$ Er verknüpft Prozesse miteinander, die sich innerhalb und zwischen den Gesellschaften Deutschlands und Russlands abspielten, wobei er bereits zuvor eröffnete Forschungsperspektiven weiterentwickelt. ${ }^{42}$ Hildermeier erkennt im Verhältnis zwischen Deutschen und Russen in der Zwischenkriegszeit eine »Wahlverwandtschaft» und folgt damit einer Wahrnehmung, die vor allem über Pressediskurse hergestellt und tradiert wurde. Transnationale gesellschaftliche Austausch- und Wahrnehmungsprozesse medialer Art bieten also Erkenntnispotential jenseits des reinen Vergleichs.

Auch neuere Forschungen blieben bei der Betrachtung von Russlandbildern komparativen Ansätzen treu. Donal O’Sullivan konzentrierte sich auf eine Gegenüberstellung des zwischen »Furcht und Faszination ${ }^{43}$ changierenden Russlandbildes in Deutschland und Großbritannien. Besondere Aufmerksamkeit verdient O'Sullivans Befund, trotz konträrer außenpolitischer Doktrinen $^{44}$ habe in beiden Ländern eine Art doppelte Abhängigkeit der jeweils

39 Laqueur, Walter: Deutschland und Russland. Berlin 1965.

40 Ebd., $168 \mathrm{f}$.

41 Hildermeier, Manfred: Germany and the Soviet Union. In: Mühle, Eduard (Hg.): Germany and the European East in the Twentieth Century. Oxford 2003, 29-44.

42 Unter anderem: Hildermeier, Manfred/Kocka, Jürgen / Conrad, Christoph (Hg.): Europäische Zivilgesellschaft in Ost und West. Begriff, Geschichte, Chancen. Frankfurt a.M. 2000.

43 O'Sullivan, Donal: Furcht und Faszination. Deutsche und britische Rußlandbilder 19211933. Köln u. a. 1996.

44 Dazu gehört im außenpolitischen Bereich vor allem die Initiative der beiden isolierten Staaten Deutschland und Sowjetunion, durch die Vertragsschlüsse von Genua (»Rapallo«) Folgen der jeweiligen Friedensschlüsse zu revidieren und ihre Isolation gemeinsam zu beenden. Dies war freilich nicht im Interesse der britischen Regierung. Dazu: Fink, Carole/Frohn, Axel/Heideking, Jürgen (Hg.): Genoa, Rapallo, and European Reconstruction. Cambridge 1992. 
zur Sowjetunion eingenommenen Positionen bestanden: Vom spezifischen Aspekt sowjetischer Ordnung, der gerade diskutiert wurde und von der politischen Position, an der sich der jeweilige Kommentator jeweils selbst verorten wollte. Dies galt gleichermaßen für Deutsche wie Briten. O'Sullivan definierte bedenkenswerte Untersuchungslinien: Muster der Fremdwahrnehmung in thematischen statt in nationalen Kontexten zu vergleichen und diesen Vergleich triangulär anzulegen. ${ }^{45}$

Dem deutschen »Russland-Komplex ${ }^{46}{ }^{6}$ widmete sich Gerd Koenen. Ohne sich die Thesen Ernst Noltes zu eigen zu machen, ${ }^{47}$ zeichnet er die ideengeschichtliche Verflechtung Deutschlands und der Sowjetunion nach. ${ }^{48}$ Dabei bezieht Koenen die doppelte Revolution von 1917/18, gemeinsame außenpolitische Ziele in der Zwischenkriegszeit und ideologische Synergien zwischen Nationalsozialismus und Bolschewismus in seine Analyse ein.

Peter Plaggenborg schließlich stellte in "Experiment Moderne ${ }^{49}$ den Gegensatz zwischen der willentlich geschichtslosen, radikalen sowjetischen Moderne und ihren zutiefst unmodernen Merkmalen heraus. ${ }^{50}$ Dazu zählten Machterhalt mittels brutalster Gewalt und das in imperialen Kategorien verharrende Territorialkonzept der Bolschewiki. Plaggenborgs Gedanke einer »integralistischen Moderne «" ${ }^{51}$, die Modernisierungsprozesse zu zentralisieren und öffentlicher Aushandlung zu entziehen suchte, öffnet neue Perspektiven

45 Einen ähnlichen Anspruch, wenn auch für die Zeit nach dem Zweiten Weltkrieg definierten Konrad Jarausch und Hannes Siegrist. Sie stellten die multiplen Umwälzungsprozesse, die im Nachkriegsdeutschland unter dem unmittelbaren Einfluss der dominierenden Besatzungsmächte USA und UdSSR stattfanden, in den Mittelpunkt des von ihnen herausgegebenen Sammelbandes: Jarausch/Siegrist: Amerikanisierung und Sowjetisierung.

46 Koenen, Gerd: Der Russland-Komplex. Die Deutschen und der Osten 1900-1945. München 2005. Die Monografie basiert auf der 2003 an der Universität Tübingen vorgelegten Dissertationsschrift Koenens: Ders.: »Rom oder Moskau«. Deutschland, der Westen und die Revolutionierung Russlands 1914-1924. Univ.-Diss., Tübingen 2003.

47 Durch seinen auf einem früheren Vortrag basierenden Artikel »Die Vergangenheit, die nicht vergehen will« in der Frankfurter Allgemeinen Zeitung (6.6.1986) hatte Nolte bekanntlich durch die These, die Gulags der Bolschewiki seien im Grunde Ursprung und historische Bedingung des Holocaust gewesen, den Historikerstreit ausgelöst.

$48 \mathrm{Zu}$ den trotz erklärter ideologischer Gegnerschaft vorhandenen komplexen Transferwirkungen zwischen der Sowjetunion und Deutschland nach dem Ersten Weltkrieg: Wirsching, Andreas: Antibolschewismus als Lernprozess. Die Auseinandersetzung mit Sowjetrussland in Deutschland nach dem Ersten Weltkrieg. In: Aust, Martin/Schönpflug, Daniel (Hg.): Vom Gegner lernen. Feindschaften und Kulturtransfers im Europa des 19. und 20. Jahrhunderts. Frankfurt a. M. 2007, 137-156.

49 Plaggenborg, Stefan: Experiment Moderne. Der sowjetische Weg. Frankfurt a. M., New York 2006.

$50 \mathrm{Zu}$ den Spezifika sowjetischer Moderne und dem komplexen Wechselverhältnis von Modernität und Ideologie: David-Fox, Michael: Crossing Borders. Modernity, Ideology, and Culture in Russia and the Soviet Union. Pittsburgh, PA 2015.

51 Plaggenborg, Stefan: Experiment Moderne, $323 \mathrm{f}$. 
auf die Sowjetunion als großangelegtes, ideologisch inspiriertes Modernisierungsprojekt der Bolschewiki.

Trotz der voneinander zu unterscheidenden Phasen »russländischer«, »russischer» (vor 1917), »sowjetrussischer« (ab 1917) und »sowjetischer« (ab 1922) Staatlichkeit wird zur besseren Lesbarkeit im Folgenden die Rede von der »Sowjetunion« und dem »sowjetischen« Länderbild sein.

\section{Die Quellen}

Einer Betrachtung der untersuchten Medien sei die Frage vorangestellt, wie die mentalen Landkarten der jeweiligen Leserschaft und das im Medium transportierte Länderbild zusammenhängen. Erschuf die Rezeption medial vermittelter Eindrücke aus dem Ausland das individuelle Länderbild? Blickte man kraft Herkunft, politischer Orientierung und fest in einem Weltbild verankert durch das mediale Schaufenster in die Welt hinaus? Zweifelsohne ist es möglich, Präferenzen in vermeintlich gut voneinander abgrenzbaren Milieus zu identifizieren: "Der Arbeiter« liest anders als »die Katholiken« oder »der Deutschnationale«. Vom bevorzugten Medium auf Wahrnehmungen des einzelnen Lesers zu schließen, erscheint also einleuchtend. Die Wahrnehmung und Beurteilung der eigenen Zeit entsteht jedoch im sich stetig wandelnden Verhältnis zwischen individuellem Herkunftskontext, Gegenwartserfahrung und Zukunftserwartung. Auch die jeweils konsumierten Medien reagieren auf Entwicklungsprozesse und verändern über die Zeit ihre Positionen ohne dass dies die Leserschaft unbedingt nachvollziehen müsste. Der direkte, mechanistische Schluss vom konsumierten Medium auf das konsumierende Individuum ist also mindestens problematisch.

Zur Untersuchung breit zirkulierender Wahrnehmungen der USA und der UdSSR ist die Analyse der massenmedialen Transmissionsebene dennoch die am besten geeignete Sonde, die in die Debatten der Zeit getrieben werden kann. Die massenmediale Perspektive birgt weniger Gefahr, Teilöffentlichkeiten auszuschließen und in kleinteilige Milieustudien abzugleiten. Von einer breiten Öffentlichkeit getragene Diskursstränge furchen milieuspezifische Debatten nämlich nicht einfach unter, sondern setzen sich vielmehr (auch) aus diesen zusammen. Innerhalb von Teilöffentlichkeiten geführte mediale Diskurse werden unter größeren Diskurssträngen subsumiert, welche ihrerseits in Massenmedien repräsentiert sind. ${ }^{52}$ Nicht nur wegen der aufgezeigten Desiderate erscheint eine medial breit gehaltene und nach thematischen $\mathrm{Ge}$ -

52 Vgl. dazu: Requate, Jörg: Öffentlichkeit und Medien als Gegenstände historischer Analyse. In: Geschichte und Gesellschaft. Nr. 25 (1999), 5-32, hier 11. 
sichtspunkten gegliederte Betrachtung also angezeigt. Auch angesichts der Eigenlogik der genutzten Quellen reduziert dieser Ansatz potentielle blinde Flecken.

Den dazu notwendigen Rahmen stellen die fünf am weitesten verbreiteten Tageszeitungen und eine Auswahl an breit zirkulierenden Illustrierten dar. Die gesamte Weimarer Öffentlichkeit ist durch diese Eingrenzung freilich nicht abzubilden. Wer sollte sinnvollerweise auch einen solchen Anspruch erheben? Durch die getroffene Auswahl wird gleichwohl ein Querschnitt durch mehrere Teilöffentlichkeiten präsentiert. Ein solcher Querschnitt lässt valide Rückschlüsse auf das Gesamtbild zeitgenössischer Wahrnehmungen der USA und der UdSSR zu.

Dank technischer Innovationen und weitgehender Alphabetisierung zirkulierten die Inhalte von Druckmedien seit der Jahrhundertwende breiter denn je. In stetig wachsendem Umfang wurden sie auch mit visuellem Material versehen. Druckmedien standen einem ebenso großen wie vielschichtigen Publikum zur Verfügung. Dies lag nicht nur an der quantitativen Verfügbarkeit von Druckerzeugnissen, sondern auch an ihrer neuen qualitativen Eindrücklichkeit. Durch die Integration visueller Inhalte erweiterten sich die medial adressierbaren Wahrnehmungsebenen, wurde doch nun die »besonders geartete Konsumptionsfähigkeit von Bildern $\aleph^{53}$ bei Leserinnen und Lesern angesprochen.

Das von Gustave Le Bon ausgerufene "Zeitalter der Massen $\aleph^{54}$ nahm seinen Anfang nicht zuletzt in dieser medialen Expansion. So liegt es nahe, eine Annäherung an die Weimarer Republik, mithin Höhe- und Wendepunkt der klassischen Moderne in Deutschland, mittels einer Betrachtung ihrer prägenden Massenmedien vorzunehmen. Die Massenprintmedien waren zugleich Bedingungsfaktor und sichtbarster Ausdruck der Massengesellschaft.

Intellektuellenzirkel, Briefwechsel, Tagebucheinträge und ähnliche Kleindiskurse sollen durch eine Fokussierung auf die Massenmedien in keiner Weise in ihrer Aussagekraft für die bewegten 15 Jahre der Weimarer Republik abqualifiziert werden. Sowohl Zeitgenossen als auch Nachgeborene ordneten jene Zeit aber stets explizit als eine Eskalation gesellschaftlicher Nivellierung und beschleunigter gesellschaftlicher Auflösung und Neuordnung ein. In der Analyse einer von solchen Umbrüchen gekennzeichneten Zeit muss also (auch) ein Ansatz verfolgt werden, der dieser als »Vermassung « wahrgenommenen Epochentendenz Rechnung trägt. Nicht die Schriften der Wenigen, sondern das Sehen und Lesen der Vielen soll daher im Mittelpunkt stehen. erstattung in populären Illustrierten der Weimarer Republik. Osnabrück 2004, 8.

54 Le Bon, Gustave: Psychologie des foules. Paris 1895. 
Dafür ist ein aus Illustrierten und Tageszeitungen kombiniertes Quellenkorpus entscheidend. Die »Entgrenzung der Information $\aleph^{55}$ wurde noch vor den aufkommenden Newsreels und Filmvorführungen durch die visuellen Inhalte der Illustrierten besorgt. Obendrein nahmen diese eine zunehmend tragende Rolle unter den gedruckten Periodika ein. Tagesaktuell berichtende Zeitungen und zeitphänomenologisch orientierte Illustrierte ergänzten sich gegenseitig zu einem für die Presselandschaft der Weimarer Republik charakteristischen Spannungsfeld. Der stete Strom von Nachrichten und Kolumnen der Tageszeitungen setzte als Grundrauschen des Diskurses Großthemen auf die Agenda. Spannungsspitzen gesellschaftlicher Kontroversen entluden sich hingegen vornehmlich in der visuell unterstützten Darstellungsform der Illustrierten. Beide Publikationsformate fungierten als gegenseitige Stichwortgeber.

\subsection{Lesermilieus}

Der Befund medialer »Vermassung « während der klassischen Moderne ist angesichts der Fortexistenz von Klassenschranken und kulturellen Milieuunterschieden sicherlich angreifbar. Allein die schichtspezifischen Präferenzen für bestimmte Publikationstypen zeigen die soziale, ökonomische oder politische Bedingtheit medialen Konsumverhaltens. Hier soll deshalb auch keine vollkommen unterschiedslose mediale Massengesellschaft konstruiert werden. Eine Massenmediengesellschaft waren die Deutschen aber sehr wohl - wenn auch eine heterogene. In einer Betrachtung, die mit den Illustrierten einen der wichtigsten kulturellen und medialen Nivellierungsfaktoren überhaupt einbezieht, ${ }^{56}$ darf der Zusammenhang zwischen medialer Expansion und gesellschaftlicher Nivellierung aber nicht bagatellisiert werden. Schon gar nicht, indem man angesichts verschiedener medialer Nischen fälschlicherweise von hermetisch abgeschlossenen Lesermilieus ausgeht. Ebenso wenig sollte man das handfeste kommerzielle Absatzinteresse der Verlagshäuser unterschätzen, das die Ansprache eines sozial vielfältigen (und damit großen) Publikums erforderte.

Konsolidierten Milieus und relativ homogenen Diskursgemeinschaften begegnet man trotz aller gesellschaftlichen Umschichtungen freilich auch in

55 Konrad Dussel hat hierzu an Hand illustrierter Beilagen zu badischen Tageszeitungen die innere Entwicklung und den äußeren Einfluss ihres visuellen Elements untersucht und an diesem Beispiel repräsentativ die (unter anderem) durch Visualisierungen vorangetriebene Entmonopolisierung der Information vorgeführt. Vgl. Dussel, Konrad: Pressebilder in der Weimarer Republik. Entgrenzung der Information. Münster 2012.

56 Heinrich August Winkler ordnete der illustrierten Presse neben Taschenbuch, Schallplatte, Film und Rundfunk die entscheidende Rolle in der "Unterspülung" der Klassengesellschaft und der Herausbildung der Massengesellschaft zu. Vgl. Winkler: Weimar 1918-1933, 296. 
der Weimarer Republik, insbesondere im katholischen Kontext. Nur ist das katholische Milieu als politisch-kulturelles Referenzsystem für die Zeit der klassischen Moderne bereits umfänglich beforscht. ${ }^{57}$ Das katholische Pressespektrum war in den politisch-weltanschaulichen Diskursen der Weimarer Republik stark repräsentiert. Über die Zentrumspartei war es überdies unmittelbar mit dem parlamentarischen Betrieb verzahnt. Einschlägige katholische Publikationen wie die »Historisch-Politischen Hefte« konnten zu Themen wie Massengesellschaft, Rationalisierung und der neuen Rolle der Frau allerdings durch ihre Grundausrichtung nur rundheraus ablehnende Positionen einnehmen. Revolution, Republik und egalitäre Volksherrschaft verurteilten sie pauschal als eine Abwendung von Gott. ${ }^{58}$

Durch die Einbeziehung entsprechender Publikationen träte die für Modernitätsdiskurse der Weimarer Republik so charakteristische Ambivalenz hinter der geschlossen antimodernen Zeitkritik des katholischen Intellektuellenmilieus zurück. Das gilt selbst angesichts von Stimmen aus katholischen Intellektuellenkreisen, die, wie Hans Rost, den Katholizismus zur »Fortschrittsreligion im besten Sinne des Wortes $"$ " ${ }^{59}$ adelten. Als Massenmedien im Sinne der Zeit sind die »Gelben Hefte« und andere katholische Periodika zudem schlicht nicht einzuordnen: Auch wenn sie von weit mehr Menschen gelesen wurden, als ihre Auflage von weniger als 2000 Stück vermuten lässt ${ }^{60}$ erreichten sie dennoch kein ausreichend breites Spektrum für eine Charakterisierung als Massenmedium. Qualitativ-inhaltliche Aspekte sprechen also ebenso gegen die Berücksichtigung katholischer Periodika wie quantitative. Schlussendlich soll in dieser Untersuchung der Liberalismus der Vereinigten Staaten und der (angestrebte) Kommunismus der Sowjetunion hinsichtlich ihrer Prägekraft im deutschen Kontext verglichen werden. Das katholische Intellektuellenmilieu und seine Publikationen sind für dieses Anliegen angesichts ihrer stets gepflegten Ablehnung beider dieser Ismen nicht produktiv. ${ }^{61}$

57 Die jüngere Weimarforschung bringt in regelmäßigen Abständen auf den politischen Katholizismus abhebende Untersuchungen hervor. Zuletzt: Gerber, Stefan: Pragmatismus und Kulturkritik: Politikbegründung und politische Kommunikation im Katholizismus der Weimarer Republik (1918-1925). Paderborn 2015.

58 Vgl. Weiß, Dieter: Katholischer Konservatismus am Scheideweg - Die »Historisch-Politischen Blätter« und die »Gelben Hefte«. In: Kraus, Hans-Christof (Hg.): Konservative Zeitschriften zwischen Kaiserreich und Diktatur. Fünf Fallstudien. Berlin 2003, 97-114, hier 104 und 111.

59 Rost, Hans: Die Kulturkraft des Katholizismus. Paderborn 1916, 22.

60 Weiß, Dieter: Historisch-politische Blätter für das katholische Deutschland. In: Historisches Lexikon Bayerns. URL: http://www.historisches-lexikon-bayerns.de/Lexikon/ Historisch-politische_Blätter_für_das_katholische_Deutschland (am 10.10.2015).

61 Man denke hierbei an die politischen und ideologischen Positionen, die bereits seit Mitte des 19. Jahrhunderts kontinuierlich in den "Historisch-Politischen Blättern" vertreten worden waren. Insbesondere seit der Herausgeberschaft Edmund Jörgs (1819-1901) war 


\subsection{Tageszeitungen}

Im Kontrast zu dieser spezifischen Form weltanschaulicher Presse sollen hier mit fünf reichsweit in hoher Auflage erscheinenden Tageszeitungen und zehn Illustrierten säkulare Quellen herangezogen werden. Es sind dies unter den Tageszeitungen die Vossische Zeitung (VZT), die Frankfurter Zeitung (FZT), die Münchner Neuesten Nachrichten (MNN), die Deutsche Allgemeine Zeitung (DAZ) und das Berliner Tageblatt (BTB). Sie werden im Folgenden kurz einzeln charakterisiert. Darauf folgt eine ebenso kurze Einordnung der Berliner »Illustrirten« Zeitung (BIZ), der Münchner Illustrierten Presse (MIP), der Arbeiter Illustrierten Zeitung (AIZ) und des Illustrierten Beobachters (ILB) als die wichtigsten untersuchten Illustrierten.

Die traditionsreiche Vossische Zeitung war zwar ein durch und durch bürgerliches, nicht aber übermäßig konservatives Blatt. Sie erschien in Grundtenor und politischer Positionierung liberal. Die Auflage bewegte sich während des Beobachtungszeitraumes zwischen 50.000 und 70.000 verkauften Exemplaren pro Tag. ${ }^{62}$ Die VZT zeichnete sich durch innovative politische Gastbeiträge aus. Unter anderem veröffentlichte Graf Coudenhove-Kalergi hier seine Vision eines künftigen $»$ Paneuropa ${ }^{63}{ }^{63}$ Der Zusammenschluss Deutschlands mit Frankreich (»Zusammenschluss oder Zusammenbruch $«)^{64}$ verhieß demzufolge dem gesamten Kontinent eine friedliche und prosperierende Zukunft. Der von der VZT verfolgte Anspruch, zugleich bürgerlich und liberal zu sein, bedeutete für eine Zeitung in der Zwischenkriegszeit vor allem die Ansprache der gebildeten Mittel- und Oberschicht.

Im bürgerlich-liberalen Milieu bewegte sich auch die Zielgruppe des Berliner Tageblatts (BTB). In seiner stärkeren Orientierung auf die kulturellen und intellektuellen Eliten einerseits und seiner spürbaren parteipolitischen Affiliation andererseits unterschied sich das BTB jedoch von der VZT. Das BTB war in Person des bereits seit 1906 amtierenden Chefredakteurs Theodor Wolff an die politische Agenda der Deutschen Demokratischen Partei (DDP) gekoppelt. Die DDP gestaltete als linksliberale Partei mit fast durchgehender Regierungsbeteiligung die Politik der Weimarer Republik maßgeblich mit. Außenpolitisch verfolgte man im BTB stets (wie Theodor Wolff bereits vor dem Krieg) entschieden das Ziel einer europäischen Friedensordnung, der

darin fortfolgend scharf gegen den "verführerischen Liberalismus« und den »gottlosen Sozialismus« polemisiert worden. Vgl. Wehler, Hans, Ulrich: Deutsche Gesellschaftsgeschichte. Bd. 3. München 1995, 249.

62 Bender, Klaus: Vossische Zeitung, Berlin (1617-1934). In: Fischer, Heinz-Dietrich (Hg.): Deutsche Zeitungen des 17. Bis 20. Jahrhunderts. Pullach bei München 1972, 25-39, hier 38.

63 Coudenhove-Kalergi, Richard Nikolaus Graf von: Paneuropa. In: VZT Nr. 541 vom 15.11.1922, 4 .

64 Ebd. 
im Zweifelsfalle auch nationale Interessen untergeordnet werden müssten. Innenpolitisch verwahrte man sich gegen die von linker wie rechter Seite vorangetriebene Demontage der Republik. Die Kommunisten kritisierten, dass das BTB für die Prinzipien des Rechtsstaats eintrat. Aus KPD-Sicht wahrte der Rechtsstaat lediglich Besitzstände und blockierte notwendige Veränderungen. Die Nationalsozialisten hingegen störten sich an der jüdischen Herkunft Theodor Wolffs, vor allem aber an dessen entschiedenem Eintreten für die parlamentarische Demokratie. ${ }^{65}$

Die Frankfurter Zeitung bezog, ähnlich wie das BTB, im Weimarer Pressediskurs Stellung für die Akzeptanz des Versailler Vertrages und der Stresemann'schen Außenpolitik sowie gegen Revisionismus und Dolchstoßlegende. Durch ihre unabhängige Informationsgewinnung aus dem politischen Berlin und dem Ausland setzte sie sich in politischen Bewertungen von den anderen Tageszeitungen ab. Diese bezogen ihre Informationen in der Regel einheitlich vom Nachrichtenbüro des Vereins Deutscher Zeitungsverleger, während die FZT ein eigenes Korrespondentennetzwerk unterhielt. Die verkaufte Auflage der FZT bewegte sich zwischen 170.000 Exemplaren pro Tag gegen Ende des Ersten Weltkriegs und 100.000 um die Zeit der "Machtergreifung ${ }^{66}{ }^{66}$ Die FZT legte relativ viel Gewicht auf das Feuilleton. Regelmäßig erschienen unter dieser Rubrik politische Wortmeldungen Kunst- und Literaturschaffender wie beispielsweise Stefan Zweig. ${ }^{67}$ Die Redaktion der FZT vertrat eine prorepublikanische Position und betonte die Bedeutung des Rechtsstaats.

Die Münchner Neuesten Nachrichten (MNN) propagierten im Gegensatz zur FZT aktiv die Dolchstoßlegende. ${ }^{68}$ Wegen wechselnder politischer und

65 Vgl. Schwarz, Gotthart: Berliner Tageblatt (1872-1939). In: Fischer, Heinz-Dietrich (Hg.): Deutsche Zeitungen des 17. Bis 20. Jahrhunderts, 315-328, hier 324f. Zu Theodor Wolff und seinem nachhaltigen Wirken zwischen Publizistik und Politik: Sösemann, Bernd: Theodor Wolff: Ein Leben mit der Zeitung. Stuttgart 2012.

66 Vgl. Paupié, Kurt: Frankfurter Zeitung (1856-1943). In: Fischer, Heinz-Dietrich (Hg.): Deutsche Zeitungen des 17. Bis 20. Jahrhunderts, 241-256, hier 249.

67 Vgl. Todorow, Almut: Das Feuilleton der »Frankfurter Zeitung« in der Weimarer Republik: Zur Grundlegung einer rhetorischen Medienforschung. Tübingen 1996, $68 \mathrm{f}$.

68 Der Verlagsleiter der MNN, Paul Nikolaus Cossmann, zum Katholizismus konvertierter Jude und tatsächlich selbst latent antisemitische Einstellungen vertretend, strengte federführend den sogenannten Dolchstoßprozess an, in dem der Beweis geführt werden sollte, Juden und Sozialdemokraten hätten die Anstrengungen der deutschen Streitkräfte während des Weltkriegs aus der Heimat derart effektiv obstruiert, dass diese - obgleich »im Felde unbesiegt « - aus politischen Gründen die Waffen hätten strecken müssen. Die juristischen Opponenten in diesem Prozess, Cossmann und Martin Gruber, Chefredakteur der entsprechend ihrer sozialdemokratischen Grundausrichtung argumentierenden Münchner Post, standen sich nicht nur vor Gericht gegenüber, sondern führten auch über ihre Zeitungen einen Deutungskampf zu den Geschehnissen um den Waffenstillstand von 1918. Dazu: Permooser, Irmtraud: Der Dolchstossprozess in München 1925. In: Zeitschrift für Bayerische Landesgeschichte. Nr. 59 (1996), 903-926, hier $906 \mathrm{f}$. 
wirtschaftlicher Einflüsse von außen besaßen sie - anders als VZT, BTB und FZT - keine durchgängig konstante politische Ausrichtung. Während der Zeit der Münchner Räterepublik fungierten die MNN unfreiwillig als deren offizielles Verkündungsblatt. Anfang der 1920er Jahre wurden sie dann zu unterschiedlichen Anteilen an ein Konglomerat der Schwerindustrie und an Alfred Hugenberg verkauft. In der Folge kann man die Grundlinie der Zeitung als rechtskonservativ mit deutlich rechtsnationalen Anwandlungen einordnen. ${ }^{69}$ $\mathrm{Zu}$ den Nationalsozialisten nahmen die meisten, wenn auch nicht alle führenden Köpfe der Redaktion Abstand, wandten sich intern wie extern gegen Hitler. Die "Auswüchse des Parlamentarismus ${ }^{70}$ lehnten gleichwohl weite Teile der MNN-Redaktion ab. Die MNN erreichten zwischen 1918 und 1933 im Schnitt eine Auflage von 120.000 verkauften Exemplaren pro Tag. ${ }^{71}$

Die Deutsche Allgemeine Zeitung ${ }^{72}$ (DAZ) schließlich hatte bereits vor dem Ersten Weltkrieg hohes internationales Ansehen genossen und fand weite Verbreitung in der politischen Elite Deutschlands. Nach einer vorübergehenden Besetzung der Redaktion durch Spartakisten wurde die DAZ als ursprünglich liberalkonservatives Blatt 1920 vom Großindustriellen Hugo Stinnes aufgekauft. Seitdem vertrat sie zumeist rechtskonservative Ansichten und damit Positionen, die denen ihres Besitzers entsprachen.$^{73}$ Stinnes bezuschusste die DAZ in beträchtlichem Maße, um sie zu einer deutschen "Times « aufzubauen. Diesem Anspruch nach hatte die DAZ überparteilich und nur dem Wohl der Nation verpflichtet zu sein. ${ }^{74}$ Diesem Wohl stand aus Sicht von Stinnes und Redaktionsleiter Rudolf Cuno besonders der Versailler Vertrag entgegen. In Redaktion wie Leserschaft der DAZ sammelten sich die Gegner der neuen außenpolitischen Ordnung. Zwischenzeitlich war sogar das Auswärtige Amt unter Gustav Stresemann Eigner der DAZ. ${ }^{75}$ Während dieser kurzen Zeit kann die DAZ als inoffizielles Organ der Regierung gelten. ${ }^{76}$ Durch die DAZ konnten die Diplomaten Positionen im öffentlichen Diskurs beziehen, welche ihnen die gebotene Zurückhaltung eigentlich verbot. Der politischen Presse

69 Vgl. Henkel, Peter: Anton Betz. Ein Verleger zwischen Weimar und Bonn. Düsseldorf 2011, $135 \mathrm{f}$.

70 Holz, Kurt: Münchner Neueste Nachrichten (1848-1945). In: Fischer, Heinz-Dietrich (Hg.): Deutsche Zeitungen des 17. Bis 20. Jahrhunderts, 191-207, hier 202.

71 Vgl. Hoser, Paul: Münchner Neueste Nachrichten. In: Historisches Lexikon Bayerns. URL: https://www.historisches-lexikon-bayerns.de/Lexikon/M\%C3\%BCnchner_Neueste_ Nachrichten (am 02.12.2015).

72 Vor 1918: Norddeutsche Allgemeine Zeitung.

73 Wulf, Peter: »Die Stimme ihres Herrn«. Hugo Stinnes und die Deutsche Allgemeine Zeitung. In: Zeitschrift für Unternehmensgeschichte. Nr. 29 (1984), 153-179, hier 155 f.

74 Vgl. Fischer, Heinz-Dietrich: Deutsche Allgemeine Zeitung (1861-1945). In: Ders. (Hg.): Deutsche Zeitungen des 17. Bis 20. Jahrhunderts, 269-282, hier 277.

75 Vgl. ebd., 278.

76 Vgl. Petersen, Klaus: Zensur in der Weimarer Republik. Stuttgart, Weimar 1995, 115. 
der Weimarer Republik, also Parteizeitungen und subventionierten Tendenzblättern, kann die DAZ dennoch nicht zugerechnet werden. An der grundsätzlich rechtsnationalen Einstellung - man forderte ab 1932 vehement eine Regierungsbeteiligung Hitlers - änderte die Einflussnahme des Auswärtigen Amtes nämlich kaum etwas. Mehr als einmal lief die Arbeit der DAZ-Redaktion den Darstellungsinteressen der Reichsregierung diametral entgegen. ${ }^{77}$

Ein Kriterium für die Auswahl dieser fünf Zeitungen ist ihre überregionale Verbreitung. Ein anderes ist der ihnen gemeine Anspruch, alle wirtschaftlichen, politischen und gesellschaftlichen Prozesse, die für die Entwicklung in ganz Deutschland maßgeblich waren, vollständig abzubilden. Sie stellten über den nationalen Rahmen hinaus anerkannte Leitmedien dar. Ihrer Themensetzung und Positionierung folgten kleinere und regionale Tageszeitungen oder nahmen entsprechend ihrer jeweiligen politischen Orientierung Bezug auf die Positionen der fünf »Großen«. Die journalistische Begleitung umfassender Modernisierungsprozesse und die Darstellung der vielfältigen Ideentransfers zwischen den USA, Deutschland und der UdSSR erforderten einen hohen thematischen Abstraktionsgrad und weit gespannte Netzwerke von Auslandskorrespondenten und Reisberichterstattern, die durch ihre individuellen Perspektiven maßgeblichen Einfluss auf die Wahrnehmung der USA und der UdSSR nahmen. Über solche Qualifikationen verfügten die fünf genannten Tageszeitungen.

Die fünf ausgewählten Tageszeitungen sind zudem in ihrer jeweiligen politischen Ausrichtung zwischen liberalem, bürgerlichem, konservativem und nationalistischem Milieu sowie ihrer territorialen Verbreitung komplementär. Alle politischen und regionalen Milieus waren durch mindestens eine von ihnen abgedeckt. Sie besaßen allesamt eine ausreichend hohe Zirkulation und Breitenwirkung, um als prominente Einflussfaktoren im öffentlichen Diskurs zu gelten. Regionale und lokale Zeitungen einzubeziehen, wäre durchaus eine Möglichkeit zur Vertiefung der Perspektive. Trotz der dadurch gewonnenen Tiefe bestünde das Risiko, die hier angestrebte Ausrichtung der Untersuchung an gesamtdeutschen Paradigmen zugunsten kleinteiligerer Perspektiven zu opfern, welche sich dann an Milieu-, Konfessions- und regionalen Grenzen orientieren.

77 So fehlt die DAZ auch in der ansonsten sehr auf Vollständigkeit bedachten Aufstellung von Heinz-Dietrich Fischer zum Phänomen der Tendenzpresse: Fischer, Heinz-Dietrich: Handbuch der politischen Presse in Deutschland 1480-1980. Synopse rechtlicher, struktureller und wirtschaftlicher Grundlagen der Tendenzpublizistik im Kommunikationsfeld. Düsseldorf 1981, $599 \mathrm{f}$. 


\subsection{Illustrierte}

Illustrierte popularisierten Moderne, indem sie sich durch ihre visuellen Ausdrucksformen an breitere Publikumssegmente richteten als Tageszeitungen. In ihrer oftmals boulevardesken Themenwahl befriedigten sie beim Publikum andere Bedürfnisse als die zur politischen Information sich verpflichtet sehende Tagespresse. Letztere stellte in Stil (gehoben) und Themenspektrum (Politik, Wirtschaft und Kultur) auf den vorbildhaft imaginierten "Staatsbürger« als Leser ab. Illustrierte Magazine nahmen hingegen den »Massenmenschen" in seiner nicht immer nur ernsthaften, mitunter sensationslüsternen Irrationalität als Konsumenten aktiv an. Mit dem visuellen Element versuchten sie die im Vergleich zur Schriftsprache unmittelbarere Wahrnehmungsebene anzusprechen, alle öffentlichkeitstauglichen Themen aufzugreifen und so plastisch wie möglich darzustellen. ${ }^{78}$ So trugen sie ihren Teil zum Anschwellen der "Flut der Bilder« bei, die sich zwar nicht erst seit den 1920er Jahren über die europäischen Öffentlichkeiten ergoss, ihren vorläufigen Höhepunkt aber in der Zwischenkriegszeit fand und die Massenkultur maßgeblich prägte. ${ }^{79}$

Die Berliner »Illustrirte« Zeitung (BIZ), die einmal wöchentlich im Berliner Verlagshaus Ullstein erschien, war schon seit der Jahrhundertwende eine Pionierin auf dem Gebiet des massentauglichen Infotainment gewesen und führend unter den Illustrierten Zeitungen. Sie erreichte während des Untersuchungszeitraums eine Auflage zwischen eineinhalb und zwei Millionen Exemplaren..$^{80}$ Ihr Profil umfasste Beiträge zu moderner Lebensart, Kultur, Reise, Sport, Technik, Unterhaltung, Klatsch, Auslandsreportagen sowie die Diskussion aktueller gesellschaftlicher und politischer Themen. Dieser eklektische Versuch, die komplexer werdenden Zeiten auf gut 40 Seiten zu bannen, resultierte in einer bemerkenswerten Mischung von Themen und einem teilweise drastischen intellektuellen Niveaugefälle: Neben tiefgründigen Reportagen, zum Beispiel über die entwürdigenden Prüfungsprozeduren auf Ellis Island (»Prüfung auf Amerika-Tauglichkeit») ${ }^{81}$ standen Berichte zum »Kaugummi-Unwesen in Berlin ${ }^{82}$. Innenpolitisch verschrieb sich die BIZ einer

78 Vgl. dazu: Gebhardt, Hartwig: »Halb kriminalistisch, halb erotisch«: Presse für die `niederen Instinkter. In: Maase, Kaspar/Kaschuba, Wolfgang (Hg.): Schund und Schönheit. Populäre Kultur um 1900. Köln u. a. 2001, 184-217.

79 Vgl. Lachenicht, Susanne: Die neue Visualität der Zeitschrift im frühen 20. Jahrhundert und die culture de masse. In: Zimmermann, Clemens/Schmeling, Manfred (Hg.): Die Zeitschrift - Medium der Moderne. Deutschland und Frankreich im Vergleich. Bielefeld 2006, 63-84, hier 64 und 82.

80 Vgl. Marckwardt, Wilhelm: Die Illustrierten der Weimarer Zeit. Publizistische Funktion, ökonomische Entwicklung und inhaltliche Tendenzen (unter Einschluß einer Bibliographie dieses Pressetypus 1918-1932). München 1982, 70.

81 Anon.: Prüfung auf Amerika-Tauglichkeit. In: BIZ, 1923, Nr. 38, Titel.

82 Anon.: Kaugummi-Unwesen in Berlin. In: BIZ, 1925, Nr. 14, 447. 
radikalneutralen Darstellung. Nur in absolut konsenssicheren Belangen bezog sie klar Stellung, so beispielsweise gegen die politische Durchsetzung der Jugend. ${ }^{83}$ In gesellschaftlichen Dingen erschien das Gesamtprofil der BIZ als bürgerlich-liberal. Das politische Interesse der Redaktion war die Bewahrung der Freiheit (auch der Kritik), welche die Republik in publizistischer Hinsicht bot.

Nahezu identisch im thematischen Zuschnitt war das Profil der 1924 auf den Markt drängenden Münchner Illustrierten Presse. Die ab Ende 1925 im Münchner Verlag Knorr \& Hirth erscheinende MIP orientierte sich erkennbar am Erfolgsmodell der BIZ. Sie erreichte bald beträchtliche Auflagenzahlen, im Schnitt eine halbe Million Exemplare. ${ }^{84}$ Ein Grund für den schnellen Erfolg waren die journalistischen Innovationen im Bereich der Fotoreportage, die vor allem der Bildredakteur Stefan Lorant vorantrieb. In der Literatur wird Lorant zuweilen gar als »Godfather of Photojournalism « bezeichnet. ${ }^{85}$ Die Weiterentwicklungen Lorants bestanden unter anderem in der Visualisierung zeitlicher Abläufe mittels serieller Bildbeiträge, was den Seitenaufbau spürbar dynamischer erscheinen ließ. Obgleich in der innenpolitischen Ausrichtung ähnlich neutral wie die BIZ, kam in der MIP wesentlich stärker das Unbehagen ob der hegemonialen Rolle der amerikanischen Wirtschaft und Kultur zum Ausdruck. So wurde durch die ostentative Benutzung von Anglizismen deren Verwendung als prätentiös und lächerlich gebrandmarkt. ${ }^{86}$ Auch die offensive Adressierung des außenpolitischen Großmachtgebarens der USA belegt die ausgeprägte Amerikaskepsis der MIP. ${ }^{87}$ Gegenüber der neuen Ordnung in Russland nahm man eine ablehnende Haltung ein, wenn auch nicht so prononciert wie im Falle der USA. Die MIP gehörte, trotz oder gerade wegen dieser kritisch-distanzierten Haltung fest zum bürgerlichen Mainstream des Weimarer Medienbetriebs.

Im krassen Gegensatz dazu stand die Arbeiter Illustrierte Zeitung. Als Teil des Medienkonzerns von KPD-Funktionär Willi Münzenberg war die AIZ als Gegenperspektive zur bürgerlichen Wahrnehmung gesellschaftlicher Fragen und internationaler Ereignisse konzipiert. Die AIZ war 1921 im Rahmen der Internationalen Arbeiterhilfe zur Mobilisierung von Spenden für Notleidende im neuen Sowjetstaat unter dem Namen »Sowjet-Russland im Bild» (SIB)

83 Anon.: Politisierung der Jugend. In: BIZ, 1923, Nr. 6, 103.

84 Vgl. Marckwardt, Wilhelm: Die Illustrierten der Weimarer Zeit, 84.

85 Hallett, Michael: Stefan Lorant: Godfather of Photojournalism. Lanham, MD 2005.

86 Anon.: »Kunst-City«. In: MIP, 1926, Nr. 8, 184 (Jahresausgabe). Sowie: Anon.: Wall Street: "Ausgepowerte« Wirtschaft. In: MIP, 1926, Nr. 12, 263 (Jahresausgabe).

87 Anon.: Amerikanische Schönheitsinvasion. In: MIP, 1927, Nr. 2, 29 (Jahresausgabe). Sowie: Anon.: Coolidge turnt. Hinterspieler in Nicaragua. In: MIP, 1927, Nr. 2, 46 (Jahresausgabe). 
gegründet worden. ${ }^{88}$ Sie dokumentierte anfangs die Herausforderung des Aufund Umbaus der russischen Gesellschaft und Wirtschaft inmitten des tobenden Bürgerkrieges. Neben empathischen Reportagen über die Zustände in Russland und Spendenwerbung hatte die AIZ von Beginn an aggressive Propaganda für die Bolschewiki im Programm und stilisierte deren Führungsfiguren zu Helden des Proletariats. ${ }^{89}$ Mit der Zeit erweiterte sich jedoch die Perspektive der Berichterstattung und schloss bald auch die deutsche Innenpolitik und das politische Weltgeschehen jenseits der Sowjetunion ein. Das Leitmotiv war stets die Kritik und »Demaskierung « der Bourgeoisie als Trägerschicht des Kapitalismus. Mit der Öffnung gegenüber leichtfüßigeren Themen der Lebensführung und Unterhaltung, die freilich ideologisch gefärbt daherkamen, brachte es die AIZ Mitte der 1920er Jahre auf eine Viertelmillion Exemplare. Gegen Anfang der 1930er Jahre wurden gar eine halbe Million pro Woche abgesetzt. ${ }^{90}$

Die USA waren in der AIZ Ziel heftiger Kritik und zwar nicht nur als vermeintliche Schutzmacht des internationalen Kapitalismus. Probleme wie die (halb-)staatliche Rassendiskriminierung und die grassierende Lynchjustiz wurden ab Mitte der 1920er Jahre verstärkt angeprangert. ${ }^{91}$

In der AIZ setzte man visuelle Medien und Bildkompositionen zunächst ausnehmend plump zu propagandistischen Zwecken ein. Mit der Zeit wurden zentrale politische Botschaften aber zunehmend kreativ und künstlerisch visuell verstärkt. Herauszugreifen ist hier das Engagement von John Heartfield (eigentlich Helmut Herzfeld), das der AIZ Fotomontagen von bis dahin ungekannter Prägnanz und Eindrücklichkeit bescherte. Herausgeber Willi Münzenberg hatte den Dadaisten Heartfield über dessen Tätigkeit für die KPD kennengelernt und für seine Hausillustrierte gewinnen können. ${ }^{92}$ Die visuelle Gestaltungskraft Heartfields und anderer Künstler ist indes keine bloße Randnotiz. Sie begründete die ausgeprägte Mobilisierungswirkung der AIZ. Die vom Münzenberg-Konzern vorangetriebene Massenmobilisierung durch den Einsatz von Bildern revolutionierte, von Heartfield orchestriert, die politische Propaganda in Deutschland. ${ }^{93}$ Fest im kommunistischen Milieu der Weimarer

88 Die Publikationen »Sowjet-Russland im Bild« (SIB), "Sichel und Hammer« (SUH) und »Arbeiter Illustrierte Zeitung " (AIZ) werden wegen ihrer sowohl institutionell als auch inhaltlich klar erkennbaren Kontinuität und ihrem während des Beobachtungszeitraumes ununterbrochenen Verbleib im Medienimperium Willi Münzenbergs in der Analyse ihrer Aussagen trotz der zweifachen Namensänderung zu einem Organ zusammengefasst.

89 Anon.: Führer und Volk. Die Oktoberrevolution. In: AIZ, 1921, Nr. 2, 10 f.

90 Vgl. Marckwardt, Wilhelm: Die Illustrierten der Weimarer Zeit, 77.

91 Anon.: Die Negerfrage in Amerika. In: AIZ, 1926, Nr. 4, Titel.

92 Vgl. Coles, Anthony: John Heartfield. Ein politisches Leben. Köln 2014, 143 f.

93 Vgl. Bavaj, Riccardo: »Revolutionierung der Augen«: Politische Massenmobilisierung in der Weimarer Republik und der Münzenberg-Konzern. In: Daniel, Ute/Marßolek, Inge/Pyta, Wolfram/Welskopp, Thomas (Hg.): Politische Kultur und Medienwirklichkeiten in den 1920er Jahren. München 2010, 81-100. 
Presselandschaft verankert, war die AIZ spürbar um die Erschütterung des entstehenden republikanischen Selbstverständnisses bemüht.

Der nationalsozialistische Illustrierte Beobachter (ILB) schließlich war das illustrierte Pendant zum Völkischen Beobachter und damit der ideologische Gegenspieler der AIZ. Er erschien ab 1926 wöchentlich im Münchner FranzEher-Verlag. Zunächst erreichte er mit etwa 40.000 Exemplaren pro Woche nur einen Bruchteil der Auflagen von BIZ und MIP. Mit der Weltwirtschaftskrise stiegen die Verkaufszahlen des ILB jedoch proportional zum politischen Zuspruch für die Nationalsozialisten. 1932 erreichten sie deutlich mehr als 300.000 abgesetzte Hefte. ${ }^{94}$ Oberflächlich glich die thematische Zusammenstellung derjenigen der BIZ, bis hin zur obligatorischen Rätsel- und Humorseite. »Unter'm Brennglas « genannt, enthielt diese Rubrik vor allem antisemitische und antirepublikanische Karikaturen, griff aber auch Phänomene wie die sich gegen Ende der 1920er Jahre ausbreitende Bandenkriminalität auf. ${ }^{95}$ Die zahlreichen Bildreportagen waren stets mit einschlägigen ideologischen Botschaften versehen. Die Parolen richteten sich in der Hauptsache gegen Juden, das amerikanische Kapital (beziehungsweise beide gemeinsam), ${ }^{96}$ die deutsche Republik und den Bolschewismus. Auch beim ILB bestand das politische Hauptinteresse darin, die republikanische Ordnung durch die kontinuierliche Verunglimpfung ihrer Repräsentanten und Institutionen zu destabilisieren. Daneben sollten die Kernbestandteile nationalsozialistischer Ideologie unters Volk gebracht werden. Während seiner Erscheinungsdauer brachte die wiederholte persönliche Beleidigung staatlicher Würdenträger und Institutionen dem ILB auf Grundlage der im Folgenden erläuterten gesetzlichen Bestimmungen zahlreiche Erscheinungsverbote ein.

94 Vgl. Marckwardt, Wilhelm: Die Illustrierten der Weimarer Zeit, 77.

95 Eine Karikatur von 1929, auf welcher der Berliner Polizeipräsident Karl Zörgiebel ängstlich vor einem maskierten Kriminellen in Deckung geht, ist mit dem Kreuzreim untertitelt: »Berlin im Kriegszustand. Das rote Auge des Gesetzes wacht!/ Mit Gönnerzwinkern blinzelt es indessen, / wenn sich in heißer, offner [sic] Straßenschlacht/Kaschemmehunde und Marxgilden messen."Anon.: Unter'm Brennglas. In: ILB, 1929, Nr. 2, 19.

96 Teils wurden Angriffe gegen das amerikanische »Kapital« und antisemitische Botschaften miteinander verknüpft und in ansonsten eher harmlose Reportagen zu gewöhnlichen Themen, wie beispielsweise zum Bergbau, integriert. So enthält eine Betrachtung des Bergbaus im Ruhrgebiet sowohl Bezugnahmen auf die finanziellen Belastungen des amerikanischen Dawes-Plans als auch den Satz, Juden sehe man wegen der harten körperlichen Arbeit nicht im Bergwerk. Anon.: 700 Meter unter Tag: Dawesfron. Juden sind nicht dabei. In: ILB, 1929, Nr. 1, $10 \mathrm{f}$. 


\subsection{Massenmedien und Gesellschaft}

Nach der Betrachtung einzelner Publikationen soll nun der rechtliche, politische und gesellschaftliche Rahmen abgesteckt werden, innerhalb dessen sich die deutsche Presse zwischen 1918 und 1933 bewegte. Zwischen der Militärzensur des Ersten Weltkriegs und der "Gleichschaltung" verfügten die Massenmedien in der Republik über relativ große Freiheit und wirkten daher ungefiltert auf den gesellschaftlichen und politischen Diskurs ein. ${ }^{97}$ Hinzu kam die bereits seit dem letzten Drittel des 19. Jahrhunderts anhaltende und sich seit der Jahrhundertwende stetig beschleunigende mediale Expansion. Diese vollzog sich qualitativ (Darstellungsmöglichkeiten) wie quantitativ (Zirkulation und Auflage). Damit ging eine direkte Transmissionswirkung zwischen medial produziertem und rezipiertem Geschehen und dem Alltagserleben der Bevölkerung und politischer Entscheider einher. Kurz: Massenmedien waren durch ihre gewachsene Bedeutung in der Lage, politische und gesellschaftliche Debatten stärker denn je mit der öffentlichen Meinungsbildung zu verzahnen. Meinung formierte sich maßgeblich im Kontext der Massenmedien.

Dennoch waren den medialen Entfaltungsmöglichkeiten und der verfassungsmäßig garantierten Pressefreiheit Grenzen gesetzt. Diese wurden in Artikel 118 der Weimarer Reichsverfassung aufgeführt. Im zweiten Absatz des Artikels sah der Gesetzgeber Einschränkungen bezüglich jugendgefährdender Erzeugnisse, der sogenannten »Schund- und Schmutzliteratur" vor. Zwar hatte der Rat der Volksbeauftragten um Friedrich Ebert am 12. November 1918 feierlich verkündet, eine Zensur der Presse finde von nun an nicht mehr statt und die »Meinungsäußerung in Wort und Schrift» sei »frei « ${ }^{98}$. Staatliche Eingriffsrechte in die Pressefreiheit bestanden jedoch fort. Der berüchtigte Artikel 48 der Weimarer Reichsverfassung gestattete dem Reichspräsidenten

97 Zur Militärzensur während des Ersten Weltkriegs: König, Marcus: Agitation, Zensur, Propaganda. Der U-Boot-Krieg und die deutsche Öffentlichkeit im Ersten Weltkrieg. Stuttgart 2014, $92 \mathrm{f}$.

98 Koszyk, Kurt: Deutsche Presse 1914-1945. Berlin 1972, 28. Diese Festlegung bildet die Grundlage für Artikel 118 der Weimarer Reichsverfassung, der folgendermaßen lautete. »(1) Jeder Deutsche hat das Recht, innerhalb der Schranken der allgemeinen Gesetze seine Meinung durch Wort, Schrift, Druck, Bild oder in sonstiger Weise frei zu äußern. An diesem Rechte darf ihn kein Arbeits- oder Anstellungsverhältnis hindern, und niemand darf ihn benachteiligen, wenn er von diesem Rechte Gebrauch macht. (2) Eine Zensur findet nicht statt, doch können für Lichtspiele durch Gesetz abweichende Bestimmungen getroffen werden. Auch sind zur Bekämpfung der Schund- und Schmutzliteratur sowie zum Schutze der Jugend bei öffentlichen Schaustellungen und Darbietungen gesetzliche Maßnahmen zulässig.« 
"zur Wiederherstellung der öffentlichen Sicherheit und Ordnung» auch explizit Eingriffe in die Pressefreiheit. ${ }^{99}$

Vage, recht freizügig anwendbare Zensurregelungen bestanden auch hinsichtlich juristisch unscharfer Tatbestände wie Geheimnisverrat oder persönlicher Ehrabschneidung. Diese Regelungen griffen, wenn die Berichterstattung die Rüstung der Reichswehr berührte, letztere öffentlich verunglimpft wurde oder der Tatbestand übler Nachrede als erfüllt angesehen wurde. Bei medialer Justizkritik wurde häufig von diesem rechtlichen Mittel Gebrauch gemacht. ${ }^{100}$ Dies führte zu einer mittelbaren Kontrolle der Presse durch Organe der Exekutive. Die nahm sich immer wieder das Recht, gegen kritische Presseberichterstattung über den Umweg des Tatbestands der üblen Nachrede vorzugehen mit durchwachsenem Erfolg. ${ }^{101}$ Vor allem links- und rechtsradikale Blätter wurden mittels der fortbestehenden Eingriffsrechte für längere Zeiträume an der Publikationstätigkeit gehindert.

Neben rechtlichen Beschränkungen existierten willkürlich herbeigeführte Einschränkungen in Form krimineller Sabotageakte. In den ersten Jahren der Republik besetzten häufig politische Kampfverbände - radikale Linke ebenso wie die rechten Kräfte des Kapp-Putsches - Redaktionen und Druckereien oder zerstörten technische Ausstattung. So versuchten sie missliebige Veröffentlichungen zu verhindern oder propagandistische Botschaften unters Volk zu bringen. ${ }^{102}$ Zumindest zeitweise war dadurch die Arbeit der Presse stark eingeschränkt.

Ein internes, nicht minder problematisches Strukturmerkmal des Weimarer Pressemarktes war die Pressekonzentration. Diese bestand in der Vereinigung zahlreicher Einzelpublikationen in Mediensyndikaten, etwa denen von Alfred Hugenberg oder Willi Münzenberg. Beträchtliche Teile des Medienspektrums unterlagen durch die politischen Ambitionen solcher Medienunternehmer de facto politischer Lenkung. Mangels unabhängiger Kontrolle nutzten die Pressekartelle ihre Macht zur weiteren Polarisierung der ohnehin stark fragmentierten politischen Landschaft. Besonders am Beispiel Hugenbergs wird

99 Genauer Artikel 48, Absatz 2 der Weimarer Reichsverfassung. Hier wurden die Bestimmungen zur Presse- und Meinungsfreiheit, die unter Artikel 118 garantiert wurden für den Fall außer Kraft gesetzt, dass die öffentliche Sicherheit und Ordnung gestört seien: "(2) Der Reichspräsident kann, wenn im Deutschen Reich die öffentliche Sicherheit und Ordnung erheblich gestört oder gefährdet wird, die zur Wiederherstellung der öffentlichen Sicherheit und Ordnung nötigen Maßnahmen treffen, erforderlichenfalls mit Hilfe der bewaffneten Macht einschreiten. Zu diesem Zwecke darf er vorübergehend die in den Artikeln 114, 115, 117, 118, 123, 124 und 153 festgesetzten Grundrechte ganz oder zum Teil außer Kraft setzen."

100 Vgl. Petersen, Klaus: Zensur in der Weimarer Republik, $114 \mathrm{f}$.

101 Vgl. ebd., 116.

102 Dussel, Konrad: Deutsche Tagespresse im 19. und 20. Jahrhundert. Münster 2004, 123. 
dies greifbar. Seine politischen und medialen Aktivitäten verband Hugenberg ganz selbstverständlich im Sinne der nationalkonservativen Sache. ${ }^{103}$

Jenseits der rechtlichen und wirtschaftlichen Bedingungen bestimmten die inneren Gesetzmäßigkeiten der Massenmedien ihre Wirkung auf die deutsche Gesellschaft. Innerhalb des Pressegefüges wirkten populäre Illustrierte ebenso wie staatstragende Tageszeitungen auf die öffentliche Meinung ein. Sie standen nicht, wie heutzutage, gleichbedeutend neben anderen Kommunikationskanälen wie Radio, Fernsehen oder Internet. Sie waren der Ort öffentlicher Diskurse schlechthin. ${ }^{104}$ Dieser Umstand qualifiziert die 1920er Jahre als das "Jahrzehnt der Presse ${ }^{105}$.

Die Verflechtung von Presse und Politik hatte symbiotischen Charakter. Politische Handlungen und gesellschaftliche Entwicklungsprozesse der Zeit sind ohne die sie begleitende Medienberichterstattung nicht zu verstehen. ${ }^{106}$ Zeitschriften und Zeitungen aller politischen Orientierungen wirkten nicht einfach am öffentlichen Meinungsbildungsprozess mit. Vielmehr formten sie oftmals erst die Realitäten, auf die sich gesellschaftliche Aushandlungsprozesse bezogen. Auch politisches Handeln vollzog sich zu erheblichen Teilen als Reaktion auf Medienwirklichkeiten. Skandalisierende Sensationsberichterstattung schuf neue politische Problemlagen. $\mathrm{Zu}$ ihnen mussten sich politische Entscheider und gesellschaftliche Akteure verhalten, wollten sie verhindern, dass sich die mediale Dynamik gegen sie selber richtete. ${ }^{107}$ Dass die Medienwirklichkeiten der Zwischenkriegszeit auch Regeln und Strategien der gesellschaftlichen und politischen Mobilisierung veränderten, wurde hier am Beispiel der visuellen Mobilisierungsstrategie der AIZ bereits erwähnt. ${ }^{108}$ Außerdem wurden politische Ereignisse und Fragen der Legitimität politischer Macht aus weltanschaulicher Motivation heraus verformt, relativiert

103 Dazu: Holzbach, Heidrun: Das "System Hugenberg". Die Organisation bürgerlicher Sammlungspolitik vor dem Aufstieg der NSDAP. Stuttgart 1981.

104 Dazu: Fulda, Bernhard: Industries of Sensationalism: German Tabloids in Weimar Berlin. In: Führer, Karl Christian/Ross, Corey (Hg.): Mass Media, Culture and Society in Twentieth-Century Germany. New York 2006, 183-203, hier 185.

105 Vgl. ebd., 184.

106 Dazu: Fulda, Bernhard: Press and Politics in the Weimar Republic. Oxford 2009.

107 Diesen Umstand erhellende Arbeiten stammen von Martin Kohlrausch und Thomas Mergel, die ausgehend vom politisch-publizistischen Komplex enger umgrenzte Themen zur Analyse auswählen. Bei Kohlrausch ist dies die gesellschaftliche Wirkung von Skandalen an der Schnittstelle von Gesellschaft, Politik und Presse im Kontext des wilhelminischen Kaiserreiches. Thomas Mergel stellt die mediale Vermittlung von Politik(ern) und die Rolle der Medien im Prozess der politischen Kommunikation und symbolhaften Politik in den Mittelpunkt. Kohlrausch, Martin: Der Monarch im Skandal. die Logik der Massenmedien und die Transformation der wilhelminischen Monarchie. Berlin 2005. Und: Mergel, Thomas: Parlamentarische Kultur in der Weimarer Republik. Politische Kommunikation, symbolische Politik und Öffentlichkeit im Reichstag. Düsseldorf 2002.

108 Nochmals: Bavaj, Riccardo: »Revolutionierung der Augen«. 
und in das jeweilige Ideologiegebäude integriert. Hiervon waren insbesondere die medial produzierten Länderbilder der USA und der UdSSR betroffen. ${ }^{109}$

Auch die Vermittlung von Zukunftserwartungen, dystopischen ebenso wie utopischen, erfolgte primär in den Massenmedien. Illustrierte und Tageszeitungen modellierten den Erwartungsraum zwischen Gegenwart und Zukunft. Sie vergegenwärtigten nicht nur das Aktuelle, sondern zeigten auch Zukunftsoptionen auf. Die offenen gesellschaftlichen Fragen der Weimarer Republik bestimmten, welche Themen bei der Betrachtung der USA und der Sowjetunion herausgegriffen und verhandelt wurden. Dass sich dabei bestimmte Themenschwerpunkte deutlich herausbildeten, andere aber keine Rolle spielten, wirft Fragen nach den Bedingungsstrukturen von Mediendiskursen auf. Im folgenden theoretisch-methodischen Teil schließen sich zur Beantwortung dieser Fragen einige diskurstheoretische Überlegungen an.

Von einem Diskurs über die Sowjetunion oder die USA kann, soviel wurde bis hierhin deutlich, keine Rede sein. NS-Presse, Kommunisten, Bürgerliche, Liberale und Konservative fügten den in der Fremdbetrachtung aufgegriffenen Themen Aspekte hinzu, die sich aus den jeweils eigenen weltanschaulichen Möglichkeiten des Sag- und Zeigbaren ergaben.

\section{Theoretische und methodische Grundlagen}

Die Untersuchung von Mediendiskursen setzt die Klärung des Diskursbegriffs an sich voraus. Dieser wird sich an den Grundzügen der von Michel Foucault entworfenen Diskurstheorie orientieren. Deren Kern besagt, dass Diskurse die Gegenstände, von denen sie handeln, ihrerseits formen. ${ }^{110}$ Diskurse, gerade mediale, sind »dasjenige, worum und womit man kämpft. ${ }^{111} \mathrm{Da} » \mathrm{man} «$ verschiedene Diskursteilnehmer umschreibt, ${ }^{112}$ geht es um die Deutungshoheit über Zeitphänomene. Presseschaffende traten durch die mediale Darstellung dieser Zeitphänomene zueinander in Deutungskonkurrenz.

Bei der Untersuchung massenmedial erzeugter Länderbilder ist zu beachten, dass die wenigsten Rezipienten die Möglichkeit hatten, zwischen medial erschaffenen Bildern und den Realitäten vor Ort zu vergleichen. Analog zum Diskursverständnis Foucaults stellten die Massenmedien für den überwiegen-

109 Dazu: Schumann, Dirk: Politische Gewalt in der frühen Weimarer Republik (1919-1923) und ihre Repräsentation in der politischen Tagespresse. In:Daniel/Marßolek/Pyta / Welskopp: Politische Kultur und Medienwirklichkeiten, 279-310.

110 Vgl. Foucault, Michel: Archäologie des Wissens. Frankfurt a. M. 1997, 74.

111 Ders.: Die Ordnung des Diskurses. Frankfurt a. M. 1993, 11.

112 Auch wenn es streng nach Foucault keinen direkten Agens im Diskurs geben dürfte. 
den Teil der Leserschaft die Gegenstände Amerika und Sowjetunion erst her. Diese Länderbilder wurden durch längerfristig tradierte Stereotype, Konzepte und Narrative angereichert, die mit den USA und Russland fest verknüpft waren. Dazu zählen beispielsweise die klassischen Narrative von den unbegrenzten Möglichkeiten Amerikas oder dem russischen Kollektivismus. Solch tradierte Diskurselemente wirkten in gleichem Maße auf Medienproduzenten wie -rezipienten und nivellierten das Machtgefälle, ${ }^{113}$ welches im unterschiedlich guten Zugriff auf Informationen aus beiden Ländern bestand. Traditionelle Amerika- und Russlandstereotype formten die "Diskursgesellschaft ${ }^{114}$ der Weimarer Republik. Eine Diskursgesellschaft ist nicht als Gesellschaft Gleichdenkender zu verstehen. Vielmehr verständigt sich eine Diskursgesellschaft über einen Gegenstand durch das Rekurrieren auf geteilte Narrative, historisch tradierte Länderbilder oder nationale Stereotype.

Auch die von Foucault betonte Rolle der Regelmäßigkeit von übereinstimmenden, zu einem bestimmten Diskursgegenstand getätigten Äußerungen (nicht: »Aussagen «) bildet ein nützliches Instrument aus seiner Werkzeugkiste. ${ }^{115}$ Erst die regelmäßige, hinreichend häufige Behandlung rechtfertigt, von einem relevanten Thema des Fremdwahrnehmungsdiskurses zu sprechen. Das Verständnis von Regelmäßigkeit als oft wiederholter Äußerungen ist hiermit allerdings nicht ausschließlich gemeint. Der Umstand, dass eine bestimmte Äußerung wiederholt geäußert wird, eine konträre allerdings unterbleibt, offenbart vielmehr die Regeln, nach denen eine Diskursgesellschaft funktioniert. Es wäre also unmissverständlicher, von der Regelgemäßheit bestimmter Aussagen zu sprechen.

Grundsätzlich soll die Überdehnung des Diskursbegriffs, nach der letztlich alles nur Diskurs sei, hier vermieden werden. Natürlich ist Realität immer auch Ergebnis diskursiver Aushandlungsprozesse. Realitäten stehen mit den über sie geführten Diskursen aber in einem reziproken Verhältnis und sind eben nicht ausschließlich deren Produkte. Jenseits des von Foucault in den Mittelpunkt gerückten Strebens nach Deutungsmacht bedarf schließlich jeder Diskurs eines Anlasses. Ein solcher Diskursanlass lag im konkreten Bedürfnis der deutschen Gesellschaft nach Selbstverortung in einer neu geordneten und neu zuordnenden Zeit, die maßgeblich von den USA und der UdSSR geprägt war.

In der Wahrnehmung beider Länder spielten über Jahrhunderte hinweg diskursiv konstruierte Stereotype eine tragende Rolle. Das gilt für die USA in höherem Maße als für die UdSSR. Die Wichtigkeit tradierter Länderbilder fügt dem theoretischen Dach dieser Arbeit ein weiteres Element hinzu, das

113 Ein weiteres Strukturmerkmal foucaultscher Diskurstheorie.

114 Foucault: Ordnung des Diskurses, $27 \mathrm{f}$.

115 Ders.: Archäologie des Wissens, 153. 
in der Lehre von Fremd- beziehungsweise Länderbildern besteht. Diese wird wahlweise als Imagologie oder interkulturelle Hermeneutik bezeichnet. ${ }^{116} \mathrm{Da}$ letztere aber auf das Verstehen des Fremden aus dessen eigenen Traditionsbeständen und Wissenssystemen heraus abhebt, soll hier dem Konzept der Imagologie Vorrang gegeben werden.

Im Folgenden wird nämlich nicht das Verstehen des Fremden aus dem Fremden heraus Thema sein, sondern dessen Aneignung auf Grundlage vertrauter Wissensbestände. Die von William Chew aufgefrischte Definition von Imagologie ${ }^{117}$ schließt erstens die Selbstreferentialität von Fremdbetrachtung ein und entwirft zweitens eine dichotomische Struktur der dahingehenden Diskurse. Das bedeutet, der Anlass zur Fremdbetrachtung besteht im Identitätsbildungsbedürfnis des Betrachtenden. Die sich darüber entspinnenden Diskurse strukturieren sich entlang gegensätzlicher aber produktiv vergleichbarer Bestandteile des Selbstbildes einerseits und des Fremdbildes andererseits. Dort wo diese Bestandteile vergleichbar (aber nicht identisch) sind, entwickelt sich ein identitätsstabilisierender oder identitätsverändernder Diskurs aus deren Gegenüberstellung. Diesen Prozess kann man in Form medial vermittelter Bekundungen der Ablehnung oder Zustimmung freilegen.

Der Übergang von der Theorie zur Methode besteht darin, diesen Vorgang an konkreten Quellenbeispielen sichtbar zu machen. Da Foucault keine Methodologie zur konkreten Durchführung von Diskursanalysen vorgelegt hat, sind zu diesem Zweck praxisorientiertere Beiträge heranzuziehen. Diese bauen auf Foucaults verwinkeltem Theoriegebäude auf und stellen in diesem Sinne tatsächlich die vielzitierte Diskursanalyse »nach" Foucault dar.

Die Arbeit an der Schnittstelle zwischen Sprache und Realität hat Philipp Sarasin in seiner auf die Geschichtswissenschaft zugeschnittenen Darstellung diskursanalytischer Verfahren vorgeführt. Sarasin selbst lehnt den Methodenbegriff für sein Verfahren ab. ${ }^{118}$ Nichtsdestotrotz zeigt er auf, wie empirisch beobachtbare Kausalitäten - er wählt das Beispiel des Zusammenhangs zwi-

116 Vor allem in der vergleichenden Literaturwissenschaft ist der Begriff der Imagologie nach wie vor gebräuchlich. Auch neuere Forschungen benutzen den Begriff. Zuletzt: Dukić, Davor (Hg.): Imagologie heute. Ergebnisse, Herausforderungen, Perspektiven. Bonn 2012; Voltrová, Michaela: Terminologie, Methodologie und Perspektiven der komparatistischen Imagologie. Berlin 2015.

117 Chew, William III: What is in a National Stereotype? An Introduction to Imagology at the Threshold of the $21^{\text {st }}$ Century. In: Language and Intercultural Communication. Bd. 6 (2006), Nr.3-4, 179-187. Zur Rolle nationaler Stereotypen für die Identitätsbildung: Hahn, Hans Henning (Hg.): Stereotyp, Identität und Geschichte. Die Funktion von Stereotypen in gesellschaftlichen Diskursen. Frankfurt a. M. u. a. 2002.

118 Sarasin, Philipp: Geschichtswissenschaft und Diskursanalyse. Frankfurt a. M. 2003. Er schreibt zur Selbsteinordnung zwischen Methode und Theorie: »Diskursanalyse beziehungsweise Diskurstheorie ist keine Methode, die man ılernen « könnte, sondern sie erscheint mir eher als eine theoretische, vielleicht sogar philosophische Haltung.» Ebd., 8. 
schen Bakterien und Krankheit - metaphorisch auf andere Diskurse (zum Beispiel über Gruppen) übertragen werden und auf diese Weise neue Sinnzusammenhänge schaffen können (»Schädlichkeit« bestimmter Gruppen). Indem er beispielhaft veranschaulicht, wie sprachliche Prozesse neue Realitäten entstehen lassen, führt er letztlich doch den Beweis zur praktischen Anwendbarkeit und Validität des diskursanalytischen Verfahrens.

Die Wichtigkeit sprachlich geschaffener Wirklichkeit, die auch in neueren diskursanalytischen Betrachtungen zur Weimarer Republik betont worden ist, ${ }^{119}$ wirft die Frage nach dem Rahmen solcher sprachlichen Handlungen auf. Achim Landwehr hat Arbeitsschritte einer historischen Diskursanalyse entwickelt, denen er Methodencharakter bescheinigt. ${ }^{120}$ Zunächst muss der Rahmen so gewählt sein, dass er hinreichend zur Produktion der Wirklichkeit des Diskursgegenstandes beiträgt. ${ }^{121}$ Diese Bedingung ist für die Wahrnehmung der USA und der UdSSR in den deutschen Massenmedien erfüllt, sofern tradierte Elemente des jeweiligen Länderbildes als Kontext in die Betrachtung miteinbezogen werden. ${ }^{122}$ Unter diesen Voraussetzungen können nach Landwehr thematisch gruppierte Textkorpora in ihrem diachronen Verlauf und hinsichtlich der in ihnen aufscheinenden widerstreitenden Wirklichkeitskonstruktionen einer Diskursanalyse unterzogen werden.

Für die konkrete Arbeit an Schriftquellen ist des Weiteren die begriffliche Unterscheidung zwischen Sprache und Diskurs von Bedeutung. ${ }^{123}$ Der Diskursbegriff schließt laut Reiner Keller ausdrücklich auch die Effekte eines Diskurses ein. Konkret bedeutet das, nicht nur die Gründe für bestimmte mediale Repräsentationen der USA und der Sowjetunion zu beleuchten, sondern genauso deren Effekte wie etwa politische Reaktionen. Drei Bestandteile - Anlass, Art der Repräsentation und Effekt - konstituieren nach diesem Verständnis einen Diskurs. Alle drei Bestandteile sollen bei der Analyse der Fallbeispiele einbezogen werden. Das bedeutet vor allem, einzelne Diskursstränge konsequent in ihrem historischen Kontext darzustellen.

Foucaults Theorie des Sagbaren und entsprechende textzentrierte Analysemethoden sollen um eine bildtheoretische Betrachtung des Zeigbaren ergänzt werden. Der Bildtheorie W. J.T. Mitchells ist es zu danken, dass sie innere wie

119 Vgl. Stötzel, Georg: Vorwort von Georg Stötzel. In: Eitz, Thorsten/Engelhardt, Isabelle: Diskursgeschichte der Weimarer Republik. Band 1. Hildesheim 2015, 6.

120 Landwehr, Achim: Historische Diskursanalyse. Frankfurt a. M. 2008.

121 Vgl. ebd., 101.

122 Damit sind auch die von Landwehr aufgeführten Arbeitsschritte »Korpusbildung« und "Kontextanalyse« vollzogen. Vgl. ebd., $101 \mathrm{f}$. und $105 \mathrm{f}$.

123 Keller, Reiner: Wissen oder Sprache? Für eine wissensanalytische Profilierung der Diskursforschung. In: Eder, Franz X.: Historische Diskursanalysen. Genealogie, Theorie, Anwendungen. 51-70. 
äußere Bilder aus dem Korsett des Illustrativen befreit hat. ${ }^{124}$ Durch seinen Beitrag ist die Gleichwertigkeit visueller und textueller Inhalte weithin anerkannt. Der Mehrwert von Bildern für historische Analysen besteht in der zentralen Rolle des Visuellen in modernen Mediengesellschaften. ${ }^{125}$

Tageszeitungen und Illustrierte ordneten den Blick auf die Welt. In der schnell komplexer werdenden Moderne machte man sich sein Bild von der Welt nicht mehr durch vollständiges Erfassen. Das Welterleben erfolgte über die Einbindung medialer Eindrücke in ein selbstreferentielles System historisch gewachsenen Wissens. ${ }^{126}$ Die Medienkonsumenten erlebten ihre Welt nicht nur synchron durch mediale Inhalte, sondern bezogen diese Inhalte auf diachron tradierte und kulturell vermittelte Sinngehalte. Retrospektiv ergibt dieses Zusammenspiel ein für die Geschichtswissenschaft ausdeutbares Bild, das sich aus Texten und visuellen Informationsträgern zusammensetzt.

Die Grundlagen zur Deutung des visuellen Anteils solcher historischen Bilder besorgte Erwin Panofsky. ${ }^{127}$ Voraussetzung jeder Interpretation ist ihm zufolge die Kenntnis zeitgenössischer Symbolhaftigkeit und die Provenienz des Interpretationsobjektes. Panofsky definierte die aufeinander aufbauenden Arbeitsschritte Beschreibung, Analyse und Interpretation als klassisches Vorgehen der Bildanalyse (Ikonologie). ${ }^{128}$ Seine Überlegungen wiesen über das einzelne Artefakt hinaus, was sie für die Geschichtswissenschaft anschlussfähig macht. Das Gebot der historischen Kontextualisierung umschrieb Panofsky mit der Mahnung, sich einem Interpretationsobjekt nur in "Kenntnis literarischer Quellen" und der "Vertrautheit mit bestimmten Themen und Vorstellungen ${ }^{129}$ der Zeit zu nähern.

124 Mitchell, W. J.T.: Iconology. Image, Text, Ideology. Chicago 1986. Besser handhabbar: Ders.: Bildtheorie. Herausgegeben mit einem Nachwort von Gustav Frank. Frankfurt a. M. 2008. Mitchell orientierte die Sprache, mittels derer er den von ihm ausgerufenen »Pictorial Turn« theoretisierte an Richard Rortys »Linguistic Turn«. Er baute somit also kein vollkommen neues Theoriegebäude, sondern gestaltete es grundlegend um und öffnete es zur Welt der (inneren wie äußeren) Bilder. Er selbst verweist in seiner Bildtheorie im Kapitel zum »Pictorial Turn« (101 f.) auf die beiden theoriebildenden Texte Rortys, nämlich: Rorty, Richard: Der Spiegel der Natur. Eine Kritik der Philosophie. Frankfurt a. M. 1987. Und: Ders.: The Linguistic Turn: Recent Essays in Philosophical Method. Chicago 1967.

125 »Auf seiten [sic] der öffentlichen Kritik macht die Herrschaft der Massenmedien die Dominanz des Bildes offensichtlich. Bildern wird für alles die Schuld gegeben - von Gewalttätigkeit bis zum moralischen Verfall.«Mitchell, W. J. T.: Bildtheorie, 279.

126 Dazu: Singer, Wolf: Das Bild in uns - Vom Bild zur Wahrnehmung. In: Maar, Christa/ Burda, Hubert (Hg.): Iconic Turn. Die neue Macht der Bilder. Köln 2005, 56-76, hier 75.

127 Grundlegend: Panofsky, Erwin: Studies in Iconology. Humanistic Themes in the Art of the Renaissance. New York 1939.

128 Ebd., $14 \mathrm{f}$.

129 Ders.: Ikonographie und Ikonologie. In: Kaemmerling, Ekkehard (Hg.): Bildende Kunst als Zeichensystem. Ikonographie und Ikonologie. Bd. 1: Theorien - Entwicklung - Probleme. Köln 1994, 207-225, hier 210 f. 
"Das Jahrhundert der Bilder ${ }^{130}$ ist allerdings nicht durch die Plastiken und Ölgemälde der alten Meister definiert, die Panofsky bei seiner Theoriebildung hauptsächlich im Sinn hatte. Es ist die kulturelle und politische Aufladung von Bildern, die den Blick auf eine das einzelne Bild umgebende visuelle Kultur freigibt. Die Visual History hat die Relevanz "profaner« Bildquellen, also Presse- und Privatfotografien, Plakaten und Karikaturen etabliert. Die Sensibilität für visuelle Kulturen hat die Bandbreite an Interpretationsmöglichkeiten hinsichtlich politischer, kultureller oder sozialer Wandlungsprozesse, die sich visuell äußern, deutlich erweitert. ${ }^{131}$ Die Visual Culture Studies haben sich darauf verständigt, den Prozess der Wahrnehmung visueller Quellen sichtbar machen, erklären und einordnen zu wollen. ${ }^{132}$ Das »Sehen « in seinem kulturellen und historischen Zusammenhang zu zeigen, stellt im Einklang mit diesem Anspruch das übergeordnete Ziel dieser Arbeit dar.

Bevor die Analysemethoden zur Erschließung (teilweise) visueller Quellenkorpora genauer erläutert werden, ist als konkrete Benennung visueller Quelleninhalte der Begriff Visual einzuführen. Dahinter verbirgt sich weder der Versuch, eine Selbstverständlichkeit durch einen Anglizismus aufzuwerten noch eine tiefergehende methodologische Innovation. Vielmehr soll die Gefahr einer begrifflichen Doppelung vermieden werden: Von den USA und der UdSSR in Deutschland wahrgenommene Bilder sind klar von den zu analysierenden visuellen Quellen zu unterscheiden. Die Bilder der USA und der Sowjetunion sind durch tradierte Sinnzusammenhänge und öffentlich ausgehandelte Interpretationen der Wirklichkeit geordnete Bestände an visuellen, textuellen, biografischen und anderweitigen Eindrücken. Dieses konzeptuelle

130 Paul, Gerhard (Hg.): Das Jahrhundert der Bilder. Bd. 1: 1900 bis 1949. Göttingen 2009. Weitere einschlägige Publikationen, die mit verschiedenen thematischen Schwerpunkten von einem wesensähnlichen Verständnis visueller Quellen ausgehen: Belting, Hans (Hg.): Bilderfragen. Die Bildwissenschaften im Aufbruch. München 2007; Burke, Peter: Augenzeugenschaft. Bilder als historische Quellen. Berlin 2003; Hartewig, Karin: Fotografien. In: Maurer, Michael (Hg.): Aufriß der Historischen Wissenschaften. Bd. 4: Quellen. Stuttgart 2002, 427-447; Jäger, Jens/Knauer, Martin (Hg.): Bilder als historische Quellen? Dimensionen der Debatte um historische Bildforschung. München 2009; Jäger, Jens: Fotografiegeschichte(n). Stand und Tendenzen der historischen Forschung. In: Archiv für Sozialgeschichte, Nr. 48, 511-538; Maurer, Michael: Bilder. In: Ders. (Hg.): Aufriß der Historischen Wissenschaften. Bd. 4: Quellen. Stuttgart 2002, 402-426; Talkenberger, Heike: Von der Illustration zur Interpretation. Das Bild als historische Quelle. Methodische Überlegungen zur Historischen Bildkunde. In: Zeitschrift für Historische Forschung, Nr. 21 (1994), 289-303.

131 Vgl. dazu: Hebel, Udo/Wagner, Christoph (Hg.): Pictorial Cultures and Political Iconographies. Approaches, Perspectives, Case Studies from Europe and America. Berlin, New York 2011.

132 Dazu nochmals: Mitchell, W. J. T.: Showing Seeing. A Critique of Visual Culture. In: Journal of Visual Culture. Bd. 1, Nr. 2 (2002)., 165-181, hier $177 \mathrm{f}$. 
Bildverständnis ist vom einzelnen visuellen Untersuchungsobjekt - eben dem Visual - begrifflich zu trennen.

Die Methodik, auf die sich das Vorgehen im Umgang mit Visuals stützt, wurde durch die Rehabilitation des Visuellen angestoßen, wie sie unter vielen anderen Panofsky, Mitchell und Paul zu verdanken ist. Das Zusammenspiel visueller und textueller Elemente im Zustandekommen von Diskursen findet seit einiger Zeit wachsende Beachtung. ${ }^{133}$ Silke Betscher hat das klassische Verfahren der Diskursanalyse für die Arbeit mit visuellen Quellen operationalisiert. ${ }^{134}$ Ausgehend von den Grundlagen der visuellen Kommunikation, ${ }^{135}$ deren zentrales Prinzip die assoziative Wahrnehmung ist, zeigte sie, wie die »visuellen Aussagen im Kontext der Gesamtstruktur von Diskurssträngen und interdiskursiver Verbindungen herauszuarbeiten ${ }^{136}$ sind.

Diskursive Strukturen visueller Art können unter Einbezug ihres sprachlich-textlichen Umfelds ikonografisch analysiert und interpretiert werden. ${ }^{137}$ Zur ikonografischen Analyse soll hier das von Gunther Kress und Theo van Leeuwen erdachte Konzept der visuellen Grammatik herangezogen werden. Der assoziative Blick auf Visuals kann so einem systematischen Schema unterworfen werden. ${ }^{138}$ Die visuelle Grammatik problematisiert kompositorische Elemente wie Perspektive und Rahmengebung. Sie trägt weniger zur Inter-

133 Bereits 2006 erschien ein von Sabine Maasen, Torsten Mayerhauser und Cornelia Renggli herausgegebener Sammelband, der die sich aus dem von Mitchell postulierten Mehrwert von Bildern ergebende Frage zu beantworten suchte, wie der wiederentdeckten Aussagekraft der Bilder ohne eine gleichzeitige Bagatellisierung des Textuellen Rechnung getragen werden könne. Maasen, Sabine/Mayerhauser, Torsten / Renggli, Cornelia (Hg.): Bilder als Diskurse - Bilddiskurse. Weilerswist 2006.

134 Beachtung findet hier insbesondere ein Aufsatz, in dem Betscher die Visuelle Diskursanalyse zunächst in ihren Grundzügen darstellt, um sie danach an visuellen Diskursen an der Zeit des Kalten Krieges vorzuführen, worin ein besonderer Ausweis für die Anwendbarkeit ihrer Methode im hier verfolgten Forschungsvorhaben besteht: Betscher, Silke: Bildmuster - Wissensmuster. Ansätze einer korpusbasierten visuellen Diskursanalyse. In: Zeitschrift für Semiotik. Bd. 35, Nr. 3-4 (2013), 285-319. Anwendung fand die visuelle Diskursanalyse in Betschers Dissertationsschrift: Dies.: Von großen Brüdern und falschen Freunden. Visuelle Kalte-Kriegs-Diskurse in deutschen Nachkriegsillustrierten. Essen 2013.

135 Dargelegt hat diese Marion Müller. Sie stellte nicht nur die grundlegenden Unterschiede zur textuellen und verbalen Kommunikation dar, sondern vermittelte darüber hinaus die Eigengesetzlichkeit visueller Kommunikation. Der wichtigste, auch von Silke Betscher zum Ausgangspunkt ihrer methodologischen Überlegungen gemachte dahingehende Unterschied ist, dass die Textlogik argumentativ ist, wohingegen die Bildlogik grundsätzlich assoziativ sei. Vgl. Müller, Marion: Grundlagen der visuellen Kommunikation. Theorieansätze und Analysemethoden. Konstanz 2003, 91.

136 Betscher, Silke: Bildmuster - Wissensmuster, 285.

137 Ebd., $288 \mathrm{f}$.

138 Kress, Gunther/van Leeuwen, Theo: Reading Images. The Grammar of Visual Design. London, New York 1996. 
pretation von Visuals als vielmehr zur Schulung des Blickes bei. Auch die Verweisfunktion und Aussagekraft visueller Inhalte machen Kress und van Leeuwen durch die Wahl des Terminus Grammatik plausibel. Sie füllen durch die Definition verbindlicher, lernbarer und nachvollziehbarer Gesetzmäßigkeiten der visuellen Kommunikation entscheidende methodologische Lücken. Der Kritik, Visuals seien der Sprache durch ihre fehlende Negationsfähigkeit, Metasprachlichkeit und ihre folglich fehlende Diskursivität in Sachen Ausdrucksfähigkeit in keiner Weise gleichwertig, ${ }^{139}$ konnte mithilfe Kress' und van Leeuwens die Spitze genommen werden.

Im Gegensatz zur intravisuellen Grammatik ist die Bildsprache der Illustrierten stets in ihrer Wechselwirkung mit dem sie umgebenden Text - in Form von Bildunterschriften oder Artikeln - zu interpretieren. ${ }^{140}$ Dieser medialen Kontextualisierung muss die historische Kontextualisierung zur Einbettung der jeweiligen Quelle in gesellschaftliche Debatten zur Seite gestellt werden. Erst hierdurch kann eine Bildsprache, die ja nicht universell, sondern je nach kultureller Prägung sehr verschiedenartig verstanden wird, ${ }^{141}$ entschlüsselt und zur Beantwortung historischer Fragestellungen fruchtbar gemacht werden. Untersuchungen zum transatlantischen Austauschprozess haben sich an den beschriebenen theoretischen und methodologischen Innovationen bereits erfolgreich versucht. ${ }^{142}$ Dieser erprobte Pfad kann auch zur Veranschaulichung triangulärer Wahrnehmungsprozesse zwischen Deutschland, den USA und der Sowjetunion beschritten werden.

Die Themenauswahl für die Veranschaulichung dieses Wahrnehmungsprozesses soll als Replik auf die Grundsatzkritik an der Diskursanalyse begründet werden. Die Auswahl der Themenblöcke Rationalisierung, Frauenemanzipation, Minderheitenfrage, politische Ordnungen sowie Jugend, Bildung und Sport ergaben sich zunächst aus deren Aussagekraft über das Moderneverständnis der Zwischenkriegszeit. Diese Einordnung ist bereits ein interpretatorischer Akt und muss sich den Vorwurf der Selektivität schlicht gefallen lassen. Die fünf von mir ausgewählten Themenblöcke zeichneten sich aber

139 Vgl. Wolf, Claudia Maria: Bildsprache und Medienbilder. Die visuelle Darstellungslogik von Nachrichtenmagazinen. Wiesbaden 2006, 115.

140 Hinsichtlich von Bildunterschriften sind zweierlei Formen zu unterscheiden: Während ein »denotativer« Bildtext lediglich zum Erkennen oder Benennen des Abgebildeten dient, legt der »signifikante« Bildtext eine Einordnung, Wertung oder zumindest Konnotation nahe. Vgl. Preisendanz, Wolfgang: Verordnete Wahrnehmung. Vom Verhältnis von Photo und Begleittext. In: Sprache im technischen Zeitalter. Nr. 37 (1971), 1-8. Auch bei: Wolf, Claudia Maria: Bildsprache und Medienbilder, 152.

141 Vgl. ebd.

142 Silke Betschers Dissertationsschrift "Von großen Brüdern und falschen Freunden" wurde bereits genannt. Zur visuellen Komponente in der Wahrnehmung transatlantischer Austauschprozesse: Depkat, Volker/Zwingenberger, Meike (Hg.): Visual Cultures Transatlantic Perspectives. Heidelberg 2012. 
ohnedies als Gravitationszentren des medialen Diskurses ab, an ihnen wurden kontroverse Entwicklungen verhandelt. Vermeintliche Pflichtthemen heutiger historischer Forschung - beispielsweise die Emanzipation von Frauen und Minderheiten - mussten nicht etwa nachträglich in die Analyse implantiert werden. Sie wurden, um hier der gängigsten Kritik an der Diskursanalyse zu begegnen, nicht im Vorhinein festgelegt. Vielmehr kristallisierten sie sich während der Erfassung und Aufbereitung des Quellenmaterials klar als Interessenschwerpunkte der zeitgenössischen Berichterstattung heraus.

\section{Modernität und Krise}

Das abstrakte Konzept Moderne ist als alternativ und verhandelbar anzusehen. Aushandlungs- beziehungsweise Konfrontationsprozesse miteinander konkurrierender Modernitätsentwürfe sind die logische Konsequenz dieser Feststellung. Diskursiv verfasste und medial vermittelte Aushandlungsprozesse binden Richtung und Verlauf von Modernisierungsprozessen an die Meinungsbildung der von ebendiesen Prozessen betroffenen Menschen. Findet diese Rückbindung nur unzureichend statt oder unterbleibt gänzlich, erscheint der Modernisierungsprozess subjektiv als eine Ansammlung von Ohnmachtserlebnissen. Diese Ohnmacht ob vermeintlich unkontrollierbarer Umwälzungen kann in einem "Unbehagen an der Moderne ${ }^{1143}$ und ihrer Wahrnehmung als Krise resultieren - ein wiederkehrendes Problem.

In der Weimarer Republik hatte der Modernebegriff seine aus dem fortschrittsbegeisterten 19. Jahrhundert stammende positive Konnotation bereits verloren. ${ }^{144}$ Stattdessen hatte im Kontext des Ersten Weltkriegs der Aspekt des Niedergangs und des krisenhaften Umschlagens von Moderne stetig an Gewicht gewonnen. ${ }^{145}$ Modernitätsdiskurse jener Zeit setzten sich einerseits aus Visionen einer wünschenswerten Zukunft zusammen. Mindestens ebenso

143 Vgl. Taylor, Charles: Das Unbehagen an der Moderne. Frankfurt a. M. 2014, 7 f. Vorher: Nipperdey, Thomas: Probleme der Modernisierung in Deutschland. In: Saeculum, Bd. 30, Nr. 2-3 (1979), $300 \mathrm{f}$.

144 Vgl. Koselleck, Reinhart: »Fortschritt» und »Niedergang» - Nachtrag zur Geschichte zweier Begriffe. In: Ders./Stierle, Karlheinz (Hg.): Niedergang: Studien zu einem geschichtlichen Thema. Stuttgart 1980, 214-230, hier 214.

145 So hatte es interessanterweise schon Leibniz in seinen "Kleinen Schriften zur Metaphysik« eingeführt, in denen er Fortschritt als den sich gegenseitig befruchtenden Wechsel von Auf- und Abwärtsentwicklungen darstellte. Vgl. Leibniz, Gottfried Wilhelm: Philosophische Schriften., Bd. 1: Kleine Schriften zur Metaphysik. Darmstadt 1965, 369 f. Ihm zufolge seien jedoch »alle Rückschläge als vorübergehend, ja letztlich als Stimulans zu neuen Fortschritten « zu verstehen. Vgl. Koselleck, Reinhart: „Fortschritt« und »Niedergang«, 222 . 
stark prägten sie Schilderungen des Krisenhaften. Zukunftshoffnungen und Zukunftsängste schlossen sich nicht gegenseitig aus. Im von Ambivalenzen geprägten Kontext der Zeit bedingten sie sich geradezu gegenseitig.

Beides zusammen zu denken eröffnet eine Perspektive, welche die verschlungenen Weimarer Debatten um die allerorten ersehnte und gleichzeitig gefürchtete Moderne strukturiert. Das Zusammenspiel aus Modernisierung und permanent hereinbrechender Krisenerfahrung führt zum Schlagwort der »verstörten Modernisierung « ${ }^{146}$. Zwar gibt es Argumente, die Krise nicht zum alleinigen Merkmal des Neuanfangs nach 1918 zu machen. ${ }^{147}$ Jedoch bietet das Verständnis von Krise als Phase der Entscheidung und Zuspitzung einen guten Zugang zu Diskursen, die sich über Modernisierungsprozesse zwischen 1918 und 1933 entfalteten.

Das Deutungsmuster der Krise verschafft Zugriff auf zentrale gesellschaftspolitische Diskurse und vereint zeitgenössische Blickwinkel mit historischen Deutungen: Einerseits wähnten sich die Deutschen, öffentlichen Debatten zufolge, meist selbst im Krisenmodus. Andererseits wurde und wird auch der Blick der Historikerinnen und Historiker auf Weimar maßgeblich unter dem Signum des Scheiterns, mithin einer Krise mit negativem Ausgang gesehen. Auch in der Bundesrepublik dient - in Zeiten politischer Polarisierung nun auch wieder verstärkt - die erste deutsche Republik stets als zentrale Referenz zur politischen Selbstverortung. Sebastian Ullrich hat dafür den treffenden Begriff des »Weimar-Komplexes" geprägt. ${ }^{148}$

Das über Epochengrenzen hinwegreichende Krisenparadigma kann, wie bereits an den Krisen des Parlamentarismus, ${ }^{149}$ der Körperlichkeit ${ }^{150}$ oder neuer Frauenrollen ${ }^{151}$ gezeigt, auf verschiedene Schlüsseldiskurse der Weimarer Republik angewandt werden. Krisen konstituieren sich in narrativen Strukturen der zeitgenössischen Wahrnehmung sich verändernder Umstände. ${ }^{152}$ Dieser These wird bei der Betrachtung der Fremdwahrnehmung der

146 Peukert: Die Weimarer Republik, 16.

147 Der Zeitabschnitt zwischen der Hyperinflation von 1923 und der 1929 beginnenden Weltwirtschaftskrise beispielsweise war durch relativ stabile gesellschaftliche Verhältnisse und wirtschaftliche Normalisierung, ja Prosperität geprägt.

148 Ullrich, Sebastian: Der Weimar-Komplex: Das Scheitern der ersten deutschen Demokratie und die politische Kultur der frühen Bundesrepublik 1945-1959. Göttingen 2009.

149 Raithel, Thomas: Funktionsstörungen des Weimarer Parlamentarismus. In: Föllmer, Moritz/Graf, Rüdiger (Hg.): Die »Krise« der Weimarer Republik. Zur Kritik eines Deutungsmusters. Frankfurt a. M. 2005, 243-266.

150 Mackenzie, Michael: Maschinenmenschen, Athleten und die Krise des Körpers in der Weimarer Republik. In: Ebd., 319-345.

151 Föllmer, Moritz: Auf der Suche nach dem eigenen Leben. Junge Frauen und Individualität in der Weimarer Republik. In: Ebd.,287-317.

152 Vgl. Föllmer, Moritz/Graf, Rüdiger/Leo, Per: Einleitung: Die Kultur der Krise in der Weimarer Republik. In:, 12. 
USA und der UdSSR zu folgen sein. Schließlich bildet die Problematisierung von Modernisierungsprozessen die thematische Klammer um das Wahrnehmungsdreieck zwischen Deutschland, den Vereinigten Staaten und der Sowjetunion. Der Krisenbegriff charakterisiert auch das Amerika- und Russlandbild der deutschen Öffentlichkeit kurz nach dem Ersten Weltkrieg. So waren es dessen unmittelbare Nachwirkungen, die zunächst das öffentliche Sprechen und Schreiben über beide Länder bestimmten: Revolution und Bürgerkrieg in Russland sowie der Versailler »Gewaltfriede«. 


\section{Modernitätsdiskurse der Weimarer Republik}

Fünf Themenkomplexe dominierten die gesellschaftspolitischen Modernisierungsdiskurse in den Printmedien der Weimarer Republik: Die wirtschaftliche und soziale Rationalisierung; die Emanzipation von Frauen; der Umgang mit Minderheiten; politische Ordnungen; sowie die miteinander verwobenen Aspekte Sport, Jugend und Bildung. Diese fünf Felder sind freilich keine exklusiven Diskursgegenstände der deutschen Zwischenkriegszeit. Sie weisen chronologisch weit darüber hinaus, bilden sie doch bis heute thematische Ankerpunkte für gesellschaftliche Selbstverständigungsprozesse. Die fünf Themenkomplexe können nicht ohne Einschränkung als Zeitphänomene bezeichnet werden, erst recht nicht als spezifisch deutsche. Großthemen wie Rationalisierung, Emanzipation oder Bildung sind vielmehr uneigentliche Zeitphänomene. Uneigentlich deshalb, weil sie unabhängig von der zeitlichen Eingrenzung generell in gesellschaftlichen Diskursen verankert sind, die vom Bewusstsein geprägt sind, dass die Menschheit in modernen Zeiten lebt. Sie fügen sich in weit bis ins 19. Jahrhundert reichende Traditionslinien ein und behielten während des 20. Jahrhunderts und bis zum heutigen Tage Brisanz. Genannt seien zur Verdeutlichung nur das Thema der Frauenemanzipation oder die Frage ethnischer und religiöser Minderheiten.

Das erste der folgenden Kapitel stellt die wirtschaftliche und soziale Rationalisierung in Gestalt der heraufziehenden Massengesellschaft in den Mittelpunkt. Es zeigt auf, wie naturräumlich-historische Erklärungsmuster für eine Annäherung an die amerikanischen Entwicklungen in Wirtschaft und Industrie zum Tragen kamen. Im Gegensatz dazu zeichnete man von vergleichbaren Prozessen in der Sowjetunion das Bild eines mit utopischen Sinngehalten des Bolschewismus aufgeladenen Rationalisierungsprogramms. Dieses Programm wurde als Teil eines großangelegten sozial-ökonomischen Transformationsprojektes wahrgenommen. Diese unterschiedliche Wahrnehmung stellt eines der prägendsten Strukturmerkmale deutscher Amerikaund Russlandbilder dar. Dieses Strukturmerkmal besteht in der chronischen Unterscheidung zwischen sich in Amerika evolutionär vollziehenden und in der Sowjetunion revolutionär vollzogenen Modernisierungsprozessen.

An dem im zweiten Kapitel behandelten Themenkomplex der Frauenemanzipation und sich verändernder Geschlechterrollen lässt sich dieses Phänomen ebenfalls feststellen. Die kategorische Unterscheidung zwischen einem Revo- 
lutions- und einem Evolutionsnarrativ tritt hier zur Herleitung emanzipatorischer Entwicklungen auf. Die Frauenemanzipation scheint durch die mediale Darstellung gleichsam als Teil des ideologischen Programms der Bolschewiki erzwungen zu werden. Dagegen vollzieht sie sich in der Sicht auf die amerikanische Gesellschaft scheinbar autonom auf Grund der historischen Gegebenheiten des "amerikanischen Raumes", was sowohl den sozialen als auch den topografischen Raum Nordamerikas meint.

Im dritten Kapitel wird die Situation von ethnischen Minderheiten in beiden Ländern im Fokus stehen. Beachtenswert ist, wie sich hier parallele Erklärungsmuster zum Frauendiskurs ergeben. Einander oberflächlich ähnelnde Zeitphänomene wurden in einer Art Diskurssynergie zusammengefasst. Die medialen Erklärungsmuster gehen hier ebenfalls von einer aus sich selbst emporwachsenden Emanzipation der Afroamerikaner aus, während die neue Situation ethnischer Minderheiten in der Sowjetunion ausschließlich unter politisch-programmatischen Gesichtspunkten perspektiviert wird. Ein besonderes Augenmerk soll in diesem Abschnitt auf die deutsche Perzeption der Juden in der Sowjetunion gelegt werden. Im »Dritten Reich" wirksam werdende Verknüpfungen zwischen Judentum und Bolschewismus lassen sich im diesbezüglichen Mediendiskurs in ihrer Entwicklung nachvollziehen.

Das vierte Kapitel widmet sich der Wahrnehmung politischer Ordnungen und Kulturen. Neben der Unterscheidung von amerikanischer Demokratie und kommunistisch verbrämtem Totalitarismus wird auch die divergierende Wahrnehmung der amerikanischen und der sowjetischen Gesellschaft deutlich. Zivilisatorische Errungenschaften wie die Trennung von weltlicher und geistlicher Macht spielen hierbei eine besondere Rolle. Dass sich weltliche und geistliche Sphäre aus deutscher Sicht in der UdSSR noch nicht klar unterscheiden ließen, manifestiert sich medial unter anderem im aufmerksam verfolgten Kampf der Bolschewiki gegen die russisch-orthodoxe Kirche und die Religion als solche. Auch die in der politischen Kultur Weimars von Zeitgenossen empfundenen Defizite politischer Symbolik werden in der Betrachtung der politischen Ordnung und Kultur der USA thematisiert.

Das fünfte und letzte Kapitel wirft schließlich einen synoptischen Blick auf die Bedeutung der Themen Sport, Jugend und Bildung sowie deren gegenseitige Verweiskraft innerhalb gesellschaftlicher Modernitätsdiskurse. Die politische Instrumentalisierung des Sports und der Jugend in den USA und der UdSSR stand in der deutschen Presse stark in der Kritik. Die Betrachtung des in vielerlei Hinsicht vorbildhaften Bildungswesens der USA fiel bisweilen in die Affekte altweltlichen Überlegenheitsdünkels gegen das jugendliche Amerika zurück. Der sowjetischen Jugend und ihrer (ideologischen) Bildung wurde indes von kommunistischer Seite höchste Bedeutung für den Erfolg des bolschewistischen Gesellschaftsprojekts attestiert. 
Das Modernitätsparadigma dient dazu, die genannten fünf Themenblöcke in einem Bezugsrahmen zwischen drei Ländern zu organisieren und zu strukturieren. Es ermöglicht, entlang der als Modernitätsparameter aufgefassten Einzelthemen Bilder der USA und der UdSSR in Deutschland vergleichend zueinander in Beziehung zu setzen.

Ohne die Einführung eines solchen, die Analyse konzeptuell zusammenbindenden Elements wäre das Ergebnis eine schlichte Sammlung dissoziativer Länderbilder der USA und der UdSSR. Denn verhalten sich Deutsche heute wie zu Zeiten der Weimarer Republik - ohne thematischen Fokus zu den Vereinigten Staaten und Russland, so orientieren sich ihre individuellen Standpunkte nicht selten an politischen und emotionalen Extremen. Die Weite und Unerbittlichkeit des russischen und amerikanischen Raumes, die aus den nationalen Entstehungsmythen sprechende Bedingungslosigkeit und nicht zuletzt die darin beschworenen schicksalhaften Geschichtskräfte - all dies nötigt deutschen Kommentatoren entweder höchsten Respekt ab oder dient umgekehrt zur Rechtfertigung selbstüberheblicher Geringschätzung.

Unter deutschen Intellektuellen fanden Apologeten einer »Restüberlegenheit der europäischen Kultur « ${ }^{1}$ zu allen Zeiten ebenso zahlreiche Belege für ihre Position wie glühende Verehrer des »American Way of Life« oder der viel besungenen $»$ Russischen Seele«. Die Betrachtung des vermeintlich im Utilitarismus gefangenen amerikanischen Geistes und des aus »europäischen Theorien und asiatischen Praktiken ${ }^{2}$ hervorgegangenen Kollektivismus Russlands bot selten Raum für Zwischentöne. Sei es in Form politischen und kulturellen Hegemonialstrebens oder völkerpsychologisch hergeleiteter »Wesensverwandtheit« des deutschen mit dem amerikanischen oder russischen Volk: Stets bestand in Deutschland ein tiefes Bedürfnis, sich über derartige Fragen in ein Verhältnis zu den beiden Nationen (und Kulturen) zu setzen, die dem 20. Jahrhundert ihren Stempel aufgedrückt haben.

Das öffentliche Sprechen über Amerika und Russland war immer ein leidenschaftlich geführtes, mitunter therapeutisch anmutendes Selbstgespräch der Deutschen. Zwar war dieser Gesprächsprozess durch zwei verheerende Kriege, gegenseitige Besatzung, Aussöhnung und schließlich Kooperation von großer Wechselhaftigkeit geprägt. In seiner ganz eigenen Ambivalenz wurde er dennoch stets systemübergreifend fortgesetzt und hat damit Kontinuität erfahren. Nicht immer standen hierbei Kulturpessimismus, Fragen der politischen und wirtschaftlichen Modernisierung oder ideologische Gegnerschaft im Mittelpunkt. Die Auseinandersetzung mit den Vereinigten Staaten und

1 Kaelble, Hartmut: Europäer über Europa. Die Entstehung des europäischen Selbstverständnisses im 19. und 20. Jahrhundert. Frankfurt a. M. 2001, $133 \mathrm{f}$.

2 Coudenhove-Kalergi, Richard Nikolaus Graf von: Paneuropa. In: VZT Nr.541 vom 15.11.1922, 4. 
der Sowjetunion war auch in einer Weise emotional aufgeladen, wie man dies ansonsten nur im Verhältnis zu den Nachbarnationen Frankreich und Polen feststellen kann.

Ohne an dieser Stelle einen Ausflug in die Gefühlsgeschichte wagen zu wollen, sollen doch in groben Zügen zwei Aspekte angeschnitten werden, die für den historischen Kontext, in dem diese Untersuchung ihren Ausgangspunkt nehmen soll, wichtig sind: die weltpolitischen Bedingungen des Jahres 1918, welche die Wahrnehmung sowohl der USA als auch der Sowjetunion maßgeblich bestimmten und emotional belasteten, und zum anderen die kollektiv empfundene Schockstarre der deutschen Öffentlichkeit unmittelbar nach dem Zusammenbruch der deutschen Kriegsanstrengung:

»Politisch wie psychologisch gleichermaßen unvorbereitet, stürzte die Nation, die an die Überlegenheit ihrer Waffen, einer zeitgenössischen Formulierung zufolge, geglaubt hatte, swie an ein Evangelium/, ins Bodenlose. [...] Die Wirkung dieses schockartigen Wechsels ,von der Siegesfanfare zum Grabgesang der Niederlage ist nicht zu überschätzen. Der Entzauberungsschlag hat die Geschichte der folgenden Jahre so nachhaltig beeinflußt, daß man sagen kann, sie sei ohne dieses Ereignis nicht wirklich zu begreifen. $\aleph^{3}$

Joachim Fest veranschaulicht in seiner Beschreibung des Kriegsendes 1918 durch seinen Rückgriff auf ein Zitat Paul von Hintzes, 1918 Staatssekretär des Äußeren, den Schock und die Desorientierung in den Tagen des Waffenstillstandes. Die Tiefe jenes Einschnitts zeigte sich in den Jahren der Republik und deutlicher noch in deren Untergang. Das traumatisierende Kriegsende, das langgehegte Gewissheiten als Illusionen entlarvt hatte, stürzte die Sicht der Deutschen auf die Welt und sich selbst in schweren Zweifel. Viel wurde über politische, gesellschaftliche, auch schnöde finanzielle Hypotheken der ersten Republik auf deutschem Boden geschrieben. Sie wurde "Demokratie ohne Demokraten ${ }^{4}$ genannt, das Fortbestehen antidemokratischer Eliten (»ostelbische Landjunker«), ${ }^{5}$ reüssierender Revanchismus ${ }^{6}$ und die Bürde der Reparationen als Faktoren für ihr Scheitern identifiziert. ${ }^{7}$

3 Fest, Joachim: Hitler. Eine Biographie. Frankfurt a. M. u. a. 1973, $113 \mathrm{f}$.

4 Vgl. Thoß, Hendrik: Demokratie ohne Demokraten. Die Innenpolitik der Weimarer Republik. Berlin 2008, $99 \mathrm{f}$.

5 Vgl. Winkler, Heinrich August: Mußte Weimar scheitern? München 1991, 28 f.

6 Vgl. hierzu: Kraus, Hans-Christof: Versailles und die Folgen. Außenpolitik zwischen Revisionismus und Verständigung 1919-1933. Bonn 2014.

7 Heinrich August Winkler beantwortete die Frage, ob Weimar als demokratisches Experiment von vornherein zum Scheitern verurteilt gewesen sei, differenziert, insbesondere das vielgestaltige "Erbe des Kaiserreichs in den Köpfen der Zeitgenossen «, was auch die einmalige Ungleichzeitigkeit wirtschaftlicher, kultureller und politischer Evolution Deutschlands mit einschließt. Der Fall der demokratischen Ordnung wurde Winkler 
Der Fokus dieser Untersuchung richtet sich indes auf den deutschen Blick nach außen. Die USA, deren Weltmachtstatus nach 1917 nicht mehr zu leugnen war und die zeitgleich aus den Wehen der Revolution entstehende Sowjetunion waren aus Sicht der deutschen Öffentlichkeit eng mit dem Trauma der eigenen Weltkriegsniederlage verwoben. Es gab zwei markante Malus, welche die öffentliche Auseinandersetzung mit beiden Ländern in der Frühphase der Republik atmosphärisch erheblich belasteten.

Dies waren im Falle der Vereinigten Staaten die enttäuschten Erwartungen an US-Präsident Woodrow Wilson und dessen Programm der 14 Punkte. In weiten Teilen der politischen Öffentlichkeit und der Presse wurde ihre Nichteinlösung wahlweise als arglistige Täuschung des deutschen Volkes oder schlichtes Versagen des Innenpolitikers Wilson angesehen.

Man hatte sich von den Vereinigten Staaten erhofft, dass sie nach dem Waffenstillstand mäßigend auf die »eigentlichen« Kriegsfeinde Frankreich und Großbritannien einwirken würden. Durch die Enttäuschung dieser Erwartung erschienen die USA nicht mehr als der ehrliche Makler, zu dem Wilson sie für die Zeit nach dem Kriege - aus deutscher Sicht - hatte machen wollen. Anfangs bestand bei den deutschen Verhandlungsteilnehmern der Pariser Friedenskonferenz die medial angefachte Hoffnung, die Amerikaner könnten allzu harsche Vergeltung durch die Entente-Mächte verhüten und Wilson würde die Aufmerksamkeit schnell »den Aufgaben des Friedens « ${ }^{8}$ zuwenden. Den Deutschen hätte dies trotz ihrer Niederlage klarere Perspektiven auf eine selbstbestimmte Zukunft eröffnet. ${ }^{9}$ Nicht trotz, sondern gerade wegen des entscheidenden amerikanischen Anteils an der deutschen Niederlage griff man also bereitwillig nach Wilsons ausgestreckter Hand, waren die Deutschen doch nun restlos von der Macht Amerikas überzeugt. Offener denn je begann sich die deutsche Öffentlichkeit mit den Eigenheiten der amerikanischen Nation zu beschäftigen, die deren so überwältigenden Vorsprung - so die kausale Schlussfolgerung - ermöglicht haben mussten. ${ }^{10}$

zufolge denn auch nicht erst mit der »Machtergreifung« 1933 herbeigeführt. Diese habe allerdings den finalen Akt des seit dem Zerbrechen der Großen Koalition 1930 schrittweisen Zerfallsprozesses dargestellt, der maßgeblich in der »Wiederherstellung eines bürokratischen Obrigkeitsstaates unter Brüning " bestand. Winkler: Mußte Weimar scheitern?, 31.

8 Dies hatte Woodrow Wilson in einer Kongressrede im Dezember 1918 angekündigt, die in deutscher Übersetzung in der FZT abgedruckt wurde. Anon.: Die Botschaft Wilsons. In: FZT Nr. 336 vom 04.12.1918, 2.

9 Vgl. Schwabe, Klaus: Deutsche Revolution und Wilson-Frieden. Die amerikanische und deutsche Friedensstrategie zwischen Ideologie und Machtpolitik 1918/19. Düsseldorf $1971,521 \mathrm{f}$.

10 Dieser gesamtgesellschaftliche Reflex des Nachahmens der Sieger in Folge verheerenden Niederlagen kann, um hier Wolfgang Schivelbuschs wegweisender Darstellung zu folgen, an vielfachen Beispielen nachvollzogen werden. Schivelbusch nennt unter anderem den 
Zwischen der Abwicklung des Kaiserreichs und dem Abschluss der Pariser Vorortverträge trübte sich das Bild des Präsidenten und damit das deutsche Amerikabild durch den »Wilson-Verrat» allerdings deutlich ein. Im Laufe des Jahres 1918 waren noch zahlreiche öffentliche Appelle an Wilson gerichtet worden. Darin wurde darauf hingewiesen, man sei bereits "als das Glück der Waffen unseren Heeren noch treu zu sein schien, für die von Ihnen [Wilson, D. F.] verkündete Lehre eingetreten. « $^{11}$ Als Gegenleistung erwartete man nun die Einlösung des Versprechens der 14 Punkte. Ab 1919 beobachtete ein wachsender Teil der deutschen Öffentlichkeit mit abnehmender Zuversicht die Auseinandersetzung Wilsons mit seinen innenpolitischen Gegnern. Die von den Deutschen erträumte Rehabilitierung blieb aus und das innenpolitische Scheitern Wilsons bedingte den schrittweisen Rückzug der Vereinigten Staaten von der Pariser Friedenskonferenz. ${ }^{12}$

»New South«, der sich nach dem amerikanischen Bürgerkrieg an den siegreichen »Yankees" orientierte, die nach dem deutsch-französischen Krieg nach preußischem Vorbild umgebaute französische Verwaltung und Armee sowie zu guter Letzt eben auch die "Amerikamoden in Deutschland nach 1918 und 1945«. Vgl. Schivelbusch, Wolfgang: Die Kultur der Niederlage. Der amerikanischen Süden 1865, Frankreich 1871, Deutschland 1918. Darmstadt 2001, 48 und 362.

11 So unter anderem ein offener Brief von Max Graf von Montgelas, der dem Empfinden zahlreicher militärischer und ziviler Eliten in Deutschland zum Ausdruck verhalf, man hätte ausschließlich wegen Wilsons Programm der 14 Punkte und nicht etwa wegen der Feldüberlegenheit der Entente 1918 die Waffen gestreckt. Montgelas war unmittelbar an den Versailler Verhandlungen beteiligt und gemeinsam mit Max Weber, Hans Delbrück und Albrecht Mendelssohn Bartholdy Teil der deutschen »Viererdelegation" gewesen. Er schreibt zum Beispiel: »In diesen entscheidenden Wochen sind die Augen der Welt auf Sie gerichtet. Vor allem blickt auf Sie das in schwerer Krise befindliche deutsche Volk, nicht zuletzt jene Deutschen, die damals schon, als das Glück der Waffen unseren Heeren noch treu zu sein schien, für die von Ihnen verkündete Lehre eingetreten sind [...]. Wir erwarten, Herr Präsident, daß Sie der von Ihnen verkündeten Lehre trotz aller Widerstände zum Siege verhelfen werden. Wir bauen auf das Wort, das sie am Grabe Washingtons gesprochen, daß jede Willkürgewalt, von welcher Seite sie auch kommen möge, vernichtet oder zur Ohnmacht verdammt werden müsse. Wir bauen auf das Wort von der unparteiischen Gerechtigkeit, die keinen Unterschied kennt zwischen solchen, gegen die man gerecht sein will und solchen, gegen die man nicht gerecht sein will, wir vertrauen, daß Sie einen Bund gleichberechtigter Nationen aufrichten wollen, in dem jedes Volk frei leben und atmen und streben, geistig und körperlich gedeihen kann [...]. Wenn unsere Erwartungen enttäuscht werden, dann werden wir zwar nicht aufhören, nach besten Kräften weiterzukämpfen für die von Ihnen in besseren Tagen verkündete Botschaft, aber wir müssen dann fürchten, daß nicht alle unsere Volksgenossen auf unsere Worte hören werden, wie das jetzt der Fall sein wird, wenn Sie Ihre Botschaft Wahrheit werden lassen. Sie haben die Macht dazu, Sie haben die Pflicht dazu.« Montgelas, Max von: Offener Brief an Präsident Wilson von General Graf Montgelas. In: MNN Nr. 639 vom 18.12.1918, 1.

12 Die innenpolitische Niederlage im US-Senat war für Wilson durch die Annahme der nach dem gleichnamigen Senator benannten »Resolution Knox" absehbar geworden, welche die Trennung der Friedensverhandlungen zwischen den Vereinigten Staaten und dem Deutschen Reich von den Vertragsschlüssen der Pariser Friedenskonferenz erzwangen. 
Die öffentliche Verbitterung darüber ging so weit, dass die Nachrufe auf Wilson nach dessen Tod 1924 zu regelrechten Abrechnungen gerieten. "Der Tod Woodrow Wilsons", so die Frankfurter Zeitung, lasse »in der Welt keine Lücke. Der kranke Mann« habe »außerhalb Amerikas längst aufgehört eine Rolle zu spielen«, das »Wort Wilsonismus nirgends mehr einen guten Klang. « ${ }^{13}$ In der Deutschen Allgemeinen Zeitung bemitleidete man Wilson gar ob seiner Durchsetzungsschwäche in Versailles. Auch zog die DAZ Parallelen zum kürzlichen Ableben Lenins und stellte beide Männer regelrecht als die Verlierer der Weltgeschichte schlechthin dar:

"Wilsons Tod ist symbolisch. Nicht nur, weil er zeitlich mit dem seines räumlichen, geistigen und politischen Gegenfüßlers Lenin zusammenfällt - mit ihm stirbt eine Welt, die so groß war, daß Lenin und Wilson in ihr Platz hatten, die so klein war, daß sie von den einfachsten Instinkten besiegt werden konnte. Er hat den großen Krieg entschieden und verloren. Es war für ihn schlimmer als für uns; denn wir werden es, trotz allem, überleben. Wilson aber ist aus den Schatten von Versailles in die Dämmerung der Vergessenheit, von da in die Nacht des Todes gesunken, was man wohl tragisch nennen darf. ${ }^{14}$

Über Lenins Sowjetunion wiederum kursierten vor und während der Frühphase der Weimarer Republik, insbesondere zwischen 1917 und 1921 grauenerregende Berichte zu den Verheerungen, die Revolution und Bürgerkrieg für die Bevölkerung mit sich brachten. Täglich war von marodierenden Bolschewiki oder rachsüchtigen Weißen Garden zu lesen. Statt eines »irdischen Utopia « ${ }^{15}$ sah man im revolutionären Russland eher die sich öffnenden Pforten einer Hölle auf Erden, in welcher der Rote Terror auf unabsehbare Zeit wüten würde. Die Berichterstattung zum großen Hunger 1921 schloss daran nahtlos an und vervollständigte so das publizistische Schreckenspanorama. Nach einer Beruhigung der Bürgerkriegslage 1922 und der sowjetischen Staatsgründung klärte sich die Situation nachhaltig auf und ermöglichte eine sachlichere Berichterstattung der deutschen Presse.

Die Wirren und Grausamkeiten im revolutionären Russland sind in ihrer Wirkung auf die deutsche Öffentlichkeit allerdings nicht zu unterschätzen.

Ebendiese Trennung hatte Wilson jedoch verhindern wollen. Über die dazugehörigen Senatsdebatten und -Beschlüsse wurde ausgiebig berichtet, unter anderem: Anon.: Die Vorbehalte des amerikanischen Senats. In: FZT Nr. 866 vom 19.11.1919, 1. Die durch die »Resolution Knox« erzwungenen Änderungen wurden einhellig und sinngemäß als mutwillige Torpedierung der Friedensbemühungen Wilsons betrachtet und kamen aus Sicht der deutschen Presse einer Kapitulation vor den Rachegelüsten Großbritanniens und Frankreichs gleich. Vgl. Anon.: Verschleppung der Friedensfrage in Amerika. In: FZT Nr. 958 vom 23.12.1919, 1.

13 Anon.: Woodrow Wilson †. In: FZT Nr. 92 vom 04.02.1924, $1 \mathrm{f}$.

14 Anon.: Wilson. In: DAZ Nr. 59 vom 05.02.1924, 2.

15 Hildermeier, Manfred: Die Russische Revolution 1905-1921. Frankfurt a. M. 1989, 229. 
Sie lösten im Verbund mit den sich abzeichnenden Unruhen auf den Straßen deutscher Städte einen »Anti-Chaos-Reflex« in Verwaltung und Regierung aus und ließen insbesondere die Sozialdemokraten eine wirklich demokratische Revolution versäumen. ${ }^{16}$ Friedrich Ebert schöpfte als neuer Reichspräsident auch wegen der »alles blockierenden Angst vor den Schreckensbildern der russischen Revolution ${ }^{17}$ das Potential für einen umfassenden politischen und gesellschaftlichen Neuanfang bewusst nicht aus. ${ }^{18}$ Die medial vermittelten Ereignisse um die Russische Revolution von 1917 herum wirkten so weit in den politischen Raum hinein, dass sie einen gewichtigen Teil zum "Steckenbleiben « der Revolution von 1918 beitrugen. ${ }^{19}$

Der Topos des "Wilson-Verrats" und die Angst vor »russischen Zuständen « sollen als Fallbeispiele Schlaglichter in den Möglichkeitsraum deutscher Amerika- und Russlandbilder nach 1918 werfen. Sie vermitteln einen deutlichen Eindruck von deren innenpolitischer Relevanz. Sie sind Ausschnitte des historischen Kontexts, innerhalb dessen sich das Sprechen über die USA und die UdSSR an der Epochenschwelle zwischen Kaiserreich und Republik orientierte: manchmal an neuen Entwicklungen, manchmal an tradierten Mustern. Dass beide Länder zu Anfang schlechten Leumund in Deutschland genossen, soll aber gerade zeigen, dass sich dieser Befund modifiziert, sobald man zum einen den thematischen Fokus enger stellt und zum anderen in eine diachrone Entwicklungsperspektive einsteigt. Dies wird an der Rationalisierungsdebatte in Deutschland deutlich, die in Bezug zu analogen Entwicklungen in den Vereinigten Staaten und der Sowjetunion stand.

16 Vgl. Löwenthal, Richard: Die deutsche Sozialdemokratie in Weimar und heute. Zur Problematik der "versäumten« demokratischen Revolution. In: Ders. (Hg.): Gesellschaftswandel und Kulturkrise. Zukunftsprobleme der westlichen Demokratien. Frankfurt a. M. 1979, 197-211.

17 In Gänze: »[E]s war eine ‘gänzlich ideenlose Revolution` [...]. Unentschiedenheit und mangelnder Mut haben die Revolution daher schon frühzeitig um ihre zweite Chance gebracht. Gewiß konnten die neuen Männer auf die herrschende große Erschöpfung hinweisen, auf die alles blockierende Angst vor den Schreckensbildern der russischen Revolution.« Fest: Hitler, $116 \mathrm{f}$.

18 Walter Mühlhausen zitiert Ebert zu diesem Thema mit folgendem Wortlaut aus einer Sitzung der SPD-Fraktion vom 23.9.1918: „Wollen wir jetzt keine Verständigung mit den bürgerlichen Parteien und der Regierung, dann müssen wir die Dinge laufen lassen, dann greifen wir zur revolutionären Taktik, stellen uns auf die eigenen Füße und überlassen das Schicksal der Partei der Revolution. Wer die Dinge in Russland erlebt hat, der kann im Interesse des Proletariats nicht wünschen, dass eine solche Entwicklung auch bei uns eintritt.« Mühlhausen, Walter: Friedrich Ebert 1871-1925. Reichspräsident der Weimarer Republik. Bonn 2007, 100.

19 Vgl. Kolb, Eberhard: 1918/19: Die steckengebliebene Revolution. In: Stern, Carola/ Winkler, Heinrich August (Hg.): Wendepunkte deutscher Geschichte 1848-1990. Frankfurt a. M. 2003, 99-125. Kolb verwendet dieses zutreffende Bild noch mehrmals, unter anderem: Ders.: Deutschland 1918-1933. Eine Geschichte der Weimarer Republik. München 2010, $31 \mathrm{f}$. 
Im Folgenden werden Fragen der Gesellschaftsorganisation im Vordergrund stehen, also soziale, politische und wirtschaftliche Aspekte. Die künstlerische Moderne hingegen wird zugunsten einer höheren thematischen Stringenz ausgeklammert bleiben. Der in der Zeit der Weimarer Republik expandierende (Ton-)Film, die Blüte des Expressionismus in Theater und Malerei sowie der über die Grenzen des deutschsprachigen Raums Anerkennung findende Literaturbetrieb standen zwar in engster Wechselwirkung mit gesellschaftlichen Modernisierungsprozessen. Die künstlerische Moderne nahm gesellschaftliche Veränderungen vorweg, verstärkte sie und stieß sie an. Den gewählten zeitlichen Rahmen würde eine Erweiterung um Literatur, Musik oder die bildenden Künste jedoch sprengen. Noch weniger als in gesellschaftlichen und wirtschaftlichen Wandlungsprozessen ließe sich hier eine chronologisch sinnvolle Eingrenzung vornehmen. 


\title{
1. Kultur der Rationalisierung und Rationalisierungskulte
}

\author{
»Rationalisierungen hat es daher auf den verschie- \\ densten Lebensgebieten in höchst verschiedener \\ Art in allen Kulturkreisen gegeben. Charakteri- \\ stisch für deren kulturgeschichtlichen Unterschied \\ ist erst: welche Sphären und in welcher Richtung sie \\ rationalisiert wurden. ${ }^{1}$
}

In seinen vielfältigen Konnotationen steht das Thema Rationalisierung exemplarisch für die Modernitätsdiskurse der Weimarer Zeit. Die Bewertung wirtschaftlicher und sozialer Rationalisierungsprozesse changierte zwischen fundamental opponierender Zeitkritik und begeistertem Heilsglauben. Beide Extreme entsprangen zwar der Diskussion der Verhältnisse und Entwicklungen in Deutschland, die Diskursteilnehmer bedienten sich aber bevorzugt der USA und der UdSSR als Projektionsflächen und Argumentationshilfen.

Ein Grund hierfür ist die Konnektivität dieses Diskursstranges. Er war zum einen an die Debatten der nationalen Wirtschafts- und Arbeitsmarktpolitik angeschlossen. Zum anderen brachte er aber auch das mit Händen greifbare Unbehagen ob der »Vermassung « und Entindividualisierung durch neue Arbeits- und Produktionsformen auf einen wirkmächtigen Begriff. Um an das einführende Zitat Max Webers anzuschließen: Über ideologische und lebensweltliche Gräben hinweg herrschte sowohl Einmütigkeit hinsichtlich der Sphäre, deren Rationalisierung zu diskutieren sei, als auch der Richtung, in welcher sich dieser Prozess vollzog. Die primäre Rationalisierungssphäre war die industrielle Produktion. Die Richtung wurde von Effizienzsteigerung und Zweckrationalismus bestimmt. Nachgeordnet schloss sich die Rationalisierung sozialen Zusammenlebens in Alltag und Gesellschaft an.

Dystopien, Heilserwartungen und eher nüchterne Vorhersagen über die Rationalisierungsperspektive Deutschlands bildeten ein Sammelsurium von Prognosen, die man in den USA aber auch in der Sowjetunion bereits verwirklicht sah. Beide Bezugsräume hielten Argumente für und wider jede einzelne Position in der deutschen Rationalisierungsdebatte bereit. Die vielfältige Assoziierbarkeit des Terminus Rationalisierung und seine immer wieder mit dem Rationalismusbegriff kollidierende Sinnstiftung hatten hieran großen Anteil. Nicht alles, was um der Rationalisierung willen geschah, war im eigentlichen Sinne rational. Rationalisierungskritikern erschien die Entwicklung im Gegenteil als in höchstem Maße unvernünftig.

1 Weber, Max: Vorbemerkungen. In: Ders.: Gesammelte Aufsätze zur Religionssoziologie. Bd. I. Tübingen 1988, $11 \mathrm{f}$. 
Dies war insbesondere dann der Fall, wenn das Ausgreifen des Rationalisierungsgedankens über die Wirtschaft hinaus in sozialen und kulturellen Kontexten zur Debatte stand. Wurden zunächst nur Probleme im Kontext industrieller Rationalisierung diskutiert, erweiterten sich die Bezüge im Laufe der Jahre zunehmend. Von der Entwertung menschlicher Arbeit durch die Mechanisierung war es nur ein kleiner Schritt zu gesellschaftlichen Grundsatzfragen: Das Verhältnis des Einzelnen zum impersonalen Kollektiv und die soziale Prägekraft eines durchrationalisierten Zusammenlebens waren bald feste Bestandteile der Rationalisierungsdebatte. Der Rationalisierungsbegriff verband die widerstreitenden Vorstellungen einer konsequenten Anwendung der menschlichen ratio und der daraus folgenden Entmenschlichung von Prozessen, Praktiken und Räumen. Aus dieser Grundspannung bezog der Rationalisierungsdiskurs der Weimarer Republik seine Dynamik.

Zwar wurden in Deutschland erst um 1924 in der Verwaltung des Reiches und der Länder sowie in Industrie und Handwerk auf breiter Front Rationalisierungsmaßnahmen ergriffen. Die Erfolge der US-Industrie hatten aber bereits um die Jahrhundertwende im Kaiserreich Bewunderung hervorgerufen. Während des Krieges hatte das amerikanische Modell den Deutschen dann schmerzhaft seine Überlegenheit vor Augen geführt. Bewunderung und beschämende Einsicht befeuerten seither die dahingehende Debatte. ${ }^{2}$

Die Diskussion der wirtschaftlichen Rationalisierung setzte also nicht erst in der Zwischenkriegszeit ein. Sie war in Bezug auf die Vereinigten Staaten bereits im Kaiserreich geführt worden und sollte auch im "Dritten Reich « unter neuen Prämissen ein intensiv erörtertes Thema bleiben. ${ }^{3}$ Jedoch wurden nach dem Übergang vom Kaiserreich zur Republik die beschleunigten gesellschaftlichen Veränderungen als Zeichen einer neuen Zeit intensiver rezipiert. In der medial und politisch erweiterten Öffentlichkeit gewann der Rationalisierungsdiskurs in der Zwischenkriegszeit an Kontur und Breitenwirkung. ${ }^{4}$

Die im Kaiserreich nach innen wie außen zur Schau gestellte Gewissheit, auch auf wirtschaftlichem Felde an der Spitze der Entwicklung zu stehen, hatte

2 Vgl. Klautke: Unbegrenzte Möglichkeiten, $97 \mathrm{f}$. Und: Schmidt, Alexander: Reisen in die Moderne, 127.

3 Zur dahingehenden Amerikadebatte im »Dritten Reich « nochmals: Gassert, Philipp: Amerika im Dritten Reich, 46-59 und 148-163.

4 Damit ist zuvörderst die öffentliche Debatte gemeint. Denn auch wenn Massenproduktion und Massenkultur amerikanischer Prägung vor 1945 in Deutschland kaum verbreitet gewesen sein soll, wie Arnold Sywottek dies feststellte, waren sie zweifelsohne (sehr) lange vor Ende des Zweiten Weltkriegs, nämlich spätestens mit dem Kriegseintritt der Vereinigten Staaten 1917 in der öffentlichen Diskussion präsent, wobei sich diese Präsenz in der Zwischenkriegszeit noch verstärkte. Vgl. dazu: Sywottek, Arnold: The Americanizazion of Everyday Life? Early Trends in Consumer and Leisure-Time Behavior. In: Ermarth, Michael (Hg.): America and the Shaping of German Society. 1945-1955. Providence, RI $1993,135$. 
mit dem Kriegsende 1918 eine enorme Erschütterung erfahren. In Deutschland wuchs dadurch die Bereitschaft der Öffentlichkeit und damit der Presse, sich in Fragen der Wirtschaftsorganisation Einflüssen aus demjenigen Land $\mathrm{zu}$ öffnen, welches vor kurzem noch schicksalsentscheidender Kriegsgegner gewesen war. Konkret mündete die Bereitschaft zur Auseinandersetzung mit amerikanischen Wirtschafts- und Produktionsformen in der publizistischen Diskussion des Taylor-Prinzips. Es kommt nicht von ungefähr, dass die Begriffe Rationalisierung und Amerikanisierung weithin synonym verwendet wurden. Die Vereinigten Staaten fungierten als der maßgebliche Impulsgeber des deutschen Rationalisierungsdiskurses. ${ }^{5}$ Schlagworte wie "Taylorismus" und $»$ Fordismus " glichen Ikonen der Rationalisierungsdebatte. ${ }^{6}$

Im Vergleich erscheint die genaue Verortung der im Rationalisierungsprozess wirkenden Antriebskräfte als grundlegender Unterschied in der Perzeption der Vereinigten Staaten und der UdSSR. Den USA wurde eine durch historische, räumliche und kulturelle Voraussetzungen bedingte, sich evolutionär vollziehende Rationalisierung attestiert. Als entscheidender Bedingungsfaktor der sowjetischen Rationalisierungsbemühungen galt indes die ideologische Zielvorstellung eines »neuen Menschen « und einer neu zu erschaffenden Kultur. Im deutschen Diskurs stand eine historisch und räumlich verankerte amerikanische Kultur der Rationalisierung einer in der Ideologie der Bolschewiki wurzelnden Rationalisierung der Kultur gegenüber.

Zunächst meinte Rationalisierung sowohl im amerikanischen als auch im sowjetischen Bezug lediglich die Industrieproduktion nach den von F. W. Taylor definierten wissenschaftlichen Prinzipien. Die politischen und wirtschaftlichen Eliten des Reiches maßen der umfassenden Adaption des Taylorismus aber eine Bedeutung bei, die im deutschen Nachkriegskontext weit darüber hinauswies. Damit verbunden war die Hoffnung, kraft der zeit- und ressourcenschonenden Produktionsmethoden eine »erhöhte nationale Produktion" zu erzielen und dadurch »das Volk aus der Gegenwartsnot herausführen und es zu neuem Konkurrenzkampf auf dem Weltmarkt kräftigen « ${ }^{7}$ zu können.

Beim Thema Rationalisierung bestand eine ausgeprägte Zielkongruenz zwischen staatlichen und wirtschaftlichen Akteuren. In der unmittelbaren

5 »Die Amerikanisierung der deutschen Wirtschaft, das heißt: die Anwendung spezifisch amerikanischer Methoden der Massenerzeugung und Produktionsvereinheitlichung ist heute wieder einmal ein viel erörtertes Thema.« Levy, Herman: "Amerikanisierung « der deutschen Wirtschaft? In: BTB Nr. 242 vom 23.05.1925, 1 f. Vgl. dazu auch: Gleye, Paul: Fordismus und Amerika in den 20er Jahren - Vorstellung und Realität. In: Bittner/Brüning: Zukunft aus Amerika. Dessau 1995, $92 \mathrm{f}$.

6 Vgl. auch: Saldern, Adelheid von/Hachtmann, Rüdiger: Das fordistische Jahrhundert. Eine Einleitung. In: Saldern, Adelheid, von/Kirsch, Jan-Holger (Hg.): Fordismus. Zeithistorische Forschungen / Studies in Contemporary History. Bd. 6 (2009), Nr. 2, 176.

7 Kahle, M.: Arbeitsökonomie. In: DAZ Nr. 520 vom 23.10.1919, $1 \mathrm{f}$. 
Nachkriegszeit wurde dabei der amerikanische Ursprung des Taylor-Systems gezielt bagatellisiert. Unter dem frischen Eindruck der Kriegsgegnerschaft und der unglücklichen Rolle der Vereinigten Staaten auf der Pariser Friedenskonferenz waren Fürsprecher der neuen Produktionsmethoden gut beraten, deren amerikanisches Moment nicht zu betonen. Stattdessen sprachen sie neutral von der Weiterentwicklung althergebrachter Grundprinzipien des Wirtschaftens. ${ }^{8}$ Dies erleichterte eine sachorientierte Debatte, indem ihr der Ballast der beschädigten deutsch-amerikanischen Beziehungen genommen wurde. Man vertrat die Position, man könne die amerikanischen Prinzipien wirtschaftlicher und sozialer Organisation nicht unverändert in Deutschland umsetzen. Man müsse sie stattdessen mit deutschen Traditionen vereinbaren und auf die hiesigen Verhältnisse zuschneiden. Auch dies diente dazu, der kulturkritisch motivierten Kritik an der Rationalisierung die Spitze zu nehmen. ${ }^{9}$

Insgesamt sah man im konservativen Milieu in einer entschlossenen Umsetzung und Ausweitung des Rationalisierungsgedankens auf den Bereich der Sozialhygiene ${ }^{10}$ einen geeigneten Weg aus der wirtschaftlichen und gesellschaftlichen Nachkriegs-Agonie. Längerfristig erschien wirtschaftlichen Eliten und konservativen Politikern die Rationalisierung sogar geeignet zur Befriedung der Gesellschaft, da sie den aggressiven, revolutionären Elementen in der Arbeiterbewegung die Grundlage entziehe.

Beiträger der qua Eigentümerstruktur ${ }^{11}$ industriefreundlichen Deutschen Allgemeinen Zeitung (DAZ) gingen denn auch davon aus, »[d]er alte, tiefeingewurzelte Widerstand der Arbeiter gegen das Taylorsystem « beginne »glücklicherweise nachzulassen. ${ }^{12}$ Die kommunistische AIZ nahm in ihrer entschiedenen Kritik gleichwohl einen ideologisch wohlfundierten Standpunkt ein,

8 "Das Erkennen mehrt sich, daß der Grundcharakter dieses Systems keine neue amerikanische Methode ist, sondern nur die bewußte und durchgebildete Anwendung eines uralten, in der Kulturgeschichte des Menschen verankerten Strebens, die Anwendung des ökonomischen Prinzips, das heißt der Forderung, mit dem geringstmöglichen Aufwand an Kraft, Stoff und Zeit die höchstmögliche Leistung zu vollbringen.« Ebd.

9 »Diesen wertvollen alten Kulturgedanken durch Beschäftigung mit den Methoden des Taylorismus und der Psychologie und der Physiologie der Arbeit für den Aufbau unserer Wirtschaft neu zu beleben, nicht aber Taylorismus und amerikanische Betriebswirtschaft in sklavischer Nachahmung bei uns einzuführen, ist heute eine der notwendigen Wirtschaftsaufgaben in Deutschland. [...] Wenn das ökonomische Prinzip auch in allen anderen Wirtschaftsfragen außerhalb des reinen Arbeitsprozesses zur Geltung kommt und eine durchgebildete Sozialhygiene die physiologischen und psychologischen Grundlagen zur Hebung des Arbeitswillens schafft(,) wird das deutsche Volk dank seiner hohen geistigen Kultur und der alten organisatorischen Schulung seiner Arbeiterschaft der schmerzhaften Selbstzerfleischung entsagen und bald auf neuen Wegen wieder aufwärts gehen.« Ebd., 1 .

10 Ebd.

11 Vgl. 3.2 Tageszeitungen.

12 Anon.: Arbeitsökonomie, 1. 
der dieser optimistischen Einschätzung diametral entgegenstand. In einem Artikel, der gegenüber dem Taylorismus eine grundsätzlich ablehnende Haltung einnimmt, wird in Text und Bild die Unvereinbarkeit von Arbeiterinteressen und Rationalisierungsmaßnahmen hervorgehoben (Abb. 1).

An der argumentativen Strategie des Textes ist das Eingangszitat aus »Das Kapital« von Marx und Engels auffällig. Es verortet den Artikel im kommunistischen Theoriekanon:

"Die Akkumulation von Reichtum auf dem einen Pol ist zugleich die Akkumulation von Elend, Arbeitsqual, Sklaverei, Unwissenheit, Brutalisierung und moralischer Degradation auf dem Gegenpol, d.h. auf Seite der Klasse, die ihr eigenes Produkt als Kapital produziert. ${ }^{13}$

Diesem Aufschlag folgt der gesamte Artikel. Obwohl sie nur der »besitzenden Klasse« diene, sei die bestmögliche Verwertung von Ressourcen und Arbeitskraft zu einem öffentlichen Anliegen stilisiert worden. Es sei »selbstverständlich [...], dass die Arbeiter der Rationalisierung feindlich gegenüberstehen $\aleph^{14}$. Versprochene Rationalisierungseffekte wie das Wachstum von Kaufkraft und Wirtschaft seien nichts als $»$ kapitalistische Liebdienerei. ${ }^{15}$ Diese $»$ Liebdienerei« lasse sich auf die USA als Inbegriff der kapitalistischen Wirtschaftsund Weltordnung beziehen. Die Interessen Deutschlands und seiner Arbeiter würden aus Sicht der AIZ auf dem Altar des Mammon geopfert. Der Autor Jacob Walcher, ein Schüler Rosa Luxemburgs, ${ }^{16}$ hatte sich bereits im Kaiserreich in der Arbeiterbewegung und dem ersten Spartakusbund engagiert und nach dem Krieg intensiv mit den sozialen Auswirkungen der Rationalisierung auseinandergesetzt. ${ }^{17}$ Er hielt als Politiker und Gewerkschafter den Taylorismus für ein besonders verhängnisvolles Instrument kapitalistischer und damit US-amerikanischer Interessenpolitik.

Zur selben Zeit wurden jedoch auch in der Wirtschaft der UdSSR umfangreiche Rationalisierungsmaßnahmen ergriffen - mit wohlwollender Billigung Lenins. Walcher erklärt, im Gegensatz zur kapitalistischen Welt würden in der Sowjetunion »die Produktivität der Arbeit und die vorhandenen Produktionsanlagen bei weitem nicht ausreichen, um den gesellschaftlichen Bedarf zu

13 Ebd. Im Original: Marx, Karl / Engels, Friedrich: Werke, Bd. 23: Das Kapital, Bd. 1. Berlin 1968, 675.

14 Walcher: Was ist Rationalisierung?, 2.

15 Ebd.

16 Vgl. Stock, Ernst/Walcher, Karl: Jacob Walcher. Gewerkschafter und Revolutionär zwischen Berlin, Paris und New York. Berlin 1998, 20.

17 Er veröffentlichte dazu neben zahlriechen Artikeln, die meist in KPD-Organen oder eben in der AIZ erschienen, auch eine Monographie, in der er sich neben einer Analyse der fordschen Produktions- und Lohnpolitik auch deren konkreten Auswirkungen auf die gesellschaftliche Stellung der Arbeiter widmete. Walcher, Jacob: Ford oder Marx: Die praktische Lösung der sozialen Frage. Berlin 1925. 
Was ist Rationalisierung?

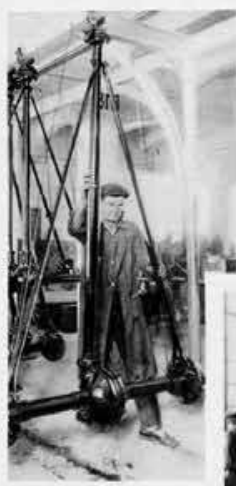

Ein krattiket Arbeiter bexinst.

Produkte ne ersenzes. Die Mittel Jaza sind: Steigenun
der Intcusilat dor Arbeit

hớticre Oricanisubon ond verbesserte Produktions. Wahirend fraber dio stân.

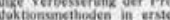
Limie eine sache des
Einzelenterelimers wimzelenterse hmer: unter dem modernon, mono:
polisierten Kapialisinas za einem offentiliches

von Jakob walcher

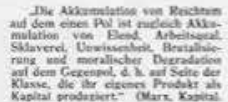

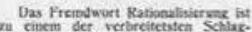
worte keworden. Was ist sein realed landelt es sicht darum Sic Asubetass

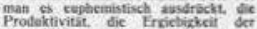

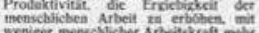

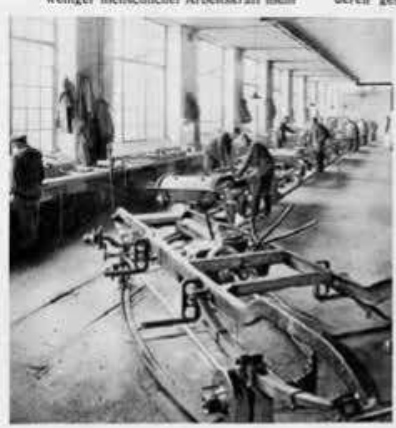

cinfugiem

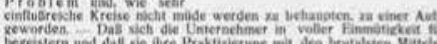

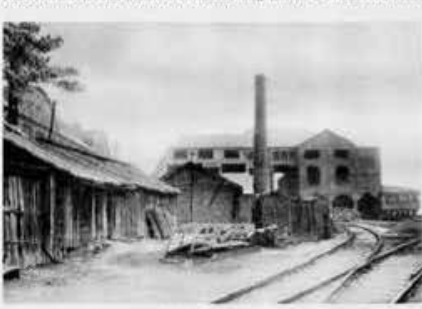
veresets Fatrikes

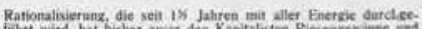

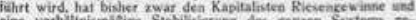

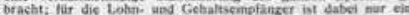
zesalitue Vermichruar des Arbeltslasendiceres, zesteinerter Drock

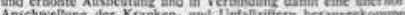

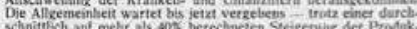

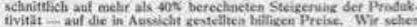

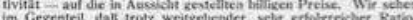

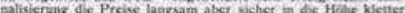

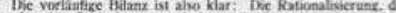
Griesmende Bereicherung zar Jer einen Seite bewinkt, bewirt

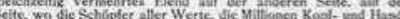

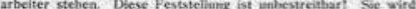
aush vos den Gewerikschaftsfichtern und feoes Sorialestisokrated

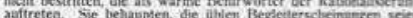

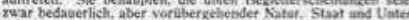

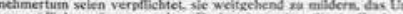

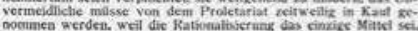
2

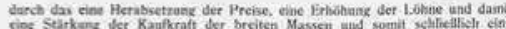

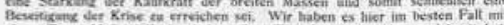

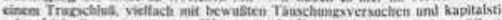

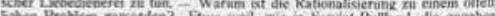

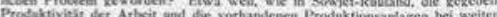

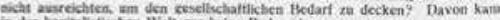
in der lapitalistikchen Welt par keine Rede sein.

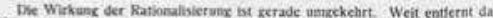

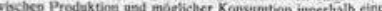

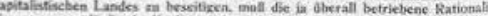

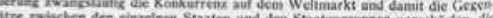
Trise tover.

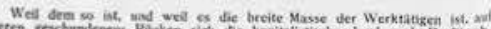

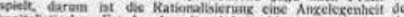
apitalistischen Fetinkle. der dic Arbciterklaswe am besteil da.

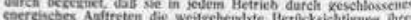

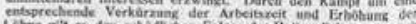

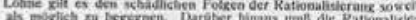

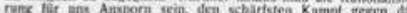
apitalistivele System und seine Verteidizor wad fir de vet-

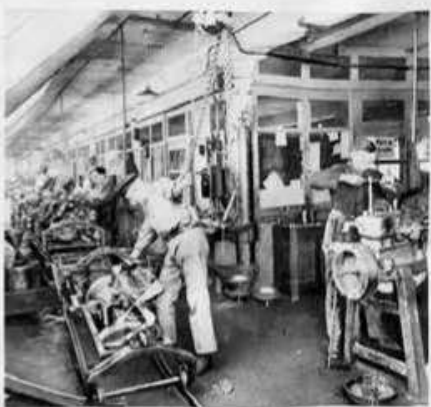

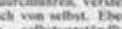
beitur der katianative.

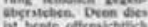

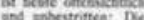

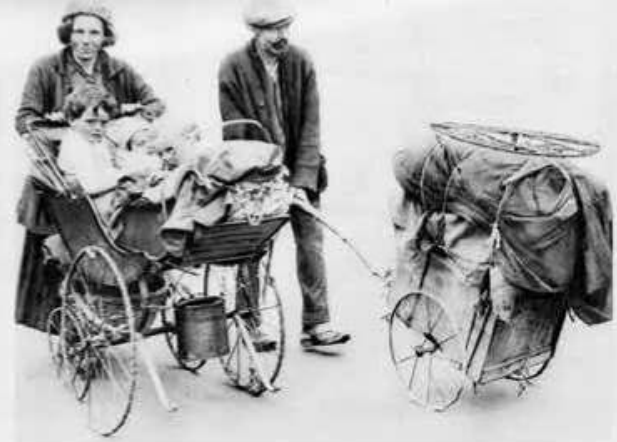

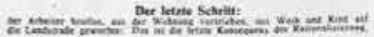

Abb. 1: Walcher, Jacob: Was ist Rationalisierung? In: AIZ, 1927, Nr. 23, 2. Der kapitalistischen Rationalisierung werden hier ihre vermeintlich fatalen Folgen gegenübergestellt. 
decken. $\aleph^{18}$ Übersetzt: Der Kapitalismus rationalisiert zu Lasten der Arbeiterschaft, um seine Produktionsmittel zu schonen, der Kommunismus aber rationalisiert aus Mangel an Kapital und Kapazitäten.

Mit dieser moralischen Setzung wird die Motivation hinter vergleichbaren wirtschaftspolitischen Maßnahmen zur entscheidenden Kategorie für deren Bewertung. Es ging Jacob Walcher also nicht zuvörderst um konkrete Fragen der Produktionsorganisation, sondern um die Frage des Systems, vor dessen Hintergrund und in dessen inhärentem Sinne sie vollzogen wird. Jedoch ist es weniger der recht vorhersehbare Text, der in der Komposition des Artikels besondere Beachtung verdient. Viel unmittelbarer wirkt auf den Betrachter die visuelle Nachempfindung des durch die Rationalisierung forcierten Niedergangs der Arbeiter ein. Ganz im Kontrast zum Versprechen wirtschaftlichen (Wieder-)Aufstiegs werden hier Visuals in der Anordnung einer Kaskade gezeigt, die den kausalen Zusammenhang zwischen dem Abstieg der Arbeiterschaft und der Einführung des Taylor-Systems verdeutlichen sollen.

Drei fotografische Anschauungsbeispiele tayloristischer Arbeitsteilung sind parallel zu zwei visuellen Chiffren wirtschaftlichen Verfalls und sozialen Abstiegs zu sehen. Ein verlassenes, »wegrationalisiertes« Fabrikgelände steht, mit entsprechender Bildunterschrift ${ }^{19}$ versehen, neben der Darstellung einer verwahrlosten Arbeiterfamilie. Ihre Habseligkeiten nebst Kindern schieben die Eltern auf Karren vor sich her - das ultimative Abstiegsszenario. ${ }^{20}$ Durch die visuelle Parallelisierung werden die existierenden sozialen Verwerfungen mit dem Zeitphänomen des Taylorismus verknüpft, ganz gleich ob Realität oder reine Dystopie eines zur Verelendung verurteilten Proletariats. ${ }^{21}$

Nicht nur in der kommunistischen und nationalsozialistischen Presse, auch im politisch gemäßigten Spektrum wurde in zahlreichen ähnlichen Artikeln eine direkte Linie von der Einführung des Taylor-System zu Entmenschlichung, Arbeits- und Identitätsverlust konstruiert. Diese Linie stellte den wirkmächtigsten Strang der Rationalisierungskritik dar.

Die Bandbreite möglicher Positionen zu wirtschaftlicher Rationalisierung reichte also von der Hoffnung auf die große volkswirtschaftliche Aufholjagd

18 Walcher: Was ist Rationalisierung?, 2.

19 „Verödete Fabriken bedingen Arbeitslosigkeit: Auch eine Folge der Rationalisierung.» Ebd.

$20 »$ Der letzte Schritt: der Arbeiter brotlos, aus der Wohnung vertrieben, mit Weib und Kind auf die Landstraße geworfen: Das ist die letzte Konsequenz der Rationalisierung.« Ebd.

21 Wie Egbert Klautke schreibt, erkannten viele Beobachter mit Blick auf die Vereinigten Staaten, dass das befürchtete Massenelend nicht durch Fortschritte in der Produktionstechnik oder der kapitalistischen Wirtschaftsordnung ausgelöst würde. Arbeiter genossen in der amerikanischen Gesellschaft erstens ein gewisses Ansehen und zeichnete sich zweitens weniger durch Konfrontation als durch Kooperation mit den Arbeitgebern aus. Vgl. Klautke: Unbegrenzte Möglichkeiten, $64 \mathrm{f}$. 
bis zum Schreckensbild scharenweise nutzlos gewordener Arbeiter. Zwischen diesen Extremen entspannte sich eine Debatte, die vordergründig das Zeitphänomen der Rationalisierung behandelte, im Kern jedoch Kultur- und Zeitkritik ausdrückte. Deutlich wurde dies zunächst in der kritischen Betrachtung Amerikas als Mutterland des Taylorismus, das diesen wegen seiner spezifischen kulturellen und räumlichen Bedingungen zwangsläufig habe hervorbringen müssen. Von der Sowjetunion zeichneten über die Wirtschaft hinausreichende Formen der Rationalisierung, vor allem des Menschen selbst, das Bild einer sich buchstäblich selbst umgrabenden Gesellschaft.

\subsection{Amerikas Tradition der Zukunft}

Die Rationalisierung der deutschen Wirtschaft wurde vielfach als kulturelle Amerikanisierung interpretiert. Rationalisierungskritik spiegelte die Ablehnung des wachsenden Einflusses amerikanischer Lebensführung wider. Diese Haltung schmälerte indes nicht das Interesse an den USA als Quelle wirtschaftlicher Innovationen. Scheinbar folgewidrig wuchs mit der Kontroversität der Debatte die Neugier auf die Bedingungen, unter denen solch umwälzende Neuerungen hatten entstehen können. Im deutschen und europäischen Amerikabild war schon seit dem 19. Jahrhundert die latent pejorative Vorstellung amerikanischer Technikaffinität verankert. ${ }^{22}$ Deren Beschreibung erhielt ihren abwertenden Duktus durch die implizite Feststellung der Abwesenheit jeglicher Hochkultur im amerikanischen »Volkscharakter«.

Bürgerlich-konservative Tageszeitungen wie die DAZ konnten das Zerrbild vom Amerikaner als tüftelndem Naivling greller zeichnen als liberale Blätter. Ihre Leserschaft definierte sich schließlich nicht zuletzt über die Zugehörigkeit zu jener Hochkultur, die dem Amerikaner angeblich vollkommen abging. Der kommunistischen AIZ als selbsternanntem Sprachrohr des Arbeiterproletariats diente die Kritik an der kapitalistischen Ausbeutung des amerikanischen Arbeiters als wohlfeiler Ersatz für derlei Kulturchauvinismus.

Die amerikanische Wirtschaftsorganisation wurde traditionell mit den historischen, materiellen und räumlichen Gegebenheiten erklärt. Dieses Erklärungsmuster bildet ein über Epochengrenzen stabiles Narrativ des deutschen Amerikabildes. Im krassen Ungleichgewicht zwischen überreichen natürlichen Ressourcen und rarem qualifizierten Personal erkannten die Beobachter den Ursprung des Strebens nach bestmöglich rationalisierter Betriebsführung.

22 Vgl. Depkat, Volker: The Birth of Technology from the Spirit of the Lack of Culture: The United States as 'Land of Technological Progress in Germany, 1800-1850. In: Wala, Michael/Lehmkuhl, Ursula (Hg.): Technologie und Kultur: Europas Blick auf Amerika vom 18. bis zum 20. Jahrhundert. Köln 2000, $23 \mathrm{f}$. 
Diese »Entwicklungslinien in der amerikanischen Industrie« bedingten die zunehmende Aufspaltung und Mechanisierung von Produktionsprozessen zur optimalen Ausnutzung menschlicher Arbeitskraft:

"Der Mangel an Arbeitskraft, gemessen an den unermesslich reichen Möglichkeiten des Landes, zusammen mit dem noch viel größeren Mangel an gelernter Arbeitskraft, zwang zur weitgehenden Zerlegung, zur Mechanisierung der Arbeit, von der Mechanisierung kam man zur Maschinisierung, da das Element Arbeitskosten doch stets das teuerste blieb, die Maschine jedoch umso billiger wurde, je größer die von ihr hergestellten Massen waren, so kam man dazu, die immer teurer werdende Arbeitskraft auf das Genaueste auszunutzen, indem man alle unwirtschaftliche Arbeit wegzuorganisieren strebte. ${ }^{23}$

Dieser sozioökonomische Determinismus führte zu soziokulturellen Analogieschlüssen auf die gesamtkulturelle Verfasstheit Amerikas. Alice Salomon fasste die von Pragmatismus und Rationalismus tief durchdrungene Alltagskultur 1924 im Schlagwort der "amerikanischen Lebenstechnik «zusammen. ${ }^{24}$ Diesem Konzept war ökonomischer Rationalismus ebenso eingeschrieben wie überzogene Vorstellungen vom amerikanischen Lebensstandard, die in Deutschland sehr weit verbreitet waren. Unbestreitbare Fakten wie die hohe Automobilität der ländlichen Bevölkerung oder die formidable technische Ausstattung amerikanischer Hausfrauen machten den Großteil von Salomons Schilderungen aus. ${ }^{25}$ Dazu mischte die Autorin maßlose Übertreibungen wie die Aussage, jeder amerikanische Junge kommuniziere wie selbstverständlich via selbstkonstruierter Funkanlage. ${ }^{26}$ So wurde ein amerikanischer homo

23 Hirsch, Julius: Entwicklungslinien der amerikanischen Industrie. In: BTB Nr. 291 vom 22.06.1928, $1 \mathrm{f}$.

24 "Der Amerikaner ist technisch und in der Nutzbarmachung von Erfindungen anderen Ländern voraus. Er hat aber auch einen rationalen Lebensstil; eine Lebenstechnik, die man ablehnen kann, die man nicht sympathisch zu finden braucht, die ihn aber für den Lebenskampf in ungewöhnlichem Maß stark macht.« Salomon, Alice: Lebenstechnik Amerikanische Eindrücke. In: VZT Nr. 185 vom 17.04.1924, 1 f.

25 »Henry Ford hat das große Verdienst, den amerikanischen Farmer seiner Isoliertheit entrissen, dem Dorfbewohner die Lockungen der Großstadt in erreichbare Nähe gebracht zu haben. Wenn man durch den mittleren Westen fährt, [...] bekommt man eine Vorstellung davon, wie das Leben der Landbevölkerung durch die Technik verändert worden ist. Ueberall sind die Landstraßen mit Autos belebt; vor jedem Dorf sieht man die Wagen stehen. Der Garage-Schuppen gehört zum Haushalt des Bauern fast so wie Stall und Scheune [...]. Das Auto ist in jeder Beziehung das Wahrzeichen der Vereinigten Staaten. Man sollte es in die die Fahne neben die Streifen und Sterne setzen.« Ebd.

26 »Auch Telephon und Rundfunk haben ihn mit der übrigen Welt verbunden. Sie sind Haushaltungsgegenstände geworden. Jeder amerikanische Junge konstruiert sich seinen eigenen Rundfunkapparat. Er braucht keine Erlaubnis zu haben, keine Gebühr zu zahlen. Er fertigt seinen Apparat an und fängt auf, was in der Luft ist. Man fährt durch Städte, in denen auf jedem Dach die Radioanlage errichtet ist.« Ebd. 
oeconomicus konstruiert, der allem Unproduktiven entsagt und kontinuierlich der Optimierung seiner selbst und der ihn umgebenden Welt frönt. ${ }^{27}$

Derlei Schilderungen mögen in ihren ausschmückenden Einzelheiten übertrieben gewesen sein. Amerika-Korrespondenten wie Salomon, die in den urbanen Zentren der Ostküste lebten und schrieben ${ }^{28}$ sahen die amerikanische Lebens- und Arbeitseinstellung trotz aller Vorbehalte als veritable Bewältigungsstrategie des modernen Lebens. Sie verstanden sich als Berichterstatter von einem Ort, der von ihrem deutschen Publikum räumlich ebenso entfernt war wie zeitlich. Im Keim waren ihre Berichte als Voraussagen über das Leben angelegt, das man in Deutschland in naher Zukunft würde führen können oder müssen.

Nicht nur die Rationalisierung der Wirtschaft, sondern jedes Einzelnen erschien als Erfordernis der kommenden Zeit. Effizienzsteigerung wurde nicht mehr nur als sektoral begrenzte Herausforderung für das produzierende Gewerbe begriffen. Die Begriffe der Amerikanisierung, Rationalisierung und Modernisierung verwiesen zunehmend aufeinander, wurden gegenseitig austauschbar. Diese Vermischung der Konzepte war in positiven, geradezu enthusiastischen Bewertungen der Amerikanisierung ebenso feststellbar wie in kulturpessimistischen Warnungen vor dem Transformationspotential amerikanischer Wirtschafts- und Kulturmacht. Auch diejenigen, die die Einebnung der europäischen Kulturen auf das Niveau einer hegemonialen amerikanischen Einheitskultur beschworen, bedienten sich der gedanklichen Verschränkung von wirtschaftlichen Rationalisierungsprozessen und deren kulturellen Varianten Banalisierung und Standardisierung.

Die Münchner Neuesten Nachrichten brachten die unterstellte kritiklose Übernahme alles Amerikanischen durch Europa mit einem Zitat des niederländisch-amerikanischen Autors Hendrik Willem van $\operatorname{Loon}^{29}$ auf den Punkt:

27 »Es ist immer gewollte Bemeisterung und Beherrschung des Lebens. Das greift auch in das individuelle Leben über. Der Begriff der geistigen Hygiene steht im Mittelpunkt des Interesses. Man will nervösen Erkrankungen vorbeugen. Man will Schwächen der Anlage überwinden. Man will die Fähigkeit entwickeln, zu Zeiten alle Energien bis aufs äußerste auszunutzen, ohne hinterher zusammenzubrechen. Dazu schafft man sich einen Rhythmus von vollkommenster Entspannung und gesteigerter Tätigkeit. >Wie man erfolgreich lebt«, das ist Gegenstand nicht nur ökonomischer, sondern psychologischer und medizinischer Betrachtungen. Als Beispiel dafür erzählt man von einem Athleten, der bis in ein hohes Alter einen wunderbar gebildeten und leistungsfähigen Körper behielt, daß er auf die Frage, wodurch er seine Kräfte erhalten habe, antwortete: er habe nie im Leben auch nur eine überflüssige Bewegung gemacht. Der Amerikaner, der Erfolg hat, der es zu einer großen Stellung bringt, wählt aus, was er tut und was er unterläßt.« Ebd.

28 »Dann aber ist die Hast, der Lärm, die Atemlosigkeit in den großen Städten des Ostens so beispiellos, daß man einer besonderen Lebenstechnik bedarf, um sie zu meistern.« Ebd.

29 Van Loon brachte sich neben seinen zahlreichen Überblickswerken (unter anderem: Van Loon, Hendrik Willem: Von Columbus bis Coolidge: Werdegang eines Weltteils. Berlin 1929.) durch pointierte kultur- und zeitkritische Beiträge in die amerikanischen und 
"Europa annektiert sich selbst an die Vereinigten Staaten. ${ }^{30}$ Dabei begehre doch sogar die intellektuelle Elite in den USA selbst gegen die kulturelle Standardisierung auf, die der wirtschaftlichen Rationalisierung folge. Unter anderem wird Sinclair Lewis, erster amerikanischer Literaturnobelpreisträger, als Widerständler genannt. ${ }^{31}$ Diese «allgemeine Geisteswende ${ }^{32}$ gegen die kulturelle Verflachung stehe Deutschland allerdings noch bevor.

Wenn Zeitgenossen der Amerikanisierung, respektive Rationalisierung auch skeptisch begegneten, suchten sie doch stets in der amerikanischen Gegenwart nach Gegenargumenten. Dem amerikanischen Modell positive Beispiele aus Deutschland oder Europa entgegenzustellen, vermochten sie nicht. Das Bild der USA als "Land des Fortschritts $\aleph^{33}$ war so wirkmächtig, dass selbst zur Formulierung von Kritik darauf zurückgegriffen wurde. Es hatte durchaus Tradition, den USA Zukunftsfähigkeit zuzuschreiben - ein Umstand, der ihnen in Debatten über künftige Entwicklungen stets die Rolle des Paradebeispiels reservierte; ungeachtet dessen, ob diese Entwicklungen Hoffnungen, diffuse Ängste oder beides zugleich weckten.

Jenseits aller Furcht vor einer Amerikanisierung der ökonomischen Kultur manifestierte sich die begründete Angst vor einer amerikanischen Übernahme der realen Wirtschaft durch Kapitalbeteiligungen. ${ }^{34}$ Amerikanische Investitionen in deutsche Betriebe waren nach Maßgabe des Dawes-Plans ab

europäischen Debatten zu den Auswirkungen kultureller Standardisierung und technischen Fortschritts ein. Ders.: Multiplex Man, or the Story of Survival through Invention. London 1928.

30 Fortsetzung: »[I]n dem Glauben, daß Amerika den Stein der Weisen gefunden hat [...]. Die Europäer lesen nur über Ford, Rockefeller, Edison, zusammenklappbare Teetische, Schuhe und Jazzplatten [...]. Europa hat unsere schlimmsten Einrichtungen kopiert, die häßliche Stupidität unserer eisernen Zivilisation. Es opfert seine Ursprünglichkeit, um die Kleider zu tragen, um die Schönheit von Unter den Linden in eine Main Street zu verwandeln und einen Babbitt zum Oberbürgermeister der Rue de la Paix zu erwählen." Anon.: Amerikanismus. Ein Spiegel aus der neuen Welt. In: MNN Nr. 259 vom 23.09.1927, 1.

31 "Auch die Bewegung der Jungen, gegen die Standardisierung und Mechanisierung des Menschen Revoltierenden des jungamerikanischen Aktivismus wird in ihrer Tragweite, ihrem sittlichen Ernst und ihrer Stoßkraft vielleicht nicht völlig richtig eingeschätzt. Es ist wohl doch nicht nur das negative des beißenden Spottes und ätzender Gesellschaftssatire, mit denen Männer wie Sinclair Lewis und H.L. Mencken sich gegen die herrschende Geistesrichtung aufbäumen $[\ldots]$..« Ebd.

32 Ebd.

33 Vgl. Depkat: Amerikabilder in politischen Diskursen, $215 \mathrm{f}$. Nur durch die bereits über ein Jahrhundert andauernde Tradierung des Bildes vom fortschrittlichen Amerika, wie es Depkat für die Zeit des politischen und kulturellen Aufbaus der Vereinigten Staaten beschreibt, ist seine Resilienz im deutschen und europäischen Diskurs zu erklären.

34 Vgl. Wala, Michael: Amerikanisierung und Überfremdungsängste: Amerikanische Technologie und Kultur in der Weimarer Republik. In: Ders./Lehmkuhl, Ursula (Hg.): Technologie und Kultur: Europas Blick auf Amerika vom 18. Bis zum 20. Jahrhundert. Köln $2000,130 \mathrm{f}$. 
1924 zwingend an Rationalisierungsmaßnahmen gebunden. ${ }^{35}$ Öffentlichkeitswirksame Akquisitionen wie die des Autobauers Opel durch General Motors 1929 verquickten diffuse, auch kulturelle Übernahmeängste und die Rationalisierungsdebatte zusätzlich. Die Polyvalenz der Debatte wurde durch die Furcht vor wirtschaftlichem Autonomieverlust um eine Facette erweitert. Sie verkomplizierte das Geflecht aus technologisch-organisatorischem Fortschritt und kultureller Egalisierung, was der Debatte stetig neuen Anschub gab.

\subsection{Taylorismus und Fordismus in der Kritik}

Mit den neuen amerikanischen Produktionsmethoden schien die Zukunft unaufhaltsam Einzug in die deutsche Wirtschaft zu halten. Dies veranlasste die Zeitungen, sich dem Thema zunächst auf instruktive Weise zu nähern. Dem deutschen Publikum sollten die grundlegenden Prinzipien des Taylorismus an Hand konkreter Anwendungsbeispiele dargelegt werden. ${ }^{36}$

Wie in heutigen Beiträgen zu technologischen Neuerungen auch, war den Beiträgern selten (nur) daran gelegen, über die neuen Methoden wertneutral aufzuklären. Meist waren entsprechende Ausführungen mit Grundsatzkritik versehen. Entweder wurde die Übertragbarkeit von Taylors Grundsätzen auf die deutsche Arbeitslandschaft in Zweifel gezogen oder die »Entseelung der Arbeit im Gleichtakt der Maschinen ${ }^{37}$ beklagt. Letztere konstatierten Konservative übrigens ebenso wie Kommunisten, die ihre Kritik mit Marx

35 Vgl. Stollberg, Gunnar: Die Rationalisierungsdebatte 1908-1933. Freie Gewerkschaften zwischen Mitwirkung und Gegenwehr. Frankfurt a. M. 1981, $45 \mathrm{f}$.

36 Zum Beispiel: »Die Mittel, deren sich das Taylor-System bedient, bestehen im genauen Studium und der sich daraus ergebenden Vereinfachung der Arbeitsvorgänge sowie in der Prüfung der Arbeiter, um für jeden die seinen Fähigkeiten am besten angemessenen Tätigkeit zu finden. Es entsteht so ein neues Gebiet der 'Wissenschaft der Arbeit‘, das oft mit verblüffend einfachen Hilfsmitteln Ueberraschendes erzielt. In einem Falle z. B. wurde in althergebrachter Weise Kohlen geschaufelt. Um zu ergründen, wie man die Tagesleistung steigern könne, wurden Versuche mit Schaufeln verschiedener Größe gemacht. Es zeigte sich, daß die beste Leistung mit einer Schaufel erzielt wurde, die 9,5 Kilo faßte. Diese Schaufel wurde dann Normalschaufel und als solche dem spezifischen Gewicht der Last angepaßt." Neuburger, Albert: Das Taylor-System. Das vielumstrittene Verfahren zur Erhöhung und Überprüfung der Arbeitsleistung. In: BIZ, 1919, Nr. 21, 182f. (Jahresausgabe). Vgl. auch: »Die Erforschung der menschlichen Leistungsfähigkeit und ihrer Grenzen ermöglicht die Aufstellung eines genauen Arbeitsplanes für die Zusammenarbeit von Mensch und Maschine, Vermeidung von Zeitverlusten, genaue Bestimmung der Lieferfristen und Sicherung des dem Arbeiter gebührenden Tagesverdienstes. Durch Einführung der Bewegungs- und Zeituntersuchung schiebt sich die mit der Ermüdungsund Pausenbeobachtung verknüpfte Frage der Arbeiterauslese in den Vordergrund: >Der rechte Mann soll an die rechte Stelle gebracht, jedermann die für ihn am besten geeignete Tätigkeit zugewiesen werden Weiß, Artur: Taylorismus. In: MNN Nr. 306 vom 24.07.1922, 1.

37 Ebd. 
wirtschaftsphilosophisch unterfüttern konnten. »Blödsinn" und »Cretinismus« durch seelenlose Maschinenarbeit, so hatte Marx vorausgesagt, sei der Preis der Arbeiter für die »Wunderwerke der Reichen $«{ }^{38}$ Anderen Diskursteilnehmern war die lückenlose Durchleuchtung des Arbeitsprozesses aber auch schlicht »zu amerikanisch«, im Sinne einer übertriebenen Empirie.

Das Odeur der Aufklärung schwang in der Erörterung des Taylorismus spürbar mit. Die empirische Erfassung des Arbeitsprozesses, die konsequente Umsetzung gewonnener Erkenntnisse in konkrete Arbeitsanweisungen und auch der amerikanische Ursprung fügten die Erkenntnisse Taylors nahtlos in die aufklärerische Entwicklungslogik ein. Vielfach wurde der kühl kalkulierende Taylorismus dem romantisierten Bild hochmittelalterlicher deutscher Handwerkstradition gegenübergestellt. ${ }^{39}$ Dahingehende Kritik konnte in Deutschland, genauer im katholisch-konservativen Milieu, auch an die tradierte Skepsis gegenüber den politischen und humanistischen Idealen der Aufklärung anknüpfen. Im nationalkonservativen Spektrum verhinderte die von Jeffrey Herf unter dem Begriff "Reactionary Modernism « zusammengefasste Traditionslinie die vollumfängliche Aufnahme des Gedankenguts der Aufklärung in den Kanon deutscher Kultur. Damit wurde »Kultur« in jenem Milieu als konzeptueller Gegenbegriff zur "Zivilisation« im Sinne der Aufklärung gebraucht. ${ }^{40}$

Dem plakativsten Beispiel für wissenschaftliche Betriebsführung nach dem Taylor-Prinzip gab deren berühmtester Anwender seinen Namen: Henry Ford. Doch die wenigsten Beiträge, die den Begriff »Fordismus« im Titel trugen, adressierten auch tatsächlich dessen weit über Taylors Grundsätze hinausreichenden Ansatz. Umgekehrt wurde die Fließbandfertigung Fords vielfach unter den Begrifflichkeiten der Taylorismus-Debatte subsumiert. Beide Begriffe wurden konvertibel benutzt. Die Faszination Fords und die Gravitation des Sammelbegriffs Fordismus war allerdings enorm. Während die "FordInvasion $\aleph^{41}$ den Automobilmarkt revolutionierte, verbreiteten Wirtschaftskolumnen eine umfassende Ford-Konfusion. Schrieben Beiträger unter der Überschrift Fordismus, beschrieben sie meist den Taylorismus, also die Op-

Marx, Karl: Ökonomisch-philosophische Manuskripte. In: Philosophische Bibliothek, Bd. 559. Hamburg 2008, $58 \mathrm{f}$.

39 »All diese Untersuchungen, Messungen und Feststellung haben ein gemeinsames Ziel: den Wirkungsgrad der persönlichen und sachlichen Betriebsmittel bis zur Höchstgrenze zu steigern. Aus diesem Grunde hat Taylor mit der Ueberlieferung des alten Meisterwesens gebrochen und Fachmeister geschaffen, die sich teils mit der Arbeitsvorbereitung, teils mit der Arbeitsausführung innerhalb des ihnen zugewiesenen engeren Wirkungskreises zu befassen haben."Weiß: Taylorismus, 1 .

40 Herf, Jeffrey: Reactionary Modernism. Technology, culture, and politics in Weimar and the Third Reich. New York u. a. 1984, $1 \mathrm{f}$.

41 Anon.: Ford-Invasion. In: MIP, 1924, Nr. 33, 583 (Jahresausgabe). 
timierung der Arbeit durch das Studium ihrer Abläufe, die Standardisierung von Werkstücken und die kleinteilige Zerlegung des Arbeitsprozesses. Die entscheidende Weiterentwicklung des Taylorismus zum Fordismus besteht aber in der Erweiterung zum sozialpolitischen Konzept: Großzügige Lohnstrukturen und die Kooperation zwischen Arbeitnehmern und Arbeitgebern sollte neben einer ausgeprägten Dienstleistungsorientierung auch die soziale Befriedung der Arbeiterschaft sicherstellen. ${ }^{42}$ Diesen Unterschied stellte Henry Ford persönlich durch eigene Gastbeiträge in deutschen Zeitungen heraus, die im nächsten Teilkapitel besprochen werden.

Einzig die flächendeckende Einführung des Fließbandes als Symbol für die rationalisierte Industrie schlechthin wurde im deutschen Kontext als originärer Beitrag Fords dargestellt. ${ }^{43}$ Die dahingehende Diskussion wies zwar ebenfalls begriffliche Unschärfen auf. Jedoch zeichnete sie die Verschmelzung der Prinzipien empirisch fundierter Arbeitsaufteilung (Taylor) und fließender Fertigung (Ford) in Deutschlands Fabrikhallen reflektiert und kritisch nach.

Presseartikel zu Funktionsweise und Auswirkungen des Fließbandes beschrieben Material, Maschine und Mensch als niemals rastende Glieder eines integrierten Herstellungsvorgangs. Leidenschaftliche Kritik provozierte dabei die fundamentale Veränderung der Rolle des einzelnen Menschen im Arbeitsprozess. Durch die Taktvorgabe des Fließbandes schien das menschliche Element in fortschreitendem Maße entbehrlich zu werden.

»Das laufende Band « war der Titel zweier Ausgaben der FZT-Reiseberichtsserie $" A m e r i k a-E u r o p a{ }^{44}$ von Arthur Feiler, der als gelernter Wirtschaftsjournalist die USA bereiste. ${ }^{45}$ Er beschrieb Amerika als einen durch Drehkreuze, Selbstbedienung und Supermärkte entpersonalisierten öffentlichen Raum und übertrug so die Rationalisierungskultur von den Fabrikhallen auf den dortigen Alltag. ${ }^{46}$ Besonders kritisierte Feiler die Degradierung des Menschen zum bloßen Impulsempfänger des Fließbandrhythmus:

42 Vgl. Fehl, Gerhard: Welcher Fordismus eigentlich? In: Bittner, Regina/Brüning, Henning (Hg.): Zukunft aus Amerika. Fordismus in der Zwischenkriegszeit. Siedlung, Stadt, Raum. Berlin 1995, $22 \mathrm{f}$.

43 Zuvor hatten bereits Schlachthöfe in Chicago Beförderungsschienen, beziehungsweise in Deutschland die Großbäckerei Bahlsen Fließbänder in der Produktion verwendet. Die flächendeckende Anwendung und Einführung in Deutschland erfolgte aber dennoch durch Fords Inspiration.

44 Erstmalig: Feiler, Arthur: Amerika-Europa. In: FZT Nr. 644 vom 30.08.1925, 1 f. Es folgten im Wochenrhythmus weitere, jeweils auf bestimmte Aspekte amerikanischer Politik, Wirtschaft und Kultur fokussierende Artikel.

45 Feiler hatte vor dem Krieg breit rezipierte Abhandlungen zum Bankenwesen und der wirtschaftlichen Entwicklung im Kaiserreich veröffentlicht bevor er zur FZT wechselte. Unter anderem: Feiler, Arthur: Die Probleme der Bankenquete. Jena 1908. Und: Ders.: Die Konjunktur-Periode 1907-1913 in Deutschland. Jena 1914.

46 Vgl. Feiler: Amerika-Europa. Das laufende Band - I. In: FZT Nr. 800 vom 27.10.1925, $1 \mathrm{f}$. 
»Der Umschlag im Charakter des Conveyors aber aus einem einfachen Transportmittel zum tyrannischen Gebieter der an ihm tätigen Menschen liegt einfach darin, daß die Arbeit, weil sie am laufenden Bande vor sich geht, sich nun auch ihr Tempo von dem Tempo des Bandes diktieren zu lassen hat. Das Tempo, in dem das Band sich dreht, bestimmt unwidersprechbar auch das Tempo, in dem die Menschen sich zu rühren haben. ${ }^{47}$

»Die völlige Entsinnung « der menschlichen Arbeit liege darin begründet, dass »die Arbeiter und Arbeiterinnen an dem Bande sitzen" und mit bloßen Teilarbeiten beschäftigt seien, »deren Zweck ihnen gänzlich verborgen ist, weil sie niemals sehen, was vorher geschah und was nachher daraus wird. ${ }^{48}$ Feiler war zwar das Gegenteil eines Marxisten, seine Kritik entspricht dennoch beinahe im Wortlaut der Marxschen Entfremdungsthese. ${ }^{49}$ Feiler teilt damit in diesem Punkt die von Marxisten am zeitgenössischen Produktionsprozess geübte Kritik voll und ganz. Taylor selbst hatte diesen Aspekt in seiner Originalschrift übrigens mehrfach und an prominenter Stelle thematisiert. Er sah sogar die Ermutigung der Arbeiter zur Eigeninitiative innerhalb seines Produktionskonzepts besser verwirklicht als in den hergebrachten Organisationsformen. ${ }^{50}$

Die Kritik an der Degradierung des (Industrie-)Arbeiters durch die Rationalisierung wurde also lagerübergreifend formuliert. Werner Mahrholz, ${ }^{51}$ freier Journalist und Literaturwissenschaftler, relativierte in der Vossischen Zeitung (VZT) jene weithin geteilte Grundsatzkritik und mahnte zur Differenzierung. Erstens sei »die Rückwirkung auf die Menschen nicht eine so ge-

47 Ders.: Amerika-Europa. Das laufende Band - II. In FZT Nr. 812 vom 31.10.1925, $1 \mathrm{f}$.

48 Ebd.

49 »Arbeitslohn ist eine unmittelbare Folge der entfremdeten Arbeit, und die entfremdete Arbeit ist die unmittelbare Ursache des Privateigentums. "Marx, Karl: Ökonomisch-philosophische Manuskripte (1844). In: Ders./Engels, Friedrich: Werke. Bd. 40 (Schriften bis 1844). Berlin 1990, 465-588, hier 520.

50 »Es mag scheinen, als ob bei dem neuen System nicht derselbe Anreiz für den Arbeiter bestünde, seine Intelligenz zur Ersinnung neuer und besserer Arbeitsmethoden [...] anzustrengen, als unter dem alten System [...]. Er soll jedoch auf jede Weise dazu ermuntert werden, Verbesserungen in den Methoden und in den Werkzeugen vorzuschlagen. Die Leitung sollte es als eine ein für allemal feststehende Regel betrachten, jede Verbesserung, die ein Arbeiter anregt, sorgfältig zu prüfen [...]. Auf diese Weise wird der gute Wille, das wahre Selbstinteresse (initiative) [sic] der Arbeiter unter wissenschaftlich-methodischer Leitung eher zur Betätigung veranlasst als unter dem alten System." Taylor, Frederick Winslow: Die Grundsätze wissenschaftlicher Betriebsführung. München 1919, 136f. Vgl. dazu auch: Hebeisen, Walter: F. W. Taylor und der Taylorismus. Über das Wirken und die Lehre Taylors und die Kritik am Taylorismus. Zürich 1999, 158 f.

51 Mahrholz beschäftigte sich mit Autobiographieforschung sowie dem literarischen Wert der Erzählungen Karl Mays. Zu seinen Veröffentlichungen zählen: Mahrholz, Werner: Karl May. In: Das literarische Echo. Jg. 21, Nr. 3. Stuttgart 1918, 130 f., sowie Ders.: Der Wert der Selbstbiographie als geschichtliche Quelle [1919]. In: Niggl, Günther (Hg.): Die Autobiographie. Zu Form und Geschichte einer literarischen Gattung. Darmstadt 1998, $72-74$. 
fährlich, seelisch-entleerende-stumpf-machende ${ }^{52}$ wie man annehme. Zweitens sei bei Ford im Unterschied zum Taylor-Prinzip festzustellen:

»Dies Ziel der Wirtschaft aber ist - nach einem alten Wort des Begründers der KruppWerke: das Gemeinwohl. Die Wirtschaft beginnt sich aus ihrer Isolierung, ihrer Selbstgenügsamkeit zu lösen. Zumindest als Forderung erscheint die Idee eines igerechten Preises`, meldet sich die Idee des `Dienstes`. Geschäft muß - auf die Länge hin gesehen - Dienst am Käufer sein. So und so allein bleibt es rentabel. Das ist die Lehre des $\gg$ Fordismus ${ }^{5}{ }^{53}$

Mahrholz löst sich von der Ebene der Produktionsorganisation und richtet die Perspektive auf den Fordismus als volkswirtschaftliche Methode mit sozialpolitischer Dimension. Es sei an der Zeit, »diese Wirtschaftsmethode - und das ist die Fließarbeit eigentlich, und nicht nur eine rein fabrikatorische Angelegenheit des Technikers - einmal in allen ihren Auswirkungen zu erörtern. ${ }^{54}$ Von der fordistischen Logik ausgehend, auch einfach qualifizierte Arbeitnehmer sollten durch hohe Löhne zu Kunden werden, leitet er außerdem einen Grundsatz amerikanischer Arbeitskultur ab: »Jedermann hat das Gefühl, eine `Chance zu haben, aufsteigen zu können durch Tüchtigkeit, nicht gehemmt zu sein durch traditionelle Vorurteile. ${ }^{55}$ Mahrholz glaubte, der Fordismus löse den Antagonismus von Arbeit und Kapital auf.

Als volkswirtschaftliches Modell erschien dies für Teile der deutschen Linken interessant, wobei sich zwei Lager gegenüberstanden. Eines sah in der Lohn- und Konsumlogik des Fordismus die Möglichkeit, das Wirtschaftssystem von der Dominanz des Kapitals zu befreien und in eine Ordnung sozialistischer Prägung zu überführen. Das andere erkannte keinen Unterschied zwischen Taylorismus und Fordismus, sondern sah beide als letztes Aufbäumen des Kapitalismus, den es ohne Kompromisse zu zähmen gelte. ${ }^{56}$

Hier berührten sich die politischen Extreme: Auch die Nationalsozialisten versprachen sich viel vom Fordismus. Sein Rezept für sozialen Ausgleich durch Wirtschaftsdirigismus ergänzte die rudimentäre Wirtschaftsagenda der NSDAP. Bei der programmatischen Übernahme ging man jedoch selektiv vor. Die laut Ford unabdingbare freie Marktumgebung wurde von den Nationalsozialisten als störendes Beiwerk empfunden, das um des sozialen Friedens willen unter den Tisch fallen konnte. Die fordistische Moderne war den Ra-

52 Mahrholz, Werner: Fordismus und Fordisation - Was ist es mit der Fließarbeit? In: VZT Nr. 137 vom 22.03.1926, 5.

53 Ebd.

54 Ebd.

55 Ebd.

56 Vgl. Rodriguez-Lores, Juan: Linkes Denken und Fordismus. Lenin und Gramsci. In: Bittner, Regina/Brüning, Henning (Hg.): Zukunft aus Amerika. Fordismus in der Zwischenkriegszeit. Siedlung, Stadt, Raum. Berlin 1995, $45 \mathrm{f}$. 
dikalen aller Richtungen willkommen, solange sie sich dem jeweiligen ideologischen "Hausstand « anpassen ließ. AIZ und ILB als Organe dieser beiden Extrempositionen übten dennoch drastische Kritik am "amerikanistischen" respektive »kapitalistischen « Rationalisierungsmodell. In der AIZ übersetzte sich dies in die Losung: „Der Kapitalismus gebraucht die Technik zur Versklavung der Menschen. Der Sozialismus zu ihrer Befreiung. ${ }^{57}$

Die vermeintlich zwangsläufig durch Kapitalismus und Rationalisierung bedingte Verelendung der Arbeiterschaft fand neben solchen Parolen auch visuell ihren Ausdruck, wie ein Beitrag von 1931 zeigt (Abb. 2). Hier kommt abermals eine (foto-)grafische Kaskade zur Anwendung, die eine Verdrängung des Menschen aus dem Produktionsprozess symbolisiert. Beigefügte Textversatzstücke suggerieren zusammen mit absteigend angeordneten Visuals die zynische Entsorgung nicht weiter benötigter Arbeiter. Das erste Visual links oben zeigt eine traditionelle Zigarettenmanufaktur, für die »hunderte von gelernten und ungelernten Tabakarbeiterinnen" nötig gewesen seien, während "heute eine Zigarettenmaschine automatisch in einer Stunde 40000 Zigaretten ${ }^{58}$ herstelle, wozu nur zwei Arbeitskräfte gebraucht würden. Das letzte Glied dieser visuellen Kaskade zeigt arbeitslose Tabakarbeiterinnen, die desillusioniert und hilfesuchend an einem Tresen stehen, mutmaßlich in einer Filiale des Reichsamts für Arbeitsvermittlung.

Die Visuals werden durch exponierte Bildunterschriften verstärkt, die den gezeigten Prozess in Schlagworte zusammenfassen. Im eigentlichen Haupttext wird die Problematik weiter ideologisch perspektiviert. Die Bildunterschriften entfalten durch ihre Anordnung eher eine visuelle denn eine textuelle Wirkung. Nach den beschriebenen Visuals aufgeteilt lauten sie: »Die Arbeitskraft des Menschen« (erstes Visual) »wird durch Maschinen ersetzt» (zweites Visual) - »Der Arbeitslose kann verhungern « (Drittes Visual). ${ }^{59}$

Diese suggerierte Zwangsläufigkeit wurde im nationalsozialistischen Spektrum mit ähnlich unerbittlicher Metaphorik verdeutlicht. Unter der Überschrift »Maschinen fressen Menschen ${ }^{60}$ wird vor den Auswirkungen technologischer Innovationen im heimischen produzierenden Gewerbe gewarnt. Ursachen und Struktur der Arbeitslosigkeit in den Vereinigten Staaten werden als Beweis für die Gefahren amerikanischer Produktionsmethoden angeführt.

Erstaunlich aktuell anmutende Schlüsselbegriffe wie »Technological unemployment ${ }^{61}{ }^{1}$ bekräftigen die Kausalität zwischen Maschineneinsatz und

59 Ebd.

60 Anon. (Re.): Maschinen fressen Menschen. In: ILB, 1930, Nr. 40, 695 (Jahresausgabe).

61 Ebd. 


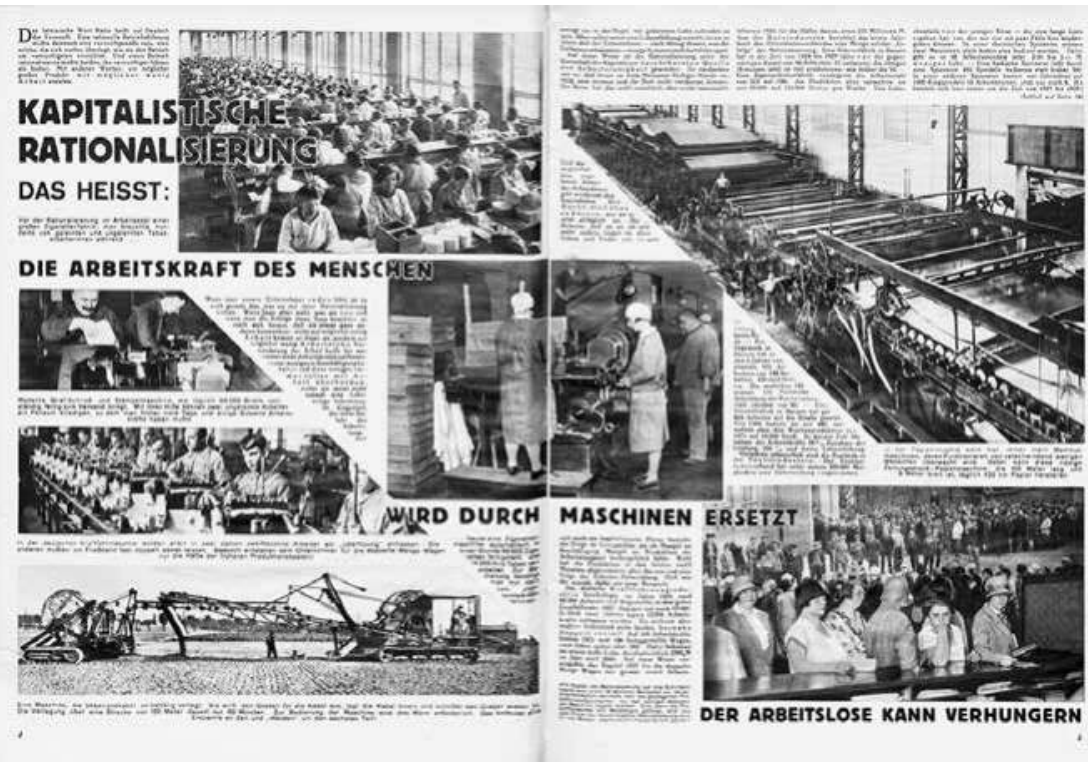

Abb. 2: Anon.: Kapitalistische Rationalisierung. In: AIZ, 1931, Nr. 1, 4 f. Das Industriekonglomerat Rummelsburg mit dem Heizkraftwerk, dem Eiswerk und den zahlreichen dort angesiedelten Industriebetrieben zum Symbol für die Menschenverachtung »kapitalistischer« Rationalisierung stilisiert.

steigender Arbeitslosigkeit. ${ }^{62}$ Auch die soziale Asymmetrie des technologisch getriebenen Wachstums wird problematisiert: Niedrig qualifizierte Immigranten und Einheimische litten besonders unter den Folgen des Maschineneinsatzes, während sich die Gewinne bei Unternehmern, Börsenspekulanten und Investoren konzentrierten, klagte der Illustrierte Beobachter an gleicher Stelle. Doch wo stand der ILB im Meinungsspektrum zwischen Rationalisierungskritik und Ford-Verehrung? Vorhandene Schnittmengen zwischen der NS-Wirtschaftsprogrammatik und dem Fordismus spiegelten sich im Blatt nicht explizit wider. Fords Auffassung von Arbeit als Dienst am Gemeinwohl teilten führende Nationalsozialisten beispielsweise vollumfänglich. ${ }^{63} \mathrm{Die}$ ambivalente veröffentlichte Haltung der Nationalsozialisten in dieser Sache erklärt sich aus den zum Veröffentlichungszeitpunkt 1930 horrenden Arbeits-

62 Unter anderem: Eine einzige Arbeiterin, die eine moderne Spinnmaschine betätigt, kann beispielsweise während eines Achtstundentages so viel Garn spinnen, als eine Armee von 45000 Hausfrauen vor 150 Jahren von ihren Spinnrollen innerhalb eines Tages abrollen konnten.«Ebd.

63 Vgl. dazu: Kocka, Jürgen: Ambivalenzen der Arbeit. In: Buggeln, Marc/Wildt, Michael: Arbeit im Nationalsozialismus. München 2014, 30. 
losenzahlen. Propagandistisch musste eine klare Abgrenzung zu effizienzsteigernden Methoden sichergestellt sein.

Ideologisch akkommodierte Versionen des Rationalisierungskonzepts nahmen in den wirtschaftsdirigistischen Entwürfen sowohl der Nationalsozialisten als auch der Kommunisten eine zentrale Stellung ein. Die Sichtweise auf das Zeitphänomen beschränkte sich also auch bei den politischen Extremen nicht auf unumwundene Ablehnung. Rationalisierung war sogar ausdrücklich positiv besetzt, wenn ihre Mittel den jeweils ideologisch definierten Zweck des »sozialen Friedens« heiligte. Die Vorstellung der Rationalisierung als Verwirklichungsgrundlage einer wünschenswerten Moderne fand Unterstützer über das gesamte politische Spektrum hinweg. Das Rationalisierungskonzept konnte gleichermaßen liberaldemokratisch-kapitalistisch oder eben nach den antiliberalen Lesarten des Nationalsozialismus und Bolschewismus ausgelegt werden, wie noch genauer zu zeigen sein wird. ${ }^{64}$

\subsection{Henry Ford zur Ehrenrettung des Fordismus}

Henry Ford hatte in den USA durch seine Methoden »das Auto volkstümlich ${ }^{65}$ gemacht und übte auf die Deutschen als Demiurg des »fordistischen« Zeitalters große, wenn auch zweischneidige Faszination aus. ${ }^{66}$ Es ist dabei mehr als nur eine interessante Fußnote, dass sich Ford jenseits seines Bestsellers »Mein Leben und Werk ${ }^{67}$ durch Gastbeiträge in deutschen Zeitungen höchstselbst zu Wort meldete. Er suchte so, seine volkswirtschaftlichen Ansichten in der

$64 \mathrm{Zu}$ der zusammenhängenden Entwicklung, die beispielsweise die Fordismus-Perzeption von den USA ausgehend in Deutschland und der UdSSR im Laufe der Zwischenkriegszeit nahm, arbeitete vor allem Stefan Link. Vgl. Link, Stefan: Transnational Fordism. Ford Motor Company, Nazi Germany, and the Soviet Union in the Interwar Years. http:// nrs.harvard.edu/urn-3:HUL.InstRepos:10288949. Faculty of Arts, University of Harvard, Cambridge. (am 21.04.2015).

65 Anon.: O. T. In: MIP, 1929, Nr. 16, 532 (Jahresausgabe).

66 Dies kann man neben dem enormen Medieninteresse an der Person Henry Ford an dem großen Erfolg ablesen, den die 1923 erschienene deutsche Ausgabe seiner autobiographischen Schrift »My Life and Work« in Deutschland hatte. Darin fanden, wie Michael Wala konstatiert, "die Deutschen vieles von dem, wonach sie suchten: Sozialpartnerschaft von Arbeit und Kapital, Rationalisierung und das Versprechen eines unaufhaltsam steigenden Lebensstandards. « Wala: Amerikanisierung und Überfremdungsängste, 124. Das als »Bibel der Weimarer Republik« bezeichnete Werk trägt diesen Titel alleine deshalb schon zu Recht, weil es annähernd ebenso viele Lesarten erlaubte wie die Heilige Schrift und damit für Publikum mannigfacher Coleur anschluss- und auslegungsfähig war. Vgl. Fehl: Welcher Fordismus eigentlich?, 22.

67 Ford, Henry: Mein Leben und Werk. Leipzig 1923. Das Werk wurde maßgeblich vom Journalisten Samuel Crowther verfasst, der ein Vertrauter Henry Fords war. Vgl. Eifert, Christiane: Antisemit und Autokönig. Henry Fords Autobiographie und ihre deutsche 
öffentlichen Debatte zu verteidigen. Dies machte Henry Ford zeitweise vom Diskussionsobjekt zum Diskursteilnehmer.

Das Finanz- und Handelsblatt der Vossischen Zeitung war wie geschaffen für Fords Einlassungen. Hier vertrat er seine Überzeugung, das Kapital sei ein wichtiges Bindeglied zwischen öffentlichen Finanzen und den Privatvermögen der Unternehmen. "Alle sogenannten Privatvermögen" seien »nichts anderes als öffentliche Reserven«, welche fortwährend »im Interesse der Öffentlichkeit zu verwenden ${ }^{68}{ }^{8}$ seien. Gewerkschafter und Sozialisten hätten schon hier unumwunden zugestimmt. Er fährt fort, »Profite« müssten sich als »Begleiterscheinung für die Arbeitsleistung einstellen ${ }^{69}$ und würden sich durch bloßes Profitstreben gar nicht erst verstetigen.

Dies als Absage an den Kapitalismus als Ganzes zu deuten ist mit Blick auf den Autor abwegig. Wie die Forderung im Titel (»Keine starre Massenproduktion!«) unterstreicht, versucht Ford aber, in der Debatte die Fixierung auf den Produktionsprozess zu vermeiden. Er lenkt den Fokus auf die volkswirtschaftlichen Rahmenbedingungen und die ökonomische Kultur. Mit seinen Ausführungen, die im Anschluss doch noch praktische Ratschläge zur Produktionsoptimierung enthalten, ${ }^{70}$ reagiert Ford auf die pauschale Kritik an der »Diktatur» des Fließbands und am Autonomieverlust der Arbeiter. Dem unbestimmten Gefühl, Aufgabe von Arbeitern und Konsumenten sei allein die Aufrechterhaltung eines gesichtslosen Systems der Massenproduktion, setzt er die Idee der Kunden- und Zweckorientierung entgegen:

"Starre Maschinenproduktion von der Art, die als Massenproduktion bekannt ist, findet schnell ihr Ende, weil sie gegen den wichtigsten Grundsatz der Produktion in großem Stil verstößt: daß die Produzenten, die Artikel, die sie herausbringen, fortwährend in Zweckmäßigkeit und Qualität verbessern müssen. « $^{71}$

Rezeption in den 1920er Jahren. In: Saldern, Adelheid von/Hachtmann, Rüdiger/Kirsch, Jan-Holger (Hg.): Fordismus. Zeithistorische Forschungen/Studies in Contemporary History. Bd. 6 (2009), Nr. 2, 211.

68 Ford, Henry: Keine starre Massenproduktion! In: VZT Nr. 192 vom 24.04.1930, 9 f.

69 Ebd., 9.

70 "Die bedeutendsten Bestandteile einer Maschine oder einer Fabrik sind die, die man nicht sehen kann - die unsichtbare Essenz aus Zeit, Hingabe und langsam erworbener Weisheit, die darin enthalten ist. Es ist unsere Aufgabe als Leiter, ein Unternehmen zu schaffen, das das Produkt herstellt, und da wir jeden Tag etwas hinzulernen sollten, wie wir unser Produkt oder den Fabrikationsprozeß verbessern können, sind Produkt und Unternehmen einer dauernden Veränderung unterworfen [...]. Wir haben es immer als unsere wichtigste Aufgabe betrachtet, für alles die beste Methode zu finden und jeden Prozeß, der bei unserer Fabrikation angewandt wird, rein experimentell zu behandeln [...]. Diese Politik läßt uns dauernd die Vorteile von Verbesserungen im Produktionsverfahren und Entwurf erwägen.« Ebd., 10.

71 Ebd. 
Mit der existenziellen Angst vor Arbeitsplatzvernichtung durch Mechanisierung versuchte Ford in einem weiteren Gastbeitrag, den wichtigsten Strang der Rationalisierungskritik zu durchschlagen. In "Mein Leben und Werk« hatte er in den Kapiteln »Mensch und Maschine« sowie »Der Terror der Maschine» entsprechende Kritik antizipiert. ${ }^{72}$ Wieder bemüht sich Ford um ein umfassenderes Verständnis der von ihm insinuierten Aufwärtsspirale zwischen ressourcensparenden Maschinen, hohen Löhnen und dadurch bedingtem hohen Produktabsatz:

"Wenn eine Maschine nur als Mittel zur Arbeitsersparnis betrachtet wird - als eine Methode, durch die ein Unternehmer mit wenig Leuten auskommen kann - dann kann sie ein Unglück für jedermann bedeuten [...]. Die Phrase sarbeitsersparend ist ein gültiger Beweis dafür, wie wenig die Funktion der Maschine verstanden wird. Denn wenn eine Maschine nicht sarbeitsfördernd ist, hat sie gar keine Existenzberechtigung. . $^{73}$

Henry Ford versucht Argumente dafür zu liefern, dass der Analogismus zwischen Rationalisierung und Ressourcenschonung einerseits und massenhafter Arbeitslosigkeit andererseits unzulässig sei. Vielmehr sei es die Aufgabe von Unternehmen und Gesetzgebern, die Lohnpolitik so zu gestalten, dass technologische Innovation nicht zur Verkleinerung des Arbeitsangebotes, sondern zu verbesserter Wertschöpfung führe. Aus seiner Sicht bestehe »gar kein Gegensatz zwischen der Versorgung mit Arbeit und der Versorgung mit Gütern", auch nicht »zwischen niedrigen Kosten und hohen Löhnen $[. ..] \ll^{74}$. Es gebe demnach »keinen Augenblick, wo die Entwicklung der Maschine zur Gefahr ${ }^{75}$ für die Arbeiterschaft werde. ${ }^{76}$

Ford war zur Ehrenrettung seines Wirtschaftskonzepts gezwungen mit Engelszungen $\mathrm{zu}$ reden. Als die apologetischen Wortmeldungen Fords im Jahre 1930 erschienen, schlug die 1929 ausgebrochene Weltwirtschaftskrise voll auf den deutschen Arbeitsmarkt durch, die Arbeitslosenzahlen stiegen

72 Vgl. Ford: Mein Leben und Werk, $106 \mathrm{f}$.

73 Ford, Henry: Warum Arbeitslosigkeit? Nicht die Maschine - die Fabrikleitung hat Schuld. In: VZT Nr. 195 vom 26.04.1930, 15.

74 Ebd.

75 Ebd.

76 Ford kleidet die Begründung für seine Position in eine eingängige Metapher: »Ein eiserner Meißel ist besser als ein steinerner, und ein Stahlmeißel besser als ein eiserner. Könnte der Augenblick eintreten, wo die Qualität des Meißels so fein würde, daß eine Gefahr daraus entstünde? Bestimmt nicht.« Ebd. Widersprüchliche Meinungen dazu existierten in der internationalen zeitgenössischen Debatte allerdings zuhauf. Am prominentesten vertrat John Maynard Keynes im selben Jahr, 1930, seine These von der Technologischen Arbeitslosigkeit gegen den Fordschen Ansatz, in der er eine natürliche Korrelation von technologischem Fortschritt und dem Anstieg der Arbeitslosigkeit annahm. Dazu: Keynes, John Maynard: Economic Possibilities for our Grandchildren. In: Essays in Persuasion. New York, 1963, 358-373, hier $362 \mathrm{f}$. 
sprunghaft an. Im Zuge der weltweiten Börsen-Baisse waren (allen voran amerikanische) Investoren gezwungen, Mittel aus Deutschland abzuziehen. Nun bewahrheiteten sich die Unkenrufe, die vor der Gefahr großer Mengen amerikanischen Investitionskapitals gewarnt hatten - unter umgekehrten Vorzeichen. Der Kapitalabzug beschleunigte den Kollaps der deutschen Wirtschaft und vergrößerte das Arbeitslosenheer. Eine Wirtschaftskonzeption wie der Fordismus, die im Ruf stand, durch technologische und organisatorische Innovationen Arbeitsplätze "wegzurationalisieren ", geriet dadurch automatisch in die Schusslinie. Unter diesen Bedingungen bestand Erklärungsbedarf, wie das Verhältnis zwischen Kapital, Mechanisierung und Arbeit aussehen sollte.

Auf diesen thematischen Dreiklang bezogen sich die immer schärfer werdenden Anwürfe, denen sich der Fordismus in Deutschland ausgesetzt sah. Ein repräsentatives Beispiel stammt vom bekannten Sozialisten und Dramatiker Ernst Toller. Er schrieb 1930 im Berliner Tageblatt (BTB):

»Ich war bei Ford. [...] Stellen Sie sich einen Riesenraum vor, in dem Tausende von Menschen, eng gepfercht, an Werkzeugtischen, bei ungeheurem Lärm arbeiten [...]. Jeder Mann tut einen Griff, acht Stunden lang unzählige Male denselben, einen Griff. [...] Der steckt eine Schraube auf, der eine Hülse, der hängt an vorüberrollende Halter Kurbelwellen [...]. Immer denselben Griff [...]. Die Mechanisierung der Arbeit, soweit sie überflüssige Arbeitskraft spart, hat für die Gesellschaft große Bedeutung. Aber wenn der Mensch zum leblosen Hebel oder Hammer herabsinkt, wird der Gewinn fragwürdig. [...] Bei Ford darf keiner seinen Platz verlassen, an dem er arbeitet, keiner darf eine andere Halle besuchen. So kann es vorkommen, dass er sein Leben lang ein und denselben Hammerschlag an einem Autoteil tut, ohne dass er je das fertige Auto, an dem er doch mitgearbeitet hat, zu Gesicht bekommt. ${ }^{77}$

Die Degradierungserfahrung, die Toller für den Arbeitsprozess beschreibt, fügt sich in frühere Klagen ein. Neu ist an der Schilderung seines Werksbesuches bei Ford, dass er die Arbeiter als geknechtete, rechtlose und infantilisierte Verfügungsmasse beschreibt. Das so entstehende Bild von amerikanischen Ford-Werken als Staat im Staate verstärkt die dystopische Komponente der deutschen Rationalisierungskritik erheblich und politisiert sie:

»Der Tag ist eingeteilt in drei Schichten. Keiner darf sprechen, keiner rauchen, keiner sich setzen [...]. Wenn jemand austreten will, muss er wie ein Schuljunge den Finger heben [...]. Wehe, wenn bei der neuen Schicht die ablösenden Männer, die hinter die alten treten, mit den Abzulösenden auch nur drei Worte tauschen. Sie würden sofort bestraft oder sofort entlassen [...]. In allen Fabrikhallen wimmelt es von Werkspolizisten [...]. Nach der Verfassung hätten sie keinerlei polizeiliche Rechte. Sie nehmen sie sich, tragen Knüppel und Revolver.« 
Angesichts solch eindrücklicher Berichte gelang es Ford erwartungsgemäß nicht, den Lauf der Debatte zu wenden. Seine Beiträge waren in Zahl und Wirkung zu marginal. Die Kritik an der Adaption fordistischer Betriebsführung in der deutschen Industrie hielt nicht nur unvermindert an, sondern intensivierte sich mit dem Fortschreiten der Wirtschaftsmisere noch. Teilweise wurde Fords volkswirtschaftlichem Ansatz mit unverhohlenem Sarkasmus begegnet. Manche seiner Äußerungen zur amerikanischen Wirtschaftskrise wurde in Glossen genüsslich demontiert, ihm selbst jegliche Kompetenz auf dem Gebiet der Nationalökonomie abgesprochen.

Zum Ende des Beobachtungszeitraums wurden betriebs- und volkswirtschaftliche Fragen, die zuvor in der Öffentlichkeit ergebnisoffen diskutiert worden waren, zunehmend apodiktisch und pessimistisch beantwortet. Auch die von Ford und seinen deutschen Anhängern bekämpfte Grundthese, der gesteigerte Einsatz von Maschinen trage den Keim für Massenarbeitslosigkeit unwiderruflich in sich, stieß auf breitestmögliche Zustimmung. Diese Überzeugung reichte bis zu der Forderung, um Schlimmeres zu verhüten, sei die technische Entwicklung staatlicherseits zu »regulieren und begrenzen".

Das amerikanische Wirtschaftsexperiment war längst zu einem deutschen geworden. Nach dem wirtschaftlichen Offenbarungseid 1918 hatte sich eine verunsicherte Öffentlichkeit bereitwillig US-Wirtschaftskonzepten geöffnet. In scharfen Debatten emanzipierte sie sich alsbald von der Imitation amerikanischer Formen und wandte sich eigenen Wegen der Rationalisierung zu. Wilhelm Düsterwald fasste dies in der VZT im April 1932 treffend zusammen:

»Aus den Vereinigten Staaten kamen die Lehren der Rationalisierung, nach denen unser Produktionsapparat von dem Raubbau des Krieges und dem Verfall der Inflation wiederhergestellt wurde [...]. Geistig hat sich die deutsche Wirtschaft schon lange von der amerikanischen emanzipiert. Die Zeiten, in denen Fordismus, Taylorismus und andere Methoden der Massenproduktion auch bei uns als der Weisheit letzter Schluß verehrt wurden, sind längst vorüber." ${ }^{78}$

\subsection{Deutsche Rationalisierungseuphorie}

Ablehnung und Kritik machten eine gewichtige, aber bei weitem nicht die bestimmende Tendenz der Weimarer Rationalisierungsdebatte aus. Bei aller Skepsis hinsichtlich der sozialen Auswirkungen, der Arbeitsplatzverluste und der vermeintlichen Fremdheit amerikanischer Produktionskultur be- 
geisterten sich die Deutschen für die Verwissenschaftlichung von Arbeits- und Produktionsprozessen. ${ }^{79}$

Täglich erfuhr die Zeitungsleserschaft von geglückten Versuchen der Rationalisierung und den Verheißungen ihrer Anwendung im großen Stil. ${ }^{80}$ Positive Resonanz und aufrichtige Begeisterung fielen zeitlich mit der kritischen Verschärfung der Rationalisierungsdebatte zusammen. Waren instruktive, ergebnisoffene Artikel in der ersten Hälfte der 1920er Jahre noch am zahlreichsten gewesen, spaltete sich nach der tatsächlichen Durchsetzung von Rationalisierungsmaßnahmen im großen Stil nach 1924/25 die massenmediale Debatte klar in Gegner und Anhänger auf. Letztere konzentrierten sich auf konkrete Beispiele gelungener Rationalisierungsmaßnahmen und die Darstellung der Vorteile. Auf der Detailebene macht sie das wenig fruchtbar für eine tiefergehende Analyse. Bei der Wahl solcher Beispiele spielte es nämlich kaum eine Rolle, ob es sich dabei um industrielle Rationalisierungsmaßnahmen, Verwaltungsreformen oder die Motorisierung der Landbewirtschaftung handelte.

Zahlreiche Themen wurden unter dem Rationalisierungsparadigma subsumiert, eine breite Streuung behandelter Sachverhalte war die Folge. ${ }^{81}$ Während unter der Überschrift "Rationalisierung« wahlweise von Ford-Traktoren, die zu Werbezwecken die bayerische Scholle umpflügten ${ }^{82}$ oder dem Reformbedarf innerpreußischer Exklaven ${ }^{83}$ die Rede war, schwang stets ein positiv konnotierter Rationalisierungsbegriff mit. Selbst Arbeitsplatzvernichtung erschien von dieser Warte als bewundernswerte Effizienzsteigerung. Die US-Herkunft von Geräten oder Maßnahmen galt nicht als Makel, sondern

79 »Die Akzeptanz neuer Technologien mutet stellenweise gar fast wie eine Manie an: Das Taylorsche System war allgegenwärtig; sogar bis in die Haushalte hinein wurden Arbeitsabläufe gemessen, um die jeweils kosten- und zeitgünstigste Methode auszuwählen.» Wala: Amerikanisierung und Überfremdungsängste, 128.

80 Unter anderem: Anon.: Rationalisierung im Großen - Empfehlungen der Genfer Konferenz. In: VZT Nr. 159 vom 04.04.1931, 1.

81 Mehr als 30 Artikel tragen den Begriff Rationalisierung mit positiver Konnotation im Titel. Einige Beispiele zur Veranschaulichung der thematischen Streuung, die alleine während des Jahres 1926 in der Frankfurter Zeitung erschienen: Halberstaedter, H.: Die Rationalisierung des Bürobetriebs. In: FZT Nr. 366 vom 19.05.1926, 1 f. Und: Buccerius, Walter: Die Rationalisierung im Handwerk. In FZT Nr. 502 vom 09.07.1926, 1f. Und: Meyer, Erna: Die Rationalisierung des Haushalts. In: FZT Nr. 812 vom 31.10.1926, 2. Und: May, Ernst: Die Rationalisierung des Bauwesens. In: FZT Nr. 273 vom 14.04.1926, 1. Und: Moede, W.: Betriebsrationalisierung auf psychotechnischer Grundlage. In: FZT Nr. 295 vom 22.04.1926, 1. Und: Ahler, Edgar.: Arbeitsphysiologie und Rationalisierung. In: FZT Nr. 311 vom 28.04.1926, 1. Und: Tietz, Leonhard Alfred: Die Rationalisierung des Detailhandels. In: FZT Nr. 330 vom 05.05.1926, $1 \mathrm{f}$.

82 Anon.: Die Fordkarawane in Deutschland. Motorpflug beim Schaupflügen in Feldkirchen bei München. In: MIP, 1926, Nr. 19, 450 (Jahresausgabe).

83 Höpker-Aschoff: Rationalisierung der Verwaltung. In: FZT Nr. 914 vom 09.12.1927, $1 \mathrm{f}$. 
Ausweis besonderer Bewährtheit, wie ein Bericht über neue Rechenmaschinen der Berliner Elektrizitätswerke zeigt:

»Es gibt wohl nicht einen einzigen Fabrikationszweig, der nicht noch vor wenigen Jahrzehnten, vielleicht auch nur Jahren, fleißige Hände dort beschäftigte, wo heute die Maschine ihr gleichmäßiges Lied singt. [...] Gerade jetzt hat man wieder eine Gelegenheit, eine neue Großtat menschlichen Erfindergeistes zu bewundern. Die Berliner Elektrizitätswerke sind es, die ihren Betrieb mit neuen amerikanischen Buchhaltungsund Statistikmaschinen ausgestattet haben; diese Maschinen, die drüben bereits ihre Feuerprobe bestanden haben, scheinen berufen, auf unsere Großbetriebe geradezu revolutionierend zu wirken! ${ }^{84}$

\subsection{Arbeitsorganisation in der Sowjetunion}

Die Aura der Alternativlosigkeit, welche die Rationalisierung umgab, formte den Zeitgeist der Zwischenkriegszeit in Europa und den USA. Die Einbindung des Rationalisierungsparadigmas in kulturell-politische Gesamtkonzepte stellte indes keine »Besonderheit der westlichen Moderne ${ }^{85}$ dar. Seine politisch-kulturelle Wirkmacht entfaltete sich gerade in Räumen, die traditionell nicht oder nur teilweise dem Rezeptionsradius der Aufklärung zugeschlagen werden. Auch die russischen Bolschewiki hatten sich den Konzepten von Taylor und Co. nicht verschlossen. In ihren Plänen zum wirtschaftlichen Totalumbau Russlands nahmen diese Konzepte sogar eine zentrale Stellung ein.

Zunächst liegt die Unvereinbarkeit des bolschewistischen Klassenkampfes mit dem Effizienzprogramm eines amerikanischen Vorzeigekapitalisten auf der Hand. Lenin persönlich erachtete den Taylorismus jedoch als entscheidenden Hebel, um »dem Kapital« die Herrschaft über Produktion und Güterverteilung zu entwinden. Für »Die Versklavung des Menschen durch die Maschine ${ }^{86}$ machte er ausdrücklich nicht die rationalisierte Betriebsführung, sondern das sie umgebende volkswirtschaftliche Gesamtsystem verantwortlich. ${ }^{87}$

84 Anon.: Der eiserne Buchhalter. Maschinen statt Menschen. In: BTB Nr. 35 vom 21.01.1926, 3.

85 Müller: Das demokratische Zeitalter, 53.

86 Lenin, V.I.: Das Taylor-System. Die Versklavung des Menschen durch die Maschine. In: Ders.: Werke. Bd. 20. Berlin 1961, 145 f.

87 Lenin schrieb unter Pseudonym einen Beitrag in der Put' Pravdy (1914, Nr. 35 (März)), der Vorläuferin der Prawda, der in deutscher Übersetzung den Titel "Das Taylor-System. Die Versklavung des Menschen durch die Maschine« trug. Darin verweist er nach einer kurzen Einführung in die empirische Arbeitsforschung darauf, dass bei einer Ausschaltung des Faktors Kapital mittels Enteignung die Rationalisierung der Produktion nach Taylor 
Die Integration des Taylorismus in seine ökonomischen Pläne versprach aus Lenins Sicht nur dann Erfolg, wenn Rationalisierung, Kollektivierung und die Errichtung eines sozialistischen Wirtschaftssystems parallel bewältigt würden. In der Sowjetunion waren einer Akzeptanz der Rationalisierung also Kautelen auferlegt, die ihr Wesen grundlegend veränderten. Das grundsätzliche Missverständnis bestand in der Annahme, das auf kapitalistische Marktsituationen maßgeschneiderte Taylor-System könne ebenso in einer kommunistisch verfassten Ökonomie funktionieren. ${ }^{88}$

Der freie Markt war aber ein entscheidender Bedingungsfaktor für den Erfolg von Taylors Konzept in den USA und - mit Abstrichen - in Europa gewesen. So zielte er als Ganzes nicht nur auf die Organisation des Einzelbetriebes, sondern bezog die Interaktion von Unternehmen auf dem freien Markt mit ein. Die Prinzipien Taylors konnten in der UdSSR unmöglich die von Lenin erhoffte Wirkung entfalten. Trotz (oder wegen) dieser Widersprüche entspann sich während der ersten Hälfte der 1920er Jahre in der Sowjetunion eine verhältnismäßig offene Diskussion über die Erforschung und anschließende Einführung entsprechender Verfahren. Konkrete Maßnahmen wie die Gründung des Zentralen Arbeitsinstituts (CIT) in Moskau waren die Folge. ${ }^{89}$

In Deutschland wurde das Experiment eines Taylorismus à la Lenin intensiv rezipiert. In ersten Berichten wurde wiederholt auf die Inkompatibilität von Taylorismus und Bolschewismus hingewiesen, obschon dem Unterfangen unter bestimmten Voraussetzungen Chancen eingeräumt wurden. ${ }^{90}$ Albert Neuburger von der BIZ folgte der Argumentation Lenins: „Wo der Kapitalismus ohne jede Einschränkung« herrsche, könne »das Taylor-System Gefahren

eine Schlüsselrolle beim Aufbau einer neuen sozialen und wirtschaftlichen Ordnung spielen werde. Vgl. Ähnlich lautend: Lenin, V. I.: Die nächsten Aufgaben der Sowjetmacht. Die Hebung der Arbeitsproduktion. In: Ders.: Ausgewählte Werke. Bd. 2. Berlin 1955, 376 f.

88 Vgl. Van Atta, Don: Why is there no Taylorism in the Soviet Union? In: Comparative Politics. Bd. 18, Nr. 3. New York 1986, 327-337, hier 327.

89 Vgl. Link, Stefan: From Taylorism to Human Relations: American, German, and Soviet trajectories of the interwar years. Paper presented to the Business History Conference, St. Louis MO, 31. März 2011, 10. Die der Gründung vorausgegangenen Diskussionen und die verschiedenen Fraktionen innerhalb der Bolschewiki machte Melanie Tatur zum Ausgangspunkt ihrer unverändert erhellenden Untersuchung zur Rationalisierung in der Sowjetunion. Vgl. Tatur, Melanie: Taylorismus in der Sowjetunion. Die Rationalisierungspolitik der UdSSR in den siebziger Jahren. Frankfurt u. a. 1983, $22 \mathrm{f}$.

90 »Des Taylor-Systems Charakterbild schwankt svon der Parteien Gunst und Haß verwirrt in der Geschichte. Kann man sich einen größeren Gegensatz denken, als daß die Arbeiter vieler Länder in ihm ein Ausbeutungsmittel des Kapitalismus, eine Erniedrigung, ein Herabdrücken zur Lohnsklaverei sehen, während andererseits Lenin, der ja gerade die Befreiung vom Kapitalismus als höchstes Ziel auf seine Fahnen geschrieben hat, einen vollkommen entgegengesetzten Standpunkt vertritt.« Neuburger, Albert: Das Taylor-System. Das vielumstrittene Verfahren zur Erhöhung und Prüfung der Arbeitsleistung. In: BIZ, 1919, Nr. 21, 182f. (Jahresausgabe). 
in sich bergen. Wo aber die Sozialisation ${ }^{91}$ fortschreite, "sozialistische« Arbeits- und Marktregelungen getroffen würden, könne man auf einen gemeinwohlorientierten Taylorismus hoffen. Man war überzeugt, es in Sowjetrussland mit dem ernsten Versuch einer Adaption zu tun zu haben, keineswegs mit Gedankenexperimenten einer Handvoll Utopisten. ${ }^{92}$

Gleichwohl wusste man in der Frankfurter Zeitung von erbitterten Flügelkämpfen zu berichten, die Lenin auszufechten hatte; im Gegensatz zu den meisten seiner Parteigenossen strebe er zur Durchsetzung einer erfolgreichen Rationalisierung den Staatskapitalismus an. ${ }^{93}$ Im Sinne seiner neuen Wirtschaftspolitik, die jenen Staatskapitalismus zum Ziel hatte, versuche Lenin, "gegen die pure Ideologie« und lästige "Linkskinderei ${ }^{94}$ in seiner Partei anzukommen, die Taylors Prinzipien als kapitalistisches Teufelszeug ablehnten, das mittlerweile ohnedies überholt sei. ${ }^{95}$

In einer bemerkenswerten Dreiecksperspektive berichten deutsche Beobachter von der sowjetischen Diskussion amerikanischer Ideen. Wie in einem Spiegelkabinett wird nicht nur der deutsche Blick auf die Sowjetunion oder der sowjetische Blick auf Amerika reflektiert: Beim Thema Rationalisierung ergeben sich auch Parallelen zwischen deutscher und sowjetischer Perspektive. Auch in der sowjetischen Taylorismus-Debatte wird den USA auf wirtschaftlichem Felde besondere Produktivität und Zukunftsfähigkeit zugeschrieben, was der deutschen Tradition sehr ähnelt. ${ }^{96}$ Ein dreiteiliges Muster, das die USA als Meister, Deutschland als Gesellen und die Sowjetunion als ambitionierten Lehrling beschreibt, durchzieht Berichte zur sowjetischen Rationalisierung. Die Volkswirtschaften des Reiches und der Sowjetunion standen aus deut-

91 Ebd., 182.

92 Jutta Scherrer hat zu Recht kritisiert, dass die Taylorismus-Debatte in Sowjetrussland trotz deren unbestreitbar großem Nachhall in der sowjetischen Wirtschaftspolitik vielfach als rein utopisches und daher von den Literaturhistorikern zu bearbeitendes Element russischer Geschichte behandelt wurde und weiterhin wird. Das Utopische ist sicherlich ein wichtiges Charakteristikum des sowjetrussischen Taylorismus-Diskurses. Es leuchtet diesen aber v. a. hinsichtlich seiner konkreten politischen und ökonomischen Umsetzungen eben nur unzureichend aus, weshalb hier Scherrer zuzustimmen ist und die realen Implikationen stärker in den Fokus gerückt werden sollen. Vgl. Scherrer, Jutta: »Einholen und Überholen«. Amerikanische Technologie aus sowjetrussischer Sicht. Die zwanziger und frühen dreißiger Jahre. In: Aust, Martin/Schönpflug, Daniel: Vom Gegner lernen. Feindschaften und Kulturtransfers im Europa des 19. und 20. Jahrhunderts. Frankfurt 2007, 182.

93 Mit dem Begriff des Staatskapitalismus verband man in Deutschland damals die während des Ersten Weltkriegs stark ausgeweitete Beteiligung des Staates an Unternehmen. Gleichwohl meinte Lenin im sowjetrussischen Kontext nichts anderes, wenn auch die Begriffe der Zwangswirtschaft und des Sozialismus weitgehend synonym verwendet wurden.

94 Anon. (F.S.): Russische Briefe. Die neue Wirtschaftspolitik. In: FZT Nr. 854 vom 16.11.1921, 1 .

95 Vgl. Link, Stefan: From Taylorism to Human Relations, 10.

96 Scherrer: »Einholen und Überholen, $187 \mathrm{f}$. 
scher Perspektive gleichermaßen vor der Herausforderung, »für einen niedergebrochenen Staat die Rettung im Taylor-System « zu suchen, »das [...] ohne Benachteiligung des einzelnen die Vergrößerung der Gesamtleistung und damit die Hebung der ganzen Volkswirtschaft ${ }^{97}{ }^{97}$ versprach. Deutschland sah man auf diesem Weg bereits ein gutes Stück voraus, die Sowjetunion schnell und entschlossen aufschließend.

In der AIZ fasste Sergej Tschachotin 1924 das amerikanisch-deutsch-sowjetische Dreigespann der Rationalisierung in ein Phasenmodell. Demzufolge sei der maschinell geprägte Taylorismus Amerikas durch die amerikanische Bevölkerungsstruktur bedingt, die Degradierung des Arbeiters kümmere dort aber niemanden. ${ }^{98}$ Die kritische Adaption des Taylorismus in Deutschland versteht Tschachotin deshalb als dringend notwendige Weiterentwicklung, die durch die Erforschung der Psychotechnik und einer stärkeren Beachtung des menschlichen Moments das zweite Entwicklungsstadium der Rationalisierung definiere. ${ }^{99}$ In der Sowjetunion biete sich im Zuge der staatlich initiierten wirtschaftlichen Umwälzungen ${ }^{100}$ nunmehr die Chance einer dritten und finalen Etappe der Rationalisierung. Das politische System führt Tschachotin als Grund an, weshalb in der Sowjetunion die Zusammenführung der Ra-

97 Neuburger, Albert: Das Taylor-System, $182 \mathrm{f}$. (Jahresausgabe).

98 »Aber Amerika ist das Land der Maschine par excellence, das Land, wo durch enorme Zuwanderung von wenig qualifizierten, wenig anspruchsvollen, weniger gelernte Arbeiter zur Verfügung stehen. Und so sehen wir, daß die Entwicklung dort Wege einschlägt, die den Menschen selbst als Teil einer maschinellen Einrichtung betrachten und entsprechend behandeln. So scheitert in Amerika der Gedanke, er verläuft sich in einer Sackgasse, denn das, worauf die ganze Entwicklung abzielt - das Herrwerden des Menschen über die Natur, das Frei- und Glücklichwerden aller - ist unerreichbar, wenn der Mensch zum Sklaven der maschinellen Einrichtung wird.» Tschachotin, Sergej: Drei Etappen des Taylorismus (Amerika - Deutschland - Sowjet-Rußland). In: AIZ, 1924, Nr. 2, 7.

99 »Eine Wandlung der Anwendung des Taylorsystems vollzieht sich in Europa erst während und zu Ende des Krieges. Der Umschwung ist dadurch bedingt, daß Europa und besonders das durch den Kriegsausgang und seine Folgen besonders mitgenommene Deutschland sich anschickt, den menschlichen Faktor in dieser Frage in den Vordergrund zu stellen. Europa mit dem wissenschaftlich am besten ausgerüsteten Deutschland voran, wird somit zum zweiten Herd der Entwicklung des Organisationsgedankens, hier entsteht und fixiert sich eine zweite Etappe. Zum zentralen Punkt wird nun die Erforschung des menschlichen Mitspiels im Organisationsbetriebe [...]. Freilich wird auch der ersten Komponente, den amerikanischen Methoden und der Maschinenforschung Aufmerksamkeit geschenkt und vieles hierin geleistet, aber als Hauptcharakteristikum dieser zweiten europäischen Etappe kann das psychotechnische Moment betrachtet werden. `Der rechte Mann auf dem rechten Platz «, das ist die Losung.« Ebd.

$100 »$ Mit dem größten Erstaunen konstatiert man, daß dort, in Sowjet-Rußland, der wissenschaftliche Organisationsgedanke festen Fuß gefaßt hat, daß dort die Bewegung enorme, noch nicht da gewesene Ausmaße annimmt, daß man dort soweit geht, ein eigenes Organisationsministerium zu errichten und die ganze Organisationsbewegung staatlich aufzubauen.« Ebd. 
tionalisierungsfaktoren Maschine und Mensch letztlich zu einem Abschluss gelangen könne:

»Wie ist es möglich, daß Rußland zur dritten Etappe (,) zum dritten Herd der Arbeitsorganisation wird? [...] Hier sind die Bedingungen verwirklicht, bei denen die letzte theoretische Forderung für das Gelingen einer wirklich rationellen Arbeitsorganisation - nämlich die Arbeitsfreude - bei den Massen der Arbeitenden gewährleistet werden kann. Der Arbeitende ist ja hier der Herr im Staate, Herr über sich selbst, über sein Tun und Wollen und über sein Schicksal. So kann sich hier die ganze Bewegung und zwar sowohl ihre maschinell-organisatorische, wie die psychotechnische Komponente, rasch und erfolgreich ausbreiten [...]. Die Analyse der Entwicklungsgeschichte des Arbeitsorganisationsgedankens in der ganzen Welt, im Zusammenhang mit der Tatsache seiner ungeahnt raschen Ausbreitung in Sowjet-Rußland lassen es mir als wahrscheinlich erscheinen, daß wir hier eine objektive Gesetzmäßigkeit vor Augen haben, nämlich: Sowjet-Rußland ist als die dritte und letzte Etappe auf dem Wege zur Arbeitsorganisation, zur tatsächlichen Menschheitsbefreiung auserkoren. $\aleph^{101}$

Dass die von Tschachotin entworfene Vision einer proletarischen Rationalisierung zum Zeitpunkt der Veröffentlichung des AIZ-Artikels kein Stück weit Realität geworden war, focht ihn nicht an. In den meisten anderen Beiträgen zum selben Thema kursierten wesentlich pessimistischere Einschätzungen. ${ }^{102}$ Die meisten Beiträger setzten aber das sowjetische Rationalisierungskonzept ebenfalls teleologisch in Beziehung zu seinem amerikanischen und deutschen Pendant. Dieser Diskursstrang verdeutlicht, dass die Fremdbetrachtung sich nicht primär an einem Land, einer Kultur oder einem politischen System ausrichtete. Vielmehr bestimmte der thematische Zusammenhang, ob eine isolierend vergleichende oder eine synthetische Perspektive eingenommen wurde, die eine Gesamtschau langfristiger Prozesse ermöglichte.

Auch in der Betrachtung der Sowjetunion tauchten viele Fremdthemen im Windschatten des Rationalisierungsbegriffs auf. Die "Straffung der Verwaltung", in der "nur noch die produktiven Kräfte am Leben bleiben« oder die »Effizienzsteigerung « und »Entlastung der Staatsbehörden ${ }^{103}$ waren Schlagworte, die in die Sphäre bürokratischer Reformen gehörten. Wie bereits in der innerdeutschen Debatte, diente der Rationalisierungsbegriff auch hier als Dachterminus.

101 Ebd.

102 Unter anderem wurde in einer weiteren Ausgabe der Reihe "Russische Briefe" vom vorläufigen Scheitern des industriellen Umbaus berichtet. Alle ideologisch motivierten Bemühungen, Arbeitsverhältnisse und Lohnstruktur seien ergebnislos geblieben und die russische Industrie sei gleichsam in einen Ur-Taylorismus mit all seinen Begleiterscheinungen zurückgefallen. Vgl. Anon. (F. S.): Russische Briefe. Das Problem der Arbeit. In: FZT Nr. 14 vom 06.01.1922, $1 \mathrm{f}$.

103 Anon. (F. S.): Russische Briefe. Der Aufbau der Industrie. In: FZT Nr. 946 vom 21.12.1921, 1. 
Wie schon zuvor in Deutschland, befürchteten Beiträger deutscher Zeitungen, der Rationalisierung nach amerikanischem Muster werde auch in der Sowjetunion die kulturelle Banalisierung auf dem Fuße folgen. Joseph Roth beklagte diese Entwicklung 1926 in der FZT und fügt sie in das Bild eines zerrütteten, aber entschlossen Anschluss an die Moderne suchenden Landes ein. In seiner Reihe »Reise nach Rußland" ordnet Roth diesen Prozess zunächst historisch ein und setzt bei der Revolution von 1917 an:

"Die Revolution war ein verschwenderischer Aufwand der Geschichte, um die geistige Physiognomie der russischen Masse jener der westeuropäischen wenigstens ähnlich zu machen. Auf materiellen, politischen und sozialen Gebieten war sie eine Revolution. Auf geistigem und geistig-moralischem war sie nur ein quantitativ gewaltiger Fortschritt. ${ }^{104}$

Die geistige »Vermassung« der russischen Kultur sei im Vergleich zur kulturellen Einebnung im Westen aber die "gesündere« Variante. Die Entfesselung produktiver Kräfte durch die Revolution stehe im Gegensatz zu den Mode-Erscheinungen eines im Niedergang begriffenen Westens:

"Wenn bei uns eine alte und, wie man sagt: müde Kultur durch Girls, Fascismus [sic], flache Romantik pathologisch banal wird, so wird hier eine eben erst geweckte, brutal kräftige Welt gesund banal. Unserer dekadenten Banalität steht gegenüber eine neurussische, frische, rotbackige Banalität. ${ }^{105}$

Danach spannt Roth den Bogen von der geistig-kulturellen Wende durch die Revolution zur Technisierungsbegeisterung in der neuen Sowjetunion, die eher nach Maschinen, Traktoren und Radios als nach den kulturellen Höhenkämmen vergangener Tage rufe. ${ }^{106}$ Daraus erschließt Roth eine Wesensnähe zur geistigen Kultur der Vereinigten Staaten, dem Geburtsort der Rationalisierung.

Der Unterschied, den er hierbei insinuiert, steht stellvertretend für eine übergreifende Tendenz des zeitgenössischen Vergleichs der USA und der UdSSR aus deutscher Perspektive: Die Kausalität zwischen Kultur und Kulturprodukt wird spiegelverkehrt imaginiert. Die Rationalisierungswelle erscheint als den Gegebenheiten des nordamerikanischen Kontinents und der Kultur der Vereinigten Staaten evolutionär entsprungen. In der Sowjetunion wird dieser Prozess unter umgekehrten Vorzeichen beschrieben. Die am Vorbild Amerika so bewunderte Technisierung und Rationalisierung bedinge, revolutionär

104 Roth, Joseph: Reise nach Rußland. XI. Rußland geht nach Amerika. In: FZT Nr. 871 vom 23.11.1926, 1.

105 Ebd.

106 Vgl. ebd. 
mit der Brechstange eingeführt, die Korrumpierung und Verflachung der russischen Kultur. Man verachte zwar das Amerika des Kapitalismus, aber:

» $[\mathrm{M}] \mathrm{an}$ bewundert Amerika, das heißt den Fortschritt, das elektrische Bügeleisen, die Hygiene und die Wasserleitung. Man will die perfekte Produktionstechnik. Aber die unmittelbare Folge dieser Bestrebung ist eine unbewußte Anpassung an das geistige Amerika. Und das ist die geistige Leere. ${ }^{107}$

Beschleunigt werde dieser kulturelle Erosionsprozess durch den revolutionsbedingten Ausfall von Klerus, Adel und Bürgertum als Hüter identitätsstiftender Werte. Um sich von diesen, politisch desavouierten Einflüssen abzusetzen, könne das Modell für den wirtschaftlichen und kulturellen Neuaufbau der Sowjet-Gesellschaft allein das "geschichtslose» Amerika sein:

"Woher also geistige Grundlagen für eine neue Welt nehmen? Was bleibt übrig? Amerika! Die frische ahnungslose, gymnastisch hygienische rationale Geistigkeit Amerikas - ohne die Hypokrisie der protestantischen Sektiererei: aber dafür mit der Scheuklappenfrömmigkeit des strengen Kommunismus. ${ }^{108}$

Dem Konzept einer aus defizitärer Kultur geborenen Technik-Weltmacht Amerika ${ }^{109}$ wurde das Komplementärkonzept einer durch die nachträgliche Rationalisierung verkümmernden russischen Kultur entgegengesetzt.

Die Verknüpfung zwischen dem technischen Fortschritt, der im Rationalisierungsparadigma seinen metaphorischen Ausdruck fand, und der Vollendung des Kommunismus wurde als geradezu schicksalhaft dargestellt. "Kommunismus - das ist Sowjetmacht plus Elektrifizierung des ganzen Landes. ${ }^{110}$ An diesem schon damals zu einiger Berühmtheit gelangten Zitat Lenins aus dem Jahre 1920 wird deutlich, welch enorme Bedeutung der Technisierung für das Gesamtsystem Kommunismus zugeschrieben wurde. Nach anfänglicher Euphorie war die Diskrepanz zwischen ideologischem Anspruch und wirtschaftlicher Realität in den 1920er Jahren allerdings stetig gewachsen. Entsprechend großes Interesse zeigte die deutsche Öffentlichkeit, wenn die Rationalisierungs- und Technisierungsbemühungen der sowjetischen Wirtschaft wieder einmal evaluiert wurden.

Unter dem Titel Sozialismus = Bolschewismus + Elektrifizierung ${ }^{111}{ }^{2 i e h t}$ Theodor Seibert im Jahr 1928 eine Zwischenbilanz und stellt das propagandis-

107 Ebd.

108 Ebd.

109 Siehe hierzu nochmals: Depkat: The Birth of Technology from the Spirit of the Lack of Culture, $23 \mathrm{f}$.

110 Lenin, V. I.: Werke. Bd. 31. Berlin 1966, 513. Leicht abgewandelt: „Kommunismus ist Sowjetmacht plus Elektrifizierung des ganzen Landes.« Ders.: Ebd., 414.

111 Seibert , Theodor: Sozialismus = Bolschewismus + Elektrifizierung. Was ist aus den russischen Technisierungsbestrebungen geworden? In: MIP, 1928, Nr. 3, 68 f. (Jahresausgabe). 
tisch überformte Technisierungspostulat Lenins in Relation zum Erreichten. So bezieht er sich denn auch nicht nur auf den Teilbereich Elektrifizierung, sondern auf den übergeordneten Prozess gesamtwirtschaftlicher Modernisierung. ${ }^{112}$ Obwohl Seibert eine für ein "zivilisiertes Land « weiterhin bemerkenswert hohe Verbreitung einfachster Handarbeit anmerkt, ${ }^{113}$ mache »die Technisierung [...] unter dem Sowjetsystem [...] Fortschritte, die für russisches Entwicklungstempo überraschend ${ }^{114}$ seien. Seiberts Ausblick fällt angesichts der deutschen Rationalisierungserfahrungen durchwachsen aus. ${ }^{115} \mathrm{Er}$ attestiert dem Sowjetsystem auf diesem Felde durchaus Fortschritte und merkt des Weiteren an, dass die Legitimation des bolschewistischen Regimes maßgeblich in der propagandistischen Vereinnahmung des Rationalisierungsprozesses bestehe, Erfolge auf diesem Felde also unabdingbar für die Fortexistenz des Sowjet-Systems seien. Die Technisierung der Sowjetunion war durch Lenins Schriften und durch die sowjetische Aufbaupropaganda mit viel ideologischem Potential aufgeladen.

Seiberts Perspektive verknüpft die per se lediglich wirtschaftspolitisch relevante Rationalisierungsfrage fest mit der Systemfrage. In der deutschen Presse beschrieb man mit Blick auf die UdSSR einen dezidiert ideologisierten Rationalisierungsprozess. In seiner propagandistischen Relevanz und festen Verankerung im bolschewistischen Ideologiegebäude unterschied sich dieser Prozess grundlegend vom als kulturbedingt dargestellten amerikanischen Pendant. Damit trafen deutsche Beobachter recht präzise den tatsächlichen Sachverhalt. Aus dem Vergleich der Berichterstattung zum Großthema Rationalisierung ergibt sich also die Tendenz, die traditionelle Wirtschaftskultur Nordamerikas begünstige ganz natürlich eine immer weiter fortschreitende Rationalisierung, während das in der Sowjetunion ideologisch formulierte Endziel des wirtschaftlichen Sozialismus diese geradezu zwingend erfordere.

112 »Die Elektrifizierungsparole ist aber nur Teil des großen Propagandarufs: >Dajosch Techniku! Zu deutsch: Gebt uns Technik! - her mit der Technik!« Ebd., 68.

113 »Neben den modernen Textilfabriken, die meist noch in der Vorkriegszeit meist von deutschen und englischen Ingenieuren errichtet worden sind, sieht man heute noch, selbst an der Peripherie der Hauptstadt, schweißtriefende Bauarbeiter mit der Bandsäge Baumstämme zerlegen, um die Bretter für die Verschalung der Holzhäuser zu gewinnen. Auf der gleichen Wolga, an der moderne chemische Werke anzuwachsen beginnen, singen die Schlepper der alten Lastkähne ihre berühmten Lieder, stöhnen die Hafenarbeiter unter Lasten, für deren Beförderung von und an Bord noch nicht einmal der einfachste Hebebaum vorhanden ist.« Ebd., $68 \mathrm{f}$.

114 Ebd., 69.

115 »Leider aber haben auch die Bolschewiki, genau wie wir bei der deutschen Rationalisierung, die Erfahrung gemacht, daß mit ihr die Arbeitslosigkeit wächst. Die Verbilligung der Produktion, die durch die Rationalisierung ermöglicht wird, wird durch den bürokratischen Betrieb der Sowjetwirtschaft großenteils absorbiert. Man rechnet infolgedessen mit einem weiteren Ansteigen der Arbeitslosigkeit in Rußland noch auf mehrere Jahre hinaus.« Ebd. 


\section{6 »Neue Arbeit, neue Menschen«}

Im sowjetischen Kontext wurde Rationalisierung sehr umfassend verstanden und hatte eine politische Konditionalität. Als Ursache wurden weder, wie in den USA, die Erfordernisse des Natur- und Wirtschaftsraumes noch die diffusen Kräfte einer sich unwillkürlich Bahn brechenden Moderne identifiziert. Stattdessen wurde der Ideologie der Bolschewiki, ihrem Ziel einer völlig neuen Wirtschaftsordnung und ihrem Idealbild vom »neuen Menschen« die Hauptrolle im Rationalisierungsprozess zugeschrieben.

Der neue Sowjetmensch sollte seinen natürlichen Egoismus zu Gunsten einer kollektivistischen Gesellschafts- und Wirtschaftsordnung unterdrücken, in ihr "natürlich « funktionieren und dabei glücklich werden. Dieses ultimative Entwicklungsziel machte die Rationalisierung nicht nur der Wirtschaft, sondern auch des Individuums selbst unausweichlich. Der sowjetische Rationalisierungsbegriff schnitt damit den Bereich allgemeiner Sozialphilosophie und wies weit über Fragen wirtschaftlicher Produktion und Organisation hinaus. Die Utopie vom »neuen Menschen" wurde indes nicht erst von den Bolschewiki (ideologisch) oder Anhängern des zeitgenössischen Proletkultes (literarisch-künstlerisch) aus der Taufe gehoben. Er stand in einem Überlieferungszusammenhang, der bis in die Mitte des 19. Jahrhunderts zurückreichte. Bereits 1863 hatte Nikolai Tschernyschewski in seinen »Erzählungen von neuen Menschen" Letzteren als vom Joch der Leibeigenschaft befreites und zur Formung seiner selbst befähigtes Individuum dargestellt, worin der Autor den Beginn einer neuen Epoche erkannte. ${ }^{116}$

Die großen Hoffnungen, die man in der Sowjetunion in die Symbiose von Arbeiter und Maschine setzte, skizzierte der Russlandreisende René FülöpMiller ${ }^{117}$ als regelrechte Apotheose. Sein Artikel »Die Maschinenanbeter ${ }^{118} \mathrm{er}-$ schien im Oktober 1923 als Auszug aus seiner Monografie »Geist und Gesicht

116 Tschernyschewski, Nikolai: Was tun? Aus Erzählungen von neuen Menschen. Berlin 1952. Das Original erschien 1863 unter dem Titel »Čto delat'?» in der Zeitschrift Sowremennik in St. Petersburg.

117 René Fülöp-Miller, der eigentlich Philipp René Maria Müller hieß, war ein Publizist, Kulturhistoriker und Soziologe. Er bereiste zwischen 1922 und 1924 die Sowjetunion und galt als einer der besten Kenner des neuen Staates sowie seiner alten und neuen kulturellen und ideologischen Grundlagen. Vgl. Scherer, Anton: Müller, Philipp. In: Neue Deutsche Biographie. Bd. 18. Berlin 1997, $467 \mathrm{f}$. Er war auch Hauptbeiträger eines eigens zur Ergründung der neuen Verhältnisse in Russland herausgegebenen Sonderheftes der Berliner Illustrirten Zeitung. Vgl. Anon.: Russland von heute. Ein Sonderheft der Berliner Illustrirten Zeitung. In: BIZ, 1924, Nr. 40, 797 f. (Jahresausgabe). Fülöp-Millers hier in Auszügen aus der VZT zitierte Monographie »Geist und Gesicht des Bolschewismus« kann als eines der, wenn nicht das umfangreichste und vielseitigste Werk zur Lage in der damaligen Sowjetunion bezeichnet werden.

118 Fülöp-Miller, René: Die Maschinenanbeter. In: VZT Nr. 485 vom 13.10.1923, 2 f. 
des Bolschewismus ${ }^{119}$ in der Vossischen Zeitung (VZT). Darin ballte FülöpMiller seine Beobachtungen zur ideologischen, pseudoreligiösen Überformung der Maschine in einer Glosse, die zunächst als satirische Überzeichnung erscheint. »Die Verehrung der Maschine im neuen Rußland«, so Fülöp-Miller, trage »in jeder kleinsten ihrer Aeußerungen die untrüglichen Zeichen eines streng geübten religiösen Kultes. ${ }^{120}$ Der Autor unterlegt dies mit illustrativen Analogien zwischen Orten religiöser Verehrung und dem bereits erwähnten Zentralen Arbeitsinstitut CIT von Aleksej Gastev in Moskau, ${ }^{121}$ welches er als Zentrum des sowjetischen Maschinenkultes beschreibt:

»Mit voller Klarheit fiel mir dies beim Besuch der `Studios` und Werkstätten der neuen Künstler (so nennen sich die Mysterientempel der Maschinenanbeter) ins Auge. Einer Wand entlang erheben sich mystisch vom Boden empor aus Eisen, Eisenbeton oder Holz gefügte Maschinen-Strukturen: die Tempelstatuen des neuen Maschinengottes. Die Wände selbst sind überall dicht behängt mit Zeichnungen, die in verschiedenen Stellungen und Querschnitten oder in verschiedenen Wesenswandlungen Gesicht und Gestalt des Gottes wiedergeben. Konstruktionsblätter a), b), c), d), die in ihrem starren keuschen [sic] Linienzug einen Augenblick lang sogar primitiv starrlinig [sic] Heiligenbilder (der heilige Maschinen-Querschnitt `A`, die heilige GeneratorDynamo $>B<$, das heilige Hüttengebläse $>C<$ usw.) zurückrufen. Alle aber zeugen für die Wahrheit des Höchsten, des Einzigen, dessen Gesetz die ganze Welt beherrscht Amen! $\aleph^{122}$

Im Weiteren werden quasireligiöse Zeremonien, Gesänge und Tänze beschrieben ${ }^{123}$ die den sowjetischen Maschinenkult satirisch zu überzeichnen schei-

119 Ders.: Geist und Gesicht des Bolschewismus. Darstellung und Kritik des kulturellen Lebens in Sowjet-Rußland. Zürich u. a. 1926.

120 Fülöp-Miller: Die Maschinenanbeter, 2.

121 Aleksej Gastev war ein Revolutionär der ersten Stunde und nicht zuletzt durch seinen erlernten Beruf des Metallarbeiters ein regelrechter Technik- und Maschinenenthusiast. In Gedichten und Pamphleten warb er für seine Idee einer durch die Symbiose von Mensch und Maschine ermöglichten Kollektivgesellschaft. Siehe dazu: Johansson, Kurt: Alexej Gastev: Proletarian Bard of the Machine Age. Stockholm 1983. Gastev war einer der kompromisslosesten Verfechter einer Vereinigung erst des Menschen mit der Maschine und dann aller derart maschinisierten Menschen miteinander zu einem kollektiven weltumspannenden Organismus. Diese quasi-religiöse Utopie verarbeitete er sowohl literarisch als auch praktisch in den arbeitsphysiologischen Studien in seinem Moskauer Institut. Vgl. dazu: Hellebust, Rolf: Flesh to Metal. Soviet Literature \& the Alchemy of Revolution. Ithaca u. a. 2003, $44 \mathrm{f}$.

122 Fülöp-Miller: Die Maschinenanbeter, 2.

123 »Hier wurde der Huldigung vor dem Maschinengott in Tanz Ausdruck verliehen. Man bemühte sich, die Gesetzmäßigkeiten der Maschine in Tanzbewegungen aufzulösen, ganz nach Art der rituellen Tänze. Die in Maschinen-Bewegungen verzückten Leiber der holden Maschinen-Priesterinnen und -Priester boten einen ganz sonderbaren Eindruck. Hier hörte ich außerdem zum erstenmal die neue religiöse Kirchenmusik der 
nen. Fülöp-Millers Schlussfolgerung jedoch, diese Kulthandlungen sollten »das Einzelbewußtsein völlig betäubt oder gar aufgelös « $^{124}$ zurücklassen, enthält eine zutreffende Interpretation der Rolle der Maschine in der Sowjetunion der frühen 1920er Jahre. Sie sollte als Transmissionsriemen an der Umformung von Mensch und Gesellschaft mitwirken.

Die Idee einer symbiotischen Beziehung zwischen Mensch und Maschine und einem dadurch ermöglichten, kollektiven Bewusstsein hat in den utopischen Vorstellungen der Bolschewiki durchaus eine gewisse Relevanz. FülöpMiller kritisiert, diese erstrebten durch die Überhöhung der Maschine »die Aufopferung des niederen Individualmenschen zum höheren maschinisierten, also bereits entseelten Kollektiv-Menschen. ${ }^{125}$ Seine Schilderungen aus Sowjetrussland offenbaren sowohl Parallelen als auch grundlegende Unterschiede zur amerikabezogenen Rationalisierungsdebatte. Einerseits enthält seine Darstellung der sowjetischen Rationalisierung auch eine »Entseelungserwartung «. Andererseits stilisiert er die Entseelung des Individuums und dessen Aufgehen in einer kollektiven Masse mechanisch ineinandergreifender Glieder - nicht mehr ganz Mensch und noch nicht ganz Maschine - zum übergeordneten Ziel. Was in der Amerikabetrachtung als ebenso ungewollte wie unvermeidbare Folgeerscheinung der Rationalisierung charakterisiert wurde, stellt sich in der Betrachtung Sowjetrusslands als geplantes und erklärtes Endziel dar:

»Ford-Organisation $\triangleleft$ mit Transportgurte [sic] für völlig automatisierte Maschinenmontage (ein Automobil in 47 Sekunden!) Taylorsystem, rationalisierte Betriebsführung, industrielle Psychotechnik [...] haben ja auch westliche Produktionsstätten fast völlig erobert. Nur tritt der Maschinenkult in Amerika und Europa noch als geheimer Hang auf den Plan, noch streng an die Arbeitsstätte gebunden. Nach außen wird weiterhin das seelenvolle Antlitz des biederen Gemütsmenschen gewendet. In Rußland aber bekennt man sich offen zum Glauben an die Maschine und lebt diesen Glauben nach echt russischer Art bis zur religiösen Verzückung. ${ }^{126}$

Anders als das Zitat suggeriert, handelte es sich weder um eine "russische" Eigenart, die Utopie eines Gesamtkörpers aus Maschinen-Menschen zu verfolgen, noch war dies die offizielle Programmatik der Bolschewiki. Die Utopisten-Bewegung des Proletkults, welcher auch CIT-Gründer Aleksej Gastev angehörte, und die Realisten unter den Bolschewiki teilten allerdings in der

Maschinenanbeter. Wuchtig und gewaltig erdröhnte die Stimme des Maschinengottes, erzitternd in der geheimnisvollen Flüstersprache der Riesenriemen, der der vielstimmige Chor von tausend Rädern, Schubstangen, Kurbelwellen, Seiltrieben und Schneidestählen scheu begleitend folgte.« Ebd.

124 Ebd.

125 Ebd.

126 Ebd., 3. 
Novemberrevolution 1917 gemeinsame Wurzeln. Die Utopie von der sowjetischen Menschen-Maschine kann also nicht losgelöst vom Ideologiegebäude der Bolschewiki und ihrer Politik betrachtet werden. ${ }^{127}$ Vor dem literarischen und ideologischen Hintergrund des sowjetischen Proletkultes erscheint die pseudo-religiöse Glosse Fülöp-Millers kaum als satirische Übertreibung. Vielmehr stellt sie eine eindrückliche Verarbeitung des hochideologisierten, quasireligiösen Ansatzes in der sowjetischen Rationalisierungsfrage dar.

Als Gegenentwurf zum »Diktat des Maschinenrhythmus" fand die Idee einer Symbiose von Arbeiter und Maschine positiven Widerhall in der AIZ, aber auch in gemäßigten und konservativen Blättern. ${ }^{128}$ Die Emanzipationswirkung technischer Weiterqualifikation der Arbeiter wurde unter dem Schlagwort "Neue Arbeit, neue Menschen ${ }^{129}$ zur Grundlage eines kollektivistischen Gemeinwesens stilisiert. Ein harmonisches Verhältnis zwischen Mensch und Maschine wurde als progressives Moment sowjetischer Rationalisierung hervorgehoben, als Bedingungsfaktor des Sozialismus.

Eine Bildunterschrift, die Fotografien von Produktionslinien in einer AIZ-Bildreportage über die A.M.O.-Automobilwerke in Moskau ${ }^{130}$ ergänzt, steht sinnbildlich für die positive Wertumkehrung der Interaktion zwischen Maschine und Arbeitern. Im Hinblick auf die USA und Deutschland wurde jene Maschine-Mensch-Beziehung als diktatorisch und menschenverachtend geschmäht, jedoch: »Anders schaffen hier die Arbeitenden als bei uns. Es ist ihr Werk. Der Rhythmus der Maschinen springt auf sie über. Für uns! Für den Sowjetstaat! Für die Werktätigen der ganzen Welt! ${ }^{131}$ Mit der positiven Konnotation des Verschmelzens von Mensch und Maschine konterkarierte die AIZ die an kapitalistischen Umsetzungen der Rationalisierung geübte Kritik,

127 Vgl. dazu: Tetzel, Thomas: Der kollektive Gott. Zur Ideengeschichte des »Neuen Menschen« in Russland. Göttingen 2013, $338 \mathrm{f}$.

128 So zum Beispiel in Heinrich Hausers Artikel »Umgang mit Maschinen« in der Frankfurter Zeitung: »Wir verfolgen dabei einen bestimmten Zweck: zwischen dem untechnischen Menschen und der Maschine eine Verständigung anzubahnen [...]. Wir wollen zeigen, daß der feindliche Gegensatz Mensch-Maschine im Grunde ein künstlich konstruierter Gegensatz ist, eine Fiktion. Wir wollen ihm etwas entgegensetzen, was wir das »Humane« der Maschine nennen möchten.«Hauser, Heinrich: Umgang mit Maschinen. In: FZT Nr. 147 vom 24.02.1928, 1.

129 Anon.: Neue Arbeit, neue Menschen. Die Stossbrigade Kopylows. In: AIZ, 1932, Nr. 12 , 268 (Jahresausgabe).

130 Die 1916 gegründeten Werke der A. M. O. (Awtomobilnoje Moskowskoje Obschtschestwo, zu Deutsch: Moskauer Automobilgesellschaft) waren in den 1920er Jahren der größte sowjetische Fahrzeughersteller und firmierten später nach einer zwischenzeitlichen Umbenennung in "Stalin-Werk" seit der Entstalinisierung unter dem Namen Sawod imeni Lichatschowa (Lichatschow-Werke). Vgl. Siegelbaum, Lewis H.: Cars for Comrades. The Life of the Soviet Automobile. Ithaca u. a. 2011, $10 \mathrm{f}$.

131 Anon.: »AMO« Das Erbe des Zarismus - "Stalin« Das Werk des Sozialismus. In: AIZ, 1932, Nr. 22, 516 (Jahresausgabe). 
wenn es sich bei Lichte besehen auch um denselben arbeitsphysiologischen Sachverhalt handelte.

Die Rationalisierungsfrage wurde überwiegend, jedoch nicht ausschließlich um die Themenblöcke Wirtschaft und Arbeit herum erörtert. Eine Reihe weiterer Themen aus anderen Zusammenhängen wurde in ihrem Zuge ebenfalls aufgegriffen. Beispielsweise wurden auch im Wohnungs- und Städtebau die Zeichen der (fordistischen) Zeit erkannt und man war bemüht, möglichst effiziente Kombinationen aus Wohn- und Arbeitsumgebung zu entwerfen. Nicht umsonst bezeichnete sich mit Walter Gropius der profilierteste Bauhaus-Protagonist selbst als »Wohn-Ford ${ }^{132}$

Visionäre Architektur und Städtebau in der Sowjetunion wurden in der Weimarer Presse wegen ihrer »brutale(n) Geistlosigkeit« und der totalen Optimierung des Arbeiters als »Kasernen der Arbeit ${ }^{133}$ abqualifiziert. Wie beispielsweise in der Kritik der Entwürfe des Stadtplaners Ernst May wurde Architektur als bloßer Ausdruck der sozialistischen Ideenwelt interpretiert. ${ }^{134}$ Der »sozialistische Städtebau« sei »nur ein trockenes und armseliges Schema; von Kopf bis Fuß rationalistisch, aber nicht rationell. ${ }^{135}$ Analoge Planungen gab es in den dezidiert nichtsozialistischen USA und in Westeuropa. ${ }^{136}$

Die Frage des rationalistischen - also nicht »sozialistischen " - Wohnungsbaus lehnte sich, wie weitere vereinzelte Fremdthemen, an den Rationalisie-

132 Vgl. Saldern, Adelheid von/Hachtmann, Rüdiger: Das fordistische Jahrhundert. Eine Einleitung. In: Saldern, Adelheid von/Kirsch, Jan-Holger (Hg.): Fordismus. Zeithistorische Forschungen/Studies in Contemporary History. Bd. 6 (2009), Nr. 2, 80. Sowie: Bernhardt, Cristoph/Vonau, Elsa: Zwischen Fordismus und Sozialreform. Rationalisierungsstrategien im deutschen und französischen Wohnungsbau 1900-1933. Ebd., 230-254.

133 Anon.: Kasernen der Arbeit. Mays sozialistische Stadt. In: FZT Nr. 135 vom 20.02.1931, 3.

134 Diese Wertung stand im Zusammenhang mit dem Engagement Mays in Moskau, wo er ab September 1930 wohnungsbauliche Großprojekte der sowjetischen Führung mitkonzipierte. Siehe dazu: Flierl, Thomas (Hg.): Standardstädte. Ernst May in der Sowjetunion 1930-1933. Texte und Dokumente. Berlin 2012. Auch meinte mancher Beiträger eine Urbanisierung und Rationalisierung im Denken selbst der ländlichen Bevölkerung Russlands zu erkennen, selbst wenn diese von den Städten weit entfernt lebe. Zu erklären sei dies mit dem Diktat der urban geprägten bolschewistischen Eliten, welches diese vermittels ideologischem »Rationalismus« über die Masse der Landbevölkerung ausübten. Der Aspekt "geplanter Urbanität", die ja auch ihren programmatischen Niederschlag in Form von Jahresplänen der Sowjetunion fand, trug zur Konnotation von geplantem Wohnungsbau und Sozialismus in der deutschen Presselandschaft bei. »Früher hieß es: der Himmel ist hoch und der Zar ist weit, jetzt aber ist Moskau scharf herangerückt an den letzten Bewohner des letzten Dorfes." Grabowsky, Adolf: Dorf und Stadt in Sowjet-Rußland. In: FZT Nr. 946 vom 19.12.1924, $1 \mathrm{f}$.

135 Anon.: Kasernen der Arbeit, 3.

136 Vgl. Bodenschatz, Harald: Analogismus von Fabrikarbeit und Arbeit außerhalb der Fabrik. Ein Essential des Fordismus? In: Bittner, Regina/Brüning, Henning: Zukunft aus Amerika, $39 \mathrm{f}$. 
rungsdiskurs an. Darunter ergaben sich besonders hinsichtlich des Moments der Entindividualisierung thematische Ausgriffe. Diese entsprangen zwar im weitesten Sinne der Verhandlung des Zeitphänomens Rationalismus, entwickelten aber eine ganz eigene Dynamik, die es zu analysieren lohnt.

\subsection{Rationalisierung und Massengesellschaft}

In der Pressebetrachtung der UdSSR wurde stets die Einebnung aller politischen, kulturellen und wirtschaftlichen Individualität als »bolschewistische Gleichmacherei« herausgestellt. Die UdSSR wurde zum Inbegriff der »Vermassung", also der Aufhebung tradierter, nach Klassen, Rassen und Geschlechtern definierter Trennlinien. In vielerlei Hinsicht stilisierte sie sich dazu auch selbst. Doch genoss die Sowjetunion diesen Ruf keineswegs exklusiv. Auch mit Blick auf die USA wurde die sich verschiebende Balance zwischen Individuum und Kollektiv beklagt - totale "Vermassung" drohte. Die Befürchtung griff um sich, in den USA entstehe ein zweckrationalistisch standardisierter »Typ " Mensch. Ein solcher Menschentyp sei, ähnlich dem "neuen Sowjetmenschen ", frei von hinderlichen individuellen Eigenheiten.

Das Schreckensbild einer fortschreitenden Kollektivierung, Vermassung und Typisierung der amerikanischen Gesellschaft wurde weniger drastisch illustriert als die Umwälzungen innerhalb der Sowjet-Gesellschaft. Dass der Vorwurf der mutwilligen »Vermassung« beiden Protagonisten der Moderne gemacht wurde, enthüllt die eigentliche Stoßrichtung der Pressekritik: Der Moderne als solcher wird angelastet, die Vermassung zu forcieren. Die Vereinigten Staaten und die UdSSR als ihre aktuell »aufregendsten « Arenen sind als Metaphern der Moderne lediglich das Vehikel für eine holistische Modernitäts- und Kulturkritik. ${ }^{137}$

Die Klage über die Entmenschlichung am Arbeitsplatz fand ihre Entsprechung in der Debatte über die Entindividualisierung in einer "vermassten" Gesellschaft. Massengesellschaft und Massenkultur, Charakteristika der klassischen Moderne, ${ }^{138}$ wurden in Zeitungen und Illustrierten auch unter Bezugnahme auf die Erfahrung rationalistischer Entindividualisierung in der Arbeitswelt verhandelt. Parallel existierte eine zeitphänomenologische Diskussion des Themas Masse, die ohne den Anschluss an den Themenkomplex wirtschaftlicher Rationalisierung auskam. Rhetorik, Konzept und Praxis

137 Der Aufstieg der Massen war laut Jan-Werner Müller ein »Gemeinplatz der Kulturkritik der Zwischenkriegszeit«. Die »A Amerikanisierung der Wirtschaft und vor allem der Kultur [...] beschleunigte in den Augen vieler europäischer Kulturkritiker das Abgleiten in eine `Massengesellschaft ‘. Müller: Das demokratische Zeitalter, 38 u. 47.

138 Vgl. Peukert: Die Weimarer Republik, 166-178. 
politischer und kultureller Massenbewegungen, dahingehende Kulturkritik intellektueller Eliten und die mediale Entwicklung der Zeit liefern überreichen Beleg für Präsenz, Wirkmacht und Kontroversität des Themas »Masse«.

Zahlreiche Ausdeuter der Moderne, unter ihnen so herausragende wie Georg Simmel, teilten die Angst vor fortschreitender »Vermassung» als Charakteristikum moderner Zeiten indes nicht. Simmel ging, um ihn als Repräsentant dieser intellektuellen Strömung heranzuziehen, vielmehr davon aus, mit zunehmender Reife des - insbesondere deutschen - Menschen zum »Vernunftmenschen« ziehe ein Zeitalter ausgeprägter Individualität herauf. Dem Kollektivprinzip seien, zumal in europäischen Gesellschaften, ${ }^{139}$ wegen des individuellen Entfaltungsbedürfnisses feste Grenzen gesetzt. ${ }^{140}$

In den Massenmedien fußten Einlassungen zum Spannungsverhältnis zwischen Masse und Individuum meistens auf dem wirtschaftsspezifischen Rationalisierungsdiskurs. Von dieser Grundlage aus begaben sie sich auf die Ebene der Gesellschafts- oder Kulturkritik, besonders aber der Zeitkritik. Beklagt wurde der allerorten um sich greifende Zweckrationalismus. Dieser stand in scharfem Gegensatz zum hergebrachten, Staat und Gesellschaft prägenden Idealismus. Doch wie waren die Rationalisierungsdebatte und der Vermassungsdiskurs konkret in medialen Kontexten aneinandergekoppelt?

Die Kritik an der Vermassungswirkung wirtschaftlicher Rationalisierung verlief entlang tradierter, länderspezifischer Deutungsmuster. Schon in den soziokulturellen Grundanlagen der amerikanischen und (sowjet-)russischen Gesellschaft machte man kollektivistische und antiindividualistische Tendenzen aus. Man griff dabei auch Elemente auf, die hier bereits unter dem Schlagwort der Kulturimmanenz des amerikanischen Rationalismus zusammengefasst wurden. Wirtschaftsrationalistische Bezüge erdeten die zahlreichen Meinungsäußerungen, die sich an der hochabstrakten thematischen Schnittstelle von Rationalisierungs- und Massediskurs bewegten.

139 Die russische Gesellschaft beziehungsweise die Gesellschaften der späteren Sowjetunion schloss er hierin nicht ein. Unter dem Terminus »europäisch" subsumierte er explizit und dem Sprachgebrauch der Zeit entsprechend, die "romanischen" und die "germanischen« Völker, weshalb sich seine Analyse zuvörderst auf West- und Westmitteleuropa bezogen haben dürfte. Vgl. Simmel, Georg: Schriften zur Soziologie. Eine Auswahl. Frankfurt a. M. 1983, 267-274.

140 Simmel schrieb in seinem Essay »Individualismus « von 1917: Das deutsche Individuum, auch wo es sich in Gesetzen, Formen, Ganzheiten s selbstlos` einordnet und dabei nur sich selbst treu bleibt, ist schließlich doch auf jene Verantwortlichkeit gestellt, die aus dem nur ihm eigenen Mittelpunkt wächst - während sie im klassischen und romanischen Individualitätsideal gewissermaßen den Brennpunkt bildet, in den ein allgemeiner Stil und ein ideell gemeinsames Formgesetz, der Typus und die überindividuelle Idee dieser Individualität selbst ihre Strahlen: Sinn und tragende Kräfte - zusammenleuchten lassen.«Ebd., 274. 
Die fixe Idee, so schrieb etwa der preußische Regierungsrat Hans Goslar ${ }^{141}$ 1922 in einem Reisebericht für die VZT, dass Amerika ein Land sei, »in dem jede Ansicht und Lebensführung freiesten Spielraum« genieße und »nirgends Grenzen für die persönliche Entwicklung« existierten, sei »ein ungeheurer Trugschluß. ${ }^{142}$ Bei näherer Betrachtung verkehre sich diese Annahme gar in ihr genaues Gegenteil. Zwar sei "Amerika in seinen Lebensformen und Institutionen demokratisch«, sanktioniere aber gleichzeitig streng übergebührlichen Individualismus sowie das Festhalten an kulturellen Eigenarten. Goslar präsentiert hier eine Negativfolie des klassischen Narrativs vom amerikanischen Schmelztiegel. In einer Art Amalgamierungsprozess werde aktiv die »Zusammenhämmerung [...] verschiedenster Rassen und Kulturen [...] zu einer glühenden und ausschließlich amerikanisch empfindenden Masse« betrieben. Jenseits der eingängigen Metaphorik sieht Goslar Parallelen zur wirtschaftlichen Rationalisierung darin, »daß Amerika nicht nur auf dem Gebiete der Warenfabrikation erfolgreich mit der Methode der Typisierung « arbeite, "sondern auch in der Menschenerziehung. ${ }^{143}$

Weitere Artikel leiten aus der Vorstellung einer noch jungen und unfertigen amerikanischen Gesellschaft sowie aus der Beschaffenheit des amerikanischen Raumes hochgradig deterministische Erklärungen für den wirtschaftlichen Rationalisierungsdrang, aber auch für die soziale Tendenz zur Entindividualisierung und Vermassung ab. Hier greifen Muster, die deutliche Parallelen zur Erklärung der amerikanischen Vorreiterrolle in Sachen Arbeitsorganisation aufweisen:

»Es [Amerika, D.F.] baut mit seinen titanischen Kräften auf einer Vergangenheitslosigkeit, die den Massenmenschen zum Kollektivprinzip erzieht und ihn zur Maschine des Zweck- und Erfolggedankens [sic] macht. Vergewaltigung des Lebens und jeder individuellen Freiheit im Sinne der Schablone und des einen materiellen Ziels. [...] Und die Natur hat alles getan durch Ausschaltung materieller und geistiger Gegenkräfte, dieses Einlullen zu unterstützen. Einen gewaltigen, mit allen irdischen

141 Vor seiner Zeit als Regierungsrat war Goslar bei der DAZ und der VZT tätig. Er war Mitbegründer des »Herzl-Clubs«, einer zionistischen Jugendvereinigung. Berühmtheit erlangte er nach dem Zweiten Weltkrieg (posthum) durch die Freundschaft seiner Tochter Hannah Pick-Goslar mit Anne Frank. Vgl. Vierhaus, Rudolf/Killy, Walther (Hg.): Deutsche Biographische Enzyklopädie. Bd. 4 (Görres - Hittorp). München 2006, 56. Er war entschiedener Anhänger der Republik. In einer Streitschrift benannte er zwar die Fehler und Unfertigkeiten der scheiternden Republik, plädierte aber für deren Reform. Vgl. dazu: Goslar, Hans: Weimar - trotz alledem! Ein Reichsverfassungs-Brevier; Grundlagen, Inhalt und Wollen der Weimarer Verfassung des Deutschen Volksstaates; mit einem Anhang: Wie Preussens Verfassung entstand. Breslau 1932.

142 Goslar, Hans: Amerikas öffentliche Meinung. Politik, Theater, Kunst, Religion. In: VZT Nr. 132 vom 18.03.1922, $1 \mathrm{f}$.

143 Ebd. 
Gütern gesegneten Kontinent, dessen Grenzen für ewige Zeiten gesichert sind, nennt der Amerikaner sein eigen. ${ }^{144}$

Man sah über die Egalisierungskräfte wirtschaftlicher Rationalisierung hinaus in der amerikanischen Kultur selbst die Tendenz zur »Gleichmacherei, insbesondere von innerlicher ${ }^{145}{ }^{145}$

Ein alles Schöpferische des Individuellen ertränkender Rationalismus der Masse wurde spiegelbildlich auch der sowjetischen Gesellschaft attestiert. Deren kulturelle Veranlagung begünstige den Kollektivismus ohnehin und werde nun durch das bolschewistische Postulat planmäßiger Kollektivierung darin bestärkt. Werner Thormann schreibt 1923 in einer Rezension zu Alfons Paquets Essaysammlung »Rom oder Moskau « ${ }^{146}$ in der FZT, für eine Gesellschaft wie die sowjetrussische sei »eine breitere Führerschicht [...], der die Massen des Volkes folgen" unabdingbar. Ein »Häuflein einflußloser Intellektueller« sei nämlich nicht in der Lage, dem »organischen Gemeinschaftsgedanken, der allein die Grundlage einer wirklichen Menschheitskultur « ${ }^{147}$ bilde, zu entsprechen. Das Sowjetsystem erscheint als Ideallösung.

Hier taucht der Gedanke einer organisch interagierenden Masse auf, wie er auch im sowjetischen Proletkult künstlerisch verarbeitet wurde. Thormann weist auf eine Reihe von Dualismen hin, an Hand derer Paquet grundsätzliche Unterschiede zwischen dem Westen (»Rom») und dem Osten (»Moskau») fassbar zu machen versucht. Darunter stechen die Begriffspaare »absolut vs. organisch« und »Individualismus vs. Solidaritätsgesinnung « ${ }^{148}$ heraus. Deren elementarer Charakter lässt »das Westliche« und »das Östliche« als genetisch gegensätzliche Gesellschaftsentwürfe erscheinen. Das Denken in dieser Art von Dichotomien suggeriert einen Entscheidungszwang zwischen westlicher Zivilisation und östlicher Ideologie.

Mancher Beitrag synthetisierte die vermeintlich analogen Kollektivismen der USA und der UdSSR, um sie dem (west-)europäischen Individualismus gegenüberzustellen, der gemeinhin als gegeben angesehen wurde. Am weitesten ging dabei Hermann Graf Keyserling, der durch seinen heftig umstrittenen Bestseller »Das Reisetagebuch eines Philosophen ${ }^{149}$ als Koryphäe der Völkerpsychologie galt. In seinem Vortrag »Europa und Amerika«, be-

144 Anon.: Amerikanismus. Ein Spiegel aus der neuen Welt. In: MNN, 1927, Nr. 259, 1.

145 »Ich hatte stets das, was ich vom `Schmelztiegel las, für übertrieben gehalten, muß aber heute sagen, daß ich bis ins Innerste betroffen war von dem Grad von Gleichmacherei, insbesondere von innerlicher, der [...] drüben erreicht worden ist." Goslar: Amerikas öffentliche Meinung, 1.

146 Paquet, Alfons: Rom oder Moskau. 7 Aufsätze. München 1923.

147 Thormann, Werner: Rom oder Moskau. In: FZT Nr. 471 vom 29.06.1923, 1 f.

148 Ebd.

149 Keyserling, Hermann: Das Reisetagebuch eines Philosophen. Darmstadt 1919. 
sprochen im Feuilleton der DAZ, nennt Keyserling »den Amerikaner [...] den einzigen echten Sozialisten«, da die »amerikanische Lebensform ähnlich wie im bolschewistischen Rußland, kollektivistisch « und folglich der "Kollektivismus [...] der neue Geist Amerikas« sei. Amerika habe zwar von »Europa alles übernommen; der Geist aber musste sich infolge der erdhaften Assimilierung verändern, neu bilden; er konnte nicht europäisch bleiben. ${ }^{150}$ Keyserling bestätigt das Muster eines räumlich-kulturellen Determinismus.

Wenn in den Fällen der USA und der UdSSR auch unterschiedliche Erklärungsmuster herangezogen wurden, so blieb in einem beträchtlichen Teil des Pressespektrums doch das Bild zweier eingeebneter, kollektivistischer Gesellschaften zurück. Der sprichwörtliche amerikanische Individualismus wurde zwar von prominenten Beiträgern, unter ihnen US-Präsident Herbert Hoover, ${ }^{151}$ in deutschen Magazinen als Fortschrittsmotor der USA gefeiert. Demgegenüber standen wirkmächtige Dekonstruktionen jenes amerikanischen Individualismus als reine Folklore, die von der Realität zunehmender Vermassung längst widerlegt worden sei. Hans Goslar oder Hermann Graf von Keyserling sind hier nur die eindrücklichsten Beispiele.

Die Furcht vor dem Untergang des Individuums kam mitunter in unerwartet metaphorischem Gewand daher. Joseph Roth nahm beispielsweise die Varieté-Darbietungen der »Tiller-Girls«, beliebt auf den Bühnen Europas und Amerikas, als Anlass zur Sorge um das moderne ästhetische Empfinden. Der maschinenhafte Tanz endloser Reihen identisch aussehender junger Damen sei nicht nur »eine Übersetzung des männlich-ernsten Militärexerzierens ins Weibliche«. Er stehe auch stellvertretend dafür, wie im Ästhetischen die Einzelne in der gleichgeschalteten Masse aufgehe, und sei auf eine bedenkliche »Sinnlichkeit berechnet, die aufs Ganze geht: eine Quantitäts-Sinnlichkeit, die das Individuum gar nicht berührt. ${ }^{152}$ In Roths Beobachtung bündeln sich Fragen der Rationalisierung und Vermassung mit der Frage von Frauenbildern. Damit stehen an dieser Stelle gleich mehrere thematische Stränge im Zentrum seiner Zeitkritik, was wiederum verdeutlicht, in wie starkem Maße die einzelnen Paradigmen der Weimarer Modernitätsdiskurse in einem reziproken Verhältnis zueinander standen.

Auch der Soziologiepionier Siegfried Kracauer verlegte sich in seiner Zeitkritik auf den Ansatz »des pars pro toto «. Die Lesart seiner Zeit zielte auf die Erfassung langfristiger, geschichtsphilosophisch zu erfassender Tenden-

150 Anon.: Europa und Amerika - ein Vortrag Hermann Keyserlings. In: DAZ Nr. 570 vom $06.12 .1930,1$.

151 Hoover, Herbert C.: Der amerikanische Individualismus. In: QUS, 1931, Nr. 8, 507-511 (Jahresausgabe).

152 Roth, Joseph: Die Girls. In: FZT Nr. 313 vom 28.04.1925, 1. 
zen. ${ }^{153}$ Diesen spürte er in konkreten kulturellen Erscheinungen wie Filmen, Romanen oder eben Tanzvorführungen nach. Für Kracauer legten diese Werke Grundmuster soziokultureller Wandlungsprozesse seiner Zeit frei und gaben ihm Anlass zur Zivilisationskritik. Kracauer kopiert Joseph Roths Analyse dabei bis auf die Beispielebene und geht sowohl auf die "Tiller-Girls" als auch auf die Parallelen zwischen deren Darbietungen und dem militärischen Exerzieren ein. Analog zu Roths Durchgriff von der modernen Ästhetik auf den Zeitgeist des rationalistischen Massenzeitalters bedient sich Kracauer als Feuilletonredakteur der FZT in seinem Aufsatz »Das Ornament der Masse« der »Tiller-Girls ${ }^{154}$ als einer Metapher für abstrakte Prozesse menschlicher Entindividualisierung und Vermassung. Er überträgt die von den Tänzerinnen geformten Massenfiguren (Sterne) allegorisch auf die moderne Massengesellschaft:

"So auch haben die lebendigen Sternbilder in den Stadions [sic] nicht die Bedeutung militärischer Evolutionen. Wie regelmäßig immer diese ausfielen, ihre Regelmäßigkeit ward als Mittel zum Zweck erachtet; patriotischen Gefühlen entstammte der Parademarsch, der wiederum in Soldaten und Untertanen Gefühle erweckte. Die Sternenbilder meinen nichts außer sich selbst und die Masse. ${ }^{155}$

153 Vgl. Band, Henri: Mittelschichten und Massenkultur. Siegfried Kracauers publizistische Auseinandersetzung mit der populären Kultur und der Kultur der Mittelschichten in der Weimarer Republik. Berlin 1999, $44 \mathrm{f}$.

1541931 illustrierte Kracauer an den »Alfred Jackson Girls« Parallelen zwischen Rationalisierung und Entindividualisierung: »Drückt man auf einen Knopf, so wird die Mädchenvorrichtung angekurbelt [...]. Alle Glieder rollen, alle Wellen geraten in Umlauf. Und während der Mechanismus dampft, zittert und dröhnt wie ein Sägewerk oder eine Lokomotive, trieft fortwährend das Oel des Lächelns in die Gelenke [...]. Zuletzt wird auf ein unhörbares Sirenenzeichen die maschinelle Tätigkeit abgestoppt, und das tote Ganze zerlegt sich automatisch in seine lebendigen Teile. Ein Zerstörungsprozeß, der das traurige Gefühl hinterläßt, daß diese Teile gar nicht selbstständig weiterzuexistieren vermögen [...]. Was wird durch sie wie durch ein fleischgewordenes Gleichnis verkörpert? Das Funktionieren einer blühenden Wirtschaft. In jener Nachkriegsära, in der die Prosperity unbegrenzt schien [...] - damals wurden die Girls der U.S.A. künstlich gezeugt und dann serienweise nach Europa exportiert. Sie waren nicht nur amerikanische Produkte, sie demonstrierten gleichzeitig die Größe der amerikanischen Produktion [...]. Wenn sie eine Schlange bildeten, die sich auf und nieder bewegte, veranschaulichten sie strahlend die Vorzüge des laufenden Bands; wenn sie im Geschwindtempo steppten, klang es wie: Business, Business; wenn sie die Beine mathematisch genau in die Höhe schmetterten, bejahten sie freudig die Fortschritte der Rationalisierung; und wenn sie stets wieder dasselbe taten, ohne daß ihre Reihe je abriß, sah man innerlich eine ununterbrochene Kette von Autos aus den Fabrikhöfen in die Welt gleiten und glaubte zu wissen, daß der Segen kein Ende nehme.« Kracauer, Siegfried: Girls und Krise. In: FZT Nr. 384 vom 26.05.1931, $1 \mathrm{f}$.

155 Kracauer, Siegfried: Das Ornament der Masse. In: FZT Nr. 420 vom 09.06.1927, $1 \mathrm{f}$. 
Für Kracauer zeigen die von Tänzerinnen geformten Ornamente, dass »ein Geschmackswandel vor sich gegangen« sei, der die ästhetische Wahrnehmung des Einzelobjekts oder der Einzelperson auf die komplexe Massenebene verlagert habe. Nach Kracauer, das Phänomen stets mit dem dahinterstehenden epochalen Wandlungsprozess zusammendenkend, sind »[d]iese Produkte der amerikanischen Zerstreuungsfabriken [...] keine einzelnen Mädchen mehr, sondern unauflösliche Mädchenkomplexe « ${ }^{156}$. Die Homogenisierung des Kulturbetriebes beschränkt sich nicht auf die Darbietenden. Dass die beschriebene Art der Vorführungen in allen Ländern gleichermaßen begeistert, sieht Kracauer als Triumph von Massentauglichkeit und Internationalität über eine individualistische und kulturspezifische Ästhetik an:

»Während sie sich in den Revuen zu Figuren verdichten, ereignen sich auf australischem und indischem Boden, von Amerika ganz zu schweigen, in immer demselben dichtgefüllten Stadion Darbietungen von gleicher geometrischer Genauigkeit. [...] Der Regelmäßigkeit ihrer Muster jubelt die durch die Tribünen gegliederte Menge zu. [...] Sie haben internationale Geltung errungen [...]. Träger der Ornamente ist die Masse. Nicht das Volk, denn wann immer es Figuren bildet, hängen diese nicht in der Luft, sondern wachsen aus der Gemeinschaft hervor. ${ }^{157}$

Das Individuum war von der Massenkultur nicht nur entfremdet, sondern mit ihr inkompatibel. "[D]ie sich als Einzelpersönlichkeit mit einer eigenen Seele wissen«, versagten »bei der Bildung der neuen Muster [...]. Als Massenglieder allein sind die Menschen Bruchteile einer Figur. ${ }^{158}$ Das Wesen des Menschlichen definierte sich im Massenzeitalter nicht mehr durch den Einzelnen, sondern durch nach Aussehen, Herkunft und Empfinden indifferente menschliche Bausteine. Diese normierten Elemente formten größere, massenhafte soziale Komplexe: »Zur Errichtung des Bauwerkes kommt es auf das Format der Steine und ihre Anzahl an. « $^{159}$

Die Brücke von der Massenkultur zur wirtschaftlichen Rationalisierung schlägt Kracauer mit einer Analogie zwischen dem "Ornament der Masse« und der kleinstmöglichen Zerlegung des Produktionsprozesses im Taylorismus. Beides entstamme "nicht rein der Natur" und sei gezwungen, »die natürlichen Organismen [zu, D. F.] sprengen, die ihm Mittel oder Widerstände sind." Durch die Degradierung des Individuums zum »Masseteilchen«, das »reibungslos an Tabellen emporklettern und Maschinen bedienen « könne, sei weltumspannende Massenproduktion überhaupt möglich. Individuelle, kulturspezifische Gestaltungsansprüche prallten wirkungslos am System ab. Die 
"Verwischung der nationalen Eigenarten und [...] Fabrikation von Arbeitermassen« lasse »Volksgemeinschaft und Persönlichkeit vergehen, wenn Kalkulabilität gefordert ${ }^{160}$ sei. Der Identitäts- und Kontrollverlust des Individuums in der rationalisierten Industrieproduktion kommt in Kracauers Schilderungen gänzlich mit der Auflösung des Individuums im Ornament der Masse zur Deckung:

"Der Produktionsprozess läuft öffentlich im Verborgenen ab. Jeder erledigt seinen Griff am rollenden Band, übt eine Teilfunktion aus, ohne das Ganze zu kennen. Gleich dem Stadionmuster steht die Organisation über den Massen, eine monströse Figur, die von ihrem Urheber dem Auge des Trägers entzogen wird und kaum ihn selbst zum Betrachter hat. - Sie ist nach rationalen Grundsätzen entworfen, aus denen das Taylorsystem nur die letzte Folgerung zieht. Den Beinen der Tillergirls entsprechen die Hände in der Fabrik. [...] Das Massenornament ist der ästhetische Reflex der von dem herrschenden Wirtschaftssystem erstrebten Rationalität. ${ }^{161}$

Im zweiten Teil seines Essays erklärt Kracauer die »organische Gesellschaftslehre, die den natürlichen Organismus zum Vorbild der gesellschaftlichen Gliederung« erhebe, zum Menetekel einer autoritär gegliederten und ideologisch formbaren Massengesellschaft. Im sowjetischen Proletkult wurde diese totalitäre Utopie zu jener Zeit bereits künstlerisch ausbuchstabiert. Sie sollte in Deutschland ihre Entsprechung in der nationalsozialistischen »Volkskörper«-Rhetorik und deren politischen Schlussfolgerungen finden. Die mythische Überformung antiindividualistischer und kollektivistischer Gesellschaftsorganisation im »Ornament der Masse« deutet Kracauer als nur scheinbar rationalen $»$ Rückschlag in die Mythologie [...], der seinerseits wieder die Abgesperrtheit der kapitalistischen Ratio gegen die Vernunft verrät. « ${ }^{162}$ Der essentielle Trugschluss des kapitalistischen Wirtschaftsrationalismus sei, dass er eine Rationalität ohne Einbeziehung des Menschen verfolge, die der finalen Entmenschlichung zwingend Vorschub leiste. ${ }^{163}$

Jenseits des Industriellen, jenseits des Kulturellen und des Sozialen lag für Kracauer in konsequent »durchrationalisiertem» Denken das Potential totalitären Handelns. Mit seinen Analogien zwischen Rationalismus und Totalitarismus kann er nicht nur die UdSSR gemeint haben, sondern muss von

160 Ebd.

161 Ebd.

162 Kracauer, Siegfried: Das Ornament der Masse - II. In: FZT Nr. 423 vom 10.06.1927, $1 \mathrm{f}$.

163 "Doch die Ratio des kapitalistischen Wirtschaftssystems ist nicht die Vernunft selber, sondern eine getrübte Vernunft. Von einem bestimmten Punkte ab läßt sie die Wahrheit im Stich, an der sie einen Anteil hat. Sie begreift den Menschen nicht ein. Weder wird durch die Rücksicht auf ihn der Ablauf des Produktionsprozesses geregelt, noch baut sich die wirtschaftliche und soziale Organisation auf ihm auf, noch ist überhaupt an irgendeiner Stelle der Grund des Menschen der Grund des Systems.« Ebd., 2. 
einer umfassenderen Wirkung des beschriebenen Kulturwandels ausgegangen sein. Dass er das Mutterland der Rationalisierung, die "modernen«, demokratischen Vereinigten Staaten ins Zentrum seiner Kritik stellte, legt nahe, dass Kracauer seine gesamte Epoche einem totalitären Risiko ausgesetzt sah.

Betrachtungen wie diese bildeten den intellektuellen Kern des Widerspruchs zwischen menschlicher Vernunft und menschengemachtem Rationalismus. Dieser Widerspruch verlieh dem Rationalisierungsdiskurs in der Weimarer Massenpresse seine einzigartige Grundspannung. Intellektuelle wie Siegfried Kracauer oder Joseph Roth wetteiferten dabei mit anderen, die zeitgleich den Spannungsraum zwischen Individuum und Masse durchmaßen. Deutungskonkurrenten wie der Soziologe Theodor Geiger attestierten der entindividualisierten Masse statt totaler Formbarkeit ein immanentes revolutionäres Potential und die Fähigkeit zur ungerichteten und destruktiven Initiative. ${ }^{164}$ Äußerte sich diese intellektuelle Konkurrenz zumeist in anspruchsvollen Monografien, imaginierten die breit zirkulierenden Artikel und Kolumnen in Tageszeitungen und Illustrierten die "Masse« jedoch als Ansammlung unterworfener, entmenschlichter Individuen. Individuelle Autonomie war an höhere Entitäten abzutreten - ganz gleich ob an ideologisch-politische Ordnungen wie den Bolschewismus oder an wirtschaftliche Produktions- und Verteilungssysteme wie den Kapitalismus.

\subsection{Zusammenfassung}

Ausgehend von akuten sozialen und wirtschaftlichen Problemlagen der Nachkriegszeit ab 1918 bündelte die Rationalisierungsdebatte durch das »Kaleidoskop" USA und UdSSR multiple, lose miteinander verbundene Einzeldebatten. Als kleinsten gemeinsamen Nenner trugen die unter dem Dachterminus »Rationalisierung" diskutierten Themen die virulente Frage nach der Ablehnung oder Unterstützung von Zeitphänomenen in sich, die im weitesten Sinne als »rationalitätsbezogen« verstanden wurden. In diesen traten kontrovers debattierte Fragen der Technologie, der Wirtschaftsphilosophie und der Rationalisierung industrieller Produktion zunehmend in den Hintergrund.

Die rationalistische Umgestaltung von Wirtschaft, Arbeit und Produktion katalysierte im weiteren Verlauf immer mehr die Verhandlung weit komplexerer Fragen. Deutlich wird dies an der Evolution der Debatte, die sich vom Verhältnis zwischen Mensch und Maschine zum Spannungsverhältnis zwischen Individuum und Kollektiv bewegte. Besonders prägend wirkten hierbei die Debatte um die »Vermassung« der Gesellschaft und die problematisierte

164 Vgl. Geiger, Theodor: Die Masse und ihre Aktion. Ein Beitrag zur Soziologie der Revolutionen. Stuttgart 1926, 36. 
Vision eines sowjetischen "neuen Menschen«, der mechanisiert arbeiten, rationalistisch denken und kollektiv fühlen sollte. Die Optimierung, Mittelbarmachung oder sogar Ausschaltung des Individuums als Bedingungsfaktor wirtschaftlicher oder ideologischer Zielsetzungen wies dabei weit über die Ausgangspunkte der Debatte hinaus und definierte entscheidend das zeitgenössische Epochenbewusstsein. 


\title{
2. Frauenbilder und Frauenemanzipation
}

\begin{abstract}
»Hier gilt es nun zunächst die Tatsache festzustellen, daß die Kultur der Menschheit auch ihren reinen Sachgehalten nach sozusagen nichts Geschlechtsloses ist und durch ihre Objektivität keineswegs in ein Jenseits von Mann und Weib gestellt wird. Vielmehr, unsre objektive Kultur ist, mit Ausnahme ganz weniger Gebiete, durchaus männlich. Männer haben die Kunst und die Industrie, die Wissenschaft und den Handel, den Staat und die Religion geschaffen. « ${ }^{1}$
\end{abstract}

So schrieb Georg Simmel weit- und klarsichtig in seinem Essay »Weibliche Kultur« von 1918. Simmel fährt fort, Frauen hätten nun die Möglichkeit, sich entweder in ursprünglich durch männliche Normen definierten Feldern zu verwirklichen oder aber »unverwirklichte Möglichkeiten, uneingelöste Versprechungen (und) gebundene Spannkräfte «² zur Entfaltung zu bringen.

Zwei der prominentesten Entwicklungslinien weiblicher Rollenbilder während und nach dem Ersten Weltkrieg nahm Simmel hier vorweg: die An- und Einnahme männlich besetzter Rollenbilder durch Frauen und die Definition neuer, genuin weiblicher Rollenbilder. Beides könne jedoch, so wandte er ein, innerhalb der durchweg männlich normierten Gesellschaft nicht zu einem Gleichgewicht der Geschlechter führen. Das eine wie das andere würde letztlich als widernatürlich abqualifiziert. ${ }^{3}$ Simmel beschrieb damit bereits früh ein Dilemma, wie es sich in publizistischen Diskursen über neue Frauenbilder während der Weimarer Zeit deutlich zeigen sollte.

Natürlich reicht Simmels Diagnose nicht an die in der heutigen Debatte weiter ausformulierten Leitlinien für die Dekonstruktion der historisch tradierten Einheit von (biologischem) Geschlecht, (sicht- und formbarem) Körper und (kulturell bedingter) Geschlechterrolle heran. Judith Butler hat diese unter Bezugnahme auf eine von Kant über Nietzsche bis Foucault reichende Argumentationslinie zur Differenzierung jener drei Kategorien erdacht. ${ }^{4}$ Den-

1 Simmel, Georg: Philosophische Kultur. Über das Abenteuer, die Geschlechter und die Krise der Moderne. Gesammelte Essais. Berlin 1983, 209.

2 Ebd., 213.

3 Vgl. ebd., 209.

4 Vgl. Butler, Judith: Gender Trouble. Feminism and the Subversion of Identity. New York u. a. 2010, $175 \mathrm{f}$. Beim Verweis auf Butler ist hierbei ausdrücklich darauf hinzuweisen, dass nicht das gesamte, mit fortschreitender Zeit immer weitere Bereiche in ihre Dekonstruktion einschließende Theoriegebäude hier zu Grunde gelegt wurde. Lediglich hinsichtlich der spezifischen Rollen, welche auf Grund des biologischen Geschlechts Individuen über 
noch zeugt Simmels zeitgenössischer Problemaufriss von der Einsicht, dass die Dekonstruktion und Neuverhandlung von geschlechterspezifischen Rollenbildern nicht ohne Konfrontation vonstattengehen könne. Das neue, »moderne « Frauenbild musste sich durch die Kollision mit männlichen Rollenbildern einerseits und dem hergebrachten Frauenbild andererseits herausbilden. Konfrontativen Charakter gewinnt diese Rollenbestimmung durch Infragestellung oder Missachtung des bestehenden, Rollenbilder festschreibenden, stilisierenden und verteidigenden Wertesystems und dessen Reaktionen auf derartige Verstöße. ${ }^{5}$

Die Weimarer Debatte über (neue) Frauenrollen verlief teils ganz wie von Simmel prognostiziert, teils aber auch dezidiert antifeministisch beziehungsweise antiemanzipatorisch. Da manche Diskursteilnehmer emanzipatorische Errungenschaften euphorisch feierten, andere diese aber marginalisierten oder verunglimpften, weist die Debatte in ihren Grundmustern die Kollisionen und Konfrontationen auf, die Simmel vorausschauend beschrieben hatte.

Die in der Weimarer Republik über die Rolle der Frau geführten Debatten waren zweifellos andere als vor dem Ersten Weltkrieg, ${ }^{6}$ bezogen sich aber in signifikanter Weise auf soziale und politische Entwicklungen der Vorkriegszeit. Der durch den Krieg beschleunigte, nicht aber bedingte Aufbruch der Frauen führte zu einem Aufbrechen ihres tradierten Bildes im öffentlichen Diskurs. Dieser antizipierte in der Reflexion amerikanischer und sowjetischer Frauenbilder Veränderungen der realen Situation der Frauen in Deutschland und lässt Rückschlüsse auf die Befindlichkeiten der deutschen Öffentlichkeit in der »Frauenfrage« $\mathrm{zu}$.

Die Presseberichterstattung zur Frauenfrage in den USA und der UdSSR diente nicht in erster Linie der Fremdbetrachtung, sondern einer Beantwortung der Frage nach einem neuen, modernen Frauenbild in Deutschland.

soziale Prozesse zugewiesen wurden, dienen Butlers Überlegungen hier der Analyse. Weitere, nicht empirisch untermauerte Annahmen - etwa die einer angeblichen Konstruiertheit des biologischen Geschlechts überhaupt und weiteres mehr - bleiben unbeachtet.

5 »Ideas about separating, purifying, demarcating and punishing transgressions have as their main function to impose system on an inherently untidy experience. It is only by exaggerating the difference between within and without, above and below, male and female, with and against, that a semblance of order is created." Douglas, Mary: Purity and Danger. Boston u. a. 1969, 4.

6 Auch diejenigen Arbeiten, die sich im Speziellen mit dem Zusammenhang zwischen dem Ersten Weltkrieg und der Frauenemanzipation beschäftigten, verwiesen stets eher auf die veränderte Wahrnehmung des Frauenbildes denn auf empirisch nachprüfbare Veränderungen der soziokulturellen Situation der Frauen in den kriegsteilnehmenden Staaten. Vgl. Daniel, Ute: Arbeiterfrauen in der Kriegsgesellschaft. Beruf, Familie und Politik im Ersten Weltkrieg. Göttingen 1989. Sowie Thébaud, Francoise: Der Erste Weltkrieg. Triumph der Geschlechtertrennung. In: Dies. (Hg.): Geschichte der Frauen, Bd. V, 20. Jahrhundert. Frankfurt a. M., New York 1995, 36. 
Dabei standen zwei Fragenkomplexe im Zentrum der Auseinandersetzung: Führte das Vordringen von Frauen in männlich definierte beziehungsweise das Männliche definierende Rollen- und Berufsbilder zu einer widernatürlichen »Vermännlichung « der Frau? Und: Wie sollte man mit der gewachsenen Anzahl politisch aktiver Frauen umgehen, die neu eröffnete Mitwirkungsmöglichkeiten beherzt ergriffen und in das politische Leben drängten? Beides verunsicherte Zeitgenossen nicht zuletzt auf Grund der Tatsache, dass neue Rollenbilder und politische Teilhabe auch als Erschütterung des (Macht-)Verhältnisses der Geschlechter zueinander gedeutet wurden.

Markant zeichnete sich dabei eine Dichotomie von Annahme und Ablehnung der von außen transportierter Frauenbilder durch die Diskursteilnehmer ab. Während Themen, die die politische Emanzipation der Frauen berührten, relativ offen diskutiert wurden, spiegelten sich erhebliche Widerstände gegen die Verwischung von Gendergrenzen ${ }^{7}$ in Zeitungen und Zeitschriften wider. Die Gründe dafür waren das Verharren in tradierten Rollenbildern und die demonstrative Wiederabgrenzung der weiblichen von der männlichen Gesellschaftssphäre. Das weitverbreitete Bedürfnis nach einer Wiederherstellung vormals fest gefügt scheinender Geschlechtersphären fand seinen Ausdruck in einer Tendenz zur ostentativen Rückverweiblichung.

Zwar hatte sich in Deutschland bereits vor 1914 die Erkenntnis durchzusetzen begonnen, es handele sich bei der Einteilung der gesellschaftlichen Sphären in privat-häuslich (weiblich) und politisch-öffentlich (männlich) um soziokulturelle und damit neu verhandelbare Konstrukte. ${ }^{8}$ Durch das Wirken der Frauenbewegung und die zunehmende Berufstätigkeit von Frauen, vor allem im Angestelltenwesen, war dies der wilhelminischen Gesellschaft in Ansätzen zu Bewusstsein gekommen. Doch erst durch den stark beachteten Beitrag weiblicher Arbeitskräfte zu den Volkswirtschaften aller am Krieg beteiligten Staaten wurde diese Erkenntnis augenfällig und erschütterte sowohl das Selbstbild der Frauen als auch deren gesellschaftliche Wahrnehmung nachhaltig. Dies zog sich verschärfende Diskurse über das Bild der modernen Frau nach sich und ließ fundamentale Deutungskonflikte zutage treten. Deren Aushandlung war spezifischen Vorbedingungen, Vorannahmen und Voreingenommenheiten der Diskursteilnehmer unterworfen. Im Falle der Frauenemanzipation tritt dies deutlicher zutage als in anderen Bereichen, da das Frauenbild einer Gesellschaft im Schnittpunkt weiterer grundlegender gesamtgesellschaftlich auszuhandelnder Themen liegt: soziale Hierarchien, Fragen der Erziehung und politische Kultur.

7 Im Sinne von den Geschlechtern kulturell zugeordneten und zugewiesenen Rollenbildern.

8 Daniel, Ute: Frauen. In: Krumeich, Gerhard/Hirschfeld, Gerhard / Renz, Irina (Hg.): Enzyklopädie Erster Weltkrieg. Paderborn 2009, 116-134, hier 116. 
Das Frauenwahlrecht in Deutschland, ${ }^{9}$ die politisch-ideologisch forcierte Gleichstellung von Mann und Frau in Russland ${ }^{10}$ und der Siegeszug der amerikanischen "New Woman ${ }^{11}$ scheinen zwar zeitlich und damit auch kausal zusammenzufallen. Allerdings waren die Voraussetzungen für diese Entwicklungen höchst unterschiedlich.

Bereits seit Ende des 19. Jahrhunderts war die einzigartige gesellschaftliche und politische Rolle der amerikanischen Frau in Deutschland verstärkt wahrgenommen und mit den Besonderheiten der amerikanischen Geschichte zu erklären versucht worden. ${ }^{12}$ Durch die seit 1918 offenkundig gewordene

9 So hat im Falle Deutschlands Ute Daniel gezeigt, dass die erhöhte weibliche Beschäftigung während des Ersten Weltkriegs nicht zu einer nachhaltigen Emanzipations- oder Gleichstellungsentwicklung führte. Das Erklärungsmuster »Emanzipation durch Krieg« erweist sich so als nicht tragfähig. Darüber hinaus sei sogar das Gegenteil, eine Demobilmachung der Frauen nach dem Kriege erfolgt. Daniel, Ute: Arbeiterfrauen in der Kriegsgesellschaft. Göttingen 1989, 106-124 und 259.

10 So wie Russland zwischen 1905 und 1917 im Zeitraffer alle revolutionären Entwicklungen westlicher Gesellschaften zwischen 1776 und 1917 nachzuholen schien, so eruptiv schien auch die Emanzipation der Frau vonstatten zu gehen. Der kausale Konnex von politischer Ideologie und Frauenemanzipation ist auch insofern schwer zu gewichten, als es zu den politischen Zielen Lenins gehörte, bei der Verwirklichung der sozialistischen Gesellschaft explizit auf die gleichberechtigte Mitwirkung der Frauen zu setzen. Vgl. Majer, Diemut: Frauen - Revolution - Recht. Die grossen europäischen Revolutionen in Frankreich, Deutschland und Österreich 1789 bis 1918 und die Rechtsstellung der Frauen. Unter Einbezug von England, Russland, der USA und der Schweiz. Zürich u.a. 2008, $371 \mathrm{f}$. Die vollkommene rechtliche Gleichstellung von Mann und Frau im Jahre 1917 und die durch sozial- und wirtschaftspolitische Maßnahmen sowie die Integration von Frauenabteilungen in die Parteihierarchien vorangetriebene Frauenförderung nach Beendigung des Bürgerkrieges 1921 qualifizieren die Frauenemanzipation dabei über die reine politische Ostentation hinaus als real stattfindende soziale Revolution inmitten der politischen. Köbberling, Anna: Aktuelle Strömungen in der russischen Frauenbewegung. In: Osteuropa, 1993, Nr. 6, 566-577; Scheide, Carmen: Kinder, Küche, Kommunismus. Das Wechselverhältnis zwischen sowjetischem Frauenalltag und Frauenpolitik von 1921 bis 1930 am Beispiel Moskauer Arbeiterinnen. Zürich 2002, 40-64.

11 Laut Aufzeichnungen der US-Arbeitsbehörden reduzierte sich die kriegsbedingte Frauenbeschäftigung auch in den USA nach 1918 deutlich. Mehr als die ökonomische, befeuerte die politische Mobilisierung für einen Kriegseintritt der USA die innenpolitische Auseinandersetzung um die Rechte amerikanischer Frauen, insbesondere in der Frage des Wahlrechts. Da eine amerikanische Intervention von Präsident Wilson maßgeblich zum Kampf für Demokratie in der Welt stilisiert worden war, ergab sich dadurch für die Frauenrechtsorganisationen ein Hebel, um auf die existierenden demokratischen Defizite im Inland hinzuweisen und schließlich auch den Präsidenten als Fürsprecher einer Einführung des Frauenwahlrechts zu gewinnen. Vgl. Matthews, Jean: The Rise of the New Woman. The Women's Movement in America, 1875-1930. Chicago 2003, $152 \mathrm{f}$.

12 Zur allgemeinen Wahrnehmung der USA vor dem Ersten Weltkrieg und der amerikanischen Frau im Speziellen: Schmidt, Alexander: Reisen in die Moderne. Der Amerika-Diskurs des deutschen Bürgertums vor dem Ersten Weltkrieg im europäischen Vergleich. Berlin 1997, 190-216. Schmidt zeigt, wie Reiseberichterstatter auf die ideelle Motivation 
Dominanz des amerikanischen Systems in Gesellschaft, Politik und Wirtschaft gewann dieses Thema weiter an Relevanz. In der Sowjetunion wurde die politische, sozioökonomische und rechtliche Gleichstellung der Frau auf allen Feldern vollzogen, die für eine volle Emanzipation als konstitutiv angesehen werden können ${ }^{13}$ und mit dementsprechend großem Interesse auch in Deutschland verfolgt.

Die Bedingtheit der sowjetischen Frauenemanzipation durch die Revolution von 1917 stellt einerseits einen großen Unterschied zur Wahrnehmung der USA dar, wo man eine lineare, »natürliche« Progression der Gleichstellung zu erkennen glaubte. Andererseits bildet die »Geburt« der Gleichstellung aus der Revolution eine Parallele zur Sicht auf die Situation in Deutschland. Diese hatte sich durch die Revolution im Innern und die Kriegsniederlage nach außen hin ebenfalls radikal verändert. Nachdem der revolutionäre Drang abgeebbt war, lief die deutsche Nachkriegsrealität aber eher auf eine Rückkehr der Frauen zum status quo ante, eine Demobilmachung der Frauen zu. Und auch in den Teilbereichen der Weimarer Reichsverfassung, die Fragen des Geschlechterverhältnisses berührten, war deutlich das Bemühen um eine Einhegung der Emanzipationsgewinne der Kriegsjahre erkennbar. ${ }^{14}$

Das Zusammenwirken dieser drei Großentwicklungen und ihrer Wahrnehmung bildet den Rahmen der Betrachtung der Frauenfrage. Als diskursive Verschränkungen zwischen der als neu wahrgenommenen Situation der Frau in Deutschland und den durch die publizistischen Darstellungen entstehenden Bildern der amerikanischen und sowjetischen Frau, dienten sie als Argumente im Kampf um die Definition des Frauenbildes. Deutsche Diskurse über das neue Bild der Frau lagen somit als Folie vor der Betrachtung amerikanischer und (sowjet-)russischer Frauenbilder. Die so entstandene Hybridität floss als

zu Frauenerwerbsarbeit, gesellschaftlichem Einfluss und der Findung neuer Geschlechterverhältnisse hinweisen, während in Europa die wirtschaftliche Notwendigkeit Frauen gegen ihren Willen dazu zwinge, derlei neue Wege zu gehen.

13 Unter anderem die Erteilung aktiven und passiven Wahlrechts, freier Berufszugang (Armee und Miliz eingeschlossen), Gleichstellung in der Bildung (Koedukation ab Mai 1918), den Arbeitsbestimmungen, sozialen Belangen sowie die Einebnung der in Westeuropa und den USA weiter bestehenden Unterschiede im Familien-, Ehe-, und Erbrecht. Vgl. dazu: Köbberling, Anna: Das Klischee der Sowjetfrau. Stereotyp und Selbstverständnis Moskauer Frauen zwischen Stalinära und Perestroika. Frankfurt a. M., New York 1997, 44. Und: Majer: Frauen - Revolution - Recht, 374.

Allerdings bedeutete die vollkommene Gleichstellung zeitweise auch, dass geschiedene Ehefrauen und Witwen, genau wie ihre männlichen Pendants, keinerlei Ansprüche auf Unterstützung hatten. Außerdem bestanden trotz der politisch verordneten völligen Gleichstellung weiterhin beträchtliche Lohnunterschiede zwischen Frauen und Männern, durchschnittlich 10-40\%. Dazu: Hutton, Marcelline: Russian and Soviet Women. 1897-1939. Dreams, Struggles and Nightmares. Iowa 1986, 471.

14 Vgl. Rouette, Susanne: Sozialpolitik als Geschlechterpolitik. Die Regulierung der Frauenarbeit nach dem Ersten Weltkrieg. Frankfurt a. M., New York, 1993, 16. 
Argument in den innerdeutschen Diskurs zurück. So gilt, übertragen auf den Weimarer Diskurs, was Francoise Thébaud bereits für die Zeit des Ersten Weltkriegs festgestellt hat:

»Gender, das sozial konstituierte Geschlecht, erscheint hier als ein Organisationsprinzip, ja als kriegswichtige Waffe, und die Konstruktion und Dekonstruktion von Geschlecht als eine Kampffront von Staaten, Gruppen und Individuen. . $^{15}$

Je nach Positionierung entlang dieser gesellschaftspolitischen Front lassen sich dabei unterschiedliche Darstellungs- und Normierungsstrategien in den einzelnen publizistischen Organen feststellen. Ungeachtet dessen bestand jedoch Einhelligkeit bezüglich der benutzten Kategorien und zu behandelnden Problemfelder. Über ideologische und institutionelle Grenzen hinweg wurden dieselben Veränderungen, die das Bild der Frau neu prägten, als diskussionswürdig identifiziert. Man war sich in der Debatte über deren Gegenstand also einig - damals wie heute keine Selbstverständlichkeit.

Das gesamte untersuchte Pressespektrum thematisierte Fragen wie die "Vermännlichung" der Frau, die Frau im politischen Leben oder auch die Besetzung männlich definierter Rollenbilder durch Frauen. Erst diese thematische Kongruenz erlaubt überhaupt eine vergleichende Betrachtung. Sie verdeutlicht zudem, dass die Identifizierung und Definition relevanter Einzelaspekte der Frauenfrage nicht primär vom Beobachtungsgegenstand, also dem tatsächlichen Status quo der Frau in den USA und der UdSSR ausging. Einzelaspekte wurden vielmehr an den thematischen Interessen der deutschen Presselandschaft ausgerichtet. Dies lässt sich an Hand der Tatsache darlegen, dass die sozialen, wirtschaftlichen und politischen Entwicklungen in der Frauenfrage in den drei betroffenen Gesellschaften zwar äußerst unterschiedlich abliefen, die Verhandlung dieser Entwicklungen aber innerhalb fast identisch gefasster Themenfelder und Kategorien erfolgte, was die Wege der amerikanischen, sowjetischen und deutschen Frauen analogisierte.

\subsection{Die »Vermännlichung» der Frau}

»Wie in Amerika emanzipieren sich die Frauen, dringen in alle Berufsarten ein, wollen arbeiten, Geld verdienen, unabhängig leben. " $^{16}$

Die konfrontative Kollision weiblicher und männlicher Rollenbilder wirkte entscheidend auf den Entstehungsprozess des Bildes der "modernen Frau« in den USA und der UdSSR ein. Artikel und Visuals, vor allem in den Illustrierten

15 Thébaud: Der Erste Weltkrieg. Triumph der Geschlechtertrennung, 36.

16 Ferrero, Guglielmo: Europas Amerikanisierung. In: DAZ Nr. 174 vom 15.04.1926, $1 \mathrm{f}$. 
und Magazinen, stellten plakativ das Eindringen von Frauen in männliche Lebenswelten dar. Salopp gesagt, waren die männlichsten der männlichen Berufs- und Rollenbilder gerade gut genug, um deren scheinbar unaufhaltsame Eroberung durch die Frau publikumswirksam zu visualisieren und zu beschreiben. Besonders der Bruch eines bis heute kontrovers diskutierten ${ }^{17}$ geschlechtsbezogenen Tabus wurde in diesem Zusammenhang intensiv rezipiert: die Ausbildung von Frauen an der Waffe sowie ihr Einsatz als Soldatinnen. Im Folgenden soll versucht werden, die grundlegenden Analogien und Differenzierungen, die bezüglich dieses wichtigen Teilaspekts vorgenommen wurden, aufzuzeigen.

In der im Jahre 1921 noch unter dem Titel »Sowjetrußland im Bild» erscheinenden späteren Arbeiter Illustrierten Zeitung (AIZ) zeigt sich deutlich, wie abhängig die Perspektive auf das Phänomen bewaffneter Frauen ${ }^{18}$ von der politischen Ausrichtung der Redaktion war. Die visuelle Darstellung der Waffenausbildung von Arbeiterinnen (Abb. 3) wurde mit einer Referenz versehen, die eine andauernde militärische Notsituation Sowjetrusslands postuliert und die daraus folgenden verteidigungspolitischen Maßnahmen erläutert:

"Durch die dauernden militärischen und kriegerischen Ueberfälle der imperialistischen Staaten war Sowjetrußland gezwungen, seine Arbeiter und Bauern in dem Gebrauch von Waffen auszubilden. Dank dieser Ausbildung [...] konnten alle räuberischen Ueberfälle der profitlüsternen Kapitalisten abgeschlagen und die Grenzen der ersten Arbeiter- und Bauernrepublik gesichert werden. ${ }^{19}$

Der im Jahre 1921 im Inneren wie im Äußeren noch unentschiedene Überlebenskampf Sowjetrusslands dient hier als Legitimation für die Soldatenausbildung. Bemerkenswerterweise findet sich im Text jedoch keinerlei Information zur weiblichen Beteiligung. Lediglich in Form der Fotografie und

17 Man betrachte die aktuellen, immer wieder aufflammenden Debatten in den USA und Europa, ob und unter welchen Bedingungen weibliche Soldatinnen in Kampftruppen eingesetzt werden sollten. Dazu repräsentativ: Fischer, Sebastian: Die neuen Front-Frauen. URL: http://www.spiegel.de/politik/ausland/frauen-beim-us-militaer-gleichberechtigungbei-kamptruppen-bis-2016-a-881944.html (am 25.3.2014). Spiegel Online GmbH, Hamburg. Und Ders./Sperber, Sandra: US-Armee: Frauen an die Front. URL: http://www. spiegel.de/politik/ausland/us-armee-obama-will-frauen-in-kampfeinsaetze-schicken-a958709.html (am 01.04.2014). Spiegel Online GmbH, Hamburg.

18 Mit dem Themenkomplex bewaffneter Frauen und deren gesellschaftlicher Rezeption befasste sich eine ganze Ausgabe der Zeitschrift WerkstattGeschichte unter dem Titel ॥Waffenschwestern«. Bettina Blum geht explizit auf die 1918/19 gleichzeitig fallenden Klassenund Geschlechterschranken ein und beleuchtet am Beispiel weiblicher Polizistinnen das Phänomen der bewaffneten Frau. Ulrike Weckel und Dagmar Ellerbrock verweisen auf die gesteigerte Akzeptanz bewaffneter Frauen in existenziellen Bedrohungslagen, wozu Bürgerkrieg und die Systemwirren nach 1917 in Russland durchaus zählen. Vgl. WerkstattGeschichte. Waffenschwestern. Nr. 64, November 2014.

19 Anon.: Freiheit und Proletarische Wehr. In: SIB, 1921, Nr. 5, 35 (Jahresausgabe). 


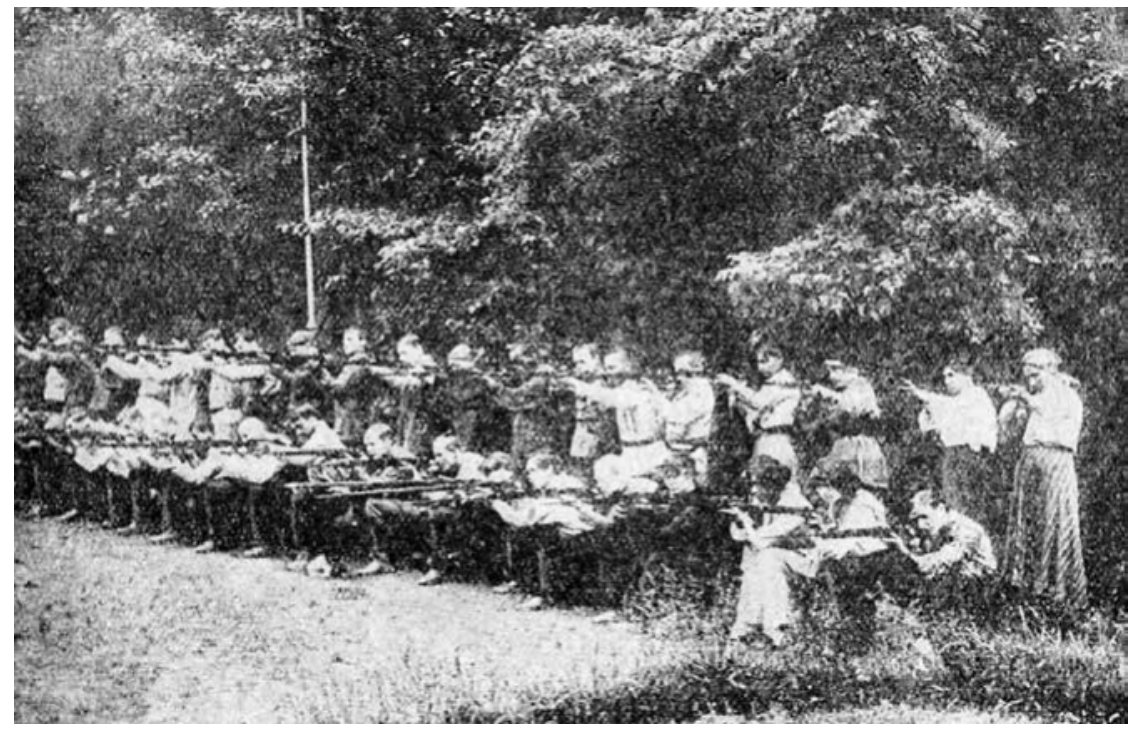

Abb. 3: Anon.: Freiheit und Proletarische Wehr. In: SIB, 1921, Nr. 5, 35. Frauen wurden visuell als zentrale Stütze der Verteidigung des Bolschewismus dargestellt.

der dazugehörigen Bildunterschrift (»Arbeiter und Arbeiterinnen üben sich im Gebrauch der Waffen. ${ }^{20}$ wird dieser Umstand deutlich. Dieses erste und in chronologischer Hinsicht frühe Beispiel gibt Anlass zu der Annahme, dass sich visuelle und textuelle Ebene qualitativ voneinander unterscheiden: Die textuelle Benennung (Sagbarkeit) bewegt sich bei diesem Beispiel in ihrer Ausdrucksfreiheit auf einer niedrigeren Ebene als die visuelle Darstellung (Zeigbarkeit). Im Visual werden Frauen als im Kollektiv eingereiht gezeigt; eine Rollenunterscheidung wird demonstrativ unterlassen. Wie der männliche Teil der russischen Bevölkerung sind Frauen gleichermaßen Teil der - mit den Worten der Zeit gesprochen - entindividualisierten Masse, auf die sich der ganze sowjetische Gesellschaftsentwurf ideologisch stützt. Sie sind nicht mehr auf das individuelle, private Wirken in der sozialen Kleinsteinheit Familie beschränkt, sondern Teil des großen politischen und sozialen Neubeginns in Russland - und eben seiner Verteidigung.

Der Einsatz dieses Visuals und die Bildkomposition bieten Anhaltspunkte dazu, welche Wirkung beim Betrachter erzielt werden soll. Bezieht man Überlegungen über Qualität und Intentionalität medialer Inhalte ${ }^{21}$ auf dieses konkrete Beispiel, ist hier eine Neuorganisation von Werten beabsichtigt. Diese

20 Ebd.

21 Zusammengefasst: Hubig, Christoph: Medialität / Medien. In: Sandkühler, Hans Jörg: Enzyklopädie Philosophie, Bd. 2 (I-P). Hamburg 2010, 1516-1522. 
fußt auf der Einheit der textovisuellen Darstellung mit ihrem beabsichtigten Ziel einerseits und der erwarteten Perzeption andererseits. ${ }^{22}$ Die Produzenten waren sich des Tabubruchs, der sich in der visuellen Darstellung von Frauen in Waffen manifestierte, nicht nur bewusst, sondern nutzten die dadurch generierte Aufmerksamkeit ${ }^{23}$ zur Verknüpfung der Textualisierung des propagandistischen Topos vom politischen Überlebenskampf mit der Visualisierung der unterschiedslosen Mobilisierung - gerade auch der Frauen. Dadurch ergibt sich ein Legitimationszusammenhang von der Ideologie über das darauf basierende und zu verteidigende politische System bis hin zur Mobilisierung, welche letztlich, ideologisch wie auch praktisch begründet, alle Glieder der Gesellschaft einschließen müsse.

Die prominente Darstellung von Frauen im Vordergrund der Fotografie verdeutlicht deren zentrale Bedeutung für die Verteidigungslinie, die das russische Proletariat und Bauerntum zum Schutze der neuen politischen Ordnung zu bilden scheint. Der propagandistische Zweck der Aufnahme ist an mehreren Details zu erkennen: Die im 18. und 19. Jahrhundert zum taktischen Standardrepertoire zählende Formation "in Linie«, wie sie auf dem Foto zu sehen ist, war bereits seit langem veraltet. Sie verleiht allerdings als fest geschlossene, undurchdringliche Reihe der beabsichtigten Botschaft bestmöglichen symbolischen Ausdruck.

Über den gesamten Untersuchungszeitraum und in allen untersuchten $\mathrm{Pu}$ blikationen finden sich vergleichbare Referenzen. Gemäß ihrer Einstellung gegenüber der Ideologie der Bolschewiki zeigen diese unterschiedliche Bewertungen des Dargestellten auf, ähneln sich aber in der fotografischen wie

22 Diese Verknüpfung des Mittels, hier die textovisuelle Darstellung bewaffneter Frauen, mit einem Ziel, hier die Betonung der Wichtigkeit des politischen Systems Sowjetrusslands und die Entschlossenheit zu seiner Verteidigung, erfüllt die klassische Definition eines Mediums als sogenanntes »inneres Mittel« nach John Dewey (1859-1952): »Medium bezeichnet vorrangig ein Vermittelndes [...]. Doch nicht alle Mittel sind auch Medien. Es gibt zwei Arten von Mitteln. Die eine ist dem, was ausgeführt wird, äußerlich; die andere wird in die erzeugten Ergebnisse aufgenommen und bleibt ihnen immanent [...]. Doch mit dem Moment, das wir Medien nennen, beziehen wir uns auf Mittel, die mit dem Ziel verbunden sind.« Dewey, John: Kunst als Erfahrung. Frankfurt a.M. 1980, 229.

23 Das Moment der Aufmerksamkeit ist im speziellen Zusammenhang des Mediums Illustrierte Zeitung zu bewerten. Die Funktion von bildlichen Darstellungen in solchen Publikationsformen hat nicht nur die Informationsvermittlung zur Aufgabe, sondern zusätzlich auch die des Gewinnens von Aufmerksamkeit. Diese erweiterten Anforderungen liegen in dem speziellen, mediumbedingten Leseverhalten begründet: »Readers of magazines [...] may flick through the magazine, stopping every now and again to look at a picture or read a headline, and perhaps returning later to some of the articles which drew their attention [...]. Yet in many pages composition does set up particular hierarchies of the movement of the hypothetical reader with and across their different elements." Kress/van Leeuwen: Reading Images, 204. 
textlichen Zusammensetzung stark. ${ }^{24}$ Anstatt nun aber eine Reihung von immer gleichen, lediglich illustrierenden Beispielen vorzunehmen, ist eine vergleichende Betrachtung sinnführender. Der Abgleich mit Beispielen innerhalb der AIZ und, darauffolgend, aus weiteren Publikationen wird Analogien und Differenzierungen verdeutlichen.

Die Relevanz publizistisch-ideologischer Selbstverortung wird im Falle der AIZ besonders augenfällig, wenn man das Thema »Frau in Waffen" anhand vergleichbarer Beiträge zu den USA betrachtet. Diesbezügliche Visuals, die neben ihrer Bildunterschrift zunächst nicht weiter kontextualisiert sind, sprechen eine eindeutige Sprache (Abb. 4).

In diesem prägnanten Beispiel aus dem Jahr 1927 werden amerikanische Frauen, genauer Studentinnen, ebenfalls bewaffnet und in quasimilitärischer Formation gezeigt. In der Flucht der Fotografie sind das politische System und die mahnende Geschichte der USA durch das Lincoln Memorial visuell integriert und so mit den Studentinnen im Vordergrund identifiziert. Nicht nur die Möglichkeit eines klassenkämpferischen Bürgerkriegs, in dem die militärische Macht des Präsidenten wie auch die Eliten stramm hinter den Interessen des Kapitals stünden, wird hier insinuiert. Die Explikation des Bürgerkriegs in der Bildunterschrift ergibt überdies Sinn, wenn man die AIZ als Anwalt der UdSSR im deutschen öffentlichen Diskurs versteht. Gemäß dieser Rolle suchte sie neben anderen "westlichen" Nationen auch die Vereinigten Staaten als ideologisches Konkurrenzmodell zu diskreditieren.

Die hier verfolgte Strategie des Absprechens und Zuschreibens von Legitimität wird im Vergleich deutlich. Im vorhergehenden Beispiel wurde der Gegner im Überlebenskampf Sowjetrusslands externalisiert, also ausschließlich mit äußeren kapitalistischen Kräften identifiziert. Im Falle der USA wird hingegen ein gesamtgesellschaftlicher Konflikt ausgemacht und als vermeint-

24 Zusammenfassend wurden in der AIZ Frauen mit Waffe immer dann als legitim dargestellt, wenn sie diese in den Dienst der richtigen, sprich kommunistischen Ideologie stellten. Der nationalsozialistische ILB lehnte bewaffnete Frauen generell ab, unter der roten Fahne der Bolschewisten naturgemäß umso entschiedener. Gemäßigte Illustrierte wandten sich ebenfalls generell gegen Frauen in Waffen. Unter anderem: Anon.: Soldaten der Roten Armee (darunter auch weibliche) auf einem Platz in Moskau. In: Zeitbilder. Beilage zur Vossischen Zeitung, 1921, Nr. 41, 2. Und: Anon.: Im Zeichen der Abrüstung! In: ILB, 1926, Nr. 5, 2. Und: Anon.: Frauen im Krieg. In: AIZ, 1927, Nr. 30, 7. Und: Binz: In's Jahr der Abrüstung 1929. In: ILB, 1929, Nr. 1, 2-3. Und: Anon.: Rußland-Konflikt mit China. In: BIZ, 1929, Nr. 33, 1. Und: Feiler, Arthur: Die Diktatur des Bolschewismus. Aus dem Tagebuch einer russischen Reise. Der Druck der Diktatur und seine Folgen. In: FZT Nr. 723 vom 28.09.1929, 1 f. Und: Anon.: Aus der Sowjet-Republik. In: ILB, 1929, Nr. 49, 660 (Jahresausgabe). Und: Anon.: Verteidigt die Sowjetunion. In: AIZ, 1930, Nr. 31, 610 (Jahresausgabe). Und: Anon.: Mädchengarde in Sowjet-Rußland. In: RDM, 1931, Nr. 10, 1062 (Jahresausgabe). Und: Herrlich: Russische Bilderbogen. Die Armee. MIP, 1931, Nr. 51, 1606 (Jahresausgabe). 


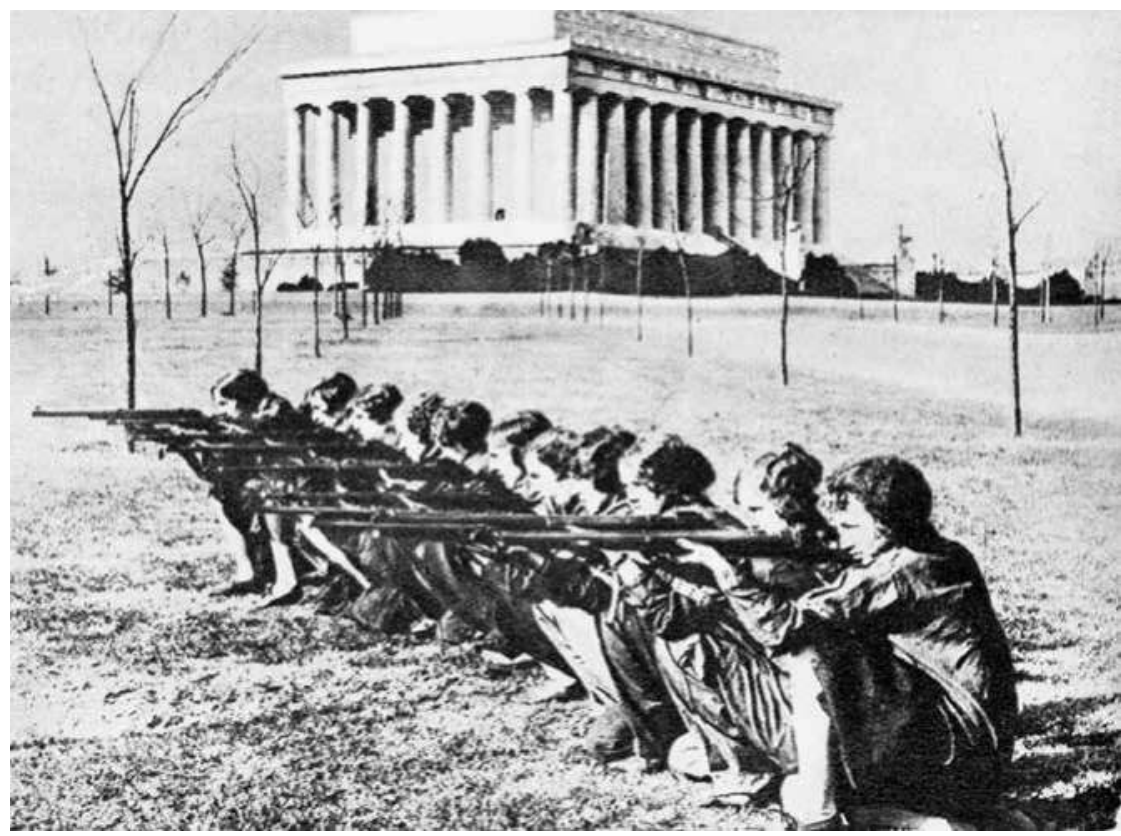

Abb. 4: Anon.: Aus Aller Welt. An der George Washington-Universität üben die Studentinnen zum Bürgerkrieg. In: AIZ, 1927, Nr.18, 16. Die angebliche Einheit militärischer Macht, Kapitalismus und »reaktionärer Aggression« wird hier visuell auf den Punkt gebracht.

lich heraufziehender Bürgerkrieg internalisiert. Dadurch wird die Ausbildung amerikanischer Frauen an der Waffe auf mehreren Ebenen delegitimiert, sowohl moralisch als auch völkerrechtlich.

Entgegen dem publizistischen Mainstream ging es der AIZ nicht um eine grundsätzliche Kritik am Einsatz bewaffneter Frauen. Entscheidend war vielmehr die Frage nach der Art des Konfliktes beziehungsweise dem übergeordneten Ziel des Kampfes. Darstellungen bewaffneter Frauen reihen sich in der AIZ in eine Kontinuitätslinie ein, die die propagandistische Beschwörung einer militärischen Bedrohung der UdSSR durch kapitalistische, zum Krieg gegen den Kommunismus rüstende Mächte zu einem weitertragenden Bedrohungsnarrativ aufbaute. ${ }^{25}$ Damit ging auch das Werben um Verständnis für die massive Aufrüstung der Sowjets selbst einher.

25 Mit dieser Rüstungskritik steht die AIZ allerdings nicht alleine. Alle Tageszeitungen und Illustrierten befassten sich eingehend mit der massiven weltweiten Rüstungstätigkeit, insbesondere der der USA. Aus ihrer Sicht verletzte diese alle Selbstverpflichtungen der Siegermächte zur Abrüstung und diskreditierte darüber hinaus die im Versailler Vertrag niedergelegten Rüstungsbeschränkungen für Deutschland. 
Die hier herausgestellte Differenzierung zeigt, dass die generell kontrovers diskutierte "Vermännlichung der Frau« ausnehmend gut zur Einflechtung ideologischer und auch realpolitischer Propaganda geeignet war. Immer dann, wenn der selbst empfundene politische Auftrag das Primat vor Beobachtung und Beschreibung hatte, zeigt sich der instrumentelle Charakter dieses Themas besonders deutlich. Politisch gemäßigte Illustrierte argumentierten generell gegen bewaffnete Frauen und deren befürchtete Vermännlichung, verzichteten aber (weitgehend) auf ideologische Einordnungen. ${ }^{26}$ So steht hier denn auch weniger die politisch motivierte Kämpferin im Fokus der Betrachtung. Die bewaffnete Frau wird als internationales, jedoch von politischen Systemen und Ideologien unabhängiges Zeitphänomen gedeutet.

Dies wird an einer doppelseitigen Bildreportage der Münchner Illustrierten Presse (MIP) deutlich, die sich in ihrer Ausrichtung auf ein bürgerliches Publikum zwar nicht als überparteilich, aber doch als unideologisch verstand (Abb. 5). Das bewusste Nebeneinanderstellen visueller »Belege« malt das Szenario einer weltweit um sich greifenden Militarisierung und Amazonisierung $^{27}$ der Frau und übt generelle Zeitkritik.

In der Anordnung der Fotografien ist folglich keine Unterteilung nach politisch-ideologischen Aspekten zu erkennen. Englische Faschistinnen und Gesellschaftsdamen (rechts oben) stehen ohne erkennbaren Zusammenhang neben "zionistischen Schiffsoffizierinnen" (Mitte) und paradierenden sowjetischen Frauenbataillonen samt Gasmaske (rechts unten). Auf der linken Hälfte der Doppelseite sind italienische Faschistinnen (oben), eine chinesische Offizierin (rechts), sowie die französische Forstmeisterin Herzogin d'Uzés dargestellt (links) - die beiden letztgenannten in militärischer Grundstellung. Dazwischen hält die Vorsitzende des Schützenclubs der Universität von Kansas ein Gewehr im Anschlag.

Erkennbar wird das Bemühen der MIP-Redaktion, möglichst viele Beispiele für den behaupteten globalen Trend einer Militarisierung der Frau (in willkürlicher Auswahl) zu einem visuell eindrücklichen Tableau zusammenzustellen. Darüber hinaus scheint hier jedoch keine (partei-) politische Agenda verfolgt zu werden. Der Text des Beitrags gibt allerdings Hinweise auf eine, dem bür-

26 Von kleinen Textteilen, über Fotos mit und ohne Bildunterschrift, bis hin zu mehrseitigen Artikeln, taucht das Schlagwort der Vermännlichung der Frau, vor allem auch im Zusammenhang mit bewaffneten Frauen häufig auf. Unter anderem: Anon.: Nun aber genug! Gegen die Vermännlichung der Frau. In: BIZ, 1925, Nr. 13, 4. Und: Anon.: Mitglieder eines New-Yorker Schwimmclubs beim Bogenschießen. Preisfrage: Wieviel Männer sind hier dabei? Ebd., 933. Und: Anon.: Die Frau als Soldat. In: RDM, 1928/29, Nr. 10, $1092 \mathrm{f}$. (Jahresausgabe). Und: Anon.: Die andere Seite. Die Vermännlichung der Amerikanerin macht große Fortschritte. In: MIP, 1930, $740 \mathrm{f}$. (Jahresausgabe).

27 "Amazonisierung" will hier die gleichzeitige Politisierung, Militarisierung und Liberalisierung (von männlicher Bevormundung) auf den Begriff bringen, wie sie das hier beschriebene und kritisierte Frauenbild zeichnet. 


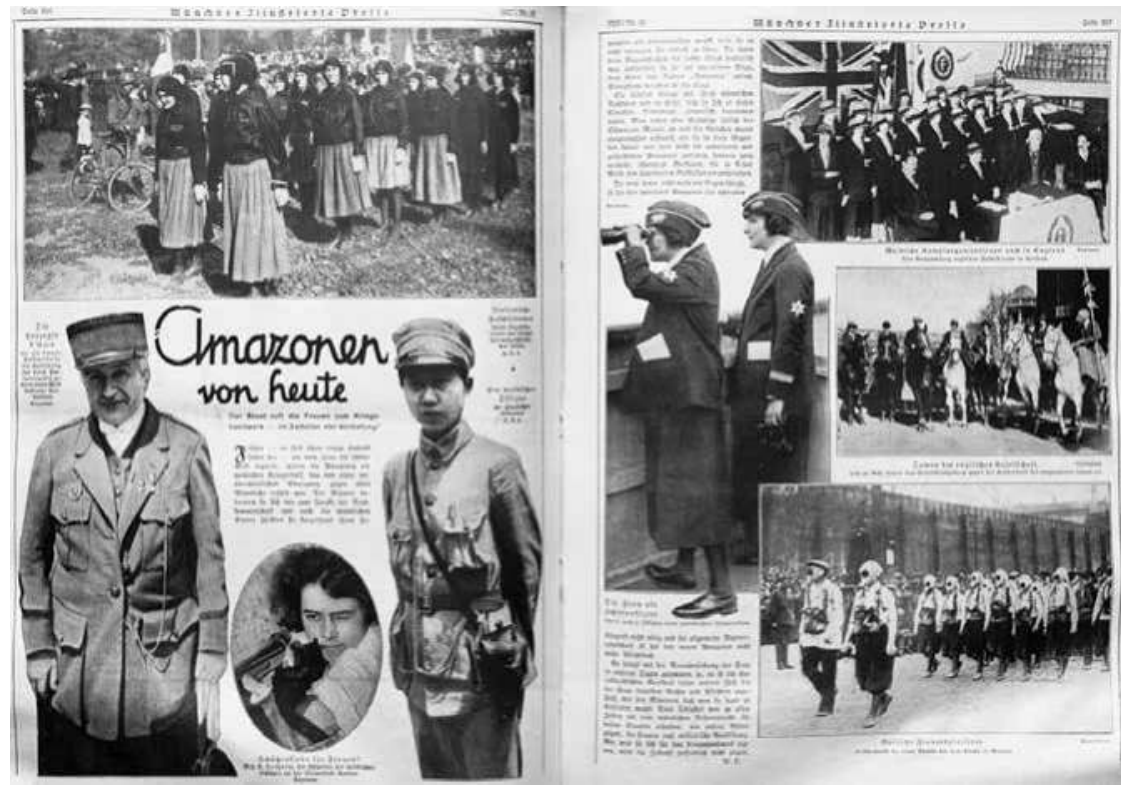

Abb. 5: Anon. (W. F.): Amazonen von heute. In: MIP, 1927, Nr.33, 27. Durch ein fotografisches Panorama wird die weltweit voranschreitende Militarisierung der Frau suggeriert.

gerlichen Publikum der MIP naheliegende, zeitkritische Fokussierung. Die generelle Ablehnung weiblicher Soldatinnen wird mit explizitem Verweis auf die hergebrachte Zuweisung der Aufgabe des Kampfes an den Mann vertreten:

»Es hängt mit der Vermännlichung der Frau in unseren Tagen zusammen, ja, es ist ein charakteristisches Merkmal dieser unserer Zeit, die der Frau dieselben Rechte und Pflichten zugesteht, wie den Männern, daß man sie sogar zu Soldaten macht. Diese Aufgabe war zu allen Zeiten ein rein männliches Reservatrecht. In vielen Staaten erhalten, wie unsere Bilder zeigen, die Frauen jetzt militärische Ausbildung. Wie weit sie sich für das Kriegshandwerk eignen, wird die Zukunft hoffentlich nicht zeigen. ${ }^{28}$

In diesem kurzen Abschnitt wird die kontroverseste Form der Vermännlichung, die Militarisierung der Frau als abzulehnendes Zeitphänomen identifiziert. Interessant erscheint hierbei, dass der Beitrag eine Fremdsteuerung der Frauen suggeriert: Die präsentierte visuelle Phalanx moderner Amazonen wird nicht etwa mit einem selbstgesteuerten Fortschritt zu gleichberechtigter, in diesem Falle sogar gleichverpflichteter staatsbürgerlicher Teilhabe konnotiert, sondern weist Frauen einmal mehr die Rolle eines von Männern kont- 
rollierten und auch weiterhin zu kontrollierenden Objekts zu. Die bewaffnete Frau als Soldatin stellt die heftigste Kollision traditioneller Frauenbilder mit männlich geprägten dar. Es sei an dieser Stelle angemerkt, dass das Konstrukt der "Amazone« dabei, auch in der langen historischen Perspektive, oftmals mit einer Sexualisierung des Frauen- und Kriegerinnenkörpers einherging. ${ }^{29}$ Weitaus weniger aufgeregt wurde das Aufkommen weiblicher Polizistinnen thematisiert. ${ }^{30}$ Hier stand im Gegensatz zur stark kritisierten Militarisierung der Frauen die Darstellung aus Interesse am Ungewöhnlichen im Vordergrund. Dennoch lassen sich auch hier, wiederum im Falle der AIZ, Tendenzen $\mathrm{zu}$ einer ideologischen Einordnung ausmachen. Ein Auszug aus dem Begleittext zu einer Bildreportage über Polizistinnen in Westeuropa und den USA legt als Grund für deren Aufstellung Interessen des Großkapitals respektive des Faschismus nahe:

»Die bürgerlich-kapitalistischen Länder entwickeln sich immer mehr zu Polizeistaaten. Da sich die Klassengegensätze zuspitzen, ist man bemüht den Macht- und Abwehrapparat der herrschenden Oberschicht auszubauen und zu erweitern. [...] Obwohl man erst in wenigen deutschen Städten wie in Dresden, usw. Straßenpolizistinnen kennt und gerne davon erzählt, dass die weibliche Polizei vor allem sozialen Zwecken dient, so zeigt doch die Entwicklung der ausländischen Frauenpolizei, wohin man mit dieser Erweiterung des Polizeiapparats eigentlich will. Die in allen bürgerlichen Ländern fieberhaft organisierten faschistischen Frauenorganisationen sind Reservetruppen der Reaktion, die in der Auseinandersetzung zwischen Kapital und Arbeit eine Rolle spielen [...]. Die Arbeiterschaft kann in der Eingliederung von Frauen in den Polizeidienst keinen Fortschritt sehen, sondern nur eine neue Methode um den bürgerlichen Staat gegen den Ansturm der proletarischen Klasse zu verteidigen. ${ }^{31}$

Ansonsten findet sich kein flächendeckendes Bewusstsein dafür, dass es sich beim weltweit (einschließlich der UdSSR) quantitativ zunehmenden weiblichen Polizeipersonal um ein Problem handeln könne. Vielmehr tendierte die Wahrnehmung von Polizistinnen zur sachlichen Feststellung einer zwar neuen, aber neutral bewerteten Entwicklung. ${ }^{32}$ Dennoch sind Darstellungen

29 Vgl. dazu Hopfner, Carla: Die Actionheldin und ihre antiken Vorbilder, in: Keller, Johannes / Kragl, Florian (Hg.): Heldinnen. 10. Pöchlarner Heldenliedgespräch 2008, Wien 2010, 33-54.

30 Vgl. unter anderem: Anon.: Frauen als Polizistinnen in Russland. In: DKM, 1929, Nr. 7, 10.

31 Anon.: Weibliche Polizei. In: AIZ, 1928, Nr. 9, 7.

32 Diese neutrale Haltung wird auch dadurch deutlich, dass weibliches Polizeipersonal auch des Öfteren zum Gegenstand der in der BIZ sehr beliebten alljährlichen Aprilscherze avancierte. Die Ungezwungenheit, mit der z.B. die angeblich kürzlich erfolgte Aufstellung einer Einheit Badeanzug tragender Strandpolizistinnen in Miami vermeldet wurde, vermittelt einen Eindruck von der eher schwach ausgeprägten gesellschaftlichen Sprengkraft des Themas. Anon.: Die neue amerikanische Strandpolizei: Ordnungspolizistin im Seebad Miami (Florida). In: BIZ, 1925, Nr. 14, Titel. 
von Polizistinnen angesichts der visuellen Egalisierung von Geschlechtsunterschieden im Kontext staatlicher Ordnungsorgane keinesfalls zu vernachlässigen. Sie bilden eine wichtige Facette des sich neuformierenden Frauenbildes der Zeit. Die Aufweichung der konnotativen Verknüpfung von männlichem Rollenbild und dem Exekutivorgan Polizei erschafft Freiräume für die sich verändernde Wahrnehmung der Frau und ihrer gesellschaftlichen Sphäre.

Im Gegensatz zu weiblichem Polizeipersonal genoss die Pilotin als Erscheinung der 1920er Jahre größere Aufmerksamkeit, insbesondere in den Illustrierten. Die ersten Bezugnahmen auf Frauen in der Fliegerei bezogen sich dabei zunächst auf Beispiele aus Deutschland. ${ }^{33}$ Deren Darstellung beschränkte sich beinahe ausschließlich auf die visuelle Ebene. Der Eindruck, dass die gewissermaßen dekorative, auf optische Reize reduzierte oder auf den Sensationseffekt abzielende Funktion der Darstellung weiblicher Pilotinnen im Vordergrund steht, wird dadurch verstärkt, dass diese vor allem auf den Titelseiten der Illustrierten zu finden sind..$^{34}$ An dieser Position fand sich in der Regel kein Inhalt, der später im Innenteil vertieft wurde oder die thematische Ausrichtung der jeweiligen Ausgabe bestimmte. Um die Bedeutung der visuellen Darstellung fliegerisch tätiger Frauen in einem größeren Zusammenhang zu bewerten, müssen einige Aspekte im Vergleich zwischen einzelnen Publikationen verdeutlicht werden.

Pilotinnen wurden meist selbstbewusst in voller Fliegermontur vor ihren Maschinen in Szene gesetzt. In den Redaktionen gemäßigt-liberaler Illustrierter überwog die Anerkennung dieses neuen Typs Frau. Der Blick in die Ferne, bekannt von Feldherrenportraits, wurde ebenso zur Heroisierung fliegender Frauen eingesetzt ${ }^{35}$ wie Schnappschüsse waghalsiger Flugeinlagen, die zur alten Frauenrolle so gar nicht passten. ${ }^{36}$ Bildunterschriften kontrastierten das geflügelte Wort vom »schwachen Geschlecht» mit Darstellungen amerikanischer Pilotinnen (Abb. 6). ${ }^{37}$

Flugschülerinnen werden in diesem Visual aus dem Jahr $1931 \mathrm{im}$ Vordergrund mit in die Hüften gestützten Händen dargestellt. Ihre Ausbilderin nimmt eine Stellung ein, die stark an die eines militärischen Vorgesetzten erinnert. Neben solchen Details, die das im Text erwähnte Attribut der Schwäche mit denen der Entschlossenheit, Kompetenz und Lernbereitschaft kon-

33 Unter anderem: Anon.: Die jüngste Fliegerin, die 13-jährige Flugschülerin Karola Drehmann, auf dem Segelflugzeug, mit dem ihr einige Flüge gelangen. In: BIZ, 1923, Nr. 34, Titel.

34 Anon.: Eine tollkühne Frau. In: BIZ, 1927, Nr. 18, Titel. Und: Anon.: Ukrainische Flugschülerin, die in Charkow zur roten Aviatikerin ausgebildet wird. In: AIZ, 1930, Nr. 7, Titel.

35 Anon.: Ein Mädchen von 1929. In: BIZ, 1929, Nr. 49, Titel.

36 Anon.: Eine Frau springt aus 1000 Meter in die Tiefe. In: MIP, 1932, Nr. 25, Titel.

37 Anon.: Das schwache Geschlecht 1931. In: RDM, 1931, Nr. 11, 1211 (Jahresausgabe). 


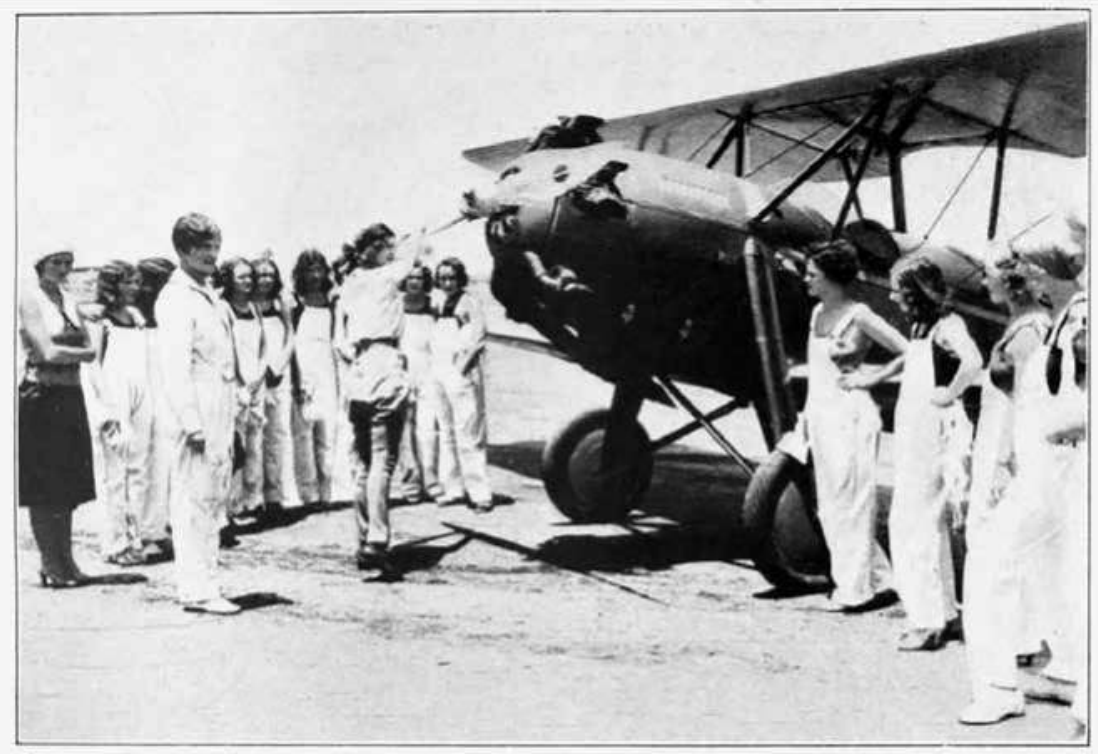

Das schwache Geschlecht 1951

Weiblidı Mifglieder einer Flieger*chule in Long Beach bereiten sich für ein Flugderby Long Bead-Chikago vor

Abb. 6: Anon.: Das schwache Geschlecht 1931. In: RDM, 1931, Nr. 11, 1211. Auf großes Interesse stießen visuelle Darstellungen weiblicher Pilotinnen.

trastieren, sorgen auch die Farbkonstraste der Schwarzweißdarstellung für visuelle Effekte. Die in strahlendem Weiß gekleideten Frauen erzeugen vor der dunklen Maschine eine visuelle Prominenz, die mit dem Bild untertäniger, sich schüchtern zurückhaltender Frauen nicht in Einklang zu bringen ist. Die weitere konnotativ-symbolische Belegung der Farbe Weiß mit Begriffen wie dem Neuen, dem Reinen und Ähnlichem mehr trägt zum Eindruck eines sich im Aufbruch begreifenden Geschlechts bei.

Generell erscheint die demonstrative Verknüpfung des weiblichen Geschlechts mit der Fliegerei, also dem Inbegriff des Modernen und der Freiheit in der Zwischenkriegszeit, bewusst herausgestellt. Der Sinnzusammenhang zwischen der Fliegerei als Metapher des Aufbruchs, des Wagemuts und technologischer Modernität mit dem weiblichen Geschlecht trägt signifikant zur Ausformung des Bildes der »neuen Frau« bei.

Die weibliche Pilotin, ein ansonsten begierig aufgegriffenes Fotomotiv, fehlt im nationalsozialistischen ILB vollkommen, keine Abbildung und kein Bericht haben sie zum Gegenstand. Man lehnte hier sowohl die Anerkennung der mit der außergewöhnlichen Berufswahl für die Frauen einhergehenden 
Widrigkeiten als auch die versinnbildlichte Einheit von Modernität und der neuen Rolle der Frau ab. Durch die Negativbewertung vergleichbarer neuer Frauenrollen bezog man deutlich Position. Die Dynamik, mit der Frauen in (Berufs-)Kontexte vorstießen, die bisher maßgeblich mit Männlichkeit konnotiert waren, sollte hierdurch abgebremst werden.

\subsection{Geschlechterverhältnisse und Politik}

Die aktive politische Tätigkeit stellt einen Bereich dar, der im deutschen Kontext in besonderem Maße als Reservat männlichen Gestaltungswillens erschien. Sieht man einmal von politischen Fragen ab, die unmittelbar Frauen und deren Rechte zum Gegenstand hatten, so befand sich diese gesellschaftliche Konvention weitgehend im Einklang mit der geringen öffentlichen Präsenz weiblichen Polit-Personals. ${ }^{38}$ Diese Kongruenz geriet jedoch durch die verstärkte Darstellung und Wahrnehmung politisch aktiver Frauen in der UdSSR und den USA aus dem Takt.

Zeitgenössische Bezugnahmen auf das politische Leben der USA verdeutlichen, wie stark sich dieses aus der Sicht mancher Beobachter an den Empfindungen der Frauen im Lande ausrichtete. Der Begriff der Empfindung ist hier wörtlich zu verstehen: "Sentimentality ${ }^{39}{ }^{39}$ meinte Erich von Salzmann 1921, könne dem darniederliegenden Deutschen Reich helfen, sich in der amerikanischen Öffentlichkeit Gehör zu verschaffen. Schließlich habe Belgien und mit ihm die Entente es vermocht, die US-Öffentlichkeit auf seine Seite zu ziehen, indem es ganz auf die Gefühlsbetontheit der Frauen abgestellt habe:

»Wenn man die politische Nutzanwendung sieht, so heißt das für unsere zukünftigen Beziehungen zu Amerika, wir haben der amerikanischen Frau das größte Interesse entgegenzubringen, sie zu studieren, um auf diesem Wege, der mir, ganz ernstlich gesprochen, als der beste erscheint, auf die fraglos vorhandene amerikanische Sentimentalität Einwirkungen zu bekommen. Die Frau hatte immer und wird immer haben Mitleid mit den Unterdrückten [...]. Die Sentimentalität, wohl das stärkste amerikanische politische Modeobjekt, hat sich nämlich inzwischen darauf besonnen, daß es augenblicklich ein Land gibt, dessen Einwohner noch viel unterdrückter sind, als die belgischen und dessen Kinder noch viel mehr zu leiden haben: Deutschland. ${ }^{40}$

Rosa Luxemburg zog, als die personifizierte Ausnahme von dieser Regel, ja nicht zuletzt wegen ihres Geschlechts zu gleichen Teilen die bedingungslose Bewunderung von Kommunisten und Sozialisten und den unverhohlenen Hass von Rechtskonservativen und Nationalisten auf sich und forderte schon durch die von ihr wahrgenommene öffentliche Rolle traditionelle Konventionen heraus.

39 Salzmann, Erich von: Sentimentality. In: VZT Nr. 82 vom 18.02.1921, 1 f.

40 Ebd., 1. 
Widerspruch greift Erich von Salzmann lapidar vor: »Die Frau herrscht! « ${ }^{41}$ Der Autor schreibt mit der frischen Verbitterung des Krieges. Dennoch lässt bereits diese frühe Einlassung erkennen, wie hoch der seit 1920 offiziell ausgeübte politische Einfluss amerikanischer Frauen von deutschen Beobachtern eingeschätzt wurde. ${ }^{42}$ Es wurde durchaus zur Kenntnis genommen, wenn auch unterschiedlich interpretiert, dass es seit Mitte des 19. Jahrhunderts eine Kontinuität des politischen Engagements von Frauen gegeben hatte. Dadurch sei die Rolle der Frau in der US-Gesellschaft graduell politisiert, das politische System der USA in der Folge wiederum feminisiert worden. ${ }^{43}$ Die Charakterisierung der politisch emanzipierten Frau als Ergebnis eines evolutionären, in die politischen Grundlegungen der USA eingeschriebenen Prozesses ${ }^{44}$ gewinnt in weiteren Ausführungen zunehmend an Schärfe. Dieses Emanzipationsnarrativ stellt sich gänzlich anders dar als im Falle der sowjetischen Frau, die erst durch den totalen Umsturz zu ihrem politischen Recht gelangt war.

Die Fundamente des Diskurses über die Frau im politischen Leben der USA werden im Vergleich zweier Amerikakorrespondenten, Gustav Frenssen ${ }^{45}$ und Alice Salomon ${ }^{46}$, deutlich. Gemäß ihrer politischen Orientierung und

41 Ebd.

42 Mit großer Aufmerksamkeit wurde über die fortgesetzte Lobbyarbeit und politische Kontrollfunktion amerikanischer Frauenbewegungen berichtet. Dabei steht die Errichtung des Hauptquartiers der National Women's Party als symbolische Besetzung des politischen Raumes Washington D.C. mit diesem sogenannten »Wacht-Turm» für Frauenrechte im Mittelpunkt des Interesses. Vgl. Anon.: Die Frauenbewegung in den Vereinigten Staaten. In: FZT Nr. 895 vom 02.12.1921, 1. Und: Anon.: Aus der amerikanischen Frauenbewegung. In: FZT Nr. 416 vom 07.06.1922, 1.

43 Zu den Wechselwirkungen zwischen amerikanischem Suffrage Movement und dem politischen System: Baker, Paula: The Domestication of Politics: Women and American Political Society, 1780-1920. In: American Historical Review, 89, 1984, 621-647.

$44 \mathrm{Zu}$ den Stadien und jeweiligen Strategien der informellen und sodann formellen weiblichen Politikbeteiligung in den USA: Klaiber, Isabell: Women's Roles in American Society: Difference, Separateness, and Equality. In: Engler, Bernd/Scheiding, Oliver (Hg.): A Companion to American Cultural History. From the Colonial Period to the End of the $19^{\text {th }}$ Century. Trier 2009, 303-330.

45 Gustav Frenssen schrieb als Reiseberichterstatter für die Frankfurter Zeitung (FZT), trat aber hauptsächlich als Romanautor in Erscheinung. Bezüglich seines Frauenbildes sind in seinem Werk eindeutige Ansichten auszumachen. So weist er ihnen zum einen die tradierten Formen ländlichen Frauenlebens (ohne Beruf und Bildung) und zum anderen als vornehmste Aufgabe die Reproduktion zu. Diese Ansicht baute er später durch rassebiologische Überlegungen zu einer Zieldefinition zur »Züchtung des Herrenvolkes« aus. Überdies legte er das nach diesen Maßgaben definierte Glück der Frau ausschließlich in die Hände des Mannes. Vgl. dazu: Küchmeister, Kornelia: »...nur ein Weib, aber Herrin ihrer Kraft«. Das Frauenbild und die Funktion von Sexualität in Gustav Frenssens Werk. In: Dohnke, Kai/Stein, Dietrich (Hg.): Gustav Frenssen in seiner Zeit. Heide 1997, $400-436$.

46 Alice Salomon war sowohl für die Vossische Zeitung (VZT) als auch das Berliner Tageblatt (BTB) als Amerikakorrespondentin tätig. Davor galt ihr Interesse der deutschen und 
Herkunft unterschieden sich ihre Ansichten zum Thema deutlich. Beide teilten die Ansicht, Amerikanerinnen hätten prinzipiell eine stärkere politische Stellung als Europäerinnen und sogar als ihre männlichen Landsleute inne. Beide führten dies, ungeachtet der politischen Dimension, auf ein verbreitetes Erklärungsmuster zurück: die "Seltenheit von Frauen im männerbestimmten Pionier- und Kolonialland Amerika ${ }^{47}$ So schreibt Salomon:

»Wodurch ist die bevorzugte Stellung zu erklären, die das weibliche Geschlecht in Amerika einnimmt? Zunächst einmal ganz einfach durch das Gesetz der Zahl, durch das Gesetz, das alle Werttheorien löst. Solange es eine amerikanische Kultur gibt, sind die Frauen stets in der Minderzahl gewesen und sie sind es auch heute in vielen Teilen des Landes in ganz erheblichem Maße. Ein solches Mißverhältnis in der Zahl von Frau und Mann wirkt aber stets zugunsten des Geschlechtes, das in der Minderzahl ist, das Seltenheitswerte repräsentiert. Es bringt eine eingeschlechtliche Vorherrschaft herbei.. ${ }^{48}$

Überraschend scheint an dieser Stelle zunächst die Feststellung einer weiblichen Vorherrschaft durch die jahrelang in der internationalen Frauenbewegung engagierte Salomon. Kenntnisreich und differenziert hatte sie bereits mehrfach über die informellen aber effektiven Einwirkungsmöglichkeiten amerikanischer Frauen auf die politischen Geschicke des Landes berichtet. ${ }^{49}$ Diese Einschätzung legt nahe, dass die Betonung der gesellschaftlichen Stärke der amerikanischen Frau nicht etwa ein Agitationsnarrativ von Antifeministen oder misogynen Reaktionären darstellte, sondern eine unter deutschen Beobachtern weit verbreitete Ansicht.

Beinahe identisch führt denn auch Gustav Frenssen das Beweisverfahren für die These von der politisch übermächtigen Amerikanerin. Er erklärt darüber hinaus, es habe sich wegen der »spärlich vorhanden(en) « ${ }^{50}$ Frauen beim amerikanischen Mann »eine Art Spaniertum «, ${ }^{51}$ also eine überzogene Kavalierskultur herausgebildet. Die Vorzugsbehandlung der Frau auf allen Ebenen

internationalen Frauenbewegung und der Verbesserung der Arbeitsbedingungen von Frauen. Sie publizierte dazu vor dem Krieg zahlreiche Artikel in einschlägigen Zeitschriften wie »Die Frau« und »Frauenbildung « und fungierte als Kontaktperson zwischen den publizistischen Organen der Frauenbewegungen in den USA, Großbritannien und dem Deutschen Reich.

47 Schmidt: Reisen in die Moderne, 192.

48 Salomon, Alice: Amerikanische Reisebriefe. III. Frau und Mann. In: BTB Nr. 305 vom 01.07.1923, $1 \mathrm{f}$.

49 So beschreibt Salomon beispielsweise die informelle Einrichtung des Frauenklubs, der auch ohne direkte politische Einflussmöglichkeiten von kommunaler Ebene aus das politische Geschehen beeinflusste. Salomon, Alice: Amerikanischer Winter. Der Klub der Frau. In: VZT Nr. 154 vom 30.03.1924, 4.

50 Frenssen, Gustav: Gustav Frenssen in Amerika. In: FZT Nr. 496 vom 08.07.1923, $1 \mathrm{f}$.

51 Ebd., 2. 
des gesellschaftlichen und politischen Lebens sei dadurch zu einem allgemeinverbindlichen Prinzip amerikanischer Kultur erhoben worden. ${ }^{52}$ Über die Betonung der Machtstellung amerikanischer Frauen hinaus wird in dieser Zuspitzung die Abwertung des amerikanischen Mannes impliziert. Hierdurch erklären sich sowohl die Schärfe als auch der tatsächliche Adressat von Frenssens Kritik. In Kenntnis seines sonstigen, bezüglich Geschlechterrollen hinreichend ausdrucksstarken literarischen Werkes wird deutlich, dass er den amerikanischen Mann als Schuldigen für die Stärke seiner Landsfrauen ausmachte: als denjenigen, der seiner Aufgabe, der weiblichen Entfaltung Regeln und Begrenzungen aufzuerlegen, aus Gier nach den raren Frauen nicht gerecht geworden sei. Frenssens These von der Übermacht der amerikanischen Frau steht in einer Kontinuitätslinie mit dem Frauenbild, welches Alexander Schmidt bereits für die wilhelminische Zeit festgestellt hat. ${ }^{53}$ Die im Gegensatz zu damals realisierte politische Gleichberechtigung und der tradierte, vermeintlich kulturimmanente hohe Respekt vor der Frau verwoben sich zu einem regelrechten Bedrohungsszenario weiblicher Doppel-Privilegierung. So auch aus Frenssens Sicht:

"Der Respekt vor dem Weibe ist so groß, daß es gefährlich ist, mit einem Weibe vor Gericht zu ziehen; Richter und Volk neigen von vornherein auf die Seite des Weibes [...]. Das Leben der Amerikanerin ist selbstständiger als das der Nordeuropäerin. Sie hat gute Stellungen inne, wird von dem Mannsvolk rücksichtsvoller behandelt. Alles ist ihr erlaubt. ${ }^{54}$

Auch Beiträger, die dem politischen Engagement amerikanischer Frauen weniger furchtsam gegenüberstanden, sahen in der Kombination aus informellem Einfluss und neu hinzugekommenen formellen Rechten Vorteile. Wolf von Dewall, der seine Reiseberichte 1929 ebenfalls in der FZT veröffentlichte, bewertete die politische Arbeit amerikanischer Frauen gar als sachorientierter, idealistischer und frei von Interessenkonflikten:

»Die Frau ist dort drüben in der Politik ungleich tätiger als der Mann [...], die Politik ist eben ein schmutziges Geschäft. Die Politik unter den Männern. Unter den Frauen jedoch hat sie einen hohen idealen Schwung. Die Frau ist stolz darauf, daß sie auf

52 Vgl. ebd.

53 "Dieser hohe Respekt vor den Frauen innerhalb der gesamten Gesellschaft und nicht nur der oberen Schichten gehörte in fast allen Berichten und Studien zum Bild der Geschlechterbeziehungen, das gerade in dieser Hinsicht fundamental von deutschen oder europäischen Verhältnissen abstach. Vor allem im Kontext einer sozialen und auch rechtlichen Gleichstellung der Frau mit dem Mann, die vielen Wilhelminern durchaus als ,Vorzugsstellung erschien, fand diese Wahrnehmung ihren Niederschlag.»Schmidt: Reisen in die Moderne 192.

54 Frenssen, Gustav: Die Amerikanerin. In: VZT Nr. 282 vom 16.06.1923, 2. 
keinerlei Geschäftsinteresse Rücksicht zu nehmen braucht, daß sie für sich selber nicht das geringste [sic] will, daß sie arbeitet lediglich für die Sache. $\aleph^{55}$

Von Dewall geht sogar auf diffuse Ängste ein, Frauen könnten durch ihre politische Arbeit ihren »natürlichen Aufgaben« nicht mehr nachkommen und würden so auf unnatürliche Weise den Männern zu ähnlich:

»Die amerikanische Frau bleibt bei aller politischen Betätigung Weib. Es sind mir in Amerika eine Unmenge Frauen begegnet, die, obwohl Vorsitzende von politischen Vereinigungen oder berufsmäßig politische Arbeiterinnen, elegant und anziehungsvoll, die als Chairmen glänzende Reden hielten, aber doch vorher ihre Verpflichtungen als Hausfrauen und Mütter in gewissenhafter Weise erfüllt hatten. ${ }^{56}$

Die Tradition politischer Frauenorganisationen wie des Women's Joint Congressional Commitee und anderer würdigt von Dewall ausdrücklich. Er erkennt jedoch im Frauenwahlrecht das finale Moment für die starke weibliche Teilhabe an nationaler Politik. Er identifiziert spezifische Zielsetzungen, die er direkt auf das Wirken von Frauen in der Politik zurückführt, sowie »weibliche« Politikstrategien, die auf temporäre Koalitionen setzen:

»Sie erhielt es [das Wahlrecht, D. F.] erst im Jahre 1920 [...]. Mit dem neuen Werkzeug hat die Frau seitdem in höchst energischer [...] Weise gearbeitet. [...] Dem sozialen Gebiete hatten die Frauen ja schon die ganze Zeit über, als sie noch nicht das Wahlrecht hatten, ihre Hauptaufmerksamkeit gewidmet. Mit der neuen Waffe ausgerüstet aber wurden sie ehrgeiziger. Sie besannen sich darauf, daß die Natur ihnen als Müttern zur Pflicht gemacht hat, die Gattung zu schützen, daß ihr Wesen anders ist als das des zum Kampfe geneigten Mannes. Die Frauen beschlossen, hinfort auch für die Wahrung des internationalen Friedens zu arbeiten. [...] Ihre Verbündeten sind dabei die Kirchen. Es ist in Europa nicht hinreichend bekannt, daß die Washingtoner Konferenz des Jahres 1921, die der Welt eine allgemeine Rüstungsbeschränkung bringen sollte, [...] großenteils auf die Tatkraft der amerikanischen Frauen zurückzuführen war. ${ }^{57}$

Die politische Ermächtigung der amerikanischen Frau wurde von den meisten Beobachtern als folgerichtiger, evolutionärer Prozess wahrgenommen. Wie aber kam es zu so weitreichender Übereinstimmung hinsichtlich eines derart heftig debattierten Themas? Alle Amerika-Erklärer der Weimarer Zeit dachten immerfort die emanzipatorischen Fundamente in der amerikanischen Unabhängigkeitserklärung und Verfassung als Ausgangspunkt der Entwicklung mit. In der Wechselwirkung zwischen deren demokratischen Prinzipien

55 Dewall, Wolf von: Rush. Eine Vortragsreise in den U.S. A. Die Frau. In: FZT Nr. 195 vom 14.03.1929, $1 \mathrm{f}$.

56 Ebd., 2.

57 Ebd. 
und der als frauenfreundlich wahrgenommenen Kultur Amerikas musste in den Augen damaliger Betrachter eine politische Kultur entstehen, die es geradezu notwendig machte, dass Frauen sich daran in gleichberechtigter Weise beteiligten.

Unter diesen Vorzeichen scheint es nicht verwunderlich, dass das Interesse der Illustrierten an Frauen in der amerikanischen Politik zwar vorhanden, aber angesichts ihrer Fokussierung auf das Außergewöhnliche nicht sonderlich ausgeprägt war. Sporadisch bot man dem Publikum ungewohnte visuelle Eindrücke von Frauen in hohen politischen Ämtern, wie im Falle der texanischen Gouverneurin Miriam Ferguson..$^{58}$ Auch Versammlungen von Frauenvereinigungen wurden weiterhin thematisiert. ${ }^{59}$ Doch stehen sowohl die Anzahl als auch die Qualität solcher Darstellungen in keinem Verhältnis zum Medieninteresse, das Frauen im politischen Leben der UdSSR zuteilwurde.

Diese Disproportionalität liegt in der vollkommen anderen Wahrnehmung politisch aktiver Frauen in der UdSSR begründet. Im Gegensatz zu dem als stimmig wahrgenommenen politischen Engagement amerikanischer Frauen brach die politische Sowjet-Frau durch die Revolution von 1917 jäh in das Bewusstsein der deutschen Öffentlichkeit ein. In der Zusammenschau mit der Revolution erschien die politisch erweckte Frau, die auch in der bolschewistischen Lehre eine zentrale Stellung einnahm, ${ }^{60}$ auch als Inbild der gesamtgesellschaftlichen Umwälzung. Und wer konnte sich damals schon sicher sein, dass diese auf die Sowjetunion begrenzt bleiben würde? Damit gewann die Inszenierung der »befreite(n) Frau in Rußland $\aleph^{61}$ unmittelbare Relevanz für die deutsche Öffentlichkeit. Dies galt insbesondere für die kommunistische Presse. Sie war bemüht, die politisch aktive Sowjet-Frau ins kommunistische Schaufenster zu stellen. Auch gemäßigte Illustrierte wollten die umfassende politische Mobilisierung des im Zarenreich politisch, bis auf Revolutionärinnen und Widerstandskämpferinnen, ${ }^{62}$ beinahe unsichtbar gebliebenen weiblichen Geschlechts thematisch abdecken. ${ }^{63}$

58 In der MIP fälschlicherweise als »May« Ferguson bezeichnet. Anon.: Der erste weibliche Gouverneur in Texas. May Ferguson bei ihrer Antrittsrede im Kapitol von Austin (Texas). In: MIP, 1925, Nr. 13, 216 (Jahresausgabe).

59 Anon.: Der Tag der Frauen. In: MIP, 1926, Nr. 30, 727 (Jahresausgabe).

$60 \mathrm{Zu}$ den ideologischen Grundlagen in der "Frauenfrage " und den sozialpolitischen Implikationen: Rosenbaum, Monika: Frauenarbeit und Frauenalltag in der Sowjetunion. Münster 1991, 11-23.

61 Seibert, Theodor: Die befreite Frau in Rußland. In: MIP, 1931, Nr. 19, 611 (Jahresausgabe).

62 Vgl. Boniece, Sally: The Shesterka of 1905-06. The Terrorist Heroines of Revolutionary Russia. In: Jahrbücher für Geschichte Osteuropas 1 (2010), 172-191.

63 Es hat auch schon vorher politisch aktive Frauen gegeben. Revolutionärinnen machten zum Beispiel durch Attentate und andere Aktionen auf sich aufmerksam. Hier ist die Sichtbarkeit im diskurstheoretischen Sinne gemeint, nicht die schiere Existenz. 
Der bis heute am 8. März stattfindende Frauentag bot neben den Maikundgebungen ${ }^{64}$ regelmäßig Gelegenheit, auf die politischen Errungenschaften der Frauen in der UdSSR hinzuweisen. Zu diesem Zweck wurden, insbesondere in der AIZ, häufig kommunistische »Frauenführerinnen« vorgestellt. ${ }^{65}$ Ihre schiere Existenz wurde zum Zeugnis der Erfüllung weiblicher Gleichberechtigung stilisiert, was als entscheidend für den Erfolg des Kommunismus angesehen wurde. Eine Funktionärin trat dabei in doppelter Hinsicht in die deutsche Öffentlichkeit: Alexandra Kollontai, ehemals führende Revolutionärin, Volkskommissarin für Wohlfahrtsfragen und sowjetische Botschafterin in Norwegen. Kollontai meldete sich in deutschen Tageszeitungen zum Thema Gleichberechtigung zu Wort und fungierte als visuelle Personifizierung des neuen Phänomens politisch aktiver Sowjet-Frauen in den Illustrierten. Sie war als Vorkämpferin für Frauenrechte zugleich Rollenvorbild. Besonders ein Visual in der Berliner »Illustrirten« Zeitung (Abb. 7) sticht dabei heraus.

In der oberen linken Bildecke ist Kollontai am Schreibtisch zu sehen, mit der Rechten einen Stift emporhaltend. Ihre schlichte, strenge Kleidung vermittelt Nüchternheit und Klarheit, ihr Blick schweift visionär in die Ferne. Dass diese Fotografie planvoll und zur Vermittlung einer Botschaft angefertigt wurde, ist evident. Kollontais Blick geht in Richtung ihres Zieles, der Stift ist ihr Mittel zu dessen Verwirklichung. Sie wird in der Pose der Rechtssetzerin gezeigt, beseelt von der Vision eines Sozialismus ohne Unterschied zwischen Klassen und (vor allem) Geschlechtern. In puncto Idealismus zeigt sich hier eine Analogie zur Darstellung amerikanischer Politikerinnen. Kollontai erscheint als Frau, die in ihrer Arbeit die eigenen Ideale kompromisslos realisiert und durch ihr politisches Handeln der Vision von der vollkommenen Gleichstellung aller Frauen zum Erfolg zu verhelfen sucht.

Das Visual auf der rechten Seite zeigt Kollontai in ihrer Funktion als Diplomatin. Als weltweit erste akkreditierte Botschafterin führte sie der deutschen und internationalen Öffentlichkeit vor Augen: Die von Lenin zu einem Hauptziel der Revolution erklärte politische Emanzipation der Frau war nicht nur programmatische Vision, sondern war in vollem Gange. Gut sichtbar mit einer Urkunde, dem Signum des Diplomaten ${ }^{66}$ dargestellt, ist sie ein Beispiel dafür, wie offizielle Funktionen und ihre traditionelle geschlechtsspezifische Konnotation auch symbolisch aufgebrochen wurden. Dies wurde in den Redaktionen der BIZ und anderer Illustrierter nicht zwangsläufig als der wichtigste Aspekt

64 Unter anderem: Anon.: Frauen im Zuge der Maikundgebung des Moskauer Proletariats. In: AIZ, 1922, Nr. 7, 52 (Jahresausgabe).

65 Unter anderem: Anon.: Russische Frauen. Kasparowa, die Führerin der kommunistischen Frauen. In: AIZ, 1927, Nr. 7, 8 f.

66 Das Monokel, welches man ebenfalls gut sehen kann, ist nicht Teil der ursprünglichen Fotografie und damit auch kein deutbarer Bestandteil - es wurde mit Bleistift in die Originalausgabe gemalt. 


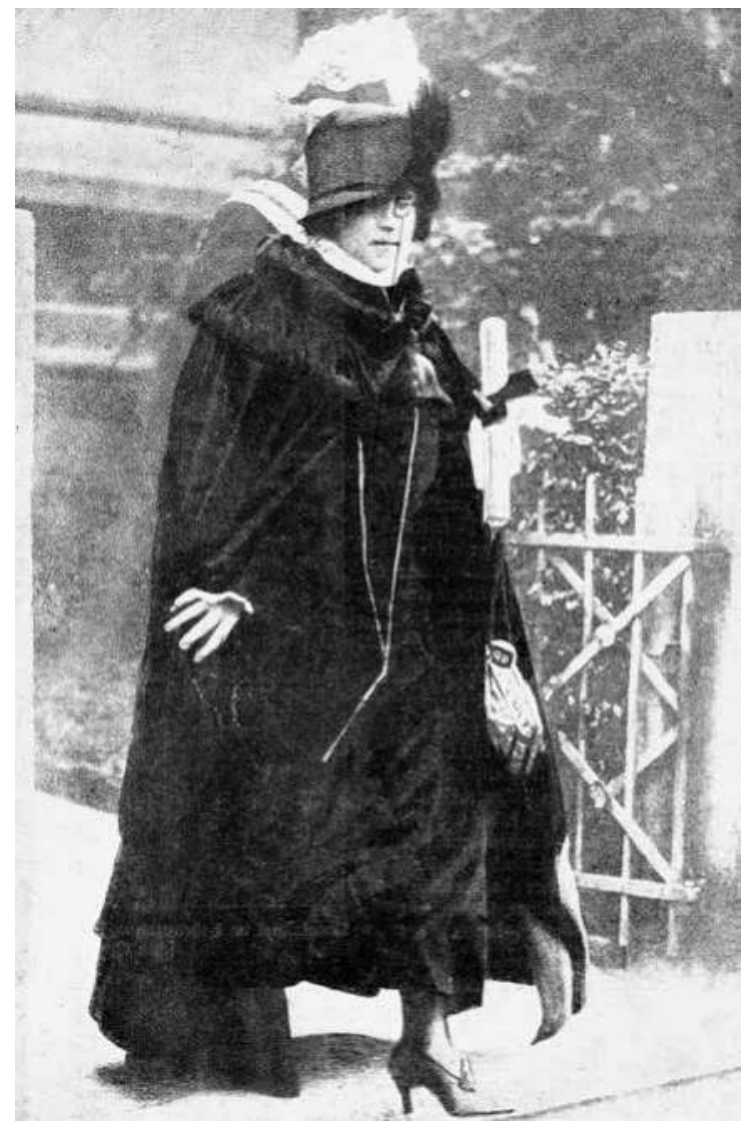

Abb. 7: Anon.: Die Frau in der Politik. In: BIZ, 1924, Nr. 40, 1083. Die Revolutionärin und Diplomatin Alexandra Kollontai wurde als tatkräftige und selbstbewusste Karrierefrau dargestellt.

angesehen. Die politisch aktive Frau wurde auch hinsichtlich anderer, vermeintlich »weiblicher« Maßstäbe betrachtet:

"Die erste Botschafterin: Die elegante Frau Kollontai (mit modernstem Umhang und Damenzylinder) als Botschafterin der russischen Sowjet-Republik in Christiania, auf dem Wege zum König, dem sie ihr Beglaubigungsschreiben überreichte.. ${ }^{67}$

Das Beispiel der Kollontai sticht aus der Masse der namentlich Unbekannten heraus, die in der Berichterstattung über Frauenkongresse der Mehrheitsfrak- 
tion der Kommunistischen Partei Russlands - kurz: KPR (B) - gezeigt wurden. Diese Berichte repräsentieren die häufigste Form visueller und textueller Inszenierung politisch aktiver Frauen in der UdSSR.$^{68}$ Die sogenannten »Deletkas" wurden mit geballter Faust am Rednerpult oder auf Gruppenbildern gezeigt. Die Bildsprache transportiert durchweg die Botschaft von politischer Befreiung und dem neuen Selbstbewusstsein, das Frauen in den entsprechenden Parteiorganisationen entwickelten. Dieses primär geschlechtsbezogene Emanzipationsmoment korrespondiert beinahe immer mit einem klassenbezogenen. Diese erzählte Koinzidenz von Frauen- und Klassenemanzipation erzeugt ein Wahrnehmungsmuster von sich gegenseitig bedingenden Phänomenen derselben Gesamtentwicklung. Frauen und Arbeiter, so das Narrativ, gelangen durch den Bolschewismus zu ihrem Recht - jeder und jede gegen die jeweiligen Unterdrücker. Zahlreiche Fotografien von Teilnehmerinnen der Frauenkongresse explizieren diesen Zusammenhang ebenso wie Textpassagen. Das folgende Leninzitat beispielsweise stammt aus der AIZ-Sondernummer zum zehnjährigen Revolutionsjubiläum:

»In Rußland gelang es nur deshalb, die Gleichberechtigung der Frauen durchzuführen, weil hier seit dem 7. November 1917 die Arbeiterklasse herrscht. Von den Gesetzen, die der Frau eine untergeordnete Stellung zuweisen, ist in der Sowjetrepublik kein Stein auf dem andern geblieben. ${ }^{69}$

Aber nicht nur die wahrlich subjektive AIZ stellte diesen Zusammenhang her. Auch in kultur- und wissenschaftsbezogenen Publikationen vergaß man selten, Reportagen über sowjetische Frauenkongresse mit Informationen über Klassenzugehörigkeit und Herkunft der Delegierten anzureichern. ${ }^{70}$ Die Egalisierung vormals unüberwindbarer Hürden auf dem Weg zu politischer Teilhabe wurde in gleichem Maße am Beispiel von Frauen wie an dem von »Proletariern" verdeutlicht - gerne auch in Personalunion als proletarische Frau. Daran indes wurden immer wieder deutliche Zweifel laut. In einem Auszug aus seinem später erschienen Buch ${ }^{71}$ wies der Reichstagsabgeordnete Theodor Seibert (DVP) im Jahr 1931 auf die Existenz dessen hin, was heute

68 Unter anderem.: Anon.: Die Entsklavung der Frau im roten Osten, In: AIZ, 1924, Nr. 2 , 6. Und: Anon.: Frauen-Kongreß in Moskau. II: All-russischer Kongreß der Arbeiterinnen- und Bäuerinnendelegierten. In: AIZ, 1927, Nr. 44, 11. Und: Foelkersam, André von: 27 Frauen fahren zum Kongreß nach Moskau. In: UHU, 1929, Nr. 1, 84 f. (Jahresausgabe).

69 Anon.: Frauen. In: AIZ, 1927, Nr. 43, 17.

70 »In der `weichen $<$ Klasse, die meist leer ist, sitzen diesmal 27 `Deletkas`, 27 sibirische Bäuerinnen, die zum Frauenkongreß nach Moskau delegiert sind. Schwerarbeiterinnen vom Lande sind es. Breitknochig mit ernsten, harten, wie aus Holz geschnitzten Gesichtern." Foelkersam: 27 Frauen fahren zum Kongreß nach Moskau, 85.

71 Seibert, Theodor: Das Rote Russland. Staat, Geist und Alltag der Bolschewiki. München 1932. 
als "glass ceiling « bezeichnet wird, also die Ausdünnung des Frauenanteils je weiter man die Stufen der Hierarchie emporsteigt:

"Die Partei macht viel Aufhebens davon, daß die Frauen auch im politischen Leben des Sowjetstaates eine große Rolle spielten. In der ersten Zeit der Revolution war das richtig: Frauen wie Vera Figner, die Kolontai und Larissa Reißner haben sicher in jenen Sturm- und Drangjahren, aktiv sowohl als stimulierend, erhebliche revolutionäre Dienste erworben. Im Kleinbetrieb des Sowjetstaates stehen auch heute noch zahlreiche Frauen an sichtbaren Stellen. Je näher man aber in der roten Hierarchie nach oben kommt, je näher man an die wirklichen Machtzentren herantritt, desto schwächer wird das weibliche Element. In den Bundesministerien und in den Reihen des Zentralkomitees [...] findet man nicht einen einzigen weiblichen Namen. Die eigentliche Parteileitung ist vollständig sfrauenrein $\_$das Regime ist ein hundertprozentig männliches Regime; höchstens noch in Italien spielen die Frauen eine gleich bescheidene politische Rolle. $\mathrm{K}^{72}$

Neben der äußeren Emanzipation in Beruf und Politik nahm auch die innere Emanzipation, das Verhältnis der Geschlechter zueinander, breiten Raum in der Berichterstattung zur sowjetischen Frau ein. War im Falle der USA das Geschlechterverhältnis stets mit historischen und kulturspezifischen Erklärungsversuchen verbunden, wurde das Verhältnis zwischen Sowjet-Mann und Sowjet-Frau grundlegend anders erklärt. Anstelle kulturimmanenter Kontinuitäten beschränkte sich die Perspektive im Falle der Sowjetunion auf die disruptive Wirkung der Revolution von 1917 und ihrer Folgen.

Die als übertrieben unbürokratisch empfundene sowjetische Ehegesetzgebung wurde ${ }^{73}$ ebenso wie völlig neue Familienideale als Ausdruck ideologisch bedingter sozialer Neuordnungsprozesse erkannt. ${ }^{74}$ Der Sowjetstaat, so berichtete die FZT 1924, der »alles, selbst das privateste Privatleben ${ }^{75}$ neu zu ordnen angetreten sei, setze diesen Anspruch konsequent um. Für Frauen in

72 Ders.: Die befreite Frau in Rußland. In: MIP, 1931, Nr. 19, 611 (Jahresausgabe).

73 In den lapidaren Berichten darüber wird eine gewisse Kritik an den nüchternen und gänzlich »entzauberten« Prozeduren auf dem Weg in und vor allem aus der Ehe nicht verhüllt: »Sie warten im `SACS $\prec$, dem staatlichen Standesamt. Hier wird die Eheschließung durch einfache Erklärung vor der Beamtin und Eintragung in die Liste vollzogen. Die Scheidung ist noch einfacher. Postkarte eines Ehepartners mit entsprechender Mitteilung genügt. Einwilligung des anderen Teils nicht nötig. [...] Im Übrigen hat die Eintragung keine besonderen Rechtsfolgen für Frau und Kind. Die Scheidung ist ja jederzeit formlos möglich und der Mann braucht für die Frau nur solange sorgen, bis sie Arbeit gefunden hat. Für die Kinder haben dann Mann und Frau gemeinsam aufzukommen."Herrlich: Russische Bilderbogen. Wie sie heiraten. In: MIP, 1931, Nr. 52, 1637 (Jahresausgabe).

74 Vgl. u.a. Anon.: Das neue Gesetz über die Ehe und die Familie. In: FZT Nr. 56 vom 22.01.1925, 1 .

75 Grabowsky, Adolf: Die neue Lebensform in Sowjetrußland. In: FZT Nr. 933 vom 14.12.1924, $1 \mathrm{f}$. 
allen Landesteilen ergäben sich dadurch tiefgreifende Änderungen, insbesondere in ihrem rechtlichen Verhältnis zum (Ehe-) Mann:

»Dabei ist aber in manchen Beziehungen das Individuum freier gestellt als in Europa. Mit der Gleichberechtigung der Geschlechter ist nicht nur im eigentlichen Rußland vollkommen Ernst gemacht, man versucht sogar bei den islamischen Nationalitäten dieser Idee Eingang zu verschaffen. Auch die Ehe steht nicht mehr über den Individuen: beide Seiten können sie gleich schnell lösen. Der Geburtszwang der Frau hat aufgehört: unter gewissen Kautelen ist die Unterbrechung der Schwangerschaft freigegeben. ${ }^{76}$

Die (beabsichtigte) totale Gleichstellung der Frau im Ehe- und Scheidungsrecht führte jedoch nicht selten dazu, dass resultierende Unterhaltsregelungen und Ähnliches der Frau zum massiven Nachteil gereichten. Zentrale Bestandteile der neuen Gesetzgebung, das Prostitutionsverbot zum Beispiel, wurde von Journalisten zwiespältig gesehen. Alexandra Kollontai erörterte das Für und Wider des Prostitutionsverbots im Gesamtzusammenhang der neuen Familien- und Ehegesetzgebung. Ihre halbfiktionale Erzählung »Frauen in Rußland ${ }^{77}$ erschien 1925 in der FZT als Auszug aus ihrem Buch »Wege der Liebe ${ }^{78}{ }^{8}$ Kollontai fasst die Wirkung der neuen Gesetzgebung auf das Zusammenleben von Mann und Frau prägnant zusammen: »Sie waren nicht nur Mann und Frau, sie waren Kameraden. $"{ }^{79}$ Am Thema Prostitution zeigt die Autorin aber auf, dass Geschlechterverhältnisse durch Gesetzgebung allein nicht verändert werden können. In ihrer Erzählung weist sie auf Risiken hin, denen Frauen wegen der undifferenzierten Gleichstellung in wirtschaftlichen Krisen ausgesetzt seien. Zuallererst werde die weibliche Belegschaft aus den Betrieben gedrängt, einige drifteten in die Armutsprostitution ab. Auch Männer fielen auf diese Weise in tradierte Macht- und Abhängigkeitsverhältnisse zurück: »Anstatt einem arbeitslosen Kameraden zu helfen, kauft er ihn, [...], kauft seinen Körper zur eigenen Befriedigung. ${ }^{80}$ Mit der Feststellung, die neue Gesetzgebung habe den Frauen zwar gesellschaftlich genutzt, könne allerdings insgesamt als verfehlt und moralistisch angesehen werden, stimmte Alexandra Kollontai mit Joseph Roth von der FZT überein. Der bilanzierte 1926: „Westeuropa kann von den neuen russischen Gesetzen manches, von seiner sozialen Fürsorge alles, von seiner angeblichen neuen Geschlechtsmoral und Sitte gar nichts lernen. Denn sie ist alt und manchmal reaktionär. ${ }^{81}$

76 Ebd., 1.

77 Kollontai, Alexandra: Frauen in Rußland. In: FZT Nr. 919 vom 10.12.1925, $1 \mathrm{f}$.

78 Dies.: Wege der Liebe. Berlin 1925.

79 Dies.: Frauen in Rußland, 1.

80 Dies.: Frauen in Rußland. In: FZT Nr. 928 vom 13.12.1925, 1.

81 Roth, Joseph: Reise nach Rußland. XII. Die Frau, die neue Geschlechtsmoral und die Prostitution. In: FZT Nr. 893 vom 01.12.1926, 2. 


\subsection{Zusammenfassung}

Am Beginn stand die These, die in der Betrachtung der USA und der UdSSR entstandenen Frauenbilder seien in erster Linie eine Antwort auf die Frage nach dem neuen Bild der Frau in Deutschland gewesen. Die Quellen fassten mit der thematischen Neuverhandlung von Geschlechterrollen, vermeintlich natürlichen Geschlechtersphären und dem Verhältnis von Frauen zu Männern die heißen Eisen der deutschen Debatte an. Sie verdeutlichten in aller Zuspitzung die Positionen einzelner Akteure in der Emanzipations- und Frauendebatte. In West wie Ost standen die Zeichen aus deutscher Sicht auf Gleichberechtigung. Die Durchdringung des politischen Lebens und das Vorstoßen in männliche Lebenswelten vermittelte den Eindruck eines nicht aufzuhaltenden Prozesses, sei er nun evolutionär oder revolutionär bedingt.

Sowjetische und amerikanische Frauenbilder prägten die Emanzipationsdebatte durch ihre hohe Anschlussfähigkeit: Wie in Russland hatte auch in Deutschland ansatzweise eine Revolution stattgefunden, die durch das weibliche Moment mitgetragen worden war. ${ }^{82}$ Wie in den USA hatte es in Deutschland bereits lange eine gut etablierte, politische Mitwirkung einfordernde Frauenbewegung gegeben. Von einer völligen Neuformierung des weiblichen Rollenbildes nach 1918 kann vor diesem Hintergrund keine Rede sein. Subjektiv verbanden sich jedoch die rasanten Veränderungen, die sich für Frauen in Deutschland nach 1918 ergaben, mit den diesbezüglichen Eindrücken aus den USA und der UdSSR. Entwicklungen in Deutschland und bereits vorhandene Debattenansätze konnten daran angebunden werden.

Standen Beiträger gemäßigter Magazine und Zeitungen der Angleichung individueller und staatsbürgerlicher Rechte von Frauen insgesamt durchaus positiv gegenüber, verharrte man bei der Neudefinition geschlechtsspezifischer Rollenbilder in tradierten Denkmustern. Je stärker Rollen- und Berufsbilder zuvor mit einem der beiden Geschlechter konnotiert gewesen waren, desto geringer war die Bereitschaft, deren Infragestellung durch Eindrücke von außen zuzulassen. Das Verwischen der Grenzen zwischen Geschlechterrollen riefen in der Presse deutlich beobachtbare Gegenreaktionen hervor.

Worin aber bestanden diese Gegenreaktionen? Zum einen fanden sich zahlreiche kritische Stimmen, die die Gesamtentwicklung infragestellten, gerade wenn es um die angebliche Vermännlichung der Frau oder um deren politischen Einfluss ging. Ostentative Grenzziehungen zwischen den Geschlechterrollen sind, jenseits der Presseperspektive, in Männlichkeitskonzeptionen wie dem Frontkämpfermythos und den Männerbünden Stahlhelm und SA

82 Man beachte die Hungerproteste von Frauen in deutschen Großstädten, die lange vor den meuternden Matrosen der kaiserlichen Marine ihren Unmut über die inneren Verhältnisse des Deutschen Kaiserreichs kundtaten. 
erkennbar. Das nationalsozialistische Bild der Frau als Mutter und Stütze des Mannes zog ebenfalls alte Geschlechtergrenzen neu, was sich auch als Gegenreaktion auf die Emanzipationsgewinne nach 1918 lesen lässt.

Zum anderen existierten parallel zu Beschreibungen fortschreitender Emanzipation bedeutende Stränge im deutschen Pressediskurs, die ein vollkommen anderes Frauenbild vermittelten. Dabei von gezielten Debattenbeiträgen oder bewusst forcierten Abwehrreaktionen zu sprechen, wäre verfehlt. Vielmehr glichen diese Darstellungen unbewussten Reflexen, die den Widerpart zur Erzählung von der (Selbst-)Ermächtigung der Frauen darstellten. Eine solche Gegenströmung stellte die stark überzeichnende Rückverweiblichung und Verdinglichung von Frauen dar.

Eine hohe Zahl von Berichten über Schönheitswettbewerbe in den USA und Deutschland ${ }^{83}$ trug mit ihrer Darstellung von Frauen als quantifizierbares Gut dazu bei, ihnen Objektcharakter zuzuschreiben. Beiträge, die vom »Beruf, dessen ganze Arbeit darin besteht, schön auszusehen $\aleph^{84}$ berichten, zeichnen ein Rollenbild, das geradezu viktorianisch anmutet und Fortschritte der Frauenemanzipation total konterkariert. Die Verdinglichung und die Rückverweiblichung werden in derlei Berichten direkt aufeinander bezogen:

"Die Frauen, die in die engere Wahl gezogen werden, haben ihr Glück gemacht. Mr. Ziegfeld (der Inhaber des größten Revuetheaters der Welt) engagiert sie, oder eine große Filmfirma gewinnt ihr Photographiergesicht mit einem großen Engagementvertrag oder einer der Dollarmillionäre heiratet sie [...]. Die Schönheiten werden registriert, nach Alter, Größe und Gewicht. ${ }^{85}$

Nicht zuletzt durch die Prämierung einzelner Körperteile ${ }^{86}$ oder unterschiedlicher $»$ Frauenkategorien ${ }^{87}$ verfestigte sich der Eindruck, dass man es bei Frauen mit standardisierbaren Einheiten zu tun habe. In diesem thematischen Zusammenhang überlagern sich zwei Ebenen: Erstens wurde der dominante, die Emanzipation der Frauen affirmativ begleitende Diskurs durch einen Gegendiskurs der Verdinglichung der Frau konterkariert. Zweitens wurde eben dieser Gegendiskurs zum Kristallisationspunkt weiterer (Zeit-)Kritik und öffnete Anknüpfungspunkte zu benachbarten Themenfeldern, wie das

83 Vgl. u.a. Anon.: Amerikanische Schönheitsinvasion. In: MIP, 1927, Nr. 2, 29 (Jahresausgabe); Anon.: Amerika industrialisiert die Schönheit. In: MIP, 1927, Nr. 43, 1229 (Jahresausgabe); Anon.: Wettbewerb der Rücken (U.S. A.). In: QUS, 1931, Nr. 9, 632 (Jahresausgabe).

84 Anon.: Amerikanische Schönheitsinvasion. In: MIP, 1927, Nr. 2, 29 (Jahresausgabe).

85 Ebd.

86 »Nachmittag: Wahl des schönsten Frauenrückens, Wahl der längsten Frauenbeine [...], Wahl der schmalsten Oberlippe [...], Prämierung der schönsten Kehrseite in Kalifornien.« Daniel, Léon: Amerika wählt.... In: RDM, 1928, Nr. 1, 60 (Jahresausgabe).

87 Beschrieben werden die Konkurrenz der Rothaarigen, Konkurrenz der "Gebobbten « und der »Ungebobbten« und viele Facetten der Schönheitswettbewerbe mehr. Vgl. ebd., $61 \mathrm{f}$. 
Beispiel der nationalsozialistischen Kritik an Schönheitswettbewerben zeigt. Der Illustrierte Beobachter (ILB) trat diesem in Deutschland relativ neuen Phänomen offensiv entgegen und kritisierte, garniert mit reichlich Antisemitismus und Antiamerikanismus, die durch solche Wettbewerbe und ihre Preisrichter standardisierten und rationalisierten Ideale weiblicher Schönheit:

»Prüften. Verglichen. Maßen. Wogen. Notierten. Stellten statistische Grundlagen, apodiktische Richtlinien auf [...]. Und das Ergebnis dieses akademischen Konklave war also das Fräulein Elisabeth Rodziel. Auf ihren Typ, ihre Figur, Beinlänge, Halsweite, Wadenansatz ward sohin der Generalnenner der deutschen Frauenschönheit von 1928 gebracht. Sie repräsentiert damit unser Ideal des weiblichen Reizes im Geschäftsjahr 1928 schlechthin, bringt den Amerikanern bei der demnächst fälligen internationalen Schönheitskonkurrenz zu ihrem nicht hundertprozentig puritanischen Bewußtsein, daß von der Maas bis an die Memel, von der Etsch bis an den Belt Fräulein Elisabeth Rodziel der Traum unserer schlaflosen Nächte ist. Läßt sich über Geschmäcker streiten? Wir stehen nicht an hinzuzufügen, daß selbst der auf jeden Bluff hereinfallende Berliner Publikus sich [...] gegen die heurige Rationalisierung des deutschen Schönheitsbegriffes sträubte.." ${ }^{88}$

Die Verschränkung zwischen Frauen- und Rationalisierungsdebatte zeigt beispielhaft die Querverbindungen zwischen einzelnen Diskursgegenständen. Das neue Frauenbild lag im Schnittpunkt weiterer, die Modernitätsdiskurse der Weimarer Zeit konturierenden Großthemen und war in besonderem Maße offen und anschlussfähig. In der Weimarer Massenpresse lassen sich zwei klare Tendenzen ausmachen: Die politische und gesellschaftliche Emanzipation der Frau wurde als Ausdruck einer sich modernisierenden Gesellschaft positiv gesehen oder wenigstens akzeptiert - eine Ausnahme bildet die NS-Presse. Gleichzeitig wurde die Aufhebung aller Schranken zwischen geschlechterspezifischen Rollenbildern, sei es als Phänomen eines unbestimmten Zeitgeistes oder ideologische Doktrin, ganz überwiegend abgelehnt. 


\section{Minderheiten: Emanzipation und Modernitätsbruch}

Der Erste Weltkrieg und die Ideologie der Bolschewiki bildeten den Ausgangspunkt der Weimarer Debatte über das neue Bild der Frau ebenso wie für die Frage nach der (Gleich-)Behandlung ethnischer Minderheiten. Hierbei standen vor allem die Afroamerikaner sowie die nationalen und religiösen Minderheiten der UdSSR im Zentrum des Medieninteresses. Deutliche Kritik an der Diskriminierung der Afroamerikaner einerseits und wohlwollende Resonanz auf emanzipatorische Anstrengungen der Minderheiten in der amerikanischen und sowjetischen Gesellschaft andererseits bildeten den bestimmenden Zweiklang der Debatte. Die mediale Begleitung der Minderheitenemanzipation wies Parallelen zur Debatte um die Emanzipation der Frau auf. Mitunter kam die öffentliche Verhandlung der Frauenemanzipation sogar mit der Berichterstattung über nationale und ethnische Minderheiten zur Deckung. Alexandra Rakovsky konstatierte beispielsweise in der VZT, dass "eine Bewegung von Dauer und Wirksamkeit zugunsten der russischen Frau entfacht« sei, »die sich von den Bergen des Kaukasus bis zur arktischen Zone und bis an den Fuß des Himalaya ${ }^{1}$ ausdehne. Damit schloss sie eben jene Regionen der UdSSR ein, die zum überwältigenden Teil von Nichtrussen bewohnt waren.

Politisch und gesellschaftlich marginalisierte Gruppen zogen durch ihr langsames aber stetiges Streben in die gesellschaftlichen und politischen Zentren ihrer Gesellschaften das Interesse der deutschen Öffentlichkeit auf sich. Die Grundsätze eines ethnischen und religiösen Pluralismus, gleicher Rechte für alle und die Toleranz der Mehrheitsbevölkerung gegenüber Minderheiten stellen zudem entscheidende Signa moderner Gesellschaftsordnungen dar. Daher muss sich dieser Themenkomplex in Modernisierungsdebatten beinahe zwangsläufig wiederfinden, da er elementare Fragen nach der gesellschaftlichen Organisation von Pluralismus aufwirft. Pluralismus muss hier in einem doppelten Wortsinne verstanden werden: Zum einen in seiner politischen Definition, nach der Interessengruppen entsprechend ihrer Größe politische Mitwirkung garantiert wird. ${ }^{2}$ Zum anderen im Sinne einer staatlich garantier-

1 Rakovsky, Alexandra: Frauenleben in Sowjet-Rußland. In: VZT Nr. 1 vom 01.01.1928, 6.

2 Diese Version von Pluralismus wird gemeinhin als Grundkonsens im politischen System der USA interpretiert, wobei die Definition solcher "Interessengruppen « durch die amerikanische Geschichte hinweg immer wieder neu gefasst wurde. Im thematischen Zusammenhang der Minderheitenemanzipation geht es um die Entwicklung der amerikanischen Black Community von einer randständigen Gruppe zu einem politischen Faktor, der die Rolle einer Interessengruppe im politischen, kulturellen und gesellschaftlichen System der Vereinigten Staaten aktiv einforderte. Zu dieser spezifischen Pluralismusdefinition: Grillo, Ralph: Pluralism and the Politics of Difference. State, Culture, and Ethnicity in Comparative Perspective. Oxford 1998, $6 \mathrm{f}$. und $141 \mathrm{f}$. 
ten, gleichberechtigten Koexistenz verschiedener ethnisch-religiöser Gruppen oder Nationalitäten.

Es lohnt auch und gerade im deutschen Kontext, dahingehende mediale Diskurse zu untersuchen. Die Relevanz des Themas rührt natürlich nicht aus der Präsenz ethnischer Minderheiten im damaligen Reichsgebiet in signifikanter Zahl und in vergleichbarer Situation - eine solche war nicht vorhanden. Für die Behandlung und Selbstverortung der ethnisch-religiösen Minderheiten in Deutschland, vor allem Juden und Sinti, bot die Außenbetrachtung der USA und der UdSSR wenig Potential. Sensibilität für das Thema war eher noch durch die schmerzhaften Erfahrungen gegeben, die Deutsche selbst als Minderheit in den Siedlungsgebieten jenseits der Reichsgrenzen oder als Teil der weltweiten deutschen Diaspora während und nach dem Ersten Weltkrieg gesammelt und mit der Heimat geteilt hatten. ${ }^{3}$

Die Brüche und Reibungen, die sich von dieser thematischen Warte in der zeitgenössischen Frage nach neuen sozialen Ordnungen ausmachen lassen, sollen hier in den Mittelpunkt gerückt werden. Die Betrachtung von Minderheiten in vermeintlich unendlich weit entfernten Gesellschaften bot überraschend konkrete Anknüpfungspunkte für die gesellschaftliche Debatte in Deutschland. Insbesondere lässt sie Rückschlüsse zu auf ein ausgeprägtes Bewusstsein, wie eine ihrem Anspruch nach moderne Gesellschaft mit ihrer ethnischen Pluralität umzugehen habe - und wie nicht.

In der kritischen Evaluation der Situation von Minderheiten in den Vereinigten Staaten entfaltet sich beispielsweise der Vorwurf, deren gesellschaftliche Stellung und Behandlung stehe dem Anspruch, »das modernste Land der Welt« zu sein, diametral entgegen. Explizit werden diese Widersprüche, wenn die Quellen gegen das Konzept von Moderne gelesen werden, auch wenn dieses für Zeitgenossen untergeordnete Bedeutung gehabt haben dürfte. Ein analytischer Gebrauch des Konzepts Moderne vermag zu identifizieren und $\mathrm{zu}$ konkretisieren, woraus sich das überraschend große deutsche Unbehagen über die Missstände einerseits und die Begeisterung für Fortschritte der Minderheitenemanzipation andererseits speisten.

Der Prozess der sozialen Selbstbeschreibung der deutschen Gesellschaft verlief zwischen 1918 und 1933 zwischen der Sehnsucht nach einer egalitären "Volksgemeinschaft ${ }^{4}$ und dem Bedürfnis, die bestehende soziale Ordnung in

3 Dazu Panayi, Panikos: Germans as Minorities during the First World War: Global Comparative Perspectives. In: Ders. (Hg.): Germans as Minorities during the First World War: A Global Comparative Perspective. Farnham, Burlington, VT 2014, 3-26; Manz, Stefan: Diaspora and Weltpolitik in Wilhelmine Germany. Ebd., 27-46.

4 Der Begriff der Volksgemeinschaft wird pauschal der nationalsozialistischen Ideenwelt zugeschlagen. Die Idee der Volksgemeinschaft war ursprünglich eine inklusive und egali- 
Zeiten raschen Wandels erhalten zu wollen. Mediale Einschätzungen zur Minderheitenfrage in den USA aber auch in der Sowjetunion dienten als Leinwand, auf die eigene Fragen zu sozialen Ordnungen und gesellschaftlicher Organisation projiziert wurden. Der in die Verhandlung der Minderheitenfrage(n) eingeschriebene Widerstreit zwischen sozialem Verharren und Voranschreiten, zwischen repressiven und emanzipatorischen Narrativen verortet das Thema Minderheiten im Kern der Modernisierungsdebatten der Zwischenkriegszeit. Emanzipationsnarrative und in der Fremdbetrachtung verhandelte soziale Deutungskonflikte der deutschen Gesellschaft stellten hierbei die beiden grundlegenden Diskursstränge dar.

Der Vorbehalt, der für die Kausalität zwischen den sozioökonomischen Entwicklungen während des Ersten Weltkriegs und der Frauenemanzipation formuliert wurde, gilt auch für die Minderheitenemanzipation: Es handelte sich keineswegs um bloße Abfolgen sich bedingender Entwicklungen, sondern um mehrfache Reflexionen zwischen objektiv stattfindenden Veränderungen und deren Perzeption und Diskussion. Das Zusammendenken von Minderheitenemanzipation und Weltkrieg im amerikanischen sowie Oktoberrevolution im russischen Kontext wurde im öffentlichen Diskurs verstärkt. Weshalb sich beide Konnotationen so nachhaltig etablierten, lässt sich jeweils an einem knappen historischen Aufriss der Minderheitenfrage in beiden Ländern erklären. So sollen die im Zentrum der Untersuchung stehenden transkulturellen Aneignungsprozesse durch Entwicklungen im jeweiligen »Impulsgeberland« kontextualisiert werden. ${ }^{5}$

Die Unmittelbarkeit, mit der die Kriegs- und Kulturerfahrungen afroamerikanischer Soldaten in Frankreich nach Kriegsende dem Konzept des »New

täre Gesellschaftsvision, die primär auf die Kohäsionskräfte jenseits der Klassen- und Religionsschranken setzte. Die hochgradig exklusive Konzeption der NS-Volksgemeinschaft steht dazu in puncto Egalität im krassen Widerspruch. Der Begriff der Volksgemeinschaft ist während der Jahre der Weimarer Republik zunächst kein weltanschaulicher Kampfbegriff, sondern ein Konzept im offenen Deutungskampf zwischen den Parteien. Vgl. Wildt, Michael: Volksgemeinschaft als Selbstermächtigung. Gewalt gegen Juden in der deutschen Provinz 1919 bis 1939. Hamburg 2007, 54f.; ders.: Die Ungleichheit des Volkes. „Volksgemeinschaft « in der politischen Kommunikation der Weimarer Republik. In: Ders. / Bajohr, Frank: Volksgemeinschaft. Neue Forschungen zur Gesellschaft des Nationalsozialismus. Frankfurt a. M. 2009, 24-40.

5 So regte Philipp Gassert für den Gegenstand der Amerikanisierung an: »Die Amerikanisierungs-Forschung deren Gegenstand ja Europa ist, könnte durch eine Zusammenarbeit mit der Amerikanistik, die sich Prozessen in den USA selbst widmet, konzeptionell einen entscheidenden Schritt weitergebracht werden." Gassert, Philipp: Amerikanismus, Antiamerikanismus, Amerikanisierung. Neue Literatur zur Sozial-, Wirtschafts- und Kulturgeschichte des amerikanischen Einflusses in Deutschland und Europa. In: Archiv für Sozialgeschichte, Bd. 39. Bonn 1999, 533 f. Dies soll hier auch gleichermaßen für die Betrachtung der Sowjetunion gelten. 
Negro ${ }^{6}$ oder der Harlem Renaissance $«$ in den USA Auftrieb verliehen, ${ }^{7}$ stellt eine Parallele zur amerikanischen Frauenemanzipation dar. Auch bei letzterer richteten sich die zur Kriegsmobilisierung formulierten Ziele und Ideale nach Kriegsende nach innen und führten zu einer unbeabsichtigten Dynamisierung des politischen Kampfes um die Rechte politisch marginalisierter Gruppen. In beiden Fällen wirkten die Veränderungen durch den Weltkrieg beschleunigend auf langfristig angelegte, sich bereits vollziehende gesellschaftliche Prozesse. Der Konflikt um Arbeitsplätze, der nach Kriegsende zwischen heimkehrenden Soldaten und Arbeitern beider Hautfarben ausbrach und eine Eskalation rassistischer Gewalt in amerikanischen Städten, den berüchtigten "Red Summer", zur Folge hatte, markierte den blutigen Widerhall des 1917 von den USA ausgegangenen Rufes zur Demokratisierung der Welt. ${ }^{8}$

Die enttäuschte Hoffnung, die Verteidigung demokratischer Prinzipien in Europa möge auch die Verhältnisse in der Heimat zum Besseren ändern, führten neben Gewaltexzessen aber auch zu einer bis dato unerreichten Konsolidierung und Professionalisierung der politischen Interessenvertretung der Afroamerikaner. ${ }^{9}$ Zeitgleich erschienen zahlreiche Veröffentlichungen

6 Insbesondere die respektvolle Behandlung afroamerikanischer Soldaten durch französische Offiziere und das Beispiel einer Gesellschaft, die (aus Sicht der amerikanischen Soldaten) ohne das Einziehen ethnischer Trennlinien auskam, wirkten am Entstehungsprozess eines afroamerikanischen Selbstverständnisses jenseits der Separation mit. Vgl. Whalan, Mark: The Great War and the Culture of the New Negro. Gainesville 2008, $9 \mathrm{f}$. und $47 \mathrm{f}$.

7 Seit den 1890er Jahren waren die Grundsätze der Arbeiten du Bois' sowie der Reden Booker T. Washingtons und Frederick Douglass' als Widerspruch zum Gedanken der White Supremacy und der eskalierenden rassistischen Gewalt kontinuierlich weiterentwickelt worden. Rayford Logan bezeichnete die Periode vom ausgehenden 19. Jahrhundert bis zum Ende des Ersten Weltkriegs als "Nadir of American Race Relations«, als absoluten Tiefpunkt, ab dem sich im Zuge des beginnenden Engagements weißer und afroamerikanischer Intellektueller und Aktivisten eine beständige Normalisierung und Verbesserung der Beziehungen zwischen den Ethnien vollzog. Vgl. Logan, Rayford: The Betrayal of the Negro. From Rutherford B. Hayes to Woodrow Wilson. New York 1997, $79 \mathrm{f}$.

$8 \mathrm{Zu}$ den weitergehenden innenpolitischen und sozialen Auswirkungen der Unruhen: McWhirter, Cameron: Red Summer. The Summer of 1919 and the Awakening of Black America. New York 2011, 236-264. Die Ereignisse zeigen nicht nur eine rassenspezifische Konfliktlinie, sondern ebenso eine klassenspezifische. Große Teile der afroamerikanischen Aktivisten waren sozialistisch geprägt und strebten gar die Errichtung einer bolschewistischen Regierung in den Vereinigten Staaten an. Vgl. Foner, Philip: American Socialism and Black Americans. From the Age of Jackson to World War II. Westport 1977, $288 \mathrm{f}$.

9 So verzehnfachte sich etwa die Mitgliederzahl der 1909 gegründeten NAACP exakt zwischen 1918 und Ende 1919, ein Indiz für die entschieden verbesserte Mobilisierung und die innere Geschlossenheit der afroamerikanischen Interessenvertretung. Vgl. Berg, Manfred: The Ticket to Freedom. Die NAACP und das Wahlrecht der Afro-Amerikaner. Frankfurt u. a. $2000,73 \mathrm{f}$. 
schwarzer Intellektueller, die das Engagement der Afroamerikaner im Kriege dokumentierten, Veränderungen der afroamerikanischen Selbstwahrnehmung beschrieben und daraus konkrete Forderungen nach echter sozialer Gleichberechtigung ableiteten und formvollendet formulierten. Ihnen wurde dabei unverhohlen von Vertretern des politischen Amerika und des Militärs sekundiert, was angesichts der angespannten innenpolitischen Lage bemerkenswert ist. ${ }^{10}$ Mit einiger Verzögerung war das Motiv, für die gebrachten Opfer sei nunmehr gesellschaftliche Anerkennung und Gleichstellung einzufordern, auch in Betrachtungen deutscher Zeitungen präsent. Mit spürbarer Empörung wurde über die Geringschätzung afroamerikanischer Weltkriegsveteranen berichtet:

»Aus einem solchen Lande [...], wo dem Schwarzen die Hotels [...] verschlossen sind, wo ihm die Gaststätten der Weißen Bedienung verweigern, wo er in besonderen Fahrstühlen, ,Für Farbige und Fracht‘, zu fahren hat, wo er ständig wachsam sein muß, kam die Mehrzahl der amerikanischen Negertruppen. In Frankreich fanden sie eine ganz andere Stellung zur Rassenfrage [...]. Sehr verbittert, aber gleichzeitig im Selbstbewußtsein gewachsen kamen viele Neger aus dem Kriege zurück. Gebildeten Mischlingen wurden von weißem Pöbel die Epauletten von den Schultern gerissen, als sie als Offiziere heimkehrten [...]. Mannigfach waren die Beschwerden, [...] daß die Negerregimenter immer zu den undankbarsten, schwierigsten und verlustreichsten Diensten herangezogen worden seien. ${ }^{11}$

Die Gründe für den lauter werdenden Ruf nach Gleichberechtigung in den unmittelbaren Auswirkungen des Krieges zu verorten, wie dies zeitgenössische Medien taten, erscheint durchaus legitim. Als alleiniger Erklärungsansatz verkürzt dies jedoch erheblich die Kausalkette, die nach Kriegsende zur sich stetig verschärfenden Frage der Gleichberechtigung führte.

10 Neben Autoren wie Allison Sweeney ist hier vor allem Emmett J. Scott zu nennen, der mit seinem mit Dankesworten von Kriegsminister Baker, General Pershing und Theodore Roosevelt gespickten Werk eine umfassende Dokumentation der großen Loyalität seiner afroamerikanischen Landsleute, sowie von deren Erfahrungen in der militärischen Ausbildung und im Krieg selbst vorlegte. Entscheidend aber sind seine beiden letzten Kapitel, in denen er die ungerechte Behandlung der heimkehrenden afroamerikanischen Soldaten beklagt (»Chapter XXX. Did The Negro Soldier Get A Square Deal?») und konkrete Forderungen aufstellt, wie die darin deutlich werdende rechtliche und soziale Benachteiligung der gesamten Black Community in den Vereinigten Staaten zu beseitigen sei (»Chapter XXXI. What The Negro Got Out Of The War.»). Vgl. Scott, Emmett J.: Scott's Official History of the American Negro in the World War. A Complete and Authentic Narration from Official Sources, of the Participation of American Soldiers of the Negro Race in the World War for Democracy. Chicago 1919.

11 Mensching, Wilhelm: Afrika in Amerika. Der Kampf der amerikanischen Neger um ihre Gleichberechtigung. In: FZT Nr. 789 vom 23.10.1927, 1 f. 
Auch mit Blick auf die UdSSR lassen sich Argumentationsmuster im Minderheitendiskurs beobachten, die parallel zu denen des Frauendiskurses verliefen. Die im Vergleich zur Zarenzeit als deutlich verbessert wahrgenommene Situation der nationalen und ethnisch-religiösen Minderheiten fußte scheinbar ebenfalls auf bolschewistischer Programmatik. Durch die Aufhebung kulturspezifischer Privilegien der russischen Mehrheitsbevölkerung sollte eine unterschiedslose soziale Ordnung, auch und gerade hinsichtlich der ethnischen und kulturellen Zugehörigkeit verwirklicht werden. ${ }^{12}$ Angesichts der von deutschen Medien festgestellten einstweiligen Beendigung der Russifizierungspolitik zaristischer Prägung schienen sich den nationalen, religiösen und ethnischen Minderheiten neue politische und kulturelle Freiheiten zu eröffnen.

Mit dieser Annahme orientierten sich die meisten Beiträger allerdings eher an den vor der Revolution von 1917 formulierten Zielen und schrieben diese quasi linear fort, anstatt deren Umsetzung beziehungsweise Nichtumsetzung ernsthaft zu überprüfen. Tatsächlich wurden zwischenzeitlich politische Maßnahmen, die wie die Sprachpolitik in der Auffassung einer überlegenen russischen Kultur gründeten, als Überbleibsel der überwunden geglaubten alten Ordnung verworfen. ${ }^{13}$ Dass sich die in vielerlei Hinsicht mit der Russifizierung vergleichbare Sowjetisierung schon bald nach der Konsolidierung der Herrschaft der Bolschewiki anschloss, wurde hingegen von deutschen Me-

12 Seine grundlegende Haltung zum Verhältnis zwischen dem Großrussentum und den nationalen und religiösen Minderheiten, die auch die Grundlinien in den ersten Jahren nach der Oktoberrevolution von 1917 bestimmen sollten, tat Lenin 1913 in der Zeitschrift Prosweschtschenije (Nr.10) kund. Dabei geht er zunächst auf die Minderheitensprachen als traditionelles Betätigungsfeld der Russifizierungspolitik und auf die Rolle der nationalen Minderheiten als Ganzes ein: „Warum soll nun das `riesige` [...] und furchtbar rückständige Rußland seine Entwicklung durch die Aufrechterhaltung eines wie immer gearteten Privilegs für eine der Sprachen hemmen? Ist es nicht umgekehrt, Ihr Herren Liberalen? Sollte nicht Rußland, wenn es Europa einholen will, so bald wie möglich, so gründlich wie möglich und so entschlossen wie möglich mit allen und jeglichen Privilegien aufräumen?» Lenin, W.I.: Werke, Bd. 20 (Dezember 1913-August 1914). Berlin 1961, 5. Weiter schreibt er: "In unlösbarem Zusammenhang mit dem Grundsatz der vollen Gleichberechtigung steht die Sicherung der Rechte der nationalen Minderheiten [...]. Dieser Beschluß verlangt die >Aufnahme eines grundlegenden Gesetzes in die Verfassung, wonach alle wie immer gearteten Privilegien der einen oder anderen Nation und alle wie immer gearteten Vorstöße gegen die Rechte einer nationalen Minderheit für ungültig erklärt werden.« Ebd., 28.

13 Dazu sei gesagt, dass mit Ausnahme Polens, Finnlands und der Baltischen Staaten bereits während des Russischen Bürgerkrieges (1918-21) alle Völker, die sich als eigenständige Nationen vom zerfallenen Russischen Reich losgesagt hatten, mit militärischen Mitteln in die entstehende UdSSR zurückgezwungen wurden. Spätestens zu diesem Zeitpunkt entsprach die politische Praxis nicht mehr der Programmatik, die Lenin erarbeitet hatte. Dennoch wurden, gewissermaßen im Nachhinein, die nationalen Minderheiten durch Programme gezielt gefördert (negative Diskriminierung und weiteres mehr) und in vielen Fällen ihre Landessprache als zusätzliche Amtssprache eingeführt. Diese Maßnahmen 
dien mit einiger Verzögerung wahrgenommen oder bereitwillig ausgeblendet. Diese Sowjetisierung war aber schon vor der vollständigen Machtübernahme Stalins ${ }^{14} 1927$ in ihrer ungleich umfassenderen Auslegung und Implementierung, die dereinst den neuen Sowjetmenschen formen sollte, von ebenso gravierendem Einfluss auf das Leben nationaler Minderheiten in der UdSSR. ${ }^{15}$ Just in diesem Punkt hatte Lenin frühzeitig Stalin freie Hand dabei gelassen, den Bolschewiki deutlich restriktivere Antworten auf die "nationale Frage» zu oktroyieren. ${ }^{16}$

Weltkrieg und Bolschewismus dienten als Klammer für den Diskurs über die Emanzipationen von Frauen und Minderheiten. Angesichts der beträchtlichen Unterschiede zwischen beiden kann hier von einer deutlichen Diskursvereinfachung gesprochen werden. Da sich aus deutscher Sicht mit dem Krieg einerseits und der Ideologie der Bolschewiki andererseits zeitliche und kausale Parallelen zwischen den Emanzipationstendenzen der Frauen und denjenigen der jeweiligen ethnischen oder religiösen Minderheiten aufdrängten, parallelisierten sich auch die darüber geführten Debatten. Auch an der allgemeinen Darstellung der Black Community in deutschen Tageszeitungen und Illustrierten lässt sich dies demonstrieren.

In der Folge wird auf thematische Schwerpunkte der deutschen Berichterstattung einzugehen sein, in der diese Diskursvereinfachung nicht griff, etwa im Kontext der Rassentrennung und -diskriminierung. Dabei spiegelt der starke inhaltliche Fokus auf Reportagen und Berichte zum Leben der Afroamerikaner im Vergleich zu den wesentlich selteneren Berichten über die nationalen Minderheiten der UdSSR die Quellensituation proportional wider. Sowohl die weitaus höhere Anzahl als auch die größere thematische Tiefe der Berichte über das »schwarze Amerika« steht in keinem Verhältnis zu den vereinzelten und relativ oberflächlichen Beiträgen über nationale Minderheiten der UdSSR. Die deutsche Medienöffentlichkeit zeigte reges Interesse

sollten verhindern, dass sich die nationalen Minderheiten auf breiter Front gegen die Bolschewiki positionierten. Vgl. Simon, Gerhard: Nationale Minderheiten in der ehemaligen Sowjetunion. In: Die neue Gesellschaft, Frankfurter Hefte, Nr. 12 (44. Jg.). Bonn 1997, 1079-1082.

14 Der Einfachheit halber werden hier und im Folgenden die Kampfnamen von Vladimir Il'ič Ul'janov (Lenin) und Iosif Vissarionovič Džugašvili (Stalin) verwendet.

15 Vgl. Weeks, Theodore: Russification/Sovietization. In: Europäische Geschichte Online (EGO), hg. vom Institut für Europäische Geschichte, Mainz. URL: http://www.ieg-ego. eu/weekst-2010-en (am 08.07.2014), $15 \mathrm{f}$.

16 Genauer gesagt bereits 1913, als Lenin Stalin sein Placet für dessen Aufsatz »Marxismus und nationale Frage« gab. Dieser hierarchisiert den Begriff der Nation derart, dass das Recht zur Selbstbestimmung nur noch einem erlesenen Kreis sprachlich, territorial und ökonomisch homogener und über ein gefestigtes Selbstverständnis als Nation verfügender Entitäten überhaupt zugestanden wurde. Vgl. Halbach, Uwe: Das sowjetische Völkerimperium. Nationalitätenpolitik und nationale Frage. Mannheim 1992, 20 f. 
am Schicksal der Afroamerikaner, ${ }^{17}$ mit Abstrichen auch an der veränderten Minderheitenpolitik der UdSSR, weil beide die Kluft zwischen Anspruch und Wirklichkeit der Moderne illustrierten sowie drängende Fragen nach der sozialer Neuordnung behandelten.

\subsection{Die Black Community in den USA}

Die mediale Betrachtung der Black Community erstreckte sich über drei Felder: erstens die Alltagsnormalität der afroamerikanischen Minderheit als sich zunehmend in der Gesamtgesellschaft verortende Gruppe; zweitens Klagen über die dazu im krassen Widerspruch stehende rassistische Gewalt und institutionalisierte Rassendiskriminierung; sowie drittens optimistische Perspektiven auf den sich abzeichnenden Aufbruch der Black Community in die Mitte und an die Spitzen der amerikanischen Gesellschaft. Die Alltagsbeschreibungen waren von exotistischer Neugier getrieben, die sich immer wieder in hergebrachten Stereotypen verfing. Die dem gegenüberstehende Kritik an rassistischer Gewalt und Rassentrennung in den Südstaaten bezog ihre Schärfe aus der Nichtvereinbarkeit archaisch anmutender Denkmuster und blanker Gewalt mit dem Konzept des modernen »Melting Pot« USA. Intensiv wurden individuelle Emanzipationserfolge rezipiert und zu afroamerikanischen Rollenvorbildern überhöht sowie politische Organisationen wie die National Association for the Advancement of Colored People (NAACP) zur pluralistischen Verheißung der amerikanischen Moderne stilisiert.

Anhand einschlägiger Quellenauszüge lässt sich zeigen, dass hinsichtlich der amerikanischen Rassenfrage ${ }^{18}$ ein für die Maßstäbe der Zeit bemerkenswert ausgeprägtes Problembewusstsein vorhanden war. Das retro-

17 Dass es ein sehr großes Interesse an der Thematik gab, lässt sich ablesen sowohl an zahlreichen und über den gesamten Beobachtungszeitraum regelhaft auftretenden synoptischen Beschreibungen der Lage der Afroamerikaner (Nearing, Scott: Schwarze Amerikaner. In: AIZ, 1928, Nr. 46, 4f.) als auch den Artikeln und Reportagen, die auf thematische Einzelaspekte afroamerikanischen Lebens, wie beispielsweise deren Wohnsituation oder zunehmende kulturelle Entfaltung fokussierten. Anon.: John D. Rockefeller Jun. baut Wohn-Blocks für - Neger! In: MIP, 1930, Nr. 19, 667 (Jahresausgabe); Anon.: Neger träumen vom Paradies. Das Zugstück der New Yorker Theatersaison. In: MIP, 1930, Nr. 31, 1075 (Jahresausgabe).

18 Der Terminus »Rassenfrage« transportiert im Deutschen hinsichtlich seiner Ähnlichkeit mit dem weltanschaulichen Begriff der »Judenfrage«, der im »Dritten Reich» durch die Nationalsozialisten zur mentalen Vorbereitung des Holocaust verwendet wurde, entsprechende Konnotationen. Hier wird er im Folgenden daher mit Anführungszeichen versehen sein. Es sei angemerkt, dass mit der amerikanischen "Rassenfrage « ausschließlich der mehrdimensionale, über den Beobachtungszeitraum hinaus ungelöste Problemkomplex des Verhältnisses zwischen weißer Mehrheitsbevölkerung und afroamerikanischer Bevölkerung in den USA gemeint ist. 
spektive Urteil, afroamerikanische Themen seien von einem übermächtigen WASP ${ }^{19}$-Narrativ von Amerikas Geschichte und Gegenwart überdeckt worden, lässt sich für die deutsche Perspektive nicht bestätigen. Die notwendige Blickwinkelverschiebung einer postkolonialistischen und auf Dekonstruktion bedachten Historiografie leuchtete fraglos viele Bereiche und Themen aus, die einst im Schatten der von nationalen Mehrheiten kanonisierten Meisternarrative standen. Die recht spezielle Konstellation eines deutschen Blickes auf die afroamerikanische Minderheit und die Widrigkeiten ihrer Existenz in Staat und Gesellschaft stellte die Ausnahme von der Regel dar. Auch sind es, um diesem berechtigten Einwand der postkolonialen Theorie vorzugreifen, freilich keine Afroamerikaner, die ihre eigene Situation schildern und Probleme identifizieren, ${ }^{20}$ sondern deutsche Journalisten. Auf eine Selbstdarstellung zielt der hier gewählte Ansatz jedoch ebenso wenig ab. Der zweifelsohne "koloniale« Blick der deutschen Massenpresse ist daher kein konzeptionelles Problem, sondern das eigentliche Untersuchungsobjekt.

Während des Krieges war in den Illustrierten aus Propagandagründen viel rassistische Stereotypenbildung betrieben worden. Afroamerikanische Soldaten wurden als marodierende Trunkenbolde oder notorische Vergewaltiger dargestellt. ${ }^{21}$ Nach Kriegsende verlagerte sich das Interesse allmählich auf die soziale, rechtliche und wirtschaftliche Situation der afroamerikanischen Bevölkerung. Dabei schwankten Beiträger wie Hans Christoph Kaergel ${ }^{22}$ zwischen der Anerkennung der Ungerechtigkeiten, die Afroamerikanern nach wie vor widerfuhren, und ihrer Charakterisierung als passive, stets einem jeweiligen Herrn unterworfene Diener. Ein Schwebezustand zwischen formaler Gleichberechtigung und fortdauernder Versklavung, so Kaergel, zementiere ihre Position als Bodensatz der amerikanischen Gesellschaft. ${ }^{23}$ Das Phlegma

19 White, Anglo-Saxon, Protestant.

20 Eine Problemlage, die auftritt, wenn Gruppen auf Grund von Ethnie oder Klassenzugehörigkeit in ihrer Selbstdarstellung und Selbstwahrnehmung negativ beeinträchtigt sind. Die statusbedingt mangelhafte Artikulationsfähigkeit im öffentlichen Diskurs beeinträchtigt die Selbstkonzeption und umgekehrt. Vgl. dazu: Spivak, Gayatri: Can the Subaltern Speak? In: Nelson, Cary/Grossberg, Lawrence (Hg.): Marxism and the Interpretation of Culture. Chicago 1988, 271-313.

21 Anon.: Die Waffenbrüder. Der Amerikaner in Frankreich: „Diese Genossen im Kampf für die Zivilisation möchte ich Wilson mal zeigen!«. In: BIZ, 1918, Nr. 30, Titel.

22 Kaergel lässt sich mit Blick auf sein literarisches Werk als völkisch-nationaler Heimatschriftsteller charakterisieren. Einige seiner späteren Veröffentlichungen reichen zu diesem Urteil aus: Kaergel, Hans Christoph: Die Heimat ruft. Gütersloh 1936. Sowie Kaergels Hitler-Biographie: Ders.: Der Volkskanzler. Leben und Werden Adolf Hitlers von der Jugend bis zum Führer des Volkes. Für Jugend und Volk erzählt. Langensalza 1938.

23 »Sie sind Sklaven geblieben, nur die Besitzer haben gewechselt. Ihr Gebieter heißt >der Dollar und er hat jetzt genug weiße Sklaven mit unter seiner Peitsche. Ich sah sie (die Schwarzen) beim Häuserbau als Ziegelträger, sie kehrten in allen Wirtschaften den 
der Black Community sei die Folge jahrhundertelanger Sklaverei und habe sich »ihren Vätern und Vorvätern mit der Sklavenpeitsche ins Gesicht" gegraben. »Heimatlos, verkauft und ins Joch gebeugt«, trügen »sie ein Gesicht, ein Leben, das im Grunde genommen nicht zu ihnen gehört. $^{24}$ Augenfällig ist die klare Objektivierung der Afroamerikaner. Der Eindruck, es handele sich bei ihnen um eine "Spezies«, die man gewaltsam aus ihrer natürlichen Umgebung gerissen habe, ${ }^{25}$ verneint die Zugehörigkeit der Black Community zur amerikanischen Gesellschaft. Diese zwischen Objektivierung und Viktimisierung oszillierende Darstellung ist die konstitutive Perspektive der Weimarer Presse auf die Black Community der USA.

Dieser Perspektive stand das Bemühen um die Vermittlung von Innenansichten einer funktionierenden, entwicklungsfähigen afroamerikanischen Gemeinschaft entgegen. Trotz deren noch ausstehender Integration in die amerikanische Mehrheitsgesellschaft sei ihr nach innen die Herstellung sozialer Normalität gelungen. ${ }^{26}$ Bei dem Versuch dies darzustellen, griffen, wie eingangs erwähnt, ähnliche Mechanismen wie im Zusammenhang der Frauenemanzipation. So wird zum Beispiel die Ausübung polizeilicher Aufgaben durch Afroamerikaner als ein Schritt in Richtung sozialer und ziviler Normalität innerhalb der Black Community dargestellt. Das Visual aus der MIP (Abb. 8) zeigt einen afroamerikanischen Verkehrspolizisten in aufrechter Haltung auf dem Mittelstreifen einer Straße beim Regeln des Verkehrs. Die erhobene Hand, der leicht angehobene rechte Fuß und die tadellose Uniform vermitteln einen Eindruck von Routine und Souveränität. Die durch diese Details fast statuen- oder ikonenhaft geratene Inszenierung ordnender Staatsgewalt und ihre Identifikation mit einem Angehörigen der afroamerikanischen Minderheit hebt die Grenze zur Mehrheitsgesellschaft und Zivilität für die Dauer des eingefangenen Moments auf. Der Versuch indes, die visuelle Darstellung textuell zu ergänzen steht beispielhaft dafür, wie unsicher deutsche Beiträger im Umgang mit derlei Eindrücken waren. So lautet die Bildunterschrift: »Der

Unrat aus den Stuben, sie schleppten als >Porter` die mächtigen Koffer, sie säubern die Straßen und stehen im Fahrstuhl. Aber überall der gleiche traurige, stumpfe Blick." Kaergel, Hans Christoph: Amerikanische Bilder. Im Negerviertel. In: MNN Nr. 187 vom 08.07.1925, $3 \mathrm{f}$.

24 Ebd., 3.

25 »Nachts aber will es, namentlich am Samstag, nicht Ruhe geben. Ich kann nicht schlafen. Durch die dünnen Holzwände heult es unaufhörlich in einem ewigen Auf und Ab. Die Neger singen. Sie hocken im Hause gegenüber in einer heimlichen `Whisky-Schenke und stürzen sich mit dem schlechtesten Gebräu aus dem Rasen ihrer Welt in die Urheimat, aus der sie im Grunde genommen nicht gerissen sind. Sie fahren in den Bretterhäusern immer wieder zurück und lärmen in den Nächten ihre Heimat herbei. Mich aber durchschauert es bei diesem Gesang." Ebd.

26 Was mit dem Begriff der Normalität oder Normalisierung in diesem Zusammenhang konkret gemeint ist, wird im Weiteren noch auszuführen sein. 


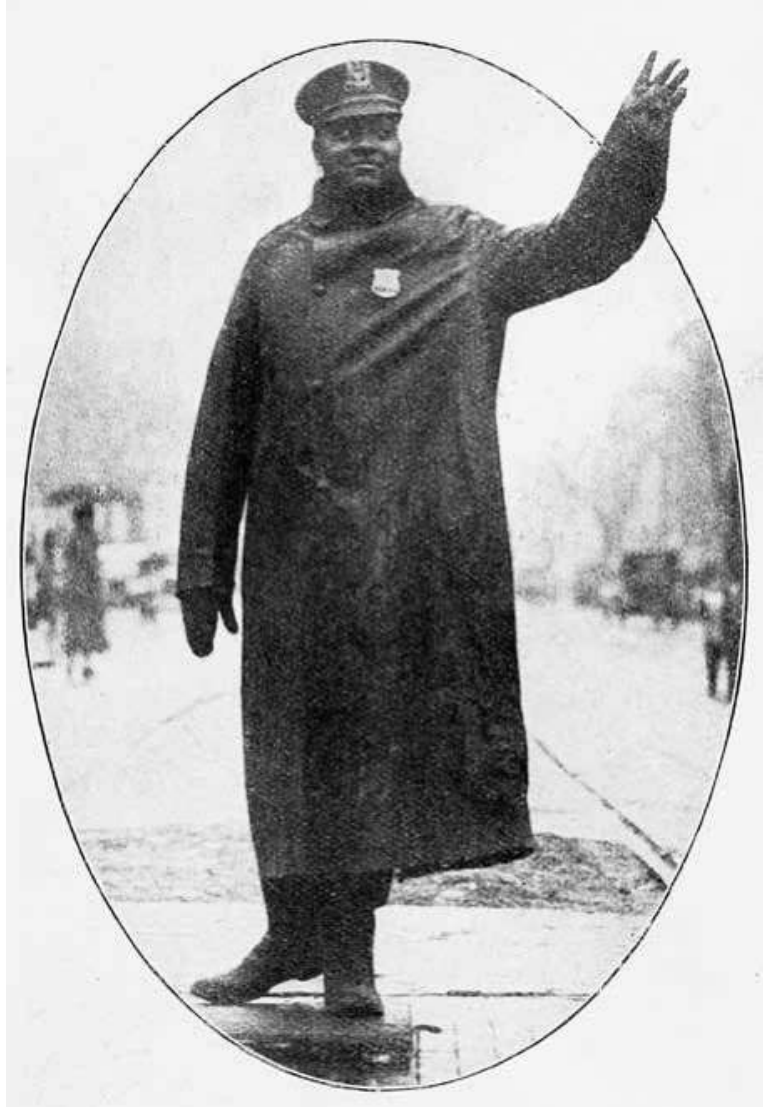

Abb. 8: Halfeld, Alfred: Das Neuyorker Stadtviertel Harlem. Die Neger-Metropole der Welt. In: MIP, 1926, Nr. 49, 1172 (Jahresausgabe). »Der schwarze Verkehrsschutzmann - er hat das Selbstbewußtsein seiner weißen Kollegen.»

schwarze Verkehrsschutzmann - er hat das Selbstbewußtsein seiner weißen Kollegen. ${ }^{27}$

Ohne den Rückgriff auf das als Norm gesetzte weiße Pendant des schwarzen Polizisten erschien zeitgenössischen Journalisten eine Beschreibung der Situation immer noch schwierig. Überhaupt unterscheiden sich Text und Visual des Artikels deutlich voneinander. Die visualisierte Ankunft der Afroamerikaner in zivilgesellschaftlichen und staatlichen Machtstrukturen relati-

27 Halfeld, Alfred: Das Neuyorker Stadtviertel Harlem. Die Neger-Metropole der Welt. In: MIP, 1926, Nr. 49, 1172 (Jahresausgabe). 
viert Halfeld unmissverständlich. Er stellt die partizipatorischen Erfolge der Black Community als freiwillige Preisgabe, als paternalistisch-gönnerhafte Gewährung durch die weiße Mehrheitsgesellschaft dar, vulgo: Weiße Amerikaner bestimmen, ob und wie weit sich die Black Community entfalten darf. Der Artikel, aus dem das Visual stammt, stilisiert das New Yorker Stadtviertel Harlem zu einem repräsentativen Beispiel dafür, wie sich die Afroamerikaner inmitten der ansonsten durch weiße Amerikaner und europäische Einwanderer dominierten Metropolen ihre eigenen Gemeinschaften aufbauen. Hier ist aber nicht von einer aus eigener Initiative und Befähigung erwachsenden Selbstbestimmung die Rede. Vielmehr bleibt der Eindruck einer defizitären (weil afroamerikanischen) Selbstorganisation von Gnaden des desinteressierten weißen Amerika zurück, wie an den Erläuterungen der Polizei- und Verwaltungsarbeit deutlich wird:

»Hier greift die weiße Polizei wenig ein; wie alles ist auch die Führung der öffentlichen Aufsicht in den unteren Stellen den Negern überlassen. So ereignet sich manches in den dunklen Seitenstraßen Harlems, wovon sich selbst die speak-easys und die Night Clubs zwischen Times Square und Columbus Circle wenig träumen ließen. ${ }^{28}$

Mit der Darstellung gesellschaftlicher Normalität in der Black Community sahen sich die Beiträger nichtsdestotrotz in einer Vorreiterrolle. Einblicke in die afroamerikanische Gesellschaft wurden von ihnen stets mit der weißen amerikanischen Norm in Beziehung gesetzt, verglichen und letztlich hierarchisiert. Die Darstellungen schwankten dabei zwischen dem ehrlichen Anliegen, authentische Einblicke in die afroamerikanische Komponente der amerikanischen Zivilisation zu vermitteln, und der Verharrung in hierarchisierenden, pejorativen Denkmustern. Hinsichtlich der Ausdrucksmittel, die diesen Zwiespalt illustrieren, zeichnet sich ein signifikantes Ungleichgewicht zwischen Visuals und Text ab. Während visuell afroamerikanisches Alltagsleben als von seinem weißen Pendant nicht unterscheidbar vermittelt wird, erfolgt die Relativierung oder Abschwächung dieses Eindrucks auf textueller Ebene.

Deutlich wird dies auch in Josef Marx' Reportage "Im Schwarzen-Viertel in Detroit ${ }^{29}$. Die Visuals illustrieren den Alltag schwarzer Amerikaner als kleinbürgerliches Idyll. $\mathrm{Zu}$ sehen ist neben einem jungen Paar beim Flanieren eine Gruppe modisch gekleideter Damen im Gespräch (Abb. 9). Auf der folgenden Seite sind eine Dame beim Einkaufen samt eigenem Auto (!), junge Passantinnen und ein Zeitungsjunge zu sehen. In keiner der Darstellungen lässt sich eine Stereotypisierung oder eines der gängigen, damals weit verbreiteten Vorurteile über Afroamerikaner ausmachen. Ganz im Gegenteil: Vergegenwärtigt man

29 Marx, Josef: Im Schwarzen-Viertel in Detroit. In: BIZ, 1928, Nr. 7, 275 f. (Jahresausgabe). 

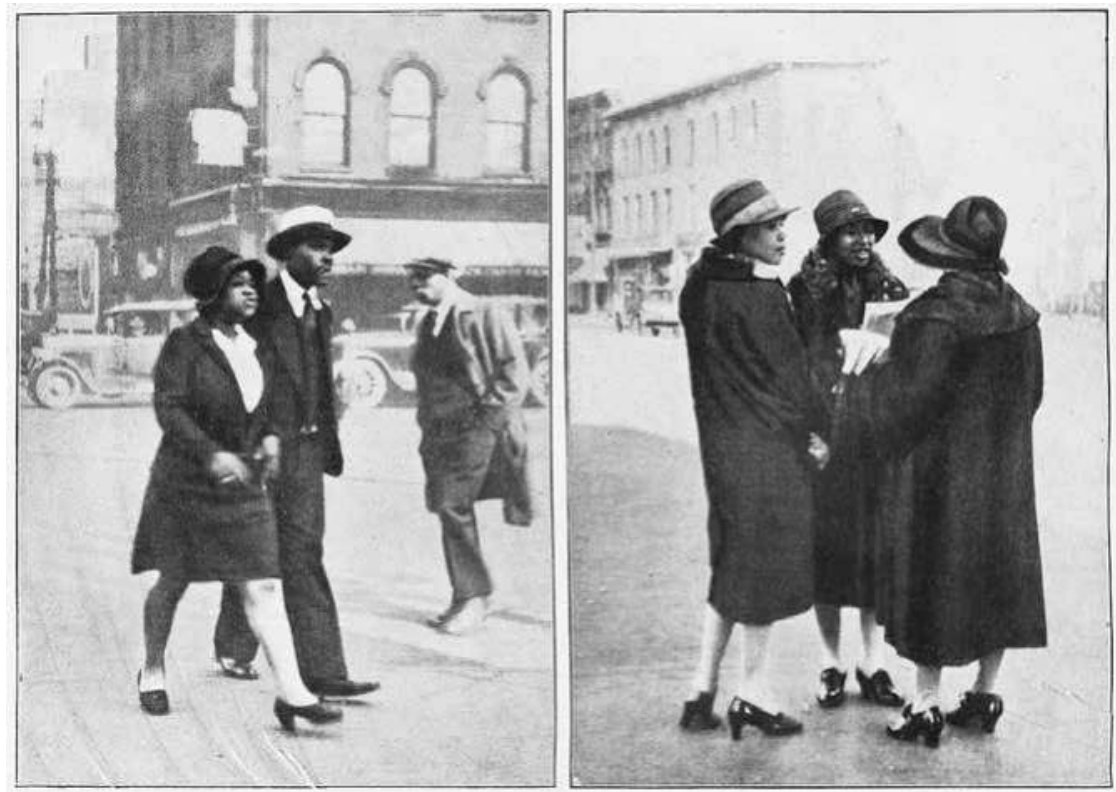

Abb. 9: Marx: Im Schwarzen-Viertel in Detroit. „Augenblicksbilder aus dem Schwarzen-Viertel der amerikanischen Stadt Detroit, dem Zentrum der Automobilindustrie. ıSie mit ihm، (Negermädchen mit ihrem Bräutigam). Gesellschaftsklatsch.»

sich die soziale und wirtschaftliche Situation der Afroamerikaner während der Zwischenkriegszeit, ist eher eine Überzeichnung bürgerlicher Normalität zu konstatieren, die für die Zeit unter keinen Umständen als repräsentativ angesehen werden kann. ${ }^{30}$

Im Gegensatz zur beschaulichen Bebilderung liest sich der Text des Artikels durchaus kritisch, insbesondere in der Beurteilung des Verhältnisses zwischen

30 Zwischen 1918 und 1932 stagnierten die Löhne ungelernter Arbeiter, größtenteils Afroamerikaner. Die schwarze Bevölkerung genoss dementsprechend nicht in gleichem Maße den Anstieg des Lebensstandards, den die 1920er Jahre für die amerikanische Gesellschaft insgesamt zeitigten. Vgl. David, Paul/Solar, Peter: A Bicentenary Contribution to the History of the Cost of Living in America. In: Research in Economic History, Nr. 2 (1977). Greenwich 1977, 59. Zudem wird die Zwischenkriegszeit aus sozial- und wirtschaftshistorischer Sicht als der Zeitabschnitt mit der insgesamt größten Einkommensungleichheit überhaupt charakterisiert. Dies legt zusätzlich zu oben genannten Faktoren und angesichts der als notorisch zu bezeichnenden Lohnunterschiede zwischen den verschiedenen Ethnien der USA eine ausgeprägte Lohnbenachteiligung der afroamerikanischen Bevölkerung nahe. Vgl. Barlevy, Gadi/Tsiddon, Daniel: Earning Inequality and the Business Cycle. Working Paper 10469. National Bureau of Economic Research. Cambridge 2004, $25 \mathrm{f}$. 
weißen Amerikanern und Afroamerikanern. Den auch im Norden weit verbreiteten Alltagsrassismus verdeutlicht Marx an einem »klassischen« Beispiel:

»Dem Gesetz nach genießt der schwarze Bürger dieses ıfreien Landes` die gleichen Rechte und Freiheiten wie sein weißer Landsmann. In Wirklichkeit sieht es damit aber ziemlich trübe aus. Eine kleine Episode, wie ich sie häufig genug beobachtet habe, die das Verhältnis zwischen Schwarz und Weiß beleuchtet: In ein Restaurant, das von einem Weißen geleitet wird, kommt ein Neger und macht eine Bestellung. >Das haben wir nicht.r Er bestellt etwas anderes und bekommt die gleiche Antwort. Noch einen dritten Versuch macht er und muß wieder hören: ১Das haben wir nicht! Er erhebt sich und geht, nein, schleicht hinaus. Ich werde den Eindruck in seinem Gesicht, gemischt aus Scham und Haß, nie vergessen. Im Süden, ihrer amerikanischen Heimat, haben die Schwarzen noch viel mehr dergleichen zu ertragen.. ${ }^{31}$

Mit dieser Beschreibung zeigt Marx das grundsätzliche Paradoxon im Verhältnis zwischen Black Community und amerikanischer Mehrheitsgesellschaft auf. Die schrittweise durch den 13. (1865), 14. (1868) und 15. (1870) Zusatzartikel kodifizierte verfassungsrechtliche Gleichstellung afroamerikanischer Staatsbürger wurde in der politischen, rechtlichen und sozialen Praxis unzureichend oder gar nicht realisiert, wobei es regionale Unterschiede gab. ${ }^{32}$ Die im Quellenauszug beschriebene Form subtiler sozialer Diskriminierung war typisch für den industriellen Nordosten der USA, wo sich Afroamerikaner während der »Great Migration« ab 1910 niedergelassen hatten. Klassenunterschiede zwischen zuwandernden Afroamerikanern aus dem Süden und weißen Industriearbeitern im Norden fielen mit ethnischer Exklusion zusammen, was zu einer »Ethnisierung der Klassenkonflikte $\aleph^{33}$ vor Ort führte. Die Problematisierung all jener Missstände durch deutsche Beobachter wie Josef Marx legt eine ausgeprägte Sensibilität für diese elementare Verwerfungslinie des sozialen Gewebes der US-Gesellschaft nahe. Am Schluss des Artikels zeigt sich aber, wie schwer es auch dem Autor fiel, den Widerspruch zwischen erlebter Normalität und empfundener Fremdheitsbedrohung für sich selbst und seine Leserschaft aufzulösen:

»An einer Ecke, im Schutze eines weißen Polizisten, knipse ich noch den snigger flapper (Negerbackfisch) mit Anhang und die drei tratschenden scoloured ladies`.

31 Ebd., 275.

32 Wobei die zeitgenössische juristische Debatte offenbarte, dass selbst bei vollumfänglicher Anerkennung der Zusatzartikel 14 und 15 das Wahlrecht für männliche Afroamerikaner nicht garantiert war. Der 14. Zusatzartikel erkannte die Wahlrechtsverweigerung aus Gründen der Rasse in den Einzelstaaten an. Der 15. wiederum gestand Afroamerikanern nicht explizit das passive Wahlrecht zu und stellte die Wahlrechtsbeschränkung aus anderen Gründen frei. Vgl. Berg, Manfred: The Ticket to Freedom. Die NAACP und das Wahlrecht der Afroamerikaner. Frankfurt u. a. 2000, $34 \mathrm{f}$.

33 Saldern, Adelheid von: Amerikanismus. Stuttgart 2013, $186 \mathrm{f}$. 
Und ich muß gestehen, ich hatte beim Anblick dieser rein menschlichen Vorgänge ein ganz behagliches Gefühl. Es gibt doch nicht nur Gegensätze zwischen Schwarz und Weiß.巛 ${ }^{34}$

Mit seinem Problembewusstsein stand Marx nicht allein. Beschäftigten sich Reiseberichterstatter mit der Black Community, so vergaßen sie nie, das je nach Region teils offizielle, teils subtile Regime der Rassentrennung zu kritisieren. Ohne es beim Namen zu nennen, stellen entsprechende Berichte episodisch das Prinzip »separate but equal" dar, das verquere Zusammendenken kodifizierter staatsbürgerlicher Gleichheit und praktizierter sozialer Ungleichbehandlung. In verklausulierter Form finden sich schlagwortartig verdichtete Beobachtungen über die unterschiedlichen Konventionen, die diesbezüglich in den Nord- und Südstaaten galten:

»Immer die Angst des Weißen: vor der mit Mühe gebändigten Wildheit dieser Erniedrigten und Beleidigten, die sich einmal Bahn brechen kann. [...] Ein einziges Mal habe ich eine weiße Amerikanerin ins Negerviertel mitgenommen. Sie zu beobachten war interessanter als jedes Buch über die Negerfrage zu lesen: sie war erregt, trunken von ihrer eigenen Tapferkeit und Toleranz - nachher bat sie mich, unseren gemeinsamen Freunden den Ausflug zu verschweigen. Im Stillen ist sie vielleicht noch nicht so ganz davon überzeugt, daß es wirklich Menschen sind. Dem Europäer, der zum erstenmal [sic] die Küste Amerikas betritt, versucht man einzureden, die Negerfrage sei nicht mehr akut [...]. In Wahrheit gibt es in Amerika nur zwei Einstellungen der Weißen zu den Negern. Der des Nordens sagt - und meint: ১Steige so hoch wie Du willst - aber komm mir um Gotteswillen nicht zu nah. Der des Südens: `Ich habe Dich gern, lebe in meiner Nähe - aber laß Dir’s nicht einfallen, zu steigen. « ${ }^{35}$

Derlei Schilderungen liegen auf einer Traditionslinie mit bereits 1848/49 in Deutschland geführten Sklaverei-Debatten. Stilisierte man die USA in Sachen bürgerliche Freiheitsrechte damals zur Referenz für die Erneuerung der deutschen Länder, folgte von konservativer Seite reflexhaft der Hinweis auf das ungeklärte Rassenverhältnis. Die Existenz der Sklaverei wurde mit der Gleichheit aller Menschen vor dem Gesetz und überhaupt konterkariert. ${ }^{36}$

Staatlich geduldete oder betriebene Rassendiskriminierung charakterisiert das auf unveräußerlichen Menschen- und Bürgerrechten fußende Verständnis Amerikas als "moderner Staat« als zutiefst inkonsistent. Dies erkannten und beschrieben konservative, liberale, nationalsozialistische und kommunistische Zeitgenossen gleichermaßen, wenn auch auf Grundlage divergenter Überzeugungen. Die sozial und verwaltungstechnisch praktizierte Trennung

34 Marx: Im Schwarzen-Viertel in Detroit, 276.

35 Anon.: Neger unter sich. Besuch im Schwarzen-Viertel. In: VZT Nr. 216 vom 09.05.1930, 15.

36 Vgl. Lerg, Charlotte: Amerika als Argument. Die deutsche Amerika-Forschung im Vormärz und ihre politische Deutung in der Revolution von 1848/49. Bielefeld 2011, $306 \mathrm{f}$. 
(qua Verfassung) gleichberechtigter Individuen entlang ethnischen Kategorien relativiert den Begriff des Staatsbürgers fundamental. Dieser aber war und ist eine Konstituante modernen Staatsverständnisses.

Amerika offenbarte hinsichtlich der Frage des Umgangs mit ethnischen Minderheiten tiefreichende Bruchlinien, die zeitgenössischen Erwartungen an Moderne zuwiderliefen. Ein historisches Urteil über die Weimarer Republik wendet sich somit auch zu einem Verdikt über die Vereinigten Staaten. Wenn Weimar "Versprechen und Tragödie ${ }^{37}$ der Moderne zugleich war, dann zeichnete sich das "tragische" Element des abgebrochenen oder nie erfolgten Aufbruchs in Moderne auch an der amerikanischen "Rassenfrage «ab. Die klassische Dichotomie der Weimar-Geschichtsschreibung, "Versprechen und Tragödie«, dürfte also ebenso auf den Ungeist der Zeit der Klassischen Moderne als Ganzes passen.

\subsection{Rassismus als Bruch amerikanischer Modernität}

Die zwischen dem Norden und Süden der USA bestehenden Unterschiede in der Praxis der Rassentrennung wurden in der deutschen Presse nicht nur an Einzelbeispielen veranschaulicht, sondern in den größeren Sinnzusammenhang einer eigenständigen Südstaatenmentalität gestellt. Zuweilen wurde, was die rechtliche und soziale Behandlung der Afroamerikaner angeht, gar von einem verspäteten Sieg der Konföderierten geschrieben. ${ }^{38}$ Diese Einordnung und ihr eklektischer Entwurf einer Südstaatenmentalität zwischen Rassentrennung, Gastfreundschaft und »Culture of Honor ${ }^{39}$ ist zweifellos fragwürdig. Dessen unbenommen betonten zahlreiche Berichterstatter und Kommentatoren, dass den im Zusammenleben verschiedener Ethnien auf-

37 Vgl. Weitz, Eric D.: Weimar Germany: Promise and Tragedy. Princeton 2007, $331 \mathrm{f}$.

38 »In der Schule hat man uns beigebracht, daß die Nordstaaten den amerikanischen Bürgerkrieg im Jahre 1865 gewonnen haben. [...] Aber das ist eine Legende. Denn manche Kriege werden erst Jahre und Jahrzehnte, nachdem der letzte Schuß gefallen ist, entschieden. Und wenn auch die politische und wirtschaftliche Führung seitdem ganz auf den Norden übergegangen ist [...], so sind in der Frage - um die dieser Krieg eigentlich geführt wurde: Sollen die Neger, die der Geschäftssinn und die Brutalität weißer Männer nach Amerika gebracht hat, hier frei und gleichberechtigt leben dürfen? - die Südstaaten - das kann man heute, sechzig Jahre später, ganz sachlich und objektiv feststellen - unzweifelhaft Sieger geblieben.« Olden, Peter: Sklaverei in Florida. In: BIZ, 1930, Nr. 14, 582 (Jahresausgabe).

39 In sozialpsychologischen Betrachtungen der Südstaaten wurde gezeigt, dass das Konzept von Ehre, "Rassenbewusstsein « und Klassenbewusstsein in direktem Zusammenhang mit der größeren Gewaltbereitschaft bei dessen Verletzung einherginge. Die individuelle, nichtstaatliche Anwendung von Gewalt stieße hier auf höhere Akzeptanz als im Norden. Vgl. Nisbett, Richard/Cohen, Dov: Culture of Honor. The Psychology of Violence in the South. Boulder 1996, 1-12 und 57-95. 
tretenden Problemen nicht etwa eine "natürliche« Logik innewohne. Eine spezielle Geisteshaltung in den Südstaaten sei stattdessen der Ursprung allen Übels, deren Exzesse in abgeschwächter Form auch im soziokulturell anders geprägten Norden Widerhall fänden. Auch die mangelnde Bereitschaft von Eliten und Mehrheitsbevölkerung, evidente Widersprüche in der politischen und sozialen Praxis der Rassentrennung aufzulösen, wurde als problematisches Moment identifiziert.

Wo aber finden sich nun Anknüpfungspunkte an deutsche Debatten? Schließlich spielten ethnische Konflikte, abgesehen vom kulturell verwurzelten und später politisch instrumentalisierten Antisemitismus, in der nach 1918 ethnisch vergleichsweise homogenen deutschen Gesellschaft kaum eine Rolle.

Zur Beantwortung dieser Frage rückt die Sonderrolle der amerikanischen »Rassenfrage« hinsichtlich des in der deutschen Perzeption konstruierten Bildes vom "modernen Amerika" in den Blick. Die deutsche Massenpresse diskutierte die Frage, wie moderne Gesellschaftsorganisation auszusehen habe, so intensiv wie kaum eine andere. Entsprechend sensibel reagierte man bei dem auf (fast) allen Zukunftsfeldern weit enteilten Vorbild Amerika auf den tiefen Bruch dieses Nimbus: die auch damals als weder zeit- noch normengemäß beurteilte Behandlung der schwarzen Minderheit. Als wunder Punkt der Amerikabetrachtung lieferte dieser Themenkomplex immer wieder denjenigen Argumente, die in den USA in Sachen Freiheit und Bürgerrechte eben kein glänzendes Vorbild für die Modernisierung Deutschlands sahen. ${ }^{40}$

In der deutschen Medienöffentlichkeit fügte sich die amerikanische »Rassenfrage« in einen intensiv laufenden Selbstverständigungsprozess ein. Elementare Kategorien wie Klasse, Stand, Gesellschaft und Volk, wurden hinterfragt, umdefiniert und für die eigene Sache besetzt. Scheinbar widersprüchliche Tendenzen wirkten dabei zusammen. Der Nachhall der Ideen von 1914 und eine verklärende Erinnerung an das Augusterlebnis, das die zersplitterte Vorkriegsgesellschaft vermeintlich geeint hatte ${ }^{41}$ kollidierten mit

40 Vgl. dazu nochmals: Lerg: Amerika als Argument, $299 \mathrm{f}$.

41 Dass der Mythos Augusterlebnis aus ideologischen Gründen während des Kriegsbeginns und nach der Kriegsniederlage von Einzelbeispielen des Kriegs-Enthusiasmus zu einem kollektiven Erweckungs- und Einigungserlebnis stilisiert wurde, stellte Andreas Wirsching fest. Er betonte, die Reaktionen auf den Kriegsausbruch seien von der Klassen- und Milieuzugehörigkeit abhängig gewesen. Bürgertum und Studenten hätten enthusiastisch, Arbeiter deprimiert auf die Kriegserklärung reagiert. Damit bestätigte er die seit den 1960er Jahren vertretene These, dass es sich bei zentralen Angelpunkten der deutschen Wahrnehmung des Ersten Weltkriegs überwiegend um mythisierte Konstruktionen handle. Vgl. Wirsching, Andreas: "Augusterlebnis« 1914 und "Dolchstoß« 1918 zwei Versionen derselben Legende? In: Dotterweich, Volker (Hg.): Mythen und Legenden in der Geschichte. München 2004, 191. 
dem Unbehagen an gesellschaftlicher Nivellierung und der Furcht vor dem Fall aller sozialen Schranken. ${ }^{42}$

Die brutale Trennlinie zwischen schwarzem und weißem Amerika stellte einen Ankerpunkt für den Zweifel an der Unumgänglichkeit gesellschaftlichen Fortschritts nach US-Muster dar. Das Benennen offenkundiger Probleme diente der Adressierung unausgesprochener Paradoxien, die sich durch die Psyche der "verworfenen Nation" Deutschland zogen. ${ }^{43}$ Die ambivalente Faszination, die für die Deutschen von Themen wie Lynchjustiz, dem angeblichen de facto-Fortbestand der Sklaverei in Gestalt sozialer und politischer Benachteiligung Schwarzer, dem Mordtreiben des Ku Klux Klan und dem "Kastenwesen ${ }^{44}$ der US-Gesellschaft ausging, ersetzte die Problematisierung der eigenen gesellschaftlichen Zerrissenheit und des Nebeneinander und Ineinander unvereinbarer Gegensätze. ${ }^{45}$

Die Beschreibung der Existenz antimoderner Erscheinungen im vermeintlich modernsten Land der Welt, einer profunden Gleichzeitigkeit des Ungleichzeitigen, ${ }^{46}$ externalisierte ein deutsches Paradoxon. Dieses bestand in der Sehnsucht nach der klassenlosen Volksgemeinschaft auf der einen und der Angst vor einer alle menschlichen Unterschiede einebnenden Moderne auf der anderen Seite. Die Vision, eine klassenlose Gesellschaft mit der Aufrechterhaltung einer für das soziale Ganze unabdingbaren Hierarchie zu vereinbaren, stellte während der Zeit der Weimarer Republik eines der wenigen

42 Dass jene Entwicklungen teils anders verliefen als wahrgenommen, teils ohne tatsächliche Grundlage vollständig imaginiert waren, hat unter anderem Jürgen Kocka gezeigt. Dazu: Kocka, Jürgen: Klassengesellschaft im Krieg. Deutsche Sozialgeschichte 1914-1918. Göttingen 1973, $96 \mathrm{ff}$.

43 Vgl. Dahrendorf, Ralf: Gesellschaft und Demokratie in Deutschland. München 1965, 59-75.

44 Johnston, Alva: Kastenwesen in Amerika. In: QUS, 1932, Nr. 8, 44. Hier werden neben der rassistischen Abgrenzung in der amerikanischen Gesellschaft quasi-aristokratische Strukturen thematisiert, mit denen sich in Verbänden organisierte alteingesessene Familien, die sich auf die Gründerväter und alte Einwanderer-Eliten englischen und holländischen Ursprungs beriefen, gegen sozialistische und emanzipatorische Bestrebungen unterprivilegierter Gruppen abzugrenzen versuchten.

45 Was dem allgemeinen Verständnis des Dahrendorfschen Wortes von der »verworfenen Nation « aber durchaus mehr entspricht, als ein ausschließlich auf Deutschland begrenzter Blick. Vgl. Dahrendorf: Gesellschaft und Demokratie in Deutschland, $65 \mathrm{f}$.

46 Bloch, Ernst: Erbschaft dieser Zeit. Gesamtausgabe, Bd.4. Frankfurt a. M. 1962, 104: "Nicht alle sind im selben Jetzt da. Sie sind es nur äußerlich, dadurch, daß sie heute zu sehen sind. Damit leben sie aber noch nicht mit den anderen zugleich. Sie tragen vielmehr Früheres mit, das mischt sich ein." Und: Ders.: Tübinger Einleitung in die Philosophie, Bd. 1. Frankfurt a.M. 1967, 201: "Der Fortschrittsbegriff duldet keine >Kulturkreise<, worin die Zeit reaktionär auf den Raum genagelt ist, aber es braucht statt der Einlinigkeit ein breites, elastisches, völlig dynamisches Multiversum, einen währenden und oft verschlungenen Kontrapunkt der historischen Stimmen.« 
konsensfähigen Gesellschaftsziele dar. ${ }^{47}$ Hinsichtlich des reaktionären Modernismus, der substantieller Bestandteil Weimarer Intellektuellendebatten und Grundkonsens des »Dritten Reichs « war ${ }^{48}$ entfaltet sich im Komplex von Ethnizität und Pluralismus ein anschauliches Beispiel für die differenzierende und selektive Wahrnehmung amerikanischer Modernität in der Weimarer Öffentlichkeit. Diese deutete das amerikanische Modernitätsmodell als relational und erkannte die Inkonsistenz von Moderne an.

Wie aber wurde die Problematik von Rassendiskriminierung und rassistischer Gewalt im öffentlichen Diskurs der Weimarer Republik konkret verhandelt? Ein Artikel über die Praxis politischer Diskriminierung von Afroamerikanern sowie die ihnen zugrundeliegende Geisteshaltung erschien 1929 in der Frankfurter Zeitung. Er zeigt stellvertretend, ${ }^{49}$ auf welche Punkte die Pressedebatte um die Rassendiskriminierung besonders abhob:

»Während der Schnellzug in tagelanger Fahrt durch Maryland, Virginia, Nord- und Süd-Carolina und Georgia dem Süden zuraste, brachte mein Reisegefährte aus Jacksonville, Florida, das Gespräch zwangsläufig auf das Thema, das schließlich immer wieder das Alpha und das Omega aller politischen Gespräche im amerikanischen Süden bilden muß: den Neger. Für uns, die wir im Norden leben - sagte ich - ist doch der Neger überhaupt kein politisches Problem [...]. Wenigstens wird ihn niemand daran hindern, wählen zu gehen, wenn er Lust dazu hat. ${ }^{50}$

Im Süden, in dem zum damaligen Zeitpunkt ungefähr drei Viertel der Afroamerikaner lebten und damit auch deren Anteil an der dortigen Bevölkerung wesentlich höher war, sei dies allerdings vollkommen anders:

»[D]ie starke Negerbevölkerung der Südstaaten läßt das Gespenst einer sschwarzen Gefahr in den Köpfen der dort lebenden Weißen nicht zur Ruhe kommen. Die traditionelle Verachtung des Negers aus der Sklavenzeit in Verbindung mit verschiedenen mißglückten Versuchen, den Neger nach dem Bürgerkrieg sozial auf eine höhere Stufe zu stellen, tut ein Übriges. Hinzu kommen die nicht gerade erhebenden Resultate der Rassenvermischung im benachbarten Mexiko, die man aus nächster Nähe zu

47 Vgl. Nolte, Paul: Die Ordnung der deutschen Gesellschaft. Selbstentwurf und Selbstbeschreibung im 20. Jahrhundert. München 2000, $159 \mathrm{f}$.

48 Herf: Reactionary Modernism, $22 \mathrm{f}$. Insbesondere die selektive Perzeption der Moderne, die technische Innovationen und größere medizinische Möglichkeiten zwar enthusiastisch begrüßte, die liberale Demokratie, Gleichberechtigung oder soziale Nivellierung jedoch ablehnte, war eine Tendenz, die sich bereits in der Weimarer Republik abzeichnete und im »Dritten Reich" voll zum Tragen kam.

49 Unter anderem für: Feder, Ernst: Unter dem Jim-Crow-System. Eindrücke im Süden Die soziale und ökonomische Trennung zwischen Weissen und Farbigen. In: BTB, 1930, Nr. 328, 1 f.

50 Anon.: Amerikanische Neger. In: FZT Nr. 952 vom 22.12.1929, 1 f. [Hervorh. im Original, D.F.]. 
beobachten Gelegenheit hatte, und schließlich gipfelt alles in dem Satz: >Wir sind weiß und wollen weiß bleiben seinem Platze.) Mit diesem Grundsatz haben wir unsere angelsächsische Rasse - was uns keiner abstreiten kann - als einzige von allen amerikanischen Völkern von farbigem Blut reingehalten. Bei uns weiß der Neger, wo er hingehört. Er weiß, daß es 'nicht gesund ‘ für ihn ist, sich gleiche Rechte mit dem Weißen anzumaßen, wählen zu gehen und dergleichen mehr. ${ }^{51}$

An dieser Stelle erscheint das rassistische Motiv der "Reinerhaltung der Rasse" als Grundlage der Rassentrennung. Hinzu kommt eine Objektivierung der Afroamerikaner, die sich in der Formulierung äußert, es sei eine politische, im Ausgang des Bürgerkrieges begründete Maßnahme, die afroamerikanische Bevölkerung "sozial auf eine höhere Stufe zu stellen. " $^{52}$ Die Verbesserungen für die Afroamerikaner werden als Resultat einer angeblichen Siegerjustiz vonseiten der Union dargestellt.

Nun wäre der Segregation alleine wohl keine so hohe Aufmerksamkeit zuteil geworden, hätte sich in ihr nicht ein so krasser Widerspruch zum Bild amerikanischer Freiheit und Gleichheit materialisiert, das sowohl in der deutschen Öffentlichkeit als auch im republikanischen Selbstverständnis Amerikas selbst prononciert wurde:

»Wie läßt sich das alles aber mit den 14. und 15. Verfassungs-Amendments vereinbaren, die die Beschränkung der Bürgerrechte sowie Diskriminierung aus Gründen der Rasse, Hautfarbe oder eines früheren Sklaverei-Verhältnisses verbieten? Die Wahrheit ist: die Südstaaten haben diese, ihnen nach dem Bürgerkrieg aufgezwungenen Verfassungs-Amendments im Herzen niemals anerkannt. Die stimmberechtigten Schwarzen - vielleicht vier bis fünf Millionen Menschen - sind politisch nahezu einflußlos. ${ }^{53}$

Der Beitrag aus der Frankfurter Zeitung konstatiert eine faktische Trennung nicht nur der Rassen, sondern auch des Geltungsbereichs der amerikanischen Verfassung und damit eine mutwillige Teilung ihrer libertären und egalitären Grundprinzipien. Die vollen Bürgerrechte und damit auch die ökonomische Teilhabe stünden Afroamerikanern folglich nur in den Industrieregionen des Nordostens frei:

"Seine Rettung sucht der sozial und politisch am Boden gehaltene Südstaaten-Neger naturgemäß im Norden, wo die Industrie-Gebiete von Illinois, Pennsylvania und New York mit ihren hohen Arbeitslöhnen eine [...] kleine, aber wirtschaftlich gut fundierte Negerschicht entstehen ließen. Ein Wahlbezirk in Chicago hat sogar einen farbigen Abgeordneten in den Kongreß entsenden können. So ist der Norden also nicht nur in wirtschaftlicher Beziehung ein `Nigger-Heaven` (Neger-Himmel), dem der Ehrgeizi-

52 Anon.: Amerikanische Neger. In: FZT, 1929, Nr. 952, $1 \mathrm{f}$.

53

Ebd., 1. 
gere unter den auf den Baumwoll-Plantagen groß gewordenen Farbigen zustrebt [...], sondern gleichzeitig das [...] Zentrum, in dem der Schwarze kulturelle Befruchtung und Anlehnung sucht. Hier betätigt sich die größte Neger-Organisation, die National Association for the Advancement of Colored People am ungehemmtesten. " ${ }^{54}$

Die Kluft zwischen Anspruch und Wirklichkeit des amerikanischen Gesellschaftsmodells, die in diesem Auszug von der Paradoxie der »Rassenfrage« abgeleitet wird, ist der essentielle Befund des Beitrags. Dessen Fazit lautet:

"Sie [die Auseinandersetzung um die Rassendiskriminierung, D. F.] ist auch völkerpsychologisch von Interesse, denn sie legt, wie vielleicht kein anderer Fall [...] den immerwährenden Konflikt zwischen menschheitsbeglückenden Theorien und rauher Wirklichkeit bloß, dem die angelsächsische Seele so ganz besonders ausgesetzt zu sein scheint. ${ }^{55}$

Bei diesem grundlegenden Missstand, daran lässt der Text keine Zweifel, handele es sich nicht um ein Versäumnis oder einen behebbaren Betriebsunfall. Von staatlicher Seite würden die Mittel des Rechtsstaates missbraucht, um planvoll ein Repressionssystem zu betreiben und aufrechtzuerhalten - für eine zeitgenössische Darstellung sehr weitreichende Einsichten.

Die Auslegung des 14. und 15. Zusatzartikels spielte dabei eine entscheidende Rolle. Jene billigte nach damaliger Rechtsauffassung den Einzelstaaten große Freiheiten in der Erteilung oder Verwehrung des Wahlrechts zu. Die einseitig zu Ungunsten der Afroamerikaner interpretierte Überprüfung der intellektuellen Befähigung zur Beurteilung politischer Fragen gehörte zur Ausgestaltung dieser Freiheiten. In letzter Konsequenz führe dies, so wird im Bericht korrekt festgestellt, zum Ausschluss großer Teile der Black Community vom Wahlrecht. ${ }^{56}$ Im Übrigen gab man sich zu keinem Zeitpunkt der Illusion hin, diese Praktiken würden schamhaft verschleiert, sondern zeigte

54 Ebd.

55 Ebd.

$56 »$ Der beliebteste und etwas verfeinerte Ausweg südstaatlicher Regierungen aus dem Dilemma, in das sie das 14. und 15. Amendment gebracht hat, wird heute zumeist durch besonders zurecht geschnitzte einzelstaatliche Verfassungsbestimmungen eröffnet, in denen der Wähler ein gewisses Mindestmaß an Bildung als Voraussetzung der Wahlberechtigung nachweisen muß. Gewöhnlich wird verlangt, der Wähler müsse die Verfassung >lesen und in einer vernünftigen Weise interpretieren können.< Der Haken liegt hierbei natürlich darin, daß das Wahlkomitee von Fall zu Fall über den erforderlichen Bildungsgrad urteilt und selbst geschulten Negern durch juristische Haarspaltereien ein Bein zu stellen vermag, während man sich natürlich gewöhnlich nicht der Mühe unterzieht, dem weißen Wahlberechtigten irgendwie auf den Zahn zu fühlen. So erzählt eine Anekdote von einem Neger, der soweit alle Aufgaben des Wahlkomitees mit einwandfreier Genauigkeit lösen konnte und dem schließlich die arglistige Frage vorgelegt wurde: ,Was bedeutet wohl: habeas corpus ad subiciendum? `Das bedeutet, , antwortete resigniert der Gefragte, >daß ein Nigger in Mississippi nicht wählen darf $\iota$ und verließ das Wahllokal.«Ebd. 
deren offiziellen und politisch gewollten Charakter mit Rückgriff auf einschlägige Zitate hochrangiger Politiker auf:

"So ist also der Kampf gegen die politische Mündigkeit des Negers die Form eines in der Stille, aber mit aller Erbitterung durchgeführten Ringens um ein theoretisch schon längst bewilligtes, in der Praxis aber konsequent mit Füßen getretenes Recht angenommen, eines Ringens, in dem der Weiße alle Schliche - von den brutalsten Gewaltmaßnahmen zu den raffiniertesten Schikanen - spielen lässt. Zur Charakterisierung der Situation finden wir keine bessere Bemerkung als den folgenden Ausspruch, der dem durchaus nicht als besonders radikal bekannten [demokratischen, D. F.] Senator [Carter, D. F.] Glass aus Virginia in den Mund gelegt wird: ‘Das Volk in den dreizehn Südstaaten flucht und spuckt auf das 15. Amendment und hat in keiner Weise die Absicht, den Neger wählen zu lassen. Wir gehorchen zwar den Buchstaben des Amendments und der Bundes-Statuten, aber wir umgehen seinen Sinn ganz offen und sind entschlossen, dies auch weiterhin so zu halten. Die weiße Überlegenheit ist uns ein zu kostbares Gut, das wir nicht einer theoretischen Gerechtigkeit zu Liebe einer Doktrin, die dem tierischen Schwarzen Gleichberechtigung mit weißen Frauen und Männern einredet - aufgeben können. « ${ }^{57}$

Es lohnte sich, den FZT-Artikel »Amerikanische Neger» an dieser Stelle so breit zu zitieren, weil er mehrere Themenkomplexe der rechtlichen und sozialen Ungleichbehandlung der amerikanischen Black Community verdichtet. Neben dem Rekurs auf regional unterschiedliche Ausmaße alltäglicher Diskriminierung von Schwarzen konzentriert sich seine Darstellung auf den systematischen Ausschluss von politischen und insbesondere sozialen Aufstiegsmöglichkeiten - dem Kern amerikanischen Selbstverständnisses. ${ }^{58}{ }$ Die schwarze Gefahr» in den Südstaaten, also die Angst vor der politischen Befreiung der Afroamerikaner und dem Ende weißer Vorherrschaft, bildet den Ausführungen zu Folge das primäre Motiv für die fortgesetzte Repression. Dies wirkt zusammen mit dem damals in den USA und anderswo verbreiteten Grundsatz, Rassen dürften sich grundsätzlich nicht vermischen, besonders dürfe die weiße nicht durch andere "verunreinigt« werden.

Mit Verweis auf die Zusatzartikel 14 und 15 expliziert der Artikel, wie sehr diese Haltung und daraus folgende Praktiken dem »sich a priori recht edel

57 Ebd.

58 Diese sich gegenseitig verstärkenden Formen sozialer, politischer und ökonomischer Diskriminierung wurden häufig in Überblicksartikeln als solche benannt, unter anderem: »Der Süden der Union ist ja nicht nur ein geographischer Begriff, sondern zugleich ein ökonomischer und sozialer [...]. Im Süden ist überall noch die Zeit des Sezessionskrieges vor 70 Jahren lebendig, in welchem der Norden dem Süden die Sklavenbefreiung aufzwang [...] «. Feder, Ernst: Unter dem Jim-Crow-System. Eindrücke im Süden.- Die soziale und ökonomische Trennung zwischen Weissen und Farbigen.- Einfluss der Industrialisierung und der Agrarkrise. Der Ausschuss für Zusammenarbeit der Rassen. Im Campus der Neger-Universität. In: BTB Nr. 328 vom 14.07.1930, 1 f. 
ausnehmenden Humanitäts-Idealismus $~^{59}$ des politischen Amerika diametral entgegenstünden. Der im Entstehungsprozess der USA grundgelegte Widerspruch zwischen dem Gleichheitsgedanken der Unabhängigkeitserklärung und der anerkennenden Ignoranz gegenüber der Sklaverei ${ }^{60}$ wirkte bis in die deutschen Amerikadiskurse der Zwischenkriegszeit hinein.

Beim gemeinen deutschen Zeitungsleser musste sich der Eindruck verfestigen, der amerikanische Zug in die Moderne führe auch durchaus archaische Elemente in seinem Windschatten mit sich, konkret das hierarchisierende Rassendenken und eine darauf beruhende Ordnung des politischen und sozialen Raumes. Das Attribut archaisch passt dabei weniger auf den institutionellen Rassismus, als auf die auffallend breite Berichterstattung zu den Umtrieben des Ku Klux Klan. Die Zahl der von diesem Geheimbund zu verantwortenden Lynchmorde erreichte in der Zeit zwischen Reconstruction und den 1920er Jahren ihren Höhepunkt. ${ }^{61}$ In der speziellen Bedeutung des Wortes archaisch als »überholt« oder "aus der Zeit gefallen« lässt sich hier durchaus operieren. Schließlich waren es die sich von der rapiden Modernisierung der amerikanischen Gesellschaft abgehängt und von den Segnungen des modernen Lebens ausgeschlossen Wähnenden, die sich mit besonderem Eifer im Klan engagierten und auch an Lynchmorden beteiligten. ${ }^{62}$

Die Berichterstattung über den banalen Rassismus und Antipluralismus des Klans zu untersuchen, bedeutet hier die Herausarbeitung der darin kodierten antimodernistischen Motivation seiner Anhänger. So gewinnt das Thema Ku Klux Klan Relevanz für die Modernitätsdebatte in den deutschen Massenmedien, die breit von den Klan-Aktivitäten berichteten. Sehr bald nachdem der 1915 gegründete Second Klan 1921 begonnen hatte, landesweit zu agieren, war er in den deutschen Zeitungen und Zeitschriften präsent. ${ }^{63}$ Früh

59 Anon.: Amerikanische Neger, $1 \mathrm{f}$.

60 Vgl. dazu: Davis, Brion David: Inhuman Bondage. The Rise and Fall of Slavery in the New World. New York 2006, $175 f$.

61 Vgl. dazu: Berg, Manfred: Popular Justice. A History of Lynching in America. Chicago 2011, 91. Beide Themenkomplexe werden mittlerweile zu Recht als zwei qualitativ unterschiedliche Faktoren betrachtet, die erst durch ihr Zusammenspiel die Aufrechterhaltung der rassistischen Ordnung in den Südstaaten sicherstellten und wurden daher in neueren Betrachtungen zum Gesamtthemenkomplex der Rassenhierarchie auf produktive Weise zusammengespannt. Vgl. Niedermeier, Silvan: Rassismus und Bürgerrechte. Polizeifolter im Süden der USA 1930-1955. Hamburg 2014.

62 Vgl. Moore, Leonard J.: Historical Interpretations of the 1920s Klan: The Traditional View and Recent Revisions. In: Lay, Shawn (Hg.): The Invisible Empire in the West. Toward a New Historical Appraisal of the Ku Klux Klan in the 1920s. Chicago u. a. 2004, 17-38. Sowie: Bennett, David H.: The Party of Fear. From Nativist Movements to the New Right in American History. Chapel Hill u. a. 1988., $204 \mathrm{f}$.

63 Anon: Ableistens des Untertaneneids des Ku Klux Klans. In: Illustrierte Beilage der DAZ, 1921, Nr. 474, O. A. 
wies man in der Vossischen Zeitung (VZT) darauf hin, dass die Neuauflage dem Ursprungs-Klan aus der Ära der Reconstruction zwar in Sachen Rassismus nicht nachstehe. Er bewege sich jedoch auf einer, den veränderten gesellschaftlichen Rahmenbedingungen angepassten Grundlage und definiere neben emanzipierten Afroamerikanern ganz neue Feindbilder:

"Das ,Unsichtbare Reich des Ku Klux Klans ist wieder erstanden. Die grotesk vermummten Reiter [...] schwärmen wieder in Massen umher, um [...] die Vorherrschaft der weißen angelsächsischen Rasse aufrechtzuerhalten. Diesmal geht es nicht allein gegen die Neger, sondern vor allem gegen Katholiken, Juden, Deutsche und andere Fremdgeborene, gegen die sogenannten Radikalen und die organisierte Arbeiterschaft [Hervorh. D.F.]. [...] Es handelt sich also bei dem neuen Ku Klux nicht bloß um eine Ausgeburt eines überspannten nationalen Bewußtseins, sondern auch um einen bösartigen Auswuchs von Klassenhaß [Hervorh. D. F.] und verblödeter nativistischer Unduldsamkeit [...]. Im Übrigen steht er auf einer viel breiteren Grundlage [...]. Der neue Ku Klux Klan verfolgt, dem Geist der Zeit Rechnung tragend, ganz neue Ziele.. ${ }^{64}$

Dass die konkreten Aktionen des Klans über die Drangsalierung der afroamerikanischen Bevölkerung hinausgingen und auf die »Erziehung« der weißen Bevölkerung abzielten, belegt die klassenmäßig definierte Stoßrichtung des neuen Klans. ${ }^{65}$

In den Betrachtungen der kommunistischen Arbeiter Illustrierten Zeitung (AIZ) zum Phänomen Ku Klux Klan kam das Element des Klassenkampfes denn auch prominent zur Geltung, was nur scheinbar evident ist. Auf einer Titelseite von 1925 zeigt die AIZ einen - wohlgemerkt weißen - »Arbeiter «, ${ }^{66}$ der den beigefügten Erläuterungen zufolge gegen den Klan agitiert hatte und dafür symbolträchtig von Klan-Mitgliedern oder deren Sympathisanten mit

64 Ruese, Alfons, M.: Ku Klux. In: VZT Nr. 475 vom 08.10.1921, $1 \mathrm{f}$.

65 »Die Sache hat aber auch eine weniger spaßhafte Seite, denn die von der Oberleitung mit Pathos propagierten Thesen des Rassen- und Klassenhasses finden natürlich auch ihre praktische Anwendung. Allenthalben beginnen die lokalen Verbände des Ku Klux, eine geheime Zensur über ihre Mitbürger auszuüben und Lynchjustiz an allen zu vollziehen, deren Anschauungen sich nicht mit den politischen und moralischen Grundsätzen des Ordens decken. Bisher sind über hundert Fälle bekannt geworden, in denen Personen von Ku-Klux-Banden gemaßregelt worden sind. Davon sind 21 Personen geteert und gefedert worden, 25 wurden durchgepeitscht, ein Mann wurde erschossen. Die Gemaßregelten waren fast sämtlich Weiße [Hervorh. D. F.]«. Ebd., 2. Des Weiteren existieren zahlreiche ähnliche Darstellungen, unter anderem: »Mr. Oven, der sich gegen die Gesetze des K. K. K. vergangen hatte, wurde eines Nachts in seinem Hause überfallen und mit dem Zeichen der Sekte gebrandmarkt." Anon.: Ku-Klux-Klan. Eine geheimnisvolle Sekte. In: MIP, 1925, Nr. 24, $526 \mathrm{f}$.

66 Zumindest laut Bildunterschrift: »Faschistischer Terror in Amerika. Mitglieder der faschistischen Organisation Ku-Klux-Klan verschleppten einen Arbeiter, der gegen sie agitiert hatte, und brannten ihm die Zeichen KKK auf den nackten Körper ein." Anon.: Faschistischer Terror in Amerika. In: AIZ, 1925, Nr. 4. Titel. 


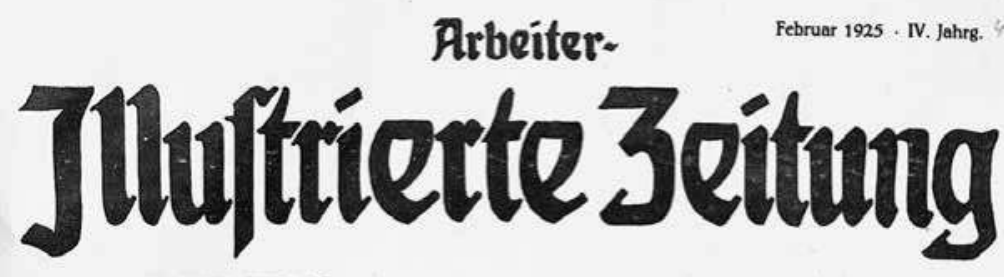

NEUER DEUTSCHER VERLAG

BERLIN W/, UNTER DEN LINDEN 11

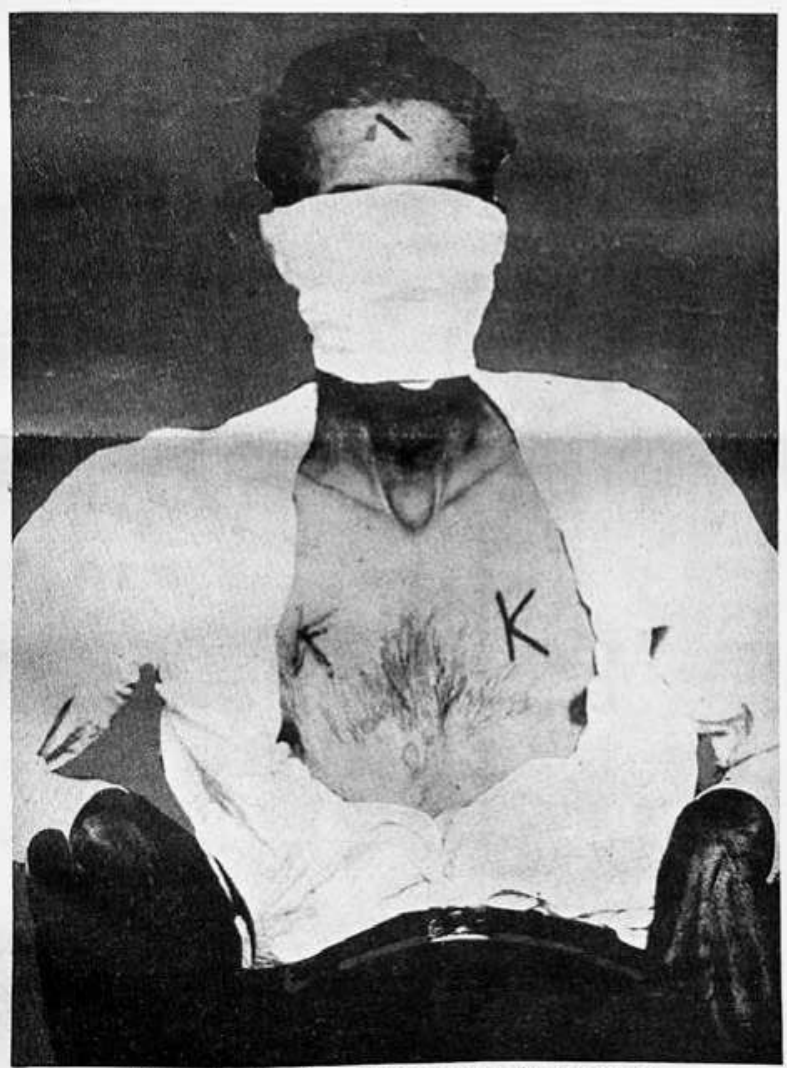

Faschistischer Terror in Amerika:

Mitglleder der faschistischen Organisation Ku-Klux.Klan verschleppten einen Arbeiter, der gegen sie agitiert hatte, und brannten inm die Zeichen KKK auf den nackten Korper ein

Abb. 10: »Faschistischer Terror in Amerika. Mitglieder der faschistischen Organisation Ku-Klux-Klan verschleppten einen Arbeiter, der gegen sie agitiert hatte, und brannten ihm die Zeichen KKK auf den nackten Körper ein.» 
drei K auf Oberkörper und Stirn gebrandmarkt worden war (Abb. 10). Deutlich wird aus diesem drastischen Beispiel für die Brutalität des Klans zweierlei: Zum einen, dass sich die Aggression gegen Weiße und Schwarze gleichermaßen richten konnte, und zum anderen, dass Adressaten der Klan-Aktionen nicht etwa nur Afroamerikaner oder Katholiken, sondern auch die weiße organisierte Arbeiterschaft und letztlich das »Proletariat» sei. Wiederum wird in diesem Beispiel die Rassenopposition relativiert und die Klassenopposition herausgestellt. Der Antirassismus spielt hier also eine weit geringere Rolle als der »Antiklassismus«.

Die Einordnung des Klans als »faschistisch « erscheint angesichts seines von europäischen Faschismusformen abweichenden Ursprungs und Entwicklungsverlaufs freilich als weitgehend willkürlich. ${ }^{67} \mathrm{Da}$ innerhalb des ideologischen Paradigmas der AIZ aber sowohl der Klan als auch der Faschismus zuvörderst gegen die rassen- und klassenlose Gesellschaft, die Befreiung der Arbeiter und demzufolge gegen den Fortschritt selbst agierten, fielen beide in der Kategorie des Fortschrittsgegners zusammen. Sie erschienen in gleicher Weise als antimodern.

Entsprechend häufig waren der Klan und sein politisch organisierter Rassismus Gegenstand der Amerikaberichterstattung in der AIZ. ${ }^{68}$ Die Klansmänner wurden trotz der ernsten Thematik auch zum Objekt beißenden Spotts, so beispielsweise in der Bildunterschrift einer AIZ-Karikatur, die Mitglieder des Klans bei der Vorbereitung einer Hinrichtung zeigt: »Unter amerikanischen Faschisten: Wir sind eigentlich die echtesten Demokraten: ob Neger oder Rote, beide werden gelyncht! « ${ }^{69}$ Trotz aller Ironie transportiert diese Zeile einmal mehr den Eindruck einer Organisation, die »unter anderem « Afroamerikaner verfolgte, deren Agenda aber weit darüber hinaus ging und eben nicht nur rassistisch, sondern klassenpolitisch angelegt war.

Im deutschen Nationalsozialismus bestanden im erbitterten Kampf gegen eine pluralistische Gesellschaftsordnung und die Nivellierung ethnisch und klassenmäßig definierter Unterschiede durchaus Parallelen zum Ku Klux Klan. Beide Bewegungen teilten beispielsweise den auf rassistischer Grund-

67 Auch wenn sich nach Robert Paxtons theoretischer Definition des Faschismus als »eine Form politischen Verhaltens, das gekennzeichnet ist durch eine obsessive Beschäftigung mit Niedergang [...] oder [der] Opferrolle einer Gemeinschaft und durch kompensatorische Kulte der Einheit, Stärke und Reinheit« durchaus Motive zeigen, die der Faschismus mit dem Ku Klux Klan teilt. Paxton, Robert O.: Anatomie des Faschismus. München 2006, 319.

68 Unter anderem: Anon.: Bilder der Woche. Die Häuptlinge der faschistischen Geheimorganisation Klu Klux Klan [sic] in Amerika in ihrem clownhaften Ordenskostüm bei einer New-Yorker Demonstration. In AIZ, 1927, Nr. 24, 2. Sowie: Anon.: Leben und Kampf der schwarzen Rasse. In: AIZ, 1931, Nr. 26. (Titel) und Anon.: Die schwarze Rasse stösst zur Roten Front. Ebd., $510 \mathrm{f}$.

69 Anon.: Humor und Satire. Unter amerikanischen Faschisten. In: AIZ, 1931, Nr. 26, 521 (Jahresausgabe). 
lage gefassten Volksbegriff und dessen Verknüpfung mit einem exklusiven Konzept von Lebensraum. ${ }^{70}$ Solche und weitere Parallelen führten bisweilen dazu, dass sich nationalsozialistische Blätter, auch und vor allem der Illustrierte Beobachter (ILB), direkt auf ihr transatlantisches »Pendant« bezogen.

So ziert das Foto von einer Demonstration weiblicher Klan-Mitglieder in Washington D.C. eine ILB-Titelseite aus dem Jahr 1926 mit der Bildunterschrift: »Parole des Ku-Klux-Klan: Amerika den Amerikanern! $\aleph^{71}$ Der hier deutlich werdende Ethnozentrismus, den die Nationalsozialisten ja mit dem Klan teilten, stellt einen klassischen Topos der Gegenreaktion auf eine sich als pluralistisch begreifende moderne Gesellschaft dar. Die Hauptziele der Aggression des Klans, vor allem Spätimmigranten aus Süd- und Osteuropa, Irland, und Deutschland verdeutlichen, worum es seinen Mitgliedern unter dem Deckmantel des Rassismus und Antikatholizismus ging: um die Besitzstandswahrung der »alteingesessenen Amerikaner« sowie um die Bekämpfung wirtschaftlich aufstrebender Immigrantengruppen und, selbstverständlich, der Afroamerikaner. ${ }^{72}$

Der proklamierte "Rassenkampf« stellt sich einmal mehr als Klassenkampf dar und erhält somit auch im deutschen Kontext Wirkmächtigkeit. Die innenpolitischen Konsequenzen solcher Denkmuster wie zahlreiche Abschiebungen und Inhaftierungen waren ebenfalls Thema in den Meinungsspalten deutscher Tageszeitungen. ${ }^{73}$ Vielfach wurden solche Deportationen

70 Sowohl der Volksbegriff der Nationalsozialisten als auch der des Klans sind unklar definiert und bewegen sich zumindest jenseits rein ethnischer Gesichtspunkte. So ist weder die in der nationalsozialistischen Rassenlehre als Deutsch definierte Gruppe, noch die alteingesessenen Amerikaner ethnisch oder »rassisch « von Katholiken, Juden, Osteuropäern etc. unterscheidbar - dennoch bildet diese künstliche, de facto eher kulturell als ethnisch definierte Unterscheidung den ideologischen Kern beider Bewegungen. In beiden Fällen ist der Volksbegriff streng genommen ironischerweise nicht einmal als "rassistisch« im eigentlichen Sinne oder als »rassisch« definiert zu bezeichnen.

71 Anon.: Keine Parade der Zuckerbäcker. In: ILB 1926, Nr. 4, Titel.

72 Die mehrheitlich katholische Konfession der Spätimmigranten verstärkte den Antikatholizismus des Klans deutlich, wenn sie ihn nicht überhaupt erst bedingte. Ähnlich argumentiert auch Adelheid von Saldern, die ebenfalls eine Korrelation zwischen dem mehrheitlich katholischen beziehungsweise jüdischen Glauben der neuen Einwanderer mit der entsprechenden Feindbildkonstruktion des Klans herstellt. Vgl. Saldern: Amerikanismus, $189 \mathrm{f}$. Sie hat außerdem gezeigt, dass der amerikanische Nativismus zwar nicht unbedingt rassistisch, sondern eher eugenisch geprägt war, in toto aber auf den Machterhalt der WASPs zielte und somit zunehmend in rassistische Denkmuster abglitt. Vgl. ebd., $141 \mathrm{f}$.

73 »Tatsache ist aber, daß die Gelegenheit wahrgenommen wird, darüber hinaus eine Propaganda gegen das neueingewanderte Element überhaupt zu treiben. Präsident Hoover empfahl in seiner letzten Botschaft an den Kongreß, die Verschärfung der Deportationsgesetze, sum der Verbrecher ledig zu werden! [ ...] Die Fremdenpolitik der Regierung hat entsprechendes Echo in der Oeffentlichkeit gefunden. Geistliche rufen von ihren Kanzeln auf zum Kampf gegen das fremde Element, das zersetzend auf das Familienleben der got- 
allein nach ethnischer Zugehörigkeit vollzogen, womit man staatlicherseits den durch die Wirtschaftskrise verstärkten fremdenfeindlichen Tendenzen in der Bevölkerung Rechnung trug.

Genau in diesem Kreuzungspunkt von Rassen- und Klassenkampf besteht der Grund, aus welchem sich die NS-Rezeption des Klans trotz offenkundiger Schnittmengen marginal ausnehmen musste. Lag die Utopie der "rassisch" homogenen Gemeinschaft beiden Gruppierungen zu Grunde, strebte der Nationalsozialismus überdies die Beseitigung jedweder sozialen Schranken innerhalb einer noch herzustellenden Volksgemeinschaft an. Das essentielle "völkische Gleichheitsversprechen ${ }^{74}$ der NS-Ideologie stellte den Massen unterprivilegierter Arbeiter und Bauern ungehinderten Aufstieg in Aussicht. Gleichzeitig verlangte es den bestehenden Eliten die vorbehaltlose Einordnung in die (materiell) egalitäre Volksgemeinschaft ab. Die dem Ku Klux Klan eigene Melange aus rassistischen und klassenkämpferischen Überzeugungen konnte hingegen nur aus den spezifischen sozialen Verhältnismäßigkeiten der Vereinigten Staaten heraus verstanden werden. Hier deckten sich ethnische Trennlinien zum guten Teil mit Klassengrenzen. Da diese (in der Klan-Ideologie angenommene) Identität der Kategorien Rasse und Klasse in deutschen Diskursen keine direkte Entsprechung hatte, fehlten schlicht die Anknüpfungspunkte.

Das Klan-Thema blieb in dieser Hinsicht Gegenstand reiner Fremdbetrachtung und fand in der illustrierten NS-Presse keinen allzu breiten Eingang. Die deutsche Perzeption des Klans mündete nur vereinzelt in konkrete Adaptionen, wie Berichte über mutmaßlich neugegründete deutsche Ableger zeigen. Diese schlossen die Vermengung nationalsozialistischer Zeichen mit Klan-Symbolik ein; ${ }^{75}$ eine reichlich groteske Erscheinung angesichts der dezidiert deutschenfeindlichen Ausrichtung des Originals jenseits des Atlantiks.

tesfürchtigen Amerikaner wirke, die Gewerkschaften, von jeher hypernational, finden endlich die gewünschte Resonanz für ihre Forderung, linkspolitische Gewerkschaften aufzulösen und die Einwanderung von Handarbeitern immer zu unterbinden. Kein Bürgermeister einer großen Stadt, der nicht längst seine Entschuldigung für die Herrschaft von `Gangstern` und `Racketeers` fertig formuliert hat: die Ausländer sind es, die das Verbrechen über Amerika gebracht haben.« Anon.: Amerika deportiert...- Der Ausländer als Sündenbock/Razzien auf die Heimatlosen/Erbitterung der Naturalisierten. In: VZT Nr. 101 vom 28.02.1931, 1 f. Und: Anon: Fremdenfeindliches Amerika - Verschärfte Ausweisung der Arbeitslosen. In: VZT Nr. 194 vom 22.04.1932, 3.

74 Aly, Götz: Hitlers Volksstaat. Raub, Rassenkrieg und nationaler Sozialismus. Bonn 2014, $358 \mathrm{f}$.

75 Anon.: Phantastische Geheimbündler in Deutschland nach amerikanischem Muster. In: BIZ 1925, Nr. 38, 1194 (Jahresausgabe). Hier werden polizeilich beschlagnahmte Fotografien eines Aufnahmerituals der rechtsradikalen Szene gezeigt, deren Authentizität ungeprüft bleibt. Weiße Kapuzen und Kreuze kommen in der abgebildeten Zeremonie ebenso zum Einsatz wie das Hakenkreuz. 
Die Bewertung des Ku Klux Klan durch die deutsche Massenpresse fiel, bei aller deutlich werdenden Faszination, insgesamt negativ aus. So wurden Meldungen über das 1928 irrtümlich vermeldete Ende des Second Klan - er bestand in Wahrheit bis 1944 - insbesondere von bürgerlicher und liberaler Seite begrüßt. Es wurde konstatiert, dass es für die Weiterentwicklung der amerikanischen Gesellschaft ein Segen sei, wenn diese »fascistisch-nationalistische [sic] Tendenz «, ${ }^{76}$ die in ihren verschiedenen Ausprägungen so häufig Thema gewesen war, ${ }^{77}$ hiermit endgültig ein Ende fände. Entgegen diesem frommen Wunsch gingen allerdings nicht nur die Brutalitäten des Ku Klux Klan noch mehrere Jahrzehnte weiter. Offiziell geduldete archaische Bestrafungsrituale, ${ }^{78}$ Lynchmorde und andere Verbrechen waren regelmäßig Gegenstand aufgeregter Berichterstattung.

Dabei wurden je nach redaktioneller Ausrichtung unterschiedliche Aspekte des Lynchwesens herausgestellt. Ein Bericht der AIZ über einen Lynchmord in Texas im Jahr 1930 sticht dabei heraus, weil er sich deutlich von mehreren Meldungen zum selben Vorgang abhebt. ${ }^{79}$ Während die Vorgänge selbst analog zur restlichen Tagespresse geschildert werden, spitzt die AIZ den Aspekt wirtschaftlicher und sozialer Konkurrenz gezielt zu:

»Die eigentliche Wurzel des Lynchens ist die Angst vor der Konkurrenz der aufstrebenden und fähigen schwarzen Rasse, ist das Interesse, die Negerarbeiter im Zustande

76 Anon.: Exit Ku-Klux-Klan. In: FZT Nr. 149 vom 24.02.1928, 1.

77 Unter anderem.: Anon.: Weiss gegen Schwarz. Das amerikanische Rassenproblem. In: MIP, 1925, Nr. 52, 1169 (Jahresausgabe). Hier wird der Bogen von einem Scheidungsprozess, in dem sich der prominente Ehemann, Leonard Rhinelander, arglistig über den »Rassestatus« seiner Ehefrau getäuscht fühlte, über die Praxis der Rassentrennung hin zum Phänomen der Lynchjustiz und den Gewaltakten des Klans gespannt. Alle genannten Punkte werden hier als verschiedenartige Phänotypen desselben, in den Grundlagen der amerikanischen Gesellschaft kodierten Konflikts dargestellt.

78 Unter anderem: Anon.: Auspeitschung eines Negers in den Südstaaten. In: DKM, 1929, Nr. 1, 47.

79 Anon.: Furchtbare Lynchjustiz in Texas. Ein Neger aus dem Gefängnis geholt. Das Gerichtsgebäude eingeäschert. Eine ganze Stadt in Aufruhr. Militär muß eingreifen. In: VZT Nr. 219 vom 10.05.1930, 1. Und: Anon.: Pöbelhaftes aus Amerika. Um einen Neger zu lynchen - Sturm auf ein Gerichtsgebäude. In: FZT Nr. 347 vom 10.05.1930, 1: „Hunderte von Personen unternahmen heute einen wütenden Angriff auf das Gerichtsgebäude von Grayson County, um einen Neger zu lynchen, der des Angriffs auf eine weiße Frau beschuldigt war. Einige Waldhüter und die Polizei schlugen den ersten Angriff zurück. Darauf goß die Menge in das Erdgeschoß des Gebäudes etwa 50 Liter Gasolin und entzündete es, nachdem sie vergeblich versucht hatte, das Gebäude mit Dynamit zu sprengen. [...] Die durch Zulauf aus den Nachbarorten rasch anwachsende Menge durchschnitt der zur Löschung des Brandes herbeigeeilten Feuerwehr die Schläuche, und das Gerichtsgebäude war bald ein einziges Flammenmeer. [...] Kurz nach $15 \mathrm{Uhr}$ nachmittags war das Gerichtsgebäude so gut wie zerstört. Der Neger ist in dem brennenden Gebäude ums Leben gekommen." 
der Versklavung zu erhalten, um sie als Arbeitstiere bis aufs äußerste wirtschaftlich auszubeuten. Darum ist der Neger vogelfrei, darum arbeiten Polizei und Justiz Hand in Hand mit den Lynchern. ${ }^{80}$

Natürlich war es der Daseinszweck der AIZ als Teil des Münzenberg-Konzerns, aus politischen und sozialen Missständen die Notwendigkeit des Klassenkampfes abzuleiten. Die Zuspitzung, mit der in dieser Darstellung operiert wird, ist vor diesem Hintergrund kritisch zu bewerten. Dessen unbenommen illustriert diese Passage abschließend, dass von einem bedeutenden Teil des deutschen Pressespektrums die gegenseitige Bedingtheit von Rassismus und sozioökonomischer Konkurrenz in der US-Gesellschaft festgestellt, analysiert und aus verschiedensten Gründen kritisiert wurde.

\subsection{Aufbegehren und Aufbruch}

Die kritische Beschreibung der amerikanischen Rassismusproblematik ging fließend in die Darstellung afroamerikanischen Aufbegehrens und emanzipatorischer Erfolgsgeschichten über. Die in diesem Selbstermächtigungsprozess eingesetzten Strategien standen im Zentrum der deutschen Berichterstattung zum Aufbruch des schwarzen Amerika.

Mediale Aufmerksamkeit erhielten ab 1919 zunächst die zahlreichen Rassenunruhen, ${ }^{81}$ die sich aus der konfliktgeladenen Gemengelage nach Kriegsende ergaben. Diese wurden von den deutschen Journalisten als, obschon gewaltsamer, so doch legitimer Widerstand der Afroamerikaner gegen die fortdauernde Diskriminierung auf sozialer und ökonomischer Ebene gedeutet. Der emanzipatorische Drang der Afroamerikaner auf der einen und dessen angstbehaftete Bekämpfung auf der anderen Seite definierten die mediale Wahrnehmung des gesellschaftlichen Frontverlaufs. Aufgrund dessen sind die Themenkomplexe der Entrechtung und des Aufbegehrens in der Presseberichterstattung kaum voneinander zu trennen. Vielmehr war die Beschreibung von Rassendiskriminierung und Rechtsbeugung regelmäßig innerhalb einzelner Artikel oder ausgabenübergreifend der Darstellung afroamerikanischen Widerstandes vorangestellt. Daraus lässt sich schließen, dass jegliche zivile und mitunter auch gewaltsame Form, in der sich die Emanzipationsbestrebungen der Black Community äußerten, mit implizitem oder explizitem Verweis auf das von ihr erlittene Unrecht legitimiert wurde. Die Textelemente

80 Friedländer, Paul: Der Sport der Hundertprozentigen. In: AIZ, 1930, Nr. 35, 683 (Jahresausgabe).

81 Unter anderem: Anon.: Die Straßenkämpfe in Chicago. In: VZT Nr. 387 vom 01.08.1919,

3. Und: Anon.: Rassenunruhen. In: BIZ, 1919, Nr. 35, 338f. (Jahresausgabe). 
der Berichte über die Rassenunruhen reihen sich hinsichtlich ihrer Ursachen also zunächst in das bereits erörterte Schema der Entrechtung ein. ${ }^{82}$

Die bereits erwähnte »schwarze Gefahr ${ }^{83}$ tritt in diesem Kontext in einer weiteren Variante hervor. Ist bis hierher die sozioökonomische Konkurrenz, die die Afroamerikaner vermeintlich für die weiße Mehrheitsbevölkerung darstellten als Kern für die latente Spannung zwischen den Rassen identifiziert worden, rückt nun deren demografisches »Gefahrenpotential« in den Vordergrund. Durch ihren niedrigen Zivilisationsgrad seien die Afroamerikaner kinderreicher als die weiße Bevölkerung und würden diese auf lange Sicht an den Rand drängen:

»Daß diese Befürchtungen einer gewissen Berechtigung nicht entbehren, wird verständlich, wenn man sich die stete Zunahme der farbigen Bevölkerung vor Augen führt. Die Zahl der Neger betrug nach der Volkszählung des Jahres 1870 rund 5 Millionen, sie hat sich seit jener Zeit mehr als verdoppelt. Nun ist allerdings auch die Gesamtbevölkerung der Vereinigten Staaten in diesen fünfzig Jahren um ein vielfaches gewachsen, dieses Wachstum ist aber in erster Linie der enormen Einwanderung aus fremden Nationen zuzuschreiben, während die Vermehrung des schwarzen Volksteils aus diesem selbst heraus erfolgte [...]. Schon Roosevelt ist gegen den auffallenden Geburtenrückgang des einheimischen weißen Elementes zu Feld gezogen, die schwarze Rasse aber wird sich mit der ihr eigenen Fruchtbarkeit weiter vermehren, und so wird sich die $>$ Negerfrage $>$ vielleicht noch zu dem größten aller Probleme entwickeln [...].. ${ }^{84}$

Die Befürchtung, die schwarze Bevölkerung könne so stark anwachsen, dass sie dereinst den Anteil der Weißen aufwiege, erscheint geradezu als Warnung vor einer feindlichen Landnahme. ${ }^{85}$ Eine solche Darstellung bekräftigt den auch sonst häufig suggerierten Eindruck, Afroamerikaner seien gar kein Teil der US-Gesellschaft, sondern dieser als Fremdkörper antagonistisch entgegengestellt. Das demografische Moment, der vermeintliche Konnex von niedrigem Bildungsgrad, hoher Geburtenrate und verminderter sozialer Wertigkeit wird hinsichtlich der Berichterstattung über die fortschreitende »Normalisierung« der Black Community noch aufzugreifen sein.

$82 »$ Trotzdem Amerika sich stets als das Land der freien Menschenrechte gebärdet, werden dem Neger die Rechte, die ihm nach der Verfassung zustehen, bis heute noch vorenthalten, von einer sozialen Gleichberechtigung vollends kann nicht die Rede sein." Anon.: Rassenkämpfe in Amerika. In: BIZ, 1919, Nr. 35, 338 (Jahresausgabe).

83 Anon.: Amerikanische Neger. In: FZT, 1929, Nr. 952, 1.

84 Anon.: Rassenkämpfe in Amerika, 338.

85 Die Bemerkungen zu den Debatten innerhalb der weißen Mehrheitsbevölkerung machten sich indes die eher randständigen Vorschläge zur Lösung des Konflikts zu eigen: »Die Furcht vor einem Ueberhandnehmen des schwarzen Bevölkerungsteiles hat in Amerika weite Kreise ergriffen, und in jüngster Zeit ist sogar die Forderung laut geworden, die gesamte schwarze Bevölkerung aus den Vereinigten Staaten zu deportieren und in Afrika anzusiedeln.«Ebd. 
Die Interessen der Black Community waren nach dieser Lesart mit denen der amerikanischen Mehrheitsgesellschaft schlicht unvereinbar. Die Diskriminierung der Afroamerikaner konnte demzufolge nicht gesamtzivilgesellschaftlich, sondern nur aus der Black Community heraus und im Widerstand gegen die Mehrheitsgesellschaft beseitigt werden. Eine zuspitzende Erkenntnis, die dennoch das damalige Lagebild der amerikanischen »Rassenfrage « zutreffend charakterisiert und als Handlungsgrundlage der amerikanischen Bürgerrechtsbewegung noch Jahrzehnte Bestand haben sollte.

Die ethnischen Gewalteruptionen der unmittelbaren Nachkriegsjahre läuteten die Berichterstattung zu den Emanzipationsbestrebungen der Afroamerikaner in der deutschen Presse zwar ein, dominierten diese aber keineswegs. So zeigt Hans Goslar in seinem Artikel "Der amerikanische Neger ${ }^{86}$ aus dem Jahr 1922 zwar die seinerzeit gängigen, ins Exotistische fließenden Stereotype über Afroamerikaner in ebensolcher Fülle auf, ${ }^{87}$ wie die weithin geteilte Kritik an deren Niederhaltung. ${ }^{88}$ Gleichzeitig öffnet Goslar aber den Blick für die aufkeimende zivilgesellschaftliche Etablierung und politische Organisation der Black Community.

Diese Perspektive bildete die zweite Säule der Weimarer Wahrnehmung des schwarzen Amerika und richtete sich auf mehrere Aspekte afroamerikanischen Aufstiegs. Dazu zählten die verstärkt wahrgenommene kulturelle Autonomie, die ökonomische Besserstellung und die politische Selbstermächtigung. Konkret stellt Goslar zunächst auf den akademischen Aufstieg der Afroamerikaner im Norden der Vereinigten Staaten ab, der die Basis jeden Aufstiegs darstelle und in dem Goslars Kollege Arthur Rundt gar einen neuen, stilprägenden »Typ des Neger-Intellektuellen ${ }^{89}$ aufkommen sah. Goslar schrieb:

"Aus meinen Unterredungen mit geistig bedeutenden und akademisch gebildeten Negern konnte ich feststellen, daß im Jahresdurchschnitt [...] ungefähr 300 Schwarze

86 Goslar, Hans: Der amerikanische Neger. In: VZT Nr. 156 vom 01.04.1922, 1.

87 »Man erzählt von ihnen, daß sie diebisch seien und - entsprechend ihrem recht kindlichen Charakter - Sachen, an denen sie Gefallen finden, sich mit naiver Hemmungslosigkeit aneignen. Man setzt außerdem einen großen Teil der Rohheitsdelikte, Körperverletzungen und Sittlichkeitsverbrechen auf ihr Konto. Aber da auch sie Menschen mit ihrem Widerspruch sind, so wird es schon stimmen, wenn ich konstatiere, daß sie auf mich, der ich oft Gelegenheit hatte, sie zu beobachten, den Eindruck von zumeist sehr gutmütigen, freundlichen und überaus kindlichen Menschen gemacht haben, die immer vergnügt sind und die alle die Verrichtungen, zu denen sie angestellt sind, willig und geschickt ausüben.« Ebd., 1.

88 »Auch heute noch kann man nicht im Ernst davon reden, daß der Neger im Süden der USA ein gleichberechtigter Bürger sei. Gesellschaftlich wird er wie ein Aussätziger behandelt, gegen den sich der Rassestolz des weißen Amerikaners auflehnt, und an der praktischen Ausübung seiner Bürgerrechte wird er selbst bei den Wahlen durch allerhand nicht immer saubere Mittelchen gehindert.« Ebd.

89 Rundt, Arthur: Die schwarze Welle. In: UHU, 1924, Nr. 11, 31. 
ihr Baccalaureus-Examen ablegen [...]. Jedes Jahr legen auch einige Neger ihr DoktorExamen ab, und im letzten Jahr wurden sogar zwei schwarze Frauen zu Doktoren der Philosophie graduiert. Die schwarze Bevölkerung verfügt heute schon über viele Ärzte, Anwälte, Pfarrer der protestantischen Negerkirche und sogar auch über Lehrer an öffentlichen Schulen. ${ }^{90}$

Das Fallen der "Schranken, die den Schwarzen von den Weißen trennen ", ${ }^{91}$ stieß dem deutsch-jüdischen Intellektuellen Goslar zufolge die Entwicklung einer afroamerikanischen Intelligenzschicht als kommende Komponente der US-Zivilgesellschaft an. Diese Einschätzung bricht mit ethnischem Determinismus, der Afroamerikanern per se einen Platz unterhalb und außerhalb der amerikanischen Gesellschaft zuwies.

Der nächste Schritt im von Goslar (und anderen) umrissenen Entwicklungsnarrativ ist die Aufnahme publizistischer Tätigkeit zur Interessenartikulation seitens der Black Community. Diese begann zwar bekanntlich nicht erst in der Zwischenkriegszeit, sondern blickte bereits auf mehrere Jahrzehnte erfolgreicher Arbeit zurück. Sie erfuhr in jenen Jahren aber sicherlich einen Entwicklungsschub hinsichtlich ihrer Breitenwirkung und politischen Schlagkraft. Letztere gründete in ihrer engen Verzahnung mit dem Aktivismus emanzipatorischer Organisationen, wie auch Goslar anklingen lässt:

»Zeichen für den beginnenden geistigen Aufstieg relativ bedeutender Teile der amerikanischen Negerbevölkerung kann man u. a. in ihrer jungen Presse erblicken, so z.B. in der recht interessanten und auf einem ganz beachtenswerten Niveau stehenden Monatsschrift der oben erwähnten `National Association for the advancement of Colored People`, der `Crisis`, als deren Herausgeber ein Mann von vielversprechenden geistigen Fähigkeiten, Dr. du Bois, wirkt. ${ }^{92}$

Das nur durch gegenteilige Vorannahmen erklärbare Erstaunen Goslars darf nicht darüber hinwegtäuschen, dass er treffend akademische Erfolge (zuvörderst W.E.B. Du Bois') als Voraussetzung für die Interessenvertretung der Afroamerikaner identifiziert. Goslar stellt die Tendenz zur akademischen Emanzipation in direkten Zusammenhang mit der neu entstandenen NAACP:

»In politischer Hinsicht sind bemerkenswerte Ansätze vorhanden um die gewaltige Masse schwarzer Staatsbürger allmählich zu einem gemeinsamen Vorgehen zur Wahrung ihrer politischen Rechte zu veranlassen. Solche Ansätze sieht man in der $>\mathrm{Na}$ tional Association for the advancement of colored people`, die bereits über 100000 organisierte Mitglieder zählt. Diese Vereinigung, wie die politischen Strömungen unter den Negern Amerikas überhaupt, beabsichtigt nun nicht, eine eigene politische

90 Goslar: Der amerikanische Neger, 1.

91 Ebd.

92 Ebd. 
Partei den zwei großen im Lande vorhandenen hinzuzufügen [...] aber sie kann doch versuchen, insbesondere in den einzelnen Staaten, wo der Neger noch ein Staatsbürger zweiter und dritter Klasse ist, negerfeindliche Gesetze und Verwaltungspraktiken zu bekämpfen. Es sitzen denn auch bereits in nicht weniger als dreizehn Staaten der Union Vertreter der farbigen Bevölkerung in der Repräsentative. ${ }^{93}$

Goslar skizziert eine Kausalkette, die von der Beseitigung der Rassenschranken über akademische Qualifizierung und publizistische Artikulation der Black Community zur politischen Organisation afroamerikanischer Interessen verläuft und schließlich in gleichberechtigte politische Teilhabe mündet.

Die »Normalisierung« der Black Community äußere sich aber nicht nur in einem erhöhten Maß an politischer Organisation, sondern ebenso im sich verändernden demografischen Moment. Hatte die BIZ im Jahr 1919 noch die hohe Geburtenrate des afroamerikanischen Bevölkerungsteils als Charakteristikum mangelnder Zivilisiertheit gedeutet, kehren sich die Vorzeichen bei Goslar in der Vossischen Zeitung um. Soziale Konsolidierung illustriert dieser Autor durch den Verweis auf das Prinzip des Neomalthusianismus, also die sich mit gesteigertem Wohlstand auf niedrigerem Niveau einpendelnde Zahl der Geburten:

"Sozial bereitet sich ein gewisser Aufstieg unter der Negerbevölkerung vielerorts vor, und wenn kein anderes Anzeichen dafür vorhanden wäre, so das eine untrügliche, daß seit verhältnismäßig kurzer Zeit ein Neomalthusianismus Platz gegriffen hat, den wir nur zu gut aus der Geschichte aller allmählich zu Wohlstand aufsteigenden weißen Völker kennen. Während noch vor zwei, drei Generationen überall die Negerfamilien mittelgroß waren, beschränkt man nun schon die Kinderzahl in den Städten auf nicht mehr als zwei. Die durchschnittliche Stärke einer Negerfamilie ist nach der offiziellen Statistik allein in der Zeit von 1890 bis 1910 von 5,3 auf 4,5 Köpfe zurückgegangen. « ${ }^{94}$

Die Tendenz, afroamerikanische Emanzipation gegen das Ideal der wirtschaftlichen, kulturellen und sozialen Assimilation zu lesen, kann als repräsentativ für die Position der bürgerlich-liberalen und konservativen Presse angesehen werden. Im Gegensatz dazu erklärte sich das kommunistische Spektrum das politische Erwach(s)en der Black Community völlig aus dem größeren $\mathrm{Zu}$ sammenhang des revolutionären Klassenkampfes.

Die AIZ ging gar nicht erst davon aus, die politischen Vertreter der Black Community strebten gesellschaftliche Teilhabe auf der Grundlage der bestehenden wirtschaftlichen und politischen Ordnung der USA an. Man legte stattdessen den Fokus auf diejenigen Kräfte, die einen revolutionären Umsturz 
verfolgten. ${ }^{95}$ Während die Führung der NAACP »von den liberalen Ideologien beherrscht« sei, gehöre »der linke Flügel [...] der radikalen Arbeiterbewegung an.» Er sei bemüht, »den Negerarbeitern ihre mit den weißen Arbeitern gemeinsame Aufgabe klarzumachen«, nämlich »die Vernichtung eines Systems, das so unerträglich auf allen Arbeitern, sowohl auf den weißen, wie auf den farbigen« laste. Der industrielle Aufschwung des Südens und die voranschreitende Ausbeutung der Arbeiter werde dazu führen, dass sich weiße und schwarze Arbeiter ihrer gemeinsamen Interessen gewahr würden und die Rassenschranken zu Gunsten eines geeinten Proletariats auf kurz oder lang fielen. ${ }^{96}$

Einmal mehr erscheint der Kampf der Afroamerikaner um Gleichberechtigung in dieser Lesart nur als Spielart des weltweiten Aufbegehrens des Proletariats. Die AIZ schreibt mit der Universalschablone des Klassenkampfes konsequent ihr Narrativ fort, welches sie bereits in ihrer Darstellung und Einordnung rassistischer Gewalt offenbart hatte. Im reflexhaften Anlegen des "Klassenkampf-Filters" machte sie sich ironischerweise die Logik des $\mathrm{Ku}$ Klux Klan zu eigen, der ebenfalls Klassengegensätze zu Rassengegensätzen stilisierte.

Repräsentativ für die veröffentlichte Meinung war diese Perspektive ohnehin nicht. Die überwiegende Zahl der Beiträge sah eine Emanzipation innerhalb und nicht gegen das bestehende Ordnungssystem der Vereinigten Staaten als einzige und sich bereits realisierende Perspektive der Black Community an. Man sah in der Breite der Berichterstattung keinen Entscheidungskampf der Klassen, geschweige denn der Rassen heraufziehen. Ganz im Gegenteil erfuhr die Ankunft der ersten Afroamerikaner in führenden Positionen von Politik und Justiz, Kirchen, Sport und Kunst wohlwollende Aufmerksamkeit. Unter dem Titel »Vom Sklaven zum Herrn ${ }^{97}$ erschien 1927 in der BIZ eine regelrechte Erfolgsbilanz der Emanzipation, die wider den verbreiteten Pessimismus Fortschritt und Aufstieg der Schwarzen würdigte:

»Wir hören in Europa fast nur von der Unterdrückung des amerikanischen Negers, von den vielen Siegen seines Kampfes um volle Gleichberechtigung hören wir fast nichts. Hier wird nun der neue Neger-Typus Amerikas gezeigt, der unaufhaltsam in

95 Während des Gründungsprozesses formierte sich innerhalb der NAACP eine sozialistisch orientierte Strömung, die im Wesentlichen aus dem sogenannten "Niagara Movement» und dem »Cosmopolitan Club « bestand. Beide Fraktionen stellten sich ausdrücklich gegen die Position Booker T. Washingtons, die Afroamerikaner sollten sich durch Bescheidenheit, Fleiß und harte Arbeit den Weißen als würdige Mitbürger erweisen und in der Folge in ihren Aufstiegsbestrebungen auf den Kapitalismus setzen. Vgl. Foner: American Socialism and Black Americans. From the Age of Jackson to World War II, $182 \mathrm{f}$.

96 Kruse, William: Die revolutionäre Neger-Bewegung in Amerika. In: AIZ, 1926, Nr. 4, 3.

97 Anon.: Vom Sklaven zum Herrn. Der Aufstieg des amerikanischen Negers. In: BIZ, 1927, Nr. 24, 948 f. (Jahresausgabe). 
wissenschaftliche, kirchliche, künstlerische, politische, kommerzielle und sportliche Berufe eindringt. ${ }^{98}$

Der zitierte Artikel hebt sich nicht durch bloße Schönfärberei von den üblicherweise negativ gefärbten Meldungen zur sozialen Situation der Schwarzen ab. Die ansonsten kritische bis pessimistische Berichterstattung zu diesem Thema sei ein Missverständnis, das sich aufkläre, sobald man erkenne, »daß man in der Welt umso mehr von der Negerbewegung, von den schwarzen Emanzipations- und Gleichberechtigungsbestrebungen« höre, »je höher der Neger schon gestiegen " $" 99$ sei. Die veröffentlichte Meinung in Deutschland bilde nur das Echo einer bereits vollzogenen Positiventwicklung ab, die sich vor allem an dem rasanten Bildungszuwachs zeige:

"Sie haben 40000 schwarze Lehrer, davon 5000 mit Hochschulbildung, es gibt $2^{1 / 2}$ Millionen schwarze Schulkinder, über 100000 schwarze Universitätsstudenten und -studentinnen. Sie bringen jährlich 15 Millionen Dollar Schulgeld auf und es gibt unter ihnen nur noch 15 Prozent Analphabeten (sie sind also im Durchschnitt viel besser gebildet als etwa die Bevölkerung Italiens oder gar Spaniens). ${ }^{100}$

Zudem sei die auf allen gesellschaftlichen Feldern zu beobachtende Aufwärtsentwicklung von einem zivilisatorischen Nullpunkt, dem Zustand der Sklaverei ausgegangen und somit in der Beurteilung derselben ein großzügigeres Maß anzulegen: »Diese ganze Entwicklung vom Sklaventum her ist in 60 Jahren zurückgelegt worden, es ist eine viel schnellere Entwicklung als die der Russen oder Japaner. ${ }^{101}$

Den eigentlichen Rahmen des Artikels bildet seine visuelle Gestaltung. Sie zeigt, prominent über dem Text positioniert, drei exponierte Vertreter der afroamerikanischen Elite, von denen im Artikel die Rede ist. Der Bildriegel zeigt somit das menschliche Antlitz des abstrakten Prozesses afroamerikanischer Elitenbildung und verleiht ihm Plastizität:

Links ist Robert Russa Moton zu sehen, der Nachfolger Booker T. Washingtons als Leiter des Tuskegee Institute in Alabama, ${ }^{102}$ der traditionsreichsten afroamerikanischen Universität der USA. Seine Visualisierung bekräftigt die Wichtigkeit des Aspekts Bildung in diesem synoptischen Versuch, die verschiedenen Pfade afroamerikanischer Aufsteiger einem breiten deutschen $\mathrm{Pu}-$ blikum nahezubringen. Das Fotoportrait zeigt ihn mit erhobener linker Hand, deren Zeigefinger an die Stirn zeigt. Er wird als Intellektueller inszeniert. In seiner gemäßigten Körperhaltung ließe sich eine Reminiszenz an die Schule

98 Ebd., 948.

99 Ebd., 949.

100 Ebd.

101 Ebd.

102 Heute Tuskegee University. 


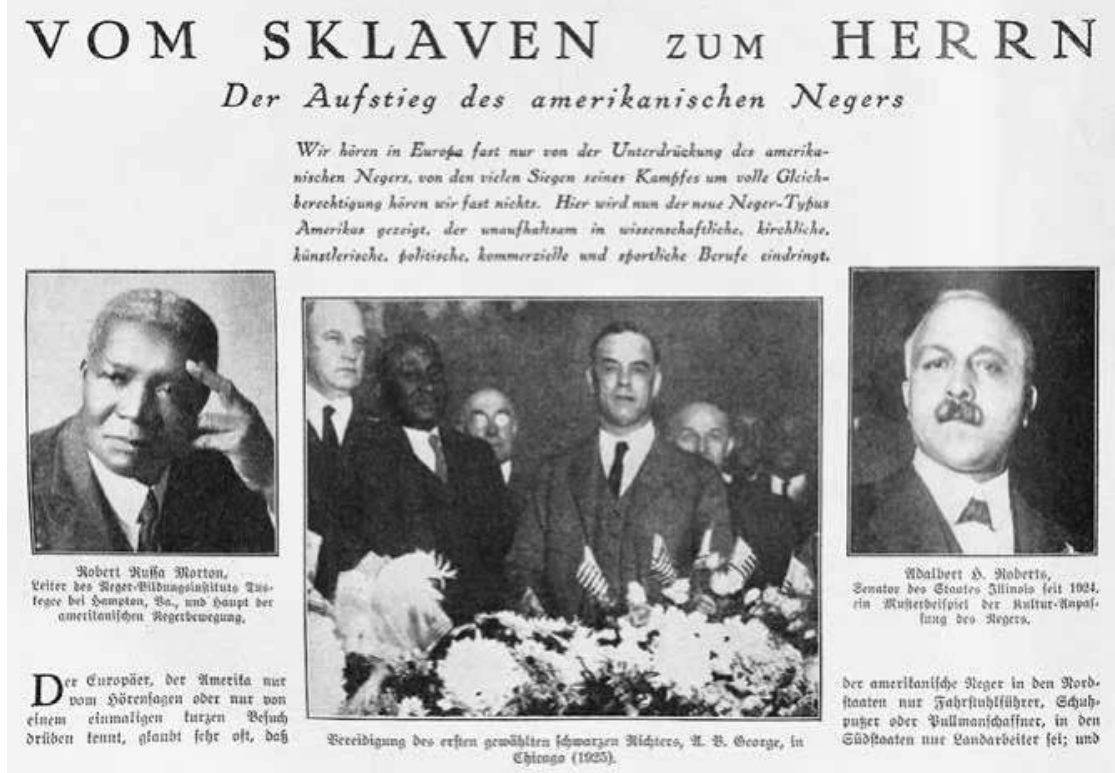

Abb. 11: Vom Sklaven zum Herrn. Der Aufstieg des amerikanischen Negers. In: BIZ, 1927, Nr. 24, 948 f. Bildungs- und Karriereerfolge prominenter Afroamerikaner wurden zur Referenz afroamerikanischen Aufstiegs stilisiert.

Booker T. Washingtons erkennen, in der Moton akademisch und politisch sozialisiert worden war. Diese hatte Friedfertigkeit, Bescheidenheit und Fleiß zu denjenigen Tugenden erhoben, die Afroamerikaner dereinst in die Mitte der US-Gesellschaft führen würden. Moton wird in der Bildunterschrift als »Leiter des Neger-Bildungsinstituts Tuskegee [...] und Haupt der amerikanischen Negerbewegung ${ }^{103}$ vorgestellt und fungiert als klassisches Rollenvorbild eines gebildeten und (deshalb) politisch engagierten Menschen. Die textovisuelle Inbezugsetzung von intellektueller Befähigung und politischer Betätigung postuliert deren wechselseitige Bedingtheit. Die intellektuelle Selbstermächtigung wird zur conditio sine qua non für die afroamerikanische Teilhabe an Staat und Gesellschaft erklärt.

Einen wichtigen Vektor dieser Teilhabe stellte die Justiz dar. Mittig findet sich im Bildriegel des Artikels eine Aufnahme von der Vereidigung des ersten demokratisch gewählten afroamerikanischen Richters, Albert B. George. ${ }^{104}$ Die

103 Anon.: Vom Sklaven zum Herrn, 948.

104 Die vorherigen Richter waren jeweils auf exekutive Anordnung des US-Präsidenten im District of Columbia eingesetzt worden, hatten sich aber keinem Abstimmungsverfahren gestellt. 
US-Flaggen als Kennzeichen von Staatlichkeit, die im Vordergrund zu sehen sind, illustrieren ebenso wie die Position von George inmitten seiner vornehmlich weißen Kollegen viel mehr als einen Verwaltungsakt. Die Inauguration Georges bedeutete den Fall einer Rassenschranke, der angesichts der zentralen Rolle der dritten Gewalt in der systematischen Diskriminierung von Afroamerikanern symbolträchtiger und wirkmächtiger nicht hätte sein können. ${ }^{105}$

Auch über seine Zuständigkeiten als Richter hinaus nahm George Einfluss auf juristische Debatten in der "Rassenfrage«, was die Symbolkraft seiner Wahl unterstrich. ${ }^{106}$ Dass George in einem ordentlichen Wahlverfahren und nicht per Dekret in Amt und Würden kam, dokumentiert das politische Erwachen der Black Community ebenso wie den allmählich schwindenden Widerstand, der ihrer emanzipatorischen Entfaltung entgegenschlug.

Das vermehrte Vorstoßen von Afroamerikanern in politische Wahlämter wird auch durch den dritten Portraitierten, Senator Adelbert H. Roberts, thematisiert. Interessant an seinem Beispiel ist nicht so sehr die visuelle Darstellung, die schlicht einen selbstbewussten Politiker zeigt. Vielmehr ist es die Bildunterschrift, die ihn als »Senator des Staates Illinois seit 1924« und »ein Musterbeispiel der Kulturanpassung des Negers ${ }^{107}$ vorstellt. Die Bildunterschrift ordnet Roberts in das regelmäßig aufscheinende Narrativ der Anpassung beziehungsweise "Normalisierung" ein - eine allgemeine Tendenz im deutschen Blick auf die Entwicklung des schwarzen Amerika.

Nur die politische, ökonomische und rechtliche Emanzipation der Black Community zu betrachten, würde einen zentralen Aspekt außer Acht lassen. Denn auch ihre kulturelle Prägekraft wurde intensiv in der Massenpresse behandelt und sollte, wenn auch negativ konnotiert, über die 1920er Jahre hinaus Kristallisationspunkt deutscher Amerikabilder bleiben. Vor allem die sogenannte Negermusik ${ }^{108}$ machte den beträchtlichen afroamerikanischen

105 Prominent waren einerseits die wahlrechtliche Diskriminierung seitens der Justiz Thema der Amerikaberichterstattung und andererseits auch die Ungleichbehandlung und unverhältnismäßig harte Bestrafung von Afroamerikanern. Unter anderem wurde von der AIZ die Verhängung der Todesstrafe für sieben Afroamerikaner kritisiert, die als blinde Passagiere auf einem Güterzug gefahren waren. Vgl. Anon.: Eine Mutter kämpft um ihre Söhne. In: AIZ, 1932, Nr. 21, 438 (Jahresausgabe).

106 George wirkte neben seinem Amt als Richter in der National Bar Association, einem Zusammenschluss von afroamerikanischen Juristen. Im Rahmen dieser Institution beschäftigte er sich insbesondere mit dem Verhältnis zwischen Staatsbürger und Gericht, wobei er vor allem auf die Unteilbarkeit von Bürgerrechten gegenüber der Justiz auf Grundlage der Rasse hinwies. Auf diese Weise übte er als Teil der Judikative auch Einfluss auf den vorpolitischen Raum und die Debatten in den afroamerikanischen Bürgerrechtsorganisationen aus. Vgl. Smith, Clay: Emancipation. The Making of the Black Lawyer. Philadelphia 1993, $557 \mathrm{f}$.

107 Anon.: Vom Sklaven zum Herrn, 948.

108 Unter anderem: Weber, Wolfgang: Negermusik. In: BTB Nr. 378 vom 12.08.1927, 2. 
Einfluss auf die kulturellen Exporte der USA deutlich. Dass afroamerikanische Musik und insbesondere der Jazz genuin amerikanisch seien und keine auf Umwegen verfeinerte Spielart afrikanischer Musikalität, wurde zwar an mehreren Stellen zum Ausdruck gebracht, ${ }^{109}$ stellte aber bei Weitem keinen Konsens dar. Stattdessen war die Tendenz, den Jazz als Menetekel kultureller Inflation und Dekadenz zu begreifen, in der deutschen Debatte der 1920er Jahre bereits deutlich erkennbar. So schreibt Paul Bernhard in einem Beitrag für die FZT aus dem Jahre 1926:

»Die allgemeine Verbreiterung, Verflachung aller menschlichen Interessensphären, wie sie sich besonders im letzten Krieg und in der Verknüpfung aller Wirtschaftsverhältnisse unverkennbar zeigt, dokumentiert sich demnächst auch in der rassenhaft abgeschlossensten aller Kulturerscheinungen: in der Musik Europas. ${ }^{110}$

Bernhard kritisiert im Weiteren nicht nur die zunehmende Ausrichtung auf ein musikalisches Massenpublikum, sondern bettet seine Beobachtungen in eine allgemeine Vermassungs- und Amerikanisierungskritik ein. ${ }^{111}$ Die in den verschiedenen Kulturen Europas gewachsenen Formen der Popularmusik begännen »jetzt eine gemeinsame Richtung einzuschlagen und sich so zu vereinfachen. ${ }^{112}$ Was man auch als bloße Zeitkritik oder Kulturpessimismus interpretieren könnte, wird durch die Attribuierung »uneuropäisch« mit dem afroamerikanischen Element des Jazz konnotiert: »Den merkwürdig uneuropäisch-fratzenhaften Klangcharakter erhält die Jazzband aber erst durch Hinzutreten des Saxophons. ${ }^{113}$ Bernhard attestiert dem Jazz außerdem eine übersteigerte Maskulinität und die Negierung von Hierarchien, welche seinem Duktus zufolge in der Natur der afroamerikanischen Musikanten liege:

$109 » U m$ es gleich vorweg zu nehmen: mit den Klängen des [sic] Jazzband hat Negermusik nicht das mindeste zu tun. Jazz ist eine Summe geschickt kombinierter Einfälle, auf dem Broadway, in der Untergrundbahn Chicagos oder bestenfalls auf Kuba von amerikanischen Mischnegern erfunden und von Routiniers für die Halls internationaler Hotels zurechtfrisiert, ohne den entferntesten Zusammenhang mit Afrika."Weber: Negermusik, 2. Es herrschte übrigens auch in den USA selbst eine erregte Debatte darüber, ob Jazz einen afroamerikanischen Anteil habe und wenn ja, wie groß dieser sei. Mancher erkannte, wie es auch heutzutage allgemeiner Konsens ist, umstandslos die afroamerikanischen Ursprünge des Jazz an, andere relativierten und minimalisierten den afroamerikanischen Einfluss auf die Entstehung der neuen Musikrichtung um die Jahrhundertwende. Vgl. Saldern: Amerikanismus, $302 \mathrm{f}$.

110 Bernhard, Paul: Soziologie des »Jazz«. In: FZT Nr. 413 vom 06.06.1926, $1 \mathrm{f}$.

111 »In den großen Städten taucht bald nach Friedensschluß daneben (der Klavierkapelle mit Pariser Besetzung) - von geschäftstüchtigen Managers eingeführt- die amerikanische Variation der Klavierkapelle auf, die ১Jazz-Band [...]. Die in den Kriegs- und Hungerjahren zurückgedämmte Tanzlust findet einen ungeheuren Stimulans und bricht in förmlichen Epidemien aus.« Ebd.

112 Ebd.

113 Ebd. 
„Das Spiel der neuen Musikanten aus Demokratenland schwingt in anderer Sphäre. Hier gibt es keine Herren mehr und keine Diener, keine Subjekte und keine Objekte der tönenden Materie [...]. Gibt es hier keine Seele? Doch, aber sie ist eine männliche. Die maskuline Epoche findet hier ihre akustische Prägung. Der Urwald ist ferne Kindheitserinnerung, verdrängt auf dem Marsch über Kriegspfade und Plantagen und verloren in der Geometrie und Mühsal unendlicher Asphaltstraßen. ${ }^{114}$

Abgesehen von kaum verhohlener Demokratiefeindlichkeit und banalem Ethnodeterminismus dient die von Bernhard vorgenommene Synchronisierung unterschiedlicher, zeitlich disparater Abläufe und Bedingungen der generellen Disqualifizierung afroamerikanischer Kultur und lässt diese als »schädlich" erscheinen. Voneinander deutlich abgrenzbare Zeitphänomene wie das Aufkommen eines musikalischen Massenpublikums, wachsender Kulturimport und die Übernahme amerikanischer Produktionsorganisation werden hier unter einem negativ besetzten Amerikanisierungsbegriff verhandelt. Negativ erscheint dieser für Bernhard auf Grund des afroamerikanischen Einflusses auf die Kultur der USA insgesamt.

Die kulturelle Wirkmächtigkeit der Black Community war - auch bei Kritikern wie Bernhard - unbestritten. In der veröffentlichten Meinung spiegelte sich also auch eine kulturelle Emanzipation wider. Der afroamerikanische Beitrag zur amerikanischen Kultur wurde zwar als eigenständig, aber gleichzeitig als in die amerikanische Mehrheitskultur integriert betrachtet. Die Black Community wurde nicht mehr (nur) als gesellschaftliches "Problem ", sondern zunehmend als kulturell produktiver Faktor angesehen - als integraler Bestandteil nicht nur der amerikanischen, sondern der gesamten westlichen Kultur.

Joseph Chapiro charakterisiert die Black Community 1929 im Berliner Tageblatt als Kulturfaktor, der über ihren eigenen sozialen Kontext hinausweist:

"Der Neger kann heute nur noch vom ökonomischen, ethnographischen und vielleicht auch politischen Standpunkt aus als Problem betrachtet werden; vom kulturellen Standpunkt aus ist er kein Problem mehr, sondern ein Faktor [...]. Zerlegen wir den Regenbogen, aus dem sich das Weiss unserer gegenwärtigen Kultur zusammensetzt, so werden wir auf den schwarzen Negerflecken stossen. Unsere milchweisse Kultur nimmt die Färbung von gebräunter Milch an. ${ }^{115}$

Ignoriert man für einen Moment die eigenwillige zeitgenössische Metaphorik, schält sich hier eine überraschend aktuelle Sichtweise auf die westliche Kultur heraus. Die in vielerlei Hinsicht bahnbrechende Konstatierung eines ohnehin

114 Ebd.

115 Chapiro, Joseph: „Die amerikanische Negerhauptstadt. Der Neger als Kulturfaktor«. In: BTB Nr. 136 vom 20.03.1929, 5. 
fest in der westlichen oder europäischen Kultur verankerten afroamerikanischen Elements überrascht ob ihrer Nonchalance. Wie erklärt sich Chapiro die integrale Prägekraft »schwarzer« Kultur?

Chapiro zeichnet am Beispiel des New Yorker Stadtviertels Harlem das Bild eines urban-industriellen Inkubators, innerhalb dessen Talent und Schaffenskraft der Afroamerikaner geweckt worden seien. Nun, so Chapiros Narrativ, ergössen sich die Produkte dieser Talente in das Gesamtgefüge amerikanischer Kultur, wodurch sich in hohem Maße auch der gesellschaftliche Aufstieg der Schwarzen beschleunige - mehr als durch Lincolns Emanzipationsproklamation:

"Amerika ist das Land, wo die Neger [...] ihre Kultur erneuern oder - wie es in Wirklichkeit ist - eine neue Kultur schaffen. Ihre geistige Hauptstadt ist zweifellos Harlem [...]. Alles steht dort im Zeichen des Negers, alles deutet auf seine hundertprozentige Herrschaft in diesem Gebiet. [...] Es ist interessant, den Gründen nachzugehen, welche die Negerstellung in so kurzer Zeit veränderten, nämlich wie Harlem das, was Abraham Lincoln mit seinem Befreiungsgesetz nicht ändern konnte, selbstständig $[. .$.$] geschaffen hat. Diese Industrialisierung und somit die Urbanisierung$ macht aus ihrem Stamm einen wichtigen Faktor [...] im politischen wie im kulturellen Leben Amerikas [...]. Indem sie sich auf geistigem Gebiet zu behaupten suchen, wollen sie in jene öffentlichen Stellungen gelangen, zu denen sie noch nicht zugelassen werden. « $^{116}$

Der Einfluss, der sich daraus auf die gesamte westliche Kultur ergebe, könne nur innerhalb des Amerikanisierungsparadigmas verstanden werden, vulgo: Heute in Amerika, morgen in Europa. Demnach finde jedwede, sich in der amerikanischen Kultur etablierende Subkultur auf kurz oder lang automatisch Eingang in die über transatlantische Austauschbeziehungen konstituierte »westliche Kultur«. Dies erscheint Chapiro jedoch nicht als ausreichender Rahmen, um den kulturellen afroamerikanischen Einfluss zu illustrieren. Sowohl zeitlich ${ }^{117}$ als auch räumlich zieht er den Rahmen noch wesentlich weiter:

116 Ebd.

117 »Der Stolz der Neger erstreckt sich nicht nur auf die lebenden oder die vor kurzem verstorbenen berühmten Schwarzen, sondern auch auf diejenigen, die von Negern abstammen. Der grosse russische Dichter Alexander Sergewitsch Puschkin, dessen Ahne von Peter dem Grossen aus Afrika hinübergeholt worden war, ist einer der populärsten Namen unter den Negern. Sie eignen sich Alexander [sic] Dumas an, der Negerblut in seinen Adern hatte. Jede Ausgrabung in Afrika wird von ihnen auf das Genaueste verfolgt, jedes Kunstwerk in Millionen Exemplaren verbreitet, und ihr Rassenstolz erstreckt sich bis auf die Aegypter, die Negerblut in sehr grosser Dosis besassen und die vor vielen Jahrtausenden eine Kultur schufen, die den Gang der Weltgeschichte beeinflusste.«Ebd. 
»[W]ir erfahren durch die illustrierten Negerzeitungen, dass sogar in Shanghai und Tokio die Negerkünstler, Niggersongs und Niggertänze die beliebtesten sind. Was dem europäischen Geschmack nie vollkommen gelungen ist: sich der ganzen Welt und allen Kulturen einzuimpfen, das gelang dem Negergeschmack, der innerhalb eines kurzen Zeitabschnittes den ganzen Erdball umsponnen hat! «18

Auch der politische Kampf um Gleichberechtigung sei keineswegs auf die Vereinigten Staaten beschränkt, sondern gleiche einer panafrikanischen Anstrengung, die weltweite Niederhaltung der Schwarzen insgesamt zu beenden. ${ }^{119}$ Ungeachtet der Tatsache, dass derlei Ziele streckenweise durchaus in der politischen und ideologischen Entfaltung der Black Community eine Rolle gespielt hatten und weiter spielten, ${ }^{120}$ waren sie doch zu jener Zeit nicht so zentral für die Bewegung, wie es das Ziel der vollen gesellschaftlichen Gleichstellung innerhalb der US-Gesellschaft war.

Chapiros Beitrag zeigt auf, wie tief der publizistische Blick aus Deutschland bisweilen in die Verästelungen der politischen Agitation der Black Community reichte. Er blieb nicht an der Oberfläche exotistischer Faszination stecken, sondern griff ausgehend von der Rassenkonfrontation bis in deren historische Wurzeln und die Beweggründe ihrer einzelnen Akteure durch.

Sowohl thematische Marginalien als auch das ein breites Publikum bewegende Anliegen, einer mutwillig entrechteten Gruppe im "Land der Freiheit" endlich zu ihrem Recht zu verhelfen, finden sich in der Weimarer Berichterstattung zur afroamerikanischen Minderheit in aller Kontroversität wieder. Im Vergleich zu diesem breiten thematischen Spektrum und den sehr zahlreichen Referenzen spielte eine andere amerikanische Minderheit eine wesentlich geringere Rolle in der deutschen Amerikaberichterstattung.

\subsection{Indigene Bevölkerung Nordamerikas}

Die indigene Bevölkerung Amerikas war in den Illustrierten der Weimarer Zeit ein thematisches Randphänomen, was angesichts der notorischen Indianerbegeisterung der Deutschen ein wenig überrascht. Ihre Betrachtung beschränkte sich in den Illustrierten weitestgehend auf Narrative des Niedergangs und des allmählichen Verschwindens, ${ }^{121}$ bot aber auch Raum für Kritik

118 Ebd.

119 Vgl. ebd.

120 Man denke an die Austauschbeziehungen zwischen den Vereinigten Staaten und Liberia. Dorthin wanderte eine große Zahl an Afroamerikanern ab den 1820er Jahren aus.

121 Unter anderem: Anon.: Die letzte Mohikanerin. "Die weiße Hirschkuh«, Tochter des "fliegenden Hirsches", die angeblich letzte Frau des Mohikanerstammes, die nun auf einer New-Yorker Bühne auftritt. In: BIZ, 1927, Nr. 20, 788 (Jahresausgabe). 
an der zwangsweisen "Zivilisierung« der Indigenen. ${ }^{122}$ Auch wenn die betreffenden Berichte dem Anspruch in keiner Weise genügten, wiesen sie teils völkerkundliche Anwandlungen auf. Sie waren oftmals spürbar vom Bestreben getragen, der Leserschaft Informationen zu Kultur und Lebensweise indigener Gruppen nahezubringen, bevor Letztere von der Bildfläche verschwänden.

Der nationalsozialistische Illustrierte Beobachter (ILB) stellte, ebenso wie weitere NS-Presseorgane, den Zugang zum Thema »Indianer« auf ganz besondere Weise her. Er verglich die »fortwährende Verleumdung« der indigenen Völker Amerikas mit der Darstellung der Deutschen als Barbaren während der Zeit des Ersten Weltkriegs. ${ }^{123}$ Es entbehrt nicht einer gewissen Ironie, dass rassistische Zuschreibungen, die durch europäische Siedler und später durch die amerikanische Regierung zur Diskreditierung und Bekämpfung der Indianer instrumentalisiert worden waren, ausgerechnet im ILB einer waschechten Dekonstruktion unterzogen wurden - schließlich produzierte der ILB solche rassistischen Feindbilder zuhauf und mit großem Eifer selbst:

"Die Amerikaner haben den erbarmungslosen Vernichtungskampf, den sie gegen ihre roten Wirte führten, mit der Behauptung zu rechtfertigen versucht, die Indianer seien von Natur faul, der Kultur unzugänglich und hartnäckig in ihrem Widerstand. Wer heute durch die Reservationen der Vereinigten Staaten reist, sieht, daß das Gegenteil der Fall ist. ${ }^{124}$

Die Aneignung des indianischen Opfernarrativs zum Zweck der Selbst-Viktimisierung stellt eine Grundtendenz der NS-Amerikabetrachtung dar. ${ }^{125}$ Die ideologischen Grundlagen der NS-Bewegung boten zahlreiche Anknüpfungspunkte für eine Identifikation mit der indigenen Bevölkerung. Dazu zählen die Sakralisierung des Bodens ${ }^{126}$ und die Vorstellung vom Krieg als Überlebenskampf der Rassen. ${ }^{127}$ Solche und andere Analogien motivierten NS-Beiträger sogar zur hanebüchenen Imagination des »faschistischen Indianers«. ${ }^{128}$ Auch innerhalb dieser schillernden Konstellation finden sich vereinzelt op-

122 Anon.: Die Pueblo- und Navajo-Indianer. Die ältesten Rassen Amerikas. In: BIZ, 1927, Nr. 37, 1476f. (Jahresausgabe).

123 »Wie ein Volk durch fortwährende Verleumdung seiner Feinde in den Augen der Welt das Aussehen von Barbaren gewinnen kann, haben wir Deutschen im Weltkriege erfahren.« Henckel, Heinz: Das wahre Gesicht des Roten Mannes. In: ILB, 1927, Nr. 13, 186 f. (Jahresausgabe).

124 Ebd.

125 Vgl. Usbeck, Frank: »Fellow Peoples«. The Influence of the German Image of Indians on German National Identity and its Appropriation by National Socialism in German Periodicals 1925-1945. Dissertation Universität Leipzig, CD-ROM. Leipzig 2010.

126 Ebd., $97 \mathrm{f}$.

127 Ebd., $218 \mathrm{f}$.

128 Vgl. Penny, Glenn: Kindred by Choice. Germans and American Indians since 1800. Chapel Hill 2013, 164. 
timistisch konnotierte Beispiele für die gesellschaftliche Selbstbehauptung der Indigenen, so etwa langsam sich einstellende Bildungserfolge oder die wirtschaftliche Konsolidierung einzelner Gruppen. ${ }^{129}$

Solcher Optimismus bezüglich der ökonomischen und politischen Perspektiven der Indigenen zeigte sich auch in anderen Organen. In einem Bericht der Münchner Illustrierten Presse (MIP) über das Pow Wow (die große Stammeszusammenkunft) von Spokane, Washington konnte man 1928 den Eindruck gewinnen, die indigene Bevölkerung der Vereinigten Staaten gewinne allmählich die Autonomie über ihre kulturelle und politische Organisation zurück. ${ }^{130}$

So ist etwa die Rede davon, alle Stämme schickten Abgesandte zur Diskussion der Lage und Ziele der indigenen Bevölkerung. ${ }^{131}$ Dabei entsteht allzu leicht der Eindruck, die verstreuten und kaum organisierten indigenen Gruppen verfügten über eine handlungsfähige Föderation zur Vertretung ihrer Interessen. Davon konnte zum damaligen Zeitpunkt keine Rede sein. ${ }^{132}$ Die Visuals zeigen Tipis inmitten der belebten Promenade von Spokane und einen Zug berittener $»$ Blackfoot $«{ }^{133}$ Dies suggeriert eine gleichberechtigte Koexistenz, von der die US-Gesellschaft damals aber noch weiter entfernt war als heute (Abb. 12).

Die fernpublizistische Auseinandersetzung mit den Indigenen war von zwei Tendenzen geprägt, die die Perspektive gleichermaßen verfälschten: von einer Idealisierung, die auf Analogien mit der eigenen Weltanschauung aufbaute oder dem Klischee vom »edlen Wilden « entsprach. ${ }^{134}$ Und von traditionellem Exotismus, der sich oftmals in der visuellen Darstellung Indigener neben Vertretern der »eigenen « Kultur erschöpfte. ${ }^{135}$ Beide Tendenzen vereinigten sich, sowohl in der nationalsozialistischen als auch der kommunistischen Propaganda, mit der ohnehin beispiellosen Romantisierung der »Indianer« in Deutschland, die durch die Klassiker eines Karl May unauslöschbar in das kollektive Bewusstsein eingegangen war und den zeitgenössischen Blick auf

$129 »$ Die stolzen Krieger von einst sind heute fleißige, teils wohlhabende Farmer [...] Sie haben landwirtschaftliche Maschinen, Autos und Radio [...]. Es gibt unter ihnen Ärzte, Journalisten, Abgeordnete und Schriftsteller [...]«. Henckel: Das wahre Gesicht des Roten Mannes.

130 Anon.: Der zweite Indianer Kongress in Spokane. In: MIP, 1928, Nr. 19, 596 f. (Jahresausgabe).

131 Vgl. ebd.

132 Nationale Interessenverbände wie z. B. der National Congress of American Indians wurden erst zum Ende des Zweiten Weltkriegs gegründet.

133 Selbstbezeichnung "Niitsítapi«.

134 Unter anderem: Anon.: Indianer. In: BIZ, 1928, Nr. 42, 1790 f. (Jahresausgabe).

135 Unter anderem: Anon.: Einstein bei den Indianern. In: MIP, 1931, Nr. 13, 386 (Jahresausgabe). 


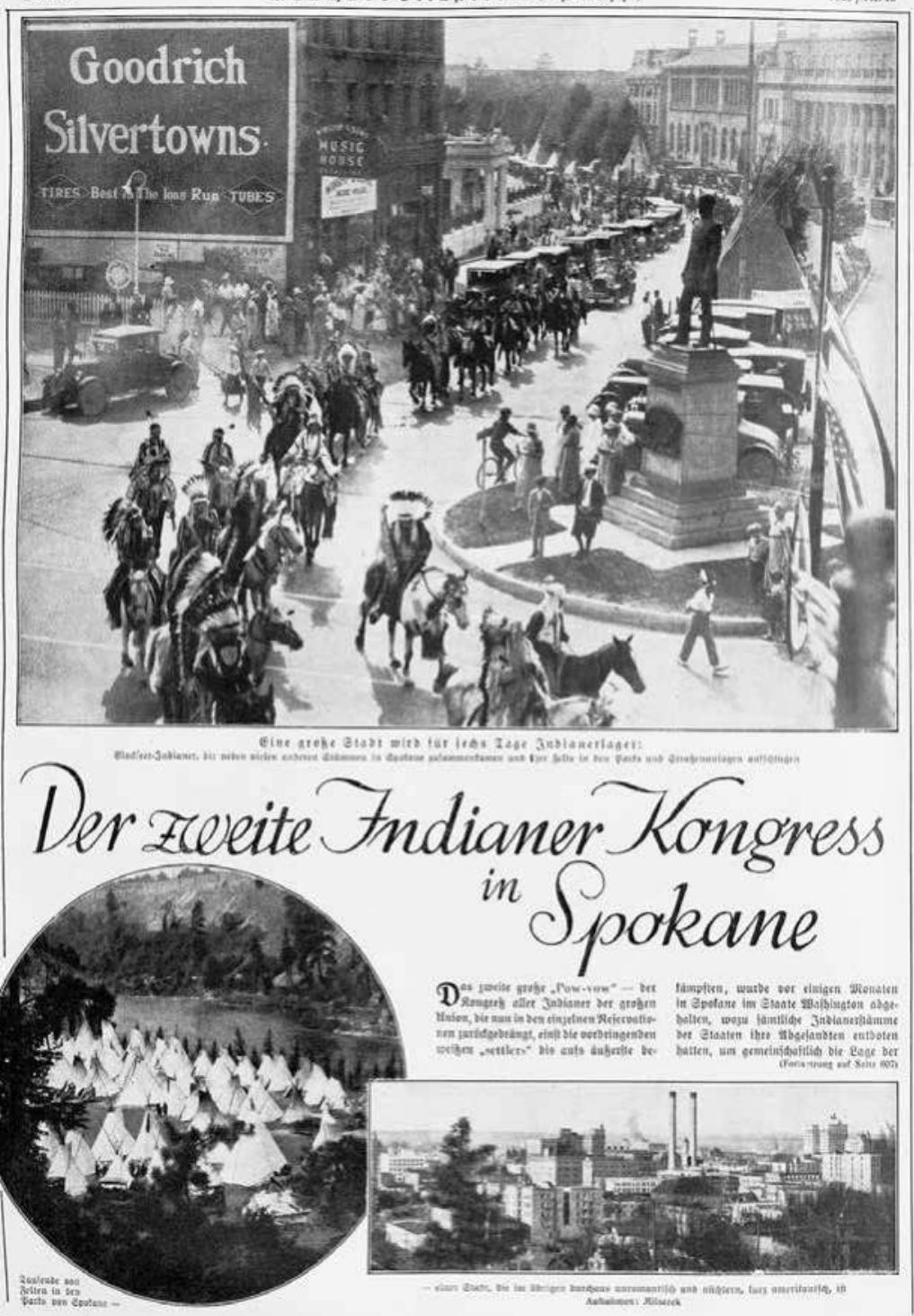

Abb. 12: Der zweite Indianer Kongress in Spokane. Durch die Darstellung der vermeintlichen Alläglichkeit von politischen Zusammenkünften indigener Gruppen wurde deren Situation euphemistisch überzeichnet. 
Amerikas indigene Bevölkerung nach wie vor beträchtlich verklärte, ${ }^{136}$ ja in ebensolchem Maße verfälschte und hierarchisierte wie es die erst seit kurzem unüblich gewordenen "Völkerschauen" in europäischen Städten und bezeichnenderweise - Zoos getan hatten. Die aufkeimende Reflexion dieser schiefen, zu Unterhaltungszwecken inszenierten Wahrnehmung illustriert zum Abschluss ein Zitat der BIZ aus dem Jahr 1927:

"Die Indianergeschichten sind schuld, dass der Weiße heute eine so verzerrte, nur aus Adlerfedern, Skalp und Tomahawk zusammengesetzte Vorstellung von dem rothäutigen Volke hat. Und Besucher in den Reservationen der nördlicheren Staaten der nordamerikanischen Union können diese Vorstellungen kaum richtigstellen, weil diese Indianer, vollkommen mit den 'Segnungen` der Zivilisation vertraut, heute fast vollständig im Dienst der Film- und Touristen-Industrie stehen. ${ }^{137}$

\subsection{Die Minoritäten und Nationalitäten der UdSSR}

Die deutschsprachige Presseberichterstattung zu den nationalen und religiösen Minderheiten der UdSSR kam oft nicht über eine bloße Fortschreibung der Ziele hinaus, die die Bolschewiki zu Beginn ihrer Herrschaft programmatisch festgehalten hatten. Dabei boten sich in der Zeit zwischen den Revolutionswirren und der Etablierung kommunistischer Herrschaft zahlreiche Gelegenheiten, diese grundlegende Fehleinschätzung zu korrigieren. Dies geschah jedoch bis zum Ende des Beobachtungszeitraumes nicht.

Nach immerhin zwölf Jahren bolschewistischer Herrschaft lobte der renommierte Reiseberichterstatter Arthur Feiler, der auch Amerikakorrespondent gewesen war, die neuen Rechte und Freiheiten der nationalen Minderheiten im Jahr 1929 in höchsten Tönen. ${ }^{138}$ Er tritt dabei (zurecht) dem in Deutschland verbreiteten Eindruck entgegen, durch die zentralistische Verwaltung der UdSSR von Moskau aus würde die politische Teilhabe nationaler Minderheiten a priori verhindert. Leider setzt er diesem Eindruck das ebenso trügerische Bild einer freiwilligen Föderation gleichberechtigter Nationen entgegen, welchen durch die »wirklich großen Befreiungstaten « des Bolschewismus »zum ersten Mal nationale Freiheit und Selbstverwaltung « zuteilwürden. ${ }^{139}$

Feiler hebt diese emanzipatorischen Errungenschaften durch den Vergleich zur zaristischen Politik der Russifizierung hervor:

136 Vgl. dazu: Küppers, Petra: Karl Mays Indianerbild und die Tradition der Fremdendarstellung. Eine kulturgeschichtliche Analyse. In: Jahrbuch der Karl-May-Gesellschaft (1996). Husum 1996, 315-345. Und nochmals: Penny: Kindred by Choice, $164 \mathrm{f}$.

137 Anon.: Die Pueblo- und Navajo-Indianer. Die ältesten Rassen Amerikas.

138 Feiler, Arthur: Die Diktatur des Bolschewismus. Aus dem Tagebuch einer russischen Reise. In: FZT Nr. 704 vom 21.09.1929, $1 \mathrm{f}$.

139 Ebd. 
»Der Zarismus hatte eine harte Russifizierungspolitik getrieben, umso härter, je mehr die unterdrückten Nationen dem eigentlichen Russentum kulturell überlegen waren [...]. Das war das alte System des Zarismus. Das neue des Bolschewismus tut von alledem diametral das Gegenteil. Es pflegt die nationalen Sprachen, die nun in den geschlossenen Siedlungsgebieten der Nationalitäten offiziell die Sprachen der Verwaltung, der Zeitungen, der Schulen usw. geworden sind. Es gewährt den Nationalitäten die nationale, politische und kulturelle Autonomie. ${ }^{140}$

Darüber hinaus bezeichnet Feiler die Nationalitätenpolitik der Bolschewiki gar als "großes und echtes Stück wirklicher Demokratie», was im Vergleich zur zaristischen Minderheitenpolitik mehr schlecht als recht zutrifft. Dass die angeblich wirkliche Demokratie nur innerhalb des strengen Korsetts der Parteiendiktatur existierte, stellt indes auch Feiler fest: »Es ist wie alles, Demokratie nur innerhalb des Rahmens der Diktatur. [...] Auch über den befreiten Nationalitäten weht die rote Fahne. ${ }^{141}$ So steht Feilers positive Einschätzung stellvertretend für viele andere Beiträger. Nur bedingt wurde (an)erkannt, dass das von der Revolution hinweggefegte Primat des Russentums durch den Alleinherrschaftsanspruch der Bolschewiki direkt ersetzt worden war.

Berichte $\mathrm{zu}$ den religiösen und nationalen Minderheiten der Sowjetunion nahmen sich in Zahl und Tiefgang viel geringer aus als diejenigen über die Lage der Afroamerikaner. Ein Grund hierfür ist zum einen der nur schwache Informationsfluss, bedingt durch das Fehlen etablierter Korrespondentennetzwerke vor Ort (besonders im Vergleich zu denen in den Vereinigten Staaten). Obwohl es auf dem Gebiet der UdSSR außer den Russen eine beinahe unüberschaubare Vielfalt an kulturell eigenständigen Gruppen gab, waren lediglich zwei tatsächlich in der Tagespresse und den Illustrierten präsent: Juden und Wolgadeutsche. ${ }^{142}$

Das Interesse der deutschen Leserschaft richtete sich vor allem auf Auslandsdeutsche in Polen und der Tschechoslowakei, die durch Meldungen über tatsächliche und vermeintliche Repressionen oft Beachtung in der Tagespresse fanden. In geringerem Umfang finden sich Meldungen, die sich den Deutschen in der (sogenannten) Autonomen Republik der Wolgadeutschen widmen. ${ }^{143}$

140 Ebd.

141 Ebd.

142 Sieht man von über den Beobachtungszeitraum verstreuten, ohne jeglichen Kontext erscheinenden Kurzbetrachtungen zu muslimischen und zentralasiatischen Minderheitenbevölkerungen ab.

143 Zur Entwicklung der verschiedenen deutschen Minderheiten:Kappeler, Andreas/Meissner, Boris/Simon, Gerhard (Hg.): Die Deutschen im Russischen Reich und im Sowjetstaat. Bremen 1987. Hier: Eisfeld, Alfred: Autonome Sozialistische Sowjetrepublik der Wolgadeutschen. Chance oder Gefahrenherd? Ebd., 49-67. Und: Buchsweiler, Meir: Die Sowjetdeutschen - außerhalb der Wolgarepublik - im Vergleich mit anderen Minderheiten 1917 bis 1941/42. Ebd., 69-96. Zur schwach ausgeprägten Berichterstattung: Köhler-Baur, 
Diese wenigen Berichte unterschieden sich in ihrem Urteil radikal. Während die AIZ die Republik der Wolgadeutschen als vorbildhafte Umsetzung kommunistischer Minderheitenautonomie inszenierte, ${ }^{144}$ beklagte die MIP die Zwangsmaßnahmen gegen deren vornehmlich großbäuerlichen Bewohner. ${ }^{145}$ Diese divergierenden Einschätzungen spiegeln sowohl die ideologischen Differenzen, als auch die mit Stalins Herrschaft einsetzende Desillusionierung wider. Ansonsten blieben die Wolgadeutschen eine Fußnote der Berichterstattung zu Minderheiten in der Sowjetunion.

\subsection{Bilder sowjetischer Juden}

Wesentlich vielschichtiger fiel die Darstellung russischer Juden aus. In manchen Fällen wurden sie in ihrer Eigenschaft als nationale und religiöse Minderheit, in anderen als integraler Bestandteil der politischen und intellektuellen Führungsschicht des entstehenden Sowjetstaates figuriert. Diese beiden völlig unterschiedlichen Sichtweisen sind schlichtweg der Heterogenität der von außen als Gruppe wahrgenommenen Juden in der Sowjetunion geschuldet. Die dortige jüdische Bevölkerung als eine in sich geschlossene Gruppe zu denken, negierte die Tatsache, dass sich während und nach der Revolution von 1917 Menschen jüdischen Glaubens an allen Fronten fanden, an denen der russische Bürgerkrieg und die inneren Auseinandersetzungen der an der Revolution beteiligten Gruppierungen ausgefochten wurden.

Es existierten zahlreiche jüdische Verbände, die vollkommen unterschiedliche Ziele verfolgten, sich verfeindeten politischen Lagern zuordneten. Selbst innerhalb jüdischer Verbände lassen sich nur schwer klare Richtungen ausmachen. Zum Beispiel arbeitete im erklärtermaßen zionistisch-marxistischen "Poale Zion" eine Fraktion an Emigrationsplänen nach Palästina, während die andere mit großem Eifer den Klassenkampf propagierte - vor allem den gegen ihre wohlhabenderen Glaubensgenossen. ${ }^{146}$ Hinzu kamen jahrzehntealte Kontroversen um die Frage, ob die geschlossene Emigration mit an-

Maria: Die deutsche Berichterstattung über die Rußlanddeutschen. »Der Auslandsdeutsche«1920-1929. In: Eisfeld, Alfred / Herdt, Victor/Meissner, Boris: Deutsche in Rußland und der Sowjetunion 1914-1941. Berlin 2007, $209 \mathrm{f}$.

144 Anon.: Bäuerin aus der autonomen Republik der Wolga-Deutschen. In: AIZ, 1927, Nr. 21. Titel. Und: Anon.: Die deutsche Wolga-Republik. In: AIZ, 1927, Nr. 42, $4 \mathrm{f}$.

145 Anon.: Neuer Schlag Rußlands gegen das Deutschtum. Enteignung der wolgadeutschen Bauerngüter - ein deutscher Pfarrer nach Sibirien verbannt. In: MNN Nr. 342 vom 16.12.1929, 1. Und: Anon.: Wolga-Bauern. Zu den Massenauswanderungen deutscher Bauern aus Rußland. In: MIP, 1929, Nr. 48, 1626 (Jahresausgabe).

146 Vgl. Solschenizyn, Alexander: »Zweihundert Jahre zusammen«. Die Juden in der Sowjetunion. Bd. 2. München 2003, 46f. Und: Judt, Tony/Snyder, Timothy: Nachdenken über das 20. Jahrhundert. Frankfurt a. M. 2015, 89 f. 
schließender Staatsgründung, ein jüdischer Staat auf russischem Territorium oder die uneingeschränkte Unterstützung der Bewegung der Bolschewiki den Interessen der Juden Russlands am besten dienten. Derlei Fragen, die sich auch immer an der grundsätzlichen Entscheidung zwischen jüdischer Tradition (religiöser Loyalität) und weltlicher Orientierung (Loyalität gegenüber dem Staat) brachen, zogen tiefe Gräben durch jüdische Verbände und Familien, was vielfach literarisch verarbeitet wurde. ${ }^{147}$ Kurz, die jüdische Bevölkerung bildete politisch und ideologisch wahrlich keine homogene Gruppe. Gemein war jüdischen Verbänden und Parteien einzig das Ziel kultureller Autonomie und allgemeiner Gleichberechtigung.

Die frühesten Meldungen und Reportagen, die sich mit der jüdischen Bevölkerung in Sowjet-Russland befassten, waren jedoch weit von der Verwirklichung solcher Wünsche entfernt. Im größtmöglichen Gegensatz dazu kündeten sie von gewalttätigen antijüdischen Pogromen und Enteignungen, die eine humanitäre Notlage zur Folge hatten. ${ }^{148}$ Die zwischen 1917 und 1923 eskalierende Gewalt gegen Juden wurde jedoch in den Zusammenhang des Russischen Bürgerkrieges gestellt und damit nicht als primär judenfeindlich betrachtet. Sie wurde von der bereits seit dem ausgehenden 19. Jahrhundert anhaltenden Gewaltserie gegen Juden getrennt. Erst nachdem der Bürgerkrieg vorüber war, geriet der in Russland historisch verwurzelte Antisemitismus ins Blickfeld, der sich seit den 1880er Jahren immer wieder in Pogromen Bahn

147 Unter anderem Scholem Alejchem in seinem um 1905 spielenden und 1916 vollendeten Roman »Tewje, der Milchmann«. Vgl. Alejchem, Scholem: Tewje, der Milchmann. Bremen 2011.

148 »Ich habe schon einmal die furchtbaren Pogrome geschildert, die, wie in Polen, so in der Ukraine stattgefunden haben. Daß die Juden die dort allein Leidenden sind, ist natürlich ausgeschlossen. Wohl aber können die Leiden der Juden einen allgemein gültigen Maßstab dafür bieten, welche Höhe die Barbarei in jenen Gegenden von neuem erreicht hat, und, was den Juden dort widerfahren, ist ein beachtenswertes Symptom für die Zustände in dem riesigen russischen Reich, wo Verarmung, Verbrechen und politische Leidenschaft, Unverstand, Raserei, augenscheinlich allerorten, hier vereinzelt, dort gehäuft, wahnsinnige Orgien feiern [...]. In der erwähnten kurzen Uebersicht heißt es: ১Während die Pogrome der ersten Periode - seit Oktober 1918 - hauptsächlich auf Plünderungen des Eigentums gerichtet waren, war die nächste Welle wie ein gewaltiger Orkan, welcher kleinere und größere Städte mit jüdischen Bewohnern vollkommen hinwegraffte.، Und eine andere Stelle des Berichts lautet: ১Die jüdische Bevölkerung in der überwiegenden Mehrzahl der kleineren und größeren Städte, in den Gouvernements Wolhynien, Podolien, Kiew und Teilen von Cherkow verlor all ihr Hab und Gut: Kleidung, Schuhe, Wäsche und Gegenstände des täglichen Bedarfs. Aus den Geschäften und auch bei den Höfern wurden alle Waren weggenommen. Die Handwerker sind all ihrer Maschinen und Werkzeuge beraubt; die Produktion ist zerstört. Die von Pogromen heimgesuchte Bevölkerung erlag außer der allgemeinen seelischen Depression dem Einfluß epidemischer Krankheiten.« Nathan, P.: Die Verantwortung der Sieger - Zu den Pogromen in Südrußland. In: BTB Nr. 87 vom 17.02.1920, 1 f. 
gebrochen hatte. ${ }^{149}$ Vom ILB wurden solche Ereignisse dankbar aufgegriffen, um die eigene antijüdische Agitation in einen Legitimationszusammenhang jenseits nationaler und ideologischer Grenzen zu stellen. ${ }^{150}$

In seiner Artikelserie »Reise in Rußland«, erschienen 1926 in der Frankfurter Zeitung, schildert der Literat Joseph Roth, selbst gebürtiger Jude aus Galizien, nicht nur Reiseeindrücke. Er versucht, seinen Lesern die politische Realität näherzubringen, die sich durch die Machtkonsolidierung der Bolschewiki und die Umsetzung ihrer ideologischen Ziele ergeben habe. ${ }^{151}$ In einer Folge seiner 17-teiligen Berichtsreihe widmet er sich den russischen Juden. Roth schickt eine Charakterisierung der vorrevolutionären Formen des gewalttätigen Antisemitismus in Russland voraus, ${ }^{152}$ bevor er sich mit der Situation der Juden als nunmehr staatlich anerkannter nationaler Minderheit befasst:

"Heute ist Sowjetrußland das einzige Land in Europa, in dem der Antisemitismus verpönt ist, wenn er auch nicht aufgehört hat [...]. Als Volk haben sie alle Rechte einer snationalen Minderheit. Die Geschichte der Juden kennt kein Beispiel einer so plötzlichen und einer so vollkommenen Befreiung. ${ }^{153}$

Er geht auch auf den Zielkonflikt zwischen der jüdischen Emanzipation innerhalb der Sowjetunion und zionistischen Vorstellungen ein, der in jüdischen Verbänden für scharfe Debatten sorgte. ${ }^{154}$ Roth hebt die zunehmende kulturelle Autonomie hervor, die er an neu entstehenden jüdischen Schulen und religiösen Ausbildungsstätten zu belegen versucht und sieht in einer nunmehr offiziell anerkannten jüdischen Gerichtsbarkeit auch die innere Autonomie der Juden verwirklich. ${ }^{155}$ Die überproportionale Präsenz jüdischer Sowjetbürger in der kommunistischen Partei und im Hochschulwesen erachtet er als Voraussetzung dafür, dass Menschen jüdischen Glaubens sich im neuen Staat etablieren und die noch im Zarenreich praktizierte Abgrenzung zur Mehrheitsbevölkerung dauerhaft überwinden könnten. Das Ziel, die Juden als

149 Vgl. Klier, John: Russians, Jews, and the Pogrom Crisis of 1881-1882. Cambridge u.a. 2011, $17 \mathrm{f}$.

150 Unter anderem: Anon.: Antisemitismus in Sowjet-Rußland. In: ILB, 1928, Nr. 32, 399 (Jahresausgabe).

151 Vgl. Magallanes, Fernando: Reiseliteratur am Beispiel Joseph Roths. In: Miladinovic Zalaznik, Mira/Lughofer, Johann Georg (Hg.): Joseph Roth: Europäisch-jüdischer Schriftsteller und österreichischer Universalist. Berlin u. a. 2011, $119 \mathrm{f}$.

152 »Man war nicht etwa bestrebt, sie (die Juden) durch Vergewaltigung zu assimilieren. Man war bestrebt, sie abzugrenzen. Die Mittel, die man gegen sie anwandte, sahen so aus, als wollte man sie vertilgen.« Roth, Joseph: Reise in Rußland - IX. Die Lage der Juden in Sowjetrußland. In: FZT Nr. 835 vom 09.11.1926, 1 f.

153 Ebd.

154 »Die Juden sind vollkommen freie Bürger - mag ihre Freiheit auch noch nicht die Lösung der jüdischen Frage bedeuten." Ebd.

155 Vgl. ebd. 
geschlossene nationale Minderheit (im Sinne der Bolschewiki) vollständig in die sowjetische Gesellschaftsordnung zu integrieren, hält der Autor jedoch angesichts des traditionellen Deutungskonfliktes über die Natur der kulturellen Zusammengehörigkeit der Juden für unerreichbar:

»Die alte, die wichtigste Frage stellt die Revolution überhaupt nicht: ob die Juden eine Nation sind wie jede andere, ob sie nicht weniger oder mehr sind, ob sie eine Religionsgemeinschaft, eine Stammesgemeinschaft, oder snur eine geistige Einheit sind, ob es möglich ist, ein Volk, das sich durch die Jahrtausende nur durch seine Religion und die Ausnahmestellung in Europa erhalten hat, unabhängig von seiner Religion als ,Volk zu betrachten, ob in diesem Fall eine Trennung von Kirche und Nationalität möglich ist, ob es möglich ist, aus Menschen mit ererbten geistigen Interessen Bauern zu machen, aus stark geprägten Individualitäten Individuen mit Massenpsychologie. « ${ }^{156}$

Joseph Roth scheint der Individualismus sowjetischer Juden mit den Erfordernissen bolschewistischer Massenorganisationen unvereinbar. Der jüdischen Befreiung durch die neue Ordnung bescheinigt er geringe Erfolgsaussichten. Namentlich der politische Zionismus mache ein Aufgehen in einem sozialistischen Nationalstaat unmöglich, da er es durch den immanenten Rückgriff auf religiös-kulturelle Selbstabgrenzung ausschließe. Die Juden der Sowjetunion seien »ein Volk mit [...] alten Talenten und neuer Nationalkultur. Der Zionismus wollte Tradition und neuzeitliches [sic] Kompromiß. ${ }^{157}$ Dieser Kompromiss hätte bedeutet, die Gründung eines jüdischen Staates mit einer auf jüdischer Tradition fußenden Ordnung mit der neuen sowjetischen $\mathrm{Na}$ tionalkultur und deren Loyalitätsanspruch zu vereinen - die Quadratur des Kreises. Roth zufolge sind Bolschewismus und Zionismus als Alternativen zu begreifen, die sich gegenseitig ausschließen. Eingedenk der weiteren Karriere des politischen Zionismus, die in der Staatsgründung Israels gipfelte, lag Roth mit dieser Einschätzung übrigens ziemlich richtig. ${ }^{158}$

156 Ebd.

157 Ebd.

158 Nicht zuletzt auf Grund strategischer Vorteile im sich abzeichnenden Kalten Krieg war die britische Mandatsmacht im Nachgang des Zweiten Weltkriegs rasch bereit, einen demokratischen, auf religiös-kulturellen Grundlagen fußenden Rumpfstaat Israel zu unterstützen. Außerdem entwickelte der Zionismus während der Gründungsphase starke antikommunistische Tendenzen, während sich in der UdSSR das auch maßgeblich von jüdischen Sowjetbürgern getragene »Antizionistische Komitee« formierte. Es war keineswegs die Religionszugehörigkeit, sondern vielmehr die politisch-ideologische Verortung, entlang derer sich Oppositionen definierten. Diese Aufteilung stellt kein spezifisch russisches Phänomen dar. Auch in Deutschland und Großbritannien, später auch in den USA teilte sich die organisierte jüdische Glaubensgemeinschaft in Zionisten und liberale Antizionisten auf. Letztere erklärten die Etablierung und Verwurzelung in ihren jeweiligen Heimatländern zum gemeinsamen Ziel. Vgl. Grill, Tobias: Antizionistische 
Dass sich entgegen der programmatischen Zielsetzung der Bolschewiki die antisemitische Gewalt im konsolidierten Sowjetstaat unvermindert fortsetzte, zerschlug auch die von Roth dahingehend geäußerte Hoffnung. Zwar wird im entsprechenden FZT-Artikel mit dem apologetischen Verweis auf die geringe rechtsstaatliche Durchdringung der Sowjetunion das antisemitische Moment relativiert - wie schon im Kontext des russischen Bürgerkrieges ${ }^{159}$ Doch wird nun den kommunistischen Autoritäten vor Ort explizit vorgeworfen, den andauernden Ausschreitungen gegen Juden in ihrem Zuständigkeitsbereich gleichgültig bis wohlwollend gegenüberzustehen. ${ }^{160}$

Die Betrachtung der Juden als Minderheit auf der Suche nach ihrem Platz in der neuen politischen Ordnung war nicht der einzige Blickwinkel, der in der Weimarer Presse auf jüdisches Leben und Wirken in der UdSSR eingenommen wurde. Sowohl im revolutionären Russland selbst als auch im Rest Europas stand dem noch die verbreitete Wahrnehmung von Juden als heimlichen Drahtziehern der Revolution und Gründungsvätern des Bolschewismus entgegen. Dies führte nicht nur zur Ermordung Zehntausender Juden durch Truppen der "Weißen" während des Bürgerkriegs, ${ }^{161}$ sondern fand auch prominenten Eingang in das deutsche Bild sowjetischer Juden.

Die zentrale Rolle von Juden in der SDAPR (B) ${ }^{162}$ und KPR $(B)^{163}$ lieferte derartigen Narrativen Nahrung. In der NS-Presse steigerten sich notorischer Antisemitismus und Antikommunismus zur Manie vom Judäo-Bolschewis-

jüdische Bewegungen. In: Europäische Geschichte Online (EGO), herausgegeben vom Institut für Europäische Geschichte (IEG), Mainz 2011. URL: http://www.ieg-ego.eu/ grillt-2011-de. (am 28.02.2015), $15 \mathrm{f}$.

159 Vgl. Anon.: Die antisemitischen Ausschreitungen in Sowjetrußland. In: FZT Nr. 907 vom 04.12.1928, 2.

160 »Dabei wird immer wieder hervorgehoben, daß die untersten Sowjetorgane im Dorf und in manchen Fällen sogar die kommunistischen Organisationen sich völlig gleichgültig verhalten und gegen die Schuldigen an der gegen die Juden betriebenen Hetze weder vorgehen noch die erforderliche ‘aufklärende Tätigkeit unter den breiten Massen ausüben.» Ebd.

161 Vgl. Gerrits, André: The Myth of Jewish Communism. A Historical Interpretation. Brüssel 2009, $15 \mathrm{f}$.

162 Während der Revolutionsphase saßen mit Trotzki, Sinowjew und Sokolnikow drei, wenn man Kamenew, der einen jüdischen Vater hatte, hinzunimmt, vier jüdische Mitglieder in der siebenköpfigen Parteiführung der SDAPR(B). Vgl. ebd., 120.

163 Repräsentative Zahlen dazu weisen für die Mitglieder des Zentralkomitees des Sowjetkongresses für das Jahr 1929 in toto 402 Russen, 95 Ukrainer, 55 Juden, 26 Letten, 13 Polen und 12 Deutsche aus, was in der Tat eine Überrepräsentation von Personen jüdischen Glaubens gemessen an der Gesamtbevölkerung darstellt. In den unteren Gliederungen der Sowjets in großen und mittleren Städten zeigte sich im Gegensatz zu den ländlichen Gebieten ebenfalls eine Überrepräsentation jüdischer Ratsmitglieder, wenn diese auch von geringem Einfluss auf die großen Linien sowjetischer Politik gewesen sein dürften. Vgl. Pinkus, Benjamin: The Jews of the Soviet Union. The History of a National Minority. New York u. a. 1990, $80 \mathrm{f}$. 


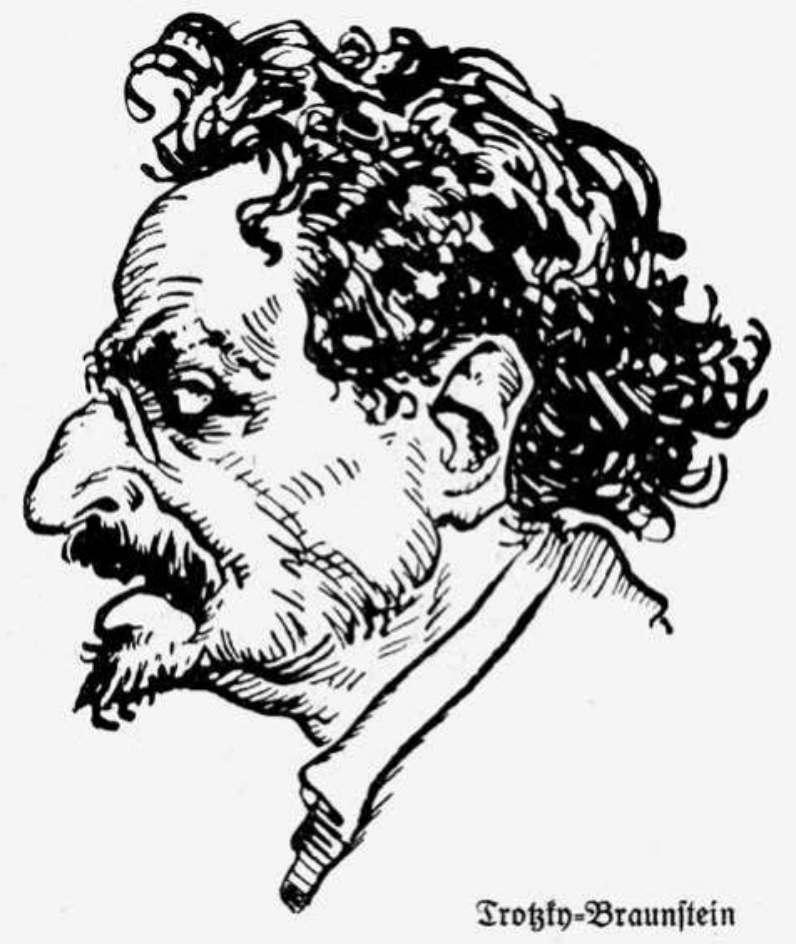

Abb. 13: Anon.: Moderne Diktatoren. Studie. Bilder von Ferdinand Bruger. In: ILB, 1927, Nr. 10, 143. Leo Trotzki, alias »Trotzky-Braunstein «, wurde in der NS-Presse durch überzeichnete Gesichtsphysiognomie zum Symbol für das Konstrukt des »Judäo-Bolschewismus«.

mus. In diesem auch in Mittel- und Osteuropa verbreiteten Denkmuster verschmolz die latente Angst vor einem bolschewistischen Umsturz mit der Obsession einer vermeintlichen jüdischen Weltverschwörung. Sein Mobilisierungspotential bezog dieses Konstrukt aus europaweit verbreiteten antijüdischen Vorurteilen. In Kombination mit der Bolschewistenangst der Zwischenkriegszeit entfaltete es unheilvolle politische Tragkraft: Die Vorstellung von der "jüdisch-bolschewistischen Weltverschwörung" hatte gewichtigen Anteil an Hitlers Weltanschauung und damit am Menschheitsverbrechen des Holocaust.

Der direkte Weg, den Bolschewismus zum Famulus jüdischer "Weltverschwörer« zu stilisieren, führte über die jüdischstämmigen Führungsfigu- 
ren der KPdSU. Mittels Nennung des vollen Namens und physiognomische Stereotypisierung wurde die Untrennbarkeit der politischen Bewegung des Bolschewismus von seinen vermeintlich ausnahmslos jüdischen Führungspersönlichkeiten zur Tatsache erklärt. Besonders der Geburtsname Leo Trotzkis, Lev Davidovič Bronštejn, geschrieben als "Leo Trotzky-Braunstein« oder "Bronstein" war als jüdisch erkennbar und wurde ostentativ verwendet. Im ILB erschien Trotzki als fleischgewordene Allianz zwischen Judentum und Bolschewismus. Die Darstellung Trotzkis, die in der völkischen Presse oft reproduziert wurde, ist ein Paradebeispiel dafür, wie durch die Betonung "jüdischer" Gesichtszüge und die Nennung des jüdischen Namens die »jüdisch-bolschewistische Bedrohung « topisch verdichtet wurde (Abb. 13).

Ähnlich wurde in Überschriften, ${ }^{164}$ Bildunterschriften ${ }^{165}$ und ganzen Texten $^{166}$ verfahren. Aber nicht nur das aktuelle Personal wurde zur Bestätigung des Schauermärchens vom Judäo-Bolschewismus genutzt. Auch in die unmittelbare Revolutionszeit wurden Umtriebe konjurierender jüdischer Revolutionäre eingeschrieben. So wurde die Brutalität, mit der die Ermordung von Zar Nikolaus II. und dessen Familie erfolgt war, im ILB mit einer Racheaktion gegen den "Antisemiten Zar Nikolaus II. « ${ }^{167}$ erklärt. Ganz so, als habe es dafür außer dem Antagonismus zwischen jüdischen Revolutionären und dem angeblich antisemitischen Zaren keinerlei weitere Motive seitens der Bolschewiki gegeben.

Der emanzipatorische Schwung der Revolution (mindestens in ideologischer Hinsicht) fiel mit dem Aufblühen von Bewegungen wie Zionisten und Antizionisten aus der Mitte der jüdischen Gemeinden zusammen. Berichte über diese Entwicklungen bildeten emanzipatorische Narrative ab, wie man sie auch aus anderen soziopolitischen Kontexten der Zeit nach dem Ersten Weltkrieg kennt. Juden in der Sowjetunion nahmen als Gegenstand der öffentlichen deutschen Wahrnehmung eine Position ein, die sich weder in ihrer Betrachtung als religiöse Minderheit noch in ihrer vermeintlich führenden Rolle in der Errichtung des Sowjetsystems fest verorten lässt. Aufgrund der Klassenorientierung der Bolschewiki eine Aufhebung der alten, an nationale und kulturelle Zugehörigkeiten gebundenen Beharrungskräfte anzunehmen

164 Unter anderem: Anon.: 10 Jahre Sowjet-Juden Diktatur. In: ILB, 1927, Nr. 20, 288 (Jahresausgabe). Und: Anon.: Mord-Poesie aus Sowjet-Judäa. In: ILB, 1928, Nr. 6, 78 (Jahresausgabe).

165 Neben Trotzki wurde auch ein Portrait Sinowjews auf ähnliche Weise (»Sinowjew-Apfelbaum«) untertitelt, wodurch die angeblich weitgehende »jüdische Durchsetzung« aller Gliederungen des sowjetischen Staates bekräftigt wurde. Unter dem Foto einer Parade der Roten Armee steht ergänzend: »Eine Parade vor Braunstein. Neben ihm ein richtiger Tscheka-Jude.« Ebd.

166 Unter anderem: Anon.: Die Sowjet-Brüder in Genf. In: ILB, 1927, Nr. 23, 323 (Jahresausgabe).

167 Anon.: Der Bolschewistenmord an dem Antisemiten Zar Nikolaus II. und seiner Familie. In: ILB, 1928, Nr. 16, 194 (Jahresausgabe). 
und die Revolution von 1917 so zum Akt der Befreiung der Juden in der Sowjetunion zu erklären, bleibt damals wie heute in der Zukunftsvision des real existierenden Sozialismus gefangen. ${ }^{168}$

Die Betrachtung des »Nationalitätenproblems« in der Sowjetunion war zu allererst von den Erwartungen gelenkt, die durch die Programmatik der Bolschewiki geweckt worden waren. Die teilweise Umsetzung emanzipatorischer Maßnahmen »von oben«, also durch die sowjetische Führung müssen aus heutiger Sicht, spätestens seit der Machtübernahme Stalins, als Makulatur angesehen werden. Von Lenin eingeleitete Schritte zur Beendigung der kulturellen Hegemonialpolitik zaristischer Prägung und die Versuche, durch die Gleichbehandlung von Minderheitensprachen und Religionsfreiheit Autonomie und Teilhabe für die jüdische Bevölkerung, die deutsche Minderheit, aber auch die Muslime im Kaukasus oder die verschiedenen Ethnien Zentralasiens zu schaffen, wurden während der Konsolidierungsphase ab Mitte der 1920er Jahre der Integrität und Stabilität des neuen Staates geopfert. Die Berichterstattung in Deutschland reflektierte diese Entwicklungen mit einiger Verzögerung. Zum Ende des Beobachtungszeitraums wurde der immer deutlicher werdende Widerspruch zwischen programmatisch angestrebter Autonomie und einer sowjetischen Staatsräson der Einheit von einzelnen Beiträgern bemerkt. Noch wollte man sich aber nicht gänzlich von der Wertschätzung der mittlerweile zu bloßen Symbolhandlungen degradierten Emanzipationsmaßnahmen der Zeit zwischen 1917 und 1926 verabschieden. Hans Kohn lobte noch 1931 die sprachpolitischen Maßnahmen, die an jedem Grenzübergang zur Sowjetunion sichtbar seien:

"Alle Aufschriften und Verlautbarungen erscheinen in vier Sprachen, weißrussisch, russisch, jiddisch und polnisch. Das hervorstechendste Moment nationaler Unterdrückung, die Verdrängung oder Minderberechtigung der nationalen Sprachen, fehlt hier, völlig verschieden von dem, was man von Polen oder Tschechoslowakei her gewöhnt ist. ${ }^{169}$

Sprachpolitische Maßnahmen wie diese symbolisierten laut Kohn die Beendigung der Kulturhegemonie der Mehrheitsrussen. Allerdings war es für Lenin und die Bolschewiki kein Selbstzweck, die gewaltsam homogenisierte

168 So schrieb Ezra Mendelsohn: »It can be argued, too, that the neighboring Soviet Union was a much more friendly place for the Jews than were most of the new East European states. In the Soviet Union the dominant ideology was based on class rather than nation, the old conservative (and anti-Semitic) elites had been destroyed, and economic dynamism was beginning to transform a typically backward East European state into a modern, industrialized colossus.« Mendelsohn, Ezra: The Jews of East Central Europe between the World Wars. Bloomington, VA 1995, 6.

169 Kohn, Hans: Die Sowjetunion und ihr Nationalitätenproblem. In: FZT Nr. 869 vom 22.11.1931, $1 \mathrm{f}$. 
ethnische Topografie des Russischen Reiches aufzubrechen und den verschiedenen Minderheiten zu politischer Teilhabe zu verhelfen. Die Anerkennung der kulturellen Vielfalt stellte vielmehr die Voraussetzung dafür dar, diese Diversität anstatt unter einer Nationalkultur unter einer Ideologie zu vereinigen. Die Möglichkeit, diesen neuen Herrschaftsraum als geschlossene ethnische Gruppe zu verlassen, wäre zwar aus der offiziellen Minderheiten- und Nationalitätenprogrammatik der Bolschewiki logisch gefolgt, wie auch Kohn bemerkte. ${ }^{170}$ Dies spielte aber in den realpolitischen Entscheidungen Lenins (geschweige denn Stalins) keine Rolle. Die positiven Erwartungen, die in der deutschen Presselandschaft in diese tatsächlich moderne Programmatik gesetzt worden waren, welche die kulturelle Identität eines jeden zu belassen und zu beschützen gelobt hatte, erwiesen sich letztlich als unberechtigt.

\subsection{Zusammenfassung}

Im Vergleich zueinander weisen die deutschen Wahrnehmungen ethnischer Minderheiten in den USA und in der Sowjetunion eine Grundopposition auf. Aus der marginalisierten Gruppe der Afroamerikaner selbst entsprangen demnach Emanzipationsbestrebungen »von unten«. Auf dem ideologischen Fundament der bolschewistischen Führung basierende Emanzipationsinitiativen "von oben«, wie man sie in der Sowjetunion beobachten zu können glaubte, unterschieden sich davon - tatsächlich und in der Wahrnehmung. Wie bereits in der zeitgenössischen Betrachtung der Frauenemanzipation stellt sich der grundsätzliche Unterschied zwischen den USA und der Sowjetunion in der Zusammenschau der analysierten Massenmedien wiederum als ein Gegensatz zwischen amerikanischer »Evolution« emanzipatorischer Initiativen aus der Gesellschaft heraus und der durch »Revolution« ermöglichten ideologischen Gleichheitsdoktrin der Bolschewiki dar, die aber zentral gesteuert und programmatisch impliziert werden sollte.

Im Falle der Afroamerikaner war die Berichterstattung wiederum aufgeteilt: Teilweise empörte Kritik an Rassentrennung, institutioneller Diskriminierung und rassistischen Lynchmorden stand der positiv rezipierten "Normalisierung" afroamerikanischer Lebensentwürfe innerhalb der gesellschaftlichen Strukturen und Institutionen der amerikanischen Gesellschaft gegenüber. Diese wurden am Beispiel zivilgesellschaftlicher Gruppen und individueller Rollenvorbilder präsentiert. In Breite wie Tiefe reichte die Berichterstattung zu den indigenen Völkern Nordamerikas daran nicht heran. Man

170 »Da schien sich mit der Machtergreifung der kommunistischen Partei Lenins Losung des Rechtes der einzelnen Völker auf Unabhängigkeit bis zur völligen Lostrennung als der Ausweg und als die einzig folgerichtige demokratische Lösung zu bieten.« Ebd. 
leistete ihrer Exotisierung und ideologiebedingten Idealisierung sogar noch Vorschub. Ausgerechnet der Illustrierte Beobachter (ILB) gerierte sich dabei auf Grund einer behaupteten Leidensgenossenschaft zwischen Deutschen und Indianern als »Anwalt der Indianer«.

Interessant nimmt sich im sowjetischen Falle aus, dass die Führung der KPR (B) lange Zeit größtenteils selbst nicht der von ethnischen Russen orthodoxen Glaubens geprägten sowjetischen Mehrheitsgesellschaft angehörte. Dieser historisch durchaus interessante Umstand wurde vor allem in der NSPresse angesichts des hohen Anteils jüdischstämmiger Funktionäre für judenfeindliche Hetze instrumentalisiert. Der ILB war es auch, der die sowjetischen Juden aktiv mit dem bolschewistischen Umsturz und den Gefahren einer "jüdisch-bolschewistischen Weltverschwörung" in Verbindung brachte. Die ganze Tragweite des Konstrukts des »Judäo-Bolschewismus«, wie es auch im restlichen Europa breit zirkulierte, zeigte sich erst während des Russlandfeldzuges 1941-1944 und im Menschheitsverbrechen des Holocaust.

Im bürgerlichen Spektrum widersprachen sich die Tendenzen der Berichterstattung. Optimistische Ausblicke auf das zukünftige Leben der jüdischen Bevölkerung als gleichberechtigte Sowjetbürger übernahmen schlicht programmatische Vorhaben der Partei und schrieben diese fort. Demgegenüber standen Berichte über antisemitische Pogrome und auf halbem Wege steckengebliebene Emanzipationsmaßnahmen.

Letzten Endes entzauberte der "Nationalitätenterror $«{ }^{171}$ also die Erschießung von mehr als 250.000 Sowjetbürgern (vor allem ethnische Polen) aus Gründen ihrer ethnischen Zugehörigkeit 1937/38, die hehren ideologischen Ziele der Bolschewiki als Luftschlösser einiger Funktionäre. Tatsächlich zum Tragen kamen diese Zielvorstellungen, wie sie die deutsche Presse des bürgerlichen und insbesondere des kommunistischen Lagers in teilweise schillernden Farben ausmalte, jedoch nicht.

171 Vgl. Snyder, Timothy: Bloodlands. Europa zwischen Hitler und Stalin. München 2011, $107 \mathrm{f}$. 


\section{Politische Ordnungen}

So intensiv der Weg der Frauen und Minderheiten zu politischer und gesellschaftlicher Gleichberechtigung in den USA und der Sowjetunion auch in Deutschland rezipiert wurde: An beiden Beispielen zeichnet sich lediglich der Grundsatz gleichberechtigter politischer Partizipation als Kardinale gesellschaftspolitischer Debatten der Weimarer Republik ab. Das Gespräch über politische Rechte und Teilhabe, auch über politische Kultur, nahm aber nicht nur über den Umweg von Emanzipationsnarrativen Gestalt an.

Vielmehr wurden politische Ordnungssysteme und konkrete Fallbeispiele wie eben die politische Minderheitenemanzipation aufeinander bezogen. Man kann zur Veranschaulichung der gegenseitigen Verweiskraft beider Themenkomplexe die nach 1918 veränderte ethnische Zusammensetzung Deutschlands und der Staaten Mittel- und Ostmitteleuropas betrachten. Die Verkleinerung des Reichsgebiets durch die Pariser Vorortverträge hatte zur Folge, dass sich eine ethnisch und sprachlich homogene Bevölkerung in einem geschlossenen Staatsgebiet unter einheitlicher (demokratisch legitimierter) Herrschaft wiederfand und somit ein Staatsvolk konstituierte. ${ }^{1}$ Analog dazu verstanden sich die "neuen « Staaten Ostmitteleuropas nunmehr als Nationen mit homogenem Staatsvolk. Dass sie das de facto nicht waren, zeigt das Beispiel der Tschechoslowakei. ${ }^{2}$ Der Zustand ethnischer Homogenität wurde von Zeitgenossen als Voraussetzung für die Gewährung politischer Teilhabemöglichkeiten verstanden. Innerhalb emanzipatorischer Diskurse - wie eben derjenigen um Frauen- und Minderheitenrechte - wurden also stets auch abstraktere Fragen gesellschaftlicher und staatlicher Organisation verhandelt und umgekehrt. Fragen demokratischer Teilhabe wurden in der Presse also meist an konkrete Beispiele geknüpft. An Hand miteinander konkurrierender Konzepte politischer Ordnung wurden sie aber auch expressis verbis for-

1 Der in nationalkultureller Hinsicht exklusive, hinsichtlich religiöser und weiterer Gruppenspezifika aber inklusive Volksbegriff stand im Zentrum der parlamentarischen Verfassungsdiskussion in der Phase der politischen Neuorganisation nach 1918. Vgl. Bollmeyer, Heiko: Der steinige Weg zur Demokratie. Die Weimarer Nationalversammlung zwischen Kaiserreich und Republik. Frankfurt a. M., New York 2007, $180 \mathrm{f}$.

2 Jan-Werner Müller zitiert in seiner diesen wichtigen Bezugspunkt zwischen Ethnie, Nation und Demokratie aufgreifenden Monografie zur Ideengeschichte der Demokratie den ersten Präsidenten der Tschechoslowakei, Tomáš Masaryk wie folgt: »Alles in allem sind die großen Vielvölkerreiche eine Institution der Vergangenheit, einer Zeit, als die materielle Macht hochgehalten und das Prinzip der Nationalität noch nicht anerkannt wurde, weil man die Demokratie nicht anerkannte." Müller: Das demokratische Zeitalter, 41. Müller zitiert: Masaryk, Tomáš Garrigue: The Problem of Small Nations and States, the Federation of Small Nations [1918]. In: Munzer, Zdenka/Munzer, Jan (Hg.): We Were and We Shall Be. The Czechoslovak Spirit through the Centuries. New York 1941, 153. 
muliert und kontrovers diskutiert. Dies kann angesichts des Charakters der ersten deutschen Republik als ein "Experiment in Demokratie ${ }^{3}$ auch nicht verwundern. Die Veränderungen der politischen Ordnung griffen tief in das deutsche Gesellschaftsverständnis ein.

Die deutsche Gesellschaft trat nach 1918 allerdings nicht jäh aus dem Dunkel des Autoritarismus in das gleißende Licht der Demokratie. Durch ihre immerhin über 40-jährige Erfahrung mit der - speziellen - demokratischen Kultur des Kaiserreichs war die Demokratie als solche für die Deutschen so neu nicht. ${ }^{4}$ Deren parlamentarische Version, eingeführt durch Reichskanzler Prinz Max von Baden, war gleichwohl auch zeitgenössischer Beobachtung zufolge »dem deutschen Volk noch immer recht unvertraut. ( $^{5}$ Die parlamentarische Demokratie kam für die politische und publizistische Öffentlichkeit, um bei der Metapher des Experiments zu bleiben, einer stark veränderten Versuchsaufstellung gleich. Mangels Übung und angesichts erheblicher Konstruktionsfehler - etwa die zusammengezwungenen Antipole Parlament und Reichspräsident - provozierte sie, stets hinterfragt zu werden.

Dieses Hinterfragen und Vergleichen übertrug sich in die Fremdbetrachtung anderer politischer Ordnungen, vor allem der gegensätzlichen Modelle der USA und der Sowjetunion. Dabei war die kritische Betrachtung beider politischen Systeme maßgeblich durch eine implizite Idealvorstellung von Demokratie und politischer Repräsentation in Deutschland selbst bedingt. Publizisten und Journalisten behandelten das Thema schließlich nicht aus rein länderkundlichem Interesse. Ihr Antrieb ergab sich aus dem Bedürfnis der Leserschaft, ihre politischen Idealvorstellungen und die in Deutschland vorgefundenen politischen Verhältnisse mit repräsentativen Alternativen in Ost und West abzugleichen.

Aufgrund des in vielem tatsächlich, in manchem nur vermeintlich experimentellen Charakters der Weimarer Ordnung wird klar, weshalb das zeitgleich ablaufende »sowjetische Experiment ${ }^{6}$ trotz der offenkundigen poli-

3 Hirsch, Helmut: Experiment in Demokratie: Zur Geschichte der Weimarer Republik. Wuppertal 1972.

4 Als »direktes, gleiches und - für jeden Deutschen«, der das Alter von 25 Jahren erreicht hatte - allgemeines Stimmrecht« veranlasste das Wahlrecht des Kaiserreichs Margaret Lavinia Anderson dazu, Deutschland im Vergleich zu den allermeisten vergleichbaren Staaten sogar eine »demokratische Frühreife« zu bescheinigen. Anderson, Margaret Lavinia: Lehrjahre der Demokratie. Wahlen und politische Kultur im Kaiserreich. Stuttgart 2009, 34.

5 Anon.: Parlamentarismus. In BIZ, 1922, Nr. 48, 926 (Jahresausgabe).

6 Dieser Begriff wird immer wieder genutzt, um den bahnbrechenden Charakter der sowjetischen Herrschaft und ihren Unwägbarkeiten auf allen politischen Gebieten zu verdeutlichen. Unter anderem: Suny, Ronald: The Soviet Experiment: Russia, the USSR and the Successor States. New York u. a. 2011. 
tischen Probleme des neuen Staates sehr aufmerksam verfolgt wurde. Beide Nationen beschritten beinahe synchron für sie bis dahin unbekannte Wege. Der Abgleich der neuen deutschen Demokratie mit der des Landes der Demokratie schlechthin drängte sich angesichts des idealdemokratischen Nimbus der Vereinigten Staaten ohnedies auf.' ${ }^{7}$ Auch war Deutschland ein ganz entscheidender Teil jener Welt, die sich Wilson in seiner berühmten Kriegsrede im April 1917 »sicher für die Demokratie« gewünscht hatte. ${ }^{8}$ Das verbreitete Bewusstsein, in Deutschland ganz maßgeblich durch die Initiative der USA überhaupt zur Demokratie gekommen zu sein, zog Interesse an der dortigen politischen Ordnung und Kultur ganz selbstverständlich nach sich.

Als Vorbild taugte die amerikanische Demokratie nicht etwa wegen ihrer systemischen Überlegenheit. Ihre Faszination ging für das deutsche Publikum vielmehr von ihrer wirkungsvollen visuellen Inszenierung und der Personalisierung politischer Institutionen aus. Insbesondere durch die Illustrierten wurde beides der Leserschaft nähergebracht. Auf die politische Ordnung der Sowjetunion hingegen wurde lediglich in der unmittelbaren Umbruchphase zwischen Revolution und Republik mit Optimismus geblickt, wie auch der vierwöchige Nachahmungsversuch der Münchner Räterepublik 1919 illustriert. Danach fiel diese Debatte aus dem Licht einer breiten Öffentlichkeit in ein Privatissimum des kommunistischen Spektrums hinab.

Eine Besonderheit bei der Betrachtung innersowjetischer Politik war der in allen Tageszeitungen und Illustrierten vollzogene Schwenk auf rein innerparteiliche Auseinandersetzungen. Diese wurden beinahe kommentarlos als politische Willensbildung in der Sowjetunion akzeptiert, ohne dabei ernsthaft die Möglichkeit wahrhaftiger Demokratie zu erörtern. Mit der planmäßigen Verkümmerung der politischen Öffentlichkeit durch die Bolschewiki rückte indes auch deren Kampagne gegen die russisch-orthodoxe Kirche als einzig verbliebener Gegner der innersowjetischen politischen Auseinandersetzung stärker in den Mittelpunkt des Interesses - dazu später mehr.

Werturteile zu politischer Ordnung, Kultur und Demokratie, wie sie sich im massenmedialen Diskurs abbildeten, wurden in wichtigen Teilen des politischen Spektrums der Zwischenkriegszeit nicht geteilt. Stimmen wie die des "Nationalrevolutionärs« Ernst Niekisch verurteilten den »Gang nach Westen« mit seinem »seichten Liberalismus" und Parlamentarismus als Irrweg und feierten »die Umkehr zum Osten« und die Besinnung auf das "preußisch-

7 Trotz aller politikphilosophischen Vorbehalte und des uneinheitlichen Gebrauchs von Begriffen wie Republik und Demokratie im deutschen Amerikadiskurs steht außer Frage, dass die Vereinigten Staaten in Deutschland traditionell als Hort der neuzeitlichen Demokratie galten. Vgl. dazu: Depkat: Amerikabilder in politischen Diskursen, $343 \mathrm{f}$.

8 Wilson, Woodrow: Address delivered at Joint Session of the Two Houses of Congress. April $2^{\text {nd }}, 1917$. United States $65^{\text {th }}$ Congress, $1^{\text {st }}$ Session, Senate Document 5. 
slawische Prinzip « dagegen als Wiederaufstieg »zu deutscher Größe«. ${ }^{9}$ Auch die Kommunisten stießen, wenn auch unter anderen Prämissen, in dasselbe Horn. Wie die extreme Rechte wähnten sie sich mitten im Entscheidungskampf für die von ihnen angestrebte Weltordnung. ${ }^{10}$ Beide politischen Extreme fürchteten entweder die Korrumpierung des »deutschen Wesens« durch den Liberalismus und Parlamentarismus des Westens oder die Unterjochung des deutschen Proletariats durch den Kapitalismus, der vermeintlich im Windschatten westlicher Demokratie Einzug hielt. Man sollte aus falsch verstandenem Idealismus nicht den Fehler begehen, die Strahlkraft autoritärer, antidemokratischer Herrschaftsentwürfe im öffentlichen Diskurs zu unterschätzen - in der Weimarer Republik ebenso wenig wie zu anderen Zeiten.

Der Antagonismus von Demokratie und Autoritarismus spielte nur zu Anfang des Beobachtungszeitraums eine Rolle im massenmedialen Diskurs. ${ }^{11}$ Dieser Gegensatz schwelte zwar im Untergrund der Debatte, ${ }^{12}$ war aber in den Tageszeitungen und Illustrierten nur mäßig präsent. Lediglich in Symbolkämpfen wie dem Streit darüber, ob die deutsche Flagge im Geiste der Revolution von 1848/49 Schwarz-Rot-Gold oder weiterhin Schwarz-Weiß-Rot sein solle, fand dieser durchaus virulente Konflikt medialen Widerhall. Trotz nur vereinzelt artikulierter Klagen über den Verlust der Monarchie zogen sich spürbare Vorbehalte gegen die »destruktiven Tendenzen einer nur auf Massenstimmungen beruhenden Demokratie« durch die konservative Presse.

9 Fest, Joachim: Hitler. Eine Biographie. Frankfurt a.M. u. a. 1973, 141 f. Fest zitiert aus: Niekisch, Ernst: Entscheidung. Berlin 1930. Niekisch war in besonderer Weise einerseits dem »traditionellen", also autokratisch-kollektivistischen russischen Modell zugetan, konnte aber aus seiner dezidiert antiwestlichen Grundeinstellung heraus, die ihn zwischen radikaler Linken und völkischer Rechten hin und her trieb, auch dem Bolschewismus sehr viel abgewinnen. Aufgrund dessen reiste er sogar kurz vor der nationalsozialistischen Machtergreifung nach Moskau. Vgl. David-Fox, Michael: Crossing Borders: Modernity, Ideology, and Culture in Russia and the Soviet Union. Pittsburgh 2015, $185 \mathrm{f}$.

10 Riccardo Bavaj drückte diese Prämissen, die sich in ihren absoluten Zukunftsbildern kaum von ihrem nationalsozialistischen Pendant unterschieden, folgendermaßen aus: »Für die Protagonisten extremistischen Denkens glich die Weimarer Republik der Kampfarena eines eschatologischen Krieges zwischen zwei Zeitaltern, dem des Bürgers und dem des Arbeiters, des >Proletariers`. Für sie stand jener Kampf zwischen `zwei Welten unmittelbar vor der Entscheidung [...].« Bavaj, Riccardo: Von links gegen Weimar. Linkes antiparlamentarisches Denken in der Weimarer Republik. Bonn 2005, 486.

11 Gallus, Alexander: Deutsche Revolution 1918/19: die Etablierung der Weimarer Republik. In: Ders. (Hg.): Deutsche Zäsuren. Systemwechsel seit 1806. Köln u. a. 2006, 133-163, hier 147.

12 Jenseits der massenmedial vermittelten gesellschaftlichen Debatten bestand eine kontinuierliche, tief verwurzelte autoritäre Grundhaltung in weiten Teilen insbesondere der staatlichen und halbstaatlichen Institutionen (wie Freikorps u. ä.) fort, die sich aber erst durch die Aktivierung seitens der erklärtermaßen gegen Republik und Demokratie angetretenen Nationalsozialisten voll entfaltete. Dazu: McElligott, Anthony: Rethinking the Weimar Republic. Authority and Authoritarianism 1916-1936. London u. a. 2014, 9 f. 
In den turbulenten Anfangsjahren der Weimarer Republik habe sich diese Massendemokratie »in ihrer abschreckendsten Form « offenbart und dadurch "Widerwillen und Abscheu ${ }^{13}$ hervorgerufen. Damit einher ging die Suche nach Alternativen, die vom Parlamentsgedanken abwichen und teils »den antizivilisatorischen Ansatz der wilhelminischen Ära beschworen. ${ }^{14}$

Die Debatte war reich an pseudodemokratischen und ihrem Wesen nach autoritären Ideen. Vorschläge zur außerparlamentarischen Auslese »charismatischer Führer« oder zur Synthese von Parlamentarismus und Führerstaat suchten von liberaler (!) Seite einerseits, die endgültige »Herrschaft der Massen" abzuwenden. Andererseits beklagten sie gleichzeitig die schwindende Akzeptanz des parlamentarischen Systems durch ebenjene »Massen«:

»Es ist kein Zweifel, daß wir mehr denn je vor Gefahren der Massenherrschaft stehen. Das Scheitern verheißungsvoller Versuche zur Stärkung der Regierungsautorität, das immer mehr den Agitationsgesetzen anheimfallende Verhalten der Parteien [...]. Es fehlen die Führer! Wenn die Demokratie sich nicht besinnt und Führer emporträgt, so ist das Grab des demokratischen Staates gegraben. Der monarchische Staat muß demokratisch regiert werden, der demokratische monarchisch, d.h. durch überragende Persönlichkeiten. Jedes Volk braucht eine stetige souveräne Gewalt. Souverän sind heute, an Stelle des Volkes, die Parteien. Der Souverän muß aber, wie Wilhelm I. es tat, dem genialen Staatsmann Platz machen. Die Parteien müssen ihre ganze Kraft daransetzen, überragende Persönlichkeiten an die Spitze des Staates zu berufen, statt in allem selber regieren zu wollen. Sie arbeiten heute nicht nach sachlichen Gesichtspunkten, sondern nach dem Geheul der Masse. Nicht die Wähler, sondern Überzeugungen müßten maßgebend sein. ${ }^{15}$

Die Kritik gilt in dieser Forderung aus dem Jahr 1926 nicht in erster Linie dem Parlamentarismus, sondern dem unterstellten Unvermögen der Parteiendemokratie, den nicht erst seit Werner Sombart in Deutschland vielgerühmten "genialen Staatsmann" zu erkennen und ihm bereitwillig den Weg zur Macht zu ebnen. ${ }^{16}$ Die Reminiszenz an das Duumvirat des frühen Kaiserreiches offenbart einerseits die rückwärtsgewandte Sehnsucht nach Macht, die aus sich selbst heraus und durch die von ihr geschaffenen Fakten legitimiert ist. Andererseits ist sie Ausdruck der in Deutschland spätestens seit Nietzsches eindringlicher Warnung vor der "Schwäche der gottlos gewordenen Masse ${ }^{17}$ be-

13 Anon.: Masse und Führer. In: MNN Nr. 53 vom 23.02.1925, $1 \mathrm{f}$.

14 Fest: Hitler, 141.

15 Anon.: Massenstaat oder Führerstaat? Appell der Liberalen Vereinigung. In: DAZ Nr. 268 vom 12.06.1926, 1.

16 Vgl. Sombart, Werner: Vom Menschen. Versuch einer geisteswissenschaftlichen Anthropologie. Berlin 1938, 186.

17 Jaspers, Karl: Nietzsche. Einführung in das Verständnis seines Philosophierens. Berlin, New York 1981, 273. 
sonders ausgeprägten Skepsis gegenüber der Massendemokratie. Diese Furcht hatte sich seit Ende des 19. Jahrhunderts in der politischen Theorie ebenso wie im Bürgertum etabliert und beklagte die Abhängigkeit der Massendemokratie von den Launen der Öffentlichkeit, die sich in der veröffentlichten Meinung und damit in Gestalt der Massenmedien manifestierte. ${ }^{18}$

Solche antiparlamentarischen und autoritären Strömungen, die im übrigen Europa teilweise noch stärker wirkten, liefen der Epochentendenz und damit dem, was gemeinhin als modern empfunden wurde, diametral entgegen. Sie entfalteten erst zum Ende des Beobachtungszeitraums während der Ära Brüning jene zerstörerische Wucht, die zum autoritären Umsturz zunächst der politischen Kultur und letztlich des politischen Systems im Ganzen führten. Die »Krisenjahre der klassischen Moderne ${ }^{19}$ zeitigten ihrem Wortsinn gemäß eine Zuspitzung des politischen Diskurses im Allgemeinen und noch deutlicher eine Radikalisierung der Diskurse über Politik und damit über Demokratie. Krisenhaft waren letztere auch insofern, als dass man sich in Deutschland - gemäß der zweiten möglichen Ausdeutung des Krisenbegriffes - vor eine Entscheidung nicht nur über die zukünftige Staatsform, sondern über die gesamte politische Kultur gestellt sah.

Insbesondere die Jahre vor der »Wetterscheide $« 1929,{ }^{20}$ die eine vorentscheidende politische Polarisierung mit sich brachte, stellten für den Demokratiediskurs nur in extrem einseitiger Lesart einen quälend langen Abgesang dar. Jener Diskurs war bis zum Amtsantritt Brünings als Reichskanzler vielmehr von der Hoffnung auf Gesundung durch Reform getragen. Eine »Erneuerung der Demokratie ${ }^{21}$ lag näher als ihre planmäßige und von einem beträchtlichen Teil der Gesellschaft gutgeheißene Demontage. Ohne die Belastungen durch die Weltwirtschaftskrise hätte für das westliche Demokratiemodell durchaus eine reelle Chance bestanden, auf mittlere Sicht von den Deutschen angenommen zu werden: US-Präsidentschaftswahlkämpfe wurden als Hochämter politischer Kultur inszeniert, ${ }^{22}$ das Wahlverfahren selbst als praktisches Anschauungsbei-

18 Vgl. Llanque, Marcus: Politische Ideengeschichte - ein Gewebe politischer Diskurse. München 2008, 390.

19 Peukert: Weimar. Krisenjahre der klassischen Moderne. Frankfurt a. M. 1987.

20 Vgl. Raphael, Lutz: Imperiale Gewalt und mobilisierte Nation. Europa 1914-1945. München 2011, $166 \mathrm{f}$.

21 Bernhard, Georg: Erneuerung der Demokratie. In: VZT Nr. 104 vom 02.03.1930, $1 \mathrm{f}$.

22 So wurden die für deutsche Verhältnisse sowohl in Fragen der Mobilisierung als auch materiell sehr aufwändigen Wahlkämpfe anerkennend mit Kabelmeldungen begleitet, so etwa das Duell von Warren Harding und James Cox 1920: „Der Wahlfeldzug in Amerika hat gestern Abend sein Ende gefunden, nachdem er in den letzten vierzehn Tagen mit einer Hartnäckigkeit und Heftigkeit geführt worden ist, wie nie zuvor. 30 Millionen wahlberechtigte Stimmen sind eingegangen, eine Zahl, die bisher bei den Wahlen noch nicht erreicht worden ist. Die beiden Kandidaten der Parteien haben sich persönlich außerordentlich in den Dienst der Wahlkampagne gestellt und beide von einem Ozean bis 
spiel der Demokratie amerikanischer Prägung wohlwollend evaluiert. ${ }^{23}$ Die Lebenslügen der amerikanischen Demokratie - wie die hier bereits erörterte Entrechtung der Afroamerikaner - wurden dabei ebenso wenig ausgeklammert wie fortbestehende demokratische Defizite, unter anderem die innere Repression von Arbeiterinteressen. Die Debatte war offen.

Anders im Falle der Sowjetunion. Das basisdemokratische Modell des Rätesystems, das in der Revolution von 1905 erprobt und nach der Februarrevolution 1917 zunächst Grundlage der politischen Entscheidungsfindung gewesen war, stellte die große Alternative zum "westlichen" Demokratiemodell und dessen Parlamentarismus dar. Die Lager, die sich in der deutschen Debatte um die künftige demokratische Ordnung bildeten, setzten sich folgendermaßen zusammen: Mehrheitssozialdemokraten, Zentrumspartei und Linksliberale bevorzugten die parlamentarische Demokratie, während der linke Flügel der USPD (ab Ende 1918 KPD) die Rätedemokratie anstrebte. ${ }^{24}$ Rechtskonservative und Deutschnationale verfolgten autoritärere Entwürfe, basisdemokratische Räte kamen für sie nicht in Frage. Einer parlamentarischen Demokratie in Reinform standen viele ebenfalls skeptisch gegenüber.

Das Rätemodell wurde kurzzeitig durchaus als Möglichkeit eines demokratischen Neubeginns in Deutschland diskutiert. Besonders bestach die Unmittelbarkeit, mit der die Mitglieder der als »Sowjets« bezeichneten Räte Einfluss auf die Exekutive ausübten - beziehungsweise idealiter ausüben sollten. Dieser direkte Durchgriff machte es den Befürwortern des Rätesystems einfach, es den Zeitgenossen auch außerhalb der Sowjetunion als dem parlamentarischen Modell überlegen (weil schneller) darzustellen. ${ }^{25}$

zum anderen in Hunderten Orten Wahlreden abgehalten. Harding hat im Verlauf seiner Kampagne, die er persönlich hauptsächlich im Mittleren Westen und Süden führte, dreitausend Meilen zurückgelegt und fünfzigmal das Wort ergriffen, Cox, innerhalb zweier Monate fünfzehntausend Meilen zurücklegend, 250 Mal.« Anon.: Der Wahlkampf in Amerika. In: DAZ Nr. 540 vom 01.11.1920, 1.

23 Unter anderem: Anon.: Der Amerikaner an der Wahlurne. In: DAZ Nr. 517 vom 04.11.1926, $1 \mathrm{f}$.

24 Vgl. Benz, Wolfgang: Abschnitt I. Der Aufbruch in die Moderne. Das 20. Jahrhundert. In: Ders. (Hg.): Gebhardt. Handbuch der deutschen Geschichte, Bd. 18: Ders./Büttner, Ursula: 20. Jahrhundert (1918-2000). Der Aufbruch in die Moderne. Das 20. Jahrhundert; Weimar - die überforderte Republik 1918-1933. Stuttgart 2010, 1-170, hier 53.

25 So schrieb der bekannte Austromarxist Max Adler in seinem Bestreben, die Vorzüge des Rätesystems gegenüber den Zwängen des Parlamentarismus darzustellen und die Unvermitteltheit der politischen Willensbildung zu betonen, im Jahre 1919: »Hier verdrängten die Anforderungen des Parlamentarismus fast alle Bedürfnisse einer unmittelbaren Anteilnahme der Massen an der politischen Tätigkeit selbst. Alle Aktion konzentrierte sich gleichsam in den Abgeordneten, deren Zusammenhang mit den Massen ein umso loserer werden mußte, als die Arbeitsbedingungen innerhalb des Parlaments oft die Notwendigkeiten des Kompromisses mit bürgerlichen Parteien oder der Zurückstellung proletarischer Forderungen schufen, welche die Massen nicht sogleich zu verstehen vermochten." Adler, Max: Demokratie und Rätesystem. Wien 1919, 22. 
Die bald schon erdrückende Dominanz der Bolschewiki zeitigte in der Realität jedoch ein Parteimonopol und eben keine repräsentative Ratsversammlung, wie sie modellhaft vorgesehen war. ${ }^{26}$ Bereits durch die radikale Einschränkung der offenen Rede innerhalb der Partei durch die Beschlüsse zur "Neuen Ökonomischen Politik» (NEP) ${ }^{27}$ und (aller)spätestens mit dem Tode Lenins 1924 war der basisdemokratische Gedanke und mit ihm das Herzstück des Rätemodells obsolet geworden und der Weg zum Totalitarismus vorgezeichnet. ${ }^{28}$

Auf Grund seines praktischen Demokratiedefizits wurde das Rätesystem in Deutschland immer weniger als Alternative wahrgenommen. Dies nicht zuletzt aufgrund des Scheiterns der bereits genannten Münchner Räterepublik 1919, die obendrein durch eine aggressive Medienkampagne vollkommen diskreditiert war. ${ }^{29}$ Auch lief die im Bolschewismus nunmehr vollends negierte Abgrenzung zwischen den drei Gewalten der bereits erwähnten Idealvorstellung eines demokratischen Rechtsstaates so eklatant zuwider, dass eine Adaption in Deutschland (wenigstens vor 1929) keine Verwirklichungschance hatte. Nur der harte Kern der KPD sah dies anders. So war die Berichterstattung zu den Ränkespielen der sowjetischen Kader in Partei und Zentralkomitee von einer nachgerade voyeuristischen Motivation getrieben, welche den undemokratischen Charakter des Sowjetsystems prononcierte. Man ging in seiner Betrachtung von einer auf das Minimalmaß rein innerparteilicher Auseinandersetzungen geschrumpften Form der »Demokratie« aus, was sich in der ausschließlichen Thematisierung der internen Konfliktlinien, beispielsweise zwischen Stalin und Trotzki, zeigt. Der Umstand, dass die Reichweite demokratischer Legitimation durch das Flächenmaß des jeweiligen Tagungsraums der Partei definiert war, erachtete man kaum als erwähnenswert - es war schlicht selbstverständlich. Die Betrachtung der demokratischen Kultur der USA wurde hingegen größtenteils am öffentlichen Prozess und der Performanz von Politik, an Wahlkämpfen oder Demonstrationen veranschaulicht, was den Eindruck großer Transparenz erzeugte.

26 Vgl. Hildermeier: Die Russische Revolution, 244.

27 Mit der »Neuen Ökonomischen Politik« (Nowaja ekonomitscheskaja politika), kurz NEP, wurde eine behutsame Öffnung der Wirtschaft, insbesondere Landwirtschaft und des Handwerks in Richtung marktwirtschaftlicher Methoden der Ressourcenverteilung und des Handels versucht, die auch eine deutliche Verbesserung der Versorgungslage zeitigte. Sie wurde 1928 von Stalin beendet. Vgl. Hildermeier, Manfred: Die Sowjetunion 1917-1991. München 2007, $22 \mathrm{f}$.

28 Vgl. Bajohr, Stefan: Kleine Weltgeschichte des demokratischen Zeitalters. Wiesbaden 2014, $295 \mathrm{f}$.

29 Vgl. dazu unter anderem: Ullrich, Volker: Die Revolution von 1918/19. München 2009, $57 \mathrm{f}$. und $92 \mathrm{f}$. Zur gezielten Diskreditierung der Arbeiterräte durch die konservative deutsche Tagespresse: Kolb, Eberhard: Die Arbeiterräte in der deutschen Innenpolitik 1918-19. Düsseldorf 1962, $183 \mathrm{f}$. 


\subsection{Symbolik und Repräsentation: Amerikas Demokratie}

In der medialen Betrachtung der politischen Systeme stellte sich das Meinungsbild entsprechend der Epochentendenz dar, die grundsätzlich einer Ausweitung und Egalisierung demokratischer Teilhabemöglichkeiten entgegenstrebte. Die Verortung funktionsfähiger Demokratien "westlich Rußlands - und in Amerika ${ }^{30}$ nahm sich in den bürgerlichen und liberalen Medien einhellig aus. Amerikanische Wahlkämpfe wurden als exemplarische Phasen demokratischer Willensbildung von der Tagespresse mit unverhohlener Spektakel-Faszination begleitet. Jedoch war das Bild des demokratischen Wettbewerbs in den USA getrübt. Insbesondere die Einschränkungen der Gleichheit der Wahl, die nur gelegentlich durchbrochene Zweiteilung des Parteienspektrums sowie die starke Rolle zahlungskräftiger Großspender aus Industrie und Hochfinanz warfen darauf deutliche Schatten. ${ }^{31}$

Das seit Ende des 18. Jahrhunderts tradierte Bild der Vereinigten Staaten als Nonplusultra demokratischen Staats- und Gesellschaftsverständnisses verfügte aber weiterhin über beträchtliche Strahlkraft. Die USA boten die bevorzugte Folie, vor deren Hintergrund sich der Zustand der politischen Ordnung in Deutschland einordnen ließ und an Hand derer sich die öffentliche Selbstvergewisserung als demokratische, moderne Gesellschaft vollzog. Angesichts seiner durch starke plebiszitäre Elemente breiten Teilhabemöglichkeiten brauchte das politische System Deutschlands den Vergleich mit dem amerikanischen Modell nicht zu scheuen. Bei einem Vergleich der politischen Kulturen fällt ein Unterschied zwischen Deutschland und den USA jedoch sofort ins Auge: ${ }^{32}$

30 Anon.: Parlamentarismus, 926.

31 Wiederholt wurden die Ausweitung der Stimmrechte der Afroamerikaner, eine höhere Vielfalt des Parteienspektrums und die Zurückdrängung des Einflusses des Großkapitals als Möglichkeiten zur Demokratisierung des amerikanischen Staatswesens aufgezeigt. Siehe etwa Anon.: Die Demokratisierung des amerikanischen Staatswesens. In: FZT Nr. 644 vom 12.09.1922, $1 \mathrm{f}$.

32 Depkat definierte den Begriff der politischen Kultur unter Rückgriff auf Karl Rohe: »Unter 'politischer Kultur soll hier die Gesamtheit aller Symbole, Wertideen und Praktiken verstanden werden, die die Legitimität einer politischen Ordnung sowie die Autorität ihrer Amtsträger begründen dem politischen Handeln in dieser Ordnung Orientierung geben. Ein zentrales Feld 'politischer Kultur ‘ ist in diesem Zusammenhang der gesamte Bereich des Visuellen, denn Herrschaftsordnungen können nur dann Legitimität und Gültigkeit für sich beanspruchen, wenn sie sich der normativen, wertideellen Grundlagen bewusst sind, auf denen ihre Autorität und ihre regulativen Funktionen beruhen. « Depkat, Volker: Von Georg II. zu George Washington: Überlegungen zur Visualisierung von Legitimität im Übergang von Monarchie zu Demokratie. In: Reitemeier, Arnd (Hg.): Kommunikation und Kulturtransfer im Zeitalter der Personalunion zwischen Großbritannien und Hannover: to prove that Hanover and England are not entirely synonymous. Göttingen 2014, 57-78, hier 59; Rohe, Karl: Politische Kultur und ihre Analyse. Probleme und Perspektiven der politischen Kulturforschung. In: Historische Zeitschrift, Nr. 250 (1990), 321-346. 
Die visuelle Inszenierung und Legitimation der demokratischen Ordnung. Diese wurde in Deutschland zwar an normativen Ideen, ${ }^{33}$ nicht aber an seinen personalen Institutionen wie dem Reichspräsidenten als Sinnperson der demokratisch-pluralistischen Wertearchitektur vorgenommen.

Die amerikanische Demokratie hauchte ihrer auf der Entzauberung der Aufklärung beruhenden politischen Ordnung durch das - auf Rousseau zurückgehende - symbolisch-mythologische Konzept der "Civil Religion" den eingebüßten Zauber wieder ein. Auch wenn im Vergleich dazu die Demokratie von Weimar nicht arm an zugkräftigen politischen Symbolen war: Politische Führung und demokratisch übertragene Macht wurden nicht vornehmlich auf die Personen wie etwa den Reichspräsidenten projiziert, sondern auf Abstrakta wie die neue Reichsverfassung, ${ }^{34}$ die für die breite Masse nicht ohne weiteres greifbar waren.

Die Politiker und damit die politische Ordnung der Weimarer Republik blieben ohne Gesicht, ${ }^{35}$ Versuche wirkungsvoller politischer Inszenierung verfingen nicht. Offenbar wird dies an der visuellen »Prachtentfaltung» des ersten Reichspräsidenten Friedrich Ebert, die Zeitgenossen wie Nachgeborenen als deutlich ausbaufähig erscheint. Sie stellt sich als ungenutzte Chance symbolisch-politischer Kommunikation dar und verdeutlicht die erfolglose deutsche »Suche nach symbolischer Repräsentation ${ }^{36}{ }^{36}$

33 Wolfram Pyta hat mit Blick auf die mangelhaften Visualisierungsstrategien der demokratischen Ordnung der Weimarer Republik auf die essentielle Bedeutung der zentralen normativen Ideen von Institutionen demokratischer Systeme und deren offensive Visualisierung und Propagierung hingewiesen:»Firstly, democratic institutions - like all other institutions - can claim legitimacy only if possessing a normative idea of their own existence. Institutions cannot be reduced to regulative and functional dimensions. Instead, the validity of institutions is conclusively guaranteed by normative ideas. Secondly, claims of legitimacy must be made visible, especially under the conditions of popular sovereignty. The political system can only be stabilized if the normative system behind the institutional system is recognizable." Pyta, Wolfram: Visualizing Democratic Legitimacy and Authority: The Case of the Weimar Republic. In: Depkat, Volker/Zwingenberger, Meike (Hg.): Visual Cultures in Transatlantic Perspectives. Heidelberg 2012, 69-83, hier 69.

34 Vgl. Buchner, Bernd: Politische Symbolik in der Weimarer Republik - wo bleibt die demokratische Tradition? In: Schultheiß, Michael/Roßberg, Julia (Hg.): Weimar und die Republik. Geburtsstunde eines demokratischen Deutschlands. Weimar 2009, 161-172, hier $165 \mathrm{f}$.

35 Thomas Mergel hat der Institution des Reichstages in die Gesellschaft hinein von »Politikern ohne Gesicht« gesprochen und der Weimarer Demokratie »fehlende Bildlichkeit» attestiert. Vgl. Mergel, Thomas: Parlamentarische Kultur in der Weimarer Republik: Politische Kommunikation, symbolische Politik und Öffentlichkeit im Reichstag. Düsseldorf 2002, $354 \mathrm{f}$.

36 Vgl. dazu Mühlhausen, Walter: Im Visier der Fotografen. Reichspräsident Friedrich Ebert im Bild. Heidelberg 2009, $10 \mathrm{f}$. Wolfram Pyta hat in seiner Hindenburg-Biografie ausgiebig herausgearbeitet, wie stark erstens die Sehnsucht der Deutschen nach personalisierten nationalen Symbolen bereits vor dem Ersten Weltkrieg war und wie Hindenburg sich 
Vor allem der unbeholfene Umgang Eberts und seines Umfeldes mit dem Medium der Fotografie ließ seine visuelle Inszenierung als republikanischer Anführer oft scheitern oder mindestens hinter ihren Möglichkeiten zurückbleiben. Ebert verkannte selbst in so epochemachenden Momenten wie der Verfassungsunterzeichnung vollkommen die Wichtigkeit visueller Kommunikation, der Ostentation und Ritualisierung demokratischer Prozesse und Kultur. Einem Paul von Hindenburg gelang dies später wesentlich besser, obgleich oder gerade weil sein Herz nicht sehr an der parlamentarischen Demokratie hing.

Legendär ist das Badehosenfoto Eberts mit Reichswehrminister Gustav Noske und Josef Rieger in der Ostsee (Abb. 14) sowie die Aufnahme von Eberts Vereidigung als Reichspräsident, auf der sein Antlitz bis zur Unkenntlichkeit verschwamm. Was Ebert nicht recht gelingen wollte, ${ }^{37}$ wurde insbesondere von den bürgerlichen und liberalen Illustrierten an der Person des amerikanischen Präsidenten vorgeführt. Sie hatten Interesse an einer demokratischen Kultur, mit der sich die Bevölkerung identifizieren und hinter der sich die Nation ungeachtet parteipolitischer Gräben vereinen konnte.

US-Präsident Warren Harding hingegen wird in der BIZ 1923 zum demokratischen Orator stilisiert, ${ }^{38}$ der dem Mobilisierungsbedarf einer durch die öffentliche Meinung bestimmten Massendemokratie aufgrund seiner politischen Selbstvermarktung mustergültig entspricht. Dass in der fotografischen Begleitung von Reden und öffentlichen Auftritten eine eigenständige visuelle Mobilisierungsstrategie besteht, buchstabiert der dazugehörige Artikel zwar nicht aus, führt diese Tatsache aber am beigefügten Bildmaterial vor (Abb. 15).

zweitens in seiner medialen Selbstinszenierung in dieses »Anforderungsprofil« einpasste. Vgl. Pyta, Wolfram: Hindenburg. Herrschaft zwischen Hohenzollern und Hitler. München $2007,69 \mathrm{f}$.

37 Zur Illustration genügt Walter Mühlhausens Beschreibung jenes symbolischen, potentiell gemeinschaftsstiftenden Termins im August 1919: „Es entsprach ganz dem auch später gepflegten bescheidenen Amtsstil Friedrich Eberts, dass die Verfassungsunterzeichnung am 11. August ohne großen Pomp verlief. Alles erfolgte ohne Zeremoniell, ohne nachhaltige Feierlichkeiten und sorgte daher auch für kein Aufsehen in der Öffentlichkeit. Die Presse nahm kaum Notiz davon. Es war ein geschäftsmäßiger Akt, dem wohl einige Minister beiwohnten.« Mühlhausen, Walter: Friedrich Ebert und die Unterzeichnung der Reichsverfassung 1919. In: Ders. (Hg.): Auftakt in Weimar. Beiträge zur Grundsteinlegung der Demokratie in Deutschland. Heidelberg 2010, 50.

38 In der Rhetorik- und Kommunikationstheorie ist der Begriff des Orators nach Joachim Knape folgendermaßen definiert: „Die Rhetoriktheorie versteht unter dem Orator einen Menschen, der in seinem Bewusstsein Intentionalität (kommunikative Zielvorstellungen, gerichtete Dynamik) ausprägt, sie im sozialen Handlungsraum per kommunikativer Intervention über Texte ausagiert, um sie letztendlich im Bewusstsein seiner Kommunikationspartner zu implementieren."Knape, Joachim: Was ist Rhetorik? Stuttgart 2000, 46f. Dieses Verständnis schließt auch Individuen ein, die nicht als Einzelperson, sondern in der Funktion oder an Stelle einer Institution, wie zum Beispiel einem politischen Amt kommunizieren. Vgl. ebd., 35. 


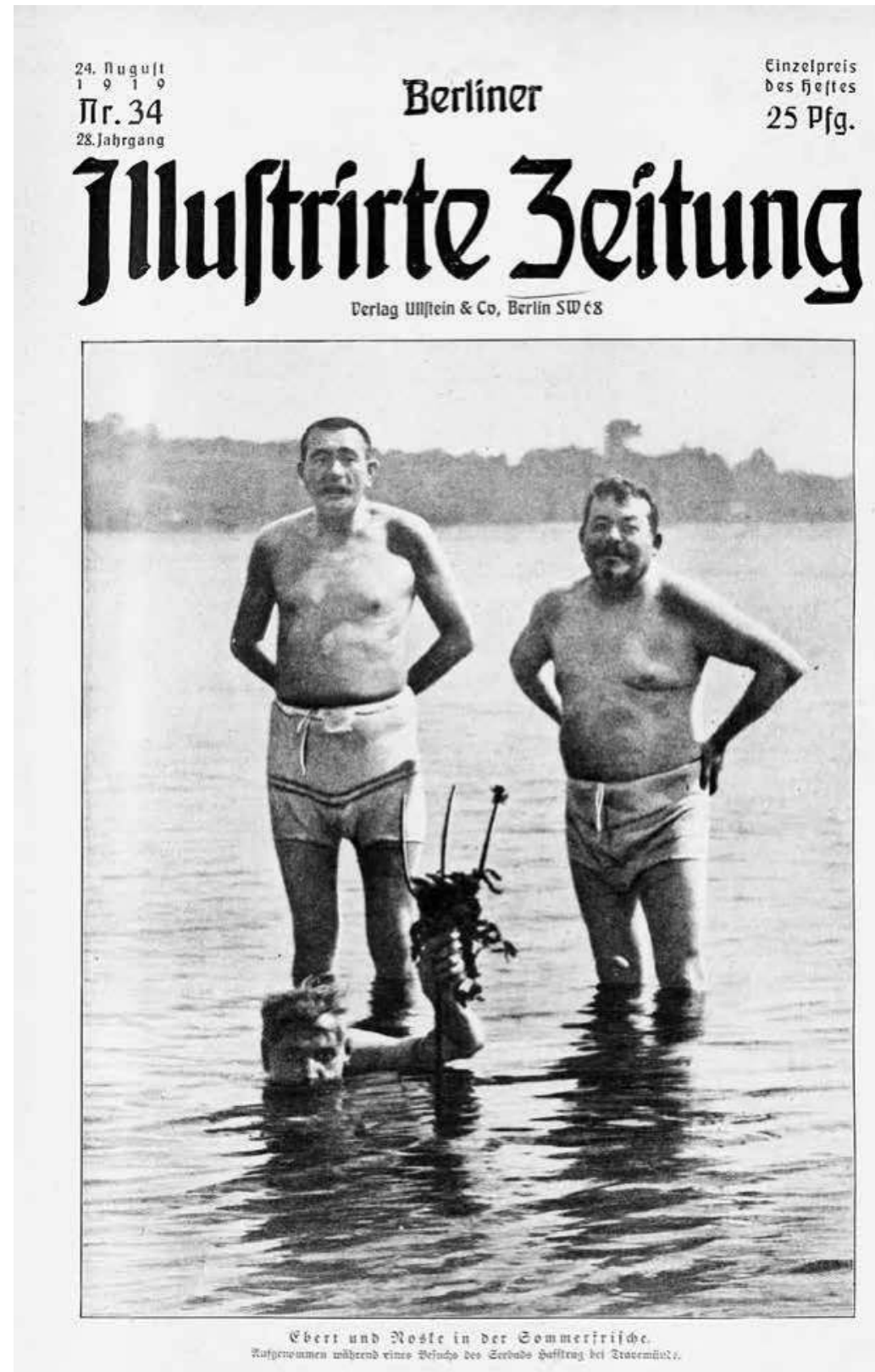

Abb. 14: Anon.: Ebert und Noske in der Sommerfrische. In: BIZ, 1919, Nr. 34, Titel. Das vielfach reproduzierte Bild ist beispielhaft für die in fataler Weise mangelhafte visuelle Kommunikation deutscher Spitzenpolitiker. In den USA wurde diese wesentlich professioneller genutzt. 


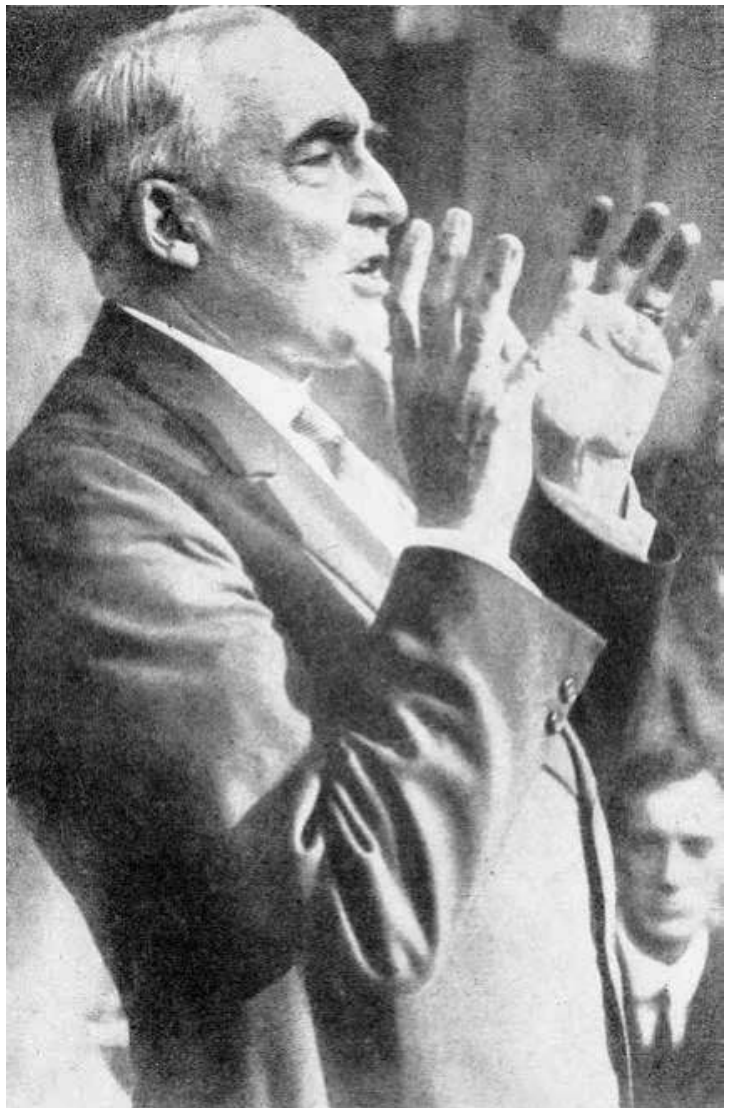

Abb. 15: Anon.: Amerikanische Rednertypen. In: BIZ, 1923, Nr. 29, 564 (Jahresausgabe). US-Präsident Harding wird professionell zum fesselnden Orator stilisiert.

Darauf ist Harding »in einer charakteristischen Rednerpose ${ }^{39} \mathrm{zu}$ sehen. Das Visual wirkt wie der beiläufige Schnappschuss eines Publikumstermins, wurde durch die BIZ aber von der zum Syndikat der "Associated Press" gehörigen Fotoagentur »Wide World« erworben. Erstere wiederum leistete traditionell der republikanischen Partei treue Dienste in der Wahlkampfberichterstattung und -inszenierung. ${ }^{40}$ Ohne diese Verbindung überinterpretieren zu müssen, macht sie in ausreichender Weise deutlich, dass nicht der Zufall, sondern das

39 Anon.: Amerikanische Rednertypen.

40 Vgl. Schwarzlose, Richard: Political Campaign Reporting. In: Ders.: The Nation's Newsbrokers. Bd. 2: The Rush to Institution: From 1865 to 1920. Evanston, IL 1990, 124-130, hier $124 \mathrm{f}$. 
Motiv gezielter Inszenierung zur Entstehung des Fotos führte. Harding ist darauf mit zum Publikum gewandten offenen Handflächen zu sehen. Diese sind, ebenso wie sein Gesicht, hell erleuchtet.

Die Darstellung des US-Präsidenten gerinnt in einer beschwörenden, gewinnenden Geste. "Er erhebt sich, sieht seinem Publikum in die Augen und beginnt [...] sein Thema, für das er es nach und nach immer mehr erwärmt...41 In der Umwerbung der Öffentlichkeit bestehen Sinn und Zweck der Veranstaltung, der ihrer fotografischen Weiterverbreitung in der Vergrößerung des Publikums. Hier zeigt sich das strategische Verhältnis der amerikanischen Politik zu visuellen Medien, noch ganz im Gegensatz zur damaligen Situation in Deutschland.

Aus Beiträgen wie diesem sprach die konsequente Öffentlichkeitsorientierung des amerikanischen Politikbetriebs. Dem deutschen Publikum wurde vorgeführt, dass eine Massendemokratie von der politischen Führung die Umwerbung der öffentlichen Meinung verlangte. Solche Betrachtungen zeigten, zusammen mit parallel in den Illustrierten zirkulierenden Analysen des politischen Systems der USA und seiner Institutionen ${ }^{42}$ "weiche « Strategien politischer Kommunikation auf. Besonders geeignet waren diese für die Verbreitung in den modernen Massenmedien, die zunehmend auf das Visuelle fixiert waren.

Zum Instrumentarium der politischen Kommunikation Amerikas gehörte auch das in der neuen deutschen Republik unterentwickelte Mittel der Personalisierung. Dem anonymen politischen System wurde ein menschliches Antlitz verliehen, zu dem sich jedermann in Beziehung zu setzen vermochte. Die gezielte mediale Entamtlichung (im Sinne von: Deabstrahierung) und Vermenschlichung des Präsidenten war ein probates Mittel, den emotionalen Abstand zwischen dem Präsidenten als Exponent der politischen Elite und dem Volk als Basisinstanz demokratischer Legitimation möglichst gering erscheinen zu lassen.

Volksnähe vermittelten zahlreiche PR-Aktionen wie die öffentliche »Ostereiersuche im Weißen Haus « ${ }^{43}$ die bis heute alljährlich von Zehntausenden Kindern und Erwachsenen besucht wird. Ein BIZ-Bericht über dieses Washingtoner Großereignis aus dem Jahre 1925 offenbart die Wirksamkeit solcher Publikumstermine über die Vereinigten Staaten hinaus: »Die alte Tradition des Volkspräsidenten in Nordamerika hat eine sehr enge Beziehung zwischen Staatsoberhaupt und Bürger geschaffen. ${ }^{44}$ Die fein orchestrierte

41 Anon.: Amerikanische Rednertypen.

42 Unter anderem: Anon.: Der Senat in Washington. In: BIZ, 1923, Nr. 10, 182f. (Jahresausgabe)

43 Anon.: Ostereiersuche im Weißen Haus. In: BIZ, 1925, Nr. 15, 450 (Jahresausgabe).

44 Ebd. Weiter heißt es: "Zwar steht der alte Brauch, daß jeder amerikanische Bürger nach Washington kommen und dem Präsidenten die Hand schütteln kann, nur noch auf dem 
Darstellung des mächtigsten Mannes der Welt als besonders volksnah und hemdsärmelig ist eine bewährte Strategie präsidialer Öffentlichkeitsarbeit. Bis heute hat sie sich in verschiedensten Ritualen gehalten und weiterentwickelt, zum Beispiel im alljährlich zelebrierten präsidialen Gnadenerlass für einen Truthahn an Thanksgiving und ähnlichem mehr. So possierlich derlei Rituale wirken: Sie erfüllten die wichtige Funktion, das politische System der USA, seine Institutionen und abstrakten Prozesse transparent und greifbar zu machen und ihnen den Anschein der Mittelbarkeit durch den kleinen Mann zu verleihen.

Die Inszenierung demokratischer Prozesse in den USA erreichte ihren Höhepunkt in der deutschen Medienlandschaft regelmäßig in den entscheidenden Phasen der Präsidentschaftswahlkämpfe. Angesichts des reichlich anfallenden und leicht verfügbaren Bildmaterials wurden diese in deutschen Illustrierten eng begleitet. ${ }^{45}$

In der ersten Hälfte der 1920er Jahre fanden noch vornehmlich Innovationen in Sachen Wahlwerbung und Wählermobilisierung die meiste Aufmerksamkeit. ${ }^{46}$ Bei der nachfolgenden Präsidentschaftswahl 1928 verlagerte

Papier. Aber an einer ganzen Anzahl Tagen des Jahres steht das Weiße Haus dem Volk fast ohne Einschränkungen offen. So versteckt am Ostersonntag die Präsidentin - sie tut es natürlich nicht selbst - eine Anzahl Ostereier unter den Büschen und im Gras der Gärten rings um das Weiße Haus, und dann dürfen die Kinder von Washington kommen und die Eier suchen. Eine ganze Anzahl Spiele [...] beleben dieses recht tumultuöse Fest, an dem alljährlich tausende Kinder, aber auch viele hundert Erwachsene teilnehmen, die den Vorwand der notwendigen Beaufsichtigung nutzen, um sich den Präsidenten und die Präsidentin aus der Nähe zu besehen, womöglich ihre Kinder von ihnen küssen zu lassen und - höchstes Glück - mit ihnen in einer Gruppe photographiert zu werden.« Ebd., 450.

45 Erstmals in größerem Ausmaß bei der Kampagne zur (Wieder-)Wahl von Calvin Coolidge, der als Vizepräsident den verstorbenen Harding beerbt hatte. Unter anderem: Anon.: Präsident Coolidge wiedergewählt. In: BIZ, 1924, Nr. 46, Titel; Anon.: Der offizielle Amtsantritt des amerikanischen Präsidenten: Präsident Coolidge mit seiner Gattin und einem Senator auf der Fahrt zu seiner Vereidigung im Kapitol von Washington. In: BIZ, 1925, Nr. 13, 387 (Jahresausgabe).

46 Unter anderem: Anon.: Wahltag in New York: Auto mit Radio-Lautsprecher-Einrichtung auf der Straße. In: BIZ, 1924, Nr. 49, 1442 (Jahresausgabe); Anon.: Redetechnik und Radiotechnik. In: BIZ, 1925, Nr. 15, 451 (Jahresausgabe). Hier werden Gemeinsamkeiten und Unterschiede zwischen dem amerikanischen und dem 1925 erstmals durchgeführten Präsidentschaftswahlkampf hinsichtlich des Einsatzes moderner Lautsprecher- und Radiotechnik behandelt: »Obwohl Deutschland jetzt zum allererstenmal [sic] einen Präsidentschaftswahlkampf veranstaltet hat, glich er im großen und ganzen in seiner Lebhaftigkeit und Massenbeteiligung sehr dem amerikanischen. Nur ein augenfälliger Unterschied war zu bemerken: Im amerikanischen Wahlkampf spielt heute Radio die erste, größte und wichtigste Rolle, im deutschen Wahlkampf spielte es überhaupt keine Rolle. In Amerika und nicht nur in Amerika, sondern ganz ebenso in England und Frankreich und anderen technisch modernen Ländern - wird heute keine politische Rede mehr gehalten, ohne daß auf dem Redner-Pult die Mikrophone des Radio-Senders und der Lautsprecher eingebaut sind [...] Die Vorteile, die ungeheure Multiplikation sind in die Augen springend 
sich das Interesse auf deren als personalisierter Zwiestreit angelegten Modus; eine Ausprägung der Wahlkultur, die sich aus dem Präsidialsystem einerseits und dem mehrstufigen amerikanischen Wahlverfahren mit Vorwahlen und Präsidentschaftswahl andererseits entwickelt hat. Sie brachte eine unverwechselbare Inszenierung und Ritualisierung jedes einzelnen Verfahrensschrittes von der Bekanntgabe der Kandidatur über die Spendeneinwerbung und innerparteiliche Mobilisierung bis hin zur "Krönungsmesse« vor dem Kapitol hervor.

Adolf Halfeld, einer der hervorragendsten und kritischsten Kenner der Vereinigten Staaten, ${ }^{47}$ steuert in der MIP dazu einen Artikel bei (Abb. 16), der konsequent die Persönlichkeiten der beiden Kandidaten Al Smith (Demokraten) und Herbert Hoover (Republikaner) einander gegenüberstellt.

Der amerikanische Präsidentschaftswahlkampf wird als Wettstreit der Politikerpersönlichkeiten, nicht als Kampf der Klasseninteressen oder gar Weltanschauungen dargestellt. Textinhalt, Visuals und sogar der Satz des Gesamtartikels dienen der Veranschaulichung des auf (vorübergehende) Polarisierung ausgelegten Wahlkampfmodus. Zur linken der Doppelseite führt Halfeld die Leserschaft in den Charakter des demokratischen Kandidaten Smith ein, dem »[i]risches und deutsches Blut [...] die rechte Mischung von bezwingender Lebensfreude und unbedingter Pflichttreue gegeben « habe und dessen Bild als »Persönlichkeit«, wohlgemerkt nicht als Vertreter spezifischer politischer Ansichten, »sich in jeder, auch der kleinsten Linie von dem seines bedeutenden Gegners im Kampf um die Präsidentenwürde«, Herbert Hoover, unterscheide. ${ }^{48}$

Letzterer bevorzuge, vollkommen gegensätzlich, die »menschenferne $\mathrm{Zu}-$ rückgezogenheit des Arbeitszimmers" und sei nicht so gewinnend und ver-

[...]. Man muß es nur einmal, z. B. in Amerika, selbst mitgemacht haben, welche Breite die politische Diskussion in den breiten Volksmassen dadurch gewinnt, wie einheitlich und klar selbst die Einstellung der kleinen Leute, denen politische Leitartikel oft zu schwer sind, zu den Grundfragen der Volksentscheidung wird, um die politische Wirkung des Radios richtig einzuschätzen. Es ist wirklich seltsam, daß Deutschland, das gerade in der Radiotechnik vollkommen auf der Höhe, ja erfinderisch führend ist, in der praktischen Anwendung seiner eigenen Erfindungen wie so oft so auch hier nur langsam und zaudernd nachfolgt."

47 Mit seiner amerikakritischen, mitunter als antiamerikanisch bezeichneten Monografie »Amerika und der Amerikanismus" von 1927 setzte Halfeld Standards der kritischen Amerikabetrachtung und lieferte dem rechten Antiamerikanismus der 1920er Jahre eine - allerdings wohl informierte und durchaus von tiefer Kenntnis der amerikanischen Gesellschaft zeugende - Grundlage. Dazu: Schwabe, Klaus: Deutscher Anti-Amerikanismus in den Zwanzigerjahren. In: Stamm-Kuhlmann, Thomas/Elvert, Jürgen/Aschmann, Birgit/Hohensee, Jens (Hg.): Geschichtsbilder. Festschrift für Michael Salewski zum 65. Geburtstag. Stuttgart 2003, 106-118, hier 114f.; Halfeld, Adolf: Amerika und der Amerikanismus. Kritische Betrachtungen eines Deutschen und Europäers. Jena 1927.

48 Halfeld, Adolf.: Die beiden Gegner, 1396. 


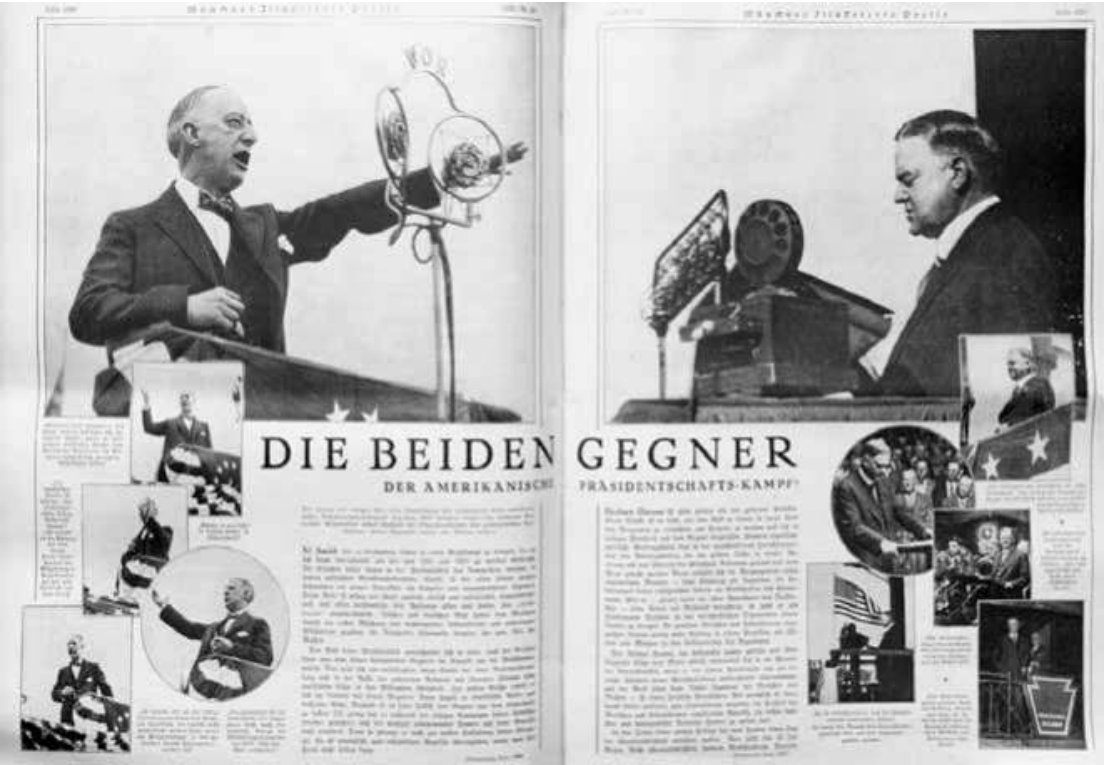

Abb. 16: Halfeld, Adolf.: Die beiden Gegner. Der amerikanische PräsidentschaftsKampf. In: MIP, 1928, Nr. 44, 1396f. (Jahresausgabe). Konsequent wird der US-Präsidentschaftswahlkampf als Duell gegensätzlicher Persönlichkeiten inszeniert.

bindlich wie sein Kontrahent, sondern »ein Ingenieur der Menschen und Massen. ${ }^{49}$ So setzt sich der Artikel bis in die Einzelheiten der Werdegänge, Prägungen und Talente beider Kandidaten fort, ohne von ihnen vertretene politische Inhalte auch nur am Rande zu erwähnen. Die visuelle Gestaltung der Doppelseite folgt mit charakteristischen Momentaufnahmen öffentlicher Auftritte demselben Muster: Während Smith mit ausladender Gestik und festem Blick in der Rolle des Volkstribuns und engagierten Redners zu sehen ist, erscheint Hoover als introvertierter, beinahe schüchterner Technokrat, der ans Rednerpult geklammert sein Manuskript nicht aus dem Auge verliert. Ein Lächeln, so suggeriert es die Bilderabfolge, ringt er seiner Miene nur bei offiziellen Fototerminen mühsam ab.

Halfeld warf der Kultur der Vereinigten Staaten als »dünne geistige Luft einer Pioniertradition ${ }^{50}$ bei jeder Gelegenheit mangelnden Tiefgang vor. Trotz seines scharf ausgeprägten Antiamerikanismus zeugen seine Ausführungen insofern von großer Sachkenntnis, als sie die Versteifung auf die persönlichen anstatt der politischen Charakteristika der Kandidaten mustergültig vorfüh-

50 Ders.: Amerika und der Amerikanismus, 176. 
ren. Der Artikel ist eine nur notdürftig getarnte Persiflage des amerikanischen Wahlkampfspektakels und der laut Halfeld effekthascherischen politischen Kultur der USA und ihrer öffentlichen Debatten.

Hoover trug am Ende mit 444 zu 87 Wahlmännerstimmen einen Erdrutschsieg davon. ${ }^{51}$ Entgegen dem von Halfeld und anderen Beiträgern wie Arthur Rundt ${ }^{52}$ entworfenen Bild der USA als Demokratie der Marktschreier hatte eben »kein Volksmann wie Al Smith [...] einen fast beispiellosen Sieg errungen " und "kein Mann des Wortes, aber der Tat. " $^{53}$ Die Wähler und vor allem Wählerinnen unterstützten Hoovers kompromisslose Prohibitionspolitik ${ }^{54}$ und hoben so den vermeintlich leidenschaftslosen Technokraten in das Präsidentenamt. Nicht obwohl, sondern gerade, weil Hoover mit dem einfachen aber konkreten Versprechen »Prosperity« in den Wahlkampf gezogen war. Diese auf den ersten Blick wohlfeile Botschaft war durch Hoovers erfolgreiche Arbeit als Handelsminister glaubwürdig hinterlegt. Aus diesem Amt zog Hoover enorme Popularität, da er sich in Fällen wie der katastrophalen Mississippi-Flut 1927 als tatkräftiger Krisenmanager erwiesen hatte. ${ }^{55}$ Seine Zurückhaltung im öffentlichen Auftreten konnte er so in eine Stärke ummünzen, frei nach dem Motto "Taten statt Worte«. Jeder der angetretenen Kandidaten - neben Hoover und Smith auch Kandidaten von Kommunisten, Sozialisten sowie der Arbeiter- und Bauernpartei - stützte sich inhaltlich auf umfangreiche Wahlprogramme. Für jeden Politikbereich waren hier konkrete Maßnahmen für den Fall des Wahlerfolgs zusammengefasst. Der in der Amerikakritik konservativer Kreise der Weimarer Republik verbreitete Topos von der leichtgläubigen, von Politikdarstellern mittels inhaltsleerer Schlagworte

51 Vgl. Fuchs, Lawrence H.: Election of 1928. In: Schlesinger, Arthur M./Israel, Fred L./Hansen, William P.: History of American Presidential Elections 1789-1968. Bd. 3 (1900-1936). New York u. a. 1971, 2585-2704, hier 2704.

52 Arthur Rundt berichtete in der BIZ in einer mehrteiligen Reportage zu den »Sonderbarkeiten« des amerikanischen Politik- und Wirtschaftsbetriebs. Er gab seinen Beobachtungen den Titel »Das lenkbare U.S.A.-Gehirn«, womit er den verbreiteten Eindruck verstärkte, in Nordamerika sei eine vollkommen neue Art des Denkens und Handelns, sogar ein neuer Mensch entstanden. Die Manipulierbarkeit der öffentlichen Meinung und die dazu verfolgten Strategien beschrieb er in einer Betrachtung des aufkommenden Public-Relations-Sektors als typisch amerikanisch: rational, empirisch und statistisch. Mit ihrer Hilfe sei die öffentliche Meinung durch ihr gezieltes Umwerben leichter zu beeinflussen als durch politische Standpunkte und reales politisches Handeln. Vgl. Rundt, Arthur: Das lenkbare U. S. A.-Gehirn. In: BIZ, 1928, Nr. 48, 2069-2071 (Jahresausgabe).

53 Anon.: Herbert Hoover, der neugewählte Präsident der Vereinigten Staaten, mit seinen Söhnen Herbert und Allan. In: BIZ, 1928, Nr. 47, 2004 (Jahresausgabe).

54 Dazu: Materson, Lisa: African American Women, Prohibition, and the 1928 Presidential Election. In: Journal of Women's History; Jg. 2009 (21), Nr. 1, 63-86.

55 Zur Mississippi-Flut und der erfolgreichen Krisenbewältigung durch Hoover: Leuchtenburg, William: Herbert Hoover. New York 2009, 68 f. 
"lenkbaren« Masse mag zwar seine Berechtigung haben, muss aber in seiner Apodiktik relativiert werden.

Die kritische Haltung gegenüber der amerikanischen Demokratie erschöpfte sich im massenmedialen Diskurs nicht in der Geringschätzung von konservativer oder rechtsnationaler Seite. Die AIZ sah, um hier beim Beispiel Herbert Hoovers und der Wahl von 1928 zu verweilen, darin ebenfalls nichts als ein pseudodemokratisches Ritual, das lediglich der Aufrechterhaltung des kapitalistischen Systems diene. "Hinter der U.S.A.-Prosperität «, ${ }^{56}$ erblickte man ohnehin die Ausbeutung der amerikanischen Arbeiter, die Unterdrückung der Gewerkschaften sowie einen politisch-industriellen Komplex zum Nachteil der einfachen Bevölkerung. ${ }^{57}$ Im kommunistischen Pressespektrum waren also nicht nur Zweifel an der Reife der politischen Kultur der USA die Triebfeder der Demokratiekritik. Die AIZ erklärte gleich das gesamte politische System zum Machtinstrument der Bourgeoisie. Man formulierte einen Vorwurf, der angesichts sich stetig höher auftürmender Spenden zur Finanzierung von US-Wahlkampagnen bis zum heutigen Tage alle vier Jahre erhoben wird: Die USA seien eine mustergültige Plutokratie.

Am Wahlsieg Hoovers kritisiert die AIZ nicht nur, dass es für die Arbeiter vollkommen gleichgültig gewesen sei, wer die Wahl gewinnt. ${ }^{58}$ Auch sei es »innerhalb der nordamerikanischen Demokratie immer noch vollkommen unmöglich, gegen die gewaltigen Wahlapparate« und »ungeheuren finanziellen Mittel der demokratischen beziehungsweise der republikanischen Partei anzukommen. ${ }^{59}$ Der Staat sei durch den großen Finanzbedarf der Parteien letztlich immer in der Hand des Großkapitals:

"Wie sehr die bürgerliche Demokratie ein Werkzeug der herrschenden Kapitalistenklasse ist, zeigt sich nirgends deutlicher als in dem Staat, der einstmals, vor vielen Jahrzehnten, mit seinen Erklärungen zu den Menschenrechten der französischen Revolution die Parolen lieferte. Der Kandidat der Republikaner, Herbert Hoover, ist gewählt. Seine Politik wird sich in nichts von der Politik seines Vorgängers, Coolidge, unterscheiden. ${ }^{60}$

Linke Amerikakritik unterstellte der amerikanischen Demokratie nicht wie die rechte einen Hang zur Demophilie, der Anbiederung an die vermutete Volksmeinung. Sie stellte die grundsätzliche Frage, ob man die politische

56 Goldschmidt, Alfons: Hinter der U.S. A.-Prosperität. In: AIZ, 1928, Nr. $24,2$.

57 Vgl. ebd.

58 »Ungeheure Summen - 10 Millionen Dollar - sind aufgewandt worden, um ein Wahlresultat zu erzielen, das für die Mehrheit des amerikanischen Volkes, für die Arbeiterschaft, wie es auch ausfällt, sehr gleichgültig ist. « Anon. (A.S.): Die Frauen haben trocken gewählt. Zur amerikanischen Präsidentschaftswahl. In: AIZ, 1928, Nr. 47, 4.

59 Ebd.

60 Ebd. 
Ordnung Amerikas überhaupt als demokratisches System bezeichnen könne. Darüber hinaus erkannte man im Land der Freiheit und Demokratie eine massive systematische Repression gegen Arbeiter und sozial Unterprivilegierte.

Das Interesse der AIZ an der Situation der Werktätigen in den USA entstand nicht aus steriler Ideologie oder weltrevolutionärer Propaganda. In Deutschland waren das Streik- und Arbeitsrecht sowie Fragen betrieblicher Mitbestimmung just Mitte der 1920er Jahre Gegenstand kontroverser, auch klassenkämpferisch konnotierter Debatten. Dabei ging es um die unterbliebene Umsetzung zentraler arbeitsrechtlicher Passagen der ausdrücklich als sozial konzipierten Weimarer Reichsverfassung. ${ }^{61}$ Nach der unruhigen Übergangsphase war die Verwaltungspraxis bald auf eine konservativere Auslegung arbeitsrechtlicher Bestimmungen eingeschwenkt. Gewerkschaftsnahe Arbeitsrechtler wie der prominente Politikwissenschaftler Ernst Fraenkel kritisierten diesen Rechts- und Vertrauensbruch scharf. ${ }^{62}$ In diesen innerdeutschen Kontext fiel die mediale Wahrnehmung und richtete sich an amerikanischen »Parallelen« dieser Problematik aus, also an niedergeschlagenen Arbeiterprotesten und weiterem mehr.

Auf besonders fruchtbaren Boden fielen derlei Eindrücke freilich bei der AIZ, die in den Streikunruhen in den Vereinigten Staaten eine Tradition der aggressiven Ignoranz gegenüber Arbeiterinteressen in den USA erkennen wollte. Das Narrativ der Repression von Arbeiterinteressen wird unter Rückgriff auf die Mythologie der internationalen Arbeiterbewegung und die sinnstiftenden »Haymarket Riots« vom 1. Mai 1886 illustriert, deretwegen dieser Tag überhaupt zum »Internationalen Tag der Arbeit» erkoren wurde.

"Die blutige Maidemonstration ${ }^{63}{ }^{3}$ von Chicago, Teil eines landesweiten Streiks zur Einführung des Achtstundentages und von Polizeieinheiten niedergeschlagen,${ }^{64}$ dient der AIZ als Vehikel, um die US-Exekutive in eine Tra-

61 Hierbei ging es insbesondere um den von Justiz, Politik und Verwaltung halbherzig umgesetzten Artikel 165. Darin war nicht nur die Frage der Arbeitnehmervertretung geregelt, sondern auch die Möglichkeit explizit erwähnt, dass entsprechende Arbeitnehmerräte Aufgaben der Verwaltung und der Kontrolle des Wirtschaftslebens übertragen werden konnten (WRV, Art. 165, Satz 5).

62 Fraenkel verfasste Aufsätze mit sozialpolitischer Note, in denen er die Erfüllung der verfassungsmäßig verankerten Passagen zum Arbeitsrecht und Arbeitsschutz forderte. Daraus ergibt sich ein Mosaik der sozial- und arbeitsrechtlichen Debatten der Weimarer Republik. Vgl. Fraenkel, Ernst: Gesammelte Schriften. Bd. 1: Recht und Politik in der Weimarer Republik. Herausgegeben von: Brünneck, Alexander von/Buchstein, Hubertus/Göhler, Gerhard. Baden-Baden 1999.

63 Anon.: Die blutige Maidemonstration Chicago 1886. In: AIZ, 1927, Nr. 17, 2 f.

64 In den Folgejahren konnte die Arbeiterbewegung aber nicht zuletzt durch die Schaffung eines Märtyrer-Mythos rund um die Geschehnisse von Chicago 1886 auch international Mobilisierungserfolge erzielen, in einigen Ländern - darunter auch Deutschland - überdies konkrete Fortschritte in Sachen Arbeitszeit und Arbeitsschutz. Dazu: Avrich, Paul: The Haymarket Tragedy. Princeton, NJ 1984, $181 \mathrm{f}$. und $401 \mathrm{f}$. 
ditionslinie der Arbeiter- und damit Demokratiefeindlichkeit zu stellen. Aus diesem Grundverständnis ist auch eine Ausgabe aus dem Folgejahr $1928 \mathrm{zu}$ interpretieren, die mit dem ironischen Titel $»$ Demokratie in Aktion ${ }^{65}$ aufmacht und sich Arbeiterprotesten und Streikaktionen in der Textilindustrie von Massachusetts widmet, welchen mit brutalen Polizeioperationen begegnet werde. Visualisierte Polizeigewalt gegen Demonstranten und Streikende bildet in der AIZ das Leitmotiv der Kritik an der amerikanischen Demokratie. Die Herrschaft des Volkes, so der zugrundeliegende Gedanke, dürfe sich nicht gegen dessen öffentlich gezeigten Unbill richten. Der gebetsmühlenartig wiederholte Verweis auf diesen prinzipiellen Widerspruch und seinen angeblich konstitutiven Charakter insinuiert einen Bruch zwischen Volkswillen und politischer Führung. Dieser Bruch äußere sich mit besonderer Drastik im Einsatz von exekutiver, sprich polizeilicher Gewalt gegen das eigene Volk.

Drastisch fallen denn auch Bildbeiträge wie jener aus dem Jahr 1931 (Abb. 17) aus, der die Erwerbslosenproteste in Los Angeles und Oakland thematisiert. Am linken Bildrand ist ein Polizist zu sehen, der sich Lederhandschuhe anzieht, mutmaßlich um den vor ihm an einem Hydranten liegenden Demonstranten zu traktieren, vielleicht auch um ihn wegzuschaffen. Durch eine die Szenerie in Vorder- und Hintergrund teilende Tränengaswolke ist eine teilnahmslose Menge von Beobachtern zu erkennen - mancher von voyeuristischem Interesse von der Szenerie angezogen, mancher mäßig interessiert das Geschehen passierend.

Von rechts bewegt sich eine zunächst nicht identifizierbare Person mit Schlagstock in die Aufnahme, die der Begleittext als Zivilpolizist ausweist. Die Polizisten hegen die Situation ein und beginnen nach der Überwältigung der Protestler nun mit der Zerschlagung der Demonstration. Die Fotografie unten links zeigt einen Mann, der während der Teilnahme an einem Demonstrationszug zwischen Kühlergrill und Stoßstange eines Autos geprügelt worden ist. So rigoros das Durchgreifen der Staatsmacht bebildert wird, so wenig Zweifel wird im Beitrag daran gelassen, wessen Interessen sich hier gegenüberstehen. Der Begleittext betont die Frontstellung Kapital gegen Arbeiter, indem man die Polizei nicht etwa als Arm der gewählten Regierung, sondern als anderer Herren Diener ausweist: »Mit Tränengas, Boxhandschuhen und Gummiknüppel versucht die Polizei des nordamerikanischen Kapitals die machtvollen Hungermärsche der über 10 Millionen Erwerbslosen dieses Landes zu verhindern. ${ }^{66}$

Artikel wie diese tauchten die gewaltsamen tariflichen Auseinandersetzungen und »Hungerproteste " von Erwerbslosen, deren Visualisierung bürgerkriegsähnliche Zustände vermittelt, in das Zwielicht »antiproletarischer»

65 Anon.: Demokratie in Aktion. In: AIZ, 1928, Nr. 41, Titel.

66 Anon.: Die Ordnung ist wieder hergestellt. In: AIZ, 1931, Nr. 16, 307 (Jahresausgabe). 


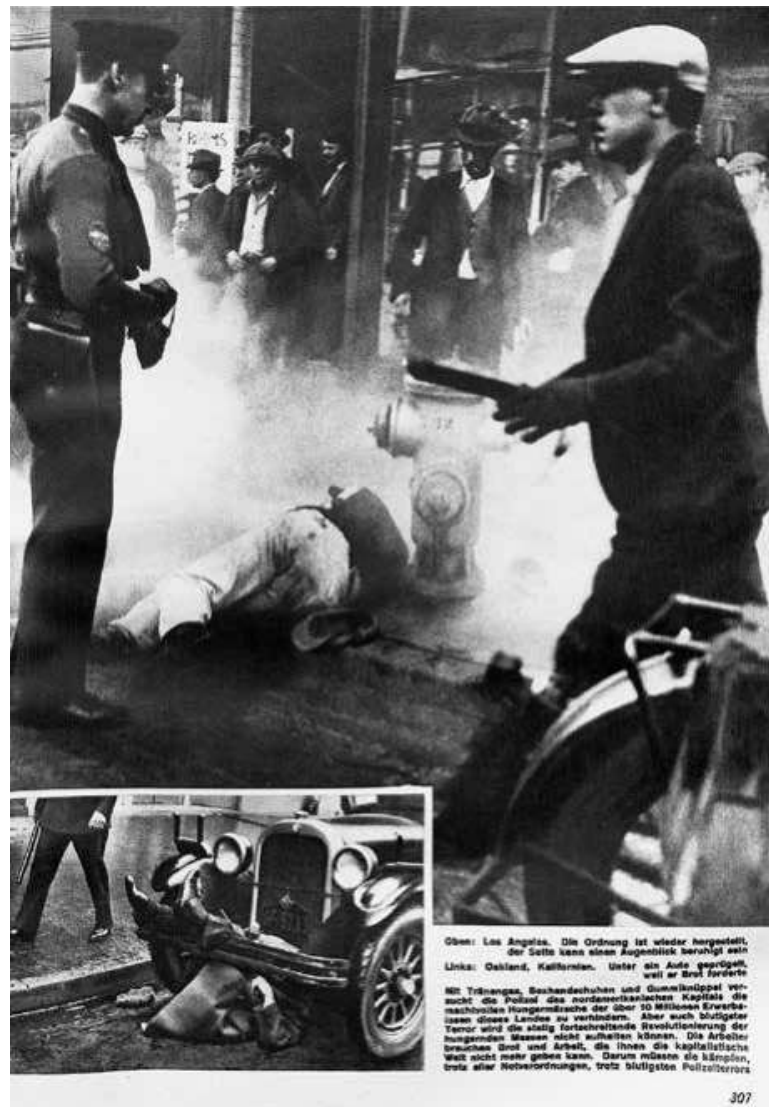

Abb. 17: Anon.: Die Ordnung ist wieder hergestellt. Bildunterschrift: »Oben. Los Angeles. Der Satte kann einen Augenblick beruhigt sein. Links. Oakland, Kalifornien. Unter ein Auto geprügelt, weil er Brot forderte.« Die amerikanische Politik und mit ihr die Polizei wird als Verbündeter des Kapitals im Kampf gegen Arbeiterinteressen dargestellt.

Repression. Dadurch verfestigte sich das Bild einer nicht nach Parteien geschiedenen, sondern zwischen Kapital und Regierung auf der einen und dem »Proletariat" auf der anderen Seite, mithin nach sozialen Gesichtspunkten eingeteilten politischen Arena. ${ }^{67}$ Das demokratische System, das nach dieser mar-

67 Die entsprechende Terminologie der rein sozial konnotierten inneramerikanischen Konflikte wird in mehreren Artikeln über die amerikanische Streikbewegung in den späten 1920er Jahren eingeführt. Besonders einschlägig: Leitner, Maria: "Weisser Abschaum«. Aus dem amerikanischen Arbeiterparadies. In: AIZ, 1929, Nr. 20, 4 f. 
xistischen Lesart nur den Interessen der materiell und politisch privilegierten Seiten dient, erscheint so zwangsläufig als Farce. Dieser Eindruck wird durch die Gegenüberstellung von Äußerungen des Bedauerns seitens politischer Eliten und der gleichzeitig fortgesetzten Niederschlagung von Streiks und Arbeitnehmerprotesten weiter verstärkt: ${ }^{68} »$ Die Demokratie des Sternenbanners führt mit den modernsten Kampfmaschinen Krieg gegen hungernde, streikende Arbeiterfamilien. ${ }^{69}$

Die Auseinandersetzung zwischen »oben" und »unten" erscheint als sich stetig verschärfender, der Entscheidung zustrebender Kampf. In Wort und Bild suggeriert die AIZ angesichts zunehmender staatlicher Gewalt gegen die Artikulation wohlfahrtsstaatlicher Interessen eine tiefgehende Legitimationskrise der amerikanischen Demokratie.

Mit der Kriminalisierung und staatlichen Bekämpfung gewerkschaftlicher Arbeit bildete die AIZ ein Problem ab, welches in der Tat den sozialen Frieden in der amerikanischen Gesellschaft strapazierte. In der sogenannten »Open Shop«-Periode von 1920 an war Arbeitnehmern der tarifliche Arbeitskampf bis zur Neuregelung durch den Wagner Act 1935 verboten. ${ }^{70}$

Die wiederholte Verknüpfung dieses virulenten Problems mit der Frage der demokratischen Legitimität des amerikanischen Staatswesens stellte jedoch eine ideologisch motivierte Projektion dar. Diese folgte der Maxime, alles Soziale sei zwangsläufig politisch und richtete die Betrachtung des politischen Systems der USA entlang dieser Weltanschauung aus. Die amerikanische Demokratie wurde zur bürgerlichen Camouflage des angeblich tobenden Klassenkampfes erklärt. So werden in einem AIZ-Artikel zum Präsidentschaftswahlkampf 1932 zwischen Hoover und Franklin D. Roosevelt Demokraten und Republikaner gleichermaßen dem bürgerlichen Lager zugerechnet. Die einzig echte Alternative wurde natürlich gleich mitgeliefert: »Die kommunistische Partei Amerikas stellt den beiden bürgerlichen Kandidaten Hoover und Roosevelt Arbeiterkandidaten entgegen, den Parteivorsitzenden [William Z., D. F.] Foster und den Negerarbeiter [James, D. F.] Ford.. ${ }^{71}$

68 »Der republikanische Präsidentschaftskandidat Hoover muß bereits einige Sätze des Bedauerns über Textilkrise und Arbeiterleid fallen lassen. Inzwischen aber werden die Operationen der Polizeiarmeen weitergeführt.« Gibarti, L.: USA: Demokratie in Aktion. Ebd., 9.

69 Ebd.

70 Wagner Act: National Labor Relations Act (NLRA). 29 U. S. C. $\$ \$ 151-169$. Beschlossen vom Repräsentantenhaus des US-Kongresses am 5. Juli 1935. Zur Entwicklung des Tarif- und Arbeitnehmerrechts zwischen Erstem Weltkrieg und New Deal im Längsschnitt: Pope, Jim: Worker Lawmaking, Sit-Down Strikes and the Shaping of American Industrial Relations, 1935-1958. In: Law and History Review. Bd. 24 (2006), Nr. 1, 45-113. Zur Verortung der Gewerkschaften im politischen Aushandlungs- und Wandlungsprozess des New Deal: Schlesinger, Arthur M.: The Coming of the New Deal, 1933-1935. Boston 2003, $385 \mathrm{f}$.

71 Anon.: Amerika im Präsidentschafts-Wahlkampf. In: AIZ, 1932, Nr. 38, 900 (Jahresausgabe). 


\section{2 »Innerparteiliche Demokratie« in der Sowjetunion}

So wichtig die Gewinnung der »öffentliche Meinung« für den politischen Betrieb der USA war, so selbstverständlich erscheint die vollständige Abwesenheit dieses Prinzips in der Sowjetunion. Auch die Klage der deutschen Presse über die unterdrückte politische Organisation der »Arbeiterklasse« in den USA wurde ins Gegenteil verkehrt: Im Sowjetstaat wählte überhaupt nur, wer in einer Parteigliederung oder Gewerkschaft organisiert war. Außerdem waren natürlich Ex-Aristokraten, Geistliche, Industrielle sowie ehemalige Angehörige von Polizei und Ochrana ${ }^{72}$ von der Wahl des Sowjets ausgeschlossen. ${ }^{73}$ Deutsche Kommunisten sahen freilich keinen Mangel an demokratischer Legitimation im Sowjetsystem.

Innerhalb des Regimes der Bolschewiki, das sich während der 1920er Jahre zur Parteidiktatur mit autokratischen Zügen entwickelte, war politischer Wettbewerb hingegen vorhanden. Er vollzog sich nur nicht öffentlich, transparent oder auf Grundlage der Volkssouveränität, was gemeinhin demokratisch genannt wird. Ganz grundsätzlich hat Raymond Aron ja auch einst festgehalten, dass der Kampf um politische Macht in allen bekannten Formen politischer Regimes tobe ${ }^{74}$ Lediglich sei dabei nicht festgelegt, in welchen institutionellen oder formellen Kontexten und mit welchen Mitteln dieser Machtkampf zwischen welchen Gegnern geführt wird. Die Kategorien aus der Analyse des politischen Wettbewerbs in Deutschland, Frankreich oder den USA taugen also nur bedingt zu einer Betrachtung der sowjetischen Politik. Hier vollzog sich jenseits all dieser »westlichen « Standards der politische Wettbewerb innerhalb einer wesentlich kleineren Gruppe, namentlich der KPR (B). Er wurde auch mit anderen Mitteln, in Form politischer Justiz und physischer Auslöschung gegen innere und weltanschauliche Gegner geführt, darunter vor allem »Reaktionäre« und die russisch-orthodoxe Kirche.

Hans Vorst, der sich als Reiseberichterstatter vor und nach der Revolution als Kenner des Baltikums und Russlands einen Namen gemacht und mehrere Monografien zu beiden veröffentlicht hatte ${ }^{75}$ widerspricht 1919 der positiven

72 »Ochrannoe otdelenie« (deutsch: Sicherheitsabteilung) war der Sammelbegriff für die Geheimpolizei des russischen Zaren und die verschiedenen Inlands- und Auslandsgeheimdienste. Bis zu ihrer Auflösung 1917 hatten diese Dienste sich immer mehr auf die Bekämpfung der Kommunistischen Partei verlegt. Vgl. Ochrana. In: Roewer, Helmut/Schäfer, Stefan/Uhl, Matthias: Lexikon der Geheimdienste im 20. Jahrhundert. Mit Organigrammen. München 2003, 325.

73 Vgl. Thatcher, Ian D.: Elections in Russian and Early Soviet History. In: Lentini, Peter (Hg.): Elections and Political Order in Russia. Implications of the 1993 Elections to the Federal Assembly. Budapest u. a. 1995, 15-35, hier $18 \mathrm{f}$.

74 Vgl. Aron, Raymond: Demokratie und Totalitarismus. Hamburg 1970, 38.

75 Unter anderem: Vorst, Hans: Die russische Krisis. Leipzig 1916. Und: Ders.: Der Bolschewismus und seine Lehren. Leipzig 1919. Und: Ders.: Revolution und Todesstrafe. Leipzig 
Bewertung des Sowjet-Wahlsystems durch deutsche Kommunisten, die er als »unsere Radikalen« bezeichnet, im BTB:

"Was übrigbleibt ist immerhin noch die große Mehrheit des russischen Volkes, und daraus folgern unsere Radikalen, daß die gewählten bolschewistischen Sowjetinstitutionen den Willen dieser Mehrheit widerspiegeln. Diese Folgerung ist falsch. Denn davon steht ja nichts in der 'Konstitution', wie zahlreiche russische Bürger und Proletarier außer den erwähnten Kategorien dadurch vom Wahlrecht ausgeschlossen sind, daß sie von der eigenartigen Ausrichtung der Sowjetwahlen einfach nicht erfaßt werden, weil sie nirgends organisiert sind oder in Kleinbetrieben arbeiten. Auch davon steht nichts in der 'Konstitution`, daß zur Mitarbeit in den Sowjets praktisch und tatsächlich nur die Angehörigen solcher Parteien und Gruppen zugelassen sind, welche sich grundsätzlich auf den Boden der Sowjetherrschaft stellen. Alle diejenigen russischen Staatsbürger also, die etwa einen demokratischen Vertreter in ihren Sowjet wählen wollten, brauchen gar nicht erst zur Wahl zu schreiten, weil es ihnen doch nichts nutzen würde.."${ }^{76}$

Sowohl auf Seiten des qualifizierten Wahlvolks als auch beim passiven Wahlrecht sieht der Konservative Vorst derart weitgehende Einschränkungen, dass man von einer demokratischen Wahl nicht mehr sprechen könne. Ferner stehe "nichts davon in der `Konstitution`, daß die Wahlen öffentlich" seien. Man könne sich also »vorstellen, was diese kleine Tatsache unter der sowjetischen Herrschaft bedeutet. " $^{77}$ Das Wort Konstitution setzt Vorst in Anführungszeichen, um darauf hinzuweisen, dass die sowjetische Verfassung seiner Meinung nach den Ansprüchen an eine solche wegen der inkonsequenten, willkürlichen Anwendung ihrer Paragrafen nicht genügt.

Öffentlichkeit kam als Faktor der politischen Organisation im Zusammenhang mit dem Wahlvorgang in der Sowjetunion also aus deutscher Sicht mit umgekehrten Vorzeichen zum Tragen als in den Vereinigten Staaten. Dort sah man in der Öffentlichkeit und der öffentlichen Meinung eine Kontrollinstanz für die politische Führung. Was Vorst im Hinblick auf das sowjetische Wahlrecht andeutet, ist der umgekehrte Einsatz von Öffentlichkeit: zur Kontrolle des Einzelnen durch die Staatsgewalt. Den Gedanken einer maximal gelenkten Demokratie im kleinstmöglichen Korridor politischer Willensbildung, wie er sich in der praktischen Anwendung des sowjetischen Wahlrechts offenbart, wird schon früh auch an anderer publizistischer Stelle geäußert. »Das Paradoxon des Bolschewismus $\aleph^{78}$ bestehe, so ein Beitrag in der DAZ, vor allem in der

1920. Er reiste aber auch durch Westeuropa und beschäftigte sich mit dem Verhältnis zwischen den »Mutterländern« Frankreich und Großbritannien zu ihren Kolonien.

Vorst, Hans: Die »Wahrheit« über Rußland. In: BTB Nr. 335 vom 23.07.1919, $1 \mathrm{f}$.

77 Ebd.

78 Anon.: Das Paradoxon des Bolschewismus. In: DAZ, 1920, Nr. 455, $1 \mathrm{f}$. 
in Deutschland trotz aller untrüglichen Anzeichen seiner Diktatur weit verbreiteten Unklarheit über die genaue Bedeutung des Begriffs Bolschewismus:

»Das Wort `Bolschewismus` hat aufgehört, ein festumrissener Begriff zu sein. Es bedeutet Diktatur des Proletariats, Diktatur der Kommissarenklique, es bedeutet Rätesystem, Kommunismus, blutiger Terrorismus und Expropriation. Wenn man heute vom Bolschewismus in Rußland spricht [...], muß man sich präziser ausdrükken. Denn in einen Begriff lassen sich die in Rußland geborenen politischen und wirtschaftlichen Erscheinungen nicht mehr zusammenzwängen. Feste Formen hat in Rußland von allem, was man unter Bolschewismus versteht, nur die Diktatur angenommen. Die Diktatur, die sich den Schein gibt, vom Proletariat ausgeübt zu werden, die aber doch nur die Diktatur einer kleinen Klasse auserwählter ist,- ja nur einzelner Persönlichkeiten. ${ }^{79}$

Bereits früh wurde erkannt, dass die äußere Form des Sowjetsystems nicht dessen wahrer Machttektonik entsprach. Diese war nicht entlang sich gegenseitig kontrollierender Instanzen und konkurrierender Interessenvertretungen ausgelegt, wie dies - weitgehend - in der deutschen Republik realisiert war. Vielmehr konzentrierte sich die wirkliche politische Macht im inneren Zirkel der Kommunistischen Partei, wenn nicht sogar bei einzelnen Personen innerhalb dieses Zirkels.

Eingedenk dieser Erkenntnis wurde also um Sowjetwahlen wenig Aufhebens in der deutschen Presse gemacht, obgleich diese weiterhin regelmäßig stattfanden. Man verlegte sich zur Ergründung des politischen Innenlebens des sowjetischen Riesenreiches stattdessen folgerichtig auf Vorgänge innerhalb der KPR (B). Das ließ die politische Arena auf die Auseinandersetzungen zwischen führenden Köpfen der Bolschewiki und deren Fußtruppen zusammenschrumpfen, sprich: »Leninisten und Trotzkisten ${ }^{80}$

Es herrschte bei liberalen und bürgerlichen Blättern Konsens, dass mit dem Begriff der Demokratie seit der Konsolidierung der Sowjet-Herrschaft nur eine innerparteiliche Demokratie gemeint sein konnte. Doch selbst die innerparteiliche Demokratie wurde durch die autokratischen Ambitionen Lenins zunehmend ausgehöhlt. In überaus zahlreichen Berichten zu den Auseinandersetzungen zwischen den Blöcken innerhalb der KPR (B) wird deutlich, wie

79 Ebd., 1.

80 Anon.: Leninisten und Trotzkisten. In: DAZ, 1921, Nr.64, 1. In diesem Artikel wird zwischen den beiden Lagern Lenins und Trotzkis unterschieden und erörtert, dass sich beide - neben politikphilosophischen Fragen - an der Frage entzweiten, welchen Einfluss Gewerkschaften in der politischen Willensbildung erhalten sollten: »In der bolschewistischen Partei Rußlands wird jetzt ein heftiger Kampf geführt über das Verhältnis der Gewerkschaften zum Sowjetstaat. Die Ansichten von Lenin und Trotzki stehen sich darin schroff gegenüber, so daß man jetzt in Sowjetrußland von zwei Gruppen der Partei spricht, die nach den Führern `Leninisten und 'Trotzkisten` genannt werden.» 
schnell und selbstverständlich sich die deutsche Tagespresse auf die eigentümlichen Spielregeln der sowjetischen »Demokratie« einstellte.

$\mathrm{Zu}$ Beginn des Beobachtungszeitraums steht Leo Trotzki als Streiter für (tatsächliche) innerparteiliche Demokratie im Zentrum des Interesses. Dies scheint angesichts der von ihm als Oberbefehlshaber der Roten Armee befohlenen Niederschlagung des Aufstandes von Kronstadt im Frühjahr 1921, ${ }^{81}$ in dem freie Wahlen sowie die Abschaffung der Pressezensur gefordert worden waren, ${ }^{82}$ nur auf den ersten Blick inkonsistent. Die Machtteilung der Bolschewiki, die das Ziel der meuternden Matrosen in der Marinefestung gewesen war, teilte Trotzki nämlich keineswegs. Ihm ging es darum, dass sich kein Einzelner aus dem Führungszirkel der Bolschewiki (sprich: Lenin und später Stalin) zum Diktator aufschwingen sollte, der sich an Beschlüsse und Mehrheitsverhältnisse innerhalb der Partei nicht mehr binden ließe. Trotzki hatte schon vor der Revolution von 1905 die Abschaffung der damals noch leidlich vorhandenen innerparteilichen Demokratie vorausgesehen, ${ }^{83}$ weshalb er Lenin immer wieder zur Einhaltung parteiinterner Entscheidungswege zwang.

Auf Drängen Trotzkis fänden zur Frage, wie viel Demokratie die Partei vertrage, nun »zahlreiche Arbeiterversammlungen in verschiedenen Städten statt, in welchen über diese Probleme Entschließungen gefasst « würden, heißt es 1921 in der DAZ. ${ }^{84}$ Noch im selben Jahr berichten die MNN gar von Lenins Bereitschaft, nach 1918 erstmals wieder eine Konstituante einzuberufen, um die Herrschaft der Bolschewiki auf eine breiter legitimierte Grundlage zu stellen. Ein demokratischer Lichtblick, der allerdings nicht aufgrund von Trotzkis Mission zur Erhaltung der innerparteilichen Demokratie zustande kam, sondern zur Abhilfe des eklatanten Devisenmangels in der sowjetrussischen Volkswirtschaft. Es sei demnach »durchaus notwendig, eine russische konstituierende Versammlung zusammenzurufen, da sonst die auswärtigen Regierungen nicht bereit seien, mit Sowjetrußland Handel zu treiben.« Darüber hinaus entledige sich Lenin durch dieses - wohlgemerkt später nicht eingelöste - Zugeständnis sogar seiner ärgsten Widersacher innerhalb der Parteiführung. So heißt es weiter, »daß Lenin verlangt habe, daß Trotzki, Bucharin

81 Trotzkis kompromissloses Vorgehen bei der Niederschlagung des Aufstandes war auch Gegenstand der tagesaktuellen Berichterstattung, unter anderem in der VZT: Anon.: Bolschewistische Menschenschlächtereien. In: VZT Nr. 116 vom 10.03.1921, 2.

82 Vgl. Hildermeier, Manfred: Geschichte der Sowjetunion 1917-1991. Entstehung und Niedergang des ersten sozialistischen Staates. München 1998, $149 \mathrm{f}$.

83 Vgl. Beyme, Klaus von: Politische Theorien in Russland 1789-1945, Wiesbaden 2001, 198 f. Er zitiert aus Trotzkis in der Schweiz erschienenen Pamphlet: Trockij, Lev: Naši političeskie zadači. Taktičeskie i organizacionnye voprosy. (deutsch: Unsere politischen Aufgaben. Taktische und organisatorische Fragen). Genf 1904.

84 Anon.: Leninisten und Trotzkisten, 1. 
und Dzershinski Moskau verlassen und sich nach der Krim begeben. Trotzki und die beiden anderen hätten sich verpflichtet, dies zu tun. ${ }^{85}$

Diese innerparteiliche Auseinandersetzung blieb bis zum krankheitsbedingten Ausscheiden Lenins 1924 die letzte, über die breit berichtet wurde, was auch am konsequenten Durchgreifen des Parteiführers lag. Um weitere Flügelkämpfe zu verhüten, hatte Lenin Fraktionen innerhalb der Partei kurzerhand verboten - selbst wohlmeinenden Beobachtern fiel es nun schwer, im Sowjetsystem noch demokratische Restbestände aufzuspüren.

Mit Stalins nunmehr hemmungslos vorgetragener Autokratisierung wurde auch sein spezieller Gebrauch des Demokratiebegriffs in der deutschen Presse in seiner bis zur Unkenntlichkeit verzerrten Version wiedergegeben, wie man sich ihrer in offiziellen sowjetischen Pressemitteilungen bediente. Das Schlagwort »Demokratisierung « meinte hier eigentlich die Ausschaltung jeglicher innerparteilichen Opposition gegen den Generalsekretär. Die Begriffsverwirrung bezüglich des Demokratiekonzepts ist indes kein Produkt des Zufalls, sondern Ausdruck des erklärtermaßen antithetischen Selbstverständnisses des Bolschewismus gegenüber der (westlichen) Vorstellung von Demokratie. Prinzipien wie Gewaltenteilung, gleiche Wahlen und ähnliches mehr waren den Bolschewiki unter Stalin überhaupt keine Kategorien mehr und wurden als fataler Irrweg abgelehnt. ${ }^{86}$ Diese dezidiert weltanschaulich bedingte Begriffsumkehrung wurde freilich in kommunistischen Blättern nicht weiter problematisiert. Überraschenderweise löste aber auch in der liberalen Tages-

85 Anon.: Lenin für Einberufung einer Konstituante. In: MNN Nr. 253 vom 20.06.1921, 1.

86 Zum grundsätzlich antithetischen Selbstverständnis des Bolschewismus zur demokratischen Idee schrieb Mark Vishniak bereits 1946 in der Zeitschrift Foreign Affairs: »To summarize, it may be said that [...] the Soviet system was defended in theory and enforced in practice as a direct antithesis to democracy and as the denial of democracy. While democracy had originated and developed through recognition of individual rights of men and citizens, the Soviet system of the heroic phase of the Bolsheviks' rule, on the contrary, remained silent as to these rights and laid emphasis on the collective right of laboring and exploited people. Throughout a century, democracy had fought [...] for recognition and consistent realization of the universal suffrage; the Soviet system rejected the universal franchise, as well as the equal franchise with direct and secret ballot, and adopted a limited suffrage with unequal, indirect and open voting. In the democratic states, representation was based on elections from districts which did not have pronounced political characteristics; the Soviets prided themselves for twenty years on representation not of persons or citizens, but of groups and institutions which the ruling party recognized as coöperative [sic] and useful bodies. Thus the entire population was divided into constituencies which were more or less privileged, and those which had no privileges at all. Democracy invariably differentiated three branches of government, struggled against the concentration of the legislative and administrative branches in the hands of a single body, and insisted on the independence of the judiciary. The Soviet system, inversely, denied the principle of the separation of powers and that of checks and balances."Vishniak, Mark: Lenin's Democracy, and Stalin's. In: Foreign Affairs, Nr. 3 (Juli), 1946, 610-621, hier 615 f. 
presse niemand solche grundlegenden Widersprüchlichkeiten auf. Stattdessen wurden sie unreflektiert übernommen.

Die VZT berichtet Anfang 1924 zu Stalins Durchsetzung der »Demokratisierung« der Kommunistischen Partei:

"Die Diskussion in der kommunistischen Parteikonferenz im Kreml über die Fragen der Organisation wurde durch eine Rede des Generalsekretärs des Zentralkomitees Stalin eingeleitet, der die Entschließung des Zentralkomitees über die geplante Demokratisierung der Partei in Erinnerung brachte [...]. Die Demokratisierung würde durchgeführt werden und der Streit über diese Frage hätte gleich nach der Erklärung des Zentralkomitees sein Ende finden können, wenn nicht Trotzki durch sein unerwartetes Auftreten in der Presse verlängert hätte. Stalin polemisierte stark gegen Trotzki und betonte die Notwendigkeit eines Konferenzbeschlusses, der nochmals das Verbot jeglicher Fraktionsbildung bestätigen sollte. ${ }^{87}$

"Die Auseinandersetzung in Moskau $«^{88}$ um die Entscheidungsfindung der Kommunistischen Partei hatte Stalin also klar für sich entschieden. Er konnte nunmehr, nachdem mit einer Rückkehr Lenins vom Krankenbett nicht mehr zu rechnen war, den Ausbau seiner von innerparteilicher Opposition unbedrohten Alleinherrschaft beginnen. ${ }^{89}$ In den Folgejahren erschien eine unübersehbare Reihe von Artikeln, die allesamt die mit schwankender Buchstäblichkeit vollzogene Liquidierung Stalins innerparteilicher Kontrahenten dokumentierten. Mit Begriffen wie "Kaltstellung", »Maßregelung" und »Unterwerfung « kam der Totalitarismus nun auch auf der verbalen Ebene an. ${ }^{90}$

87 Anon.: Die Kreml-Konferenz. In: VZT vom 20.01.1924, Nr. 34, 3.

88 Anon.: Die Auseinandersetzung in Moskau. In: VZT Nr. 36 vom 22.01.1924, 3.

89 Die Neuerungen bezüglich der innerparteilichen Opposition nahmen sich folgendermaßen aus: »Die Resolution enthält folgende Formel über die Demokratie: Die Arbeiterdemokratie bedeutet eine freie und offene Behandlung der wichtigsten Fragen des Parteilebens durch alle Parteimitglieder, Diskussionsfreiheit, Wählbarkeit der Funktionäre von unten nach oben, setz aber keineswegs eine freie Gruppenbildung voraus, welche mit den Organisationsgrundsätzen der Kommunistischen Partei unvereinbar ist.« Ebd.

90 Um einen Eindruck von der Fülle und Vielfalt der entsprechenden Artikel zu geben, seien hier nur einige repräsentativ genannt. Allein an Hand ihrer Betitelung lässt sich der Verlauf der Stalinschen Kampagne gegen seine Opponenten gut nachvollziehen: Anon.: Sinowjew kaltgestellt - Der erste Schritt der Sowjetregierung gegen die Opposition. In: DAZ Nr. 343 vom 26.07.1926, 1; Anon.: Unterwerfung der Sowjet-Opposition. Reue-Bekenntnis der Oppositionsführer. In: MNN Nr. 289 vom 23.10.1926, 1.; Anon.: Entscheidungskampf in Moskau. Nach dem Ausschluß Trotzkis. In: MNN Nr. 297 vom 31.10.1927, 1; Anon.: Verbannung der russischen Oppositionsführer. In: FZT Nr. 26 vom 10.01.1928, 1; Anon.: Trotzki und Wujowitsch gemaßregelt - Aus Mitglieder- und Kandidatenliste des Exekutivkomitees gestrichen. In: DAZ Nr. 460 vom 01.10.1927, 1; Anon.: Die Verschickung der russischen Oppositionsführer. In: FZT Nr. 29 vom 11.01.1928, 1; Anon.: Die Verhaftung der Trotzkisten. Sie werden angeklagt, den Bürgerkrieg vorzubereiten. In: BTB Nr. 42 vom 11.02.1929, 1; Anon.: Vor dem Sowjet-Parteitag. Sündenregister der Rechtsopposition. In: MNN Nr. 171 vom 26.06.1930, 1 f.; Anon.: Stalins Sieg auf dem Parteitag. Programmgemäßer Verlauf. In: MNN Nr. 179 vom 04.07.1930, $1 \mathrm{f}$. 
Trotzkis Rückschau »Die Verratene Revolution «" ${ }^{91}$ lehnt die historische Einordnung dieser Ereignisse an die Verhaftung und Hinrichtung Robespierres und seiner Fraktion während der Französischen Revolution an. Der von Trotzki verwendete Begriff des "Sowjetthermidor «" ${ }^{92}$ lässt trotz der evidenten Befangenheit des Autors keine Frage zum Vorgehen Stalins offen. Die deutschen Presseartikel zum Thema führen allein durch ihre schiere Masse das gewaltige Interesse an den gänzlich undemokratischen Machtdemonstrationen Stalins vor Augen, enthalten darüber hinaus allerdings wenig Erhellendes, weshalb sie hier nicht eingehender betrachtet werden müssen. Die Tagespresse zitierte in der Berichterstattung zur »Bereinigung in Moskau ${ }^{93}$ meist direkt aus offiziellen Mitteilungen des Zentralkomitees.

Durch Zeitungskorrespondenten und Gastbeiträger wurde allerdings ein wenig Licht in das Dunkel von Stalins Diktatur gebracht. Die Diskrepanz zwischen dem deutschen Demokratieverständnis und dem sowjetischen wurde betont, was die wichtige Rolle der Reiseberichterstatter und Korrespondenten als »Länderbildner« des öffentlichen Bewusstseins unterstreicht.

Der für das BTB in Moskau tätige Paul Scheffer erklärt den neuen Kurs der sowjetischen Führung zu einer logischen Konsequenz der Staatskonzeption der Bolschewiki. Russland sei nicht erst durch Revolution, Bürgerkrieg und die Umkehrung sozialer Hierarchien zum Kampf- und Klassenstaat geworden, in dem gegen politischen Widerspruch und jeden intellektuellen Gegner brutal vorgegangen werde. Der Kurs, den die Sowjetunion nun einschlage, sei im Erbgut der bolschewistischen Bewegung angelegt und mit politischen Ordnungsbegriffen wie Demokratie nie kompatibel gewesen. Folglich lasse er sich auch nicht durch solche Kategorien beschreiben:

»Es hat sich niemals darum handeln können, daß das Sowjetsystem in die westliche Form von Staat und Wirtschaft übergleiten werde. In der Grundanlage ist heute jeder europäische und außereuropäische Staat liberal, ungeachtet aller Parodien darauf, die sich aus der Durcheinanderwirbelung aller Schichten durch den Krieg ergeben haben [...]. Der Sowjetstaat ist Klassenstaat; eine Schicht in ihm, die die Macht hat, verneint vollkommen eine andere, bis ins letzte ihrer privaten Existenz hinein [...]. Der Sowjetstaat ist ein Kampfstaat. Es läßt sich doch nicht einfach darüber hinwegsehen, daß er sich revolutionär nennt, auch nach der Revolution [...]. Er nennt sich revolutionär nicht nur um der Weltrevolution willen, sondern vor allem wegen des fortgesetzten

91 Trockij, Lev: Die verratene Revolution. Was ist die USSR und wohin treibt sie? Zürich u. a. 1936.

92 Der von Trotzki geprägte Begriff des "Sowjetthermidor« ist an die Verhaftung und Hinrichtung Maximilien de Robespierres angelehnt, die nach dem französischen Revolutionskalender am 9. Thermidor (=27. Juli) 1794 stattfand und in Trotzkis Augen eine Reaktion gegen die Weiterführung der Revolution darstellte.

93 Anon.: Politische »Bereinigung« in Moskau. Stalins neuer Kampf gegen die Opposition. In: MNN Nr. 299 vom 28.10.1926, 1. 
Kampfes gegen die bürgerliche Welt im eigenen Bereich, den er mit seinen Machtmitteln ungleich aktiver führen kann als gegen die bürgerliche Welt draußen. Er regiert freilich zentralistisch, verfeindet mit dem Individuellen, absolutistisch [...], ist sich ausschließlicher Selbstzweck bis zur Grausamkeit [...]. Weil dies Staatswesen ein Kampfstaat ist, wird es immer ein Element der Unberechenbarkeit, der Unsicherheit enthalten, denn heute wird hier, morgen dort das Vergangene in seinen Resten angegriffen; nach der großen terroristischen Schlacht der Guerillakrieg, bald schwächer, bald stärker, je nach den Bedürfnissen der Ausbreitung oder der Beseitigung oder der Verteidigung des staatssozialistischen, kommunistischen Aufbaues. So seit Beginn, seit 1917. ${ }^{94}$

Die ideologischen Ziele der Revolution waren mit ihrer Erfüllung nicht obsolet geworden. Das Endziel der Revolution war die Herrschaft der Ideologie. Diese Erkenntnis war im bürgerlichen Lager der deutschen Publizistik spät, aber nachhaltig gereift. Die Einsicht, dass damit eine Teilhabe aller sozialen Schichten ausgeschlossen war, griff nun vom optimistischsten Beobachter bis zu traditionell skeptischen Beiträgern der konservativen Tagespresse Raum.

Politische Auseinandersetzungen betrachtete man von nun an zuvörderst im Spannungsfeld zwischen Diktatur und Dissidenz, personalisiert im Duell Stalin gegen Trotzki. Zwar hatten die inneren Angelegenheiten der Sowjetunion kaum direkte Auswirkungen auf das politische Leben in Deutschland. Die Auseinandersetzung der beiden zog aber deshalb so viel Aufmerksamkeit auf sich, weil sich in ihr metaphorisch der zur Niederlage strebende Überlebenskampf einer dezimierten politischen Öffentlichkeit gegen die rohe Gewalt der Macht vollzog. Der seit Beendigung des Bürgerkrieges herrschende Eindruck, die politischen Dinge in der Sowjetunion seien wie die sozialen im Fluss, wich der Gewissheit einer sich konsolidierenden Diktatur, die auf zwei Asymmetrien beruhte: derjenigen zwischen dem Generalsekretär der Kommunistischen Partei und dessen persönlichem Umfeld gegenüber den übrigen Parteimitgliedern sowie derjenigen zwischen der schmalen Schicht des städtisch geprägten (selbsternannten) »Proletariats « gegenüber der breiten Masse der ländlichen Bevölkerung.

Dies beobachtet auch der sich den Liberalen zuordnende Münchner Volkswirtschaftsprofessor Walther Lotz. ${ }^{95}$ Anlässlich der Jubiläumsfeier der Russischen Akademie 1925 war er in die UdSSR gereist und schilderte die dortigen politischen Verhältnisse für das BTB in einem Gastbeitrag. Lotz geht dabei zu-

94 Scheffer, Paul: Der neue innerpolitische Kurs in Sowjetrußland - die Rückwirkungen auf Wirtschaft und Ausland. In: BTB Nr. 202 vom 29.04.1924, 1 f.

95 Lotz war ein Schüler Lujo Brentanos und nahm bei seinen nationalökonomischen Analysen mehr als seine übrigen Kollegen die historischen Wurzeln kultureller Unterschiede im wirtschaftlichen Handeln in den Blick. So verfügte er über ein geschultes Sensorium auch für die Erfassung der politischen Kultur einer Gesellschaft. Vgl. Braeuer, Walter: Lotz, Walther. In: Neue Deutsche Biographie, Bd. 15. Berlin 1987, 252. 
nächst auf die augenfällige Unwucht der politischen Repräsentation ein. Diese bestehe darin, dass in »einem ganz überwiegend landwirtschaftlichen Lande [...] eine von kommunistischen Ideen erfüllte, sehr kleine städtische Minderheit über die große Masse der Bauern« herrsche. Jene äußerst dünne Schicht sei »erfüllt von den Gesichtspunkten des revolutionären, großindustriellen, städtischen Proletariats«.

Bei Lotz' weiteren Ausführungen drängt sich der Gedanke an einen der Hauptgründe der amerikanischen Revolution, die finanzielle Ausbeutung ohne entsprechende politische Vertretung, förmlich auf: »In Steuern und Lebensmitteln trägt die Landbevölkerung, ohne politisch führend zu sein, ganz überwiegend die Kosten der Belleitäten einer verschwindenden [...] kommunistischen Minderheit. ${ }^{96}$ Auf diese Weise bestätige sich auch die Illegitimität der Diktatur Stalins. Im Wesentlichen gründe sie auf der massiven Einschränkung der Presse- und Meinungsfreiheit, der Unmöglichkeit demokratischer Wahlen sowie der Konzentration aller drei Gewalten. Lotz schreibt:

»Es herrscht heute viel mehr die sogenannte Diktatur des Proletariats. Während man in der übrigen Welt seit Montesquieu eine Trennung der gesetzgebenden, richterlichen und ausführenden Gewalt sorgsam anstrebte [...], bedeutet die derzeitige russische Verfassung eine uneingeschränkte Herrschaft einer streng kommunistisch gesinnten Minderheit. Die russische Besonderheit ist nicht nur aus Definitionen der Verschiedenheit von Kommunismus und Sozialdemokratie oder überhaupt begrifflich zu konstruieren; sie ist nur als politische Schöpfung, die aus der Mentalität der russischen Revolutionäre hervorging, zu begreifen. ${ }^{97}$

Aus deutscher Perspektive ging eine Legitimitätskrise zwingend mit der Fragilität des sowjetischen Regimes einher. Die »Parteidiktatur im Sowjetbunde» könne, "so fest diese Diktatur auch scheint und so lange sie auch schon währt, doch schließlich nur mit ihrem freiwilligen Abbau oder ihrem Sturze enden «. ${ }^{98}$ Vorausgesetzt wurde bei dieser Einschätzung allerdings eine wie in Westeuropa oder Deutschland strukturierte publizistische Öffentlichkeit. Für die öffentliche Sphäre, wie sie in der Sowjetunion bestand, traf diese Einschätzung schlicht nicht zu. »Öffentlichkeit», mithin die Grundvoraussetzung für Meinungsbildung fand in Stalins Sowjetunion dort und dann statt, wo und wann dies vom Regime zugelassen und kontrollierbar war. ${ }^{99}$

96 Lotz, Walther: Reiseeindrücke aus Sowjetrußland. In: BTB Nr. 512 vom 29.10.1925, $1 \mathrm{f}$.

97 Ebd., 2.

98 Anon.: Die Krisis der kommunistischen Diktatur. In: DAZ Nr. 155 vom 25.03.1925, $1 \mathrm{f}$.

99 Vgl. Rittersporn, Gábor/Behrends, Jan C./Rolf, Malte: Öffentliche Räume und Öffentlichkeit in Gesellschaften sowjetischen Typs. Ein erster Blick aus komparatistischer Perspektive (Einleitung). In: Dies. (Hg.): Sphären von Öffentlichkeit in Gesellschaften sowjetischen Typs. Public Spheres in Soviet-Type Societies. Frankfurt a. M. 2003, 9 f. 
Außerdem war, so wie in der sozialen Stratifizierung der sowjetischen Gesellschaft auch, die publizistisch verfasste Öffentlichkeit in eine kleine, sich über politische Theorien und anderes mehr austauschende Schicht der ideologischen Avantgarde und die breite Masse der Arbeiter und Bauern unterteilt. Letztere griffen freilich nicht selbst in die öffentliche Debatte ein, sondern wurden mit den für sie von der ideologischen Avantgarde als nützlich erachteten Informationen versorgt - zum Beispiel via Litfaßsäule oder Wandzeitung.

Die »Oeffentliche Meinung in Rußland « ${ }^{100}$ so Artur Just 1926 in der FZT 1926, werde vor allem über die literarisch und ideologisch durchgebildete publizistische Schiene der »Prawda" gelenkt. In deren ideologischem Windschatten folgten regionale Zeitungen für die Arbeiter- und Bauernkollektive, die von »Mitmach-Redaktionen«, also Laienjournalisten geführt würden. In »Prawda« und anderen Parteizeitungen würde »schärfste Kritik geübt und nicht nur geduldet, sondern gewollt« und außerdem »Moral gelehrt, Rechtsnormen gebildet [...], also Dinge getan, welche anderswo zu den Obliegenheiten der öffentlichen Meinung " gehörten. In den anderen Zeitungen finde sich neben »30 Prozent Falschmeldungen « und »jeder Menge Denunziationen ${ }^{101}$ kaum brauchbare Information jenseits der offiziellen Parteipropaganda, um daraus eine individuelle Meinung zu bilden.

Aus der Unterscheidung zwischen streitbarer Partei-Avantgarde und vermittels stetig ausgesandter Propaganda kontrollierter "Masse" spricht eine theoretische Besonderheit des Leninismus, deren praktische Umsetzung aus Lotz' Beobachtungen deutlich wird. Im Gegensatz zum klassischen Marxismus, der eine sukzessive sich einstellende Identität von »Masse« und Partei annimmt, sah Lenin die Partei als die Steuerungseinheit. Die »Masse« war durch politische Propaganda (»Aufklärung«) zu ihrem kommunistischen Glück zu zwingen. ${ }^{102}$ In dieser dichotomischen Beziehung zwischen Partei und Volk sollten reelle Maßnahmen und Propaganda, beides in der Hand der Partei, erstens zu einer Verbesserung der Lebensbedingungen der Menschen und zweitens zu wachsender Akzeptanz der - nichtdemokratischen - politischen Ordnung führen.

Die sowjetische Propaganda der Zwischenkriegszeit, der in der Theorie eine so wichtige Rolle zukam, kann allerdings weitestgehend als eine Reklame der

100 Just, Artur W.: Oeffentliche Meinung in Rußland. In: FZT Nr. 672 vom 09.09.1926, 1.

101 Ebd.

102 Zur klassischen Analyse der Interaktion zwischen Partei und Öffentlichkeit in der Sowjetunion: Inkeles, Alex: Public Opinion in Soviet Russia. Cambridge 1951, $11 \mathrm{f}$. Zur Beziehung, dem Informationsgefälle und der Gestaltung der öffentlichen Meinung zwischen Intellektuellen und »Arbeitern« in der Sowjetunion unter Lenin sowie den theoretischen Unterschieden zwischen Marxismus- und Leninismustheorie: Kautsky, John H.: Marxism and Leninism, not Marxism-Leninism. An Essay in the Sociology of Knowledge. Westford, CT u. a. 1994, $42 \mathrm{f}$. 
Politik angesehen werden, die sich in einer Politik der Reklame erschöpfte. Der einzelne Propagandaakt war äußerst selten durch die propagandistisch verbreiteten Fakten und Maßnahmen hinterlegt. Dies führte zur treffenden Charakterisierung der Sowjetunion als $»$ Reklamestaat ${ }^{103}$ in dem staatliches Handeln - neben dem Klassenkampf - in nichts anderem als der Propaganda bestehe.

In der staatlichen Hegemonie über den vollständig durchdrungenen »öffentlichen « Raum bestand durch die hemmungslose Zensur nach Ansicht mancher Betrachter wiederum eine Gefahr für die Glaubwürdigkeit des Regimes. Arthur Feiler, Korrespondent der FZT in der Sowjetunion, ordnet die aus seiner Sicht in groteskem Umfang betriebene "Staatsreklame« vor dem Hintergrund ihrer exklusiven Deutungshoheit ein, die nicht durch eine kritische Presse, geschweige denn von einem zivilgesellschaftlichen Korrektiv ergänzt werde. Er greift zur Veranschaulichung der Konsequenzen, welche diese Struktur des öffentlichen Raumes in der Sowjetunion habe, auf das Beispiel der Ausweitung der Pressezensur in Deutschland während des Krieges zurück: ${ }^{104}$

»Keine Pressefreiheit also. Keine Freiheit des öffentlichen Wortes, keine Freiheit der Meinung. Die Folge aber ist die gleiche, die stets einer solchen Unterdrückung der Freiheit des Wortes folgt und die ja auch wir während des Krieges und der Kriegszensur zur Genüge ausprobiert haben: Skepsis und Mißtrauen gegenüber jedem offiziell gesprochenen und gedruckten Worte bis zur völligen Ungläubigkeit.« ${ }^{105}$

103 Anon.: Der Reklame-Staat. Beobachtungen aus Sowjet-Rußland. In: MIP, 1927, Nr. 27, $780 \mathrm{f}$. (Jahresausgabe).

104 Wobei dieser Verglich hinsichtlich des Motivs und der Zielrichtung der Pressezensur hinkte. So versuchte man nach der Verkündung des uneingeschränkten U-Boot-Krieges seitens der politisch Beteiligten, sich im Wissen um die Unbeliebtheit solcher Maßnahmen die politische Verantwortung für diese Entscheidung gegenseitig zuzuschieben. Außerdem diente die militärische Zensur, wie von großen Teilen der Bevölkerung akzeptiert, der militärischen Geheimniswahrung aus taktischen Gründen. Eine darüber hinausgehende dezidiert politische Zensur hingegen wurde im nach wie vor stattfindenden öffentlichen Diskurs abgelehnt und führte zu einer nachhaltigen Entfremdung zwischen Volk und politischer wie militärischer Führung - letztere freilich seit 1917 weitgehend deckungsgleich. Vgl. König, Marcus: Agitation - Zensur - Propaganda. Der U-Boot-Krieg und die deutsche Öffentlichkeit im Ersten Weltkrieg. Stuttgart 2014, 395.

105 Feiler, Arthur: Die Diktatur des Bolschewismus. Aus dem Tagebuch einer russischen Reise. Der Druck der Diktatur und seine Folgen. In: FZT Nr. 723 vom 28.09.1929, $1 \mathrm{f}$. 


\subsection{Der bolschewistische "Kirchenkampf"}

Arthur Feilers Hinweis auf den »Unglauben«, der die Öffentlichkeit ob der stetig niederprasselnden Evangelien des Bolschewismus befiel, liefert das Stichwort für einen speziellen Aspekt des politischen Wettbewerbs in der UdSSR: den Kampf gegen die russisch-orthodoxe Kirche. Diese hatte vor allem auf dem Land das Monopol über die Spiritualität der einfachen Bevölkerung und war Taktgeber des öffentlichen Lebens. Zunächst kaum durch die Bolschewiki zu kontrollieren, war die Kirche ein potentiell gefährlicher Gegner und ein mächtiges Symbol des »heiligen Russland«, der alten, von Zarentum und Orthodoxie getragenen Staatsordnung. Die Institution Kirche verfügte außerdem über ein landesweites Netzwerk "politisch Nichtgläubiger « ${ }^{106}$ mit direktem Einfluss auf die Bevölkerung, was dem ideologischen Antagonismus zwischen Kommunismus und Religion eine realpolitische Dimension gab. ${ }^{107}$

Die Attacken der Bolschewiki trafen keine integre und allseits geschätzte Organisation. Zu inneren Ränken um die religiöse Ausrichtung und Pfründe, die lange vor der Revolution das Ansehen der Kirche beschädigt und Teile der Bevölkerung von ihr entfremdet hatten, kam der bolschewistische Angriff nun lediglich hinzu. ${ }^{108}$ Die Bedeutung für die deutsche Wahrnehmung der Sowjetunion besteht darin, dass weltliche und geistliche Macht in der Sowjetunion noch nicht so weit entflochten waren, als dass man überhaupt von getrennten Sphären und einer säkularen, also »modernen " Gesellschaft sprechen konnte. Dies stand im Gegensatz zur ihrerseits an christlichen Referenzen überreichen, aber dezidiert säkular verstandenen »Civil Religion« der USA. Gerade in ihrer Transmissionsfunktion an der Schnittstelle zwischen Öffentlichkeit, Politik, Regierung und nationaler Mythologie repräsentierte die Zivilreligion ein wichtiges Element der politischen Ordnung der USA.

Eine Betrachtung der Sowjet-Kampagne gegen die Religion unter dem Signum politischer Kultur ist darüber hinaus legitim, weil die Bolschewiki zur

106 Um mit den Worten Karl Dietrich Brachers zu sprechen, der in seiner Betrachtung "politischer Religionen«, zu denen auch die Bewegung der Bolschewiki gehört, auf deren unbedingte Entschlossenheit zur Bekämpfung aller Kräfte außerhalb ihrer ideologischen Glaubensgemeinschaft hinweist. Vgl. Bracher, Karl Dietrich: Zeit der Ideologien. Eine Geschichte politischen Denkens im 20. Jahrhundert. Stuttgart 1984, 53.

107 Mit der theoretischen Dimension ist hier der im Werk von Karl Marx deutlich erkennbare Messianismus gemeint, der ihn als Denker beinahe mehr für die Rolle eines Religionsstifters denn eines Philosophen qualifiziert. Klaus Hornung schreibt dazu: »Man hat Marxens Wirkung nicht zu Unrecht mit derjenigen von Religionsstiftern und Reformatoren verglichen. Seine Lehren waren nicht nur, wie er selbst immer wieder betonte, ein Programm politischer Revolution; sie beanspruchten eine Totaldeutung von Sinn und Ziel der menschlichen Geschichte, des kollektiven wie individuellen Lebens des Menschen." Hornung, Klaus: Das totalitäre Zeitalter. Bilanz des 20. Jahrhunderts. Berlin 1993, 82.

108 Vgl. Shevzov, Vera: Russian Orthodoxy on the Eve of the Revolution. Oxford u. a. 2004, $258 \mathrm{f}$. 
Durchsetzung der Herrschaft der Ideologie zwangsläufig den Konflikt mit der Religion forcieren mussten. Ihr Kampf gegen die Kirche war seiner Natur nach also eine politisch-ideologische Auseinandersetzung. Bolschewistische Ideologie und orthodoxe Religion glichen sich hinsichtlich ihrer Erlösungsvorstellungen, vor allem aber in ihrem Alleinvertretungsanspruch. Sie waren konkurrierende ideologische Sinnsysteme. Die Konstellation in der Sowjetunion ließ für die Auseinandersetzung der Bolschewiki mit der Kirche also nur die alternativen Ausgänge der Mediatisierung des einen durch das andere (wie es der erklärte Atheist Hitler im Kirchenkampf weitgehend erreichte) oder die Zerstörung einer der beiden durch den anderen zu. Dieses Denken beruhte auf Gegenseitigkeit: Der 1917 gewählte Patriarch Tichon verstand sich immerhin als geistiger Führer der Konterrevolution und belegte die Bolschewiki 1918 sogar mit einem kirchlichen Bannfluch. 1923 war er schließlich gezwungen, eine Loyalitätsbekundung gegenüber dem Regime abzugeben. ${ }^{109}$

Im theokratischen Selbstverständnis der Bolschewiki liegt der Gedanke begründet, dass sie in ihrem missionarischen Eifer die Religion als direkten und aus der russischen Staatstradition heraus starken Konkurrenten betrachteten. ${ }^{110}$ Jenseits institutioneller Konkurrenz mussten sie also auch deren Wirkmächtigkeit im öffentlichen Diskurs schmälern. Es ging für die Bolschewiki um die Herbeiführung einer »Homogenität der Denkbasis «"11, ohne dass die Bevölkerung zwischen Kirche und Partei entscheiden musste oder konnte.

109 Vgl. Schilling, Heinz-Dieter: Religionen unterm roten Stern. Christen, Moslems, Juden und Buddhisten in der Sowjetunion. Köln, 1988, $44 \mathrm{f}$.

110 Zum theokratischen Selbstverständnis des internationalen Kommunismus am Beispiel der Britischen Kommunistischen Partei schreibt Raphael Samuel: »The ambitions of the Communist Party - and the self-perception of members - were unmistakably theocratic. Organizationally we conceived ourselves to be a community of the elect, covenanted to a sacred cause. Politically, we aspired to be teachers and guides."Samuel, Raphael: The Lost World of British Communism. London 2006, 58f. Sich auf die Überlegungen Kenneth Jowitts stützend, schreibt Jan-Werner Müller zum religiösen Faktor der in der Mobilisierungsstrategie der Bolschewiki und Lenins als Führerfigur: »Die Partei hatte [...] all jenen etwas zu bieten, die nicht nach einer charismatischen Person, sondern nach einer charismatischen Institution suchten. Die Parteimitglieder pflegten eine intensive Hingabe und Opferbereitschaft an den Tag zu legen [...]. Gewiß war es nicht so, daß persönliches Charisma gar keine Rolle in »Lenins Sekte« gespielt hätte, wie Kritiker sie nannten. Lenin selbst flößte ein außergewöhnliches Maß an Vertrauen ein; mit 33 Jahren nannten ihn seine Anhänger bereits starik, den weisen Alten, als wäre er einer von jenen alten Propheten, die Weber als zentrale Beispiele charismatischer Führungspersönlichkeiten gedient hatten. Und viele Bolschewiki pflegten gar zu berichten, wie sie sich quasi in ihren Anführer verliebten.« Müller: Das demokratische Zeitalter, 107.

111 Mannheim, Karl: Die Bedeutung der Konkurrenz im Gebiete des Geistigen. In: Meja, Volker/Stehr, Nico (Hg.): Der Streit um die Wissenssoziologie. Bd. 1: Die Entwicklung der deutschen Wissenssoziologie. Frankfurt a. M. 1982, 325-370, hier 339. Zuerst erschienen in: Verhandlungen des Sechsten Deutschen Soziologentages, 17. bis 19. September 1928 in Zürich. Tübingen 1929, 35-83. 
Der öffentliche Raum musste durch Zensur und staatlichen Zwang zum abgeschlossenen Erlebnisraum zwischen Partei und Proletariat werden. Hinzu kam das fundamentale Ziel aus der marxistischen Theorie, einen Staat ohne Religion aufzubauen. Vom entsprechend durchgebildeten Spitzenpersonal der Bolschewiki wurde dieser "Glaubenssatz« als Handlungsanweisung für die Revolutionierung der Lebensverhältnisse verstanden.

Auch im institutionellen Sinne suchten die Bolschewiki der Bevölkerung eine Alternative zur Religion aufzuzeigen oder eben aufzuzwingen. Atheistische Schulen und Treffpunkte wurden eingerichtet sowie das paradox anmutende Unterfangen einer atheistischen $»$ Missionierung « umgesetzt. ${ }^{112}$ In diesem Kontext ist die Berichterstattung über die sowjetische "Gottlosenbewegung" und die Repressalien gegen die Kirchen (die katholische Kirche war ebenso betroffen $)^{113} \mathrm{zu}$ sehen. Auch der Begriff des »Kirchenkampfes« ist als ein missionarischer zu verstehen, auch wenn dieser im Zusammenhang mit der Kampagne der Bolschewiki zur Zerstörung der orthodoxen Kirche oftmals als zu eng kritisiert wurde. ${ }^{114}$ Die begriffliche wie geistige Verwandtschaft mit

112 Dazu.: Froese, Paul: The Plot to Kill God. Findings from the Soviet Experiment in Secularization. Berkeley u. a. 2008, 5 f. Der Alltag in den antireligiösen Schulen wird in einem MNN-Gastbeitrag von Nicolai von Arseniew, Theologe an der Universität Königsberg, folgendermaßen beschrieben: »Durch Gesetz ist die Erteilung jeglichen religiösen Unterrichts an Personen unter 18 Jahren unterdrückt unter Verhängung schwerer Strafen. Im Gegenteil, der Unglaube, die Verspottung der Religion wird den Kindern in der Schule zwangsmäßig eingeimpft. Nicht nur werden Schulaufführungen während der großen christlichen Feiertage gegeben, bei denen die Erzählungen der Evangelien in rohester, zynischster Weise verlacht und verhöhnt werden (so z. B. aus Anlaß der Weihnachtsgeschichte wird Josef als betrunkener Zimmermann dargestellt und daran reiht sich eine Kette von unanständigen Gotteslästerungen), dabei ist die Beteiligung der Schuljugend und der Pädagogen an diesen Schulaufführungen obligatorisch - nicht das allein, sondern was viel wichtiger ist, sogar während der regelmäßigen Gesangsstunden werden den Kindern gewaltsam schmutzige Hohnlieder gegen den christlichen Glauben aufgezwungen [...]. Und dieser Kampf dauert fort, wird immer systematischer, immer verwickelter.» Arseniew, Nicolai von: Das Kreuz im Osten. Vom Martyrium der russischen Kirche. In: MNN Nr. 186 vom 07.07.1926, $1 \mathrm{f}$.

113 Einige der am eindrucksvollsten bebilderten Schauprozesse wurden beispielsweise gegen einen katholischen Prälaten und auch den katholischen Erzbischof von St. Petersburg geführt. Dieser Prozess erschien sogar auf der Titelseite der BIZ: Anon.: Politische Schreckensurteile. Die Verhandlungen vor dem Moskauer Revolutionsgericht gegen die katholischen Geistlichen, von denen der Prälat Budkiewicz zum Tode verurteilt und erschossen, der Erzbischof von Petersburg zu langer Zuchthausstrafe verurteilt wurde. In: BIZ, 1923, Nr. 15, Titel.

114 Stefan Plaggenborg hat darauf hingewiesen, dass sehr viele Priester der russisch-orthodoxen Kirche gleichzeitig auch Konterrevolutionäre beziehungsweise Monarchisten waren und sich so der Kampf gegen die Kirche eher in den Kontext des "Roten Terrors" einordnen lasse. Vgl. Plaggenborg, Stefan: Ordnung und Gewalt. Kemalismus - Faschismus - Sozialismus. München 2012, $308 \mathrm{f}$. 
dem Kirchenkampf im »Dritten Reich« besteht im Ziel der Mittelbarmachung oder Zerstörung kirchlicher Strukturen.

$\mathrm{Zu}$ Zeiten des Bürgerkrieges stand die bolschewistische Konfrontation der russisch-orthodoxen Kirche bis auf vereinzelte antiklerikale Karikaturen in kommunistischen Illustrierten kaum im Fokus der deutschen Presse. ${ }^{115}$ Das erstaunt insofern, als bereits während der Oktoberrevolution massive Maßnahmen gegen das Personal und die Organisation der russisch-orthodoxen Kirche ergriffen worden waren. ${ }^{116}$ 1924, als mit der Machtübernahme Stalins die Repressalien gegen die Kirche breit in der Presse verhandelt wurden, äußerte sich mit Oswald Spengler einer der prägendsten rechtskonservativen Intellektuellen zur Verschmelzung von Politik und Spiritualität in der UdSSR. Das von Spengler ursprünglich dem schwedischen Svenska Dagbladet zum »russischen Problem ${ }^{117}$ gegebene Interview druckten die MNN ab.

Spengler beginnt mit der (fehlgehenden) Prognose, Trotzki würde in der Nachfolge Lenins als »der russische Napoleon [...] die in Rußland entfesselten Volkskräfte« und die pseudoreligiösen Ideale der Revolution über die sowjetischen Grenzen hinauszutragen suchen. Dass diese Ideale mit denen der westeuropäischen Sozialisten und Kommunisten harmonieren würden, bestreitet Spengler allerdings mit Hinweis auf den genuin russischen Wesenszug des bolschewistischen Sozialismus. »Der Unterschied« liege vor allem darin, »daß der Bolschewismus in Rußland [...] nunmehr von dem russischen Volke aufgenommen« und $\mathrm{zu}$ »einer mystischen Einheit mit den ursprünglichen sozialen Institutionen der Russen und mit deren ebenso ursprünglichen und lebendigen Religiosität verschmolzen « sei. ${ }^{118}$ Durch diese Metamorphose im Inkubationsraum Russland unterscheide sich der Bolschewismus entscheidend von seinen westeuropäischen Pendants:

»Während der westländische Sozialismus auch unter utopischen Zeitabschnitten abgesehen von gewissen rein persönlichen Phänomenen, eine ganz und gar materielle

115 Anlässlich der geplanten Beschlagnahmung des Kirchenschatzes zeigt die "Sowjetrußland im Bild « (SIB) 1921 in einer besonders beispielhaften dieser Karikaturen einen Verhungernden, der seine Hand flehend dem Patriarchen Tichon entgegenstreckt, auf dass ihm dieser seinen wertvollen Kelch überlasse. Die Karikatur ist folgendermaßen untertitelt: »Der Hungernde: `Gib ab den Kelch - verkauf das Gold - gib Brot! ২ Darauf der Patriarch (Oberster >Kirchenherr Rußlands): `Abgeben kann ich den Kelch nicht; denn siehe, in einer Stunde wirst Du ihn schon gebrauchen müssen, wenn ich Dir die letzte Oelung geben werde, zum Geleit ins Himmelreich.« Anon.: Zur Beschlagnahme der Kirchenschätze in Rußland. In: SIB, 1921, Nr. 10, 9.

116 Vgl. Skarovskij, Michail: Die russische Kirche unter Stalin in den 20er und 30er Jahren des 20. Jahrhunderts. In: Hildermeier, Manfred (Hg.): Stalinismus vor dem Zweiten Weltkrieg. Neue Wege der Forschung. München 1998, 233-253, hier 233.

117 Anon.: Das russische Problem. Eine Unterredung mit Dr. Spengler. In: MNN Nr. 306 vom 09.11.1924, $1 \mathrm{f}$.

118 Ebd., 1. 
Bewegung ist, darauf angelegt, ein demokratisches Ideal des größtmöglichen Nutzens für eine größtmögliche Anzahl zu verwirklichen, ist der russische Bolschewismus seinem Wesen nach eine religiöse Bewegung. Und der russische kann am ehesten mit dem der Wiedertäufer und der ersten Christen verglichen werden. ${ }^{119}$

Nicht die sozialistischen Ideen seien Spengler zu Folge der entscheidende Faktor in der Genese des Bolschewismus gewesen - schließlich hätten diese auch in Westeuropa existiert -, sondern deren kulturelle Adaption im spirituell geprägten Russland. Spenglers Geschichtsdeterminismus wird in seiner Aussage deutlich, die russische Geschichte habe niemals dem Ziel einer aufgeklärten Zivilgesellschaft zugestrebt, sondern sei nunmehr in ihre ureigenen Bahnen zurückgekehrt:

"Was in Rußland geschah, ist die Rückkehr der russischen Seele zu ihren eigenen Voraussetzungen. Das Rußland Peters d. Gr. und Katharinas II. war ein vergeblicher Versuch, die Russen zu Weltländlern zu machen, eine Abirrung von dem eigenen Weg russischer Geschichte. Was wir jetzt sehen, ist der Sieg der Dostojewski-Richtung über die westliche Orientierung. Der Bolschewismus war gewiß eine westländische Bewegung, und ihre Führer sind und waren ihrer Geistesrichtung nach Westeuropäer, aber wie bei der Romanisierung Galliens der germanische Einschlag den Kulturformen einen ganz anderen Charakter verlieh, so haben die Russen den Bolschewismus nach ihrem eigenen Wesen umgeschaffen. ${ }^{120}$

Nicht nur aus intellektueller Perspektive lässt sich das Motiv der direkten politisch-ideologischen Konkurrenz zwischen der Kirche und den Bolschewiki im Diskurs der Weimarer Massenmedien ersehen. Der russisch-orthodoxe Theologe und Publizist Nikolaus von Arseniew, 1918 aus Moskau nach Königsberg geflohen, ${ }^{121}$ veröffentlichte in den MNN einen Gastbeitrag, in dem er eine (exil-)russische Lesart der Konstellation liefert. Das »Martyrium der russischen Kirche « ${ }^{122}$ rühre von ihrer geistigen Macht, die zu erringen aber eines der dringlichsten Ziele der Bolschewiki sei. »Wäre sie [die Kirche, D.F.] nicht eine geistige Macht und zwar ersten Ranges, so wäre sie nicht gegenwärtig so gehaßt, so verfolgt und so gefürchtet seitens der bolschewistischen Regierung. ${ }^{123}$

Seit der Machtübernahme Stalins, habe sich »das wahre Gesicht des Bolschewismus vollkommen geoffenbart« und es habe sich herausgestellt, »daß der Bolschewismus weit mehr als nur sozial-politisches Programm, sozial-politische Erscheinung, weit mehr als Kommunismus oder Sozialismus« sei, sondern

119 Ebd.

120 Ebd., 2.

$121 \mathrm{Zu}$ den biografischen Angaben vgl. Erler, Rolf-Joachim (Hg.): Karl Barth - Charlotte von Kirschbaum. Briefwechsel. Bd. 1 (1925-1935). Zürich 2008, 148.

122 Arseniew, Nikolaus von: Das Kreuz im Osten, 1.

123 Ebd. 
»in erster Linie eine Weltanschauung und das ist das Hauptsächliche, das Wichtigste an ihm. ${ }^{124}$ Die Unterstützung atheistischer und antireligiöser $\mathrm{Pu}$ blikationstätigkeit und Bildungseinrichtungen durch den zuständigen Volkskommissar Anatoli Lunatscharsky diene nur dem Zweck, den Glauben an irgendetwas außerhalb der Weltanschauung der Bolschewiki zu zerstören. ${ }^{125}$

In Tageszeitungen und Illustrierten wurde das sich ab Mitte der 1920er Jahre verfestigende Bild von der »natürlichen Feindschaft« des Bolschewismus zur russisch-orthodoxen Kirche vielfach reproduziert. ${ }^{126}$ Auch Berichte über die planmäßige Umsetzung antireligiöser Politik (»Gottlosen-Fünfjahresplan«), ${ }^{127}$

\section{Ebd.}

125 »Und das Zentrum [...] dieser Weltanschauung ist Haß gegen Gott, gegen alles göttliche, gegen eine objektive höhere bindende Moral, gegen eine höhere Weltordnung. >Unsere Aufgabe`, schreibt die bolschewistische Regierung in einer offiziellen Kundgebung, >ist nicht diejenige irgendeiner Reform, sondern einer völligen Vernichtung jeglicher Religion, jeglicher Moral.^ (Angeführt bei Marc Cramer, L’internationale Bolchévique contre la religion. Genéve. 1925. S. 19). Lunatscharsky, bolschewistischer Kommissar für Volksaufklärung, schreibt als Einleitung zur Zeitschrift >Der Gottlose`: IIch wünsche von ganzem Herzen >dem Gottlosen vollen Erfolg in seinem Kampf gegen das widerliche Gespenst der Gottheit...< usw. Der Bolschewismus will das Göttliche ausrotten aus dem Bewußtsein der Menschheit, darum so wichtig für ihn, ja am wichtigsten, wie er selbst verkündet, ist die >pädagogische Frontr. Es soll eine neue Menschheit herangezüchtet werden, die vollständig von der Idee der Gottheit befreit ist. Denn dies ist der Feind, der auf diesem oder jenem Wege - vernichtet werden muß, und in erster Linie das Christentum. Ihm gilt der stärkste Kampf, der beste, unversöhnlichste Haß des Bolschewismus, besonders in der Gestalt der russischen Kirche.« Ebd., 2.

126 So schreibt Erhard Schlund in den MNN noch 1932 über das Verhältnis zwischen Staat und Kirche in der Sowjetunion: "Der neue Staat, der Staat der bolschewistischen Revolution mußte mit psychologischer Notwendigkeit ein Gegner der Kirche sein. [...]. Wenn der Bolschewismus mit seinem Sowjetsystem sich halten und durchsetzen wollte, dann mußte er sich gegen die zarentreue Kirche wenden [...]. Kirche und Bolschewismus hätten niemals Freunde werden können. Der Bolschewismus ist bewußt und gewollt Materialismus, reinster und extremster Materialismus. Dazu kommt, daß der Bolschewismus zum Kollektivismus fortschreiten, also das Individuum und den Individualismus bekämpfen mußte. Er muß also auch eine Institution bekämpfen, die namentlich den seelischen Wert des Individuums betont. [...]. Eine Kirche um die andere wurde weggenommen, ein Priester nach dem anderen verschickt oder hingerichtet."Schlund, Erhard: Bolschewismus und russische Kirche. In: MNN Nr. 43 vom 14.02.1932, $1 \mathrm{f}$.

127 »Im ersten Jahr (1932/33) soll ein genauer Plan für die Schließung aller Kirchen und Gebetshäuser aufgestellt werden, die praktisch bis zum Frühjahr 1937 beendet sein soll. Im zweiten Jahr (1933/34) sollen alle religiösen Zellen innerhalb der Familie >liquidiert werden und gleichzeitig alle religiös gesinnten Personen aus den staatlichen Aemtern und Betrieben entfernt werden. Die gesamte religiöse Literatur und alle religiösen Kulte sollen verboten werden. Das dritte Jahr (1934 bis 1935) dient der Aktivierung der Gottlosenzellen. Bis dahin sollen mindestens 150 religionsfeindliche Filme hergestellt sein, die insbesondere zur Vorführung in den Schulen bestimmt sind. Alle Diener religiöser Kulte, die sich weigern, ihr geistliches Amt aufzugeben, sollen aus der Sowjetunion verbannt werden. Im vierten Jahr (1935/36) soll die Uebergabe aller Kirchengebäude, Synagogen und Kapellen, an die Ortsbehörden und ihre Umwandlung in Lichtspiel- 
ihre symbolhaft inszenierten Exzesse, ${ }^{128}$ sowie deren in Deutschland durch zahlreiche Exilanten erfahrbaren Konsequenzen stellten den Aspekt der ideologisch-religiösen Konkurrenz regelmäßig heraus. ${ }^{129}$

Zum Abschluss bleibt die Frage nach der Wahrnehmung des Kirchenkampfes seitens der nationalsozialistischen Presse. Die persönlichen Ansichten Adolf Hitlers hinsichtlich der Rolle der Kirchen als angebliche Bewahrer einer morschen Ordnung, die sich aus Hitlers Sicht dem »Angriff der Weltanschauung ${ }^{130}$ und damit der Herrschaft der Ideologie am entschiedensten in den Weg stellen würden, kamen denen Stalins in der Tat sehr nahe. Ob es gerade wegen dieser ideologischen Überschneidung so lange gedauert hat, bis Zeitschriften wie der ILB auf die antiklerikalen Kampagnen der Bolschewiki reagierten, sei dahingestellt. Die Art der Reaktion legt diese Interpretation jedoch nahe.

Denn nicht die bolschewistische Religionsverfolgung an sich wird in einer Ausgabe des Jahres 1930 kritisiert, sondern die nicht parallel zur spirituellen Enteignung gelungene materielle Beglückung der Massen. Dass die ideologischen Ziele vor die materiellen gestellt würden, diskreditiere die Bolschewiki. Diese Kritik wird mal mit deskriptiv gehaltenen Berichten zum »Kirchensturm in der Sowjethölle « ${ }^{131}$ mal mit unbeholfen ironischen Referenzen zu den ständigen Hungersnöten zum Ausdruck gebracht. Die Bolschewiki hätten demnach zwar »die Gottesdienste verhöhnt und verboten «, »das kirchliche Inventar verbrannt und die Kirchen in Klubs verwandelt.« Dafür hätten sie aber

häuser, Klubhäuser usw. durchgeführt werden. Das letzte Jahr (1936/37) soll den Gottlosen-Fünfjahresplan zum Abschluß bringen, mit dem Ergebnis, daß jeder Gottesbegriff aus dem Herzen des Volkes ausgemerzt ist.« Anon.: Gottlosen-Fünfjahresplan in der Sowjetunion - Vollständige Ausrottung der Religion bis 1937 geplant. In: DAZ Nr. 492 vom 21.09.1932, 1.

128 Plakativ war unter anderem »Moskaus Kampf gegen das Weihnachtsfest«, der neben der Verweigerung einiger schulfreier Tage für die Kinder und Jugendlichen vor allem im strikt durchgesetzten Verbot jeglicher öffentlicher Religionsausübung, worunter sogar der Erwerb von Weihnachtsbäumen "unter Strafe wegen Waldfrevels« gestellt wurde. Vgl. Anon.: Moskaus Kampf gegen das Weihnachtsfest - Keine Schulferien über die Feiertage. In: DAZ Nr. 602 vom 24.12.1928, 1. Über die von der bolschewistischen Führung propagandaträchtig inszenierte Sprengung des Simonow-Klosters wurde mit so umfangreichem Bildmaterial in der BIZ berichtet, dass anzunehmen ist, die entsprechenden Bilder seien mit hohem Aufwand produziert und breit zirkuliert worden. Anon.: Kampf gegen die Kirche in Sowjet-Russland. In: BIZ, 1930, Nr. 7, 244 (Jahresausgabe).

129 Unter anderem: Anon.: Bei den russischen Auswanderern in Kiel - ein Besuch im Lagerhaus am Nordhafen - Was die Auswanderer von den grausigen Zuständen daheim und vor Moskau erzählen. In: DAZ Nr. 532 vom 15.11.1929, 2; Ehlers: Das heilige Rußland im Exil. In: MIP, 1931, Nr. 40, $1276 \mathrm{f}$.

130 Hitler, Adolf: Der Angriff der Weltanschauung. In: ILB, 1931, Nr. 24, 501 (Jahresausgabe).

131 Bruger, Ferdinand: Der Kirchensturm in der Sowjethölle. In: ILB, 1930, Nr. 6, 91 f. 
auch »das ständige Fasten eingeführt [u]nd die Anzahl der Kreuze im ganzen Reich ins unendliche [sic] vermehrt. ${ }^{132}$

Die Lesart des sowjetischen »Kirchenkampfes« als bloße Variante des später von Hitler im ILB ausgerufenen "Angriffs der Weltanschauung ${ }^{133}$ wird weder thematisiert noch angedeutet. Selbst die Verquickung von Antisemitismus und Antiklerikalismus, die die Propagandaoffensive gegen Kirche und Religion durchzieht, stößt im ILB nicht auf Zustimmung. Stattdessen erklärt man die Diskreditierung des christlichen Glaubens in antiklerikalen Karikaturen zum Ausweis bolschewistischer Wertenegation. Letzteres liegt sicherlich im Wissen um den Einfluss der beiden großen Kirchen auf in kommenden Wahlen noch zu erobernde Milieus begründet.

Man erregt sich im ILB besonders über in der Sowjetpresse zirkulierende Karikaturen, die das Christentum als Trugbild darstellen, das nur dazu diene, Christen in die Falle des Kapitalismus zu locken. Die Karikatur oben rechts (Abb. 18) zeigt Jesus samt ihm folgenden Gläubigen, die am Ende einer Klippe in den Rachen eines als Jude stereotypisierten »Kapitalisten« stürzen. Die Bildunterschrift ignoriert dieses Detail vollends: „Das Plakat stellt die Masse der Gläubigen dar, wie sie Jesus Christus nachzufolgen versuchen, dabei aber in den Rachen des Kapitalismus stürzen. " ${ }^{134}$ Auch in der Karikatur darunter folgen Gläubige, gebeugt unter der Last eines Kreuzes, dem Erlöser und verkennen in ihrer Mühsal den auf dem Kreuz thronenden, mittels physiognomischer Kodierung als Jude gekennzeichneten »Kapitalisten«, der jeden Einzelnen am Gängelband hält. Ähnliche Karikaturen, teilweise auf den Titelseiten des ILB nachgedruckt, ${ }^{135}$ weisen dieselbe »Blindheit« für das in bolschewistischer Kirchenkritik prononcierte antijüdische Klischee auf.

Dass die angeblichen »Sowjetjuden « analog zu den Nationalsozialisten systematisch antikapitalistische, antisemitische und antichristliche Propaganda miteinander verwoben, bedeutete für die Macher des ILB, ihrerseits bestens vertraut mit dem visuellen Vokabular antijüdischer Demagogie, ein Problem: Dem Publikum hätte die Trennschärfe zwischen NS-Bewegung und Bolschewiki abhandenkommen können. Diese Feindschaft jedoch war für die Selbstbeschreibung ihrer Parteigänger essentiell. So wurde nicht nur die von der Propaganda beider Ideologien verbreitete Judenhetze vorsichtshalber ignoriert. Auch die aus dem Konstrukt des Judäo-Bolschewismus stammende Assoziation von Bolschewismus und Judentum wurde entgegen der visuellen

132 Anon.: Die Bolschewisten und die christliche Religion. In: ILB, 1930, Nr. 13, 205 f.

133 Hitler: Der Angriff der Weltanschauung, 501.

134 Anon.: Der Kampf der Sowjetjuden gegen die christliche Religion. In: ILB, 1930, Nr. 16, 252 (Jahresausgabe).

135 U. a. Anon.: Der Sowjetkrieg gegen Gott. Eines der typischen antireligiösen Plakate der Sowjetregierung in ihrem unerhörten Kampf gegen das Christentum. In: ILB, 1930, Nr. 21, Titel. 
Darstellung in den Vordergrund gerückt. »In alledem «, so wird ausgeführt, zeige sich »immer wieder der abgrundtiefe uralte jüdische Haß gegen alles Nichtjüdische und insbesondere gegen das Christentum. ${ }^{136}$

Im Vergleich nimmt sich die Berichterstattung zur Religion in Amerika in »säkularen" Zeitungen und Illustrierten sehr knapp aus. So wurde zwar die Fremd- und Selbstbeschreibung Amerikas als »Gottes eigene Staaten $«{ }^{137}$ leicht abfällig thematisiert und technische Innovationen in Gottesdiensten besprochen. ${ }^{138}$ Eine Kontroverse oder ideologische Aufladung, wie sie sich in der Betrachtung der Sowjetunion zu diesem Thema ergab, kam dabei jedoch nicht zustande. In anderen Organen, vor allem aus dem katholischen Milieu, wurden derartige Themen ungleich breiter und mit einer höheren Relevanz für die Selbstkonzeption des Publikums behandelt. ${ }^{139} \mathrm{Da}$ den Vereinigten Staaten die Trennung von Kirche und Staat ein Gründungsauftrag war und die „Civil Religion« einen säkularen politisch-öffentlichen Raum für gemeinschaftsstiftende Performanz ermöglichte, kollidierten beide Gesellschaftsbereiche weder weltanschaulich noch politisch. Auch in der medialen Betrachtung spielten derartige Konflikte mit Blick auf die USA keine Rolle.

\subsection{Zusammenfassung}

In der Gesamtschau stellt sich die Debatte über die politischen Ordnungen der USA und der Sowjetunion in den Massenmedien der Weimarer Republik in einem doppelten Konsens dar. Dieser nahm die Integrität, Funktionsfähigkeit und Konsistenz des amerikanischen Systems demokratischer Legitimation und - insbesondere visuellen - Kommunikation an. Auch bestand weitgehender Konsens darüber, es in der Sowjetunion mit einem politischen System zu

136 Anon.: Der Kampf der Sowjetjuden gegen die christliche Religion. In: ILB, 1930, Nr. 16, 252.

137 Unter anderem: Hausleiter, Leo: Gottes eigene Staaten. In: MIP, 1931, Nr. 39, 1221-1237 (Jahresausgabe).

138 Anon.: Religion und Rundfunk. In: ILB, 1928, Nr. 19, 235 (Jahresausgabe).

139 Das bekannteste Beispiel hierfür ist die Zeitschrift »Abendland«, deren katholisch-klerikales Publikum sich ebenso wie die Herausgeber trotz der mehrheitlich protestantischen Konfession der Amerikaner für die in den USA trotz der Trennung von Staat und Kirche im täglichen Leben »des Amerikaners« omnipräsente und kulturell überaus prägende Religiosität interessierte. Auf der anderen Seite kritisierte man (auch unter Bezug auf die Vereinigten Staaten) mit Aufklärung und Nationalismus zwei Grundfesten der "Civil Religion" und definierte sich somit gegen die amerikanische Moderne. Vgl. Conze, Vanessa: Abendland. In: Europäische Geschichte Online (EGO), hg. vom Leibniz-Institut für Europäische Geschichte (IEG). Mainz 2012. URL: http://www.ieg-ego.eu/conzev2012-de (am 17.11.2015), $7 \mathrm{f}$. In beiden Fällen aber dienten die USA als Bezugspunkt für diese und andere Veröffentlichungen und damit auch für die durch sie geschaffenen Teilöffentlichkeiten. 


\section{Der Rampf \\ Sowjetjuden oxern die driftlíde Religion}

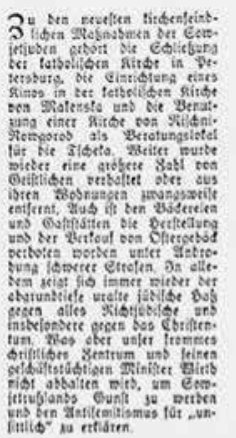

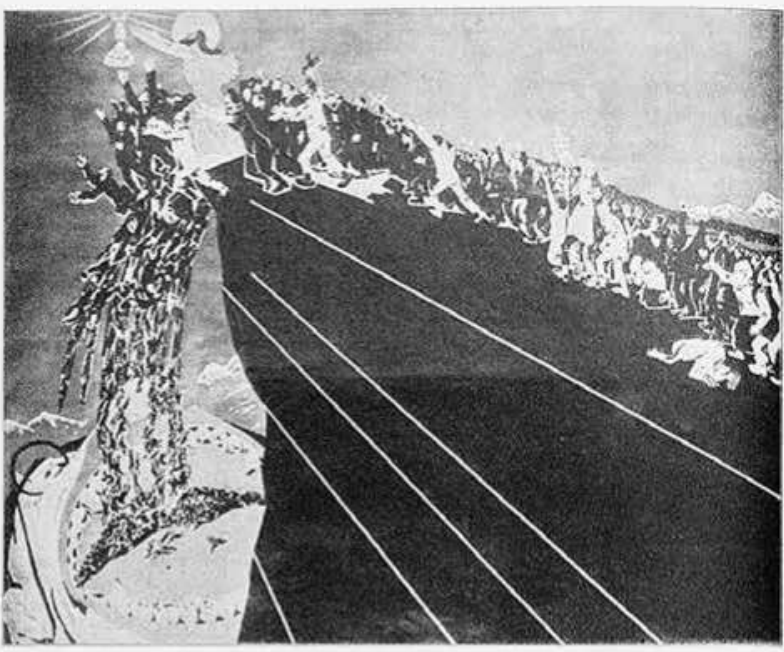

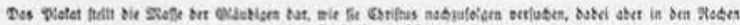
Bes Rapitatisavs tirjen.

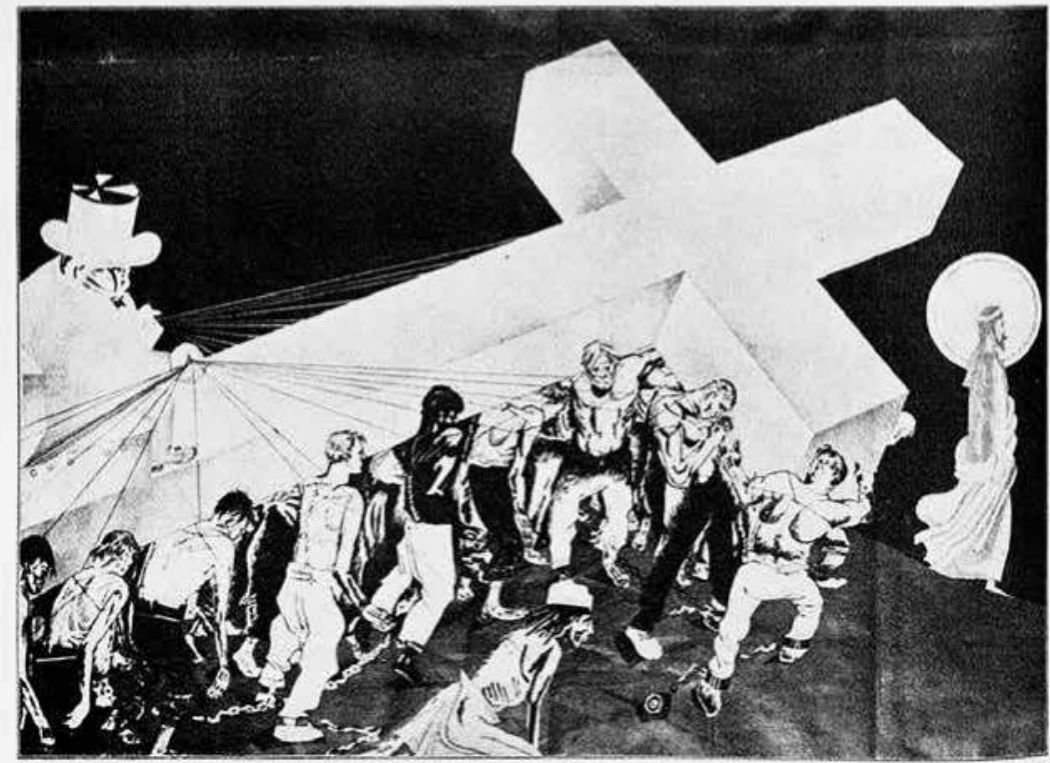

Der zrienob bes cbrilicatans"

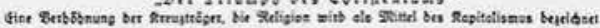

Abb. 18: Anon.: Der Kampf der Sowjetjuden gegen die christliche Religion. In: ILB, 1930, Nr. 16, 252. Aus bolschewistischen Karikaturen leitete der nationalsozialistische Illustrierte Beobachter einen »jüdisch-bolschewistischen« Kampf gegen das Christentum ab - obwohl auch die bolschewistischen Karikaturen mit antisemitischen Stereotypen operierten. 
tun $\mathrm{zu}$ haben, welches sich nicht durch »westliche« Kategorien und Konzepte wie Demokratie oder Gewaltenteilung beschreiben ließ und dessen Führung sich selbst gegen diese Konzepte definierte.

Der stete Abbau demokratischer Teilhabe in der Sowjetunion erschien in der Weimarer Berichterstattung als logische Konsequenz aus den ideologischen Grundsätzen der Bolschewiki, weshalb der totalitäre Umbau Russlands zu einer Parteiendiktatur kaum problematisiert wurde. Die stalinistische Repression erschien in diesem Lichte gleichsam als zentrales Prinzip des bolschewistischen Modernitätsprojekts, nicht etwa als Abkommen vom Entwicklungspfad hin zu einer Demokratie westlicher Prägung. Es wurde als das Beschreiten eines vollkommen anderen Weges zur Umformung der Gesellschaft unter ausschließlich nach ideologischen Grundlagen ausgerichteten Prämissen wahrgenommen, die Repression, Gewalt und Autoritarismus als durch den ideologischen Zweck geheiligte Mittel ansahen. ${ }^{140}$

In diesen Kontext lässt sich auch der sowjetische "Kirchenkampf» einordnen, der sich zu einer Konfrontation auf politisch-ideologischer Ebene entwickelte und in einer Verbannung der Kirche aus dem öffentlichen Raum und der Hegemonie der Bolschewiki resultierte. In der aufmerksam verfolgten Konfrontation der Sowjetmacht mit der russisch-orthodoxen Kirche stellt sich die UdSSR als unaufgeklärtes politisches System dar. Statt eine Entwicklung der Zivilgesellschaft durch die Schaffung eines säkularen Staates anzustoßen, ersetzte sie schlicht die unaufgeklärte Autorität der Religion durch die ebenso unhinterfragbare Autorität der Ideologie.

140 Dazu: Shearer, David: Stalinist Repression, Modernity, and the Social Engineering Argument. In: Harris, James (Hg.): The Anatomy of Terror. Political Violence Under Stalin. Oxford 2013, 105-119, hier $107 \mathrm{f}$. 


\section{Sport, Jugend und Bildung: Fundamente der neuen Zeit}

Das ohnehin starke Augenmerk auf das Modernitätsphänomen »Masse«, den auf wirtschaftlichem, sozialem und kulturellem Felde raumgreifenden Kollektivismus in der Sowjetunion und sein Pendant in der amerikanischen Massenkultur zeitigte in der deutschen Presse großes Interesse an den dortigen Massendarbietungen und - insbesondere sportlichen - Massenveranstaltungen. Auch der in beiden Ländern öffentlich zelebrierte Sport samt seiner modernen Sportheroen war in Deutschland längst populär geworden. ${ }^{1}$

Gleichgeschaltete Bewegungsabläufe, vorgeführt von jungen Menschen mit gesunden Körpern, dienten nicht bloß der körperlichen Ertüchtigung der Teilnehmer. Sie stellten ein sowohl metaphorisch verstandenes als auch praktisch wirksames Instrument zur Gesunderhaltung und Mittelbarmachtung des »Volkskörpers« dar, zu dessen Anwendung man sich zum Wohle der Allgemeinheit durchaus verpflichtet sehen konnte. ${ }^{2}$ Derlei Darbietungen spielten in der Performanz und Perzeption des biologistischen Konstrukts »Volkskörper« eine wichtige Rolle. Die Ideologisierung des Körpers, die sich vom »Maschinenmenschen " in der Fabrik bis zur öffentlich zelebrierten Athletik der Massen durch die Gesellschaften der klassischen Moderne zog, erschütterte auch die körperliche Privatheit.

In die Idealvorstellung eines gesunden »Volkskörpers « waren die Jugend, also Personen zwischen dem dreizehnten und einundzwanzigsten Lebensjahr, als dessen vornehmlicher Träger sowie deren Bildung und ideologische Formung integriert. ${ }^{3}$ Ihre physische und intellektuelle Stärkung kam der Wertigkeit einer Gesellschaft aus der zeitgenössischen, noch immer maßgeblich von eugenischen Vorstellungen geprägten Perspektive direkt zugute. Gerade im Kontext von Gesellschaftsentwürfen wie dem nationalsozialistischen oder bolschewistischen gewann der Gesamtthemenkomplex Jugend hohe Relevanz für ideologisch geführte Erneuerungsdiskurse.

1 Dazu: Scharenberg, Swantje: Die Konstruktion des öffentlichen Sports und seiner Helden in der Tagespresse der Weimarer Republik. Paderborn u. a. 2012.

2 "The idea of sport as a duty was prevalent, and sports scholars focused constantly on cultivating a sense of fitness-duty on a mass-scale. This image of the Volk as a regiment to be marshaled and a patient to be treated is all the more disturbing when one brackets it with the World War I-era rhetoric of heroism and the Nazi vision of a strong, contaminant-free national body, but it is also in keeping with concerns about racial hygiene and national strength that had significant currency during the republic itself.« Rippey, Theodore: Athletics, Aesthetics, and Politics in the Weimar Press. In: German Studies Review, Bd. 28, Nr. 1 (2005), 91.

3 Vgl. zur genauen Eingrenzung der Gruppe der Jugendlichen: Schubert, Klaus/Klein, Martina: Das Politiklexikon. Bonn 2007, 152. 
Doch auch in den demokratisch gefestigten Gesellschaften Westeuropas und der Vereinigten Staaten wuchs die Bedeutung, die man der Jugend - insbesondere der körperlich leistungsfähigen - als Träger gesellschaftlichen Fortschritts zuschrieb. ${ }^{4}$ Die metaphorische Bedeutung der Jugend für nationale Narrative war von der Jahrhundertwende zur Zwischenkriegszeit hin länderübergreifend gewachsen und nicht nur Projektionsfläche für »Volkskörper«-Vorstellungen totalitärer Ideologen. ${ }^{5}$

Mit dieser hohen Relevanz für nationale Narrative ging auch die prominente Stellung des Themenfelds Jugend innerhalb spezifischer Debatten über die Weiterentwicklung von Gesellschaft einher. In Deutschland rief der krisenhafte Übergang zur Republik zudem begründete Sorgen vor einer politischen Indoktrinierung der Jugend hervor, welche in der Fremdbetrachtung der USA und der Sowjetunion verarbeitet wurden.

Die Aspekte Jugend, Bildung und Sport waren zum einen auf der Metaebene miteinander verwoben, wurden mitunter aber auch explizit aufeinander bezogen, wenn beispielsweise die Bedeutung des amerikanischen Hochschulsports für die Charakterbildung junger Männer erörtert wurde. Debatten um die Rolle des Sports, die Situation der Jugend und die Verfasstheit des Bildungswesens verfügten über hohe gegenseitige Verweiskraft. Andererseits wiesen sie für sich genommen eine thematische Inhärenz innerhalb der Diskurse über Modernität auf - allein aufgrund der Nähe der Zeitkonzepte Jugend und Zukunft, Jugend und Moderne sowie ihres Charakters als Bedingungsfaktoren für die Realisierung jeglicher Gesellschaftsvisionen. In dieser logischen Verknüpfung zeigt sich die zwiespältige Position der Jugend in gesellschaftlichen und kulturellen Wandlungs- und Modernisierungsprozessen.

4 Vgl. insbesondere für das Beispiel der »Boy’s Clubs« in Großbritannien und der von ihnen transportierten Männlichkeitskonzepte: Tebbutt, Melanie: Being Boys. Youth, Leisure and Identity in the Inter-War Years. Manchester u. a. 2012, 91 f. Für die Vereinigten Staaten und die stark gestiegene Bedeutung der Jugend für die Selbstbeschreibung der amerikanischen Gesellschaft seit Ende des Ersten Weltkriegs vgl. Modell, John: Into One's Own. From Youth To Adulthood In The United States 1920-1975. Berkeley u. a. 1989, $67 \mathrm{f}$.

5 »Youth assumed an important metaphorical significance in the inter-war years, particut larly in the early 1920s as nationalist, political, religious and military movements across Europe idealized young people as a force for change and moral regeneration, and educated and politicised youth gave literary vent to sgrievances` which helped to shape an sunprecedented opposition of sthe young ‘ and sthe old ‘." Tebbutt: Being Boys, 44. Dass die Unterordnung des Lebens unter die Erfordernisse der "modernen Zeit» auch nicht vor den Lebensphasen von Kindern und Jugendlichen haltmachte, drückt sich in der historischen Kindheitsforschung auch im Schlagwort der "fordistischen Kindheit« aus. Vgl. Schubert, Volker: Die fordistische Kindheit. In: Baader, Meike/Eßer, Florian/Schröer, Wolfgang (Hg.): Kindheiten in der Moderne. Eine Geschichte der Sorge. Frankfurt a. M. 2014, 226-256. 
Hinsichtlich des sowjetischen Beispiels wurden Jugendliche und junge Menschen als Erschaffer und Erschaffene des Sozialismus bezeichnet, ${ }^{6}$ was im größeren Zusammenhang gesellschaftlicher Erneuerung ebenso auf die USA und Deutschland zutraf. So ist die Jugend zwar das tragende Element der aktiven Umsetzung von Moderne. Gleichzeitig ist sie deren Gestaltungskraft unmittelbar als Objekt ausgesetzt, weshalb Modernisierungsprozesse insbesondere auch in der Gesellschaft der Weimarer Republik mit ihren im Vergleich zum Kaiserreich schwachen sozialen Relais-Mechanismen ungefiltert auf sie einwirkten. Diese Unmittelbarkeit bestand (und besteht ebenso heute) in der altersbedingten Unfähigkeit, die »eigene« Zeit vergleichend gegen die Erfahrung bereits erlebter Zeit lesen zu können, wie dies Zeitkritiker, die generationell älteren Kohorten angehörten im öffentlichen Raum weidlich taten.

\subsection{Sport und Körperkult(ur)}

Einer dieser Zeitkritiker war Siegfried Kracauer (Jahrgang 1889). ${ }^{7}$ In seiner hier bereits zitierten Polemik "Das Ornament der Masse« kritisierte er nicht nur wirtschaftsphilosophische Fehlentwicklungen und die kulturellen Schneisen, welche diese durch moderne Gesellschaften zogen. Er erblickte auch in der aufkommenden Begeisterung für Körperkultur und sportliche Großveranstaltungen Omina einer sich Bahn brechenden Ideologisierung des Massengedankens. So seien zwar all die »Preislieder auf die Körperkultur [...] als Ideologien leicht zu durchschauen ${ }^{8}$. Aber die aus unbedarfter Sicht eher harmlos erscheinende »rhythmische Sportgymnastik« habe »über die Privathygiene hinaus das Ziel, [...] Seelengehalte auszudrücken, zu denen [...] nicht selten noch Weltanschauungen mitgeliefert" würden.

Kracauer ging von einem über die Ästhetik harmonisierter menschlicher Bewegung hinausgehenden Aussagegehalt des massenhaften Sport- und Gymnastikbetriebs für den Zeitgeist aus. Sport vollzieht sich gemeinhin als soziales Handeln, ist durch Traditionen geprägt, lädt aber vor allem zu zeitgeistiger

6 Hilary Pilkington folgte diesem Leitmotiv einer Doppelrolle aus »constructors « und »constructed« durch ihre Gesamtbetrachtung russischer beziehungsweise sowjetischer Jugendlicher, deren Abschnitte zur Rolle der Jugendlichen und jungen Menschen in Lenins programmatischen Überlegungen, während der Revolutionszeit und in den Aufbaujahren der Sowjetunion für die hier vorliegende Arbeit am wertvollsten sind. Vgl. Pilkington, Hilary: Russia's Youth and its Culture. A Nation's Constructors and Constructed. London u. a. $1994,46 \mathrm{f}$.

7 Vgl. Witte, Karsten: Kracauer, Siegfried. In: Neue Deutsche Biographie, Bd. 12. Berlin 1980, $630 \mathrm{f}$.

8 Kracauer, Siegfried: Das Ornament der Masse - II. In: FZT Nr. 423 vom 10.06.1927, $1 \mathrm{f}$. 
politischer Sinngebung ein. Das hier bereits thematisierte Konzept des neuen Sowjetmenschen verweist beispielsweise auf den instrumentalisierten Sport der Sowjetunion. So war es dort Konsens, dass nur junge, durchtrainierte Menschen jener in die Programmatik der Bolschewiki eingegangenen Utopie zur Umsetzung würden verhelfen können. ${ }^{9}$ Der Sozialismus sollte von einer "sportiven Gesellschaft" getragen sein. ${ }^{10}$

Anlass, ideologische Sinngehalte und Massengymnastik aufeinander zu beziehen, gaben Fotobeiträge wie derjenige von einer Jugendturnveranstaltung vor dem Winterpalais zu St. Petersburg (Abb. 19). Die aus Menschen - vielmehr aus deren ihrer Individualität beraubt scheinenden Körpern - gebildete Sternformation versinnbildlicht das Aufgehen des Individuums »im Zeichen" einer auf die Mittelbarmachung der Massen ausgelegten Ideologie. Das spielerisch wirkende Vorturnen der Jugendlichen überdeckt dies nur notdürftig. Selbst in diesem sorgfältig inszenierten Visual ist an den zahlreichen Choreografen und ringsherum positionierten roten Fahnen gut zu erkennen, dass die jugendlichen Turner nur Mittel zum Symbolzweck sind: jederzeit versetzbar für den höheren bolschewistischen Sinn, dem sie huldigen. ${ }^{11}$ Sie sind Kommunikationsmittel, weniger noch, Bauteil eines solchen. Der großflächige Einsatz von Massenfesten diente der politischen Kommunikation, der »inneren Sowjetisierung «. Er war sowohl räumlich, vom Zentrum Moskau zu den Peripherien, als auch machtvertikal zur Harmonisierung des Gegensatzes zwischen dem Herrschaftsanspruch der Bolschewiki und dem Gemeinschaftssinn in der sowjetischen Gesellschaft hin ausgerichtet. ${ }^{12}$

9 "Once in power, the Bolsheviks set about turning the myth of the New Person into reality. Ever-changing needs and circumstances, however, resulted in diverse interpretations of what precisely constituted this new being. The general consensus was that he or she would be young and physically fit." O'Mahony, Mike: Sport in the USSR. Physical Culture - Visual Culture. London 2006, $22 \mathrm{f}$.

10 Vgl. Katzer, Nikolaus: Die sportive Gesellschaft als ideale Ordnung. Zum sowjetischen Konzept der Körperkultur. In: Pietrow-Enker, Bianka (Hg.): Russlands imperiale Macht. Integrationsstrategien und ihre Reichweite in transnationaler Perspektive. Köln u. a. 2012, 85-102, hier $87 \mathrm{f}$.

11 Wobei davon auszugehen ist, dass solcherlei Huldigungen nicht immer freiwilligem Engagement entsprangen, sondern durch gewisse Zwangsmaßnahmen an Kindern und Jugendlichen erzwungen wurden, welche sich solchen Veranstaltungen entzogen. Dazu passend schrieb zwei Jahre zuvor die VZT: »In den Schulen wird bolschewistische Propaganda getrieben, die Kinder werden gezwungen, an allerlei bolschewistischen Feierlichkeiten teilzunehmen. Als im Frühling des vergangenen Jahres eine englische Arbeiterdelegation Petersburg besuchte, waren alle Schulkinder der Stadt verpflichtet, an der Manifestation auf dem Platz vor dem Winterpalais teilzunehmen. Die Säumigen wurden mit der Entziehung des Frühstücks für die Dauer einer Woche bestraft. Anon. (B.E.): Bildungsnotstand im bolschewistischen Rußland. Die Lage der Gelehrten. In: VZT Nr. 123 vom 15.03.1921, 9 .

12 Vgl. Rolf, Malte: Das sowjetische Massenfest. Hamburg 2006, 108-117 und 156-278. 


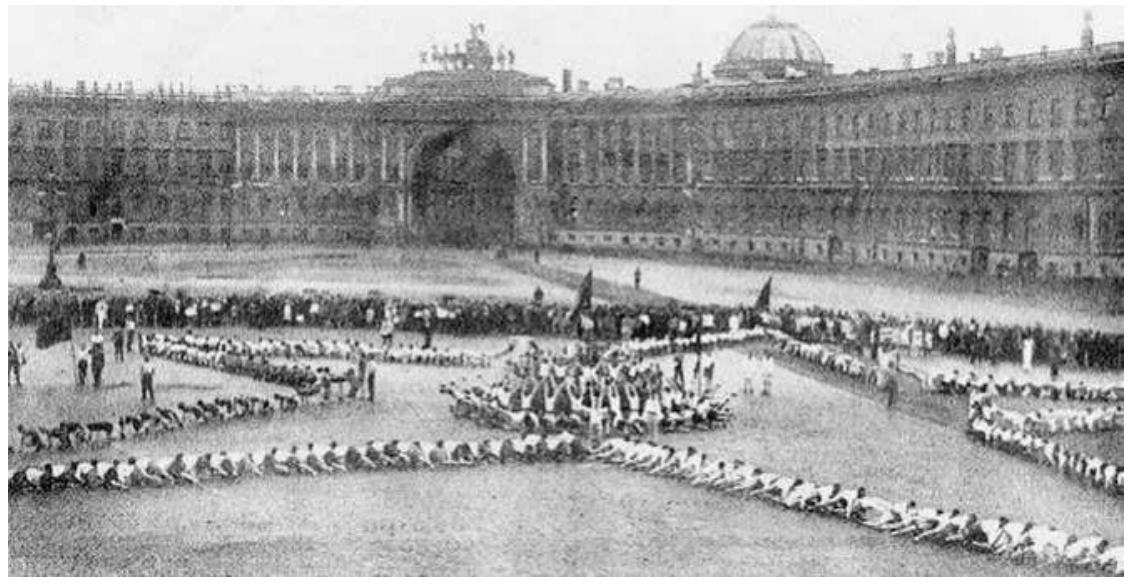

Abb. 19: Anon.: Aus Sowjet-Rußland: Eine Jugendorganisation bei Turnspielen vor dem Winterpalais in St. Petersburg. In: BIZ, 1923, Nr. 37, 734 (Jahresausgabe). Die einzelnen Jugendlichen gehen im politisch-ideologischen Symbol des Sowjetsterns auf.

Wie später auch im faschistischen Italien und dem nationalsozialistischen Deutschland wurde der Sport in der Sowjetunion konsequent vor den Karren der Politik gespannt. Die sich in der öffentlichen Zurschaustellung des politischen Systems durch Massenveranstaltungen ${ }^{13}$ manifestierende sowjetische Inszenierungsgesellschaft wurde in der Weimarer Presse zwar durchaus erkannt. ${ }^{14}$ Gleichwohl wurden ihre kritischen Aspekte nicht allzu tiefgreifend problematisiert, sieht man von allgemein orientierten zeitkritischen Warnungen eines Siegfried Kracauer und anderer ab.

Die Verquickung von Sport und Politik war in der Sowjetunion so eng, dass kaum ein Turn- oder Sportfest ohne politische Demonstration, aber ebenso fast keine politische Feier ohne dazugehöriges Sportfest auskam. Es liegt in der internationalen Orientierung der kommunistischen Bewegung und der

13 Dabei stellten derartige Massenveranstaltungen und politische Feste in Russland kein wirkliches Alleinstellungsmerkmal des politischen Systems der Sowjetunion dar. Bereits im Zarenreich waren öffentliche Massenveranstaltungen seitens der Eliten, also meist des Adels, gezielt zur politischen Kommunikation und zur klassischen Prachtentfaltung gegenüber dem Volk genutzt worden. In Ausmaß und dem Grad ideologischer Aufladung erreichten die sowjetischen Massenfeste allerdings bis dahin unerreichte Ausmaße. Vgl. Rolf, Malte: Soviet Mass Festivals. 1917-1991. Pittsburgh 2013, hier insbesondere 17-63.

14 Der Begriff der Inszenierungsgesellschaft wurde von Herbert Willems und Martin Jurga geprägt und bezieht sich auf die öffentlich inszenierte legitimatorische Selbstdarstellung politischer Regime und den ihnen zugrundeliegenden Ideologien. Vgl. Willems, Herbert/Jurga, Martin (Hg.): Inszenierungsgesellschaft. Ein einführendes Handbuch. Opladen 1998, $9 \mathrm{f}$. 
nicht geringen Größe ihrer Anhängerschaft im Deutschen Reich begründet, dass auch dort Veranstaltungen des "Arbeitersports« großen Anklang fanden. Die kommunistische Presse berichtete naturgemäß breit darüber und erklärte die Bolschewiki richtiggehend zu den »Schöpfern« des Massensports in Russland. ${ }^{15}$

Vornehmliches Ziel der mehrseitigen Reportagen war es laut AIZ, aufzuzeigen, »daß die Arbeitersportbewegung für das Proletariat Möglichkeiten genug « biete, "nach der Fron in Werkstatt und Bureau [...] Körper und Geist aufzufrischen und zu kräftigen. ${ }^{16}$ Im selben Bericht geht die Zeitschrift jedoch auch auf die über die Erholung des geschundenen Arbeiterkörpers hinausgehenden Implikationen politisch organisierten Massensports für alle Bereiche der sowjetischen Gesellschaft ein: »[K]eine Schule, keine Fabrik, kein Truppenteil ohne besondere Abteilung für Körperkultur und Sport. ${ }^{17}$ Der süffisanten Bemerkung, der kapitalistische Profi-Sport sei lediglich »zur Anregung sonntagsbemüßigter Kleinbürger« nütze, folgt die unverhohlen vorgetragene Zielvorstellung organisierten Massensports in der Sowjetunion:

"Oberstes Ziel sozialistischer Körperkultur ist die Durchbildung des menschlichen Körpers im Millionenmaßstabe [...]. Unmittelbarstes Ziel des roten Sportes ist die Ertüchtigung der Körper für Höchstleistungen auf dem Felde der Arbeit und - des Kampfes gegen die Feinde der Revolution. Diese Einreihung von Körperkultur und Sport in den Dienst der revolutionären Bewegung [...] verleiht dem russischen Sport seinen eigenartigen, mitreißenden Charakter. Die rote Armee spielt in der Sportbewegung eine ähnlich ausschlaggebende kulturelle Rolle, wie auf dem Gebiete der geistigen Aufklärung: kein Rotarmist verläßt die Truppe als Analphabet und ohne politische und sonstige Elementarkenntnisse. Gerade der rote Armeesport zeigt am ausgeprägtesten den Charakter des sozialistischen Sportes überhaupt, wenngleich mit Betonung seiner besonderen Aufgabe: Maßstab und Anhaltspunkte zu liefern für die Leistungsfähigkeit des menschlichen Körpers im militärisch-revolutionären Kampf.« ${ }^{18}$

So verfliegt noch im selben Artikel die den kommunistischen Massensport umwehende Aura der proletarierbeglückenden Erholungsveranstaltung, die ansonsten gerne konstruiert wurde. ${ }^{19}$ Stattdessen entsteht das Bild eines sportlich-ideologischen Komplexes, der dem Sport die Rolle des gesellschaftlichen

15 Z.B.: »Vor dem Kriege wurde in Rußland kein Sport betrieben. Erst die Eroberung der politischen Macht durch die Arbeiter und Bauern schaffte auch die Voraussetzung für die körperliche Gesundheit aller Volksschichten. Anon: Sport. In: AIZ, 1927, Nr. 43, 12.

16 Anon.: Internationaler Arbeitersport. Zum 4. Reichs-Arbeitersporttag im Stadion am 22. Juni 1924. In: AIZ, 1924, Nr. 9, 8.

17 Ebd., 9.

18 Ebd.

19 Unter anderem: Anon.: Russischer Arbeitersport. In: AIZ, 1925, Nr. 10, 14. Und: Anon.: Wintersport in Sowjet-Russland. In: AIZ, 1929, Nr. 4, Titel. 
Multiplikators politischer Inhalte zuweist. Der ideologische Zweck des Massensports war die Erziehung des »neuen Menschen«. Bereits sehr früh, 1919, hatten deshalb die Bolschewiki die politische und operative Kontrolle der Sportverbände übernommen. ${ }^{20}$ Die Kommunikationsfunktion des Sports war von Beginn an eine der zentralen Strategien der Bolschewiki zur Durchherrschung ihres »Imperiums ${ }^{21}{ }^{21}$

Entsprechende Sportveranstaltungen lassen nicht nur optisch und programmatisch teils frappierende Ähnlichkeit mit den Inszenierungen der NSInitiative »Kraft durch Freude» (KdF) im »Dritten Reich« erkennen. Sie dienten letzterer als Referenz, die es zu übertrumpfen galt. So erübrigt sich auch die Frage, weshalb einschlägige Reportagen und visuelle Darstellungen aus der Sowjetunion in den NS-Publikationen vollständig fehlten: Sie hätten schlicht Werbung für die weltanschauliche Konkurrenz auf einem propagandistisch hochlukrativen Feld bedeutet. Nicht nur die Zieldefinition von sowjetischem Arbeitersport und späterer KdF-Programmatik - die Erhaltung und Erhöhung der Arbeits- und Kampfkraft der arbeits- und wehrfähigen Bevölkerungsteile - war identisch. ${ }^{22}$ Auch die Angebote, von der hochsubventionierten Sportveranstaltung über die Organisation von Strandurlauben bis hin zu Kreuzfahrten ähnelten sich. Betrachtet man ein repräsentatives Beispiel aus der AIZ (Abb. 20), ist es ohne Überschrift und Bildunterschriften kaum von einer KdF-Veranstaltung zu unterscheiden. Die Abordnungen regionaler Parteigliederungen, die sich in wohlgeordneter Freizeitatmosphäre zur öffentlichkeitswirksamen Leibesertüchtigung an mustergültig ausgestatteten Sportanlagen einfinden, könnten auch in einer ILB-Ausgabe nach 1933 erscheinen.

Ähnlich verhält es sich mit einem Beispiel (Abb. 21), das in seiner Inszenierung an die Werke Leni Riefenstahls erinnert. Tatsächlich zeigt es eine Veranstaltung des »Moskauer Gouvernementsrats der Gewerkschaften ${ }^{23}$. Die

20 So wird unter der Überschrift »Der Aufbau des Sozialismus in der Sowjetunion und der Klassenkampf« explizit gefordert, Massensportorganisationen zu gründen oder sich ihrer zu bemächtigen, um in der breiten Masse der Arbeiter und Bauern Mobilisierungsbemühungen im Sinne der Partei zu ermöglichen oder zu befördern. Vgl. Das Programm der kommunistischen Partei Rußlands (Bolschewiki): Angenommen auf dem 8. Parteikongreß (18. bis 23. Mai 1919). Leipzig 1919. Punkt V./1.

21 Dazu: Rolf, Malte: Die schönen Körper des Kommunismus. Sportparaden in der Sowjetunion der Dreißiger Jahre. In: Malz, Arié/Rohdewald, Stefan/Wiederkehr, Stefan (Hg.) Sport zwischen Ost und West. Beiträge zur Sportgeschichte Osteuropas im 19. und 20. Jahrhundert. Osnabrück 2007, 309-325, hier $312 \mathrm{f}$.

22 Vgl. zu den Zielen, Methoden und den ideologischen Wurzeln von »Kraft durch Freude«: Baranowski, Shelley: Strength through Joy. Consumerism and Mass Tourism in the Third Reich. Cambridge u. a. 2004, $40 \mathrm{f}$.

23 »Sprünge vom Turm der Wasserstation des Moskauer Gouvernementsrat der Gewerkschaften. Die Wasserstation liegt am Moskau-Flusse." Anon.: Arbeitersport in Russland. In: AIZ, 1929, Nr. 33, 19. 


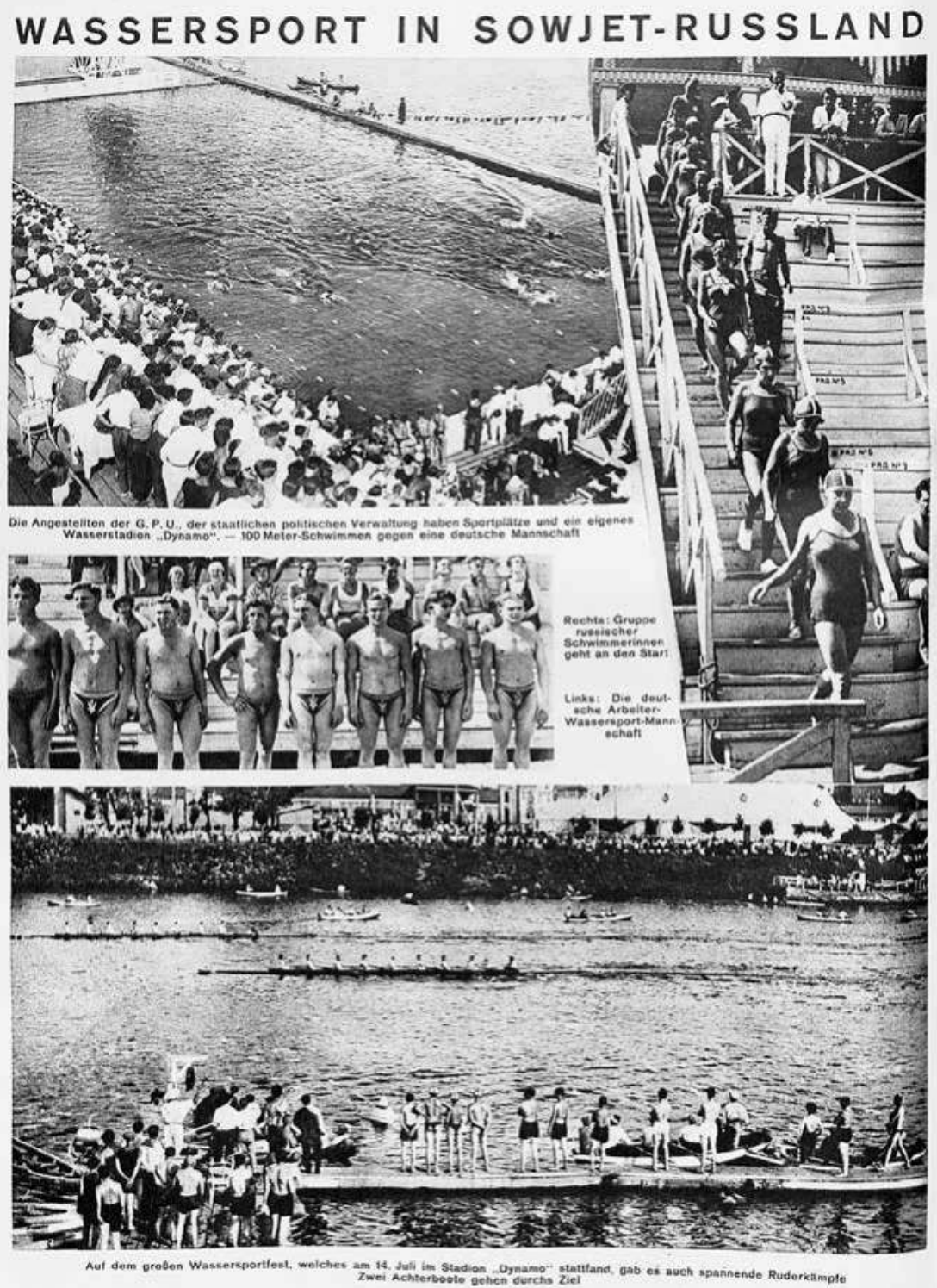

18

Abb. 20: Anon.: Wassersport in Sowjet-Russland. In: AIZ, 1929, Nr. 31, 18. Auf den ersten Blick sind die organisierten Sport- und Erholungsangebote in der Sowjetunion kaum von jenen im nationalsozialistischen Deutschland zu unterscheiden. Sie nahmen auch eine ähnliche gesellschaftliche Funktion wahr. 


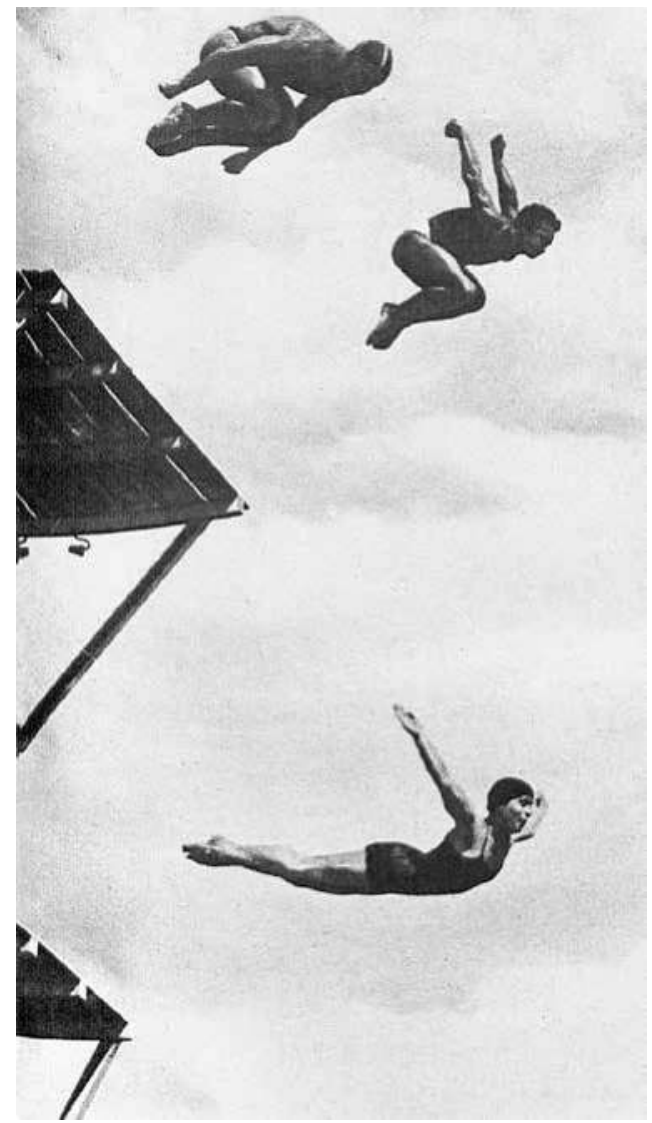

Abb. 21: Anon.: Arbeitersport in Russland. In: AIZ, 1929, Nr. 33, 19. Arbeitersport in Russland. Die Bildsprache erinnert stark an die späteren Werke Leni Riefenstahls.

Turmspringer, die sich durch absolute Körperbeherrschung und beste Gesundheit auszeichnen, wirken schwerelos, sind aber fest in ihre Dreiecksformation

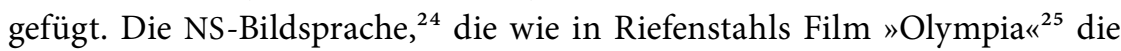
kraftstrotzende Gesundheit jugendlicher, sportreibender Körper ins bewegte Bild setzte, griff auf die Vor-Bilder des ideologischen Erzfeindes zurück Übrigens tauchen auch in Riefenstahls »Olympia«-Film Turmspringer auf. Sie 
bilden - aufgrund der innovativen Kameraführung scheinbar schwerelos in der Luft rotierend - den Abschluss des Abschnitts »Fest der Schönheit ${ }^{26}{ }^{6}$

Bei der länderspezifischen Sportrezeption in deutschen Massenmedien ist ein starkes Ungleichgewicht zu konstatieren zwischen Quellen, die sich mit dem ideologisch instrumentalisierten und ästhetisierten Sowjet-Sport beschäftigten und den Berichten zum amerikanischen Unterhaltungs- und Universitätssport. Die Annahme, die ideologische Aufladung kommunistischer Sportveranstaltungen habe zu deren Attraktivität als Gegenstand massenmedialer Berichterstattung beigetragen, liegt nahe. ${ }^{27}$

Der amerikanische Profi- und Freizeitsport wurde nur sehr selektiv betrachtet. Hervorgehoben wurde in Zeitungen und Zeitschriften lediglich, dass er eine wesentlich höhere gesellschaftliche Bedeutung genieße als der Sport in Deutschland und dass gänzlich andere Sportarten als in Deutschland populär seien. Vor allem der hohe Stellenwert des Basketball, Baseball sowie des als »sehr roh und gefährlich $\aleph^{28}$ eingeschätzten American Football an amerikanischen Universitäten wurde mit großem Unverständnis bedacht und despektierlich als eigentliche »Hauptbeschäftigung ${ }^{29}$ der Studierenden bezeichnet.

Mit Blick auf den American Football betonten die Beobachter wahlweise dessen Rolle bei der militärischen und staatsbürgerlichen Erziehung junger Männer oder kritisierten seine Brutalität, den ungezügelten Konkurrenzgedanken und die zunehmende Kommerzialisierung. ${ }^{30}$ Neben der Leibesertüchtigung erfülle diese Sportart insbesondere an den Universitäten die Aufgabe der »Erziehung zur Unterordnung des einzelnen unter den Gruppenwillen «, ${ }^{31}$

26 Olympia. TC: 1:21:06-1:25:10. Vgl. auch: Downing, Taylor: Olympia. London 2012, $108-112$.

27 So blickte Deutschland auf eine lange, wenn nicht sogar die längste Tradition des politisch funktionalisierten Sportbetriebs zurück. Sie reicht bis zur Turnbewegung Friedrich Ludwig Jahns zur »Rettung Deutschlands und Preußens« zurück, die weltanschaulich eng mit der deutschen Nationalbewegung verknüpft war. Vgl. dazu Ohmann, Oliver: Friedrich Ludwig Jahn. Frisch, frei, fröhlich und fromm. Erfurt 2009, 47 f. Über den Beobachtungszeitraum hinaus fand auch im $»$ Dritten Reich $«$ sowie in der DDR die »Tradition« der politischen Vereinnahmung des Sports ihre jeweils beinahe ungebrochene Fortsetzung. Dazu: Schmitz, Frank: Zur Ideologisierbarkeit des Sports. Eine vergleichende Untersuchung zum Zusammenhang von politischer Ideologie und Sport im Nationalsozialismus und in der DDR (Dissertation). Braunschweig 2001.

28 Siebourg, Hellmut: Sport-Erziehung an den USA-Hochschulen. Basketball, Baseball und Football als Hauptbeschäftigung. In: VZT Nr. 319 vom 05.07.1932, 7.

29 Ebd.

30 Andererseits gab es Darstellungen, die die vermeintliche Brutalität, den ungezügelten Konkurrenzgedanken und die zunehmende Kommerzialisierung des American Football aufs Schärfste kritisierten. So unter anderem: Kisch, Egon Erwin: Fussball in Amerika. In: AIZ, 1929, Nr. 47, $10 \mathrm{f}$.

31 Siebourg: Sport-Erziehung an den USA-Hochschulen, 7. 
was angesichts des von äußerem Zwang weitgehend befreiten Aufwachsens amerikanischer Jugendlicher auch nötig sei. Denn:

»Erst beim Sport lernt die Jugend Amerikas, daß die einzelne Höchstleistung durch freiwillige Einordnung ins `Teamwork ihren schönsten Wert gewinnt. Im Sportspiel liegt die erfolgreichste und vielfältigste Methode amerikanischer Erziehung zu Kameradschaftlichkeit und Hilfsbereitschaft, zur Demokratie ${ }^{32}$

Sport wurde sowohl im amerikanischen als auch im sowjetischen Bezugsrahmen eine erzieherische Funktion attestiert. Die viel selteneren Beispiele aus den USA betonen den Aspekt der sozialen Einordnung des einzelnen jungen Menschen in ein bestehendes soziales Gefüge. Dem gegenüber steht im sowjetischen Kontext die ideologische Erziehung mit dem Ziel, einer ganzen Gesellschaft eine neue ideologische Ordnung mithilfe von Sportmassenveranstaltungen $\mathrm{zu}$ vermitteln. Aufs Neue scheint in diesem Themenfeld die Grundopposition zwischen einer kulturell "gewachsenen « Initiationsfunktion des Sports in den USA, insbesondere im Bildungswesen, und einer gezielten, um nicht zu sagen »erzwungenen« Maßnahme zur Einflussgewinnung und Repräsentation der politischen Führung der UdSSR auf.

\subsection{Jugend in jungen Ländern}

Jugend war zu Zeiten der Weimarer Republik ein relativ neues Konzept. Noch im 19. Jahrhundert war der Eintritt ins Erwachsenenalter sozial und materiell eher übergangslos vonstattengegangen. Aufgrund der Möglichkeit längerer Schulbildung und sinkender Geburtenzahlen öffnete sich die biografische Lücke zwischen Kindheit und Erwachsenenleben immer weiter, was einer der Gründe dafür war, das 20. Jahrhundert als »Jahrhundert der Jugend ${ }^{33} \mathrm{zu}$ bezeichnen.

Auch der Zeitgeist machte das 20. Jahrhundert und somit die Zwischenkriegszeit empfänglich für eine Verherrlichung des Heranwachsens. Das Phänomen Jugend reflektiert als Projektionsfläche die für die öffentlichen Debatten um Modernisierungsprozesse typische Ambivalenz zwischen Aufbruchsbegeisterung und Angst vor dem Verlust tradierter sozialer, ökonomischer und kultureller Ordnungsmuster. ${ }^{34}$ Die begriffliche Assoziation des

32 Ebd.

33 Sander, Uwe: 100 Jahre Jugend in Deutschland. In: Aus Politik und Zeitgeschichte, Bd. 1920 (2000): Jugend in Deutschland. URL: http://www.bpb.de/apuz/25608/100-jahre-jugendin-deutschland (am 20.07.2015).

34 Vgl. Trommler, Frank: Mission ohne Ziel: Über den Kult der Jugend im modernen Deutschland. In: Koebner, Thomas/Janz, Rolf-Peter/Trommler, Frank: »Mit uns zieht die neue Zeit«. Der Mythos Jugend. Frankfurt a. M. 1985, 15. 
Jugendkonzepts mit den Vereinigten Staaten und der Sowjetunion als »Ländern der Jugend $\aleph^{35}$ verweist auf einen weiteren Aspekt: In der Betrachtung dieser im Vergleich zu den Nationen der »Alten Welt» sehr jungen Staaten überschnitt sich dieses metaphorische, auf die Nation bezogene Jugendkonzept an verschiedenen Stellen mit dem konkreten Gegenstand der Jugendlichen in diesen Nationen selbst. Auch wurden die USA traditionell als Synonym für den »jungen « Kontinent Amerika im Gegensatz zum »alten« Europa wahrgenommen. ${ }^{36}$

Politisch gesehen war das biografische Zwischenstadium der Jugend eine Phase weltanschaulicher Formbarkeit und ein prekäres Stadium erhöhter Empfänglichkeit gegenüber politischen Utopien. Jugendliche und junge Leute wurden zu den Hauptadressaten ideologischer Indoktrination und politischer Ideen, galten sie doch gemeinhin als »Hoffnungsträger und Gestalter einer neuen Zeit ${ }^{37}$ und damit als wichtiger politischer Faktor. Freilich lassen sich kaum allgemeingültige Aussagen über die Lebenswelten von Jugendlichen in der Weimarer Republik, den Vereinigten Staaten oder der Sowjetunion treffen. Dazu waren die individuellen, kulturellen und klassenspezifischen Unterschiede innerhalb und zwischen den drei Ländern schlichtweg zu disparat - und kamen obendrein zeitversetzt zum Tragen. Nur mit der Engführung auf bestimmte Milieus und konkrete Zeitabschnitte können Bedingungen jugendlichen Lebens und, mittels Ego-Dokumenten, auch die zahlreichen Selbstkonzeptionen von Jugendlichen valide untersucht werden. ${ }^{38}$

35 Die Teilüberschrift nimmt Bezug auf die 1926 veröffentlichte Monografie »Jugend im Land der Jugend « des BIZ-Amerikakorrespondenten Fritz Zielesch, in der er sich mit den Bedingungen und Besonderheiten jugendlichen Aufwachsens in der amerikanischen als ihrerseits im Jugendstadium befindliche Gesellschaft auseinandersetzt. Er falsifiziert darin unter anderem den weitverbreiteten Mythos, Kinder und Jugendliche in den USA litten keinerlei materielle Not, sondern weist stattdessen auf die beträchtlichen Zahlen unter- und mangelernährter Kinder hin. Vgl. Zielesch, Fritz: Jugend im Land der Jugend. Ein Amerikabuch. Hamburg 1926.

36 In seiner hier bereits mehrfach erwähnten Untersuchung wilhelminischer Amerikabilder hat Alexander Schmidt-Gernig dieser metaphorisch-konzeptuellen Entgegensetzung Amerikas und Europas einen Abschnitt unter der Unterüberschrift "Alter Europas versus `Jugend A Amerikas « gewidmet, in dem er dies ausführt. Vgl. Schmidt, Alexander: Reisen in die Moderne. Der Amerika-Diskurs des deutschen Bürgertums vor dem Ersten Weltkrieg im europäischen Vergleich. Berlin 1997, $267 \mathrm{f}$.

37 Sander, Uwe/Vollbrecht, Ralf: Jugend im 20. Jahrhundert. In: Dies. (Hg.): Jugend im 20. Jahrhundert. Sichtweisen - Orientierungen - Risiken. Neuwied u. a. 2000, 9.

38 So hat sich z. B. Detlev Peukert dem spezifischen Milieu der Arbeiterjungen in der Zeit der Weimarer Republik gewidmet. Er arbeitete heraus, dass selbst innerhalb eines solch vermeintlich geschlossenen Milieus nochmals eine beträchtliche Vielfalt an Lebensentwürfen existierte, also selbst für eine einigermaßen gut abgrenzbare Gruppe verbindliche Aussagen zu deren Lebenswelten nur schwierig und unter großen Vorbehalten zu treffen sind. Vgl. Peukert, Detlev: Jugend zwischen Krieg und Krise. Lebenswelten von Arbeiterjungen in der Weimarer Republik. Köln 1987, hier insbesondere $304 \mathrm{f}$. 
Außerdem brachte der Blick (erwachsener) Journalistinnen und Journalisten aus Deutschland auf Jugendliche in den USA und der UdSSR zwar in sich schlüssige Vorstellungen von deren Lebenswelten hervor, konnte aber stets Erfahrungslücken aufweisen. Sie machten nichtsdestotrotz einen gewichtigen Teil des Bildes aus, welches man sich in Deutschland von der amerikanischen und sowjetischen Gesellschaft als »modernes« Ganzes machte.

Die Beziehung der sowjetischen Gesellschaft zu ihrer jungen Generation und darüber hinaus die Bedeutung der Jugend für die kommunistische Sache insgesamt wurde in der deutschen Medienlandschaft als geradezu schicksalhaft eingeschätzt. ${ }^{39}$ Dies lag insbesondere in der Gleichsetzung des politischen Bruchs der Revolution von 1917 mit einem generationellen Bruch in der russischen Gesellschaft begründet, wodurch die junge Generation zu einer Art Garantiemacht der bolschewistischen Ordnung stilisiert wurde. Dies entsprach auch vollkommen der zentralen Rolle, die Lenin der Jugend beim Totalumbau der Gesellschaft und dem Aufbau einer sozialistischen Ordnung zugedacht hatte. ${ }^{40}$ Nicht nur die Bolschewiki, sondern kommunistische Initiativen generell sahen in der Mobilisierung der Jugend ihrer Länder eine tragende Säule für ihren Erfolg und betrieben diese systematisch. ${ }^{41}$

Unabhängig vom konkreten Bezugsrahmen USA und Sowjetunion herrschte in der deutschen Presse jedoch spürbares Unbehagen ob der zunehmenden politischen Vereinnahmung und $"$ Militarisierung der Jugend..$^{42}$ Diese Problematik war im deutschen Diskurs angesichts der stark an Zulauf gewinnenden Jugendorganisationen der politischen Parteien im Reich virulent. Unter Bezugnahme auf deren ab 1923/24 stark wachsende Bedeutung wie auch in der Betrachtung paramilitärischer und politischer Jugendorganisationen im Ausland war die politische Mobilisierung Jugendlicher ein ebenso prominentes wie kontroverses Thema. ${ }^{43}$

Die Klage über die zunehmende Politisierung und Militarisierung weit über den politischen Raum hinaus stellt eine Grundsatzkritik an der zeittypischen Dominanz des Ideologischen und seiner Durchdringung der gesamten Gesell-

39 So titelte die damals noch unter dem Namen »Sichel und Hammer « erscheinende spätere AIZ 1924 unter einem Bild paradierender Junger Pioniere in Moskau: »Sowjetrußland und seine Jugend sind Garantien für den siegreichen Aufstieg der arbeitenden Klasse.« Anon.: Sieben Jahre Sowjetrußland. In: SUH, 1924, Nr. 1, Titel. (Die Zählung erfolgte bei "Sichel und Hammer" gemäß dem Jahrestag der Oktoberrevolution, weshalb die Novemberausgabe die Nummer 1 trug.)

40 Vgl. Lenin, V. I.: Werke. Bd. 7. September 1903-Dezember 1904. Berlin 1968, 28-44.

41 Dazu: Whitney, Susan: Mobilizing Youth. Communists and Catholics in Interwar France. Durham, London 2009.

42 Zum Beispiel: Anon.: Politisch missbrauchte Kinder. In: BIZ, 1929, Nr. 36, 1607 (Jahresausgabe).

43 Vgl. Krabbe, Wolfgang (Hg.): Parteijugend zwischen Wandervogel und politischer Reform. Eine Dokumentation zur Geschichte der Weimarer Republik. Münster 2000, 16. 
schaft, eben auch kindlicher und jugendlicher Lebenswelten, dar. Über den gesamten Beobachtungszeitraum erschienen zum Beispiel in der BIZ immer wieder Plädoyers wider die "politische Verhetzung der Jugend $\aleph^{44}$, die nicht nur seitens der politischen Extreme ${ }^{45}$ sondern über das gesamte politische und weltanschauliche Spektrum hinweg erfolge. Auch das Auftreten von »[d]emokratische[n] Jugendliche[n] bei einer pazifistischen Kundgebung ${ }^{46}$ war nicht von der Kritik an der Instrumentalisierung der Jugend ausgenommen. Ausnahmslos alle politischen Parteien waren Adressaten entschiedener Kritik an der politischen Mobilisierung von Jugendlichen. Mithin war die Kritik an jenem politischen Missbrauch, die besonders in liberalen Illustrierten wie eben der BIZ, aber auch in eher biederen und politisch wenig meinungsbildenden Magazinen wie Scherl's Magazin (SMZ) ${ }^{47}$ zum Ausdruck kam, ganz prinzipieller Natur und keineswegs von der politischen Verortung abhängig die Parteisprachrohre AIZ und ILB ausgenommen. Deshalb kam sie nicht nur auf die parteipolitische Auseinandersetzung in Deutschland, sondern als Generalkritik an diesem Zeitproblem auch auf die Betrachtung der Vereinigten Staaten und der Sowjetunion zur Anwendung.

Im Unterschied zur »Politisierung" der Jugend in Deutschland war hinsichtlich der USA und der UdSSR jedoch von »Militarisierung « die Rede, was

44 Anon.: Gegen die politische Verhetzung der Jugend. Haltet die Jugend vom Parteiwesen fern! In: BIZ, 1925, Nr. 22, 677 (Jahresausgabe).

45 So wurde bereits sehr früh Kritik am gezielten Werben der Nationalsozialisten um die Gunst von Jugendlichen und sogar Kindern geübt. Unter anderem: Anon.: Nationalsozialistische Politisierung der Jugend. In: BIZ, 1923, Nr. 6, 103 (Jahresausgabe).

46 »Und alle Parteien [...] haben sich an solchem Unfug mitschuldig gemacht. Zuerst hatten radikal-sozialistische Agitatoren damit angefangen, die Jugend auf die Straße zu führen, aber rechts auf der Gegenseite hat man nicht lang gezögert, dem schlechten Beispiel zu folgen und schließlich ist es allgemeiner Brauch und geradezu ein Stolz jeder Partei geworden sagen zu können: Wir haben die Jugend für uns! [...] Aber je besser die Kinder begreifen, um was es sich bei politischen Kundgebungen handelt, desto schlimmer für sie; Ins Parteileben hineingezogen lernen sie vorzeitig zu hassen, in einem Alter, das so bereit ist zu lieben [...]. Der junge Mensch hat nicht eine einzige Meinung, sondern viele, alle Meinungen, so rasch nacheinander, daß es beinah gleichzeitig ist. Doch Charaktere bilden sich nur in dieser Freiheit.« Anon.: Gegen die politische Verhetzung der Jugend, 678.

47 Dieses, im Hugenberg-Konzern erscheinende, Magazin kann als seichtes Unterhaltungsmagazin bezeichnet werden. Zwar transportierte es entsprechend der nationalkonservativen Ausrichtung des Hugenberg-Imperiums vergleichsweise konservative Ansichten in Fragen des Lebensstils, mied aber allzu dezidierte Stellungnahmen zu tagesaktueller Politik. Die entsprechende Kurzcharakterisierung des Portals »Illustrierte Magazine der Klassischen Moderne«: »Das entsprechend biedere 'Scherl's Magazin kam 1924, etwa zeitgleich mit dem UHU und `Das Magazin heraus. Unter Chefredakteur Arthur Ploch kommt das Niveau der Beiträge zu kulturellen und reinen Unterhaltungsthemen - ebenso wie das Bildmaterial - dem UHU-Magazin nur ausnahmsweise nahe." Anon.: Scherl's Magazin. URL: http://magazine.illustrierte-presse.de/die-zeitschriften/kurzportraets/ scherls-magazin/ (am 12.08.2015). 
die Problematik in einer gänzlich anderen Konstellation darstellte: Nicht konkurrierende politische Gruppierungen unterhalb der Regierungsebene rückten in den Brennpunkt der Kritik, sondern die vermeintlich staatlicherseits im großen Stil vorangetriebene paramilitärische Ertüchtigung von Kindern und Jugendlichen. Diese Kritik war im Falle der USA nicht völlig ohne Grundlage, sondern sprach eine dortzulande real existierende Kultur des Militarismus und maskulinen Heroismus an. In bemerkenswertem Widerspruch zur isolationistischen Weltvergessenheit US-amerikanischer Außenpolitik entfaltete diese Kultur in amerikanischen Jugendbewegungen, vor allem den BoyScouts, und Bildungseinrichtungen spürbar ihre Wirkung. ${ }^{48}$ Auch in der sich seit ihren Anfängen vom »kapitalistisch-militaristischen Ausland « belagert wähnenden Sowjetunion ging die rasch vorangetriebene organisatorische Einbindung der Jugend in die Hierarchien der KPR (B), insbesondere im Komsomol, ${ }^{49}$ tatsächlich mit der paramilitärischen Ertüchtigung von Jugendlichen beiderlei Geschlechts einher. ${ }^{50}$

\subsection{1 „Wie man in Amerika Bürger macht«}

In einem reich bebilderten sechsseitigen Artikel widmete sich Scherl's Magazin (SMZ) im Jahr 1928 der »Militarisierten Jugend ... bei den anderen« (Abb. 22). Darin drücken die prominent gehaltenen Visuals im Vergleich zum Text sehr viel stärker jenes Unbehagen aus, das man über Publikationen verschiedenster inhaltlicher und weltanschaulicher Couleur hinweg ob der paramilitärischen Sozialisierung einer ganzen Generation empfand.

48 Die 1910 gegründeten Boy-Scouts und deren komplementäres Angebot für Mädchen, die Girl Scouts, avancierten durch ihre Popularität und professionellen Strukturen zum wichtigsten Faktor der »Paramilitarisierung« amerikanischer Jugendlicher. Von Staats wegen war diese Wirkung zunächst auf die Mobilisierungsbemühungen am Vorabend des Kriegseintritts gerichtet gewesen, setzte sich aber über die gesamte Zwischenkriegszeit und, nach kurzer Stagnation, bis zum nächsten Kriegseintritt 1941 fort. Vgl. Collins, Ross: Children, War and Propaganda. New York 2011, 69.

49 Der im November 1918 gegründete Komsomol war der KPR (B), der späteren KPdSU, direkt unterstellt. Sein Ziel war die Erziehung von Kindern und Jugendlichen im kommunistischen Sinne. Mittelbar sollten in ihrem kommunistischen Weltbild gefestigte junge Menschen eine tragende Rolle beim Aufbau einer sozialistischen Gesellschaft spielen, wozu sie mit Propagandatätigkeiten und dem Aufbau entsprechender Untergliederungen auf dem Lande betraut wurden. Vgl. Long, John: Communist Youth Organizations of the Soviet Union. In: Wieczynski, Joseph (Hg.): The Modern Encyclopedia of Russian and Soviet History. Bd. 7. Gulf Breeze, FL 1978, 228-235.

50 Neben gemäßigten Gruppen existierten auch militante, so die»Bratushki« (»kleine Brüder«), die sich auf Traditionen der Revolutions- und Bürgerkriegszeit bezogen. Vgl. Gorsuch, Anne: Youth in Revolutionary Russia. Enthusiasts, Bohemians, Delinquents. Bloomington $2000,80 \mathrm{f}$. 


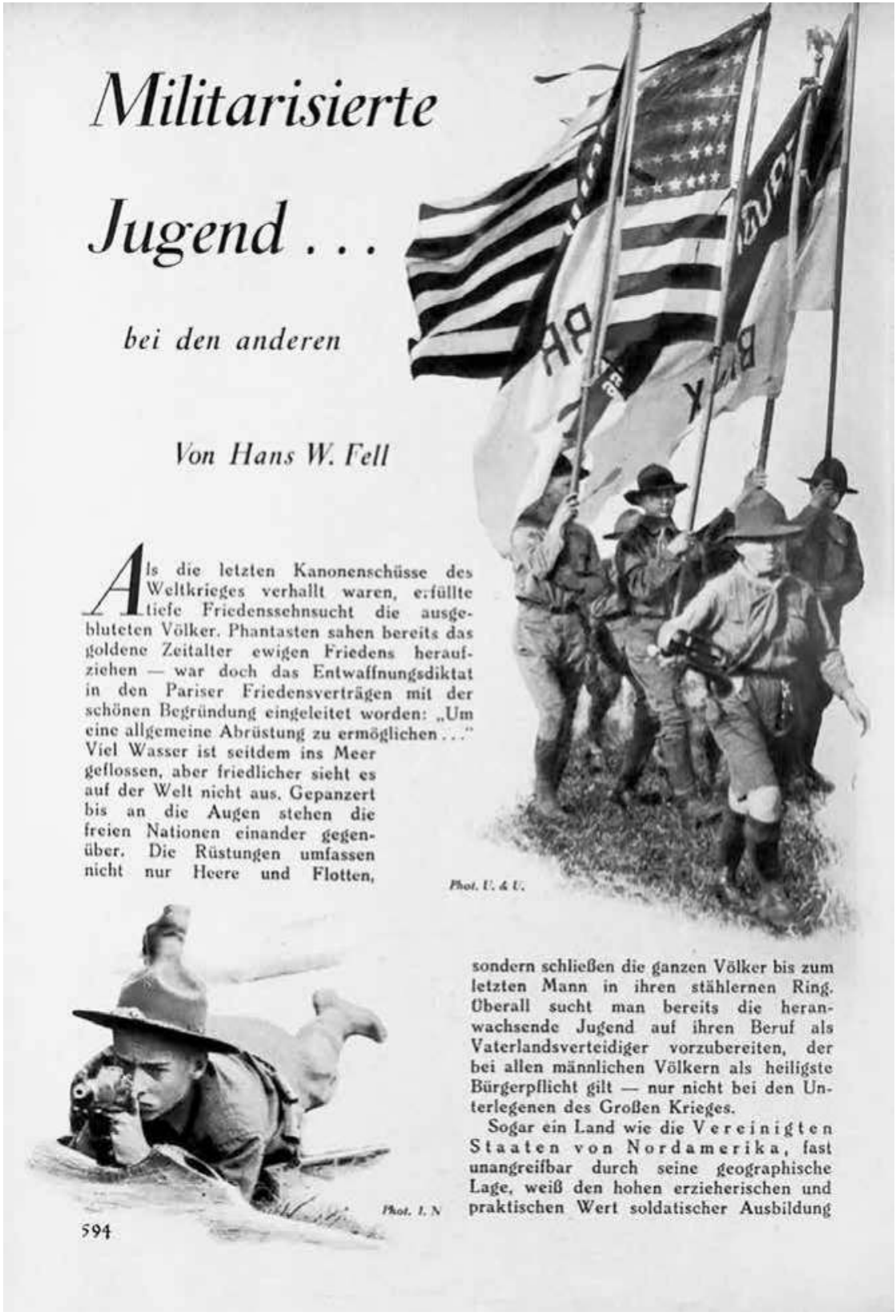

Abb. 22: Fell, Hans: Militarisierte Jugend ... bei den anderen. In: SMZ, 1928, Nr. 6, 594. Bei den US-amerikanischen Boy-Scouts wurde deren angeblich paramilitärische Ausbildung kritisiert. Durch eindrückliche Bebilderung verstärkte sich deren bedrohliche Ausstrahlung. 
Die mit wehenden Fahnen marschierenden US-amerikanischen Boy-Scouts sind durch keinerlei Rahmen von der Gesamtseite abgegrenzt, sondern bewegen sich gleichsam aus der Seite heraus, im Stile eines Freistellers. Das erzeugt im Auge des Betrachters Unmittelbarkeit und Dynamik, ein sich Nähern. Die Marschrichtung von links nach rechts vermittelt eine zeitlich wie räumlich interpretierbare Vorwärtsbewegung, die vor dem geistigen Auge des Betrachters leicht die Vorstellung hervorrufen könnte, dass die fünf noch recht jungenhaften Pfadfinder alsbald schon als kampfbereite Soldaten weitermarschieren. Noch eindrücklicher wirkt die konfrontative Darstellung eines Boy-Scouts am unteren linken Seitenrand, der seinen Karabiner direkt auf den Betrachter anlegt. Er scheint in seiner »Deckung « am unteren Rand der Seite bereit zum Abfeuern der Waffe, für einen kurzen Augenblick wähnt man sich ihm Auge in Auge gegenüber.

Der Text fügt diesen und weiteren sehr eindrücklichen Visuals, unter anderem von britischen Internatsschülern beim Sturmangriff und faschistischen Zeltlagern in den italienischen Alpen, lediglich Kontextinformationen hinzu. Es wird betont, dass es sich beim Gezeigten um flächendeckende, staatliche Maßnahmen zur Erziehung und Rekrutierung militärischen Nachwuchses handelt - nicht etwa um eine gesellschaftliche Nischenerscheinung mit Freizeitcharakter auf freiwilliger Basis:

"Sogar ein Land wie die Vereinigten Staaten von Nordamerika, fast unangreifbar durch ihre [sic] geographische Lage, weiß den hohen erzieherischen und praktischen Wert soldatischer Ausbildung für die heranwachsende Jugend zu schätzen. Die Erfahrungen des Großen Krieges wirken dort besonders stark nach. Denn das Führerproblem, der Mangel gründlich vorgebildeter Offiziere und Unteroffiziere, bildete die größte Schwierigkeit, die sich der schnellen Aufstellung eines starken Volksheeres entgegenstellte. Ihr dienen nicht nur die altberühmten Kadettenanstalten von West Point und Annapolis, die seit 150 Jahren den Offizierersatz für Heer und Flotte liefern, sondern vor allem die an jedem Gymnasium, an jeder Universität bestehenden Korps für die Reserveoffizier-Ausbildung (Reserve Officers Training Corps). Die Teilnahme an dieser Ausbildung ist nicht etwa freiwillig, sondern Pflicht. Kein junger Amerikaner der gebildeten Stände kann heute auf Bestehen der Prüfungen oder spätere Anstellung im Staats- oder Bundesdienste rechnen, wenn er nicht die nötigen militärischen Kenntnisse nachweist [...]. Im ganzen [sic] aber läßt sich wohl sagen, daß die gesamte Jugend Amerikas in durchaus militärischem Geiste erzogen wird und daß bei einem künftigen Konflikt den Vereinigten Staaten ein treffliches Führermaterial zur Aufstellung eines Volksheeres zur Verfügung steht. ${ }^{51}$

Die Empörung über die zunehmende Militarisierung der Jugend rührte, dies klingt in diesem Quellenausschnitt an, von einer breiten Debatte zum 
wachsenden Militarismus in den Gesellschaften der Siegermächte des Ersten Weltkriegs her. Die Aufrüstung und die Militarisierung von Frauen und Jugendlichen sorgten vor dem Hintergrund der Friedensziele, die Wilson den Deutschen für die Zeit nach dem Krieg aufgezeigt hatte, dafür, dass die deutsche Öffentlichkeit besonders sensibel für derlei Themen war. Die Vorstellung, man habe in deutschen Illustrierten zuallererst aus Sorge um den Weltfrieden gegen die Hochrüstung der ehemaligen Entente und der USA polemisiert, geht insofern fehl, als stets die für Deutschland dahingehend festgelegten Obergrenzen als Bezugspunkt der Rüstungskritik dienten. ${ }^{52}$

Die Militarisierung repräsentierte nur eine von mehreren Möglichkeiten der Formung Jugendlicher zu tauglichen Staatsbürgern, die man in den Vereinigten Staaten als Teil einer ganzen Staatsphilosophie des "Citizen Making " interpretierte.$^{53}$ Die dahinter stehende Denkfigur imaginiert die USA als junge Nation, die mangels fest gefügter Traditionslinien auf die planmäßige »Formung " von Staatsbürgern zwingend angewiesen sei. Eine Vorstellung im Übrigen, die bis heute ein fundamentales Spannungsfeld im Vergleich europäischer und nordamerikanischer Staatsbürgerschaftskonzepte und konkreten Staatsbürgerschaftsrechts ausmacht.

52 Der mühsam unterdrückte Revanchismus, der in der Rüstungskritik der Illustrierten offenbar wurde, wandelte sich nach der »Machtergreifung « relativ abrupt in eine unverhohlene Propagandaoffensive für die Aufrüstung Deutschlands und die Inszenierung der "neuen deutschen Wehrmacht«. Dazu: Unger, Eva-Maria: Illustrierte als Mittel zur Kriegsvorbereitung in Deutschland 1933 bis 1939. Köln 1984. Ohne das zwischen 1918 und 1933 regelmäßig beklagte "Zukurzkommen« Deutschlands in Rüstungsfragen wäre dieser Schwenk nicht so schnell möglich gewesen.

53 Wolf von Dewall, Amerikakorrespondent der FZT, berichtet von seinem Erstaunen über die militärische Ausrichtung und Ausstattung staatlicher Universitäten in den USA, an denen junge Männer wie auch Frauen eine verpflichtende und vollumfängliche militärische Ausbildung erhielten: „Der nächste Gang war in die armoury, das militärische Rüsthaus [...]. Ich sah die Uniformkammer, ich sah eine Menge von Gewehren, ich sah ein riesiges Geschütz, das wohl von der Küstenverteidigung stammte, ich sah zwei Dutzend Pferde, ich sah, wie sich ein girl auf dem Schießstand im Scharfschießen übte [...]. Hier war ich in ein Nest geraten, in dem nähere Untersuchungen von Wert schienen. Der Major erklärte mir, daß nach dem Statut der Hochschule alle männlichen Zöglinge sich im militärischen Dienst als Infanteristen, Kavalleristen oder Pioniere ausbilden lassen müssen, daß Ausnahmen nicht geduldet würden, [...] daß auch die girls Scharfschießen lernen können und gerade von ihnen manche die besten Scharfschützen werden [...]. Auf sechsundachtzig amerikanischen Universitäten und Hochschulen ist der militärische Drill als zwangsmäßige Einrichtung eingeführt, auf vierundvierzig Universitäten und Hochschulen ist er für die Studenten ein freiwilliger Dienst. [...] Manche Universitäten besitze wahre Heereslager, z.B. die Staatsuniversität von Ohio, der nicht weniger als vierundvierzig Offiziere und Mannschaften attachiert sind."Dewall, Wolf von: Rush. Eine Vortragsreise in den U.S. A. Boys and Girls. In: FZT Nr. 214 vom 21.03.1929, $1 \mathrm{f}$. 
»Wie man in Amerika Bürger macht $^{54}$, erklärt Fritz Zielesch 1926 in der BIZ. Der Autor fasst die verschiedenen Hebel privater Jugendförderung in den Vereinigten Staaten zusammen. Der größte industrielle Komplex Amerikas und der Welt, davon zeigt Zielesch sich fest überzeugt, sei weder die amerikanische Auto- noch die Maschinen- oder Textilindustrie:

»Amerika hat eine noch größere entdeckt. Sie steht in keinem Lexikon. Sie arbeitet nicht mit Maschinen und Aktien und Dividenden. Sie jagt nicht dem rollenden Dollar nach. Sie ist eine Industrie ganz ungeschäftlicher Art, wenn sie auch zur Volkswirtschaft in engster Beziehung steht. >Citizen Making ‘ heißt diese Industrie [...]. >Citizen Making ‘, das bedeutet `Bürger machen`, das bedeutet junge Menschen zu arbeitsfrohen, tüchtigen Staatsbürgern heranbilden. ${ }^{55}$

Unterprivilegierte Jugendliche stellten die amerikanische Gesellschaft und Wirtschaft dabei vor größere Herausforderungen als Bürgersöhne und -töchter. Letztere würden reibungslos durch die Institutionen geschleust. ${ }^{56} \mathrm{Zielesch}$ beschreibt eine Melange aus sozialer Fürsorge, staatsbürgerlicher Erziehung und Ertüchtigung zu produzierenden und konsumierenden Teilnehmern am Kapitalismus als Motive der Geldgeber solcher Initiativen. ${ }^{57}$ Die Mittel unterschieden sich kaum von denen staatlicher Stellen: Sport, Spiel, handwerkliche Ausbildung und romantisch verbrämter militärischer Drill. Die private Sozialarbeit habe staatlicherseits bereits Anerkennung gefunden, sei doch an »der Notre Dame Universität zu Indiana [...] der erste Lehrstuhl für `Boys Work errichtet ${ }^{58}{ }^{8}$ worden. Zielesch sieht das Motiv zur Jugendförderung zuvörderst im »Selbsterhaltungstrieb« des Kapitalismus - eindrücklich auf den Punkt gebracht in seiner fordistischen Metapher vom »Laufband der Erziehungsmaschinerie«. Danach folgten allgemeinnützige Fragen der Jugendfürsorge und nicht zuletzt der Kriminalitätsprävention.

54 Zielesch, Fritz: Im Klub der Strassenjungen. Wie man in Amerika »Bürger macht«. In: BIZ, 1926, Nr. 3, 69 f. (Jahresausgabe).

55 Ebd., 69.

56 »Die Söhne der begüterten Kreise Amerikas werden auf dem Laufband der Erziehungsmaschinerie zwischen Schule, Elternhaus und Jugendorganisation zum Bürger geformt. Aber wer denkt an die sechs Millionen `underprivilegeds`, die Kinder ohne rechtes Heim, die Mutterlosen oder Vaterlosen, die Straßenjungens in den dunklen Vierteln der Städte. Was wird aus denen?«. Ebd., 70.

57 »Aber die Großkapitalisten der Neuen Welt sind einsichtig. Sie wissen, daß verarmte vernachlässigte Menschen, die mit sich und der Welt unzufrieden sind, für die Wirtschaft nicht nur nutzlos bleiben, sondern ihr Schaden zufügen. Die amerikanischen Großkapitalisten wollen arbeitende, verdiendende, also zahlungsfähige Bürger haben. Also öffnen sich die Tresore, wo es nur immer gilt, den Lebensstandard des Volkes zu heben. Im letzten Jahrzehnt flossen den Wohlfahrtsorganisationen nicht weniger als 2500 Millionen Dollars aus privaten Händen zu. `Citizen Making` ist ein Geschäft auf weiteste Sicht, aber es ist ein großes und gutes Geschäft.« Ebd.

58 Ebd. S. 70 . 
Die Jugendkriminalität, seit der »Erfindung» der Jugend zu Anfang des 20. Jahrhunderts mediales Dauerthema und umkämpftes Feld gesellschaftspolitischer Auseinandersetzungen, ${ }^{59}$ verschaffte der Leserschaft der Illustrierten durch explizite Beschreibung auch der abseitigsten Verbrechen sowie durch die Zurschaustellung von Polizeifotos jugendlicher Delinquenten und ihrer Opfer den erhofften Grusel. ${ }^{60}$ Jenseits dieser Boulevardisierung jugendspezifischer Probleme in der US-Gesellschaft erschöpfte sich das Interesse am "jungen Amerika« bis auf vereinzelte Artikel der kommunistischen Presse $\mathrm{zu}$ vernachlässigten amerikanischen Arbeiterkindern ${ }^{61}$ jedoch im genannten Schwerpunkt der Militarisierung und Betrachtungen zum amerikanischen Bildungswesen.

\subsection{2 »Kinderhölle« und Pioniergeist}

Die Klage über die Militarisierung wurde spiegelbildlich in der Berichterstattung über die amerikanische und sowjetische Jugend geführt, wie an der visuellen Darstellung im Artikel »Mißbrauch der Jugend «(Abb. 23) deutlich wird. ${ }^{62}$ »Russische Backfische am Maschinengewehr" und Kinder beim »Unterricht im Gebrauch der Gasmaske« erzeugen das Bild einer über alle Alters- und Geschlechtergrenzen hinweg militarisierten Gesellschaft. Die Ausbildung von Frauen an Kriegswaffen stellte ohnehin ein Reizthema in der Betrachtung der Sowjetunion dar. Durch das jugendliche Alter der dargestellten "Backfische» gewann der bereits im Frauendiskurs etablierte Eindruck von der Sowjetunion als Regime, das um des Erhalts der neuen Ordnung willen alle Tabus zivilisierter Kriegführung verwarf, zusätzlich an Kontur.

Am oberen rechten Seitenrand sind Kinder mit Schutzmasken zu sehen. Der Anblick von Kindern in Vorbereitung auf die Eventualität eines Gasangriffs dürfte bei einer Leserschaft, die der Verheerungen der Gaskriegführung im Ersten Weltkrieg noch auf schmerzhafte Weise gewahr war, besonders heftige Reaktionen (und Irritationen) hervorgerufen haben. Beide Visuals transportieren in explizierten Tabubrüchen die Botschaft der unbedingten Entschlossenheit der Bolschewiki zur Verteidigung der neuen politischen Ordnung. Die allumfassende, die Ebene der Staatlichkeit und damit hergebrachte Regeln

Vgl. Dollinger, Bernd: Jugendkriminalität als Kulturkonflikt. Wiesbaden 2010, insbesondere 11-34.

60 »Ein anderer 14 jähriger Bursche brachte mit Vorliebe Züge zum Entgleisen, um dann bei angeblicher Hilfeleistung die Verwundeten und Toten ungestört plündern zu können." Scharf, Fritz: Vergiftete Jugend in Amerika. In: RDM, 1927, Nr. 2, 178 (Jahresausgabe).

61 Unter anderem: Anon.: Amerikanische Arbeiterkinder. In: AIZ, 1932, Nr. 51, Titel. Und: Anon.: Obdachlose Kinder. In: Ebd., 1188-1189 (Jahresausgabe).

62 Lorant, Georg: Mißbrauch der Jugend. In: RDM, 1931, Nr. 10. S. 1063 (Jahresausgabe). 
stellen soll, staft auf dem shwellend-elastivitien Natur. teppich am die Wette m lanfen, sidh zu balgen and ra raufen. Drei hinder nie. len, und vier fruadisene schauen prifend za. Welches Interene, meine Herren l.r. wathenen! Wieseid ihe doch uth die Juzxnd besorzt: E, is fast ruhrend, eure Sork: falt zu beobaditen. Tut ilires aber, wirklich nur aus reincm
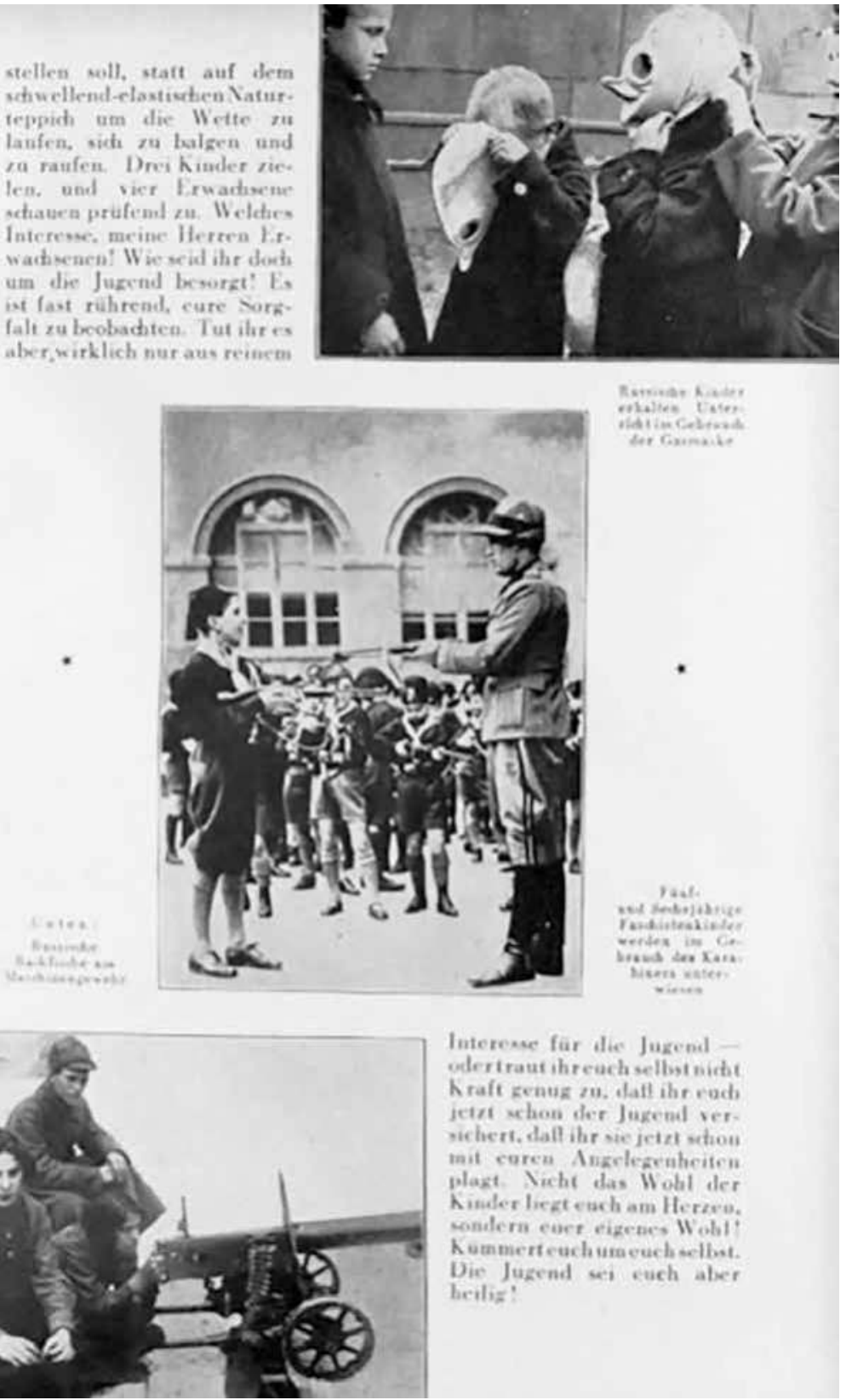

Abb. 23: Lorant, Georg: Mißbrauch der Jugend. In: RDM, 1931, Nr. 10. S. 1063 (Jahresausgabe). Gleich mehrere Tabus werden durch die Darstellung militärisch ausgebildeter jugendlicher Mädchen und die Vorbereitung der Jugendlichen insgesamt auf einen möglichen Gasangriff gebrochen. 
bewaffneter Auseinandersetzungen nationaler Streitkräfte übersteigende Bedeutung bolschewistischer Ideologie hebt nach dieser Lesart die dahingehend gültigen Normen auf. Anders formuliert: Der übergeordnete Zweck des Selbsterhalts des ideologisch verfassten Sowjetsystems heiligt die Mittel - auch die Militarisierung von Frauen und Kindern.

Das Bemühen bolschewistischer Propaganda um die enge Einbindung der sowjetischen Jugend fußte auf deren elementarer Bedeutung für den Aufbau einer sozialistischen Gesellschaft. Die Umsetzung des von Lenin ausgegebenen programmatischen Zieles der Bolschewiki, die Jugend erstens für die revolutionäre Sache zu gewinnen und in einem zweiten Schritt mit ihrer Hilfe den Sozialismus aufzubauen, ${ }^{63}$ wurde auch in der ideologischen Auseinandersetzung der politischen Extreme in Deutschland rezipiert.

Primär in der AIZ und dem ILB finden sich zahlreiche Berichte zur Förderung respektive Vernachlässigung sowjetischer Kinder und Jugendlicher, die unter den jeweiligen propagandistischen Vorzeichen standen. Während die AIZ Erfolge der Kinder- und Jugendförderung seitens bolschewistischer Organisationen wie des Komsomol oder der Jungen Pioniere in das kommunistische Schaufenster der Medienöffentlichkeit stellte, ${ }^{64}$ suchte der ILB mit apokalyptischen Berichten zum »Kinderelend in Sowjetrußland $\aleph^{65}$ das Gegenteil zu erreichen. Um die Darstellung der Sowjetunion als "Kinderparadies" zu konterkarieren, setzte der ILB auf eine Schockkampagne, welche die durch politische Säuberungen in der Landwirtschaft und die daraus resultierenden Versorgungsengpässe erwachsende Not von Millionen Kindern textuell wie visuell drastisch in Szene setzte (Abb. 24).

Die abgebildeten Kinder sind unterernährt oder verkrüppelt. Auffällig ist außerdem die Abwesenheit jeglichen Betreuungspersonals; die Kinder sind augenscheinlich auf sich allein gestellt. Im Text wird der Begriff des Paradieses wiederholt auf sarkastische Weise verwendet. Dies geschieht mit dem Ziel, dahingehende Botschaften der kommunistischen Gegenseite durch die

63 Vgl. Pilkington: Russia's Youth and its Culture, $47 \mathrm{f}$.

64 So wurde nicht nur in Bezug auf die Arbeiter und Bauern, sondern explizit im Hinblick auf die Kinder und Jugendlichen von deren Befreiung durch den Bolschewismus geschrieben: »Die Oktoberrevolution in Rußland hat nicht nur die Arbeiter und Bauern aus der Knechtschaft des Zarismus befreit, sie befreite vor allem die Kinder aus der Knechtschaft, Verlogenheit und Heuchelei der bürgerlichen Gesellschaft, deren Erziehungsideal es ist und sein muß, dem Kinde schon in seinem zartesten Alter die Prinzipien der Profitgier, des rücksichtslosen Konkurrenzkampfes und der Ausbeutung beizubringen. Ueberall in Rußland wurde sofort nach dem Siege der Bolschewiki daran gegangen, dem Kinde den Weg zu ebnen aus diesem Sumpf der kapitalistischen Verdummung in die weite und helle Landschaft der natürlichen Erkenntnis.« Anon.: »Spartak«. Haus der Kinder in Moskau. In: AIZ, 1927, Nr. 3, 13.

65 Anon.: Kinderelend in Sowjetrußland. In: ILB, 1928, Nr. 19, 223-236 (Jahresausgabe). 
1930 / golge 30 Jifultierter geabahter.

Eeite 83

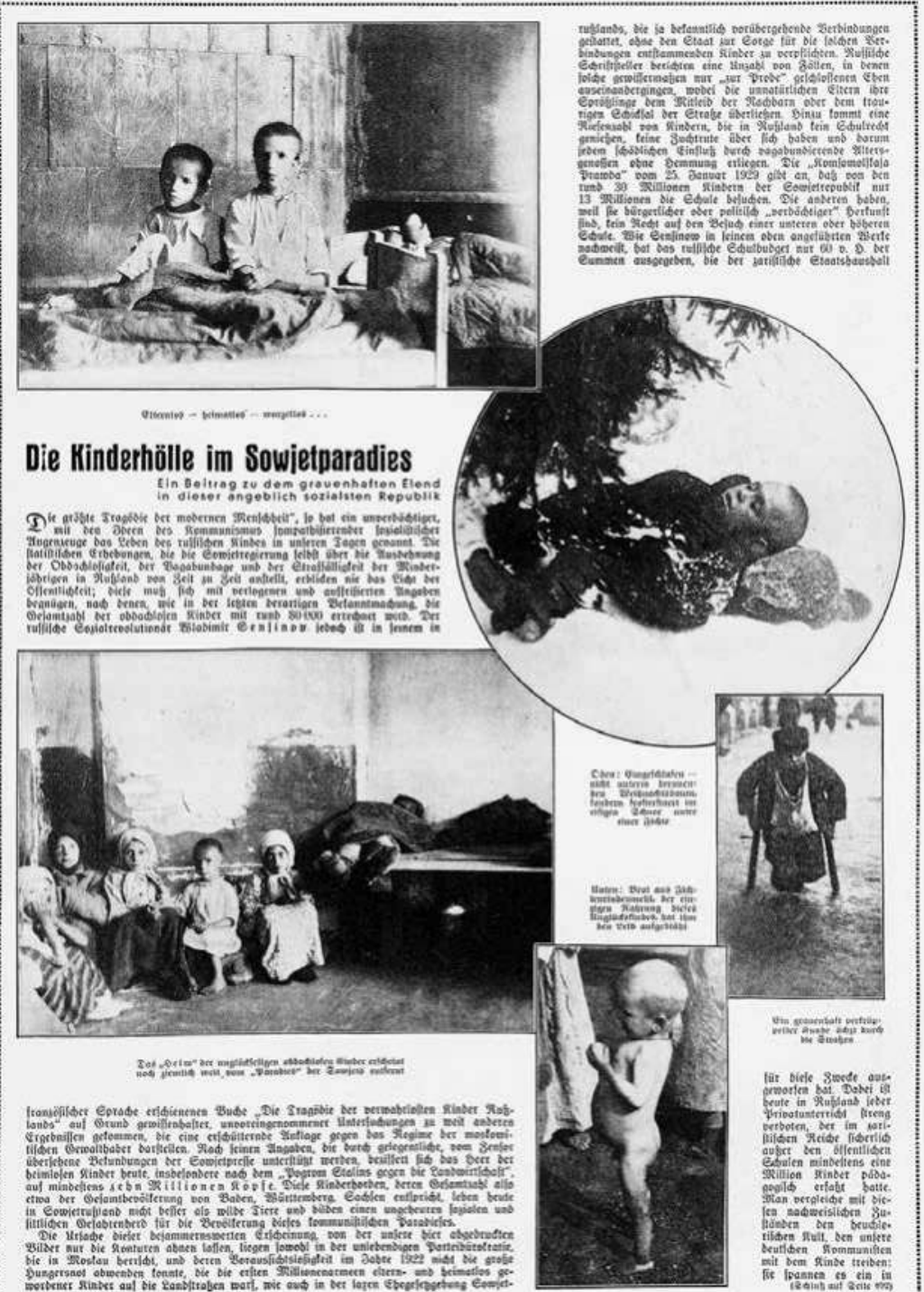

Abb. 24: Anon.: Die Kinderhölle im Sowjetparadies. In: ILB, 1930, Nr. 50, 889. Durch die drastische Darstellung von Missständen versuchte der nationalsozialistische ILB, das Propagandakonstrukt des »Kinderparadieses« Sowjetunion zu zerstören. 
vermeintlich unwiderlegbare Beweiskraft visueller Anschauung zu entlarven ${ }^{66}$ Dabei verkannte die Redaktion des ILB sogar noch die eigentliche Tragweite der Hungerkatastrophe als strategisches Mittel Stalins und damit die Chance auf einen noch größeren propagandistischen Coup. Sie klagte die sowjetische Führung lediglich wegen des "Versagens" in der Ernährungskrise an und führte die hohe Zahl obdachloser Kinder auf grobe Verwaltungsdefizite zurück. $^{67}$

Als reine Gegenpropaganda im innenpolitischen Deutungskampf um die größere "Kinderfreundlichkeit« zwischen den ideologischen Kontrahenten KPD und NSDAP lässt sich dies indes nicht abtun: Die Jahre 1927 bis 1932 und damit der unmittelbare zeitliche Kontext der betreffenden Artikel war die entscheidende Phase in Stalins Hungerkrieg, den das Regime insbesondere gegen die Kulaken in der Ukraine mit großer Brutalität führte. Bis weit in die 1930er Jahre hinein forderte dieser Millionen von Todesopfern. ${ }^{68}$

Auch gemäßigte Illustrierte reagierten durch eine entsprechende Gegenberichterstattung auf die von der AIZ prononcierte Vorstellung von der Sowjetunion als einem $»$ Land der Kinder ${ }^{69}$. So zeigt die MIP bereits 1926 Berge von Leichen verhungerter Kinder und konterkariert damit die bolschewistische Programmatik zur Kinder- und Jugendfürsorge. ${ }^{70}$ Die BIZ berichtet mehrmals über hohe Zahlen obdachloser und »verwilderter« Kinder, die durch das Raster staatlicher Fürsorge fielen beziehungsweise im Wissen um die schmalen Ressourcen der Kinder- und Jugendfürsorge bewusst vernachlässigt würden. ${ }^{71}$

$66 »$ Diese Kinderhorden [...] leben heute in Sowjetrußland nicht besser als wilde Tiere und bilden einen ungeheuerlichen sozialen und sittlichen Gefahrenherd für die Bevölkerung dieses kommunistischen Paradieses.« Anon.: Die Kinderhölle im Sowjetparadies, 889.

67 "Die Ursache dieser bejammernswerten Erscheinung, von der unsere hier abgedruckten Bilder nur die Konturen erscheinen lassen, liegen sowohl in der unlebendigen Parteibürokratie, die in Moskau herrscht, und deren Voraussichtslosigkeit im Jahre 1922 nicht die große Hungersnot abwenden konnte, die die ersten Millionenarmeen eltern- und heimatlos gewordener Kinder auf die Landstraßen warf, wie auch in der laxen Ehegesetzgebung Sowjetrußlands, die ja bekanntlich vorübergehende Verbindungen gestattet, ohne den Staat zur Sorge für die solchen Verbindungen entstammenden Kinder zu verpflichten.» Ebd.

68 Vgl. Conquest, Robert: The Harvest of Sorrow. Soviet Collectivization and the TerrorFamine. London 2002, hier insbesondere 58-163; Graziosi, Andrea: The Great Soviet Peasant War. Bolsheviks and Peasants, 1917-1933. Cambridge, Massachusetts 1996, 46-70.

69 "So darf Rußland heute ohne Uebertreibung das Land der Kinder genannt werden [...]«. Anon.: »Spartak«. Haus der Kinder in Moskau. S. 13.

70 Anon.: Die Kinderhölle in Rußland. Streiflichter zum Problem des bolschewistischen Staates. In: MIP, 1926, Nr. 26, 606 (Jahresausgabe).

71 Bloem, Walter: Verwilderte Kinder in Rußland. In: BIZ, 1927, Nr. 21, 841-843 (Jahresausgabe). Und: Rundt, Arthur: Die Landstraßenkatze wird gezähmt. Der Kampf gegen die verwilderten Kinder in Sowjetrußland. In: BIZ, 1931, Nr. 2, 58 f. (Jahresausgabe). 
Dagegen affirmierte die AIZ konsequent das Narrativ vom Bolschewismus als dem Befreier der Jugend von den gesellschaftlichen und wirtschaftlichen Zwängen des Zarismus. Gleichzeitig verwies sie auf die Abhängigkeit eines gelingenden Sozialismus von der jungen Generation, ohne deren Hilfe sich die neue Ordnung nicht gegen die Beharrungskräfte der überwundenen Zeit aufrechterhalten lasse. Insbesondere am Beispiel der Jungen Pioniere wird die Stilisierung der Jugendlichen zur inneren Garantiemacht des Bolschewismus und zu Wegbereitern des Sozialismus deutlich. ${ }^{72}$

Die AIZ veröffentlichte zahlreiche Artikel zu den Jungen Pionieren, die apologetisch auf die Kritik an der Militarisierung der Jugendlichen in der UdSSR reagierten. Man versuchte, den vollständigen staatlichen und parteilichen Durchgriff auf Jugendliche und ihre Lebenswelt, wie er nicht nur von den genannten bolschewistischen Jugendorganisationen Komsomol und Pionieren, sondern in erheblichem Maße auch von der Roten Armee angestrebt wurde, in ein aufklärerisches Bildungsnarrativ einzubetten. Ausländern könne es dieser Darstellung zufolge zwar beim Anblick der »vor Gesundheit und Kraft strotzenden" sowjetischen Jugend »bei Demonstrationen oder Festzügen" so scheinen, »als ob die jungen Pioniere sich durch Sport und Leibesübungen auf die Rote Armee « vorbereiteten. Dies jedoch würden höchstens »die Pfadfinder im nationalen Deutschland« tun, nicht aber die Jungen Pioniere. Ihnen gehe es nicht um die Pflege des kriegerischen Geistes. Vielmehr sei die Rote Armee »von Anfang an eine Hochburg gegen den Analphabetismus, gegen jegliche Unwissenheit überhaupt ${ }^{73}$ gewesen und nehme somit lediglich ihren erzieherischen Auftrag in der Jugendausbildung wahr.

Weiter wird die übergeordnete Aufgabe der Pioniere von der AIZ als Missionstätigkeit für den Bolschewismus beschrieben, die ohne Alphabetisierung schlechterdings unmöglich gewesen sei. Die AIZ räumt also die propagandis-

72 Zuvor waren bereits die engen Verbindungen zwischen Komsomol, Jungen Pionieren und der Roten Armee während des russischen Bürgerkrieges und darüber hinaus im Vorläufer der AIZ, "Sichel und Hammer«, beschrieben worden: "Das ist der Geist des Russischen Kommunistischen Jugendverbandes, des Komsomol. Den rein militärischen Aufgaben folgten friedliche, organisatorische und produktive, aber der Geist der Initiative, des >die Jugend an die Front! ist der gleiche geblieben. Den sechshunderttausend drei- und viermal gesiebten Mitgliedern der Russischen Kommunistischen Partei stehen ebenso viele `Komsomolzen`, Jungkommunisten, gegenüber als `Sfjena`, als Ablösung [...]. Sie bildet den Grundstock der Roten Armee, die Cadres der Roten Offiziersschulen und Universitäten, den Nachwuchs für die Verwaltung des Produktions- und des Staatsapparates, sie ist die Hoffnung auf eine neue Gesellschaft. - Wie der 'Komsomol nach oben organisch in die Partei hineinwächst, ebenso organisch wurzelt er nach unten in der Organisation der Jungen Pioniere [ ...] 600.000 Mann ist diese Armee der jungen Leninisten stark." Anon.: Junge Pioniere. In: SUH, 1924, Nr. 1, 13. Ähnlich: Anon.: Russlands Junge Generation. In: AIZ, 1929, Nr. 30, 6.

73 Anon.: Sowjet-Rußlands Sorge um seine Jugend. In: AIZ, 1925, Nr. 12, 4. 
tische Zielsetzung der Alphabetisierungsbemühungen und der Jugendbetreuung ein. Auf dem Lande waren Jugendliche oft die einzigen Multiplikatoren für Botschaften der Partei, was sie für eine großflächige propagandistische Verankerung ideologischer Inhalte unverzichtbar machte. "Sowjet-Rußlands Sorge um seine Jugend " war zuvörderst eine Sorge um die Sicherung einer ausreichend breiten Machtbasis in der Bevölkerung. ${ }^{74}$

Bürgerliche, nationalsozialistische und kommunistische Publikationen traten beim Thema Jugend in einen konfrontativen Dialog. Im Rahmen dessen reagierten alle Beteiligten, je nach Blickwinkel, auf allzu schillernde Darstellungen der sowjetischen Jugendförderung oder auf die Kritik an deren Methoden. Dabei entstanden Verweisketten zwischen »neutralen« Publikationen und denen der politischen Ränder. Diese zeigten sich besonders ab 1925, als sich die Polarisierung der deutschen Gesellschaft zu verstärken begann. Das Diskursobjekt Jugend spielte eine Doppelrolle: einerseits als schützenswertes gesellschaftliches Fundament, andererseits als besonders scharfes Schwert im Kampf für die Realisierung politischer Utopien. Deutlich wird dies im verbissenen Wettbewerb der politischen Extreme um die Gunst der jugendlichen Generation. Dieser Kampf wurde von gemäßigten Medien mit mahnenden Worten begleitet, die (zurecht) die ideologische Instrumentalisierung einer ganzen Generation fürchtete. Es ist diese Ambivalenz, die die Jugend von den meisten anderen Diskursgegenständen unterscheidet: Sie ist zugleich Objekt und Adressat der über sie geführten Debatten.

74 Ein Lenin-Zitat, das in einer AIZ-Ausgabe zum zehnjährigen Jubiläum der Revolution von 1917 erschien, fasst dies so zusammen: »Diejenige Generation, die heute 15 Jahre alt ist und die in 10 bis 12 Jahren in der kommunistischen Gesellschaft leben wird, muß eben die Aufgabe ihrer Erziehung so stellen, daß in einem jeden beliebigen Dorfe, in einer jeden beliebigen Stadt täglich die oder jene Aufgabe der gemeinsamen Arbeit praktisch von der Jugend gelöst wird, und wenn sie auch noch so klein oder leicht ist. In dem Maße, wie das in jedem Dorfe stattfinden wird, in dem Maße, wie die Jugend beweisen wird, daß sie imstande ist, ihre Arbeit solidarisch zu organisieren, zu vereinigen - in dem Maße werden auch die Erfolge des kommunistischen Gesellschaftsaufbaus gesichert werden." Lenin, V. I.: Jugend. In: AIZ, 1927, Nr. 43, 13. In der deutschen Presse wurde von einzelnen Beiträgern im Übrigen auch angezweifelt, dass die Jugend der Sowjetunion tatsächlich so politisiert und durch staatliche Stellen vereinnahmt sei. Zwischen den vielen Artikeln zur politisierten Jugend der UdSSR fanden sich auch wenige, welche die jugendliche Lebenswelt jenseits von Staat, Ideologie und Politik zu beleuchten versuchten. Unter anderem: White, William C.: Junge Leute zwischen 18 und 24. Der dritte Aufsatz unserer Veröffentlichung »So lebt der Mensch in Rußland«. In: UHU, 1932, Nr.7, 47-55. 


\subsection{Bildung}

Max Weber war der Meinung, eine Gesellschaft könne der Jugend und damit ihrer eigenen Zukunft den gewünschten Charakter nicht aufzwingen, gleich welchen Anforderungen er genügen, welchen Idealen er folgen solle. "Aber wir können wollen", so fährt Weber fort, "daß sie (die ‘Zukunft», d.h. die Nachgeborenen) in unserer Art die Art ihrer eigenen Ahnen erkennt. Wir, mit unserer Arbeit und unserem Wesen [...] wollen die Vorfahren des Zukunftsgeschlechts sein. « $^{75}$

In der institutionalisierten Erziehung, also dem Bildungswesen einer Gesellschaft, manifestiert sich diese Einsicht. Es sichert den erwachsenen Zeitgenossen vorübergehende Deutungshoheit über Werte und Sinngehalte, die in das kollektive Bewusstsein der nachfolgenden Generation eingeschrieben werden. Politische Systeme, vor allem neue und totalitäre, sind zur Kontrolle der Gesellschaft und weitgehenden Umdeutung tradierter Sinngehalte in besonderem Maße auf diese Deutungshoheit angewiesen. Staatlich organisierte Bildung ist also unverzichtbar zur politischen Zukunftssicherung einerseits und zur Realisierung programmatischer Inhalte andererseits. Die Sozialisation nachkommender Generationen im Einklang mit Grundsätzen und Utopien, die als modern und zukunftsweisend empfunden wurden, dient der Übertragung von in der Vergangenheit oder Gegenwart gesteckten, gesellschaftlichen Zielen auf die Zeit, in der sie schlussendlich zur Realisierung kommen sollen.

Angesichts seiner herausragenden Sozialisationsfunktion überlappte sich die Berichterstattung zum Bildungswesen der Vereinigten Staaten und der Sowjetunion zu großen Teilen mit dem Jugenddiskurs. Der trotz widerstreitender Bewertungen und Interpretationen in allen Publikationen ausgeprägte Fokus auf die Förderung oder eben Instrumentalisierung von Jugendlichen brachte in der Konsequenz auch zahlreiche Betrachtungen der Bildungsanstrengungen in beiden Ländern mit sich. Die lebhafte Diskussion über Art und Qualität des Bildungswesens dient als Ausweis der Wichtigkeit, die der Heranbildung der kommenden Generation beigemessen wurde. Die Bildung der Jugend erschien in entsprechenden Betrachtungen gleichermaßen als die Formung der Zukunft und - insbesondere im Falle der USA - als Reproduktion und Tradierung eines angenommenen Volkscharakters" materialistischer und praktischer Prägung.

75 Weber, Max: Gesammelte Politische Schriften. Hg. von Johannes Winckelmann. Tübingen $1958,13$. 


\subsubsection{Sowjetische »Nationsbildung"}

Der Aufbau eines vollkommen neuen Gesellschaftsmodells erforderte in der UdSSR über den Umbruch von 1917 hinaus im doppelten Wortsinn die »Bildung « einer neuen Nation. Selbst im Vergleich zum deutschen Bildungssystem, das zwischen Kaiserreich und Republik von Lehrplänen und -methoden bis zur Neuaushandlung der Rolle der Kirchen tiefgreifende Veränderungen erfuhr, ${ }^{76}$ nahmen sich die Pläne zum Aufbau eines sowjetichen Erziehungswesens geradezu gigantisch aus. Sucht man in dessen zeitgenössischer Betrachtung nach belastbaren Fakten, steht man noch mehr als in anderen Zusammenhängen vor der Aufgabe, sich einen Weg durch das Dickicht aus Jubelmeldungen der kommunistischen Presse, durch ebenso ideologiegetränkte Schreckensmeldungen rechtskonservativer Blätter und vorsichtig pessimistische Bestandsaufnahmen der Bürgerlichen zu bahnen.

Hans Vorst begibt sich 1919 im BTB auf ebendiese Suche nach der "Wahrheit über Rußland ${ }^{77}$ und unterzieht die fantastischen Erfolgsmeldungen, die er der kommunistischen Presse in Deutschland entnommen hat, einer kritischen Prüfung. Skeptisch ist Vorst insbesondere gegenüber den dort zitierten Berichten des Volkskommissariats für Volksaufklärung. Jenes will mit der "neuen Schule« im Handumdrehen »eine gänzlich neue und wahrscheinlich höchst fruchtbare Art der Kindererziehung geschaffen« und »nicht nur allen Kindern ohne Ausnahme das formale Recht, die ihrem Alter entsprechenden Bildungsanstalten zu besuchen " verschafft haben. Auch die Versorgung »mit Nahrung, Kleidung und Schuhwerk" sei für alle Kinder und Jugendlichen nunmehr vollständig sichergestellt. ${ }^{78}$

Das »authentische Material« des Volkskommissariats, welches auch Vorst in seinem Text wohlweislich apostrophiert, erscheine seines Erachtens angesichts von »Hungersnot und Stillstand der Industrie« wie viele andere gesteckte Ziele bolschewistischer Bildungspolitik mehr als frommer Wunsch der Regierung denn als tatsächlich erreichbar. ${ }^{79}$ In Vorsts Beurteilung neuer Wege der Pädagogik, die künftig der »Bildung und Erziehung die produktive Arbeit zu-

Dazu: Lamberti, Marjorie: The Politics of Education. Teachers and School Reform in Weimar Germany. New York u. a. 2002.

77 Vorst, Hans: Die »Wahrheit« über Rußland. In: BTB Nr. 335 vom 23.07.1919, 1 f.

78 Ebd., 1.

79 „Für die Arbeiter werden in den Fabriken Vorlesungen über Geschichte und Nationalökonomie veranstaltet. Zur Aufklärung der Analphabeten werden allgemeinverständliche Vorlesungen über wissenschaftliche und über die brennendsten Lebensfragen abgehalten. Und vollends die Hochschule! Sie ist jetzt, ohne jedes Diplom allen zugänglich, die zu lernen wünschen, eine Zahlung wird nicht mehr erhoben, im Gegenteil, der bolschewistische Staat sorgt jetzt für die >soziale Sicherstellung`aller Studierenden [...]. Man könnte sagen, das sauthentische Material unserer Radikalen zeige doch wenigstens den guten Willen der Sowjetregierung.« Ebd., 2. 
grunde« legen wollten anstatt sie um den Inhalt von Lehrbüchern herum zu konzipieren, ${ }^{80}$ flüchtet er sich angesichts der bestehenden und auch von anderen Beiträgern ähnlich beurteilten ${ }^{81}$ desolaten Versorgungslage in Sarkasmus: »a, leider kann sie oft genug keine Bücher mehr zugrunde legen, einfach weil die russische Bücherproduktion so zurückgegangen ist, daß nicht genügend Bücher da sind und die Kinder ohne Bücher in der Schule sitzen müssen. ${ }^{82}$

Auch Vorsts zeitweiser Kollege Maxim Gorki sah in der schlechten Versorgung mit Büchern das Hindernis für die von den Bolschewiki angestrebte Bildungsexpansion. Gorki verfasste während seines Deutschlandaufenthaltes 1921/22, der ebenso durch eine Tuberkulosebehandlung wie durch Dissonanzen mit Lenin bedingt war, Gastbeiträge für die BTB. ${ }^{83}$ Vor allem die Zensur verhindere laut Gorki eine Lösung des Bücherproblems. Ihretwegen gebe es »neue Bücher in Rußland beinahe gar nicht, die alten« würden »verbraucht, vernichtet, oder sie verschwinden.«Ironischerweise sei selbst bolschewistische

$80 \mathrm{Zu}$ diesen neuen Wegen in der Wissensvermittlung schrieb beispielsweise die AIZ: „Gott fürchten und den Zaren ehren, das war das Motto der alten zaristischen Schule. Die Kinder lernten in erster Linie Gebete, außerdem etwas Lesen, Schreiben und Rechnen. Nach drei bis vier Jahren war das Gelernte, was in keinerlei Beziehung zu dem Leben und Schaffen des Bauern und Arbeiter stand, in den meisten Fällen wieder vergessen [...]. Lenin war es, der am Tage nach dem Oktoberumsturz die Losung aufwarf: ,Weg mit dem Analphabetentum! «, was ebenso für die Kinder wie für die Erwachsenen galt. Ebenso unaufschiebbar war die Schaffung einer einheitlichen Arbeitsschule für alle Kinder der Sowjetrepubliken, die mit der Schule der nationalen Unterdrückung und Klassenherrschaft ein Ende machte [...]. Die Sowjetarbeitsschule lehrt nicht etwa bestimmte Fächer, sondern geht unmittelbar auf das schaffende Leben ein, auf die gesellschaftlichen Beziehungen und endlich auf die Natur und deren Beherrschung. Versuchsgärten und Werkstätten lehren höhere, kollektive Arbeits- und Wirtschaftsformen und helfen durch Agitation und Beispiel die Umgestaltung aller wirtschaftlichen und gesellschaftlichen Verhältnisse durchzuführen. A Anon.: Sowjetrußlands Jugend. In: AIZ, 1925, Nr. 8, 13. Und: »Daneben - aber erst an zweiter Stelle stehen die neuen Erziehungsanstalten, die neuen Schulmethoden, die neuen - geglückten oder mißlungenen - Experimente. Sie haben drei Grundtendenzen verfolgt: erstens, die Jugend mit dem sogenannten `kollektivistischen Bewußtsein zu erfüllen; zweitens, sie für eine praktische Tätigkeit innerhalb einer dem Sozialismus entgegenschreitenden Gemeinschaft heranzubilden; drittens, sie zur Areligiosität, wenn nicht zur Antireligiosität zu erziehen.« Roth, Joseph: Reise in Rußland. XVII. Die Schule und die Jugend. In: FZT Nr. 43 vom 18.01.1927, 2.

$81 »$ Von Bedeutung ist auch das Problem der Versorgung der Schule mit Büchern und Lehrmitteln. Seit drei Jahren werden in Rußland, mit der Ausnahme bolschewistischer Propagandaschriften, so gut wie keine Bücher gedruckt. Sogar in den Städten sind keine Schulbücher vorhanden, um von Schulheften schon gar nicht zu reden. Die russischen Kinder haben schon seit drei Jahren keine Hefte gesehen. Es gibt fast gar keine Schreibfedern, es fehlt an Tinte und Bleistiften.» Anon. (B.E.): Bildungsnotstand im bolschewistischen Rußland. Die Lage der Gelehrten. In: VZT Nr. 123 vom 15.03.1921, 9.

82 Vorst: Die Wahrheit über Rußland, 2.

$83 \mathrm{Zu}$ Gorkis Zeit in Deutschland und seiner zeitweiligen Entfernung von der Sache der Bolschewiki: Yedlin, Tovah: Maxim Gorky. A Political Biography. Westport, Connecticut u. a. $1999,147-176$. 
Agitationsliteratur »schwer zu bekommen, von den Büchern, die einen allgemeinen kulturellen Charakter haben, gar nicht zu sprechen. ${ }^{84}$ Die »Liquidation der Analphabeten ", gemeint ist die des Analphabetismus, habe zwar zarte Erfolge gezeitigt, es fehle aber an der Lektüre, die neu gewonnen Lesekenntnisse auch tatsächlich anzuwenden. ${ }^{85}$ Dass in der Einschätzung Gorkis, ohne die flächendeckende Versorgung mit aufklärerischer Literatur würden »die Massen eine tote Kraft bleiben «, ein zentraler Grund seines Zerwürfnisses mit Lenin bestand, sei hier nur am Rande erwähnt.

Die Alphabetisierung, das wird aus diesen beiden Quellenbeispielen deutlich, wurde von Beginn an als die elementare Aufgabe sowjetischer Bildungspolitik angesehen. Sie sollte noch bis Ende der 1920er Jahre das bestimmende Thema in diesem Kontext bleiben. Die Maßnahmen, die im Zusammenhang mit grundständiger Bildung und Alphabetisierung diskutiert wurden, adressierten aus deutscher Perspektive indes Problemlagen, die man eher der Sphäre der historischen Bildungsforschung zuschlug. ${ }^{86}$ Sie dürften daher kaum als Ausdruck einer ausgeprägten sowjetischen Fortschrittlichkeit in Sachen Bildung interpretiert worden sein. Man betrachtete diese Anstrengungen vielmehr als Versuch, die zweifelsohne vorhandenen Defizite in diesem für Industriegesellschaften so wichtigen Bereich aufzuholen. Als glänzendes Vorbild taugte all dies nicht.

Die Gewährleistung rudimentärer Bildung, die in den Augen der meisten nichtkommunistischen Beiträger wegen der massiven ideologischen Durchsetzung des Lehrangebots noch zusätzlich entwertet wurde ${ }^{87}$ galt in der Beurtei-

84 Gorki, Maxim: Der Bücherhunger in Rußland. In: BTB Nr. 549 vom 29.11.1921, 5.

85 »Man hat sehr viel von der `Liquidation der Analphabeten geschrieben, und es ist mir gut bekannt, daß diese Arbeit in sehr vielen Fällen gute Resultate gezeitigt hat: während kurzer Zeit hat man sehr vielen das Lesen beigebracht. Nun gibt es aber für diese Menschen keine Lektüre. Die Agitationswerke sind für sie meist unverständlich und werden dabei auch noch so gedruckt, daß auch gutgebildete Leute sie nur mit großen Schwierigkeiten lesen können. Deshalb bemerken wir immer wieder Rückfälle in den Analphabetismus: zum [sic] Frühling hat man dem Menschen das Lesen beigebracht, und zum Herbst hat er schon diese Kunst verlernt, da er keine Gelegenheit und Möglichkeit hatte, sie praktisch anzuwenden und sich zu üben.« Ebd.

86 So hatte im deutschsprachigen Raum das Herzogtum Pfalz-Zweibrücken bereits 1592 die Schulpflicht eingeführt. Bis Anfang des 19. Jahrhunderts war in allen Gebieten deutscher Sprache der Schulbesuch per Gesetz verpflichtend, wenn diese Pflicht auch mit unterschiedlicher Strenge durchgesetzt wurde. Vgl. Sehling, Emil (Begr.)/Wolgast, Eike/Seebaß, Gottfried (Hg.): Die evangelischen Kirchenordnungen des 16. Jahrhunderts. Band 18: Rheinland-Pfalz I. Tübingen 2006, $406 \mathrm{f}$.

87 »Der Hauptzweck der Schule drüben aber ist die Politik. Der Kommunismus ist der einzige Wertmesser, wie ehedem die Religion der Klosterschule. Und ganz mit den gleichen Mitteln wappnet sich dieser neue Glaube: mit 8 Jahren werden die jungen >Pioniere auf den Kommunismus vereidigt. Die Bildung ist nicht frei, oberste Richtschnur ist immer der Kommunismus.«Schmitz, K.E. F.: Das rote Gesicht. Ein russischer Bilderbogen von Dr. K.E. F. Schmitz. In: RDM, 1927, Nr. 6, 645 (Jahresausgabe). 
lung der sowjetischen Bildungspolitik als das gerade noch Machbare - man müsse schlicht im Hinblick auf die Sowjetunion andere, niedrigere Maßstäbe ansetzen. ${ }^{88}$ Die deutsche Bildung indes, so der selbstvergewissernde Tenor, habe »darum ganz andere, viel höhere Aufgaben, ist sich selbst Zweck und zielt auf die höchste Leistung. $"{ }^{89}$ Die erste schulpolitische Frage in Deutschland sei also die nach dem Erfolg einer spezifischen Lehrmethode oder einer bestimmten Schulform. In Sowjetrussland laute sie schlicht und ergreifend: „Wie viele Analphabeten hat Sowjetrußland? «" Man sehe also dort nicht zuerst "etwa lauter überraschend neue Schulen [...], sondern lauter Analphabetenkurse. (Das ist kein Tadel, sondern ein Lob).."11

Zwar waren die Alphabetisierungskampagnen angesichts des hohen Wertes, der dem geschriebenen Wort in Propagandafragen beigemessenen wurde, nicht auf die Jugend beschränkt. Sie setzten, zumindest laut Plan, bei allen Schichten und Altersgruppen an..$^{92}$ Ihrer zentralen Rolle in der »Aufklärung" der sowjetischen Bevölkerung entsprechend, wurden aber zuvörderst die Jugendlichen in der kommunistischen illustrierten Presse zu regelrechten Epigonen der bolschewistischen Heilslehre stilisiert. Vielfach wurden sie im Kreise ihrer jüngeren, des Lesens unkundigen Bewunderer und Pionierkameraden

88 »Andere Länder - andere Maßstäbe! Für Rußland mag dieses Prinzip vielleicht das einzig richtige sein, denn es gilt hier ja zunächst einmal ein Fundament zu legen, allgemeine Bildung überhaupt erst zu schaffen, die bei uns ja seit Jahrzehnten schon besteht.« Ebd.

89 Ebd.

90 Roth, Joseph: Reise in Rußland. XVII, 1.

91 Ebd.

92 So berichtete man in der Deutschen Allgemeinen Zeitung (DAZ) von einem regelrechten Kult um Bücher und Broschüren, der durch die zunehmende Alphabetisierung auch breiterer Bevölkerungsschichten ausgelöst worden sei: »Das Symbol der Bestrebungen um ,Volksaufklärung`, die seitens der Sowjetregierung systematisch betrieben wird, ist die Verbreitung von Buch und Broschüre. Aus einer reinen intellektualistischen Kulturauffassung heraus glaubt der Sowjetstaat, in dem gedruckten Wort die wertvollste Waffe zu haben, um die Mentalität der Bevölkerung zu wandeln [...]. Selbst Männer und Frauen im Greisenalter erlernen noch mühsam das Lesen und Schreiben; breite Schichten versuchen durch Lektüre besonders von Lehrbüchern und Broschüren ihre elementarsten Kenntnisse zu erweitern. Kaum in einer anderen Stadt sieht man in der Straßenbahn soviel [sic] Menschen mit einer Druckschrift sitzen wie in Moskau, und man sieht vielen der Leser die große Mühe an, die es sie kostet, das gedruckte Wort aufzunehmen.«Fischer, Max: Das Buch im Sowjetstaat. In: DAZ Nr. 586 vom 14.12.1928, 1. Parallel war auch die AIZ bemüht zu zeigen, dass ganze Familien von den Maßnahmen der »Volksaufklärung" profitierten. Sie stellte mitunter sogar den gesamten familiären Alltag als um die vermeintlich reichhaltigen Bildungsangebote herum organisiert dar. Unter anderem: Anon.: 24 Stunden aus dem Leben einer Moskauer Arbeiterfamilie. In: AIZ, 1931, Nr. 38, 750-765 (Jahresausgabe). Und auch die Bauern wurden laut AIZ mit grundlegenden wissenschaftlichen Kenntnissen vertraut gemacht, was dem Zweck diente, dieses Wissen in der Folge beim Aufbau landwirtschaftlicher Großbetriebe einzusetzen. Vgl. Anon.: Aufklärung unter den Bauern. In: SUH, 1924, Nr. $1,7$. 
ins Bild gesetzt, wie sie offizielle Bekanntmachungen verlasen oder Artikel aus der Jugendzeitung des Komsomol vortrugen. ${ }^{93}$

Juristisch, so wusste man in der FZT zu berichten, ging man flankierend mit absurd harten Urteilen gegen Menschen vor, die sich Maßnahmen zur Alphabetisierung entzogen, war doch dekretiert worden, »das Uebel [des Analphabetismus, D.F.] von Grund aus [sic] zu beseitigen«. Die Regierung war fest entschlossen, »das Unkraut, das die Bildungsgefilde des ihnen anvertrauten Bezirks verunglimpfte, mit der Wurzel auszurotten. ${ }^{94}$ Gegen Ende der 1920er Jahre hatte sich zwar in der Beurteilung der Gesamtlage des sowjetischen Bildungswesens keine Wende zum Positiven vollzogen. Dennoch begannen aus Sicht erfahrener Russlandberichterstatter wie Arthur Feiler von der FZT, die radikalen Maßnahmen zur Durchalphabetisierung der nachkommenden Generation Wirkung zu zeigen. Dies wurde, bei aller weiterhin vorhandenen Skepsis, als Erfolg der Bolschewiki anerkannt:

„Der Kampf gegen das Analphabetentum [...] gehört zu dem Positivsten, was das neue Regime leitet und plant. Bei allen Mängeln und Unzulänglichkeiten des Anfangs empfindet man es wirklich wie eine riesige Volksprozession in die Schulen [...]. [U]nter dem Zarismus 35000 Schulkinder und darunter 400 Mädchen, unter der menschewikischen Regierung 1919/20 55000 Schulkinder, darunter 1500 Mädchen, jetzt 175000 Schulkinder und darunter 55000 Mädchen [...]. Erhebliche Summen aus den Erträgen der industriellen staatlichen Unternehmungen und aus den einzelstaatlichen Budgets, vielfach mehr als ein Drittel der genannten Einnahmen dienen dieser Bildungsarbeit. ${ }^{95}$

Ungeachtet der fragwürdigen Verlässlichkeit der Zahlen, entsteht hier durchaus der Eindruck einer - auch unter emanzipatorischen Gesichtspunkten erfolgreichen Bildungsoffensive. Mehr noch: Anfang der 1930er Jahre zeigte sich, entgegen dem zuvor festgefügten Bild vom geistig armen Russland, die Tendenz, dieses als Musterbeispiel gelungener Bildungspolitik zu preisen. In der Nachlese eines Vortrags von Anatoli Lunatscharski, seines Zeichens Volkskommissar für das Bildungswesen, wird der Besprechung der gemachten Fortschritte ${ }^{96}$ die Mahnung angefügt, in der deutschen Bildungspolitik sei

93 Unter anderem: Anon.: Aus aller Welt. Im Pionierhaus des Moskauer Volksbildungsinstituts: Der Gruppenführer liest die Jugendzeitung vor. In: AIZ, 1927, Nr. 2, 16.

94 Goritsch, A.: Analphabeten-Prozeß in Rußland. In: FZT Nr. 348 vom 11.05.1925, 1.

95 Feiler, Arthur: Das Experiment des Bolschewismus. Aus dem Tagebuch einer russischen Reise. In: FZT Nr. 603 vom 15.08.1929, $1 \mathrm{f}$.

96 »Was haben die Sowjets in den 14 Jahren ihres Regimes kulturell geschaffen? Zunächst die Liquidierung des Analphabetentums. Aus den von Herrn Lunatscharski zitierten Statistiken wurde man nicht recht klug. Aber das war auch nicht nötig. Daß die Zahl der Analphabeten auf ein Minimum zusammengeschrumpft ist, wissen wir auch aus anderen Quellen; wir freuen uns darüber weil dies wirklich ein kultureller Fortschritt ist, und wir erkennen die Bemühungen der neuen russischen Pädagogen in diesem Falle an. Große 
nun nicht »kritiklos alles Sowjetrussische nach Deutschland (zu) übertragen«. Kritisiert wird auch der weit verbreitete Enthusiasmus »der Leute, die jedesmal [sic] vor Begeisterung hochgehen, sowie nur von Rußland die Rede ist, die jedes russische Fetzchen preisen, bloß, weil es russisch ist« und darüber "unser ganzes deutsches Kulturgut verneinen, bloß, weil es deutsch ist. ${ }^{47}$

Die Redaktion der AIZ war, qua politischen Sendungsbewusstseins, gegen solch mahnende Worte freilich immun, galt es ihr doch, die Anziehungskraft des Kommunismus als Gesellschaftsmodell in der deutschen Öffentlichkeit zu erhöhen. Am besten war dies im thematischen Zusammenhang des Bildungsdiskurses mit Fingerzeigen auf Defizite des deutschen Bildungswesens und Potentiale der sowjetischen Reformpädagogik zu bewerkstelligen. Deren Grundzüge und behauptete Vorteile wurden seit Ende der 1920er Jahre regelmäßig in der AIZ vorgestellt, was angesichts der nunmehr größeren Offenheit gegenüber bildungspolitischen Anregungen aus der UdSSR den erhofften Werbeeffekt versprach. Insbesondere die starke Ausrichtung der sowjetischen Pädagogik auf die Praxis in Produktion und Wirtschaft, die Erhöhung der Teilhabechancen sowie die Kooperation im Wissenserwerb wurden als zukunftsweisend heraus- und den angeblichen Fehlentwicklungen in der deutschen Bildungspolitik gegenübergestellt. ${ }^{98}{ }$ Aus dieser wahrhaft modernen, der sozialistischen

Verdienste haben sich diese Pädagogen unzweifelhaft auch erworben mit den Grammatiken, Lehrbüchern, Schulen, die sie den 25 oder 30 Völkergruppen verschafft haben, die in dem riesigen Slawenreiche versprengt leben.« Anon.: Kulturaufbau in Sowjetrußland Herr Lunatscharski prophezeit Herz und Gemüt. In: DAZ Nr. 502 vom 27.09.1931, 2.

97 Ebd.

98 »Jeder Arbeiter, der Kinder hat, weiß, daß es mit 'moderner Erziehung allein nicht getan ist. Die wirkliche Bildung ist in den bürgerlichen Ländern doch Monopol der herrschenden Klasse. Die Masse der Kinder der Werktätigen kann zu einer höheren Bildung praktisch nicht aufsteigen. Schon in den Mittelschulen, geschweige denn in den Hochschulen sind Arbeiter- und Bauernkinder eine Seltenheit. Dazu kommt dann noch, daß die Errungenschaften der modernen Erziehung in den letzten Jahren eine nach der anderen abgebaut werden: durch die von den Sozialdemokraten beschlossenen oder begünstigten Abmachungen zwischen den Regierungen und den Kirchen (die sogenannten Konkordate) wird die Schule mehr und mehr den Priestern ausgeliefert, und die Ansätze zu einer neuen Erziehung in den wenigen freien Schulen werden durch Streichungen an den Unterrichtsmitteln, am Werkunterricht und der Schulhygiene nach und nach beseitigt [...]. Durch den Beschluß des 16. Parteitages der Bolschewistischen Partei wird die ganze Jugenderziehung nach dem Grundsatz der 'polytechnischen Erziehung` aufgebaut. Das Ziel dieser Erziehung ist, die Jugend vom ersten Schultag an wirklich in die moderne Gesellschaft einzuführen und insbesondere sie fähig zu machen, die wirtschaftlichen Grundlagen des Lebens, den industriellen Arbeitsprozeß und die moderne Technik zu verstehen und zu beherrschen. Alle Unterrichtsfächer werden von Anfang an mit der produktiven industriellen Arbeit verbunden [...]. Darum gibt es in dieser Erziehung kein Verbot des Abschreibens und des Einsagens, die Schüler werden im Gegenteil dazu angehalten, sich bei ihren Arbeiten gegenseitig zu helfen.» Kurella, Alfred: Sozialistische Erziehung. In: AIZ, 1932, Nr. 34, $804 \mathrm{f}$. 


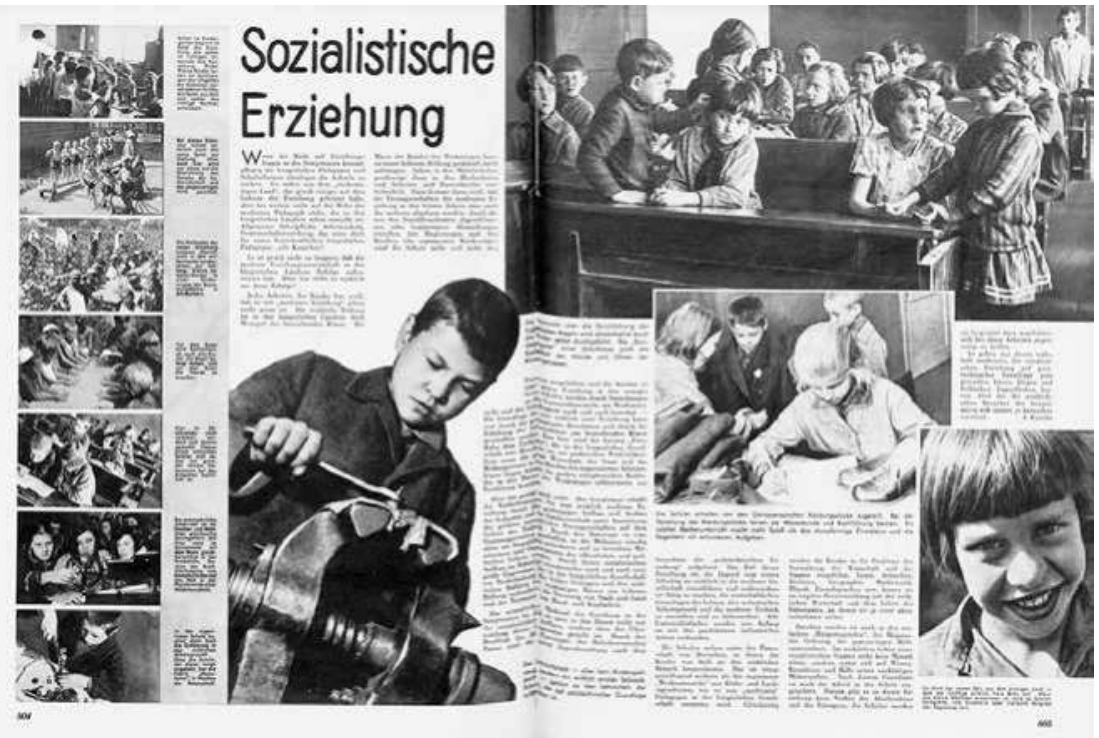

Abb. 25: Kurella, Alfred: Sozialistische Erziehung. In: AIZ, 1932, Nr. 34, 804 f. Der kooperative und praktische Charakter »sozialistischer« Pädagogik und Schulausbildung wurde in der kommunistischen Presse stark betont.

Erziehung", so die Quintessenz eines Gastbeitrags des Komsomol-Funktionärs und späteren ZK-Mitglieds der SED Alfred Kurella (Abb. 25), gingen »jene freien, klugen und fröhlichen Jugendlichen hervor, über die die ausländischen Besucher der Sowjetunion sich immer so besonders « wunderten. ${ }^{99}$

In der visuellen Gestaltung des Artikels spiegeln sich die beschriebenen Grundprinzipien, insbesondere der Praxisbezug und der kooperative Wissenserwerb wider. Auf der linken Seite sind in einem stilisierten Filmstreifen die verschiedenen Abschnitte der Jugendbetreuung nachvollzogen, vom Kindergarten (»Aber auch hier wird vor allem auf die Entwicklung des Geistes der Kameradschaft und der gegenseitigen Hilfe geachtet.« ${ }^{100}$ bis zum koedukativen Unterricht an der polytechnischen Schule (»Die Frau steht im Sowjetstaat mit dem Mann gleichberechtig in der Produktion. $)^{101}$. Die im Vordergrund befindliche Darstellung eines Jungen am mechanischen Schraubstock soll verdeutlichen, in welchem Maße sich die Definition von Praxisnähe in der sozialistischen Schulbildung vom beschaulichen »sogenannte(n) Werkunterricht 
mit seinen Klebe- und Laubsägearbeiten ${ }^{102}$ in Deutschland unterscheide. Artikel ähnlichen Zuschnitts, die die Vorzüge "sozialistischer Erziehung" priesen, erschienen im Jahre 1932 in regelmäßigen Abständen. ${ }^{103}$

Hinter der bildungspolitischen Kraftanstrengung der Alphabetisierung und Erstbeschulung der Kinder und Jugendlichen blieb das mediale Interesse an der Hochschulbildung und der Wissenschaftslandschaft der Sowjetunion merklich zurück. Umso pointierter wurde es auf den entsprechenden Meinungsseiten thematisiert. Zunächst verlief die diesbezügliche Berichterstattung unter dem Eindruck von Revolution, Bürgerkrieg und politischen Säuberungen im Lehrkörper russischer Universitäten erwartungsgemäß im omnipräsenten Katastrophenmodus in der Russlandberichterstattung.

In den Hochschulblättern der Vossischen Zeitung ist im Bürgerkriegsjahr 1921 angesichts mehrfach kolportierter Erschießungen ${ }^{104}$ antibolschewistisch gesonnener Professoren die Rede von der "Bildungsnot im bolschewistischen Rußland « ${ }^{105}$ Darunter leide - neben dem erschossenen Lehrpersonal, möchte man ergänzen - insbesondere der wissenschaftliche Austausch mit Westeuropa. In der Zusammenschau derart drastischer, über den gesamten Beobachtungszeitraum wiederholt thematisierter ${ }^{106}$ Repressionen und der finanziellen Vernachlässigung des Hochschulwesens insgesamt entsteht das Bild eines dezidierten Antiintellektualismus der Bolschewiki. In ihrer das Proletariertum idealisierenden Sicht verachteten Letztere umgekehrt den Hochschulgelehrten als Vertreter der Bourgeoisie. Immer wieder entsteht bei derartigen Meldungen zudem der (zutreffende) Eindruck, die Bolschewiki entledigten sich durch solche Repressalien der intellektuellen Konkurrenz, die aus ihrer Grundverfasstheit heraus eine Gefahr für die Hegemonie ihrer Ideologie, ja des Ideologischen und Hegemonialen per se darstellte.

Daneben waren durch den Anspruch der Universitäten auf innere und äußere Autonomie ohnedies Konflikte zwischen der auf vollen gesellschaftlichen Durchgriff drängenden Staatsmacht und der Professorenschaft pro-

102 Ebd.

103 Unter anderem: Anon.: Sowjet-Jugend. In: AIZ, Nr. 44, 1038f. (Jahresausgabe).

104 Unter anderem: Anon.: Neue Schreckenstaten der Bolschewisten. Hervorragende Gelehrte ermordet. In: VZT Nr. 419 vom 06.09.1921, 1.

105 Anon (B.E.): Bildungsnot im bolschewistischen Rußland. In: VZT Nr. 123 vom 15.03.1921, 9.

106 So schrieb die FZT 1930: »Im Zusammenhang mit diesen neuen Verhaftungen muß daran erinnert werden, daß erst vor kurzem Mitglieder der ukrainischen Akademie der Wissenschaften in Kiew, und zwar ebenfalls unter der Beschuldigung gegenrevolutionärer Verschwörung einem Gerichtsverfahren unterworfen worden sind. Die jetzigen Verhaftungen deuten darauf hin, daß eine neue Periode der Verfolgung von Intellektuellen und Fachleuten beginnt." Anon.: Massenverhaftungen von russischen Gelehrten. Unter der Beschuldigung der Teilnahme an einer gegenrevolutionären Verschwörung. In: FZT Nr. 657 vom 04.09.1930, 1. 
grammiert und wurden nicht selten mit den »bewährten« Mitteln der Inhaftnahme, Entlassung oder Schlimmerem gelöst. ${ }^{107}$ Namentlich nicht genannte russische Professoren werden mit der Aussage zitiert: "Wir sind keine Bolschewisten, sondern theoretische Gegner der jetzigen Regierung. ${ }^{108}$ Mit Fridtjof Nansen, aus dessen Gastbeitrag für die VZT dieses Zitat stammt, beklagte ein prominenter Akteur der internationalen Diplomatie und Koordinator humanitärer Hilfe für das zerrüttete Bürgerkriegsland die geistige Abschottung Sowjetrusslands, die seines Erachtens durch fehlenden internationalen Austausch Studierender und Lehrender entstehe. Studierende, noch mehr Lehrende in der Sowjetunion litten »doch sehr unter ihrer geistigen Isolierung ", war der nun weitgehend abgebrochene personelle Austausch mit Hochschulen Westeuropas doch entscheidender Träger des Kulturkontaktes und intellektuellen Austausches gewesen. Um diese Isolation zu beenden, sei es "an der Zeit, daß die regelmäßigen wissenschaftlichen Verbindungen zwischen den ausländischen und russischen Universitäten wieder hergestellt« ${ }^{109}$ würden. Dies laufe der Wichtigkeit des Bildungssektors im Prozess der Sowjetisierung der Gesellschaft jedoch aus Sicht der Bolschewiki zuwider, denn »hauptsächlich" sei der Hochschulunterricht Mittel der Propaganda, »um die Massen zu der kommunistischen Lehre, ich [Nansen, D.F.] möchte fast sagen: zu der kommunistischen Religion<, zu bekehren. ${ }^{110}$

Die Klage über die verkümmernde Wissenschaftslandschaft der UdSSR war indes keineswegs Konsens unter den verschiedenen Kolumnisten. Insbesondere für anwendungsorientierte Bildungseinrichtungen fielen die Einschätzungen deutlich positiver aus. Dies kann auf die von den Bolschewiki als Ziel ausgegebene Fokussierung auf praktisch anwendbare Lehrinhalte für die Ausbildung parteitreuer "Spezialisten « zurückgeführt werden, die dereinst die unverzichtbare, aber teils illoyale technische Intelligentsia « ersetzen sollten. ${ }^{111}$ Die Umlenkung finanzieller Mittel folgte dieser Prioritätensetzung und ließ die bevorzugten Institutionen in der Betrachtung deutscher Beobachter in bemerkenswert hellem Lichte erscheinen. Georg Graf von Arco, der nach einer Reise nach Nischni-Nowgorod in seiner Funktion als Geschäftsführer der Telefunken ${ }^{112}$ für das BTB einen Reisebericht verfasste, stellte die Situation der technischen Hochschulen als nachgerade vorbildhaft dar:

107 Vgl. Finkel, Stuart: On the Ideological Front. The Russian Intelligentsia and the Making of the Soviet Public Sphere. New Haven, CT u. a. 2007, $42 \mathrm{f}$.

108 Nansen, Fridtjof: Russisches Bildungswesen. In: VZT Nr. 191 vom 24.04.1923, $1 \mathrm{f}$.

109 Ebd., $1 \mathrm{f}$.

110 Ebd., 2.

111 Vgl. dazu auch: Lampert, Nicholas: The Technical Intelligentsia and the Soviet State. A Study of Soviet Managers and Technicians 1928-1935. London 1979, 12-37.

112 Gesellschaft für drahtlose Telegraphie m.b.H., System Telefunken. 
»Die exakte Erfahrungswissenschaft ist in Rußland wie in keinem anderen Lande der Erde, die lückenlose Richtschnur für alle staatlich beeinflußten Formen des Lebensaufbaus [...]. Alle modernen Einsichten [...] will man mit großer Zielbewusstheit verwirklichen. Vorzüglich sind die Einrichtungen der russischen Pädagogik [...] bis zu den höchsten Erscheinungsformen [...]. Die Ausstattung mit technischen Hilfsmitteln ist zum Teil musterhaft. Nicht nur das Alte, vorhanden Gewesene ist für die unterrichtliche und experimentelle Lehrtätigkeit wieder hergerichtet worden, augenscheinlich sind in Rußland auch große Mittel freigemacht worden für die Einrichtung neuer Institute und die Aufstellung der neuesten Spezialmaschinen. ${ }^{113}$

Die Verlagerung des Hochschulbetriebs, weg von den philologischen und sozialwissenschaftlichen Fächern hin zur »exakten Erfahrungswissenschaft « brachte für das Regime einen angenehmen Nebeneffekt mit sich: Trotz der Euphorie technikaffiner Zeitgenossen und des ja tatsächlich brennenden Bedarfs an technischem Personal erschwerte der Aufbau einer "marxistischen Wissenschaft mit konsequent materialistischer Grundausrichtung die (neuerliche) Formierung wissenschaftlicher Netzwerke. Mit ihrem Einfluss auf die zukünftigen Eliten des Landes hätten diese beachtliches Gefahrenpotential für die Bolschewiki bedeutet. Aus der Sicht deutscher Russlandreisender hatte dieser "politische« Umbau des höheren Bildungswesens Methode, worauf besonders der bereits zitierte Joseph Roth hinwies:

»Man hat ihn [den Studenten, D. F.] mit festen, für die Ewigkeit geschmiedeten Gedanken- und Wortkomplexen genährt und ihm die fruchtbare Mühe der selbstständigen Synthese und Analyse abgenommen. Man hat ihn ferner aus Angst vor der Philologie, die in Rußland bürgerlich verdächtig ist, von der Sprache weggeführt, vom Wort, von der Logik der Grammatik - zur simpleren Logik der `Tat‘ und der Maschine, zu der robusteren Struktur des Mechanismus. ${ }^{114}$

Das Bild sowjetischer Hochschulpolitik, wie es sich in den einschlägigen Kolumnen abzeichnete, war das eines politischen Instruments zur Umgestaltung der Gesellschaft und ihrer künftigen Eliten. Das Ideal höherer Bildung, das Erkenntnisstreben causa sui, blieb ausgeblendet. Im Gegensatz zur teils sehr wohlwollenden Kommentierung von neuen Bildungsangeboten für Kinder und Jugendliche sowie die Alphabetisierung der sowjetischen Bevölkerung, erschien die Hochschule sowjetischen Stils als seines ureigentlichen Sinnes beraubtes Werkzeug in den Händen der politischen Führung.

113 Arco, Georg von: Die Wissenschaft im neuen Rußland - Graf Arcos Moskauer Eindrücke. In: BTB Nr. 7 vom 04.01.1924, 2.

114 Roth Joseph: Reise in Rußland. XVII., 2. 


\subsubsection{Geistesleben als Spiegel des »Volkscharakters»}

Im Gegensatz zu dem im reißenden Fluss des gesellschaftlichen Umbaus befindlichen sowjetischen Bildungswesen, blickte man bei seinem amerikanischen Pendant auf eine vermeintlich konsolidierte Universitätslandschaft. Man sah die höhere Bildung der USA und ihre Institutionen als dem amerikanischen »Volkscharakter" entwachsen an und wähnte ihre Traditionen fest in diesem verankert. Bezüglich Bildung, Kultur und Kunst wirkte unter Europäern in der Zwischenkriegszeit noch das Empfinden einer europäischen $»$ Restüberlegenheit« nach, ${ }^{115}$ was einen unverstellten Blick auf derlei Fragen auch in Deutschland erschwerte. Speziell im Zusammenhang mit Bildung und Hochkultur bestanden aber im Amerikabild wesentlich längere Traditionslinien als im Hinblick auf die Sowjetunion.

Fragen grundständiger Bildung oder gar der Alphabetisierung streiften hier kaum das Gesichtsfeld deutscher Beiträgerinnen und Beiträger. Zwar wiesen die Vereinigten Staaten, insbesondere unter Afroamerikanern, ebenfalls sehr hohe Analphabetenraten und in den ländlichen Regionen des Südens eine immer noch recht lückenhafte Beschulung auf. Trotzdem stellte sich angesichts der mit Amerika konnotierten Vorstellungen von - auch bildungspolitischer Fortschrittlichkeit die Frage danach nicht so selbstverständlich wie in Bezug auf den als (noch) rückständig betrachteten »Arbeiter- und Bauernstaat» im Osten.

Das Hochschul- und Collegewesen der Vereinigten Staaten stand klar im Mittelpunkt des Interesses. In der Verbreitung hochschul- und bildungsspezifischer Beobachtungen taten sich beinahe ausschließlich Korrespondenten der VZT hervor, die damit der Selbstbeschreibung ihres Blattes (»Berlinische Zeitung von Staats- und gelehrten Sachen«) zu genügen bemüht schienen. Dem amerikanischen Geistesleben wurde, ebenso wie dem sowjetischen, eine im Vergleich zu Westeuropa starke Fixierung auf praktische Inhalte attestiert. Hans Goslar schrieb 1922:

"Das was heute seine [des amerikanischen Volkes, D. F.] >Spezialität $<$ ist, [ist] die stark verstandesgemäß ausgebildete, reichlich materialistische Lebensauffassung [...] sowie die naive Freude am technischen Fortschritt, im Großen und im ganz kleinen [sic] des täglichen Bedarfs [...]. Was heute in Amerika augenscheinlich vorherrscht, ist die rein praktische Gesinnung, die theoretische Arbeit weder liebt noch zu bewerten vermag, wenn nicht ein sofort in Dollar greifbar auszudrückendes Resultat ihr Erfolg ist. ॥ $^{116}$

115 Kaelble: Europäer über Europa, $133 \mathrm{f}$.

116 Goslar, Hans: Amerikas Geistesleben 1922 - Wissenschaft, Universitäten, Schulen. In: VZT Nr. 120 vom 11.03.1922, $1 \mathrm{f}$. 
Abstrakte Wissenschaft und ausgiebige Theoriebildung habe in dieser strikt auf den "nervus rerum«, also das Wesentliche, das Greifbare der Sache und letztlich das Geld ausgerichteten Wissenschaftskultur »keinen Raum und Geltung«. Trotz des von Goslar beteuerten Bemühens, gerade auf Aspekte jenseits des Klischees vom materialistischen Amerika zu achten, schlügen ihm »immer wieder die Worte: money, business und so und so viel Dollar entgegen." Es fehle in den Vereinigten Staaten trotz der enormen finanziellen Ausstattung der Universitäten an einem "Gelehrtenstand mit gesellschaftlicher Geltung". Die von Goslar befragten Professoren beklagten denn auch »das Fehlen einer geistigen Atmosphäre für das theoretisch-wissenschaftliche Studium « und die Abwesenheit »eines wissenschaftlichen Gedankenaustauschs in halbwegs europäischem Sinne ${ }^{117}{ }^{17}$ Der »tiefer schürfende Gelehrte« sei schlicht »isoliert in diesem Lande praktischer, schneller, zielsicherer Arbeit." Goslar führt illustrative Beispiele an, die letztlich alle der materialistischen Korruption hehrer europäischer Wissenschaftsideale durch die geistige Umgebung des allzu praktisch orientierten Amerika das Wort reden.

In der Betrachtung der Wissenschaftslandschaft schien somit - bedingt durch einen Mangel an gewachsenen Kulturbeständen - erneut das tradierte Motiv praktisch-technischer Orientierung, das parallel auch in der Rationalisierungsdebatte vernehmbar war, auf. ${ }^{118}$ Was die Möglichkeiten der Teilhabe an höherer Bildung betrifft, kann Hans Goslar jedoch dem amerikanischen Hochschulsystem auch positives abgewinnen. Durch die Verpflichtung eines jeden Bundesstaates, eine öffentliche Universität zu unterhalten, »an der jeder junge Amerikaner und jede junge Amerikanerin kostenfrei studieren und graduieren« könne, sei einer breiten Schicht die Erlangung eines Hochschulabschlusses möglich. Der de facto weitgehende Ausschluss von Afroamerikanern von dieser Möglichkeit tut Goslars Einschätzung, dieses Modell könne auch in Deutschland zu einer »Entplutokratisierung und Demokratisierung der Bildung ${ }^{119}$ beitragen, keinen Abbruch.

Über rein deskriptive Betrachtungen hinaus wurde dem amerikanischen Bildungswesen eine besondere Aussagekraft in völkerpsychologischer Hin-

117 An anderer Stelle hingegen wird das Professorenleben in den USA als nicht ganz so trist und zum Beispiel in Bezug auf das dort weitverbreitete Sabbatjahr als durchaus inspirierend für die deutsche Professorenschaft dargestellt: »Wundervoll und nachahmenswert ist die hier wie an allen anderen amerikanischen Universitäten eingeführte Einrichtung, daß sowohl die Ordinarien wie die außerordentlichen Professoren alle sieben Jahre ein sogenanntes Sabbatjahr haben, d. h. sie sind ein Jahr frei von allen Verpflichtungen gegen die Universität bei weiterlaufendem halbem Gehalt.« Stein, Ludwig: Die Yale-Universität - Gänge durch Amerikas Hochschulen. In: VZT Nr. 170 vom 09.04.1924, 5.

118 Vgl. dazu nochmals Depkat: Birth of Technology, $23 \mathrm{f}$.

119 Goslar: Amerikas Geistesleben 1922, 2. 
sicht attestiert. Joachim Friedrich, deutscher Gaststudent in den USA, ${ }^{120}$ deutet das amerikanische Bildungswesen nicht nur als kulturelle Sinngehalte reproduzierende Einrichtung. Er erkennt in ihm auch eine Quelle, die sich zum Studium des amerikanischen »Volkscharakters« besonders eigne. Die Quintessenz seiner Beschreibung des straff organisierten, mit allerlei technischen Hilfsmitteln nur den einen rationalen Zweck der Selbstoptimierung verfolgenden Alltags der Studierenden lautet: »Das Hochschulleben in Amerika und Deutschland weist in seiner Verschiedenheit auf Grundunterschiede in Leben und Anschauung der Welt in beiden Völkern hin. ${ }^{121}$ Seien es die aus Friedrichs Sicht kleinlichen - Anwesenheitskontrollen, ${ }^{122}$ dicht gestaffelte Leistungsnachweise ${ }^{123}$ oder die große Ernsthaftigkeit und Konkurrenz im Sport: ${ }^{124}$ All dies sind für ihn bedenkliche Anzeichen eines zunehmend geschäftsmäßig durchrationalisierten Menschenproduktionsprozesses, die ihn ob der zunehmenden Abwesenheit des Menschlichen und der wachsenden Bedeutung des Rationalen im amerikanischen Bildungswesen zur nachdenklichen Frage veranlassen: »Doch was bedeutet es, wenn die Studenten einer Nation in solch einem Zwang aufwachsen, wenn aus einer der letzten Hochburgen einer anderen Zeit, der Universität, ein Geschäftsunternehmen wird? ${ }^{125}$

Solcherlei Rückschlüsse von der amerikanischen Bildungsphilosophie auf deren zentrale Funktion in der Herausbildung eines amerikanischen »Volkscharakters" zogen auch exponiertere Vertreter der VZT-Korrespondenten-

120 Die Information wurde dem Originalartikel entnommen: „Der Verfasser, ein deutscher Student, hält sich als Gast amerikanischer Hochschüler drüben auf und berichtet jetzt nach längerer Pause weiter über seine Eindrücke.« Friedrich, Joachim: Amerikanisches Hochschulleben. In: VZT Nr. 279 vom 15.06.1923, 5 f.

121 Ebd.

$122 » \operatorname{Er}$ [der Student, D. F.] unternimmt sein Studium in der festen Ueberzeugung, seinen Grad `einzuernten` (earn a degree) für regelmäßige Teilnahme an den Vorlesungen, Arbeiten in den classes usw. Das würde ihn ja nicht so sehr von einem deutschen sogenannten >Philister` unterscheiden; doch für jede Vorlesung, Arbeit usw. erhält er einen Bonus im großen Hauptbuch des Dekans. Dieser Bonus wird bezeichnenderweise >credit ‘ genannt. Wie aber werden diese Kredite akkreditiert? Fragt der geschulte `businessman<. Sehr einfach: Alle Vorlesungen werden täglich auf ihre Teilnehmer hin überprüft, wie in der lieben, alten Schule morgens vor dem Beten. Und jeder Fehlende wird notiert. Wenn eine bestimmte, sehr geringe Anzahl von Fehltagen überschritten wird [...] wird eine Erlangung des credit unmöglich gemacht.« Ebd., $5 \mathrm{f}$.

123 »Die zweite und fürchterlichere Daumenschraube ist die wöchentliche oder vierzehntägige [sic] Prüfungsarbeit in allen >classes $₫$ das Extemporale des deutschen Gymnasiums.» Ebd., 6.

124 »Der Sportplatz ist aber auch gar keine Stätte der Erholung, er ist auch keine Stätte des Austobens, er ist eine Stätte des Kampfes um die Macht: wer gewinnt den Preis? Die entscheidende Note in allen diesen Sportkämpfen, im Gegensatz zu Spielen, ist der Rausch und die Genugtuung, die Macht und Herrschaft gewähren, an Stelle von Freude und Glück, die das Spiel gewährt.« Ebd.

125 Ebd. 
schaft wie beispielsweise Alice Salomon. Salomon betont zunächst den hohen, alläglich in die Tat umgesetzten Wert, der allgemeiner Bildung und persönlicher Weiterbildung von allen Amerikanern, ungeachtet der Schicht und ethnischen Zugehörigkeit zugeschrieben werde. ${ }^{126}$ Die nationalkulturelle Bewältigung jener Heterogenität, die Salomon als zugleich prägendste und problematischste Eigenschaft der amerikanischen Bevölkerung ansieht, sei letzten Endes das Kernanliegen jeglicher Bildungsanstrengung in den Vereinigten Staaten: »Alles hat das eine Ziel, dem alle amerikanischen Bildungseinrichtungen dienen: Amerikanisierung, Schaffung einer Nation. ${ }^{127}$ Der unbedingte Glaube an die einigende Macht der Bildung nehme im nationalen Bewusstsein der säkularen Vereinigten Staaten dieselbe Stellung ein, wie sie im mittelalterlichen Europa die Religion als Gemeinsinn stiftender, kulturellen wie sozialen Konsens ermöglichender Faktor eingenommen habe. Selbst den neuzeitlichen Sündern des modernen Kapitalismus räume dies die Möglichkeit zum bildungsfördernden Dispens ein:

»Ein amerikanischer Gelehrter hat diesen Glauben mit dem der mittelalterlichen Kirche verglichen. Wie jener Glaube sich in den hervorragenden Baudenkmälern der alten Welt, in Kathedralen und Domen, manifestierte, so drückt der Amerikaner seine Haltung zu den Werten in den monumentalen Bauten von Schulen und Bibliotheken aus, >diese wie jene oft von Sündern des Reichtums gestiftet, um für sich selbst zu sühnen und die Menschheit zu erretten`«« ${ }^{128}$

Dieser "Glaube an die Wunderkraft der Bildung" sei in den USA deshalb so weit verbreitet, weil dort »Menschen so vieler Rassen und Sprachen nebeneinander« lebten, dass »die Herstellung einer Ordnung schlechthin unmöglich"sei, wenn sie nicht durch Bildungseinrichtungen einander angeglichen würden. »Es ist dies das erste große nationale Bedürfnis: die Amerikanisie-

$126 »$ Die Haltung des amerikanischen Volkes zu Bildung und Erziehung ist von den Amerikanern selbst als >Der große amerikanische Aberglaube bezeichnet worden. In der Tat ist Bildung für sie ein magnetisches Wort. Sie sind überzeugt, daß alle Uebel der Welt durch mehr und bessere Bildungsmittel zu beseitigen sind. Die Aufnahmefähigkeit, die Nachfrage nach Zeitungen und Vorträgen ist unbegrenzt [...]. Die Amerikaner hören zu jeder Zeit des Tages Vorträge, morgens, mittags, abends. Die Klubs veranstalten Vorträge in der Mittagsstunde, daß auch die berufstätige Frau während der Arbeitspause Zeit hat, einen Vortrag anzuhören. Hat sie nicht genug Zeit zu einem ganzen Vortrag, so tut sie es mit einem halben. Am Sonntag nachmittag und abend [sic] vereinigen die Städte ihre Bürger, Weiße und Farbige, Gebildete und Ungebildete, Eingesessene und Eingewanderte, Männer und Frauen zu einem `Forum‘, das ist eine Veranstaltung, in der im Anschluß an einen Vortrag jeder fragen kann, was er will. Von dem Vortragenden wird erwartet, daß er allwissend ist. Seine Schlagfertigkeit wird mit Applaus belohnt.» Salomon, Alice: Amerikanische Bildung. In: VZT Nr. 218 vom 08.05.1924, 1 f.

127 Ebd.

128 Ebd. 
rung. ${ }^{129}$ Mit dieser Version des Amerikanisierungsbegriffs meint Salomon die Einebnung kulturell bedingter Unterschiede. Sie schlägt den Bogen von der spezifischen Betrachtung des Themas Bildung zum Großnarrativ des rationalistischen, standardisierten, eben »amerikanisierten« Massenmenschen.

Der Bildungsbetrieb erscheint als zweite Säule des auch in der Rationalisierungsdebatte diskutierten Amalgamierungsprozesses, der kulturell heterogene Individuen in eine, dereinst das amerikanische Staatsvolk darstellende, Standardform zu gießen vermöge - eine ganz spezielle Lesart des sprichwörtlichen amerikanischen $»$ melting pot $« .{ }^{130}$ Parallelen zwischen der Berichterstattung zum amerikanischen Bildungswesen und der Rationalisierungsdebatte zeigen sich auch in Salomons Feststellung, »der amerikanische Mensch, der Mann zum mindesten, « falle zunächst durch »seinen Mangel an Unkompliziertheit und Undifferenziertheit auf, « und zwar »in einem Maße, daß man in geistiger noch mehr als in körperlicher Beziehung fast von einem millionenfach wiederholten Typ reden ${ }^{131}$ könne. Der amerikanische Bildungsbetrieb erscheint bei Salomon als zentraler Faktor in der Herstellung des »Standard-Amerikaners", die Universität gleichsam als Menschenfabrik:

"Vor allem bringt er [der Bildungsbetrieb, D. F.] ein Gleichmaß der Lebensformen, des Ausdrucks, einer Uebereinstimmung des Geschmacks, eine Uniformierung der Gewohnheiten hervor, die anderen Völkern ganz unerträglich wäre. Die Individualität ist ausgelöscht. Sie ist dem Amerikaner kein Ideal [...]. Diese Uebereinstimmung, diese 'Amerikanisierung ist das wirkliche Bildungsziel [...]. Amerikanisierung ist Ziel und Inhalt. Das öffentliche Unterrichtswesen funktioniert wie eine Propagandaabteilung des Staates [...]. Was nehmen sie als Ausstattung mit hinaus? Sicherlich eine große Fähigkeit zur Einordnung, einen starken Gemeinschaftssinn, disziplinierte Impulse und

129 Ebd.

130 Identische Aussagen wurden später auch in anderen Betrachtungen des amerikanischen Universitätsbetriebs getroffen. Unter anderem: »[D]ie amerikanische Universitätserziehung ist eine Erziehung zur Uniformität. Noch ein paar Jahre weiter und die Studierenden der Hochschulen in den Vereinigten Staaten gleichen sich wie ein Ei dem anderen. Die Uniformität ist ein ungeschriebenes Gesetz. Sie zeigt sich in der Sinnesart, wie in Aeußerlichkeiten.« Weer, Reinhard: College-Boys. In: DAZ Nr. 315 vom 10.07.1929, 1.

131 Goslar, Hans: Der amerikanische Mensch. In: VZT Nr. 190 vom 22.04.1922, 1 f. Eine weitere, wenn auch weniger dichte Verbindung zeigt sich bezüglich des spezifisch amerikanischen Geschlechterverhältnisses, wie es von Goslar in Gestalt der an amerikanischen Universitäten üblichen koedukativen Erziehung als weiterer Grund für den Nivellierungsdruck auf »den amerikanischen Mann« angeführt wird. Da »die Stellung der Frau [...] >drüben eine grundverschiedene von der in Europa« sei, gestalte sich »die gesamte Atmosphäre des öffentlichen und wohl auch des privaten Lebens [...] fast unerotisch [...] zum mindesten aber erotisch indifferent«. Durch die durchgängig gemeinsam erfolgende Erziehung von Jungen und Mädchen würde »der undurchdringliche Schleier eines mystischen Geheimnisses von den Beziehungen der Geschlechter zueinander genommen" und schaffe eine "sexuell ungesunde Atmosphäre" für die, insbesondere männliche, amerikanische Jugend. Ebd. 
geordnete Werturteile. Unter dem Gesichtspunkt praktischer Lebensvorbereitung, der Entwicklung von Bürgertugenden, der `Amerikanisierung`, ist die amerikanische Universität sicherlich ein großer Erfolg. Aber sie ist es nicht in gleichem Maße als Ausgangspunkt geistiger Kultur. « ${ }^{132}$

Einer Beantwortung der Frage, ob Schulen und Universitäten nun lediglich Ausdruck dieses kollektiven amerikanischen "Volkscharakters" seien oder diesen erst erschüfen, enthält sich Alice Salomon nur rhetorisch. ${ }^{133}$ Ihre Aussage, das amerikanische Bildungswesen diene »in ausgesprochener Weise der Propaganda für die bestehende Ordnung ${ }^{13}{ }^{134}$ weist darauf hin, dass sie in selbigem ein Instrument zur Erschaffung einer Intellektualität erkennt, welche die politischen und wirtschaftlichen Verhältnisse in Frage zu stellen unfähig ist. ${ }^{135}$ Ähnlich lautende Kritik, die die staatliche Sanktionierung des kapitalistischen Wirtschaftssystems beklagte, war erwartungsgemäß auch vonseiten der kommunistischen AIZ zu vernehmen. Diese beschreibt die Repression sozialistisch gesonnener amerikanischer Hochschullehrer, welche nach ihrer Entlassung aus dem staatlichen Hochschulbetrieb eine mit privaten Spenden finanzierte »Arbeiterhochschule« betreiben. ${ }^{136}$

\subsection{Zusammenfassung}

Die Themen Sport, Jugend und Bildung sind in ihrer gegenseitigen Durchdringung als Themenbündel anzusehen, an Hand dessen in der hier gesichteten Publizistik die Frage nach der zukunftsträchtigsten Ressource einer modernen Gesellschaft verhandelt wurde. Die Jugend der USA beziehungsweise der UdSSR und ihre Qualifikation und Formung wurde unter Bezugnahme auf die Prämissen der amerikanischen und der im Werden begriffenen sowjetischen Gesellschaft mit spezifischen Bedeutungsgehalten versehen.

Dem Sport wurde, insbesondere in der Betrachtung der Sowjetunion, eine performative Funktion in der ideologischen Formung des Selbstbildes

132 Salomon: Amerikanische Bildung, 2.

133 »In nichts stimmen die Menschen hier so überein wie in diesem Wunsch nach Konformität. Sie tragen die gleichen Moden, lesen dieselben Bücher, haben dieselben Redewendungen. Wie weit diese Gleichförmigkeit des Lebens Ergebnis der Erziehungsmethoden ist, oder ob sich im Bildungswesen nur der Volkscharakter ausdrückt, sei dahingestellt. Jedenfalls scheinen Schulen und Universitäten diesem Ziel zu dienen.« Ebd.

134 Ebd.

135 »Es gibt öffentliche Schulen, an denen Lehrer entlassen würden, wenn sie das kapitalistische System angreifen. Das ist in Preußen früher ja auch keine unbekannte Praxis gewesen.« Ebd.

136 Vgl. Kläber, Ernst: Brookwood. Eine amerikanische Arbeiterhochschule. In: AIZ, 1927, Nr. $4,4$. 
Jugendlicher zugeschrieben, was sich in der eingehenden Beschäftigung mit sowjetischer Körperkultur und dem kommunikativen Wert von Massensportveranstaltungen für die bolschewistische Führung niederschlug. Auch die besondere Ästhetik, später vielfach kopiert und weiterentwickelt, transportierte ideologische Sinngehalte, die in Deutschland gängige Konzepte wie die Vorstellung eines formbaren, verbesserungsfähigen "Volkskörper" aufriefen. Ein erzieherischer Aspekt schien auch in der Betrachtung des US-Sports auf, wenngleich als eher unpolitische soziale Eingliederungsfunktion.

Die Erkundung jugendlicher Lebenswelten in den USA und der UdSSR konzentrierte sich auf staatlich organisierte Formen der Jugendbetreuung. In beiden Fällen provozierte diese Perspektive die scharfe Verurteilung der Militarisierung von Jugendlichen, die sich sowohl am Beispiel der amerikanischen Boy-Scouts als auch bei den sowjetischen Jungen Pionieren andeutete. Die Sensibilität gegenüber diesem Thema lag in der schwelenden innerdeutschen Debatte um die politische Instrumentalisierung von Jugendlichen begründet. Politisierung und Militarisierung wurden in Deutschland als Übergriff auf die verletzliche und besonders schützenswerte Lebenswelt von Kindern und Jugendlichen verurteilt. Das Bemühen, die deutsche Jugend vor allerlei verderblichen Einflüssen - dem sogenannten »Schmutz und Schund"zu schützen, war bereits im Kaiserreich gesellschaftlicher Konsens gewesen und erschien auch in der Weimarer Medienöffentlichkeit als soziale Zielvorstellung. ${ }^{137}$ Die Erklärung für die in der Ferne registrierte Übergriffigkeit wurde aus dem Interesse des betreffenden Staates an militärischem Nachwuchs und loyalen Staatsbürgern (USA) und der Perpetuierung und Multiplikation bolschewistischer Ideologie (UdSSR) erklärt. Die Rolle der Jugend als innere Garantiemacht des Bolschewismus war es auch, die in der Beurteilung der sowjetischen Bemühungen um die Alphabetisierung und Schulausbildung seiner Bevölkerung als zentrales Motiv gesehen wurde, neben dem Ziel einer, an die Erfordernisse einer modernen Industrienation angepassten Arbeiterschaft.

Dass Letztere angesichts der zu bewältigenden Aufgabe der Industrialisierung der Sowjetunion vor allem aus technisch ausgebildeten "Spezialisten « $\mathrm{zu}$ bestehen hatte, wurde kohärent aus der Berichterstattung deutlich. Dass dadurch die Vernachlässigung sozialwissenschaftlicher, philologischer und philosophischer Lerninhalte bedingt war, wurde ebenso kritisiert wie die politische Gleichschaltung des sowjetischen Hochschulwesens. Diese Kritik konzentrierte sich auf den in der Betrachtung beider Länder zu Tage tretenden Materialismus, der im Falle der UdSSR nicht nur durch die wirtschaftlichen

137 Vgl. dazu: Maase, Kaspar: Die Kinder der Massenkultur. Kontroversen um Schmutz und Schund seit dem Kaiserreich. Frankfurt, New York 2012, $31 \mathrm{f}$. 
Umstände bedingt war, sondern ebenso fest in den, der sowjetischen Bildungspolitik zugrunde gelegten ideologischen Maßgaben.

Der in der Sowjetunion zum Ausbildungsprinzip erhobene Materialismus unterminierte nach einhelliger Meinung der Beiträger die wissenschaftliche Erkenntnis als eigentlichen Sinn höherer Bildung. Ebenso verhielt es sich mit dem, vermeintlich im notorisch pragmatischen amerikanischen "Volkscharakter« begründet liegenden Materialismus, der durch das dortige Bildungssystem stetig reproduziert wurde. Mit der in Deutschland verbreiteten Vorstellung von Amerika als einem Land der Freiheit und des Individualismus waren derartige Schilderungen, zumindest was deren intellektuelle Dimension anbelangt, nachgerade unvereinbar. Hier kollidierte das in den Massenmedien der Weimarer Republik entstehende Amerikabild mit gängigen Amerikastereotypen. Stattdessen erschien der amerikanische Hochschulbetrieb, analog zur durchrationalisierten Wirtschaft, als gut geölte Maschinerie zur Herstellung standardisierter, amerikanisierter »Massenmenschen«. 


\title{
III. Schlussbetrachtung
}

\begin{abstract}
»Ein Nirgendwo-Land hat die Menschheit immer gebraucht, um ihre ungestillte Sehnsucht aus der Welt der Tatsachen dorthin zu flüchten. Es ist ein Kennzeichen unserer Zeit, daß sie ihre Sehnsucht in $\mathrm{Zu}$ kunftsträume kleidet. ${ }^{1}$
\end{abstract}

Die »Nirgendwo-Länder« (das Fremdwort hierfür wäre: Utopien), derer sich die Diskursgemeinschaft der Weimarer Massenpresse zwischen 1918 und 1933 als Projektionsflächen bediente, waren die Vereinigten Staaten und die Sowjetunion. Sie eigneten sich aus Sicht der verschiedenen Diskursteilnehmer angesichts ihres Charakters als langfristig angesetzte Gesellschaftsprojekte mit ihrem alle Lebensbereiche überwölbenden ideellen Anspruch dazu, ansonsten schwierig fassbare Modernisierungsprozesse $\mathrm{zu}$ ordnen, greifbar zu machen und $\mathrm{zu}$ vergleichen - auch und gerade wegen der darin vielfach aufscheinenden Widersprüche.

Die Bezugnahme auf das Beispiel der USA beziehungsweise auf das Beispiel der UdSSR verlieh den Sehnsüchten und Ängsten, in jedem Fall aber bislang unerfüllten utopisch wie dystopisch ausgerichteten Erwartungen an die zukünftige gesellschaftliche und wirtschaftliche Entwicklung Deutschlands Plastizität. Sie dynamisierte die zahlreichen, in der Weimarer Medienöffentlichkeit parallel verlaufenden Modernisierungsdebatten. Durch das Heranziehen von Anschauungsbeispielen, wie die Gesellschaften der Vereinigten Staaten und der Sowjetunion mit den Herausforderungen grundstürzender sozialer und wirtschaftlicher Veränderungen umgingen, sie initiierten, förderten oder zu unterbinden suchten, positionierten sich die medialen Diskursteilnehmer auch zu den analogen Entwicklungen in Deutschland. Jene Beispiele fungierten entweder als Mahnung oder Vorbild und dienten oftmals auch der Selbstvergewisserung, die Entwicklung sei im eigenen Lande auf einem besseren Wege als in den beiden Gravitationszentren der Moderne, deren Chancen und Krisen dort bildhaft wurden.

Die ordnende Funktion der Fremdbetrachtung der Vereinigten Staaten und der Sowjetunion trat besonders deutlich beim Themenkomplex der Rationalisierung und damit verbundenen Debatten um die im Zuge dessen heraufziehende Massengesellschaft in den Vordergrund. Diese beiden vielfach miteinander vermengten Stränge des Modernisierungsprozesses in Deutschland

1 Anon.: Traumland. In: DAZ Nr. 308 vom 06.07.1926, 1 f. 
zerfielen durch die Bezugnahme auf Amerika und die Sowjetunion in ihre verschiedenen Komponenten. Die USA als »Mutterland« industrieller Rationalisierung und die Bolschewiki als entschieden auf die Vision eines "neuen Menschen " in einem kollektiven Gesellschaftsverbund hinarbeitende ideologische Kraft stellten die notwendigen Kategorien zur Verfügung, um das komplexe Zeitphänomen Rationalisierung greifbar zu machen.

Den Ausgangspunkt der Betrachtung bildete das während des Krieges offenbarte Rationalisierungsdefizit der deutschen Industrie. Dieses erschien nur durch die konsequente Adaption amerikanischer Prinzipien der Wirtschaftsund Produktionsorganisation behebbar. Zum davon analytisch, nicht aber auf der Wahrnehmungsebene trennbaren sozialen Aspekt einer Rationalisierung der Gesellschaft führte vor allem die Betrachtung des sowjetischen Gesellschaftsprojekts. Rationalisierung wurde hier in erster Linie als Vehikel der gesellschaftlichen Reorganisation begriffen. Beide Länder dienten in der deutschen Debatte somit als thematische Filter, durch die zuvor miteinander verwobene Aspekte des Zeitphänomens Rationalisierung aufgetrennt und separat diskutiert werden konnten. Die ideologischen Dispositionen der an diesem Diskurs teilnehmenden Redaktionen wurden hier insbesondere dadurch deutlich, dass per se identische wirtschaftliche Ausdifferenzierungsprozesse teilweise eklatant unterschiedlich bewertet wurden.

Die medialen Wahrnehmungen der USA und der UdSSR wirkten auf unterschiedliche Weise auf Modernisierungsdebatten in Deutschland ein. Zum einen formierten sich Fragestellungen aus dem deutschen Kontext heraus, die dann im Zuge der Fremdbetrachtung verhandelt wurden. Besonders kontrovers wurde dabei das Zeitphänomen der "neuen Frau" und die vermeintliche Verwischung tradierter Geschlechtergrenzen diskutiert. Obgleich die dahingehenden Entwicklungs- und vor allem Emanzipationstendenzen mitnichten ihren Anfang in der Zwischenkriegszeit genommen hatten, wurden sie in das Bild einer sich rasant wandelnden Gesellschaft eingefügt und auf die Wahrnehmung der USA und der UdSSR übertragen. Die auf ideologischen Sinngehalten beruhende und durch staatliche Maßnahmen vorangetriebene Gleichstellung von Mann und Frau in der Sowjetunion, die auch mit der Aufhebung von geschlechterspezifischen Schutzräumen (wie beispielsweise beim Einsatz von Frauen als Soldatinnen) einherging, stand in der medialen Darstellung im Gegensatz zu einer sich gegen gesellschaftliche Widerstände behauptende Frauenemanzipation in den USA. Die Entgegensetzung einer Revolutionierung der Verhältnisse »von oben « und einer evolutionären Entwicklung »von unten« stellte dabei eine Grundtendenz dar, die sich auch in weiteren Themenfeldern nachweisen lässt. Die deutsche Entwicklungsgeschichte der Frauenemanzipation spiegelte indes Elemente aus beiden Vergleichsgesellschaften wider. So hatten hier wie in den Vereinigten Staaten bereits seit langem Frauenverbände politische und wirtschaftliche Gleichstellung einge- 
fordert - wie in der Sowjetunion jedoch wurden diese Forderungen letztlich im Zuge eines revolutionären Umbruchs Realität, nachdem die untergehende Ordnung des Kaiserreichs die hergebrachten offiziellen Geschlechterschranken mit sich fort genommen hatte. Somit fanden sich beide Narrative - das revolutionäre ebenso wie das evolutionäre - im deutschen Kontext wieder und lieferten somit Diskursversatzstücke für die verschiedenen publizistischen Positionen zur Frauenfrage in Deutschland.

Im Gegenzug stießen aus der Fremdbetrachtung stammende thematische Impulse mediale Debatten in Deutschland an, die zwar nicht von unmittelbarer Relevanz für die deutsche Gesellschaft waren, mittelbar aber Grundprinzipien moderner Gesellschaftsorganisation adressierten. So im Falle der in Deutschland sehr aufmerksam verfolgten und lebhaft diskutierten amerikanischen »Rassenfrage«. Hier waren mit Demokratie, Liberalität, Egalität und Pluralität gleich mehrere Grundfesten berührt, auf denen die Epochentendenz der klassischen Moderne fußte. Daraus ergab sich - trotz zunächst scheinbar fehlender Bezugspunkte - eine hohe Relevanz der Minderheitenemanzipation für die innerdeutsche Debatte.

Auch in der Betrachtung dieser Frage schien die Grundopposition zwischen evolutionärem und revolutionären Entwicklungsverläufen in der Fremdbetrachtung beider Länder auf. In den USA begehrten die Betroffenen selbst gegen gesellschaftliche und staatliche Diskriminierung auf, in der UdSSR trat der Staat - mit zweifelhaftem Erfolg - für die Gleichstellung ethnischer Minderheiten ein. Weitere Bezugspunkte ergaben sich hinsichtlich der ethnischen Minderheiten in der Sowjetunion an den politischen Rändern des Pressespektrums. Der Antisemitismus der Nationalsozialisten fand in sowjetischen Juden ein geeignetes Ziel, um Ängste vor der vermeintlichen »jüdisch-bolschewistischen Weltverschwörung zu schüren. Die kommunistische AIZ feierte die angebliche Befreiung der Minderheiten Russlands und ihr Aufgehen in der unterschiedslosen Gemeinschaft eines ideologisch und nicht mehr ethnisch verfassten Gesellschaftsmodells. Hier bot sich ein Vehikel, um ideologische Sinngehalte in die Fremdbetrachtung der Sowjetunion einzuschreiben und so dem deutschen Zielpublikum näherzubringen.

Die Debatte um die politischen Ordnungen in den USA und der UdSSR bot sowohl denjenigen publizistischen Kräften Argumente, die eine Anlehnung Deutschlands an die demokratische Kultur des Westens befürworteten, als auch denjenigen, die eine autoritäre Umgestaltung der politischen Ordnung in Deutschland ersehnten. Ihre gegensätzlichen Positionen betteten sie gleichermaßen »konsistent « in die Betrachtung der Vereinigten Staaten und der Sowjetunion als klare konzeptuelle Gegenpole ein. Überdies zeigte sich hier der Gegensatz zwischen einer aus dem logischen Evolutionsprozess gesellschaftlicher Organisation hervorgegangenen, einstweilig »höchsten« Entwicklungsstufe modernen politischen Interessenausgleichs und einer allen 
bisherigen Modernisierungspfaden radikal entsagenden totalitären Ordnung ideologischen Zuschnitts, die einen Resonanzboden für Grundtendenzen der politischen Auseinanderentwicklung in Deutschland bot.

Der »Entzivilisierungsschub $«,{ }^{2}$ wie er sich in der aufmerksam verfolgten politischen Auseinandersetzung in der Sowjetunion manifestierte, bezog seine Faszinationskraft aus der Spannung, die auch in Deutschland zwischen Demokratisierungswillen und autoritären Gesellschaftsvisionen bestand. Im nationalkonservativen und nationalsozialistischen wie auch im kommunistischen Spektrum wurden die Eindrücke brutaler Machtkämpfe und die Errichtung der stalinistischen Diktatur eng begleitet. Hinsichtlich der politischen Ordnung und Kultur der Vereinigten Staaten nahm die politische Personalisierung und Ritualisierung im Rahmen der amerikanischen "Civil Religion" angesichts des vielfach beschriebenen symbolischen Defizits des Weimarer Politikbetriebs breiten Raum ein. Die Demokratie der Vereinigten Staaten erschien im Vergleich zum alle Lebensbereiche vereinnahmenden Machtanspruch der Bolschewiki als differenzierteres, weiter fortgeschrittenes Staatswesen, das neben weitgehender Demokratie auch auf weiche Strategien politischer Kommunikation setzte.

Der Themenkomplex, der sich aus den eng miteinander verbundenen Aspekten Sport, Jugend und Bildung zusammensetzte, erwies sich hinsichtlich seines analytischen Potentials für Modernisierungsdebatten als reich an impliziten wie expliziten Sinngehalten. Als implizit ist dabei zunächst die logische Bedeutung junger Menschen für die von ihnen dereinst zu formende $\mathrm{Zu}$ kunft herauszustellen. Jugend strebt per se der kommenden, »modernen« Zeit entgegen und verkörpert diese. In biologistischer Hinsicht wie auch als Mittel der politischen Kommunikation nahm der Massensport hier eine Transmissionsfunktion wahr. Darüber hinaus bestand zwischen dem Jugendbegriff und den Vereinigten Staaten als »junger Nation « traditionell eine konzeptuelle Assoziation, die nun in doppelter Hinsicht auch in der Betrachtung der Sowjetunion griff. Zum einen war Letztere ebenfalls als junge, sich noch findende Ordnung aus den Wirren der Revolution hervorgegangen. Zum anderen war die UdSSR wegen der multiplen gesellschaftlichen und staatlichen Umbauprozesse wie kein anderes Land auf die Unterstützung derer angewiesen, die sie selbst nach ihren ideologischen Grundsätzen zu formen imstande war. Die Kinder und Jugendlichen galten als zukünftiger »Volkskörper« - ein Konzept, das in totalitären Gesellschaftsmodellen der Zeit eine ebenso zentrale Stellung einnahm wie in den westlichen Demokratien. Die Jugend bezog ihre

2 Nach der Begriffsprägung von Norbert Elias, mit der er das Zurückfallen hinter erreichte zivilisatorische Errungenschaften unter den Nationalsozialisten beschrieb. Vgl. Elias, Norbert: Studien über die Deutschen. Machtkämpfe und Habitusentwicklung im 19. und 20. Jahrhundert. Frankfurt a. M. 1989, $401 \mathrm{f}$. 
Relevanz vornehmlich aus ihrer Rolle als Garantiemacht für das zukünftige Schicksal der Nationen. Die Ästhetisierung der physischen und ideologischen Ertüchtigung der Jugend verfing dabei im deutschen Diskurs, wohingegen die Militarisierung und Politisierung von Kindern und Jugendlichen scharfe Ablehnung erfuhr.

Daran angeschlossen war die Betrachtung der amerikanischen und sowjetischen Bildungseinrichtungen, denen eine materialistische Ausrichtung attestiert wurde. Im amerikanischen Bildungswesen meinte man ein Vehikel zur stetigen Reproduktion des »Volkscharakters« zu erkennen, während die materialistische Neuausrichtung der Sowjetbildung im Kontext mit den neuen ideologischen und wirtschaftlichen Erfordernissen wahrgenommen wurde.

Die sich in den behandelten Diskurssträngen herausbildenden Länderstereotype definierten also nicht nur Gegenstände bloßer Fremdbetrachtung, sondern lieferten in Form potentieller Antworten auf drängende sozioökonomische Fragen innerhalb der deutschen Gesellschaft Versatzstücke einer prototypischen deutschen Moderne. »Amerika und sein Geheimnis« wurden, wie es der Sozialtheoretiker Götz Briefs 1927 treffend im BTB formulierte, von den Deutschen auf diese Weise zum zweiten Mal entdeckt:

"Die Augen der neuen Entdecker sahen je nachdem die Vorbildlichkeit seiner demokratischen Einrichtungen, seiner Sozialverfassung, die Springquellen seines ungeheuren Reichtums, den technischen Fortschritt in höchst entwickelten Formen, den anscheinend erreichten Ausgleich zwischen Kapital und Arbeit, um den Europa vergeblich bisher gerungen hat. ${ }^{3}$

»[D]er problematische Einschlag des heutigen amerikanischen Lebens« wurde, entgegen Briefs' zeitgenössischer Mahnung, dabei keineswegs »übersehen «, sondern während der Diskursverläufe, wie sie durch die hier vorgenommene Analyse der berührten Themenkomplexe freigelegt wurden, kontrovers debattiert. Deutschlands "Amerikanisierung " erscheint in der Zusammenschau jener Diskursstränge nicht als einseitiger Modernisierungseinfluss Amerikas auf Deutschland. Die vielbeklagte »Amerikanisierung « bedeutete tatsächlich einen sich erst in der Problematisierung ihrer vermeintlichen und tatsächlichen Resultate manifestierenden Aneignungsprozess der Moderne selbst.

In der Betrachtung der USA trat deutlich die Anbindung aktueller Themenschwerpunkte der Zwischenkriegszeit an historisch tief wurzelnde, seit langem tradierte Deutungsmuster hervor. Diese gingen stets von der Unterschiedlichkeit, mitunter von der Unvereinbarkeit amerikanischer Verhältnisse mit europäischen Gesellschaftsentwürfen aus. »Europa« und damit auch Deutschland konnte, wie der Soziologe Guglielmo Ferrero 1926 schrieb, denn 
auch »keine Kopie Amerikas werden. Denn gewisse Elemente seiner alten Zivilisation bedeuten seine ganze Existenz. $\aleph^{4}$ Aus dem Zusammenwirken und der Konfrontation jener "gewissen Elemente - gemeint sind politische, soziale und kulturelle Traditionen - mit den Modernisierungseinflüssen von jenseits des Atlantiks erwuchsen die hier untersuchten Diskurse. In ihnen formte sich das Bild der eigenen Epoche als Zeit der vielfältigen Umbrüche, die sich in Deutschland besonders abrupt vollzogen.

Der disruptive Charakter der Epoche trat am Beispiel der Sowjetunion umso deutlicher hervor, als sie ihre noch junge soziale, politische, wirtschaftliche und geistige Ordnung einer allumfassenden Revolution verdankte. Auch trieb ihre politische Elite die Revolutionierung aller Lebensbereiche kontinuierlich weiter voran. Die Sowjetunion verkörperte für die deutsche Medienöffentlichkeit und maßgebliche politische Akteure der extremen Rechten und der kommunistischen Linken den gewaltsamen, sich vom vorgezeichnet scheinenden Modernisierungspfad westlicher Prägung radikal abwendenden Umbruch. Aus dessen kompromissloser Fortführung sprach die totale Negation zuvor allgemeingültiger Zivilisationsgrundsätze, welche die oben bereits genannte Epochentendenz definierten. Das imponierte denjenigen in Deutschland, die ihr Unbehagen an der Moderne auf die ihnen ohnehin suspekten Sinngehalte zurückführten, die aus der Aufklärung erwachsen waren. Die in der bolschewistischen Weltanschauung aufs Neue zusammengezwungenen Elemente weltlicher und geistlicher Macht und die konsequent auf den Erhalt und die Expansion einer Ideologie mit Exklusivitätsanspruch ausgerichtete Unterordnung von Staat und Gesellschaft erschien den Gegnern der aktuellen Ordnung in Deutschland - wenn auch mit jeweils unterschiedlichen Zielvorstellungen - als Alternative zur pluralistischen Republik.

Nicht nur hinsichtlich der Kategorien von Annahme und Ablehnung zerfiel die mediale Perspektive auf die USA und die Sowjetunion in verschiedene, nicht klar nach weltanschaulicher Voreingenommenheit, sondern vor allem durch Einzelthemen abgegrenzte Spektren. Homogene Länderbilder, gar eine damit einhergehende homogene Ausdeutung der eigenen "modernen " Zeit existierten nicht. Die Art und Weise, in der sich die untersuchten Länderbilder in medialen Diskursen formierten, weist aber durchaus Konstanten auf. So ist trotz des prägenden Einflusses synchroner Wahrnehmungen Amerikas festzustellen, dass sein, in den deutschen Massenmedien der Weimarer Republik gezeichnetes Bild sich zuvörderst aus tradierten Komponenten und erst in zweiter Ordnung aus der Diskussion aktueller Entwicklungen zusammensetzte. Dem stand das, sich erst herausbildende und stark auf seine revolutionären Brüche konzentrierte Bild der Sowjetunion gegenüber.

4 Ferrero, Guglielmo: Europas Amerikanisierung. In: DAZ Nr. 174 vom 15.04.1926, $1 \mathrm{f}$. 
In diesem Gegensatz offenbaren beide Fremdwahrnehmungsprozesse den komplementären Charakter der Sicht der Deutschen auf sich und ihre Zeit, die zwischen dem Verharren im Vertrauten und dem unbedingten Gestaltungswillen der Moderne zerrissen war. 


\section{Danksagung}

Wie am Anfang des Projekts steht auch am Anfang meiner Danksagung mein Doktorvater Volker Depkat (Regensburg). Schon als Jungfuchs in den ersten Proseminaren und Vorlesungen hat er mich durch seine überwältigende Leidenschaft (natürlich nicht nur) für die Geschichte und die Amerikanistik an das wissenschaftliche Arbeiten und eine akademische Sicht auf die Welt herangeführt. Auch das Vorhaben einer Dissertation konnte nur gelingen, weil Volker Depkat mir nach dem Staatsexamen das nötige Vertrauen und intellektuelle Starthilfe zuteilwerden ließ. Auch die während meiner Promotionszeit sehr hilfreiche Stelle beim Themenverbund Ost-West-Transfers der Universität Regensburg war mit seiner Initiative verbunden.

Hier erfolgte auch der Erstkontakt mit meinem umtriebigen Zweitbetreuer Ulf Brunnbauer (Regensburg), der als Antragssteller gemeinsam mit Martin Schulze Wessel (München) die Graduiertenschule für Südost- und Osteuropastudien ins Leben rief. Beiden möchte ich für die institutionellen und materiellen Möglichkeiten danken, die meine Kommilitonen und mich vor den menschenunwürdigen Promotionsbedingungen bewahrt haben, die alle Genannten noch während ihrer Promotionszeit »im Kalten Krieg« (Depkat) vorgefunden hatten. Ich bedanke mich auch herzlich für die Aufnahme in ihre Reihe »Schnittstellen«.

In der Graduiertenschule ist besonders Heidrun Hamersky und Tünde Rist-Kaip (beide Regensburg) zu danken. Sie haben als Geschäftsführerin und Bürokraft bravourös einen soliden Rahmen um die hochtrabenden Gedanken und Aktivitäten der Betreuer und Doktoranden gelegt. In München seien dafür Caroline Fricke und Christoph Hilgert herzlich bedankt.

Überhaupt war die Graduiertenschule als akademischer und sozialer Raum ein wichtiger Bedingungsfaktor für mein weitgehend unbeschwertes Doktorandenleben. Dieses habe ich gerne mit meinem Mitdoktoranden Henner Kropp aus Bremen geteilt, der mir trotz seiner fanatischen Unterstützung des SV Werder nach wie vor ein guter Freund ist. Ihm ist auch für Einblicke in die russische Kultur, Politik und Sprache zu danken, die auch die vorliegende Arbeit an einigen Stellen vorangebracht haben. Nicht minder überraschend ist die nach wie vor bestehende Freundschaft zu Jasper Trautsch (Berlin), der als Post-Doc neben seiner Expertise zur Genese von »Westen « und »Abendland « stets als väterlicher Ratgeber in fast allen Lagen zur Verfügung stand. Tobias Grill (München) gab, ebenfalls als Post-Doc, besonders in der Anfangsphase des Projekts wertvolle Anstöße, insbesondere hinsichtlich der Geschichte der Juden in Russland. 
Allen Münchner und Regensburger Kommilitonen der Graduiertenschule gebührt Dank für die Zusammenarbeit in den Studiengruppen und den meist geistreichen, manchmal kurzweiligen Austausch auf Jahrestagungen, Sommerfesten und Kolloquien. Für das Lektorat danke ich herzlich Tino Jacobs (Bern), der unter erschwerten Bedingungen hervorragende Arbeit geleistet hat. Auch meiner Familie sei gedankt: Meine Eltern Michael Franz und Angela Fröhlich haben als Inspiration und Unterstützer großen Anteil am Gelingen dieser Dissertation, ebenso wie meine Geschwister Simon und Sarah. Meinen Großeltern Kurt und Renate Fröhlich sowie meinen während der Arbeit an diesem Buch verschiedenen Großeltern Josef und Olga Maria Franz danke ich herzlich für die tatkräftige Unterstützung, vor allem zwischen den erfolgreichen Karriereschritten.

Zu guter Letzt danke ich meiner Freundin Mira Ehrenfeld. Durch Studium und Promotion hinweg war sie mir die wichtigste Stütze von allen und ertrug (obwohl fachfremd!) die promotionsbedingte räumliche Trennung ebenso wie meine Launen und Grübeleien tapfer. 


\section{Abkürzungen}

Kürzel der gesichteten Zeitungen und Zeitschriften (detaillierte Angaben zu Verlag und Erscheinungsort finden sich in der Quellenübersicht im Anhang):

$\begin{array}{lll}\text { AIZ } & \text { Arbeiter Illustrierte Zeitung } & (1925-1933) \\ \text { AUT } & \text { Auto-Magazin } & (1928-1930) \\ \text { BIZ } & \text { Berliner Illustrirte Zeitung } & (1891-1945) \\ \text { BTB } & \text { Berliner Tageblatt } & (1872-1939) \\ \text { DAZ } & \text { Deutsche Allgemeine Zeitung } & (1861-1945) \\ \text { DKM } & \text { Das Kriminal-Magazin } & (1929-1933) \\ \text { FZT } & \text { Frankfurter Zeitung } & (1856-1943) \\ \text { ILB } & \text { Illustrierter Beobachter } & (1926-1945) \\ \text { MIP } & \text { Münchner Illustrierte Presse } & (1924-1945) \\ \text { MNN } & \text { Münchner Neueste Nachrichten } & (1848-1945) \\ \text { QUS } & \text { Der Querschnitt } & (1921-1936) \\ \text { RDM } & \text { Revue des Monats } & (1926-1933) \\ \text { SIB } & \text { Sowjetrußland im Bild } & (1921-1923) \\ \text { SMZ } & \text { Scherl's Magazin } & (1924-1933) \\ \text { SUH } & \text { Sichel und Hammer } & (1923-1924) \\ \text { UHU } & \text { UHU } & (1924-1934) \\ \text { VZT } & \text { Vossische Zeitung } & (1918-1934)\end{array}$

Weitere Abkürzungen:

$\begin{array}{ll}\text { CIT } & \text { Zentrales Arbeitsinstitut Moskau (Central'nyj institut truda) } \\ \text { DVP } & \text { Deutsche Volkspartei } \\ \text { KdF } & \text { Kraft durch Freude } \\ \text { Komsomol } & \text { Kommunistischer Jugendverband (Kommunističeskij sojuz molodëži) } \\ \text { KPD } & \text { Kommunistische Partei Deutschlands } \\ \text { KPdSU } & \text { Kommunistische Partei der Sowjetunion } \\ \text { KPR (B) } & \text { Kommunistische Partei Russlands (Mehrheitsfraktion). } \\ \text { NAACP } & \text { National Association for the Advancement of Colored People } \\ \text { NEP } & \text { Neue Ökonomische Politik (Novaja ékonomičeskaja politika) } \\ \text { NS- } & \text { Nationalsozialismus, nationalsozialistisch } \\ \text { NSDAP } & \text { Nationalsozialistische Deutsche Arbeiterpartei } \\ \text { SA } & \text { Sturmabteilung (der NSDAP) } \\ \text { SDAPR (B) } & \text { Sozialdemokratische Arbeiterpartei Russlands } \\ \text { USPD } & \text { Unabhängige Sozialdemokratische Partei Deutschlands } \\ \text { UdSSR } & \text { Union der sozialistischen Sowjetrepubliken } \\ \text { WASP } & \text { White Anglo-Saxon Protestant }\end{array}$




\section{Quellen- und Literaturverzeichnis}

\section{Quellen}

Arbeiter Illustrierte Zeitung. Neuer Deutscher Verlag, Berlin (1925-1933). Jg. 1925-1933. Abkürzung: AIZ.

Auto-Magazin. Verlag »Das Magazin« Dr. Eysler, Berlin (1928-1930). Jg. 1928-1930. Abkürzung: AUT.

Berliner Illustrirte Zeitung. Ullstein-Verlag, Berlin (1891-1945). Jg. 1918-1933. Abkürzung: BIZ.

Das Kriminal-Magazin. Verlag Wilhelm Goldmann, Leipzig (1929-1933). Jg. 19291933. Abkürzung: DKM.

Der Querschnitt. Verlag der Galerie Flechtheim, Berlin-Düsseldorf/ Ullstein-Propyläen, Berlin (1921-1936). Jg. 1921-1933. Abkürzung: QUS.

Illustrierter Beobachter. Franz-Eher-Verlag, München (1926-1945). Jg. 1926-1933. Abkürzung: ILB.

Münchner Illustrierte Presse, Knorr \& Hirth Verlag/Franz-Eher-Verlag, München (1924-1945). Abkürzung: MIP.

Revue des Monats. Verlag »Revue des Monats«, Berlin (1926-1933). Jg. 1926-1933. Abkürzung: RDM.

Scherl's Magazin. August Scherl-Verlag, Berlin (1924-1933). Jg. 1924-1933. Abkürzung: SMZ.

Sichel und Hammer. Internationale Arbeiterhilfe/Neuer Deutscher Verlag, Berlin (1923-1924). Jg. 1923-1924. Abkürzung: SUH.

Sowjetrußland im Bild. Internationale Arbeiterhilfe, Berlin (1921-1923). Jg. 1921-1923. Abkürzung: SIB.

UHU. Ullstein-Verlag, Berlin (1924-1934). Jg. 1924-1933. Abkürzung: UHU.

Berliner Tageblatt. Verlag Rudolf Mosse (1872-1939). Jg. 1918-1933. Abkürzung: BTB.

Deutsche Allgemeine Zeitung. Reimar Hobbing Verlag, Berlin/ Norddeutsche Buchdruck u. Verlagsgesellschaft (1861-1945). Jg. 1918-1933. Abkürzung: DAZ.

Frankfurter Zeitung. Frankfurter Societäts-Druckerei (1856-1943). Jg. 1918-1933. Abkürzung: FZT.

Münchner Neueste Nachrichten. Knorr \& Hirth-Verlag, München (1848-1945). Jg. 19181933. Abkürzung: MNN.

Vossische Zeitung. Ullstein-Verlag, Berlin (1918-1934). Jg. 1918-1933. Abkürzung: VZT. 


\section{Quellennachweise nach Kapiteln}

\section{Einführung}

Anon.: Die Botschaft Wilsons. In: FZT Nr. 336 vom 04.12.1918, 2.

Anon.: Führer und Volk. Die Oktoberrevolution. In: AIZ, 1921, Nr. 2, 10 f.

Anon.: Politisierung der Jugend. In: BIZ, 1923, Nr. 6, 103

Anon.: Prüfung auf Amerika-Tauglichkeit. In: BIZ, 1923, Nr. 38, Titel.

Anon.: Kaugummi-Unwesen in Berlin. In: BIZ, 1925, Nr. 14, 447.

Anon.: Die Negerfrage in Amerika. In: AIZ, 1926, Nr. 4, Titel.

Anon.: »Kunst-City«. In: MIP, 1926, Nr. 8, 184 (Jahresausgabe).

Anon.: Wall Street: »Ausgepowerte« Wirtschaft. In: MIP, 1926, Nr. 12, 263 (Jahresausgabe).

Anon.: Amerikanische Schönheitsinvasion. In: MIP, 1927, Nr. 2, 29 (Jahresausgabe).

Anon.: Coolidge turnt. Hinterspieler in Nicaragua. In: MIP, 1927, Nr. 2, 46 (Jahresausgabe).

Anon.: Die neue Zeit. Länder der Zukunft. In: DAZ Nr. 1 vom 01.01.1928, 1 f.

Anon.: Unter'm Brennglas. In: ILB, 1929, Nr. 2, 19.

Anon.: 700 Meter unter Tag: Dawesfron. Juden sind nicht dabei. In: ILB, 1929, Nr. 1, 10 f.

Coudenhove-Kalergi, Richard Nikolaus Graf von: Paneuropa. In: VZT Nr. 541 vom 15.11.1922, 4 .

Rost, Hans: Die Kulturkraft des Katholizismus. Paderborn 1916, 22.

Trausil, Hans: Was ist Amerikanismus? In: DAZ Nr. 443 vom 22.09.1926, $1 \mathrm{f}$.

Vorreiter, Anabert: Rußland und Europa. In: VZT Nr. 572 vom 03.12.1922, 21.

\section{Die Modernitätsdiskurse in der Weimarer Republik}

Anon.: Die Vorbehalte des amerikanischen Senats. In: FZT Nr. 866 vom 19.11.1919, 1.

Anon.: Verschleppung der Friedensfrage in Amerika. In: FZT Nr. 958 vom 23.12.1919, 1.

Anon.: Wilson. In: DAZ Nr. 59 vom 05.02.1924, 2.

Anon.: Woodrow Wilson $†$. In: FZT Nr. 92 vom 04.02.1924, $1 \mathrm{f}$.

Amerikanismus. In: Der Große Brockhaus. Bd. 1. Leipzig 1928, 390.

Coudenhove-Kalergi, Richard Nikolaus Graf von: Paneuropa. In: VZT Nr. 541 vom 15.11.1922, 4.

Montgelas, Max von: Offener Brief an Präsident Wilson von General Graf Montgelas. In: MNN Nr. 639 vom 18.12.1918, 1.

\section{Kultur der Rationalisierung und Rationalisierungskulte}

Anon.: Das Taylor-System. In: BIZ, 1919, Nr. 21, 182-183. (Jahresausgabe).

Anon. (F.S.): Russische Briefe. Die neue Wirtschaftspolitik. In: FZT Nr. 854 vom 16.11.1921, 1 .

Anon. (F.S.): Russische Briefe. Der Aufbau der Industrie. In: FZT Nr. 946 vom 21.12.1921, 1.

Anon. (F. S.): Russische Briefe. Das Problem der Arbeit. In: FZT Nr. 14 vom 06.01.1922, 1 f. 
Anon. (H.H.): Fliessende Fertigung. In: MIP, 1926, Nr. 3, 52 (Jahresausgabe).

Anon.: Der eiserne Buchhalter. Maschinen statt Menschen. In: BTB Nr. 35 vom 21.01.1926, 3 .

Anon.: Die Fordkarawane in Deutschland. Motorpflug beim Schaupflügen in Feldkirchen bei München. In: MIP, 1926, Nr. 19, 450 (Jahresausgabe).

Anon.: Amerikanismus. Ein Spiegel aus der neuen Welt. In: MNN Nr. 259 vom 23.09.1927, 1 .

Anon.: Rummelsburg. In: AIZ, 1927, Nr. 3, 2.

Anon.: Das praktische Amerika. In: UHU, 1929, Nr. 7, $58 \mathrm{f}$.

Anon.: O. T. In: MIP, 1929, Nr. 16, 532 (Jahresausgabe).

Anon. (P.H.): Europa und Amerika - ein Vortrag Hermann Keyserlings. In: DAZ Nr. 570 vom 06.12.1930, 1.

Anon. (Re.): Maschinen fressen Menschen. In: ILB, 1930, Nr. 40, 695 (Jahresausgabe). Anon.: Kapitalistische Rationalisierung. In: AIZ, 1931, Nr. 1, $4 \mathrm{f}$.

Anon.: Kasernen der Arbeit. Mays sozialistische Stadt. In: FZT Nr. 135 vom 20.02.1931, 3. Anon.: Rationalisierung im Großen - Empfehlungen der Genfer Konferenz. In: VZT Nr. 159 vom 04.04.1931, 1.

Anon.: Neue Arbeit, neue Menschen. Die Stossbrigade Kopylows. In: AIZ, 1932, Nr. 12, 268-272. (Jahresausgabe).

Anon.: »AMO« Das Erbe des Zarismus - »Stalin« Das Werk des Sozialismus. In: AIZ, 1932, Nr. 22, 516-518. (Jahresausgabe).

Ahler, Edgar: Arbeitsphysiologie und Rationalisierung. In: FZT Nr. 311 vom 28.04.1926, 1. Buccerius, Walter: Die Rationalisierung im Handwerk. In FZT Nr. 502 vom 09.07.1926, $1 \mathrm{f}$. Düsterwald, Wilhelm: Die amerikanische Gefahr. In: VZT Nr. 197 vom 24.04.1932, 13. Feiler, Arthur: Amerika-Europa. In: FZT Nr. 644 vom 30.08.1925, $1 \mathrm{f}$.

Feiler, Arthur: Amerika-Europa. Das laufende Band - I. In: FZT Nr. 800 vom 27.10.1925, $1 \mathrm{f}$.

Feiler, Arthur: Amerika-Europa. Das laufende Band - II. In FZT Nr. 812 vom 31.10.1925, $1 \mathrm{f}$.

Ford, Henry: Mein Leben und Werk. Leipzig, 1923.

Ford, Henry: Keine starre Massenproduktion! In: VZT Nr. 192 vom 24.04.1930, 9 f.

Ford, Henry: Warum Arbeitslosigkeit? Nicht die Maschine - die Fabrikleitung hat Schuld. In: VZT Nr. 195 vom 26.04.1930, 15.

Fülöp-Miller, René: Die Maschinenanbeter. In: VZT Nr. 485 vom 13.10.1923, 2 f.

Fülöp-Miller, René: Geist und Gesicht des Bolschewismus. Darstellung und Kritik des kulturellen Lebens in Sowjet-Rußland. Zürich u. a. 1926.

Geiger, Theodor: Die Masse und ihre Aktion. Ein Beitrag zur Soziologie der Revolutionen. Stuttgart 1926.

Goslar, Hans: Amerikas öffentliche Meinung. Politik, Theater, Kunst, Religion. In: VZT Nr. 132 vom 18.03.1922, $1 \mathrm{f}$.

Grabowsky, Adolf: Dorf und Stadt in Sowjet-Rußland. In: FZT Nr. 946 vom 19.12.1924, $1 \mathrm{f}$.

Hauser, Heinrich: Umgang mit Maschinen. In: FZT Nr. 147 vom 24.02.1928, 1.

Halberstaedter, H.: Die Rationalisierung des Bürobetriebs. In: FZT Nr.366 vom 19.05.1926, $1 \mathrm{f}$. 
Hirsch, Julius: Entwicklungslinien der amerikanischen Industrie. In: BTB Nr. 291 vom 22.06.1928, $1 \mathrm{f}$.

Hoover, Herbert: Der amerikanische Individualismus. In: QUS, 1931, Nr. 8, 507-511 (Jahresausgabe).

Höpker-Aschoff: Rationalisierung der Verwaltung. In: FZT Nr. 914 vom 09.12.1927, 1 f.

Kahle, M.: Arbeitsökonomie. In: DAZ Nr. 520 vom 23.10.1919, $1 \mathrm{f}$.

Keynes, John Maynard: Economic Possibilities for our Grandchildren. In: Essays in Persuasion. New York, 1963, 358-373.

Keyserling, Hermann: Das Reisetagebuch eines Philosophen. Darmstadt 1919. Neuauflage: St. Goar 2000.

Kracauer, Siegfried: Das Ornament der Masse. In: FZT Nr. 420 vom 09.06.1927, $1 \mathrm{f.}$

Kracauer, Siegfried: Das Ornament der Masse - II. In: FZT Nr. 423 vom 10.06.1927, $1 \mathrm{f}$.

Kracauer, Siegfried: Girls und Krise. In: FZT Nr. 384 vom 26.05.1931, 1 f.

Kracauer, Siegfried: Das Ornament der Masse. Essays. Frankfurt a. M. 1963.

Lenin, V.I.: Werke, Bd. 20. Berlin 1961.

Lenin, V.I.: Werke, Bd. 31. Berlin 1966.

Levy, Hermann: »Amerikanisierung« der deutschen Wirtschaft? In: BTB Nr. 242 vom 23.05.1925, $1 \mathrm{f}$.

Mahrholz, Werner: Fordismus und Fordisation - Was ist es mit der Fließarbeit? In: VZT Nr. 137 vom 22.03.1926, 5.

Marx, Karl/Engels, Friedrich: Werke, Bd. 23: Das Kapital, Bd. 1. Berlin 1968.

Marx, Karl Ökonomisch-philosophische Manuskripte (1844). In: Ders. / Engels, Friedrich: Werke. Bd. 40 (Schriften bis 1844). Berlin 1990, 2. Aufl., 465-588.

Marx, Karl: Ökonomisch-philosophische Manuskripte. In: Philosophische Bibliothek, Bd. 559. Hamburg 2008.

May, Ernst: Die Rationalisierung des Bauwesens. In: FZT Nr. 273 vom 14.04.1926, 1.

Meyer, Erna: Die Rationalisierung des Haushalts. In: FZT Nr. 812 vom 31.10.1926, 2.

Mitnitzky, Mark: Macht die Maschine arbeitslos? In: VZT Nr. 257 vom 29.05.1932, 2 f.

Moede, W.: Betriebsrationalisierung auf psychotechnischer Grundlage. In: FZT Nr. 295 vom 22.04.1926, 1.

Neuburger, Albert: Das Taylor-System. Das vielumstrittene Verfahren zur Erhöhung und Prüfung der Arbeitsleistung. In: BIZ, 1919, Nr. 21, 182 f. (Jahresausgabe).

Paquet, Alfons: Rom oder Moskau. 7 Aufsätze. München 1923.

Roth, Joseph: Reise nach Rußland. XI. Rußland geht nach Amerika. In: FZT Nr. 871 vom 23.11.1926, 1.

Roth, Joseph: Die Girls. In: FZT Nr. 313 vom 28.04.1925, 1.

Rundt, Arthur: Amerika - abgeschminkt III. In: BIZ, 1930, Nr. 13, 547 f.

Salomon, Alice: Lebenstechnik - Amerikanische Eindrücke. In: VZT Nr. 185 vom 17.04.1924, $1 \mathrm{f}$.

Seibert, Theodor: Sozialismus $=$ Bolschewismus + Elektrifizierung. Was ist aus den russischen Technisierungsbestrebungen geworden? In: MIP, 1928, Nr. 3., 68 f. (Jahresausgabe).

Taylor, Frederick Winslow: Die Grundsätze wissenschaftlicher Betriebsführung. München 1919.

Thormann, Werner: Rom oder Moskau. In: FZT Nr. 471 vom 29.06.1923, 1 f. 
Tietz, Leonhard Alfred: Die Rationalisierung des Detailhandels. In: FZT Nr. 330 vom 05.05.1926, $1 \mathrm{f}$.

Toller, Ernst: Besuch bei Ford. In: BTB Nr. 44 vom 24.01.1930, 5 f.

Tschachotin, Sergej: Drei Etappen des Taylorismus (Amerika - Deutschland - SowjetRußland). In: AIZ, 1924, Nr. 2, 7.

Tschernyschewski, Nikolai: Was tun? Aus Erzählungen von neuen Menschen. Berlin 1952.

Walcher, Jacob: Was ist Rationalisierung? In: AIZ, 1927, Nr. 23, 2.

Weber, Max: Vorbemerkungen. In: Ders.: Gesammelte Aufsätze zur Religionssoziologie. Bd. I. Tübingen, 1988, $11 \mathrm{f}$.

Weiß, Artur: Taylorismus. In: MNN Nr. 306 vom 24.07.1922, 1.

\section{Frauenbilder und Frauenemanzipation}

Anon.: WOMEN IN INDUSTRY. In: Monthly Labor Review, Vol. 9, No. 3 (September). Bureau of Labor Statistics, US Department of Labor 1919, 259-271.

Anon.: WOMAN IN INDUSTRY AND CHILD LABOR. In: Monthly Labor Review, Vol. 8, No. 6 (June). Bureau of Labor Statistics, US Department of Labor 1919, 224. Anon.: Freiheit und Proletarische Wehr. In: SIB, 1921, Nr. 5, 35 (Jahresausgabe).

Anon.: Im Zeichen der Abrüstung! In: ILB, 1926, Nr. 5, 2.

Anon.: Frauen im Krieg. In: AIZ, 1927, Nr. 30, 7.

Anon.: Rußland-Konflikt mit China. In: BIZ, 1929, Nr. 33, 1.

Anon.: Aus der Sowjet-Republik. In: ILB, 1929, Nr. 49, 660 (Jahresausgabe).

Anon.: Verteidigt die Sowjetunion. In: AIZ, 1930, Nr. 31, 610 (Jahresausgabe).

Anon.: Mädchengarde in Sowjet-Rußland. In: RDM, 1931, Nr. 10, 1062 (Jahresausgabe).

Anon.: Aus Aller Welt. An der George Washington-Universität üben die Studentinnen zum Bürgerkrieg. In: AIZ, 1927, Nr. 18, 16.

Anon.: Nun aber genug! Gegen die Vermännlichung der Frau. In: BIZ, 1925, Nr. 13, 4. Anon.: Mitglieder eines New-Yorker Schwimmclubs beim Bogenschießen. Preisfrage: Wieviel Männer sind hier dabei? In: BIZ, 1925, Nr. 13, 933 (Jahresausgabe).

Anon.: Die Frau als Soldat. In: RDM, 1928/29, Nr. 10, 1092-1095 (Jahresausgabe).

Anon.: Die andere Seite. Die Vermännlichung der Amerikanerin macht große Fortschritte. In: MIP, 1930, $740 \mathrm{f}$. (Jahresausgabe).

Anon.: Frauen als Polizistinnen in Russland. In: DKM, 1929, Nr. 7, 10.

Anon.: Weibliche Polizei. In: AIZ, 1928, Nr. 9, 7.

Anon.: Die neue amerikanische Strandpolizei: Ordnungspolizistin im Seebad Miami (Florida). In: BIZ, 1925, Nr. 14, Titel.

Anon.: Die jüngste Fliegerin, die 13-jährige Flugschülerin Karola Drehmann, auf dem Segelflugzeug, mit dem ihr einige Flüge gelangen. In: BIZ, 1923, Nr. 34, Titel.

Anon.: Eine tollkühne Frau. In: BIZ, 1927, Nr. 18, Titel.

Anon. (W.F.): Amazonen von heute. In: MIP, 1927, Nr. 33, $27 \mathrm{f}$.

Anon.: Ukrainische Flugschülerin, die in Charkow zur roten Aviatikerin ausgebildet wird. In: AIZ, 1930, Nr. 7, Titel.

Anon.: Ein Mädchen von 1929. In: BIZ, 1929, Nr. 49, Titel. 
Anon.: Eine Frau springt aus 1000 Meter in die Tiefe. In: MIP, 1932, Nr. 25, Titel.

Anon.: Das schwache Geschlecht 1931. In: RDM, 1931, Nr. 11, 1211 (Jahresausgabe).

Anon.: Die Frauenbewegung in den Vereinigten Staaten. In: FZT Nr. 895 vom 02.12. 1921, 1.

Anon.: Aus der amerikanischen Frauenbewegung. In: FZT Nr. 416 vom 07.06.1922, 1.

Anon.: Der erste weibliche Gouverneur in Texas. May Ferguson bei ihrer Antrittsrede im Kapitol von Austin (Texas). In: MIP, 1925, Nr. 13, 216 (Jahresausgabe).

Anon.: Der Tag der Frauen. In: MIP, 1926, Nr. 30, 727 (Jahresausgabe).

Anon.: Frauen im Zuge der Maikundgebung des Moskauer Proletariats. In: AIZ, 1922, Nr. 7, 52 (Jahresausgabe).

Anon.: Russische Frauen. Kasparowa, die Führerin der kommunistischen Frauen. In: AIZ, 1927, Nr. 7, 8 f.

Anon.: Die Frau in der Politik. In: BIZ, 1924, Nr. 40, 1083 (Jahresausgabe).

Anon.: Die Entsklavung der Frau im roten Osten, In: AIZ, 1924, Nr. 2, 6.

Anon.: Frauen-Kongreß in Moskau. II: All-russischer Kongreß der Arbeiterinnenund Bäuerinnendelegierten. In: AIZ, 1927, Nr. 44, 11.

Anon.: Frauen. In: AIZ, 1927, Nr. 43, 17.

Anon.: Das neue Gesetz über die Ehe und die Familie. In: FZT Nr. 56 vom 22.01.1925, 1.

Anon.: Amerikanische Schönheitsinvasion. In: MIP, 1927, Nr. 2, 29 (Jahresausgabe).

Anon.: Amerika industrialisiert die Schönheit. In: MIP, 1927, Nr. 43, 1229 (Jahresausgabe).

Anon.: Wettbewerb der Rücken (U.S. A.). In: QUS, 1931, Nr. 9, 632 (Jahresausgabe).

Anon.: Schönheitsköniginnen: ein neuer jüdischer Unfug. In: ILB, 1928, Nr. 31, 2 f.

Binz: In's Jahr der Abrüstung 1929. In: ILB, 1929, Nr. 1, 2 f.

Daniel, Léon: Amerika wählt.... In: RDM, 1928, Nr. 1, 60 (Jahresausgabe).

Dewall, Wolf von: Rush. Eine Vortragsreise in den U.S.A. Die Frau. In: FZT Nr. 195 vom 14.03.1929, $1 \mathrm{f}$.

Feiler, Arthur: Die Diktatur des Bolschewismus. Aus dem Tagebuch einer russischen Reise. Der Druck der Diktatur und seine Folgen. In: FZT Nr. 723 vom 28.09.1929, $1 \mathrm{f}$. Ferrero, Guglielmo: Europas Amerikanisierung. In: DAZ Nr. 174 vom 15.04.1926, $1 \mathrm{f}$. Frenssen, Gustav: Die Amerikanerin. In: VZT Nr. 282 vom 16.06.1923, 2.

Frennsen, Gustav: Gustav Frenssen in Amerika. In: FZT Nr. 496 vom 08.07.1923, $1 \mathrm{f}$.

Foelkersam, André von: 27 Frauen fahren zum Kongreß nach Moskau. In: UHU, 1929, Nr. 1, 84 f. (Jahresausgabe).

Grabowsky, Adolf: Die neue Lebensform in Sowjetrußland. In: FZT Nr. 933 vom 14.12.1924, $1 \mathrm{f}$.

Herrlich: Russische Bilderbogen. Die Armee. MIP, 1931, Nr. 51, 1606 (Jahresausgabe). Herrlich: Russische Bilderbogen. Wie sie heiraten. In: MIP, 1931, Nr. 52, 1637 (Jahresausgabe).

Kohn, Hans: Der Sowjetbund zwischen Orient und Okzident. In: FZT Nr. 635 vom 27.08.1931, $1 \mathrm{f}$.

Kollontai, Alexandra: Frauen in Rußland. In: FZT Nr. 919 vom 10.12.1925, $1 \mathrm{f}$.

Kollontai, Alexandra: Frauen in Rußland. In: FZT Nr. 928 vom 13.12.1925, 1.

Roth, Joseph: Reise nach Rußland. XII. Die Frau, die neue Geschlechtsmoral und die Prostitution. In: FZT Nr. 893 vom 01.12.1926, 2. 
Salomon, Alice: Amerikanische Reisebriefe. III. Frau und Mann. In: BTB Nr. 305 vom 01.07.1923, $1 \mathrm{f}$.

Salomon, Alice: Amerikanischer Winter. Der Klub der Frau. In: VZT Nr. 154 vom 30.03.1924, 4 .

Salzmann, Erich von: Sentimentality. In: VZT Nr. 82 vom 18.02.1921, $1 \mathrm{f}$.

Seibert, Theodor: Die befreite Frau in Rußland. In: MIP, 1931, Nr. 19, 611 (Jahresausgabe).

\section{Minderheiten: Emanzipation und Modernitätsbruch}

Anon.: Die Waffenbrüder. Der Amerikaner in Frankreich: »Diese Genossen im Kampf für die Zivilisation möchte ich Wilson mal zeigen!«. In: BIZ, 1918, Nr. 30, Titel.

Anon.: Die Straßenkämpfe in Chicago. In: VZT Nr. 387 vom 01.08.1919, 3.

Anon.: Rassenkämpfe in Amerika. In: BIZ, 1919, Nr. 35, 338 (Jahresausgabe).

Anon.: Faschistischer Terror in Amerika. In: AIZ, 1925, Nr. 4, Titel.

Anon.: Ku-Klux-Klan. Eine geheimnisvolle Sekte. In: MIP, 1925, Nr. 24, 526f. (Jahresausgabe).

Anon.: Phantastische Geheimbündler in Deutschland nach amerikanischem Muster. In: BIZ 1925, Nr. 38, 1194 (Jahresausgabe).

Anon.: Weiss gegen Schwarz. Das amerikanische Rassenproblem. In: MIP, 1925, Nr. 52, 1169 (Jahresausgabe).

Anon.: Keine Parade der Zuckerbäcker. In: ILB 1926, Nr. 4, Titel.

Anon.: Moderne Diktatoren. Studie. Bilder von Ferdinand Bruger. In: ILB, 1927, Nr. 10, 143 (Jahresausgabe).

Anon.: 10 Jahre Sowjet-Juden Diktatur. In: ILB, 1927, Nr. 20, 288 (Jahresausgabe).

Anon.: Die Sowjet-Brüder in Genf. In: ILB, 1927, Nr. 23, 323 (Jahresausgabe).

Anon.: Bilder der Woche. Die Häuptlinge der faschistischen Geheimorganisation Klu Klux Klan [sic] in Amerika in ihrem clownhaften Ordenskostüm bei einer New-Yorker Demonstration. In: AIZ, 1927, Nr. 24, 2.

Anon.: Die letzte Mohikanerin. "Die weiße Hirschkuh", Tochter des "fliegenden Hirsches«, die angeblich letzte Frau des Mohikanerstammes, die nun auf einer New-Yorker Bühne auftritt. In: BIZ, 1927, Nr. 20, 788 (Jahresausgabe).

Anon.: Vom Sklaven zum Herrn. Der Aufstieg des amerikanischen Negers. In: BIZ, 1927, Nr. 24, 948 (Jahresausgabe).

Anon.: Bäuerin aus der autonomen Republik der Wolga-Deutschen. In: AIZ, 1927, Nr. 21, Titel.

Anon.: Die Pueblo- und Navajo-Indianer. Die ältesten Rassen Amerikas. In: BIZ, 1927, Nr. 37, 1476f. (Jahresausgabe).

Anon.: Die deutsche Wolga-Republik. In: AIZ, 1927, Nr. 42, $4 \mathrm{f}$.

Anon.: Mord-Poesie aus Sowjet-Judäa. In: ILB, 1928, Nr. 6, 78 (Jahresausgabe).

Anon.: Der Bolschewistenmord an dem Antisemiten Zar Nikolaus II. und seiner Familie. In: ILB, 1928, Nr. 16, 194 (Jahresausgabe).

Anon.: Der zweite Indianer-Kongreß in Spokane. In: MIP, 1928, Nr. 19, 596 f. (Jahresausgabe).

Anon.: Exit Ku-Klux-Klan. In: FZT Nr. 149 vom 24.02.1928, 1. 
Anon.: Antisemitismus in Sowjet-Rußland. In: ILB, 1928, Nr. 32, 399 (Jaresausgabe).

Anon.: Indianer. In: BIZ, 1928, Nr. 42, $1790 \mathrm{f}$. (Jahresausgabe).

Anon.: Die antisemitischen Ausschreitungen in Sowjetrußland. In: FZT Nr. 907 vom 04.12.1928, 2.

Anon.: Auspeitschung eines Negers in den Südstaaten. In: DKM, 1929, Nr. 1, 47.

Anon.: Neuer Schlag Rußlands gegen das Deutschtum. Enteignung der wolgadeutschen Bauerngüter - ein deutscher Pfarrer nach Sibirien verbannt. In: MNN Nr. 342 vom 16.12.1929, 1.

Anon.: Wolga-Bauern. Zu den Massenauswanderungen deutscher Bauern aus Rußland. In: MIP, 1929, Nr. 48, 1626 (Jahresausgabe).

Anon.: Amerikanische Neger. In: FZT Nr. 952 vom 22.12.1929, 1 f.

Anon.: John D. Rockefeller Jun. baut Wohn-Blocks für - Neger! In: MIP, 1930, Nr. 19, 667 (Jahresausgabe).

Anon.: Neger träumen vom Paradies. Das Zugstück der New Yorker Theatersaison. In: MIP, 1930, Nr. 31, 1075 (Jahresausgabe).

Anon.: Neger unter sich. Besuch im Schwarzen-Viertel. In:VZT Nr. 216 vom 09.05.1930, 15.

Anon.: Furchtbare Lynchjustiz in Texas. Ein Neger aus dem Gefängnis geholt. Das Gerichtsgebäude eingeäschert. Eine ganze Stadt in Aufruhr. Militär muß eingreifen. In: VZT Nr. 219 vom 10.05.1930, 1.

Anon.: Pöbelhaftes aus Amerika. Um einen Neger zu lynchen - Sturm auf ein Gerichtsgebäude. In: FZT Nr. 347 vom 10.05.1930, 1.

Anon.: Amerika deportiert...- Der Ausländer als Sündenbock / Razzien auf die Heimatlosen / Erbitterung der Naturalisierten. In: VZT Nr. 101 vom 28.02.1931, $1 \mathrm{f}$.

Anon.: Leben und Kampf der schwarzen Rasse. In: AIZ, 1931, Nr. 26, Titel.

Anon.: Die schwarze Rasse stösst zur Roten Front. In: AIZ, 1931, Nr. 26, 510 f.

Anon.: Humor und Satire. Unter amerikanischen Faschisten. In: AIZ, 1931, Nr. 26. S. 521 (Jahresausgabe).

Anon: Fremdenfeindliches Amerika - Verschärfte Ausweisung der Arbeitslosen. In: VZT Nr. 194 vom 22.04.1932, 3.

Anon.: Eine Mutter kämpft um ihre Söhne. In: AIZ, 1932, Nr. 21, 438 (Jahresausgabe).

Anon.: Einstein bei den Indianern. In: MIP, 1931, Nr. 13, 386 (Jahresausgabe).

Alejchem, Scholem: Tewje, der Milchmann. Bremen 2011. (Erstauflage 1916).

Bernhard, Paul: Soziologie des »Jazz«. In: FZT Nr. 413 vom 06.06.1926, $1 \mathrm{f}$.

Chapiro, Joseph: „Die amerikanische Negerhauptstadt. Der Neger als Kulturfaktor«. In: BTB Nr. 136 vom 20.03.1929, 5.

Feder, Ernst: Unter dem Jim-Crow-System. Eindrücke im Süden.- Die soziale und ökonomische Trennung zwischen Weissen und Farbigen.- Einfluss der Industrialisierung und der Agrarkrise. Der Ausschuss für Zusammenarbeit der Rassen. Im Campus der Neger-Universität. In: BTB Nr. 328 vom 14.07.1930, 1 f.

Feiler, Arthur: Die Diktatur des Bolschewismus. Aus dem Tagebuch einer russischen Reise. In: FZT Nr. 704 vom 21.09.1929, $1 \mathrm{f}$.

Friedländer, Paul: Der Sport der Hundertprozentigen. In: AIZ, 1930, Nr. 35, 683 (Jahresausgabe).

Goslar, Hans: Der amerikanische Neger. In: VZT Nr. 156 vom 01.04.1922, 1. 
Halfeld, Adolf: Das Neuyorker Stadtviertel Harlem. Die Neger-Metropole der Welt. In: MIP, 1926, Nr. 49, 1172 (Jahresausgabe).

Henckel, Heinz: Das wahre Gesicht des Roten Mannes. In: ILB, 1927, Nr. 13, 186 f. (Jahresausgabe).

Johnston, Alva: Kastenwesen in Amerika. In: QUS, 1932, Nr. 8, 44.

Kaergel, Hans Christoph: Amerikanische Bilder. Im Negerviertel. In: MNN Nr. 187 vom 08.07.1925, $3 \mathrm{f}$.

Kaergel, Hans: Die Heimat ruft. Gütersloh 1936.

Kaergel, Hans: Der Volkskanzler. Leben und Werden Adolf Hitlers von der Jugend bis zum Führer des Volkes. Für Jugend und Volk erzählt. Langensalza 1938.

Kohn, Hans: Die Sowjetunion und ihr Nationalitätenproblem. In: FZT Nr. 869 vom 22.11.1931, $1 \mathrm{f}$.

Kruse, William: Die revolutionäre Neger-Bewegung in Amerika. In: AIZ, 1926, Nr. 4, 3.

Lenin, V.I.: Werke, Bd. 20 (Dezember 1913-August 1914). Berlin 1961.

Marx, Josef: Im Schwarzen-Viertel in Detroit. In: BIZ, 1928, Nr. 7, 275 f. (Jahresausgabe).

Mensching, Wilhelm: Afrika in Amerika. Der Kampf der amerikanischen Neger um ihre Gleichberechtigung. In: FZT Nr. 789 vom 23.10.1927, $1 \mathrm{f}$.

Nathan, P.: Die Verantwortung der Sieger - Zu den Pogromen in Südrußland. In: BTB Nr. 87 vom 17.02.1920, $1 \mathrm{f}$.

Nearing, Scott: Schwarze Amerikaner. In: AIZ, 1928, Nr. 46, $4 \mathrm{f}$.

Olden, Peter: Sklaverei in Florida. In: BIZ, 1930, Nr. 14, 582 f. (Jahresausgabe).

Rakovsky, Alexandra: Frauenleben in Sowjet-Rußland. In: VZT Nr. 1 vom 01.01.1928, 6.

Roth, Joseph: Reise in Rußland - IX. Die Lage der Juden in Sowjetrußland. In: FZT Nr. 835 vom 09.11.1926, $1 \mathrm{f}$.

Ruese, Alfons M.: Ku Klux. In: VZT Nr. 475 vom 08.10.1921, 1 f.

Rundt, Arthur: Die schwarze Welle. In: UHU, 1924, Nr. 11, 31.

Scott, Emmett J.: Scott's Official History of the American Negro in the World War. A Complete and Authentic Narration from Official Sources, of the Participation of American Soldiers of the Negro Race in the World War for Democracy. Chicago 1919.

Weber, Wolfgang: Negermusik. In: BTB Nr. 378 vom 12.08.1927, 2.

\section{Politische Ordnungen}

Anon.: Der Wahlkampf in Amerika. In: DAZ Nr. 540 vom 01.11.1920, 1.

Anon.: Bolschewistische Menschenschlächtereien. In: VZT Nr. 116 vom 10.03.1921, 2. Anon.: Lenin für Einberufung einer Konstituante. In: MNN Nr. 253 vom 20.06.1921, 1. Anon.: Zur Beschlagnahme der Kirchenschätze in Rußland. In: SIB, 1921, Nr. 10, 9. Anon.: Die Demokratisierung des amerikanischen Staatswesens. In: FZT Nr. 644 vom 12.09.1922, $1 \mathrm{f}$.

Anon.: Politische Schreckensurteile. Die Verhandlungen vor dem Moskauer Revolutionsgericht gegen die katholischen Geistlichen, von denen der Prälat Budkiewicz zum Tode verurteilt und erschossen, der Erzbischof von Petersburg zu langer Zuchthausstrafe verurteilt wurde. In: BIZ, 1923, Nr. 15, Titel. 
Anon. (D. G.): Die Kreml-Konferenz. In: VZT vom 20.01.1924, Nr. 34, 3.

Anon. (Russ. Telegr.-Ag.): Die Auseinandersetzung in Moskau. In: VZT Nr. 36 vom 22.01.1924, 3 .

Anon.: Parlamentarismus. In BIZ, 1922, Nr. 48, 926.

Anon.: Der Senat in Washington. In: BIZ, 1923, Nr. 10, $182 \mathrm{f}$. (Jahresausgabe).

Anon.: Das Oberhaupt der russischen orthodoxen Kirche, Patriarch Tychon, der von der Sowjet-Regierung des Hochverrats beschuldigt und in den nächsten Tagen vor Gericht gestellt wird. In: BIZ, 1923, Nr. 17, 324 (Jahresausgabe).

Anon.: Amerikanische Rednertypen. In: BIZ, 1923, Nr. 29, 564 (Jahresausgabe).

Anon.: Das russische Problem. Eine Unterredung mit Dr. Spengler. In: MNN Nr. 306 vom 09.11.1924, $1 \mathrm{f}$.

Anon.: Präsident Coolidge wiedergewählt. In: BIZ, 1924, Nr. 46, Titel.

Anon.: Wahltag in New York: Auto mit Radio-Lautsprecher-Einrichtung auf der Straße. In: BIZ, 1924, Nr. 49, 1442 (Jahresausgabe).

Anon.: Masse und Führer. In: MNN Nr. 53 vom 23.02.1925, $1 \mathrm{f}$.

Anon.: Der offizielle Amtsantritt des amerikanischen Präsidenten: Präsident Coolidge mit seiner Gattin und einem Senator auf der Fahrt zu seiner Vereidigung im Kapitol von Washington. In: BIZ, 1925, Nr. 13, 387 (Jahresausgabe).

Anon.: Ostereiersuche im Weißen Haus. In: BIZ, 1925, Nr. 15, 450 (Jahresausgabe).

Anon.: Redetechnik und Radiotechnik. In: BIZ, 1925, Nr. 15, 451 (Jahresausgabe).

Anon.: Die Krisis der kommunistischen Diktatur. In: DAZ Nr. 155 vom 25.03.1925, $1 \mathrm{f}$.

Anon.: Massenstaat oder Führerstaat? Appell der Liberalen Vereinigung. In: DAZ Nr. 268 vom 12.06.1926, 1.

Anon.: Unterwerfung der Sowjet-Opposition. Reue-Bekenntnis der Oppositionsführer. In: MNN Nr. 289 vom 23.10.1926, 1.

Anon.: Politische »Bereinigung« in Moskau. Stalins neuer Kampf gegen die Opposition. In: MNN Nr. 299 vom 28.10.1926, 1.

Anon.: Sinowjew kaltgestellt - Der erste Schritt der Sowjetregierung gegen die Opposition. In: DAZ Nr. 343 vom 26.07.1926, 1.

Anon.: Der Amerikaner an der Wahlurne. In: DAZ Nr. 517 vom 04.11.1926, $1 \mathrm{f}$.

Anon.: Die blutige Maidemonstration Chicago 1886. In: AIZ, 1927, Nr. 17, 2 f.

Anon.: Der Reklame-Staat. Beobachtungen aus Sowjet-Rußland. In: MIP, 1927, Nr. 27, $780 \mathrm{f}$. (Jahresausgabe).

Anon.: Entscheidungskampf in Moskau. Nach dem Ausschluß Trotzkis. In: MNN Nr. 297 vom 31.10.1927, 1.

Anon.: Trotzki und Wujowitsch gemaßregelt - Aus Mitglieder- und Kandidatenliste des Exekutivkomitees gestrichen. In: DAZ Nr. 460 vom 01.10.1927, 1.

Anon.: Religion und Rundfunk. In: ILB, 1928, Nr. 19, 235 (Jahresausgabe).

Anon.: Helden des Proletariats. In: AIZ, 1928, Nr. 32, 11.

Anon.: Verbannung der russischen Oppositionsführer. In: FZT Nr. 26 vom 10.01.1928, 1. Anon.: Die Verschickung der russischen Oppositionsführer. In: FZT Nr. 29 vom 11.01.1928, 1 .

Anon.: Demokratie in Aktion. In: AIZ, 1928, Nr. 41, Titel.

Anon.: Herbert Hoover, der neugewählte Präsident der Vereinigten Staaten, mit seinen Söhnen Herbert und Allan. In: BIZ, 1928, Nr. 47, 2004 (Jahresausgabe). 
Anon.: Moskaus Kampf gegen das Weihnachtsfest - Keine Schulferien über die Feiertage. In: DAZ Nr. 602 vom 24.12.1928, 1.

Anon.: Die Verhaftung der Trotzkisten. Sie werden angeklagt, den Bürgerkrieg vorzubereiten. In: BTB Nr. 42 vom 11.02.1929, 1.

Anon.: Bei den russischen Auswanderern in Kiel - ein Besuch im Lagerhaus am Nordhafen - Was die Auswanderer von den grausigen Zuständen daheim und vor Moskau erzählen. In: DAZ Nr. 532 vom 15.11.1929, 2.

Anon.: Kampf gegen die Kirche in Sowjet-Russland. In: BIZ, 1930, Nr. 7, 244 (Jahresausgabe).

Anon.: Vor dem Sowjet-Parteitag. Sündenregister der Rechtsopposition. In: MNN Nr. 171 vom 26.06.1930, $1 \mathrm{f}$.

Anon.: Die Bolschewisten und die christliche Religion. In: ILB, 1930, Nr. 13, $205 \mathrm{f}$.

Anon.: Stalins Sieg auf dem Parteitag. Programmgemäßer Verlauf. In: MNN Nr. 179 vom 04.07.1930, $1 \mathrm{f}$.

Anon.: Der Kampf der Sowjetjuden gegen die christliche Religion. In: ILB, 1930, Nr. 16, 252.

Anon.: Der Sowjetkrieg gegen Gott. Eines der typischen antireligiösen Plakate der Sowjetregierung in ihrem unerhörten Kampf gegen das Christentum. In: ILB, 1930, Nr. 21, Titel.

Anon.: Die Ordnung ist wieder hergestellt. In: AIZ, 1931, Nr. 16, 307 (Jahresausgabe).

Anon.: Amerika im Präsidentschafts-Wahlkampf. In: AIZ, 1932, Nr. 38, 899-901 (Jahresausgabe).

Anon.: Gottlosen-Fünfjahresplan in der Sowjetunion - Vollständige Ausrottung der Religion bis 1937 geplant. In: DAZ Nr. 492 vom 21.09.1932, 1.

Adler, Max: Demokratie und Rätesystem. Wien 1919.

Arseniew, Nikolaus von: Das Kreuz im Osten. Vom Martyrium der russischen Kirche. In: MNN Nr. 186 vom 07.07.1926, $1 \mathrm{f}$.

Bernhard, Georg: Erneuerung der Demokratie. In: VZT Nr. 104 vom 02.03.1930, $1 \mathrm{f}$.

Bruger, Ferdinand: Der Kirchensturm in der Sowjethölle. In: ILB, 1930, Nr. 6, $91 \mathrm{f}$.

Ehlers: Das heilige Rußland im Exil. In: MIP, 1931, Nr. 40, $1276 \mathrm{f}$.

Feiler, Arthur: Die Diktatur des Bolschewismus. Aus dem Tagebuch einer russischen Reise. Der Druck der Diktatur und seine Folgen. In: FZT Nr. 723 vom 28.09.1929, 1.

Fraenkel, Ernst: Gesammelte Schriften. Bd.1, Recht und Politik in der Weimarer Republik. Herausgegeben von: Brünneck, Alexander von/Buchstein, Hubertus/ Göhler, Gerhard. Baden-Baden 1999.

Gibarti, L.: USA: Demokratie in Aktion. In: AIZ, 1928, Nr. 41, $8 \mathrm{f}$.

Goldschmidt, Alfons: Hinter der U.S. A.-Prosperität. In: AIZ, 1928, Nr. 24, 2.

Halfeld, Adolf: Amerika und der Amerikanismus. Kritische Betrachtungen eines Deutschen und Europäers. Jena 1927.

Halfeld, Adolf: Die beiden Gegner. Der amerikanische Präsidentschafts-Kampf. In: MIP, 1928, Nr. 44, 1396f. (Jahresausgabe).

Hausleiter, Leo: Gottes eigene Staaten. In: MIP, 1931, Nr. 39, 1221-1237 (Jahresausgabe).

Hitler, Adolf: Angriff der Weltanschauung. In: ILB, 1931, Nr. 24, 501 (Jahresausgabe). Just, Artur W.: Oeffentliche Meinung in Rußland. In: FZT Nr. 672 vom 09.09.1926, 1. 
Leitner, Maria: „Weisser Abschaum«. Aus dem amerikanischen Arbeiterparadies. In: AIZ, 1929, Nr. 20, $4 \mathrm{f}$.

Lotz, Walther: Reiseeindrücke aus Sowjetrußland. In: BTB Nr. 512 vom 29.10.1925, $1 \mathrm{f}$.

Lyons, Eugene: Sacco und Vanzetti. Ihr Leben und Sterben. Berlin 1928.

Niekisch, Ernst: Entscheidung. Berlin 1930.

Rundt, Arthur: Das lenkbare U.S. A.-Gehirn. In: BIZ, 1928, Nr. 48, 2069-2071 (Jahresausgabe).

Scheffer, Paul: Der neue innerpolitische Kurs in Sowjetrußland - die Rückwirkungen auf Wirtschaft und Ausland. In: BTB Nr. 202 vom 29.04.1924, $1 \mathrm{f}$.

Scheffer, Paul: Hinter der Kremlmauer. In: BTB Nr. 402 vom 26.08.1927, $1 \mathrm{f}$.

Schlund, Erhard: Bolschewismus und russische Kirche. In: MNN Nr. 43 vom 14.02.1932, $1 \mathrm{f}$.

Sombart, Werner: Vom Menschen. Versuch einer geisteswissenschaftlichen Anthropologie. Berlin 1938.

Trotzki, Leo/ Trockij, Lev: Naschi polititscheskie sadatschi taktitscheskie i organisazionnye woprosy (deutsch: Unsere politischen Aufgaben. Taktische und organisatorische Fragen). Genf 1904.

Trotzki, Leo/Trockij, Lev: Die verratene Revolution. Was ist die USSR und wohin treibt sie? Zürich u.a. 1936.

Vorst, Hans: Die »Wahrheit« über Rußland. In: BTB Nr. 335 vom 23.07.1919, $1 \mathrm{f}$.

Vorst, Hans: Die russische Krisis. Leipzig 1916.

Vorst, Hans: Der Bolschewismus und seine Lehren. Leipzig 1919.

Vorst Hans: Revolution und Todesstrafe. Leipzig 1920

Wilson, Woodrow: Address delivered at Joint Session of the Two Houses of Congress. April $2^{\text {nd }}$, 1917. United States $65^{\text {th }}$ Congress, $1^{\text {st }}$ Session, Senate Document 5.

\section{Sport, Jugend und Bildung: Fundamente der neuen Zeit}

Anon.: Führer und Volk. In: SIB, 1921, Nr. 2, 10.

Anon. (B.E.): Bildungsnot im bolschewistischen Rußland. Die Lage der Gelehrten. In: VZT Nr. 123 vom 15.03.1921, 9.

Anon.: Neue Schreckenstaten der Bolschewisten. Hervorragende Gelehrte ermordet. In: VZT Nr. 419 vom 06.09.1921, 1.

Anon.: Der Sport in Sowjetrußland. In: SIB, 1922, Nr. 8, 61 (Jahresausgabe).

Anon.: Nationalsozialistische Politisierung der Jugend. In: BIZ, 1923, Nr. 6, 103 (Jahresausgabe).

Anon.: Aus Sowjet-Rußland: Eine Jugendorganisation bei Turnspielen vor dem Winterpalais in St. Petersburg. In: BIZ, 1923, Nr. 37, 734 (Jahresausgabe).

Anon.: Sieben Jahre Sowjetrußland. In: SUH, 1924, Nr. 1, Titel.

Anon.: Aufklärung unter den Bauern. In: SUH, 1924, Nr. 1, 7.

Anon.: Junge Pioniere. In: SUH, 1924, Nr. 1, 13.

Anon.: Sowjetrußlands Jugend. In: AIZ, 1925, Nr. 8, 13.

Anon.: Russischer Arbeitersport. In: AIZ, 1925, Nr. 10, 14.

Anon.: Sowjet-Rußlands Sorge um seine Jugend. In: AIZ, 1925, Nr. 12, 4. 
Anon.: Gegen die politische Verhetzung der Jugend. Haltet die Jugend vom Parteiwesen fern! In: BIZ, 1925, Nr. 22, 677 f. (Jahresausgabe).

Anon.: Die Kinderhölle in Rußland. Streiflichter zum Problem des bolschewistischen Staates. In: MIP, 1926, Nr. 26, 606 (Jahresausgabe).

Anon.: Aus aller Welt. Im Pionierhaus des Moskauer Volksbildungsinstituts: Der Gruppenführer liest die Jugendzeitung vor. In: AIZ, 1927, Nr. 2, 16.

Anon.: »Spartak«. Haus der Kinder in Moskau. In: AIZ, 1927, Nr. 3, 13.

Anon: Sport. In: AIZ, 1927, Nr. 43, 12.

Anon.: Kinderelend in Sowjetrußland. In: ILB, 1928, Nr. 19, 223-236 (Jahresausgabe).

Anon.: Wintersport in Sowjet-Russland. In: AIZ, 1929, Nr. 4, Titel.

Anon.: Russlands Junge Generation. In: AIZ, 1929, Nr. 30, 6.

Anon.: Wassersport in Sowjet-Russland. In: AIZ, 1929, Nr. 31, 18.

Anon.: Politisch missbrauchte Kinder. In: BIZ, 1929, Nr. 36, 1607 (Jahresausgabe).

Anon.: Massenverhaftungen von russischen Gelehrten. Unter der Beschuldigung der Teilnahme an einer gegenrevolutionären Verschwörung. In: FZT Nr. 657 vom 04.09.1930, 1.

Anon.: Die Kinderhölle im Sowjetparadies. In: ILB, 1930, Nr. 50, 889-892 (Jahresausgabe).

Anon.: 24 Stunden aus dem Leben einer Moskauer Arbeiterfamilie. In: AIZ, 1931, Nr. 38, 750-765 (Jahresausgabe).

Anon.: Kulturaufbau in Sowjetrußland - Herr Lunatscharski prophezeit Herz und Gemüt. In: DAZ Nr. 502 vom 27.09.1931, 2.

Anon.: Sowjet-Jugend. In: AIZ, Nr. 44, 1038-1039 (Jahresausgabe).

Anon.: Amerikanische Arbeiterkinder. In: AIZ, 1932, Nr. 51, Titel.

Anon.: Obdachlose Kinder. In: AIZ, 1932, Nr. 51, 1188-1189 (Jahresausgabe).

Arco, Georg von: Die Wissenschaft im neuen Rußland - Graf Arcos Moskauer Eindrücke. In: BTB Nr. 7 vom 04.01.1924, 2.

Bloem, Walter: Verwilderte Kinder in Rußland. In: BIZ, 1927, Nr. 21. S. 841-843 (Jahresausgabe).

Das Programm der kommunistischen Partei Rußlands (Bolschewiki): Angenommen auf d. 8. Parteikongreß (18. bis 23. Mai 1919). Leipzig, 1919, V./1.

Dewall, Wolf von: Rush. Eine Vortragsreise in den U.S.A. Boys and Girls. In: FZT Nr. 214 vom 21.03.1929, $1 \mathrm{f}$.

Feiler, Arthur: Das Experiment des Bolschewismus. Aus dem Tagebuch einer russischen Reise. In: FZT Nr. 603 vom 15.08.1929, $1 \mathrm{f}$.

Fell, Hans: Militarisierte Jugend ... bei den anderen. In: SMZ, 1928, Nr. 6, 594-600 (Jahresausgabe).

Fischer, Max: Das Buch im Sowjetstaat. In: DAZ Nr. 586 vom 14.12.1928, 1.

Friedrich, Joachim: Amerikanisches Hochschulleben. In: VZT Nr. 279 vom 15.06.1923, $5 \mathrm{f}$.

Goritsch, A.: Analphabeten-Prozeß in Rußland. In: FZT Nr. 348 vom 11.05.1925, 1.

Gorki, Maxim: Der Bücherhunger in Rußland. In: BTB Nr. 549 vom 29.11.1921, 5.

Goslar, Hans: Amerikas Geistesleben 1922 - Wissenschaft, Universitäten, Schulen. In: VZT Nr. 120 vom 11.03.1922, $1 \mathrm{f}$.

Goslar, Hans: Der amerikanische Mensch. In: VZT Nr. 190 vom 22.04.1922, 1 f. 
Kracauer, Siegfried: Das Ornament der Masse - II. In: FZT Nr. 423 vom 10.06.1927, $1 \mathrm{f}$. Kisch, Egon Erwin: Fussball in Amerika. In: AIZ, 1929, Nr. 47, 10 f.

Kläber, Ernst: Brookwood. Eine amerikanische Arbeiterhochschule. In: AIZ, 1927, Nr. 4, 4.

Kurella, Alfred: Sozialistische Erziehung. In: AIZ, 1932, Nr. 34, $804 \mathrm{f}$.

Lenin, V.I.: Jugend. In: AIZ, 1927, Nr. 43, 13.

Lorant, Georg: Mißbrauch der Jugend. In: RDM, 1931, Nr. 10, 1060-1063 (Jahresausgabe). Nansen, Fridtjof: Russisches Bildungswesen. In: VZT Nr. 191 vom 24.04.1923, $1 \mathrm{f}$.

Olympia. R.: Riefenstahl, Leni. Deutschland 1938. (Filmquelle)-

Roth, Joseph: Reise in Rußland. XVII. Die Schule und die Jugend. In: FZT Nr. 43 vom 18.01.1927, $1 \mathrm{f}$.

Rundt, Arthur: Die Landstraßenkatze wird gezähmt. Der Kampf gegen die verwilderten Kinder in Sowjetrußland. In: BIZ, 1931, Nr. 2, 58 f. (Jahresausgabe).

Salomon, Alice: Amerikanische Bildung. In: VZT Nr. 218 vom 08.05.1924, $1 \mathrm{f}$.

Scharf, Fritz: Vergiftete Jugend in Amerika. In: RDM, 1927, Nr. 2, 178-181 (Jahresausgabe).

Schmitz, K.E. F.: Das rote Gesicht. Ein russischer Bilderbogen von Dr. K. E. F. Schmitz. In: RDM, 1927, Nr. 6, 641-645 (Jahresausgabe).

Siebourg, Hellmut: Sport-Erziehung an den USA-Hochschulen. Basketball, Baseball und Football als Hauptbeschäftigung. In: VZT Nr. 319 vom 05.07.1932, 7.

Stein, Ludwig: Die Yale-Universität - Gänge durch Amerikas Hochschulen. In: VZT Nr. 170 vom 09.04.1924, 5.

Vorst, Hans: Die »Wahrheit« über Rußland. In: BTB Nr. 335 vom 23.07.1919, $1 \mathrm{f}$.

Weer, Reinhard: College-Boys. In: DAZ Nr. 315 vom 10.07.1929, 1.

White, William C.: Junge Leute zwischen 18 und 24. Der dritte Aufsatz unserer Veröffentlichung »So lebt der Mensch in Rußland«. In: UHU, 1932, Nr.7, 47-55.

Zielesch, Fritz: Jugend im Land der Jugend. Ein Amerikabuch. Hamburg, 1926.

Zielesch, Fritz: Im Klub der Strassenjungen. Wie man in Amerika »Bürger macht«. In: BIZ, 1926, Nr. 3, 69 f. (Jahresausgabe).

\section{Schlussbetrachtung}

Anon.: Traumland. In: DAZ Nr. 308 vom 06.07.1926, $1 \mathrm{f}$.

Briefs, Götz: Amerika und sein Geheimnis. In: BTB Nr. 481 vom 11.10.1927, 1 f.

Ferrero, Guglielmo: Europas Amerikanisierung. In: DAZ Nr. 174 vom 15.04.1926, $1 \mathrm{f}$.

\section{Internetquellen}

Fischer, Sebastian: Die neuen Front-Frauen. URL: http://www.spiegel.de/politik/ ausland/frauen-beim-us-militaer-gleichberechtigung-bei-kamptruppen-bis-2016a-881944.html. Spiegel Online GmbH Hamburg (am 25.3.2014).

Fischer, Sebastian/Sperber, Sandra: US-Armee: Frauen an die Front. URL: http:// www.spiegel.de/politik/ausland/us-armee-obama-will-frauen-in-kampfeinsaetzeschicken-a-958709.html. Spiegel Online GmbH Hamburg (am 01.04.2014). 


\section{Literatur}

Aly, Götz: Hitlers Volksstaat. Raub, Rassenkrieg und nationaler Sozialismus. Bonn 2014.

Ambrosius, Lloyd E.: Nationale Selbstbestimmung im Ersten und im Zweiten Weltkrieg: Eine Vergleichsstudie von Wilson bis Roosevelt. In: Berg, Manfred / Gassert, Philipp (Hg.): Deutschland und die USA in der internationalen Geschichte des 20. Jahrhunderts. Festschrift für Detlef Junker. Stuttgart 2004, 237-262.

Anderson, Margaret Lavinia: Lehrjahre der Demokratie. Wahlen und politische Kultur im Kaiserreich. Stuttgart 2009.

Aron, Raymond: Demokratie und Totalitarismus. Hamburg 1970.

Avrich, Paul: The Haymarket Tragedy. Princeton, NJ 1984.

Baberowski, Jörg: Verbrannte Erde. Stalins Herrschaft der Gewalt. München 2012.

Bajohr, Stefan: Kleine Weltgeschichte des demokratischen Zeitalters. Wiesbaden 2014.

Baker, Paula: The Domestication of Politics: Women and American Political Society, 1780-1920. In: American Historical Review, 89 (1984), 621-647.

Band, Henri: Mittelschichten und Massenkultur. Siegfried Kracauers publizistische Auseinandersetzung mit der populären Kultur und der Kultur der Mittelschichten in der Weimarer Republik. Berlin 1999.

Baranowski, Shelley: Strength through Joy. Consumerism and Mass Tourism in the Third Reich. Cambridge u. a. 2004.

Barlevy, Gadi / Tsiddon, Daniel: Earning Inequality and the Business Cycle. Working Paper 10469. National Bureau of Economic Research. Cambridge, MA 2004.

Baudelaire, Charles: Der Künstler und das moderne Leben. Essays, „Salons«, Intime Tagebücher. Herausgegeben von Henry Schumann. Leipzig 1994.

Baudelaire, Charles: Sämtliche Werke, Bd. 5 (Briefe). Aufsätze zur Literatur und Kunst 1857-1860. Darmstadt 1989. Bavaj, Riccardo: »Revolutionierung der Augen«: Politische Massenmobilisierung in der Weimarer Republik und der Münzberg-Konzern. In: Daniel, Ute/Marßolek, Inge/Pyta, Wolfram/Welskopp, Thomas (Hg.): Politische Kultur und Medienwirklichkeiten in den 1920er Jahren. München 2010, 81-100.

Bavaj, Riccardo: Von links gegen Weimar. Linkes antiparlamentarisches Denken in der Weimarer Republik. Bonn 2005.

Becker, Hellmut / Kluchert, Gerhard: Die Bildung der Nation. Schule, Gesellschaft und Politik vom Kaiserreich zur Weimarer Republik. Stuttgart 1993.

Behrends, Jan C./ Klimó, Árpád von / Poutrous, Patrice G. (Hg.): Antiamerikanismus im 20. Jahrhundert. Studien zu Ost- und Westeuropa. Bonn 2005.

Belting, Hans (Hg.): Bilderfragen. Die Bildwissenschaften im Aufbruch. München 2007.

Bender, Klaus: Vossische Zeitung, Berlin (1617-1934). In: Fischer, Heinz-Dietrich (Hg.): Deutsche Zeitungen des 17. bis 20. Jahrhunderts. Pullach bei München 1972, 25-39.

Benjamin, Andrew: Benjamin's Modernity. In: Ferris, David (Hg.): The Cambridge Companion to Walter Benjamin. Cambridge 2004, 97-114. 
Benjamin, Walter: Gesammelte Schriften. Bd.I, 2. Hg. von Rolf Tiedemann und Hermann Schweppenhäuser. Frankfurt a. M. 1991.

Benjamin, Walter: Über den Begriff der Geschichte. Hg. von Gérard Raulet. Berlin 2010.

Bennett, David H.: The Party of Fear. From Nativist Movements to the New Right in American History. Chapel Hill, NC u. a. 1988.

Berg, Manfred: Popular Justice. A History of Lynching in America. Chicago 2011.

Berg, Manfred: The Ticket to Freedom. Die NAACP und das Wahlrecht der Afroamerikaner. Frankfurt a. M. u. a. 2000.

Bernhardt, Cristoph / Vonau, Elsa: Zwischen Fordismus und Sozialreform. Rationalisierungsstrategien im deutschen und französischen Wohnungsbau 1900-1933. In: Saldern, Adelheid von / Hachtmann, Rüdiger / Kirsch, Jan-Holger (Hg.): Fordismus. Zeithistorische Forschungen / Studies in Contemporary History. Bd. 6 (2009), Nr. 2, 230-254.

Betscher, Silke: Bildmuster - Wissensmuster. Ansätze einer korpusbasierten visuellen Diskursanalyse. In: Zeitschrift für Semiotik. Bd. 35, Nr. 3-4 (2013), 285-319.

Betscher, Silke: Von großen Brüdern und falschen Freunden. Visuelle Kalte-KriegsDiskurse in deutschen Nachkriegsillustrierten. Essen 2013.

Beyme, Klaus von: Politische Theorien in Russland 1789-1945, Wiesbaden 2001.

Bloch, Ernst: Erbschaft dieser Zeit. Gesamtausgabe, Bd. 4. Frankfurt a. M. 1962.

Blome, Astrid: Das deutsche Rußlandbild im frühen 18. Jahrhundert. Untersuchungen zur zeitgenössischen Presseberichterstattung über Rußland unter Peter I. Wiesbaden 2000 .

Blome, Astrid / Depkat, Volker: Von der »Civilisirung« Rußlands und dem »Aufblühen" Nordamerikas im 18. Jahrhundert. Leitmotive der Aufklärung am Beispiel deutscher Rußland- und Amerikabilder. Bremen 2002.

Bodenschatz, Harald: Analogismus von Fabrikarbeit und Arbeit außerhalb der Fabrik. Ein Essential des Fordismus? In: Bittner, Regina / Brüning, Henning (Hg.): Zukunft aus Amerika. Fordismus in der Zwischenkriegszeit. Siedlung, Stadt, Raum. Berlin 1995, 38-43.

Bollmeyer, Heiko: Der steinige Weg zur Demokratie. Die Weimarer Nationalversammlung zwischen Kaiserreich und Republik. Frankfurt a.M., New York, NY 2007.

Bracher, Karl Dietrich: Zeit der Ideologien. Eine Geschichte politischen Denkens im 20. Jahrhundert. Stuttgart 1984.

Braeuer, Walter: Lotz, Walther. In: Neue Deutsche Biographie, Bd. 15. Berlin 1987, 252. Bruendel, Steffen: Volksgemeinschaft oder Volksstaat. Die »Ideen von 1914 « und die Neuordnung Deutschlands im Ersten Weltkrieg. Berlin 2003.

Buchner, Bernd: Politische Symbolik in der Weimarer Republik - wo bleibt die demokratische Tradition? In: Schultheiß, Michael/Roßberg, Julia (Hg.): Weimar und die Republik. Geburtsstunde eines demokratischen Deutschlands. Weimar 2009, 161-172.

Budde, Gunilla/Conrad, Sebastian/Janz, Oliver (Hg.): Transnationale Geschichte. Themen, Tendenzen und Theorien. Göttingen 2006.

Burke, Peter: Augenzeugenschaft. Bilder als historische Quellen. Berlin 2003. 
Büttner, Ursula: Weimar, die überforderte Republik 1918-1933: Leistung und Versagen in Staat, Gesellschaft, Wirtschaft und Kultur. Stuttgart 2008.

Chew, William III: What is in a National Stereotype? An Introduction to Imagology at the Threshold of the $21^{\text {st }}$ Century. In: Language and Intercultural Communication. Bd. 6 (2006), Nr. 3-4, 179-187.

Coles, Anthony: John Heartfield. Ein politisches Leben. Köln 2014.

Collins, Ross: Children, War and Propaganda. New York, NY 2011.

Conquest, Robert: The Harvest of Sorrow. Soviet Collectivization and the TerrorFamine. London 2002.

Conze, Vanessa: Abendland gegen Amerika! Europa als antiamerikanisches Konzept im westeuropäischen Konservatismus (1950-1970) - Das CEDI und die Idee des Abendlandes. In: Behrends, Jan C. / Klimó, Árpád von / Poutrous, Patrice G. (Hg.): Antiamerikanismus im 20. Jahrhundert. Studien zu Ost- und Westeuropa. Bonn 2005, 204-224.

Conze, Vanessa: Abendland. In: Europäische Geschichte Online (EGO), hg. vom LeibnizInstitut für Europäische Geschichte (IEG). Mainz 2012. URL: http://www.ieg-ego. eu/conzev-2012-de (am 17.11.2015).

Conze, Vanessa: Das Europa der Deutschen. Ideen von Europa in Deutschland zwischen Reichstradition und Westorientierung (1920-1970). München 2005.

Dahrendorf, Ralf: Gesellschaft und Demokratie in Deutschland. München 1965.

Daniel, Ute: Arbeiterfrauen in der Kriegsgesellschaft. Beruf, Familie und Politik im Ersten Weltkrieg. Göttingen 1989.

Daniel, Ute / Marßolek, Inge/Pyta, Wolfram/Welskopp, Thomas (Hg.): Politische Kultur und Medienwirklichkeiten in den 1920er Jahren. München 2010.

David, Paul/Solar, Peter: A Bicentenary Contribution to the History of the Cost of Living in America. In: Research in Economic History, Nr. 2 (1977), 1-80.

David-Fox, Michael: Crossing Borders: Modernity, Ideology, and Culture in Russia and the Soviet Union. Pittsburgh, PA 2015.

David-Fox, Michael: Introduction: Entangled Histories in the Age of Extremes. In: Ders. / Holquist, Peter / Martin, Alexander M. (Hg.): Fascination and Enmity. Russia and Germany as Entangled Histories, 1914-1945. Pittsburgh, PA 2012, 1-12.

Davis, Brion David: Inhuman Bondage. The Rise and Fall of Slavery in the New World. New York, NY 2006.

Deilmann, Astrid: Bild und Bildung. Fotografische Wissenschafts- und Technikberichterstattung in populären Illustrierten der Weimarer Republik. Osnabrück 2004.

Depkat, Volker: Amerikabilder in politischen Diskursen. Deutsche Zeitschriften von 1789 bis 1830 . Stuttgart 1998.

Depkat, Volker: The Birth of Technology from the Spirit of the Lack of Culture: The United States as »Land of Technological Progress « in Germany, 1800-1850. In: Wala, Michael/Lehmkuhl, Ursula (Hg.): Technologie und Kultur: Europas Blick auf Amerika vom 18. bis zum 20. Jahrhundert. Köln 2000, 23-53.

Depkat, Volker: Von Georg II. zu George Washington: Überlegungen zur Visualisierung von Legitimität im Übergang von Monarchie zu Demokratie. In: Reitemeier, Arnd (Hg.): Kommunikation und Kulturtransfer im Zeitalter der Personalunion 
zwischen Großbritannien und Hannover: »to prove that Hanover and England are not entirely synonymous«. Göttingen 2014, 57-78.

Depkat, Volker/Zwingenberger, Meike (Hg.): Visual Cultures - Transatlantic Perspectives. Heidelberg 2012.

Dewey, John: Kunst als Erfahrung. Frankfurt a. M. 1980.

Diner, Dan: Feindbild Amerika. Über die Beständigkeit eines Ressentiments. Berlin 2002.

Dohnke, Kay/Stein, Dietrich (Hg.): Gustav Frenssen in seiner Zeit. Heide 1997.

Dollinger, Bernd: Jugendkriminalität als Kulturkonflikt. Wiesbaden 2010.

Douglas, Mary: Purity and Danger. An analysis of Concepts of Pollution and Taboo. London u. a. 1969.

Downing, Taylor: Olympia. London 2012.

Dukić, Davor (Hg.): Imagologie heute. Ergebnisse, Herausforderungen, Perspektiven. Bonn 2012.

Dussel, Konrad: Deutsche Tagespresse im 19. und 20. Jahrhundert. Münster 2004.

Dussel, Konrad: Pressebilder in der Weimarer Republik. Entgrenzung der Information. Münster 2012.

Eifert, Christiane: Antisemit und Autokönig. Henry Fords Autobiographie und ihre deutsche Rezeption in den 1920er Jahren. In: Von Saldern, Adelheid/ Hachtmann, Rüdiger / Kirsch, Jan-Holger (Hg.): Fordismus. Zeithistorische Forschungen / Studies in Contemporary History. Bd. 6 (2009), Nr. 2, 209-229.

Eisenstadt, Shmuel M.: Multiple Modernities: Der Streit um die Gegenwart. Berlin 2010.

Eisenstadt Shmuel: Die Vielfalt der Moderne. Weilerswist 2000.

Eitz, Thorsten / Engelhardt, Isabelle (Hg.): Diskursgeschichte der Weimarer Republik. Band 1. Hildesheim 2015.

Elias, Norbert: Studien über die Deutschen. Machtkämpfe und Habitusentwicklung im 19. und 20. Jahrhundert. Frankfurt a. M. 1989.

Ellwood, David: The Shock of America. Europe and the Challenge of the Century. Oxford 2012.

Engler, Bernd / Scheiding, Oliver (Hg.): A Companion to American Cultural History. From the Colonial Period to the End of the $19^{\text {th }}$ Century. Trier 2009.

Erler, Rolf-Joachim (Hg.): Karl Barth - Charlotte von Kirschbaum. Briefwechsel. Bd. 1 (1925-1935). Zürich 2008.

Fairclough, Norman: Critical Discourse Analysis. The Critical Study of Language. London 2010.

Fehl, Gerhard: Welcher Fordismus eigentlich? In: Bittner, Regina/Brüning, Henning (Hg.): Zukunft aus Amerika. Fordismus in der Zwischenkriegszeit. Siedlung, Stadt, Raum. Berlin 1995, 18-37.

Ferry, Luc/ Renaut, Alain: Heidegger and Modernity. Chicago, IL 1990.

Fest, Joachim: Hitler. Eine Biographie. Frankfurt a. M. u. a. 1973.

Figes, Orlando: Hundert Jahre Revolution. Russland und das 20. Jahrhudert. Berlin, München 2014.

Fink, Carole/Frohn, Axel/ Heideking, Jürgen (Hg.): Genoa, Rapallo, and European Reconstruction. Cambridge, Washington, DC 1992. 
Finkel, Stuart: On the Ideological Front. The Russian Intelligentsia and the Making of the Soviet Public Sphere. New Haven, CT u. a. 2007.

Fischer, Heinz-Dietrich: Deutsche Allgemeine Zeitung (1861-1945). In: Ders. (Hg.): Deutsche Zeitungen des 17. bis 20. Jahrhunderts, Pullach bei München 1972, 269-282.

Fischer, Heinz-Dietrich: Handbuch der politischen Presse in Deutschland 1480-1980. Synopse rechtlicher, struktureller und wirtschaftlicher Grundlagen der Tendenzpublizistik im Kommunikationsfeld. Düsseldorf 1981.

Flierl, Thomas (Hg.): Standardstädte. Ernst May in der Sowjetunion 1930-1933. Texte und Dokumente. Berlin 2012.

Föllmer, Moritz: Auf der Suche nach dem eigenen Leben. Junge Frauen und Individualität in der Weimarer Republik. In: Ders. / Graf, Rüdiger (Hg.): Die »Krise« der Weimarer Republik. Zur Kritik eines Deutungsmusters. Frankfurt a. M. 2005, 287-317.

Föllmer, Moritz/Graf, Rüdiger/Leo, Per: Einleitung: Die Kultur der Krise in der Weimarer Republik. In: Föllmer, Moritz / Graf, Rüdiger (Hg.): Die »Krise« der Weimarer Republik. Zur Kritik eines Deutungsmusters. Frankfurt a. M. 2005, 9-41.

Foner, Philip: American Socialism and Black Americans. From the Age of Jackson to World War II. Westport, CT, London 1977.

Foucault, Michel: Archäologie des Wissens. Frankfurt a. M. 1997, 74.

Foucault, Michel: Die Ordnung des Diskurses. Frankfurt a. M. 1993.

Froese, Paul: The Plot to Kill God. Findings from the Soviet Experiment in Secularization. Berkeley, CA u.a. 2008.

Fuchs, Lawrence H.: Election of 1928. In: Schlesinger, Arthur M./Israel, Fred L./ Hansen, William P.: History of American Presidential Elections 1789-1968. Bd. 3 (1900-1936). New York, NY u. a. 1971, 2585-2704.

Fulda, Bernhard: Industries of Sensationalism: German Tabloids in Weimar Berlin. In: Führer, Karl Christian;/Ross, Corey (Hg.): Mass Media, Culture and Society in Twentieth-Century Germany. New York, NY 2006, 183-203.

Fulda, Bernhard: Press and Politics in the Weimar Republic. Oxford 2009.

Galechko, Igor: Vorstellungen der Deutschen der Weimarer Republik von Sowjetrussland, 1919-1933. Univ.-Diss., Universität Wladiwostok 2002.

Gassert, Philipp: Amerika im Dritten Reich. Ideologie, Propaganda und Volksmeinung 1933-1945. Stuttgart 1997.

Gassert, Philipp: Amerikanismus, Antiamerikanismus, Amerikanisierung. Neue Lite ratur zur Sozial-, Wirtschafts- und Kulturgeschichte des amerikanischen Einflusses in Deutschland und Europa. In: Archiv für Sozialgeschichte, Bd. 39. (1999), 531-561.

Gebhardt, Hartwig: »Halb kriminalistisch, halb erotisch«: Presse für die »niederen Instinkte«. In: Maase, Kaspar/Kaschuba, Wolfgang (Hg.): Schund und Schönheit. Populäre Kultur um 1900. Köln u. a. 2001, 184-217.

Gerber, Stefan: Pragmatismus und Kulturkritik: Politikbegründung und politische Kommunikation im Katholizismus der Weimarer Republik (1918-1925). Paderborn 2015.

Gerrits, André: The Myth of Jewish Communism. A Historical Interpretation. Brüssel 2009.

Gessner, Dieter: Die Weimarer Republik. Darmstadt 2015. 
Gleye, Paul: Fordismus und Amerika in den 20er Jahren - Vorstellung und Realität. In: Bittner, Regina/Brüning, Henning: Zukunft aus Amerika. Fordismus in der Zwischenkriegszeit: Siedlung, Stadt, Raum. Dessau 1995, 92-105.

Gorsuch, Anne: Youth in Revolutionary Russia. Enthusiasts, Bohemians, Delinquents. Bloomington, IN u. a. 2000.

Goslar, Hans. In: Vierhaus, Rudolf/Killy, Walther (Hg.): Deutsche Biographische Enzyklopädie. Bd. 4 (Görres - Hittorp). München, 2006, 56.

Graf, Rüdiger: Die Zukunft der Weimarer Republik. Krisen und Zukunftsaneignungen in Deutschland 1918-1933. München 2008.

Graziosi, Andrea: The Great Soviet Peasant War. Bolsheviks and Peasants, 1917-1933. Cambridge, MA 1996.

Grill, Tobias: Antizionistische jüdische Bewegungen. In: Europäische Geschichte Online (EGO), Institut für Europäische Geschichte (IEG), Mainz 2011. URL: http:// www.ieg-ego.eu/grillt-2011-de (am 28.02.2015).

Grillo, Ralph: Pluralism and the Politics of Difference. State, Culture, and Ethnicity in Comparative Perspective. Oxford 1998.

Grimm, Heinrich: Huttichius, Johannes. In: Neue Deutsche Biographie, Bd. 10. Berlin 1974.

Groh, Dieter: Rußland im Blick Europas. 300 Jahre historische Perspektiven. Frankfurt a.M. 1993.

Gumbrecht, Hans Ulrich: Art.»Modern«, »Moderne«, »Modernität«. In: Brunner, Otto/Conze, Werner/Koselleck, Reinhart. (Hg.): Geschichtliche Grundbegriffe. Historisches Lexikon zur politisch-sozialen Sprache in Deutschland. Bd. 4. Stuttgart 1978, 100.

Habermas, Jürgen: Der philosophische Diskurs der Moderne. Zwölf Vorlesungen. Frankfurt a. M. 1986.

Hachtmann, Rüdiger: Rezension zu: Gassert, Philipp: Amerika im Dritten Reich. Ideologie, Propaganda und Volksmeinung 19331945. Stuttgart 1997. In: HSozKult. URL: http://www.hsozkult.de/publicationreview/id/rezbuecher-335 (am 18.12.2011).

Hahn, Hans Henning (Hg.): Stereotyp, Identität und Geschichte. Die Funktion von Stereotypen in gesellschaftlichen Diskursen. Frankfurt a. M. u. a. 2002.

Halbach, Uwe: Das sowjetische Völkerimperium. Nationalitätenpolitik und nationale Frage. Mannheim 1992.

Halberstam, Judith: Female Masculinity. Durham, NC, London 2006.

Hallett, Michael: Stefan Lorant: Godfather of Photojournalism. Lanham, MD 2005.

Hansen, Miriam: America, Paris, the Alps: Kracauer and Benjamin on Cinema and Modernity. In: Lüdtke, Alf/ Marßolek, Inge/Saldern, Adelheid von (Hg.): Amerikanisierung: Traum und Alptraum im Deutschland des 20. Jahrhunderts. Stuttgart 1996, 161-198.

Hardtwig, Wolfgang (Hg.): Ordnungen in der Krise. Zur politischen Kulturgeschichte Deutschlands 1900-1933. München 2007.

Hardtwig, Wolfgang (Hg.): Politische Kulturgeschichte der Zwischenkriegszeit 19181939. Göttingen 2005.

Hartewig, Karin: Fotografien. In: Maurer, Michael (Hg.): Aufriß der Historischen Wissenschaften. Bd. 4: Quellen. Stuttgart 2002, 427-447. 
Haumann, Heiko: Geschichte Russlands. München, Zürich 1996.

Hebeisen, Walter: F. W. Taylor und der Taylorismus. Über das Wirken und die Lehre Taylors und die Kritik am Taylorismus. Zürich 1999.

Hebel, Udo / Wagner, Christoph (Hg.): Pictorial Cultures and Political Iconographies. Approaches, Perspectives, Case Studies from Europe and America. Berlin, New York, NY 2011.

Hegel, Georg Wilhelm Friedrich: Phänomenologie des Geistes. Frankfurt a. M. 1996.

Hegel, Georg Wilhelm Friedrich: Die Philosophie des Rechts. Vorlesung von 1821/22. Frankfurt a. M. 2005.

Heidegger, Martin: Sein und Zeit. Erste Hälfte. Halle a. d. Saale 1927.

Hellebust, Rolf: Flesh to Metal. Soviet Literature \& the Alchemy of Revolution. Ithaca, NY u.a. 2003.

Henkel, Peter: Anton Betz. Ein Verleger zwischen Weimar und Bonn. Düsseldorf 2011. Herf, Jeffrey: Reactionary Modernism. Technology, Culture, and Politics in Weimar and the Third Reich. Cambridge, MA u. a. 1984.

Hildermeier, Manfred: Germany and the Soviet Union. In: Mühle, Eduard (Hg.): Germany and the European East in the Twentieth Century. Oxford 2003, 29-44.

Hildermeier, Manfred: Geschichte der Sowjetunion 1917-1991. Entstehung und Niedergang des ersten sozialistischen Staates. München 1998.

Hildermeier, Manfred: Die Russische Revolution 1905-1921. Frankfurt a. M. 1989.

Hildermeier, Manfred: Die Sowjetunion 1917-1991. München 2007.

Hildermeier, Manfred / Kocka, Jürgen / Conrad, Christoph (Hg.): Europäische Zivilgesellschaft in Ost und West. Begriff, Geschichte, Chancen. Frankfurt a. M. 2000.

Hirsch, Helmut: Experiment in Demokratie: Zur Geschichte der Weimarer Republik. Wuppertal 1972.

Holz, Kurt: Münchner Neueste Nachrichten (1848-1945). In: Fischer, Heinz-Dietrich (Hg.): Deutsche Zeitungen des 17. bis 20. Jahrhunderts, 191-207.

Holzbach, Heidrun: Das »System Hugenberg«. Die Organisation bürgerlicher Sammlungspolitik vor dem Aufstieg der NSDAP. Stuttgart 1981.

Hornung, Klaus: Das totalitäre Zeitalter. Bilanz des 20. Jahrhunderts. Berlin 1993.

Hoser, Paul: Münchner Neueste Nachrichten. In: Historisches Lexikon Bayerns. URL: https://www.historisches-lexikon-bayerns.de/Lexikon/M\%C3\%BCnchner_ Neueste_Nachrichten (am 02.12.2015).

Hubig, Christoph: Art. Medialität / Medien. In: Sandkühler, Hans Jörg: Enzyklopädie Philosophie, Bd. 2 (I-P). Hamburg, 2010, 1516-1522.

Hutton, Marcelline: Russian and Soviet Women. 1897-1939. Dreams, Struggles and Nightmares. Univ.-Diss. University of Iowa 1986.

Inkeles, Alex: Public Opinion in Soviet Russia. Cambridge, MA 1951.

Jäger, Jens: Fotografiegeschichte(n). Stand und Tendenzen der historischen Forschung.

In: Archiv für Sozialgeschichte, Nr. 48, 511-538.

Jäger, Jens / Knauer, Martin (Hg.): Bilder als historische Quellen? Dimensionen der

Debatte um historische Bildforschung. München 2009.

Jäger, Siegfried: Kritische Diskursanalyse. Eine Einführung. Münster 2004.

Jarausch, Konrad/Siegrist, Hannes (Hg.): Amerikanisierung und Sowjetisierung in

Deutschland 1945-1970. Frankfurt a. M., New York, NY 1997. 
Jaspers, Karl: Nietzsche. Einführung in das Verständnis seines Philosophierens. Berlin, New York, NY 1981.

Judt, Tony/Snyder, Timothy: Nachdenken über das 20. Jahrhundert. Frankfurt a.M. 2015.

Jugend. In: Schubert, Klaus / Klein, Martina: Das Politiklexikon. Bonn 2007, 152.

Kaelble, Hartmut: Europäer über Europa. Die Entstehung des europäischen Selbstverständnisses im 19. und 20. Jahrhundert. Frankfurt a. M. 2001.

Kappeler, Andreas / Meissner, Boris / Simon, Gerhard (Hg.): Die Deutschen im Russischen Reich und im Sowjetstaat. Bremen 1987.

Katzer, Nikolaus: Die sportive Gesellschaft als ideale Ordnung. Zum sowjetischen Konzept der Körperkultur. In: Pietrow-Enker, Bianka (Hg.): Russlands imperiale Macht. Integrationsstrategien und ihre Reichweite in transnationaler Perspektive. Köln u. a. 2012, 85-102.

Kautsky, John H.: Marxism and Leninism, not Marxism-Leninism. An Essay in the Sociology of Knowledge. Westford, CT u. a. 1994.

Keller, Reiner: Wissen oder Sprache? Für eine wissensanalytische Profilierung der Diskursforschung. In: Eder, Franz X.: Historische Diskursanalysen. Genealogie, Theorie, Anwendungen, 51-70.

Klautke, Egbert: Unbegrenzte Möglichkeiten. "Amerikanisierung" in Deutschland und Frankreich (1900-1933). Stuttgart 2003.

Klein, Annika: Korruption und Korruptionsskandale in der Weimarer Republik. Göttingen 2014.

Klier, John: Russians, Jews, and the pogrom crisis of 1881-1882. Cambridge, New York, NY 2011.

Knape, Joachim: Was ist Rhetorik? Stuttgart 2000.

Köbberling, Anna: Aktuelle Strömungen in der russischen Frauenbewegung. In: Osteuropa, Nr. 6 (1993), 566-577.

Köbberling, Anna: Das Klischee der Sowjetfrau. Stereotyp und Selbstverständnis Moskauer Frauen zwischen Stalinära und Perestroika. Frankfurt a. M. u. a. 1997.

Koch, Lars (Hg.): Modernisierung als Amerikanisierung? Entwicklungslinien der westdeutschen Kultur 1945-1960. Bielefeld 2007.

Kocka, Jürgen: Ambivalenzen der Arbeit. In: Buggeln, Marc/Wildt, Michael: Arbeit im Nationalsozialismus. München 2014, 25-32.

Kocka, Jürgen: Klassengesellschaft im Krieg. Deutsche Sozialgeschichte 1914-1918. Göttingen 1973.

Koenen, Gerd: »Rom oder Moskau«. Deutschland, der Westen und die Revolutionierung Russlands 1914-1924. Univ.-Diss., Tübingen 2003.

Koenen, Gerd: Der Russland-Komplex. Die Deutschen und der Osten 1900-1945. München 2005.

Köhler-Baur, Maria: Die deutsche Berichterstattung über die Rußlanddeutschen. »Der Auslandsdeutsche« 1920-1929. In: Eisfeld, Alfred/Herdt, Victor/Meissner, Boris: Deutsche in Rußland und der Sowjetunion 1914-1941. Berlin 2007, 209-218.

Kohlrausch, Martin: Der Monarch im Skandal. Die Logik der Massenmedien und die Transformation der wilhelminischen Monarchie. Berlin 2005.

Kolb, Eberhard: 1918/19: Die steckengebliebene Revolution. In: Stern, Carola/ Winkler, 
Heinrich August (Hg.): Wendepunkte deutscher Geschichte 1848-1990. Frankfurt a. M. 2003.

Kolb, Eberhard: Die Arbeiterräte in der deutschen Innenpolitik 1918-19. Düsseldorf 1962.

Kolb, Eberhard: Deutschland 1918-1933. Eine Geschichte der Weimarer Republik. München 2010.

Kolb, Eberhard: Die Weimarer Republik. München, Wien 1984.

König, Marcus: Agitation - Zensur - Propaganda. Der U-Boot-Krieg und die deutsche Öffentlichkeit im Ersten Weltkrieg. Stuttgart 2014.

Koselleck, Reinhart: »Fortschritt« und »Niedergang« - Nachtrag zur Geschichte zweier Begriffe. In: Ders./Stierle, Karlheinz (Hg.): Niedergang: Studien zu einem geschichtlichen Thema. Stuttgart 1980, 214-230.

Koselleck, Reinhart: Vergangene Zukunft: zur Semantik geschichtlicher Zeiten. Frankfurt a. M. 2000.

Koszyk, Kurt: Deutsche Presse 1914-1945. Berlin 1972.

Krabbe, Wolfgang: Parteijugend zwischen Wandervogel und politischer Reform. Eine Dokumentation zur Geschichte der Weimarer Republik. Münster 2000.

Kraus, Hans-Christof: Versailles und die Folgen. Außenpolitik zwischen Revisionismus und Verständigung 1919-1933. Bonn 2014.

Kress, Gunther/van Leeuwen, Theo: Reading Images. The Grammar of Visual Design. London u. a. 2008.

Krumeich, Gerhard/Hirschfeld, Gerhard/Renz, Irina (Hg.): Enzyklopädie Erster Weltkrieg. Paderborn 2009.

Kuhn, Robert: Die Vertrauenskrise der Justiz (1926-1928). Der Kampf um die »Republikanisierung« der Rechtspflege in der Weimarer Republik. Köln 1983.

Küppers, Petra: Karl Mays Indianerbild und die Tradition der Fremdendarstellung. Eine kulturgeschichtliche Analyse. In: Jahrbuch der Karl-May-Gesellschaft (1996). Husum 1996, 315-345.

Lachenicht, Susanne: Die neue Visualität der Zeitschrift im frühen 20. Jahrhundert und die culture de masse. In: Zimmermann, Clemens / Schmeling, Manfred (Hg.): Die Zeitschrift - Medium der Moderne. Deutschland und Frankreich im Vergleich. Bielefeld 2006, 63-84.

Lamberti, Marjorie: The Politics of Education. Teachers and School Reform in Weimar Germany. New York, NY u.a. 2002.

Lampert, Nicholas: The Technical Intelligentsia and the Soviet State. A Study of Soviet Managers and Technicians 1928-1935. London u.a. 1979.

Landwehr, Achim: Historische Diskursanalyse. Frankfurt a. M. u. a. 2008.

Laqueur, Walter: Deutschland und Russland. Berlin 1965.

Laqueur, Walter: Mythos der Revolution. Deutungen und Fehldeutungen der Sowjetgeschichte. Frankfurt a. M. 1967.

Le Bon, Gustave: Psychologie des Foules. Paris 1895.

Lehnert, Detlef: Die Weimarer Republik. Parteienstaat und Massengesellschaft. Stuttgart 1999.

Leibniz, Gottfried Wilhelm: Philosophische Schriften, Bd I. Kleine Schriften zur Metaphysik. Herausgegeben von Herbert Herring. Darmstadt 1965. 
Leibniz, Gottfried Wilhelm: Philosophische Schriften, Bd. II/1. Herausgegeben von Herbert Herring. Darmstadt 1985.

Lerg, Charlotte: Amerika als Argument. Die deutsche Amerika-Forschung im Vormärz und ihre politische Deutung in der Revolution von 1848/49. Bielefeld 2011.

Leuchtenburg, William: Herbert Hoover. New York, NY 2009.

Link, Stefan: From Taylorism to Human Relations: American, German, and Soviet trajectories of the interwar years. Paper presented to the Business History Conference, St. Louis MO, 31. März 2011.

Link, Stefan: Transnational Fordism. Ford Motor Company, Nazi Germany, and the Soviet Union in the Interwar Years. URL: http://nrs.harvard.edu/urn-3:HUL.Inst Repos:10288949 (am 21.04.2015).

Llanque, Marcus: Politische Ideengeschichte - ein Gewebe politischer Diskurse. München 2008 .

Logan, Rayford: The Betrayal of the Negro. From Rutherford B. Hayes to Woodrow Wilson. New York, NY 1997.

Long, John: Communist Youth Organizations of the Soviet Union. In: Wieczynski, Joseph L. (Hg.): The Modern Encyclopedia of Russian and Soviet History. Bd. 7. Gulf Breeze, FL 1978, 228-235.

Longerich, Peter (Hg.): Die Erste Republik. Dokumente zur Geschichte des Weimarer Staates. München 1992.

Löwenthal, Richard: Die deutsche Sozialdemokratie in Weimar und heute. Zur Problematik der »versäumten« demokratischen Revolution. In: Ders. (Hg.): Gesellschaftswandel und Kulturkrise. Zukunftsprobleme der westlichen Demokratien. Frankfurt a. M. 1979, 197-211.

Lüdtke, Alf: Ikonen des Fortschritts. Eine Skizze zu Bild-Symbolen und politischen Orientierungen in den 1920er und 1930er Jahren in Deutschland. In: Ders. / Marßolek, Inge/Saldern, Adelheid von (Hg.): Amerikanisierung: Traum und Alptraum im Deutschland des 20. Jahrhunderts. Stuttgart 1996, 199-212.

Maase, Kaspar: »Amerikanisierung der Gesellschaft«. Nationalisierende Deutung von Globalisierungsprozessen? In: Jarausch, Konrad/Siegrist, Hannes (Hg.): Amerikanisierung und Sowjetisierung in Deutschland 1945-1970. Frankfurt a. M. 1997, 219-241.

Maase, Kaspar: Happy Endings? Massenkultur und Demokratie in Deutschland im 20. Jahrhundert. In: Linke, Angelika / Tanner, Jakob (Hg.): Attraktion und Abwehr. Die Amerikanisierung der Alltagskultur in Europa. Köln u. a. 2006, 137-160.

Maase, Kaspar: Die Kinder der Massenkultur. Kontroversen um Schmutz und Schund seit dem Kaiserreich. Frankfurt a. M., New York, NY 2012.

Maasen, Sabine / Mayerhauser, Torsten / Renggli, Cornelia (Hg.): Bilder als Diskurse Bilddiskurse. Weilerswist 2006.

Mackenzie, Michael: Maschinenmenschen, Athleten und die Krise des Körpers in der Weimarer Republik. In: Föllmer, Moritz / Graf, Rüdiger (Hg.): Die »Krise« der Weimarer Republik. Zur Kritik eines Deutungsmusters. Frankfurt a. M. 2005, 319-345.

Magallanes, Fernando: Reiseliteratur am Beispiel Joseph Roths. In: Miladinovic Zalaznik, Mira/Lughofer, Johann Georg (Hg.): Joseph Roth: Europäisch-jüdischer Schriftsteller und österreichischer Universalist. Berlin u. a. 2011, 119-128. 
Majer, Diemut: Frauen - Revolution - Recht. Die grossen europäischen Revolutionen in Frankreich, Deutschland und Österreich 1789 bis 1918 und die Rechtsstellung der Frauen. Unter Einbezug von England, Russland, der USA und der Schweiz. Zürich u.a. 2008.

Mannheim, Karl: Die Bedeutung der Konkurrenz im Gebiete des Geistigen. In: Meja, Volker/Stehr, Nico (Hg.): Der Streit um die Wissenssoziologie. Bd. 1: Die Entwicklung der deutschen Wissenssoziologie. Frankfurt a. M. 1982, 325-370. Zuerst erschienen in: Verhandlungen des Sechsten Deutschen Soziologentages, 17. bis 19. September 1928 in Zürich. Tübingen 1929, 35-83.

Manz, Stefan: Diaspora and Weltpolitik in Wilhelmine Germany. In: Panayi, Panikos (Hg.): Germans as Minorities during the First World War: A Global Comparative Perspective. Farnham, UK, Burlington, VT 2014, 27-46.

Marckwardt, Wilhelm: Die Illustrierten der Weimarer Zeit. Publizistische Funktion, ökonomische Entwicklung und inhaltliche Tendenzen (unter Einschluß einer Bibliographie dieses Pressetypus 1918-1932). München 1982.

Masaryk, Tomáš Garrigue: The Problem of Small Nations and States, the Federation of Small Nations [1918]. In: Munzer, Zdenka/Munzer, Jan (Hg.): We Were and We Shall Be. The Czechoslovak Spirit through the Centuries. New York, NY 1941, 152-158.

Materson, Lisa: African American Women, Prohibition, and the 1928 Presidential Election. In: Journal of Women's History; Bd. 21 (2009), Nr. 1, 63-86.

Matthews, Jean: The Rise of the New Woman. The Women's Movement in America, 1875-1930. Chicago, IL 2003.

Maurer, Michael: Bilder. In: Ders. (Hg.): Aufriß der Historischen Wissenschaften. Bd. 4: Quellen. Stuttgart 2002, 402-426.

McElligott, Anthony: Rethinking the Weimar Republic. Authority and Authoritarianism 1916-1936. London 2013.

McWhirter, Cameron: Red Summer. The Summer of 1919 and the Awakening of Black America. New York, NY 2011.

Mendelsohn, Ezra: The Jews of East Central Europe between the World Wars. Bloomington, IN, Indianapolis, IN 1995.

Mergel, Thomas: Parlamentarische Kultur in der Weimarer Republik: Politische Kommunikation, symbolische Politik und Öffentlichkeit im Reichstag. Düsseldorf 2002.

Meyer, Klaus: Sowjetrussland und die Anfänge der Weimarer Republik. Vortrag vor der Historischen Gesellschaft. Berlin (West), 5. Februar 1969. In: Ders./Schorkowitz, Dittmar (Hg.): Rußland - Vertraute Fremde. Neues und Bleibendes in historischer Perspektive. Ausgewählte Beiträge von Klaus Meyer (†). Frankfurt. a. M. 2008, 88-104.

Mitchell, W. J. T.: Bildtheorie. Herausgegeben mit einem Nachwort von Gustav Frank. Frankfurt a. M. 2008.

Mitchell, W. J. T.: Iconology. Image, Text, Ideology. Chicago, IL 1986.

Mitchell, W. J. T.: Showing Seeing. A Critique of Visual Culture. In: Journal of Visual Culture. Bd. 1, Nr. 2 (2002)., 165-181.

Modell, John: Into One's Own. From Youth to Adulthood in the United States 19201975. Berkeley, CA u.a. 1989. 
Mommsen, Hans: Aufstieg und Untergang der Republik von Weimar. 1918-1933. Berlin 1998.

Moore, Leonard J.: Historical Interpretations of the 1920s Klan: The Traditional View and Recent Revisions. In: Lay, Shawn (Hg.): The Invisible Empire in the West. Toward a New Historical Appraisal of the Ku Klux Klan in the 1920s. Chicago, IL, Urbana, IL 2004, 17-38.

Mühlhausen, Walter: Friedrich Ebert 1871-1925. Reichspräsident der Weimarer Republik. Bonn 2007.

Mühlhausen, Walter: Friedrich Ebert und die Unterzeichnung der Reichsverfassung 1919. In: Ders. (Hg.): Auftakt in Weimar. Beiträge zur Grundsteinlegung der Demokratie in Deutschland. Heidelberg 2010, 44-61.

Mühlhausen, Walter: Im Visier der Fotografen. Reichspräsident Friedrich Ebert im Bild. Heidelberg 2009.

Müller, Jan-Werner: Das demokratische Zeitalter. Eine politische Ideengeschichte Europas im 20. Jahrhundert. Bonn 2013.

Müller, Marion: Grundlagen der visuellen Kommunikation. Theorieansätze und Analysemethoden. Konstanz 2003.

Nicolás, Juan Antonio: Einleitung. Leibniz zwischen der Entstehung und der Krise der Modernität. In: Ders. (Hg.): Leibniz und die Entstehung der Modernität. LeibnizTagung in Granada, 1.-3. November 2007. Stuttgart 2010, 9-18.

Niedermeier, Silvan: Rassismus und Bürgerrechte. Polizeifolter im Süden der USA 1930-1955. Hamburg 2014.

Nipperdey, Thomas: Probleme der Modernisierung in Deutschland. In: Saeculum, Bd. 30, Nr. 2-3 (1979), 292-303.

Nisbett, Richard/Cohen, Dov: Culture of Honor. The Psychology of Violence in the South. Boulder, CO 1996.

Nolan, Mary: The Transatlantic Century. Europe and America, 1890-2010. New York, NY 2012.

Nolan, Mary: Visions of Modernity: American Business and the Modernization of Germany. New York, NY 1994.

Nolte, Paul: Die Ordnung der deutschen Gesellschaft. Selbstentwurf und Selbstbeschreibung im 20. Jahrhundert. München 2000.

Nolte, Paul: Was ist Demokratie? Geschichte und Gegenwart. München 2012.

O’Mahony, Mike: Sport in the USSR. Physical Culture - Visual Culture. London 2006.

O’Sullivan, Donal: Furcht und Faszination. Deutsche und britische Rußlandbilder 1921-1933. Köln u.a. 1996.

Ochrana. In: Roewer, Helmut/Schäfer, Stefan/Uhl, Matthias: Lexikon der Geheimdienste im 20. Jahrhundert. Mit Organigrammen. München 2003, 325.

Ohmann, Oliver: Friedrich Ludwig Jahn. Frisch, frei, fröhlich und fromm. Erfurt 2009.

Opdycke, Sandra: The Routledge Historical Atlas of Women in America. London u. a. 2000.

Osborne, Peter: The Politics of Time. Modernity and Avant-Garde. London 1995.

Panayi, Panikos: Germans as Minorities during the First World War: Global Comparative Perspectives. In: Ders. (Hg.): Germans as Minorities during the First 
World War: A Global Comparative Perspective. Farnham, UK, Burlington, VT 2014, 3-26.

Panofsky, Erwin: Ikonographie und Ikonologie. In: Kaemmerling, Ekkehard (Hg.): Bildende Kunst als Zeichensystem. Ikonographie und Ikonologie. Bd. 1: Theorien Entwicklung - Probleme. Köln 1994, 207-225.

Panofsky, Erwin: Studies in Iconology. Humanistic Themes in the Art of the Renaissance. New York, NY 1939.

Paul, Gerhard (Hg.): Das Jahrhundert der Bilder. Bd. 1: 1900 bis 1949. Göttingen 2009. Paupié, Kurt: Frankfurter Zeitung (1856-1943). In: Fischer, Heinz-Dietrich (Hg.): Deutsche Zeitungen des 17. bis 20. Jahrhunderts, Pullach bei München 1972, 241-256.

Paxton, Robert O.: Anatomie des Faschismus. München 2006.

Penny, Glenn: Kindred by Choice. Germans and American Indians since 1800. Chapel Hill, NC 2013.

Permooser, Irmtraud: Der Dolchstossprozess in München 1925. In: Zeitschrift für Bayerische Landesgeschichte. Nr. 59 (1996), 903-926.

Petersen, Klaus: Literatur und Justiz in der Weimarer Republik. Stuttgart 1988.

Petersen, Klaus: Zensur in der Weimarer Republik. Stuttgart, Weimar 1995.

Peukert, Detlev: Jugend zwischen Krieg und Krise. Lebenswelten von Arbeiterjungen in der Weimarer Republik. Köln 1987.

Peukert, Detlev: Die Weimarer Republik. Krisenjahre der klassischen Moderne. Frankfurt a.M. 1987.

Pinkus, Benjamin: The Jews of the Soviet Union. The History of a National Minority. New York, NY u. a. 1990.

Plaggenborg, Stefan: Experiment Moderne. Der sowjetische Weg. Frankfurt a.M., New York, NY 2006.

Plaggenborg, Stefan: Ordnung und Gewalt. Kemalismus - Faschismus - Sozialismus. München 2012.

Pope, Jim: Worker Lawmaking, Sit-Down Strikes and the Shaping of American Industrial Relations, 1935-1958. In: Law and History Review. Bd. 24 (2006), Nr. 1, 45-113.

Preisendanz, Wolfgang: Verordnete Wahrnehmung. Vom Verhältnis von Photo und Begleittext. In: Sprache im technischen Zeitalter. Nr. 37 (1971), 1-8.

Pyta, Wolfram: Hindenburg. Herrschaft zwischen Hohenzollern und Hitler. München 2007.

Pyta, Wolfram: Visualizing Democratic Legitimacy and Authority: The Case of the Weimar Republic. In: Depkat, Volker / Zwingenberger, Meike (Hg.): Visual Cultures in Transatlantic Perspectives. Heidelberg 2012, 69-83.

Raithel, Thomas: Funktionsstörungen des Weimarer Parlamentarismus. In: Föllmer, Moritz / Graf, Rüdiger (Hg.): Die »Krise« der Weimarer Republik. Zur Kritik eines Deutungsmusters. Frankfurt a. M. 2005, 243-266.

Raphael, Lutz: Imperiale Gewalt und mobilisierte Nation. Europa 1914-1945. München 2011.

Requate, Jörg: Öffentlichkeit und Medien als Gegenstände historischer Analyse. In: Geschichte und Gesellschaft. Nr. 25 (1999), 5-32.

Riley, Patrick: Leibniz and Modernity: Against the "Voluntarism« of Calvin, Descartes, Hobbes and Spinoza. In: Nicolás, Juan Antonio (Hg.): Leibniz und die 
Entstehung der Modernität. Leibniz-Tagung in Granada, 1.-3. November 2007. Stuttgart 2010, 41-48.

Rippey, Theodore: Athletics, Aesthetics, and Politics in the Weimar Press. In: German Studies Review, Bd. 28, Nr. 1 (2005), 85-106.

Rittersporn, Gábor / Behrends, Jan C. / Rolf, Malte: Öffentliche Räume und Öffentlichkeit in Gesellschaften sowjetischen Typs. Ein erster Blick aus komparatistischer Perspektive (Einleitung). In: Dies. (Hg.): Sphären von Öffentlichkeit in Gesellschaften sowjetischen Typs. Public Spheres in Soviet-Type Societies. Frankfurt a. M. 2003, 7-35.

Rodriguez-Lores, Juan: Linkes Denken und Fordismus. Lenin und Gramsci. In: Bittner, Regina/Brüning, Henning (Hg.): Zukunft aus Amerika. Fordismus in der Zwischenkriegszeit. Siedlung, Stadt, Raum. Berlin 1995, 44-63.

Rohe, Karl: Politische Kultur und ihre Analyse. Probleme und Perspektiven der politischen Kulturforschung. In: Historische Zeitschrift, Nr. 250 (1990), 321-346.

Rolf, Malte: Die schönen Körper des Kommunismus. Sportparaden in der Sowjetunion der Dreißiger Jahre. In: Malz, Arié / Rohdewald, Stefan/Wiederkehr, Stefan (Hg.) Sport zwischen Ost und West. Beiträge zur Sportgeschichte Osteuropas im 19. und 20. Jahrhundert. Osnabrück 2007, 309-325.

Rolf, Malte: Soviet Mass Festivals. 1917-1991. Pittsburgh, PA 2013.

Rolf, Malte: Das sowjetische Massenfest. Hamburg 2006.

Rorty, Richard: Der Spiegel der Natur. Eine Kritik der Philosophie. Frankfurt a. M. 1987.

Rorty, Richard: The Linguistic Turn: Recent Essays in Philosophical Method. Chicago, IL 1967.

Rosenbaum, Monika: Frauenarbeit und Frauenalltag in der Sowjetunion. Münster 1991.

Rössler, Patrick: Moderne Illustrierte - illustrierte Moderne. In: Trost, Vera (Hg.): Moderne Illustrierte, illustrierte Moderne. Zeitschriftenkonzepte im 20. Jahrhundert. Katalog zur Ausstellung in der Württembergischen Landesbibliothek vom 17. Juni bis 1. August 1998. Stuttgart 1998, 9-26.

Rouette, Susanne: Sozialpolitik als Geschlechterpolitik. Die Regulierung der Frauenarbeit nach dem Ersten Weltkrieg. Frankfurt a. M., New York, NY 1993.

Sabrow, Martin: Organisation Consul (O.C.), 1920-1922. In: Historisches Lexikon Bayerns. URL: http://www.historisches-lexikon-bayerns.de/artikel/artikel_44323 (am 19.11.2015).

Saldern, Adelheid von: Amerikanismus. Kulturelle Abgrenzung von Europa und USNationalismus im frühen 20. Jahrhundert. Stuttgart 2013.

Saldern, Adelheid von / Hachtmann, Rüdiger: Das fordistische Jahrhundert. Eine Einleitung. In: Dies. / Ders / Kirsch, Jan-Holger (Hg.): Fordismus. Zeithistorische Forschungen / Studies in Contemporary History. Bd. 6, Nr. 2 (2009), 174-185.

Samuel, Raphael: The Lost World of British Communism. London 2006.

Sander, Uwe: 100 Jahre Jugend in Deutschland. In: Aus Politik und Zeitgeschichte, Bd. 19-20 (2000): Jugend in Deutschland. URL: http://www.bpb.de/apuz/25608/ 100-jahre-jugend-in-deutschland (am 20.07.2015).

Sander, Uwe/ Vollbrecht, Ralf: Jugend im 20. Jahrhundert. In: Dies. (Hg.): Jugend im 20.Jahrhundert. Sichtweisen - Orientierungen - Risiken. Neuwied u. a. 2000, 7-30. 
Sarasin, Philipp: Geschichtswissenschaft und Diskursanalyse. Frankfurt a. M. 2003.

Scharenberg, Swantje: Die Konstruktion des öffentlichen Sports und seiner Helden in der Tagespresse der Weimarer Republik. Paderborn u. a. 2012.

Scheide, Carmen: Kinder, Küche, Kommunismus. Das Wechselverhältnis zwischen sowjetischem Frauenalltag und Frauenpolitik von 1921 bis 1930 am Beispiel Moskauer Arbeiterinnen. Zürich 2002.

Scherer, Anton: Müller, Philipp. In: Neue Deutsche Biographie. Bd. 18. Berlin 1997, $467 \mathrm{f}$.

Scherrer, Jutta: »Einholen und Überholen«. Amerikanische Technologie aus sowjetrussischer Sicht. Die zwanziger und frühen dreißiger Jahre. In: Aust, Martin/ Schönpflug, Daniel: Vom Gegner lernen. Feindschaften und Kulturtransfers im Europa des 19. und 20. Jahrhunderts. Frankfurt 2007, 179-208.

Schivelbusch, Wolfgang: Die Kultur der Niederlage. Der amerikanischen Süden 1865, Frankreich 1871, Deutschland 1918. Darmstadt 2001.

Schlesinger, Arthur M.: The Coming of the New Deal, 1933-1935. Boston, MA 2003.

Schmidt, Alexander: Reisen in die Moderne. Der Amerika-Diskurs des deutschen Bürgertums vor dem Ersten Weltkrieg im europäischen Vergleich. Berlin 1997.

Schmitz, Frank: Zur Ideologisierbarkeit des Sports. Eine vergleichende Untersuchung zum Zusammenhang von politischer Ideologie und Sport im Nationalsozialismus und in der DDR. Braunschweig 2001.

Schubert, Volker: Die fordistische Kindheit. In: Baader, Meike / Eßer, Florian / Schröer, Wolfgang (Hg.): Kindheiten in der Moderne. Eine Geschichte der Sorge. Frankfurt a. M. 2014, 226-256.

Schumann, Dirk: Politische Gewalt in der frühen Weimarer Republik (1919-1923) und ihre Repräsentation in der politischen Tagespresse. In: Daniel, Ute / Marßolek, Inge/Pyta, Wolfram/Welskopp, Thomas (Hg.): Politische Kultur und Medienwirklichkeiten in den 1920er Jahren. München 2010, 279-310.

Schwaabe, Christian: Antiamerikanismus. Wandlungen eines Feindbildes. München 2003.

Schwabe, Klaus: Deutsche Revolution und Wilson-Frieden. Die amerikanische und deutsche Friedensstrategie zwischen Ideologie und Machtpolitik 1918/19. Düsseldorf 1971.

Schwabe, Klaus: Deutscher Anti-Amerikanismus in den Zwanzigerjahren. In: StammKuhlmann, Thomas/Elvert, Jürgen/Aschmann, Birgit/Hohensee, Jens (Hg.): Geschichtsbilder. Festschrift für Michael Salewski zum 65. Geburtstag. Stuttgart 2003, 106-118.

Schwabe, Klaus: Eine neue Weltordnung? Der Beitrag Amerikas zur Lösung der Deutschlandfrage durch den Friedensschluss von Versailles. In: Berg, Manfred/ Gassert, Philipp (Hg.): Deutschland und die USA in der internationalen Geschichte des 20. Jahrhunderts. Festschrift für Detlef Junker. Stuttgart 2004., 263-278.

Schwark, Sebastian: Zur Genealogie des modernen Antiamerikanismus in Deutschland. Baden-Baden 2008.

Schwarz, Gotthart: Berliner Tageblatt (1872-1939). In: Fischer, Heinz-Dietrich (Hg.): Deutsche Zeitungen des 17. bis 20. Jahrhunderts, Pullach bei München 1972, 315-328. 
Schwarzlose, Richard: The Nation's Newsbrokers. Bd. 2: The Rush to Institution: From 1865 to 1920. Evanston, IL 1990.

Scott, Benjamin: Hubbard, William DeHart. In: Salzmann, Jack/Smith, David/ West, Cornel (Hg.): Encyclopedia of African-American Culture and History, Bd. 3. New York, NY 1996, 1322.

Sehling, Emil (Begr.)/Wolgast, Eike/Seebaß, Gottfried (Hg.): Die evangelischen Kirchenordnungen des 16. Jahrhunderts. Band 18: Rheinland-Pfalz I. Tübingen 2006.

Shearer, David: Stalinist Repression, Modernity, and the Social Engineering Argument. In: Harris, James (Hg.): The Anatomy of Terror. Political Violence Under Stalin. Oxford 2013, 105-119.

Shevzov, Vera: Russian Orthodoxy on the Eve of the Revolution. Oxford u.a. 2004.

Siegelbaum, Lewis H.: Cars for Comrades. The Life of the Soviet Automobile. Ithaca, NY 2011.

Siemens, Daniel: Die "Vertrauenskrise der Justiz« in der Weimarer Republik. In: Föllmer, Moritz / Graf, Rüdiger (Hg.): Die »Krise« der Weimarer Republik. Zur Kritik eines Deutungsmusters. Frankfurt a. M. 2005, 139-163.

Simmel, Georg: Philosophische Kultur. Über das Abenteuer, die Geschlechter und die Krise der Moderne. Gesammelte Essais. Berlin 1983.

Simmel, Georg: Schriften zur Soziologie. Eine Auswahl. Frankfurt a. M. 1983.

Simon, Gerhard: Nationale Minderheiten in der ehemaligen Sowjetunion. In: Die neue Gesellschaft, Frankfurter Hefte. Bd. 44, Nr. 12 (1997), 1079-1082.

Singer, Wolf: Das Bild in uns - Vom Bild zur Wahrnehmung. In: Maar, Christa / Burda, Hubert (Hg.): Iconic Turn. Die neue Macht der Bilder. Köln 2005, 56-76.

Skarovskij, Michail: Die russische Kirche unter Stalin in den 20er und 30er Jahren des 20. Jahrhunderts. In: Hildermeier, Manfred (Hg.): Stalinismus vor dem Zweiten Weltkrieg. Neue Wege der Forschung. München 1998, 233-253.

Smith, Clay: Emancipation. The Making of the Black Lawyer. Philadelphia, PA 1993. Snyder, Timothy: Bloodlands. Europa zwischen Hitler und Stalin. München 2011.

Solschenizyn, Alexander: »Zweihundert Jahre zusammen«. Die Juden in der Sowjetunion. Bd. 2. München 2003.

Sösemann, Bernd: Theodor Wolff: Ein Leben mit der Zeitung. Stuttgart 2012.

Spivak, Gayatri: Can the Subaltern Speak? In: Nelson, Cary/Grossberg, Lawrence (Hg.): Marxism and the Interpretation of Culture. Chicago, IL 1988, 271-313.

Stock, Ernst/Walcher, Karl: Jacob Walcher. Gewerkschafter und Revolutionär zwischen Berlin, Paris und New York. Berlin 1998.

Stollberg, Gunnar: Die Rationalisierungsdebatte 1908-1933. Freie Gewerkschaften zwischen Mitwirkung und Gegenwehr. Frankfurt a. M. 1981.

Suny, Ronald: The Soviet Experiment: Russia, the USSR and the Successor States. New York, NY u.a. 2011.

Sutton, Katie: The Masculine Woman in Weimar Germany. New York, NY 2011.

Sywottek, Arnold: The Americanizazion of Everyday Life? Early Trends in Consumer and Leisure-Time Behavior. In: Ermarth, Michael (Hg.): America and the Shaping of German Society. 1945-1955. Providence, RI 1993, 132-152.

Talkenberger, Heike: Von der Illustration zur Interpretation. Das Bild als historische 
Quelle. Methodische Überlegungen zur Historischen Bildkunde. In: Zeitschrift für Historische Forschung, Nr. 21 (1994), 289-303.

Tatur, Melanie: Taylorismus in der Sowjetunion. Die Rationalisierungspolitik der UdSSR in den siebziger Jahren. Frankfurt a. M. u. a. 1983.

Taylor, Charles: Das Unbehagen an der Moderne. Frankfurt a. M. 2014.

Tebbutt, Melanie: Being Boys. Youth, Leisure and Identity in the Inter-War Years. Manchester u. a. 2012.

Temkin, Moshik: The Sacco-Vanzetti Affair. New Haven, CT u. a. 2009.

Tetzel, Thomas: Der kollektive Gott. Zur Ideengeschichte des »Neuen Menschen« in Russland. Göttingen 2013.

Thatcher, Ian D.: Elections in Russian and Early Soviet History. In: Lentini, Peter (Hg.): Elections and Political Order in Russia. Implications of the 1993 Elections to the Federal Assembly. Budapest u. a. 1995, 15-35.

Thébaud, Francoise (Hg.): Geschichte der Frauen, Bd. V, 20. Jahrhundert. Frankfurt a. M., New York 1995.

Theoharis, Athan: The FBI and the Politics of Anti-Communism, 1920-1945: A Prelude to Power. In: Goldstein, Robert Justin: Little >Red Scares $\triangleleft$. Anti-Communism and Political Repression in the United States, 1921-1946. Farnham, UK, Burlington, VT 23-44.

Thoß, Hendrik: Demokratie ohne Demokraten. Die Innenpolitik der Weimarer Republik. Berlin 2008.

Thurner, Manuela Andrea: Girlkultur and Kulturfeminismus. Gender and Americanism in Weimar Germany 1918-1933. New Haven, CT 1999.

Todorow, Almut: Das Feuilleton der »Frankfurter Zeitung« in der Weimarer Republik: Zur Grundlegung einer rhetorischen Medienforschung. Tübingen 1996.

Trommler, Frank: Mission ohne Ziel: Über den Kult der Jugend im modernen Deutschland. In: Ders. / Koebner, Thomas / Janz, Rolf-Peter: »Mit uns zieht die neue Zeit«. Der Mythos Jugend. Frankfurt a. M. 1985, 14-49.

Ullrich, Volker: Die Revolution von 1918/19. München 2009.

Unger, Eva-Maria: Illustrierte als Mittel zur Kriegsvorbereitung in Deutschland 1933 bis 1939. Köln 1984.

Urban, Markus: Offizielle und halboffizielle Amerikabilder im Dritten Reich: Deutsche Amerikaliteratur als Spiegel der politischen Entwicklung. In: Behrends, Jan C. / Klimó, Árpád von / Poutrous, Patrice G. (Hg.): Antiamerikanismus im 20. Jahrhundert. Studien zu Ost- und Westeuropa. Bonn 2005, 52-71.

Usbeck, Frank: »Fellow Peoples «. The Influence of the German Image of Indians on German National Identity and its Appropriation by National Socialism in German Periodicals 1925-1945. Univ.-Diss. Universität Leipzig, CD-ROM. Leipzig 2010.

Van Atta, Don: Why is there no Taylorism in the Soviet Union? In: Comparative Politics. Bd. 18, Nr. 3 (1986), 327-337.

Vishniak, Mark: Lenin's Democracy, and Stalin's. In: Foreign Affairs, Nr. 3 (Juli), 1946, 610-621.

Voltrová, Michaela: Terminologie, Methodologie und Perspektiven der komparatistischen Imagologie. Berlin 2015. 
Wala, Michael: Amerikanisierung und Überfremdungsängste: Amerikanische Technologie und Kultur in der Weimarer Republik. In: Ders. / Lehmkuhl, Ursula (Hg.): Technologie und Kultur: Europas Blick auf Amerika vom 18. bis zum 20. Jahrhundert. Köln 2000, 121-146.

Weber, Max: Gesammelte Politische Schriften. Hg. von Johannes Winckelmann. Tübingen 1958.

Weeks, Theodore: Russification/Sovietization. In: Europäische Geschichte Online (EGO), Institut für Europäische Geschichte (IEG) Mainz 2011. URL: http://www. ieg-ego.eu/weekst-2010-en (am 08.07.2014).

Wehler, Hans, Ulrich: Deutsche Gesellschaftsgeschichte. Bd. 3. München 1995.

Weiß, Dieter: Historisch-politische Blätter für das katholische Deutschland. In: Historisches Lexikon Bayerns. URL: http://www.historisches-lexikon-bayerns. de/Lexikon/Historisch-politische_Blätter_für_das_katholische_Deutschland (am 10.10.2015).

Weiß, Dieter: Katholischer Konservatismus am Scheideweg - Die »Historisch-Politischen Blätter« und die »Gelben Hefte«. In: Kraus, Hans-Christof (Hg.): Konservative Zeitschriften zwischen Kaiserreich und Diktatur. Fünf Fallstudien. Berlin 2003, 97-114.

Weitz, Eric D.: Weimar Germany: Promise and Tragedy. Princeton, NJ 2007.

Whalan, Mark: The Great War and the Culture of the New Negro. Gainesville, FL 2008.

Whitney, Susan: Mobilizing Youth. Communists and Catholics in Interwar France. Durham, NC, London 2009.

Wildt,Michael:DieUngleichheitdes Volkes.»Volksgemeinschaft«inderpolitischen Kommunikation der Weimarer Republik. In: Ders. / Bajohr, Frank: Volksgemeinschaft. Neue Forschungen zur Gesellschaft des Nationalsozialismus. Frankfurt a. M. 2009, $24-40$.

Wildt, Michael: Volksgemeinschaft als Selbstermächtigung. Gewalt gegen Juden in der deutschen Provinz 1919 bis 1939. Hamburg 2007.

Willems, Herbert/Jurga, Martin (Hg.): Inszenierungsgesellschaft. Ein einführendes Handbuch. Opladen 1998.

Winkler, Heinrich August: Mußte Weimar scheitern? München 1991.

Winkler, Heinrich August: Weimar 1918-1933. Die Geschichte der ersten deutschen Demokratie. München 1994.

Wirkus, Bernd: Die kulturelle Moderne zwischen Demokratie und Diktatur. Die Weimarer Republik und danach. Konstanz 2007.

Wirsching, Andreas: Antibolschewismus als Lernprozess. Die Auseinandersetzung mit Sowjetrussland in Deutschland nach dem Ersten Weltkrieg. In: Aust, Martin / Schönpflug, Daniel (Hg.): Vom Gegner lernen. Feindschaften und Kulturtransfers im Europa des 19. und 20. Jahrhunderts. Frankfurt a. M. 2007, 137-156.

Wirsching, Andreas: »Augusterlebnis« 1914 und »Dolchstoß« 1918 - zwei Versionen derselben Legende? In: Dotterweich, Volker (Hg.): Mythen und Legenden in der Geschichte. München 2004, 187-202.

Witte, Karsten: Kracauer, Siegfried. In: Neue Deutsche Biographie, Bd.12. Berlin $1980,630 \mathrm{f}$. 
Wolf, Claudia Maria: Bildsprache und Medienbilder. Die visuelle Darstellungslogik von Nachrichtenmagazinen. Wiesbaden 2006.

Wulf, Peter: »Die Stimme ihres Herrn«. Hugo Stinnes und die Deutsche Allgemeine Zeitung. In: Zeitschrift für Unternehmensgeschichte. Nr. 29 (1984), 153-179.

Yedlin, Tovah: Maxim Gorky. A Political Biography. Westport, CT u. a. 1999.

Zarusky, Jürgen: Die deutschen Sozialdemokraten und das sowjetische Modell. Ideologische Auseinandersetzung und außenpolitische Konzeptionen 1917-1933. München 1992.

Zimmerman, Michael E.: Heidegger's Confrontation with Modernity. Technology, Politics, and Art. Bloomington, IN u. a. 1990. 


\section{Bildnachweis}

Abb. 1: Was ist Rationalisierung? In: AIZ, 1927, Nr. 23, 2.

Abb. 2: Kapitalistische Rationalisierung. In: AIZ, 1931, Nr. 1, $4 \mathrm{f}$.

Abb. 3: Freiheit und Proletarische Wehr. In: SIB, 1921, Nr. 5, 35 (Jahresausgabe).

Abb. 4: Aus Aller Welt. An der George Washington-Universität üben die Studentinnen zum Bürgerkrieg. In: AIZ, 1927, Nr. 18, 16.

Abb. 5: Amazonen von heute. In: MIP, 1927, Nr. 33, 27.

Abb. 6: Das schwache Geschlecht 1931. In: RDM, 1931, Nr. 11, 1211 (Jahresausgabe).

Abb. 7: $\quad$ Die Frau in der Politik. In: BIZ, 1924, Nr. 40, 1083 (Jahresausgabe).

Abb. 8: Das Neuyorker Stadtviertel Harlem. Die Neger-Metropole der Welt. In: MIP, 1926, Nr. 49, 1172 (Jahresausgabe).

Abb. 9: Im Schwarzen-Viertel in Detroit. In: BIZ, 1928, Nr. 7, 275 f. (Jahresausgabe).

Abb. 10: Faschistischer Terror in Amerika. In: AIZ, 1925, Nr. 4, Titel.

Abb. 11: Vom Sklaven zum Herrn. Der Aufstieg des amerikanischen Negers. In: BIZ, 1927, Nr. 24, 948 (Jahresausgabe).

Abb. 12: Der zweite Indianer Kongress in Spokane. In: MIP, 1928, Nr. 19, $596 \mathrm{f}$. (Jahresausgabe).

Abb. 13: Moderne Diktatoren. Studie. Bilder von Ferdinand Bruger. In: ILB, 1927, Nr. 10, 143 (Jahresausgabe).

Abb. 14: Ebert und Noske in der Sommerfrische. In: BIZ, 1919, Nr. 34, Titel.

Abb. 15: Amerikanische Rednertypen. In: BIZ, 1923, Nr. 29, 564 (Jahresausgabe).

Abb. 16: Die beiden Gegner. Der amerikanische Präsidentschafts-Kampf. In: MIP, 1928, Nr. 44, 1396 f. (Jahresausgabe).

Abb. 17: Die Ordnung ist wieder hergestellt. In: AIZ, 1931, Nr. 16, 307 (Jahresausgabe).

Abb. 18: Der Kampf der Sowjetjuden gegen die christliche Religion. In: ILB, 1930, Nr. 16, 252.

Abb. 19: Aus Sowjet-Rußland: Eine Jugendorganisation bei Turnspielen vor dem Winterpalais in St. Petersburg. In: BIZ, 1923, Nr. 37, 734 (Jahresausgabe).

Abb. 20: Wassersport in Sowjet-Russland. In: AIZ, 1929, Nr. 31, 18.

Abb. 21: Arbeitersport in Russland. In: AIZ, 1929, Nr. 33, 19.

Abb. 22: Militarisierte Jugend ... bei den anderen. In: SMZ, 1928, Nr. 6, 594.

Abb. 23: Mißbrauch der Jugend. In: RDM, 1931, Nr. 10. S. 1063 (Jahresausgabe).

Abb. 24: Die Kinderhölle im Sowjetparadies. In: ILB, 1930, Nr. 50, 889.

Abb. 25: Sozialistische Erziehung. In: AIZ, 1932, Nr. 34, $804 \mathrm{f}$. 


\section{Register}

\section{Personenregister}

Adler, Max 196

Arco, Georg Graf von $270 \mathrm{f}$.

Aron, Raymond 213

Arseniew, Nikolaus von 226-228

Baden, Prinz Max von 191

Baker, Newton D. 137

Bernhard, Paul 170-172

Brentano, Lujo 220

Briefs, Götz 285

Bucharin, Nikolai Iwanowitsch 216

Chapiro, Joseph 172-174

Coolidge, Calvin 30, 65, 204-208

Coudenhove-Kalergi, Richard Nikolaus Graf von 25, 49

Cox, James M. $195 \mathrm{f}$.

Delbrück, Hans 52

Dewall, Wolf von $122 \mathrm{f}$., 252

Du Bois, William Edward Burghardt 136, 165

Dumas, Alexandre (d. Ä.) 173

Düsterwald, Wilhelm 78

Dzierżyński, Feliks Edmundowitsch 217

Ebert, Friedrich 33, 54, 199-201

Edison, Thomas Alva 66

Engels, Friedrich 60, 70

Ford, James W. 212

Foster, William Z. 212

Foucault, Michel 36-39, 103

Fraenkel, Ernst 209

Frenssen, Gustav 120-123

Friedrich, Joachim 274

Fülöp-Miller, René 88-91

Gastev. Aleksej $89 \mathrm{f}$.

Geiger, Theodor 101

George, Albert $169 \mathrm{f}$.

Gibarti, L. 212

Glass, Carter 154

Gorki, Maxim $263 \mathrm{f}$.

Goslar, Hans 95-97, 164-166, 272-276

Gropius, Walter 92

Halfeld, Adolf 205-208

Halfeld, Alfred 142-144

Harding, Warren 195f., 200-204

Hauser, Heinrich 91

Hindenburg, Paul von 12, $199 \mathrm{f}$.

Hintze, Paul von 50

Hitler, Adolf 19, 27 f., 50, 54, 141, 160, $185,189,193$ f., 200, 225-231

Hoover, Herbert 97, 159, 205-208, 212

Hugenberg, Alfred 27, 34f., 248

Jahn, Friedrich Ludwig 244

Just, Artur 222

Kaergel, Hans-Christoph $141 \mathrm{f}$.

Katharina II. (Zarin) 228

Keynes, John Maynard 76

Keyserling, Hermann Graf $96 \mathrm{f}$.

Kohn, Hans $187 \mathrm{f}$.

Kollontai, Alexandra $125 \mathrm{f}, 129 \mathrm{f}$. 
Kracauer, Siegfried 17, 97-101, 237-239

Kurella, Alfred $267 \mathrm{f}$.

Le Bon, Gustave 22

Lenin, Wladimir Iljitsch 9, 19, 53, 60, 71, 80-87, 106, 125-127, 138 f., $187 \mathrm{f}$., 197, 215-218, 222, 225-227, 237, 247, 256-264

Lewis, Sinclair 66

Lincoln, Abraham 112, 173

Lotz, Walther 220-222

Lunatscharsky, Anatoli 229, $266 \mathrm{f}$.

Luxemburg, Rosa 60, 119

Mahrholz, Werner $70 \mathrm{f}$.

Marx, Josef 144-147

Marx, Karl 9, 60, 67-70, 224

Masaryk, Tomáš 190

May, Ernst 92

May, Karl 70, 176-178

Mendelssohn Bartholdy, Albrecht 52

Montgelas, Max Graf von 52

Moton, Robert Russa $168 \mathrm{f}$.

Münzenberg, Willi 30f., 34, 162

Müller, Philipp René M.: siehe Fülöp-Miller

Nansen, Fridtjof 270

Neuburger, Albert 67, 81-83

Nikolaus II. (Zar) 186

Noske, Gustav $200 \mathrm{f}$.

Paquet, Alfons 96

Pershing, John J. 137

Peter I. (Zar) 18, 173, 228

Ploch, Arthur 248

Puschkin, Alexander S. 173

Reißner, Larissa 128

Riefenstahl, Leni 241-244

Rieger, Josef 200

Roberts, Adelbert H. 170

Rochechouart de Mortemart, Anne de (Herzogin von Uzès) 114
Rockefeller, John D. 66, 140

Rodziel, Elisabeth 132

Roosevelt, Franklin D. 9, 212

Roosevelt, Theodore 137, 163

Roth, Joseph 85 f., 97 f., 101, 129, 182-184, 263, 265, 271

Rundt, Arthur 164, 207, 258

Rousseau, Jean-Jacques 199

Salomon, Alice 64f., 120 f., 275-277

Salzmann, Erich von $119 \mathrm{f}$.

Scheffer, Paul $219 \mathrm{f}$.

Schlund, Erhard 229

Scott, Emmett Jay 137

Seibert, Theodor 86f., 124-127

Simmel, Georg 94, $103 \mathrm{f}$.

Smith, Al 205-207

Spengler, Oswald 227-229

Stalin, Josef 91, 107, 139, 180, 187 f., 197, 216-221, 227-230, 234, 258, 284

Sweeney, Allison 137

Taylor, Frederick Winslow 58-63, 67-71, 79-82, 84, 90, 99f.

Tichon (Patriarch von Moskau) 225-227

Toller, Ernst $77 \mathrm{f}$.

Trotzki, Leo 184-186, 197f., 215-220, $227 \mathrm{f}$.

Tschachotin, Sergej $83 \mathrm{f}$.

Tschernyschewski, Nikolai 88

Van Loon, Hendrik Willem $65 \mathrm{f}$.

Vishniak, Mark 217

Vorst, Hans 213 f., 262 f.

Walcher, Jacob 60-62

Washington, Booker T. 136, 167-169

Weber, Max 52, 56, 225, 261

Weber, Wolfgang 170

Wilhelm I. (Deutscher Kaiser) 194

Wilson, Woodrow 9, 17 f., 51-54, 106, 136, 141, 192, 252

Zielesch, Fritz 246, 253 


\section{Sachregister}

Adel (Russland) 86, 213, 239,

Afroamerikaner

- Alltag und Kultur der Black Community $140,144,146,154$

- gesellschaftlicher Aufbruch/Aufstieg $140,148,154,162-174$

- Intellektuelle; Akademisierung 136, $137 \mathrm{f} ., 153,164-166,168-170,173$

- institutionalisierte Diskriminierung 31, 133, 139f., 147 f., 148-162, 164, 170, $188 \mathrm{f} ., 283$

- Interessenvertretung: siehe NAACP

- "Negermusik«: siehe Jazz

- »New Negro«-Konzept $135 \mathrm{f}$.

- Rassentrennung in den USA $139 \mathrm{f}$., 140, 147-152, 161, $188 \mathrm{f}$.

- Rechte, rechtlicher Status 137 f., 174, 190, 196, 198

- "separate but equal« 147

- Sklaverei, -diskurse, -analogien $141 \mathrm{f} ., 147-155,167-170$

- Stereotypisierung $140 \mathrm{f} ., 144 \mathrm{f} ., 154$, $163 \mathrm{f}$.

- siehe auch Gewalt; Minderheiten; Ku Klux Klan; Lynchmorde; Rassenunruhen; Rassismus

Alphabetisierung / Analphabetismus 22, 168, 240, 259-266, 269-272, 278 »Amazonisierung« 114

Amendments: siehe Verfassung American Football: siehe Sport Amerika, Amerikabilder

- als Chiffre der Moderne 8, 134

- Ambivalenz 7, 14-18, 49f., 52, 63

- »American way of life« 49, 64

- Amerikabild in der NS-Zeit $17 \mathrm{f}$., 36, 73, 132, 151, $158 \mathrm{f} ., 160,170,175 \mathrm{f}$.

- Amerikanisierung 8, 11, 15-17, 20, 58, 63-66, 74, 79, 93, $108 \mathrm{f} ., 135$, 171-173, 275-277, $285 \mathrm{f}$.

- Amerikanismus 8, 17 f., 66f., 96, $135 \mathrm{f} ., 146,159,171,205 \mathrm{f}$.
- Mentalität 49,64-66, 80, 85 f., 94-98, 119 f., 148, 151 f., 156, 173, 206f., 251, 272-279

- Vorstellungen vom Lebensstandard, -stil $64 \mathrm{f} ., 74,145,253,276$

- siehe auch Amerikanisierung; USA

Antiamerikanismus $17 \mathrm{f} ., 24,49,132$, 135, 193, 272

- linke Amerikakritik 18, 135, 208

- rechte Amerikakritik 18, 132, 205-207

Antidemokratismus 16, 50, 172, 193, 205, 208, 210, 217, 219

Antimodernismus 18, 24, 150, 155, 158

Antisemitismus 18, 26, 32, 132, 149, 181-186, 189, 231-233, 283

Arbeit

- Arbeitslosigkeit 61f., 72-78, 87, 129, 160

- »Entseelung«/»Entmenschlichung" der Arbeit 57, 62, 67, 90, 93 f., 100

- Mechanisierung 57, 64-66, 72, 76f., 90, 102

- siehe auch Arbeiter; Fabriken; Rationalisierung; Wirtschaft

Arbeiter

- Arbeiterbewegung, -interessen 59f., 75, 160f., 167, 196, 208-212

- Arbeiterklasse 21, 59, 62 f., 68-70, $72 \mathrm{f} ., 75-77,83,87 \mathrm{f} ., 91 \mathrm{f} ., 100,109 \mathrm{f}$., $116,127,136,145$ f., 149, 156-161, $167,172,193,208-211-213,218,222$, 240-243, 254-256, 277

- Degradierungdurch Rationalisierung 69 f., 77 f., 83, 99

- Repressionen 196,209-211

- Verhältnis zu Maschinen 69f., 81, 89-91

- siehe auch Arbeit; Proletariat; Streiks Arbeiter Illustrierte Zeitung (AIZ) 25, 30-32, 35, 59-61, 63, 72 f., 83f., 91, 109-117, 125-127, 140, 156-158, 
161 f., 166 f., 170, 180, 208-212, 240244, 247 f., 254-260, 263, 265-269, $277,283 \mathrm{f}$.

Architektur 92

Aufklärung 9, 68, 80, 199, 232, 286

Aufstände

- Haymarket Riot (Chicago, 1886) 209

- Kronstädter Aufstand (1921) 216

- siehe auch Revolutionen; Streiks

Autokratie, Autokratisierung 193, 213, 215-217

Automobil 64, 67 f., 74, 77, 90 f., 98, 144f., 176, 204, $210 \mathrm{f}$.

Autoritarismus 7, 9 f., 193-196, 234

Atheismus $225 \mathrm{f}, 229$

Bauern 64, 109-111, 160, 180, 183, 207, 221, 240 f., 256, 263, 265, 267, 272

Berliner Illustrirte Zeitung (BIZ) 25, 29-33, 67, 81, 88, 112, 114, 116f., $125 \mathrm{f} ., 141,144,148,160,162 \mathrm{f}$., 166-169, 174-178, 191, 200-204, 207 f., 226, 230, 239f., 246-248, 253, 258

Berliner Tageblatt (BTB) 25-27, 58, 64, 77, 80, 120 f., 151, 154, 170-172, 181, 214, 218-221, 262-264, 270 f., 285

Bildtheorie, -wissenschaft 23, 39-43

Bildung, Bildungswesen 43, $47 \mathrm{f}$., 107, 153, 163, 168 f., 176, 229, 235 f., 261, 271-279

- Alphabetisierung: siehe dort

- Bildungspolitik 22, 229, 235, 262-267, 279, $284 \mathrm{f}$.

- Hochschulbetrieb: siehe Universitäten

- in Amerika 15, 245, 249, 254, 272

- in Russland/UdSSR 229, 238 f., 259, 262-271

- Reformpädagogik $262 \mathrm{f}$., $267 \mathrm{f}$.

- Schulwesen 245

Black Community: siehe Afroamerikaner

Bolschewismus, Bolschewiki 9, $19 \mathrm{f}$., 32, 47 f., 53, 58, 74, 80 f., 86-91, 101,
110 f., $127,133,139,178$ f., 181-189, 192f., 197, 213-219, 223-231, 234, 238-241, 247, 254-259, 263, 266, 269-271, 278, 282-284

- Autokratisierung unter Stalin $217 \mathrm{f}$. 221, 234, 284

- innerparteiliche Strömungen; Machtkämpfe 192, 197, 213-220, 284

- "Kirchenkampf« 224-232, 234

- Legitimität der Herrschaft 87, $111 \mathrm{f}$., 197, 213-216, 221, 232 f., 239

- Oktoberrevolution: siehe Revolutionen

- Partei(en)diktatur 179, 213, 221, 234

- Primat der Ideologie 217, 220, 222, 225, 230

- Staatskonzeption 217,219f., 222, 225, 228, 232-234

- siehe auch Kommunismus; Parteien; UdSSR

Boulevardisierung 29, 254

Boy Scouts of America 249-251, 278

Bücher 263-267

Bundesrepublik Deutschland 45

Bürgerrechtsbewegung (USA) 164, 170

Christentum: siehe Katholizismus; Orthodoxie; Religion

Civil Religion: siehe Zivilreligion

Citizen Making: siehe Jugend; Staatsbürger

Demokratie 13f., 26, 45, 48, 50, 106, 172, 179, 190-200, 203, 207-210, 212-224, 245, 283

- Demokratiedefizit 196, 208, 210, 212, 221, 228

- Demokratiekonzepte, -theorien 123, 195, 217, 234

- Demokratisierungsprozesse 54, 136, 190-196, 213, $283 \mathrm{f}$.

- innerparteiliche Demokratie 213-223

- siehe auch Antidemokratismus

Detroit 144-147 
Deutsche Allgemeine Zeitung (DAZ) 8 f., 25, 27 f., 53, 58f., 63, 95-97, 108, $155,194,196,214-216,218,221,230$, $265,267,276,281,286$

Deutschland

- Selbstbeschreibung $7 \mathrm{f}$, , 11, 13-15, 20, 32, 37 f., 40, 45, 47-51, 134, 149, 151, 191, 198, 265, 281

- Staatssystem 7-14, 24f., 33f., 45, 48, 50 f., 54, 107,190-195, 198 f., 209, 237, 284

- siehe auch Bundesrepublik; Kaiserreich; Weimarer Republik; Nationalsozialismus

Diktatur 75, 112, 175-179, 213-215, 219-223, 234, 284

Diskriminierung 31, 133, 139f., 147, 151-154, 162, 164, 170, 188, 283

Diskurs, Diskurse 7-28, 33-39, 42-48, 56-58, 68, 75, 84, 94f., 97, 103-105, $107 \mathrm{f} ., 124,131 \mathrm{f} ., 139,190,225,235 \mathrm{f}$, 254, 260, 281-286

- Diskursbegriff 36-39

- Diskursanalyse 38f., 42-44

- Diskurstheorie 36-38, 124

DNVP 27, $34 \mathrm{f}$.

Dolchstoßlegende 26

»Drittes Reich«: siehe Nationalsozialismus

Dystopien 36, 53f., 56, 62f., 77, 93, 262, 281

Elektrifizierung 80, $86 \mathrm{f}$.

Elite, Elitenbildung 14, 25, 27, 50, 52, $58 \mathrm{f} ., 66,92,94,112,149 \mathrm{f} ., 160,168$, 187, 203 f., 212, 239, 271, 286

Emanzipation: siehe Frauen; Minderheiten

Epochengrenzen 12f., 45, 54, 63, 88, 286

Erster Weltkrieg

- »Augusterlebnis« 149

- Gaskrieg 254

- Kriegsende, Friedensschluss 9, 13, 19, 50-52, 58, 107, 135-137, 141, 149, 162

- Mythisierung $149 \mathrm{f}$.
- Rolle der Entente und Alliierten 51 f., $58 \mathrm{f}$., 119, 252

- Waffenstillstand 12, 26, $50 \mathrm{f}$.

- siehe auch Reparationen; Versailler Vertrag

Europa

- Europagedanke 8, 10, 15, 49, 65f., 94-98, 171, 173, 219, 246, 272, 275, 285

- Paneuropa 25, 49

- siehe auch »Westen»

Fabriken $62,69,71,75-77,80,87$, 92-100, 235, 240, 262, 276

- siehe auch Fließband; Fordismus; Rationalisierung; Taylorismus; Wirtschaft

Faschismus 116, 156-158, 175, 239, 251

Fließband 68-70, 75

Fordismus 17, 58, 67-78, 92, 236, 253

Fortschritt, Fortschrittsglaube 14, $16 \mathrm{f}$., 24, 44, 66 f., 76, 85-87, 97 f., 115 f., 131, 134, 150, 158, 236, 264, 272, 285

Fotografie 22, $30 \mathrm{f} ., 41,62,72,91$, 109-118, 125-127, 159f., 168, 186, 199, 200-203, 210, 238, 254

Frankfurter Zeitung (FZT) 25-27, 51-53, 69f., 79, 82, 84 f., 91 f., 96-100, 112, 120-123, 128f., 137, 151 f., 154, $161-163,171,178,182-184,187,198$, 218, 222f., 237, 252, 263, 266, 269

Frauen

- als Pilotinnen: siehe Pilotinnen

- Berufswahl 104-108, 118f., 123, 128, $130 \mathrm{f}$.

- Bewaffnung; Dienst als Soldatinnen/ Polizistinnen 109, 113-117, 252, 254, 256, 282

- Emanzipation 10, 43, $47 \mathrm{f} ., 103-132$, 135 f., 142, 188, 282

- Frauenkörper; Schönheitswettbewerbe $89,116,120,131 \mathrm{f}$.

- Frauenwahlrecht 106f., 123

- Gleichstellung in der UdSSR 106, 110, 124f., 127-132

- in der Arbeitswelt 105, 107 
- in der Politik 119-130

- Rollenbilder 45, 103-105, 108f., 110, $117,119,122,125,130-132$

- Verdinglichungsdiskurs 131

- „Vermännlichung« der Frau 108-119

- siehe auch »Amazonisierung«; Geschlechterrollen

Fremdheit, »das Fremde « 78, 146

- Fremdbilder, -wahrnehmung 8, 12, 14, 20, 36-38, 45, 84, 104, 135, 191, 232, 236, 281-287

- Fremdheitsbedrohung 146, 163

- Fremdenfeindlichkeit/Überfremdungsangst 16, 66, $159 \mathrm{f}$., 163

Führerstaat: siehe Nationalsozialismus

Geschlechterrollen 7, 13, 17, 45, 47, 103, 105,108

Gesellschaft

- Aufstiegschancen, Mobilität 93, 128, 154, 160, 164-169, 173, 247

- Gesellschafts-/Kulturkritik 17,24, $93 \mathrm{f}$.

- Integration 142, 238

- Sozialhygiene 59

- Stände 150, 251

Gewalt, -erfahrung 20, 36, 85, $135 \mathrm{f}$., 140-142, 148-151, 154, 161 f., 164, $167,170,181$ f., 184,186 f., 194 f., 210-212, 219-221., 226, 234, 244, 258,286

Gottlosenbewegung 226-230

Harlem $143 \mathrm{f} ., 173$

Heiliges Russland 224

Holocaust 20, 140, 185, 189

Holodomor 258

Hunger, Hungersnot 30, 53, 130, 210, $212,227,230,258,262$

Identität, Identitätsstiftung, Identitätsverlust $38,62,86,100,160,188$

Ideologie 9, 17, $20 \mathrm{f}$., 32, 36, 48-51, 56-59, 72-74, 82-89, 91 f., 96,100 f., $106,110-112,114,116,124,128$,
132 f., 139, 158, 160, 174f., 180-183, 186-189, 209, 212, 220, 222, 224f., 230-235, 237 f., 239-247, 256, 258-260, 262, 264, 269f., 277-279, $282-286$

Illustrierter Beobachter (ILB) 25, 32,72 f., 112, 118, 132, 159, 175, 182, 185f., 189, 230-233, 241, 248, 256-258

Imperialismus, Imperium, imperiale Kategorien 20, 109, 139, 195, 238, 241

Indigene (Amerika), »Indianer«

- Exotisierung 176, 189

- "Faschistischer Indianer" 175

- Idealisierung, »edler Wilder« 176, 189

- Opfernarrativ 175

- Repressionen; Vernichtung $174 \mathrm{f}$.

- Romantisierung 176, 178

- siehe auch Minderheiten; Rassismus Individuum, Individualismus $8,21,88$, 90, 93-97, 183, 229, 238, 279

- Entindividualisierung 56, 88, 90, 93-102, 238

- siehe auch "Masse»

Industrie $27,47,56-59,64,69 \mathrm{f}$., 73 , 78 f., $84,90,100-102$, 145f., 152, 167, $173,198,210,213,221,253,262-267$, 278,282

Intellektuelle 15, 17, 22, 24f., 49, 66, 94, 96, 101, 136f., 151-153, 164f., 168 f., 180, 219, 222, 227 f., $269 \mathrm{f}$.

- russische Intelligenzija 180

- siehe auch Philosophie; Wissenschaft

Jazz 66, $170 \mathrm{f}$.

Juden, Judentum

- als kommunistische Parteifunktionäre $184-186$

- Antisemitismus: siehe dort

- Auswanderung 180f., 183

- in der Sowjetunion 180

- Konstrukt des »Judäo-Bolschewismus«, Weltverschwörungsnarrative 184-186, $231 \mathrm{f}$. 
- Pogrome (Russland, UdSSR) $181 \mathrm{f.}$ 184

- Stereotypisierung 185 f., 231

- Zionismus: siehe dort

Jugend

- als Träger/Akteur der Zukunft 235-237, 246f., 259, 278, 285

- generationeller Aspekt/jugendliche Lebenswelten 246-248, 278

- Jugendkriminalität 254

- Jugendorganisationen 239, 247, 249, 253, 256, 259, 266

- Kinder- und Jugendfürsorge 253, 256, 258-260

- Militarisierung 247-252, 254-256, 259, 278, 285

- Politisierung, Instrumentalisierung 30, 48, 247 f., 260 f., 278, 285,

- staatsbürgerliche Erziehung/Citizen Making 249, 252-254

- Visualisierung unterernährter Kinder (UdSSR) 256-258

- siehe auch Boy Scouts of America; Komsomol; Junge Pioniere

Justiz 34, 162, 167-170, 209, 213

Kapitalismus $9 \mathrm{f}$.

- Kapitalismuskritik 18, 31, 62, $71 \mathrm{f}$., 75, 113, 193, 231, 253, 275

- Staatskapitalismus 82

- Verquickung mit politischer Sphäre 113, 193, 208

- siehe auch Marxismus; Wirtschaft

Karikatur 32, 41, 158, 227, 231, 233

Katholizismus

- Antikatholizismus 156-159, 226

- römisch-katholische Kirche 226

- katholisches Milieu 21, 24, 68, 232

- siehe auch Religion

Kinder: siehe Jugend

"Kirchenkampf« 224-232, 234

Klassen, Klassenkampf 23, 60, 80, 93, 109, 112, 116, 125-127, 135 f., 141, 146, 148-150, 156-162, 166f., 180,
$186,205,208$ f. $212-215,219,223,241$, 246f., 263, 267

Klerus 48, 86, 159, 213, 224, 226, 229, 286

Kollektivismus, Kollektivierung 37, 49, 57, 81, 88-102, 193, 229, 235, 263, 277, 282

Kommunismus 24, 62, 86, 113, 125 , 184, 215, 221, 224f., 228, 267

Kommunistische Partei Deutschlands (KPD) 26, 30 f., 60, 196f., 258

Kommunistische Partei der Sowjetunion (KPdSU) 186, 249

Kommunistische Partei Russlands (Mehrheitsfraktion) [KPR (B)] 127, $184,189,213,215,249$

Komsomol 249, 256, 259, 266-268

Konservatismus 9, 15,18f., 24-28, $35 \mathrm{f}$., 59, 67 f., 147, 193, 207-209, 214, 227, 248

Konsum 23, 29, 40, 71, 75, 253

Körperkult(ur): siehe Sport

Kraft durch Freude (KdF) 241

Krieg, Kriege

- Amerikanischer Bürgerkrieg (1861-65) 52, 148, 151 f., 154, 173

- Erster Weltkrieg: siehe dort

- Mobilisierung 136, 249

- Russischer Bürgerkrieg (1918-22) 31, 46, 53, 106, 109, 112, 138, 180 f., 184, $219 \mathrm{f} ., 227,249,259,269 \mathrm{f}$.

- Zweiter Weltkrieg 18, 147, 249

- siehe auch Aufstände; Revolutionen

Kriminalität 32, 212, $253 \mathrm{f}$.

Kriminal-Magazin (DKM) 116, 161

Krise, Krisenerfahrung 13f., 42-46, 236, 281

- Krisenbegriff $45 \mathrm{f}$.

- Krisenparadigma 14,44-56

Ku Klux Klan 150, 155-161, 167

Kulaken 258

Länderbilder 12, 21, 36-39, 219, 286

Liberalismus 7, 9, 10, $24 \mathrm{f}$., 74, 147, $192 \mathrm{f}$., 220, 283

Lynchmorde 31, 150, 155-161, 188 
Macht, -erhalt 12, 15, 20, 34 f., 37, 48, $51 \mathrm{f} ., 65,80,105,112,116,121 \mathrm{f}$., 128f., 141, 143, 182, 187, 194, 199, 204, 208, 213, 215 f., 219 f., 224, 228, 238, 247, 259f., 269, 278, 284-286

Marxismus 70, 139, 180, 196, 222, 226, 271

Maschinen, Maschinisierung: siehe Technik, Technisierung

Masse, Massenkultur

- Massengesellschaft: siehe dort

- Massenpsychologie 22, 183

- „Ornament der Masse« (Kracauer) 98-100, 237

- »Vermassung « 16, 18, 22 f., 56, 85, 93-98, 101, 171

- siehe auch Gesellschaft; Individuum; Rationalisierung

Massendemokratie 194f., 200, 203

Massenfest 238f.

Massengesellschaft, -mensch 10, 14, 22-24, 47, 93-100, 281

Massenmedien

- Ordnungs- und Reduktionsfunktion 21-24, $34 \mathrm{f}$.

- Presse: siehe dort

- Radio, Rundfunk 23,35, 64

- Rezeption 21f., 33-35

- siehe auch Öffentlichkeit

Massenproduktion 57, 75-78, 99

Milieus, Milieubildung 14, 16-18, 21-25, 28, 31, 59, 68, 149, 231 f., 246

Militarisierung

- der Frau 108-119, 252, 254, 256, 282

- der Jugend 247-252, 254-256, 259, 278, 285

Minderheiten

- Afroamerikaner: siehe dort

- Auslandsdeutsche $179 \mathrm{f}$.

- Diskriminierung 18, 26, $31 \mathrm{f.,} 132 \mathrm{f}$., 139f., 147-162, 164, 170, 181-186, $188 \mathrm{f} ., 231-233,283$

- Emanzipation; rechtliche Gleichstellung 48, 133, 137, 142-155, 162-174,178-181, 283,
- ethnische Minderheiten in der UdSSR 178-180

- Ethnodeterminismus 172

- »Indianer«: siehe Indigene (Amerika)

- religiöse Minderheiten 178-188

- Russifizierung: siehe dort

- sprachpolitische Maßnahmen (UdSSR) 138, 187

- siehe auch Rassenunruhen; Rassismus

Moderne, Modernität

- Ambivalenzen 7, 20, 24, 44f., $150 \mathrm{f}$., 245

- Antimodernismus: siehe dort

- Begrifflichkeiten; Konnotationen 8, 13, 18, $44 \mathrm{f} ., 49,55 \mathrm{f} ., 65,68,80,93 \mathrm{f}$., $101,118,133,281,285$

- Gleichzeitigkeit des Ungleichzeitigen 150

- Modernitätsversprechen 7, 134, 140, 277, 281, 285

- multiple Moderne 151, 285

- Nivellierungsaspekt 15, 18, 22 f., 65, $85,93,150,158$

- Reactionary Modernism 68, 151

- Wahrnehmung 47, 148, 285-287

Modernisierung

- Begriff 44-46

- Gleichsetzung mit Amerikanisierung 10, 15f., 18, 65, $285 \mathrm{f}$.

- Modernisierungsdiskurse 11, 28, 44, 47, 133, 135, 245, 281 f., 284

- Paradoxien 45, 149, 155, 245

- Prozess 7, 9, 13f., 20, 28, 47, $236 \mathrm{f}$., 245, 284

- Wahrnehmung 7, 14, 16, 28, $44 \mathrm{f}$., 245,281

- siehe auch Rationalisierung

Münchner Illustrierte Presse (MIP) 25, $30,32,68,74,79,86,112,114 \mathrm{f} ., 117$, 124, 128, 131, 140, 142 f., 156, 161, 176, 180, 205f., 223, 230, 232, 258

Münchner Neueste Nachrichten (MNN) 25-27, 52, 66f., 96, 142, 180, $194,216-219,226-229$ 
NAACP 136, 140, 146, 165, 167

Navajo 175, 178

Nationalismus 8, 28, 161, 232

Nationalsozialismus, "Drittes Reich «

- Führerstaat, -prinzip 19, 194

- Ideologie 19, 32, 100, 131, 134, $159 \mathrm{f}$., 175 f., 235

- "Machtergreifung « 12, 26, 51, 188, 193, 252

- NSDAP 35, 71, 258

- Wirtschaftspolitik 71,73

- siehe auch Deutschland; Holocaust; Kraft durch Freude

»Neue ökonomische Politik«: siehe Wirtschaft

"Neuer Mensch" (utopisches Konzept, UdSSR) 88-93, 193, 238

Nordstaaten (USA) 148

Öffentlichkeit $11 \mathrm{f}$., $21 \mathrm{f} ., 29,46,50-53$, $57 \mathrm{f} ., 67,75,78,86,104,119,124 \mathrm{f}$., 133, 139, 149, $151 \mathrm{f} ., 191 \mathrm{f} ., 195,199$, 203 f., 214, 220-224, 232, 241, 252, $256,267,278,281,286$

Öffentliche Meinung

- Steuerung in der UdSSR $213 \mathrm{f}$.

- Öffentliche Meinung in der Politik der USA 95f., 200, 207 f., 213

Opel 67

Orthodoxie/russisch-orthodoxe Kirche

- Ansehensverlust 224

- Einfluss 224f., 228

- Kirchenkampf gegen Bolschewiki 224-234

- Patriarchen 225, 227

- siehe auch Religion

Osteuropa 241, 106, 124, 159, 185

Ostmitteleuropa 190

Parlamentarismus 27, 45, 191-198

- parlamentarische Demokratie 26, 191, 196

Parteien 14, 54, 81, 135, 181, 194-198, 208, 211, 214, $247 \mathrm{f}$.
- Politische Extreme, Extremismus 71, 74, 193, 248, 256, 260, 286

- siehe auch Parlamentarismus; einzelne Parteien

Personalisierung: siehe Politik, Politikbetrieb

Pfadfinder: siehe Boy Scouts of America

Pioniere (UdSSR) 247, 252, 256, 259, 264, 278

Pilotinnen 117-119

Pogrome: siehe Juden, Judentum

Politik, Politikbetrieb

- Inszenierung/mangelnde Inszenierung $35,48,127,192,199-205,239$, 241, 252, 284

- Personalisierung, Selbstvermarktung (USA) 192, 200, 203, 207, 284

- politische Kommunikation 24, 35, $199 \mathrm{f}$.

- politische Ordnungen 43, 47, 101, 190-234

- Politisierung 30, 77, 114, 120, $247 \mathrm{f}$., 260, 278, 285

- Repräsentation 36, 191, 198 f., 221, 245

- Symbolik; politische Ikonographie 17, 35, 40, 48, 198 f., 284

- US-Politikbetrieb 198-212

- Verquickung mit Wirtschaftsinteressen 208

- Wahlkämpfe, Kampagnen 195-207, 212

- siehe auch Parteien; Präsident (USA)

Polizei 32, 77, 116f., 142, 144, 155, 160-162, 209-213

Postkolonialismus 141

Präsident (USA) 51 f., 97, 112, 200, 202 f., 207

- Präsidentschaftswahlen 195-208

- Präsidentschaftswahlkämpfe 195f., 204-208

Presse

- bürgerliche Presse 25, 28, 30, 36, 63, $114,161,166,189,198,200,215,220$, 260, 262 
- Illustrierte $22 \mathrm{f} ., 25,29-32,35 \mathrm{f}$., 40, 42 f., 73, 93, 101, 108f., 112-114, $117,124 \mathrm{f} ., 132,139-141,156,159 \mathrm{f}$., 174-176, 179, 189, 192 f., 200, 203 f., 227, 229, 232 f., 248, 252, 254, 258, 265

- kommunistische Presse 31, 48, $59 \mathrm{f}$, 62 f., 124 f., 147, 156, 166, 189, 192, $208,217,227,240,254,256,260,262$, $265,268,277,283 \mathrm{f}$.

- Konzerne 27,30f., 34f., 162, 248

- Korrespondenten 26, 28, 65, 120, 178f., 219, 223, 246, 252, 272-274

- Lesermilieus $23 \mathrm{f}$.

- liberale Presse 25, 27 f., 30, 36, 63, $117,147,161,166,194,198,200,215$, $217,220,248$

- nationalsozialistische Presse 32, 36, $62,72,112,118,132,147,159 f$., 175 , 184f., 230, 233, 257, 260, 284

- Tageszeitungen 25-28

- wirtschaftlicher Aspekt 23, 34

- siehe auch Pressefreiheit; Pressekonzentration; einzelne Zeitungstitel

Pressefreiheit $33 \mathrm{f} ., 223$

Pressekonzentration 34

Produktion: siehe Fabriken

Proletariat 31, 54, 62f., 84, 110 f., 116, $125,127,158,167,193,210 \mathrm{f.}, 214 \mathrm{f}$., $220 \mathrm{f} ., 226,240,269$

Proletkult 88, 90f., 96, 100

Propaganda 31, 87, 114, 141, 176, 209, $222 \mathrm{f} ., 231,256 \mathrm{f} ., 265,270,276 \mathrm{f}$.

Der Querschnitt (QUS) 97, 131, 150

Rassenunruhen $162 \mathrm{f}$.

- »Red Summer« (1919) 136

Rassismus

- als Modernitätsbruch 148-151, $154 \mathrm{f} ., 188 \mathrm{f}$.

- Rassenunterschiede vs. Klassenunterschiede $159 \mathrm{f}$., $188 \mathrm{f}$.

- »Rassenkampf« 159, 163

- »Reinerhaltung der Rasse« 152
- siehe auch Afroamerikaner; Gewalt; Ku Klux Klan; Rassenunruhen Räterepublik 27, 192, 197

Rationalisierung

- Begriff, Konzept 56, 74, 84, 88

- Debatte, Diskurs 54, 56f., 273, 276, 281

- "Diktat des Maschinenrhythmus" 69, 91

- Effizienzsteigerung 65,76

- Folgen für die Arbeiterschaft 60-62, 70, $72 \mathrm{f} ., 77$

- Gleichsetzung mit Amerikanisierung $58,63,65,282$

- In Deutschland 56f., 74, 78, 282

- in den USA 282

- in der UdSSR 47, 80-88, 282

- Rationalisierungsbegeisterung $78 \mathrm{f}$.

- Standardisierungs-/Homogenisierungsaspekt 57, 59, $65 \mathrm{f}$., 282

- Tanzformationen als Zeichen von Maschinisierung 89, 97-100

- Verknüpfung mit Konzept des »neuen Menschen" 58, 84, $90 \mathrm{f}$.

- Zusammenhang mit Massengesellschaft 93-101, 281

- siehe auch Arbeit; Fließband; Fordismus; Taylorismus; Technik

Reactionary Modernism: siehe Moderne, Modernität

Reichspräsident 33f., 54, 191, $199 \mathrm{f}$.

Reichstag 12, 35, 127, 199

Reichswehr 34, 200

Reiseberichte, -berichterstatter 15, 69, 95, $106,120,122,147,178,213,219,270$

Reklame $222 \mathrm{f}$.

Reparationsleistungen 50

Revolutionen

- 1776 (USA) 9, 14, 106, 135, 221

- 1789 (Frankreich) 14, 219

- 1848/49 (Deutschland, Europa) 147, 193

- 1905 (Russland) 196, 216

- 1917 (Oktoberrevolution, Russland) 9, 20, 53f., 85, 91, 106f., 109, 124, 
$128,135,138,180,187,192,196,220$, 224 f., 227, 247, 256, 260, 262, 284

- 1917 (Februarrevolution, Russland) 196

- 1918 (Novemberrevolution, Deutschland) 12 f., 20, 54, 130, 192

- Russische Revolutionswirren als Schreckensbild 51, 53 f., 109, 178

- siehe auch Aufstände; Krieg, Kriege

Revue des Monats (RDM) 112, 114, $117 \mathrm{f}$., 131, $254 \mathrm{f}$., 264

Russifizierung 138, $178 \mathrm{f}$.

Russland, Russlandbilder 19, 46 f., 54

- Aspekt der Territorialität 20, 139, 238

- "russische Seele« 49, 228

- Russischer Bürgerkrieg: siehe Krieg, Kriege

- siehe auch Bolschewismus; UdSSR; Zar

Rüstung, Aufrüstung 34, 112f., 123, 252

Scherl's Magazin (SMZ) 248-250

Schulen: siehe Bildung, Bildungswesen

Sichel und Hammer (SUH) 31, 247, 249, 265

Sowjetrußland im Bild (SIB) $30 \mathrm{f}$, 109 f., 227

Sowjetunion: siehe UdSSR

Sozialdemokratische Arbeiterpartei Russlands [SDAPR (B)] 184

Sozialdemokratische Partei Deutschlands (SPD) 54

Sozialismus 9f., 25, 72, $86 \mathrm{f}$., 91, 125, 160, 187, 227 f., 237 f., 256, 259

Sport 237-245

- American Football 244

- erzieherische Funktion 245, 278

- Kommunikationsfunktion 240-243

- Leistungsgedanke 236, 240, 245, 265

- politisch-weltanschauliche Vereinnahmung 48, 237-240

- Körperkult(ur), Ästhetisierung 237-240, 244, 278, 285

- Profisport in den USA 244

- Turn- und Sportfeste 238-244
- universitärer Sport (USA) $244 \mathrm{f}$.

- Unterhaltungsaspekt 244

- Zusammenhang mit »Volkskörper«Konzept 235f., 278, 284

Staatsbürger, staatsbürgerliche Erziehung 29, 115, 130, 146-148, $165 \mathrm{f}$., 170, 214, 244, 252 f., 278

Städte, Stadtplanung $64 \mathrm{f} ., 69,92 \mathrm{f}$., 143-145, 171, 173, 184, 220 f., 260, 263

Ständeordnung $150 \mathrm{f} ., 251$

Stahlhelm, Bund der Frontsoldaten (gegr. 1918) 130

Streiks 209-212

Südstaaten (USA) 140, $147 \mathrm{f} ., 151 \mathrm{f}$,, 154f., 161

Tanz 89, 97-99, 171, 174

Taylorismus 58-63, 67-71, 78-84, 99

Technik, Technisierung

- Amerika als `Technik-Weltmacht $86 f$.

- Beziehung Mensch/Maschine 58,69, 84, 89-91

- Lenin'sches Technisierungspostulat 87

- Maschinenkult in der UdSSR 88-92

- Technikeuphorie 85, 271

- Technikskepsis 63,71f.

Telefunken 270

Tiller-Girls 97-100

Totalitarismus 48, 100, 197, 213, 218

Trotzkismus 215, 218

Tuskegee-Institut $168 \mathrm{f}$.

UdSSR

- Materialismus 229, $278 \mathrm{f}$.

- Sowjetisierung 11, 16, 20, $138 \mathrm{f}$., 238, 270

- siehe auch Bolschewismus; Kommunismus; Russland

UHU (Zeitschrift) 127, 164, 248, 260

Universitäten

- in Amerika 113f., 154, 168, 244, 251-253, 272-277

- in Russland/der UdSSR 182, 226, $259,262,267,269-271,278$ 
USA

- als Weltmacht 9f., 51, 57

- Lebensstil 49,64f., 145

- Materialismus, Mentalität 63, $119 \mathrm{f}$., 148, 261, 271-277

- Selbstfindungsprozess 232

- Unabhängigkeit 8,123,155

- siehe auch Amerika, Amerikabilder; Antiamerikanismus

USPD 196

Utopien

- politische Utopien 9, 246, $260 \mathrm{f}$.

- rassistische Utopien 160

- topisierte Utopien (USA und UdSSR) 14

- utopisches Denken in der UdSSR 9, $88-91,100,238$

- siehe auch »Neuer Mensch«; Dystopien

Verfassung(en)

- Amendments (US-Verfassung) 146, 152-154

- amerikanische Verfassung 77, 123, 146, 148, 163

- sowjetische Verfassung/»Konstitution« 138, 214, 221

- Weimarer Reichsverfassung 33f., 95, 107, 190, 199f., 209

Versailler Vertrag 26f., 46, 51 f., 59, 113, 190

Visuals, Visualisierung 29f., 41-43, 199

- Bildanalyse 40,43f.

- Fotografie: siehe dort

- Visual History $41 \mathrm{f}$.,

- visuelle Grammatik $42 \mathrm{f}$.

- Zeigbarkeit vs. Sagbarkeit 110

- siehe auch Bildtheorie; Karikatur

»Volksgemeinschaft« 100, 134f., 150, 160

»Volkskörper« 100, 235 f., 278, 284

Vossische Zeitung (VZT) 10, 25, 27, 49, 64, 70 f., 75 f., 77-79, 88 f., 95, 119-122, $133,147,156,160-164,195,216,218$, $238,244,263,269 f ., 272-276$
Wahlen

- in Deutschland 12, 191, 194, 231

- in den USA $151 \mathrm{f}$., 154, 164, $169 \mathrm{f}$., 195 f., 197 f., 202, 204-208, 210, 212

- in der UdSSR 213-218, 221, 225

- Wahlrecht 106f., 123, 136, 146, 151-154, 164, 170, 191, 213 f., 217

WASP 141, 159

Weimarer Republik

- Demokratiedefizit 191, 197

- Forschungsstand 12-14

- politische Ordnung 35, 190-197, $199 \mathrm{f}$.

- soziale Spannungen, Polarisierung 13, 34, 45, 195, 260

- Scheitern; Narrativ des Scheiterns 13 f., 45, 50f., 95, 200

Weltanschauung 7, 176, 185, 205, 212, 229-231, 237, 286

Weltordnung 9, 60, 193, 229

Westeuropa 85, 92, 107, 116, 129, 214, 221, 227 f., 236, 269 f., 272

"Westen«, »westliche Kultur« 10, 18, 80, 85, 90, 96, 106, 112, $172 \mathrm{f}$., $192 \mathrm{f}$., 195f., 198, 213, 217, 219, 228, 234, 283 f., 286

Winterpalais (St. Petersburg) $238 \mathrm{f}$.

Wirtschaft

- Neue Ökonomische Politik (Novaja ékonomičeskaja politika) 197

- NS-Wirtschaftspolitik 71,73

- Produktionsprozesse, -organisation: siehe Arbeit; Fabriken

- Volkswirtschaften 62, 71, 74f., 78, 80, 82 f., 105, 216, 220, 253,

- siehe auch Arbeit; Arbeiter; Fordismus; Kapitalismus; Rationalisierung; Taylorismus

Wissenschaft 269-273, $278 \mathrm{f}$.

- Verwissenschaftlichung von Arbeits-/ Produktionsprozessen 58, $67 \mathrm{f}$., 70, 79

- siehe auch Bildung, Bildungswesen; Universitäten

Wolgadeutsche $179 \mathrm{f}$. 
Zar, Zarentum, Zarismus 124,138 , 178f., 182, 186f., 213, 224, 239, 256, 259, 266

Zeitkritik 24, 56, 63, 94, 97, 114, 171, 237

Zeitschriften: siehe Presse

Zeitungen: siehe Presse

Zensur 12, 27, 33 f., 216, 223, 226, 263

Zentrumspartei 24, 196

Zionismus 95, $186 \mathrm{f}$.

Zivilisation, Zivilisationskritik 10, 66, $68,96,98,141,144,163,178,286$
Zivilreligion

- Begriff, Konzept 199, 224

- Civil Religion (USA) 199, 224, 232, 284

Zukunft

- Zukunftsangst 45, 65, 115, 281

- Zukunftserwartung 13, 21, 36, 65

- Zukunftsfähigkeit 10, 63, 66, 82

- Zukunftsmodell 9, 19,63, 149

- Zukunftsoptionen 36, 261

- Zukunftsvision 7, 9, 14, 25, 44 f., 187, 261, 281 